A
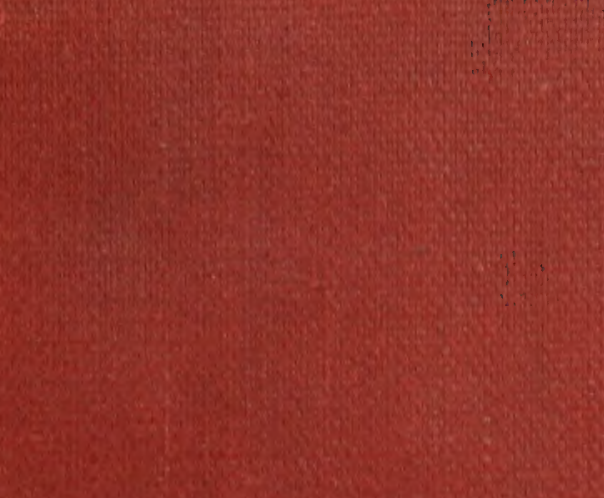

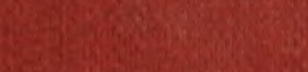

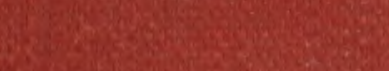


$\alpha$

58359

\section{U5 \\ 1890}

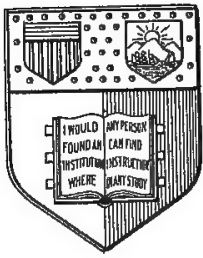

New York

State College of Agriculture At Cornell University

Itbaca, N. Y.

Library 
Cornell University Library

SB 359.U5 1890

Fruit culture in foreign countries.Repor

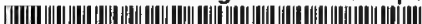

31924002826174 


\section{Cornell University Library}

The original of this book is in the Cornell University Library.

There are no known copyright restrictions in the United States on the use of the text.

http://www.archive.org/details/cu31924002826174 


\section{-PEAIAL CONSULAR REPORTS.}

\section{FRUIT CULTURE}

ix

\section{FOREIGN COUNTRIES.}

REPORTS, FROM THE CONACLS OF THE UNITED STATES, ON FRUIT CULTURE IN THEIR SEVERAL DISTRICTS, IN ANSWER TO

A ClRCULAR FROM THE DEPARTMENT OF STATE.

\section{ARRANGEMENT.}
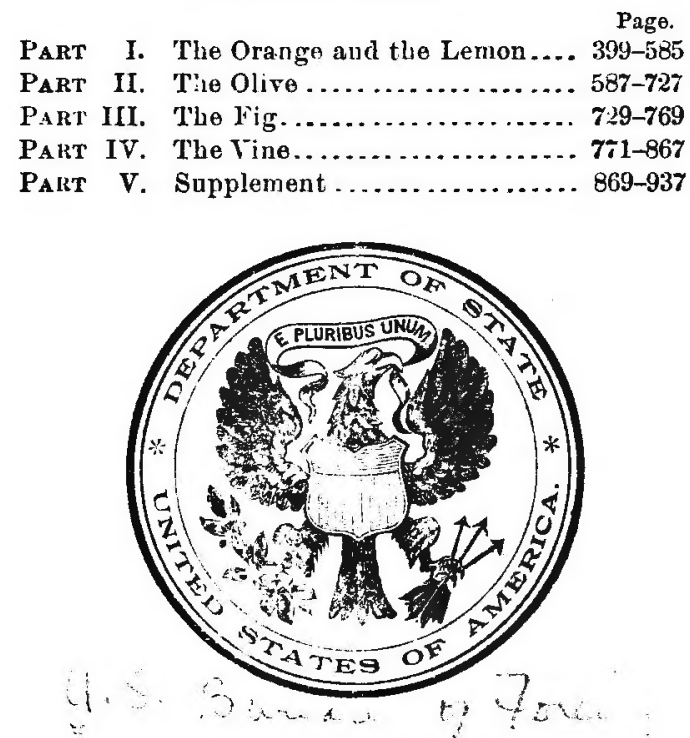

WASHINGTON:

GOVERNMENT PRINTING OFFICE. 1890 . 




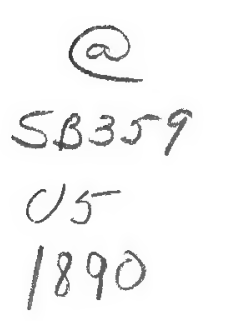

P136,971 


\title{
FRUIT CIRCULAR.
}

\author{
DePARTMEN'l OF STATE, \\ Washington, September 28, 1889.
}

\section{To the Oonsular Officers of the United States:}

Gentlamen: At the request of the California State Board of Horticulture, acting through $\mathrm{Mr}$. B. M. Lelong, its secretary, the inclosed series of questions relative to the cultivation of oranges, lemons, figs, and olives is sent to you for reports. You are requested to give such information in response thereto as you can acquire without expense to the Government or to yourselves. But should you find it impracticable to make a satisfactory report withont outside aid, you will submit to the Department an estimate of the anticipated cost before you ubligate yourself for any specific sum.

I am, gentlemen, your obedient servant,

\section{ALVEY A. ADEE, Acting Secretary.}

\section{QUESTIONS ABOUT ORANGIS AND LEMONS.}

(1) Name of best variety for profit.

(2) Names of other choice varieties worthy of culture and for profit.

(3) Location-where are the trees grown that produce the varioties named above?

(a) Distance from sea.

(b) Elevation above sea-level.

(c) Exposure to sun.

(d) Hilly, rolling, or level land, and which is best?

(e) Soil formation and character, also subsoil, otc.

(4) Climatic influences.

(a) Temperature-minimum, maximun, aud average.

(b) Nights cold or warm, sultry days, moist, ordinary atmosphere.

(c) Rain-fall, in inches, for year.

(d) When rain falls, as to growth of trees and fruit?

(5) Irrigation-when and how ?

(a) At what stage of growth of fruit?

(b) How much at a time, and how often, and other particulars?

(6) Cultivation-when and low ?

(7) Fertilizers-what, when, and how applied?

(8) Pruning - what stage of growth; high from ground or low, and particulars?

(9) Picking.

(a) When picked.

(b) Stage of ripeness.

(c) How curet.

(d) Packing and shipping. 
(10) Distance planted apart.

(11) How are trees propagated?

(12) Are best varieties seedling or budded ?

(13) Are orchards large or small?

(14) Age of fruiting; age when largest crops; maturity of treos.

(15) What insect pests, and how treated ?

(a) Are there any beneficial insects?

(b) Are there any parasites of the injurious insects?

(c) Name parasites, and tell how they work.

(16) Give particular information as to picking and curing lemons before shipping, season picked, etc.

(17) Send any printed information as to processes; prices or stalistics issued by Government or otherwise.

\section{QUESTIONS ABOUT FIGS.}

(1) Name of best variety for drying.

(2) Name of best variety for eating when ripe.

(3) Name of other varieties worthy of culture and for profit.

(4) Where are the trees grown that produce the varieties above named?

(a) Distance from sea.

(b) Elevation above sea-level.

(c) Exposiure to sun.

(d) Hilly, rolling, or level land, and which is best.

(e) Soil and subsoil character.

(5) Climatic influences.

(a) Temperature-minimum, maxinum, and average.

(b) Rain-fall, in inches.

(c) When rain falls, as to growth of trees and fruit, and how much and effects?

(6) Irrigation-method, when and how much, aud during what growth of trees and fruit?

(7) Cultivation-when and how:

(8) Fertilizers-what, when, and how

(9) Pruning-when and how?

(10) Picking.

(a) At what stage of ripeness, time of day, etc.?

(b) Give process, from picking to boxing of figs, minutely.

(e) Are they dipped in some solution; what and how ?

(11) Distance planted apart.

(12) How are trees propagated?

(13) Are orchards large or small ?

(14) What age do trees attain and how long fruitfal?

(15) What insect pests, and how treated ?

(a) Are there any beneficial insects?

(b) Are there any parasites of the injurious insects ?

(c) Name parasites, and tell how they work.

(16) How are cuttings of best varieties to be secured ?

(17) Can you secure any printed matter, such as reports, methods, or statistics jssued by Government or otherwise, and send us?

\section{QUESTIONS ABOUT OLIVES.}

(1) Name of best variety for pickled olives.

(2) Name for best variety for olive oil?

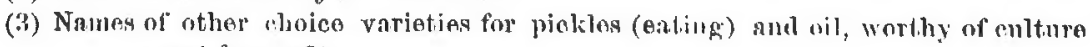
and for profitio 
(1) Where are the trers grown that frotuce the rarinties above?

(a) Distance from stá.

(b) Hloration allove sia-level.

(c) Exposure to suu.

(d) Hilly, rolling, or level land, and which is best.

(e) Soil and subsoil charaeter.

(5) Climatic influence.

(a) Temperature-minimum, maximum, ant average.

(b) Rain-fall, in inches.

(c) When rain falls, as to growth of trees and fruit, and how wuch?

(6) Irrigation-method, whon and how much, and during what growtl of trees and fruit.

(7) Cultivation-when and how 9 .

(8) Pruning-when and how 8

(9) Picking.

(a) At what stage of ripeness, both for pickling and oil.

(b) Next step after picking.

(o) Give minutely the process of pickling and making oil until completed ready for market.

(10) At what age do trees commence fruiting?

(11) What is the average yield per tree or acre?

(12) What distance apart plauted?

(13) How are trees propagated $\$$

(14) Can you give other information that will help growers of olives in California to succeed?

(15) Can you secure any printed matter, reports, methods, or statistics issued by the Government, agricultural colleges, newspapers, or otherwise:

(16) What insect pests, and how treated?

(a) Are there any beneficial insects?

(b) Are there any parasites of the injurious insects

(c) Name parasites, and tell how they work. 

PARTI.

ORANGES AND LEMONS. 



\title{
FRUIT CULTURE IN FOREIGN COUNTRIES. \\ ORANGES AND LEMONS.
}

\author{
CONTINENT OF AFRICA。
}

\section{CAPE COLONY.}

IREPORT BY OONSUL HOLLTS, OF CAPE TOTN.

The time was, and not so long ago, when the orange crop of this colony meant a good revenne to the farmer. With the advent of the Australian bum, whose scientific name I bare forgotten, all this is changed, and in place of trees loaded with luscions fruit now only remain a few blackened stnmps to mark where the orchards once stooi.

No systematic effort was made to eradicate the pest, A. saying it was useless for him to struggle against the evil while B., whose orehard was close by, gave the bug free license to breed and multiply.

I have just heard of a new method of destroying these insects which may be worth a trial. It is to make a cross incision in the bark $L$ shaped, and after rolling back the bark dust the wound with flowers of sulphur. Wax and bind up as after budding.

Years ago I found that the juices of the squash vine was a solvent of sulphur and would take it into the circulation of the plant. At all events, it will cost nothing to try, and will do no injury to the tree.

Geo. F. Hollis.

Consul.

United States (Jonsulate,

Cape Toun, March 5, 1890. 


\section{EGYPT.}

In reply to the circular of the Department, dated September 28,1889 , asking certain questions about the cultivation of oranges, lemons, figs, and olives, I have the honor to inform you that these fruits are not cultivated to any extent for commerce in this country, although they are sometimes to be found in private gardens.

EUGENE SCHUYLER.

United States Consulate-General,

Cairo, November 22, 1889.

\section{MOROCCO.}

REPORT BY CONSUL MATHETS, OF TANGIERS.

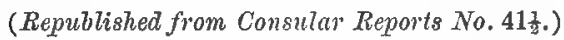

Vurieties.-As most of the trees are seedlings, the varieties are numerous; the most valuable are the round, sweet orange, and the small aromatically flavored fruit known as the Mandarin orange. The Mandarin is the most valuable.

Maturity.-Nine sears from seed; two years after grafting or buriding. Seedlings remain fruitful over a century; grafted or budded, from thirty to forty years.

Propagating.-They are propagated from seeds, inarching, grafting, budding, and by cuttings.

Planting. - Fifteen feet apart, or about 150 trees to the acre, if graftings; seedlings, 20 feet apart, 100 trees to the acre.

Insect pests. - Various vine-fretters and kermes are very troublesome, and cause considerable dnmage to orange trees. The common remedy to a certain extent is to wash the trunk and main branches with a lotion of lime-water, and by watering the leaves with the land pump. Trees too closely planted, or placed in damp and shady localities, or eren not properly pruned to permit light and air through all their branches, create a parasite or leaf disease known as the "demantium mouophyllum " or charcoal, which corers the leaves with a black adhesive dust; also the "lichen auranti," which appears as a crust of a gray whitish color. The bad state of health of the trees creates these parasites and fungus. I bave cured these with petroleum, which must be applied in a mixed state by churning milk and petroleum to a consistency of cream, as potroleum mixed with water is often injurious. These liquids are unmixable, and when applied in some parts ouly the petroleum tonches the trunk or leaves, and on the others the water alone, while, if well mixed with milk, the strength of the petroleum is 
roduced, the anplinalion is mifor'm, and the results most, certain and beneficial to all trees.

Situation.-Orange orchards are planter both inland and on the sencoast, on valleys, hillsides, and uplazds. They yield best results in well drained low-lying lands sheltered from the cold north winds.

Some are within 200 yards of the sea on the sand.

Irrigation.-They aro irrigated artificially, mostly from wells from which the water is drawn by animal power, with very primitive drawwells.

Cultivation.-The ground is manured and cultivated with a heavy hoe once a year. The yield and proceeds can not be ascertained in Morocco. The cost of cultivation, including manuring, in the best orange orchards is at the rate of 25 cents per tree per anuum; laborer's and pruner's wages from 18 to 20 cents per day.

\section{OBSERVATIONS ON ORANGE CULTURE.}

In any country where the medium temperature in winter is superior to $40^{\circ}$ and in summer rises to $85^{\circ}$, the cultivation of orange orchards can be made lucrative.

Orange trees are not particular with regard to soil; they grow lux. uriantly in the sand, and even in strong and very inferior soils, provided they are manured and copiously watered in the summer. There have been empirics who have written on the orange trees and on the manner of composting the soil, recommending all sorts of filthy nos. trums and unwholesome composts which nature never designed, and nobody can form an idea of the mischief which such people do. In nine cases out of ten the leading cause of failure, where trees get diseased or where neither fruit nor flowers are had with any certainty, is due to ill-treatment and poisoning of the roots with the obnoxions mixtures.

Seedlings are always preferred, as they stand cold weather and their yield is enormous; besides, the objects to be attained in raising the orange trees from seed, are, first, to procure new varieties, all of which are more or less acceptable as to size, flavor, and shape; secondly, to provide hardy stocks for grafting or budding known fancy varieties, in preference to grafting or budding on stock raised from the cnttings of citrons, or even of orange cuttings, which are more delicate, of less growth, and short life. In recurring to budding, the hardiest stock of all is that of the bitter or sour orange, the most beantiful of the tribe in form, elegance of foliage, and abundance of fruit. When the medium atmospherical temperature of the spring has reached $70^{\circ}$ the seed may be sown and watered regularly, and in fifteen days they will come up. If the seeds are from the finest, ripest fruits, there will be no necessity of budding to perfectionate the fruit. The fruits from trees raised from seed are the earliest and stand transportation well ; the flowers of these trees stand the cold weather best. 
Fxcessive daupness and humidity in the soil produces the "chlorosis," or yellow of the leaves, which at last ends in destroying the treo.

Lxcessive aridity of the soil is also another cause of suffering to the orange tree, but does not cause its death.

Strong winds only cause the fall of the fruit before ripening.

T'he fogs and white frost of spring sometimes cause an alteration in the orange tree, which afterwards is shown in the shape of reddish spots on the exterior part of the skin of the fruit, which renders it unfit for use

\section{VARIETIES OULTIVATED.}

The races and varieties known are innumerable, the majority of which are still unclassified. The most interesting are divided in eight groups, namely: (1) sweet orange, (2) sour orange, (3) Mandarin orange, (4) limes, (5) Bermagots, (6) Pampelmuses, (7) lemons, (8) citrons.

(1) Sweet orange.-The sweet orange raised from seed in a warm climate is a vigorous tree, which reaches the height of 15 feet; its foliage large and oblong prolongated, of a dark brilliant greev. The flowers are hermaphrodite and pure white. The fruit is quite round, with a smooth, yellowish skin. It commences to ripen in the middle of Norember, and in March arrives at full maturity. 'Trees from seed without grafting gire the largest crops, and it is not unusual for an adult tree to produce from three to four thonsand oranges per annum. These trees, if conveniently sheltered from the cold winters, live centuries. Grafted or budded orange trees hardly grow higher than 10 feet in their proper climate, while in others they only reach 6 or 7 feet, and even less, and their life is short. The principal sweet-orange trees which are selected by those engaged in the orange culture are the Bigaradia (Citrus vulgaris ligaradia) Imperial, the Royal Bigaradia, the Bigaradia of silvery leaf (C. vulguris argentea), the Bigaradia of spotted leaf (C. vulgaris variegata), the Bigararias of double flower and of violet flower, and the Big. aradias of round fruit, angulated fruit, spotted fruit, and crowned fruit; also the Bigaradia of myrtle le.if and that of double flower, producing cake-shaped fruit; the Balenic or Malloren orange, large, smooth, thin skin, of vigorous growth; the Portugal or China orange, of less growth than the Balearic, but producing very large fruit; the orange of Nice, hishly favored in Provence for its elegance aud beautiful frnit. The Maltese or blood orange is very rich, and also an abuudant bearer, the frut laving a pulp stained with crimson; the foliage resembles that of the I'or'tugal or China orange. There are numerous other varieties, most of which are more nominal than real, mostly the results of hybrid. ixiug, and which are more of a botanieal ornament than of profit.

(2) Sour orange.-The sour or bitter orange, many of which hare curious and very interesting.foling', portly and bandsome trees, with gold and silver-striped-leaves, myrtle leafed, willow leafed, plain and striped, tricolor striped, and many others very showy. The flowers of these trees bring the highest prices in market. Their fruit is preferred for 
confectionery, marmalades, etc. The sour or bitter orange tree is still more rustic and hardier than the sweet orange from seeds, and its growth is more rapid. There is of this tribe the China sour-orange tree, which is dwarf, only growing to about 4 or 5 feet in height the most.

(3) Mandarin.--The Mandariu orange, originally frorn China, propagated also from seed, was introduced in lurope about the middle of the present century; only grow from seed to a height of 12 feet, and to about 6 feet when propagated ly grafting or budding. The pulp of the Mandarin orange is almost free from the rind; the latter is very aromatic. The Tangerine orange, recently introduced in Europe, is a variety of the Mandarin; its fruit is less than half the size of the Mandarin, in fact often no larger than a walnut, but exceedingly sweet and perfumed. The Japanese orauge is a shrub which the Chinese cultivate on a large scale, and known by the name "Kumkoat;" is almost unknown in Europe; it attains a height of 4 feet, and by pruning it is grown in pots, where it only grows to about 20 iuches, covering itself with a fruit no larger than a good-sized cherry. The rind is so thin and smooth that it is eatable. They are preserved whole in sugar. I have four in pots from 15 to 18 inches in height with ripe fruit; thes have ripe fruit from December to April ; they resist the cold weather better than the hardiest of the orange tribe, but in summer they require hot weather to bring their fruit to maturity. I strongly recommend this interesting and profitable shrub to our California orange-growers. One acre of land will accommodate 500; manure annually, and if possible in summer. An irrigation or two of manure water will bring the fruit to perfection.

(4) Sweet limes (Citrus limeta).-The sweet-lime tree has the bearing and foliage of the lemon tree; small white flowers; the fruit more or less large or small, according to the varieties; its color is of a pale cellow; the pulp is au insipid sweet, slightly bitter. The varieties known in the south of Spain and in Morocco, where they abound, are the "Roman," the "Melaroce," aur "St. Jerome."

(5) Bergamot orange (Citrus bergamia).-Tall trec; oblong lenves of medium size, of a lively green on the upper surfaco and paler on the under part than the other varieties of orange; very small Howers and of a particularly mild aroma. The fruit is depressed in shape, smooth, and of a lemon-yellow color; the pulp is slightly sour and of a pronounced aromatic flavor. The chief varieties are the common Bergamot, the orange Bergamot, the sweet lemon Bergamot, und the Adam apple Bergamot, and some others which probably are only monstrosities propagated by grafting. The cultivation of the ordinary Bergamot is very lucrative by the great quantity of volatile oil extracted from the rind of its fruits.

(6) Pampelmuse.-Pampelmnse (Citrus decumana) probably is a species entirely distinct from the preceding, nevertheless it has certain similari. ties to the natural ordinary sweet orange from seed; it grows the : hright; very few thorns. It differs in foliage-lorond labres and large 
flowers of a pure white. The fruit is depressed and of immense size, of a pale yollow, and only matures on the second year; they require shelter and a warm locality. The "Lumias" are a variety of the Pampelmuse.

(7) Lemons (Citrus limonum).-This species is more a large shrub than a small tree; they require a warmer elimate thau oranges do; their flowers are white inside and reddish on the outside. There are numerous varieties. They require less irrigation than the orange tree; are easily propagated from cuttings, which the dealers in orange trees use extensicely for budding or graftiug.

(8) Citron.-There are various varieties-the ordiuary citron, the lemon citron, the St. Jerome citron of very large frnit, the Florence citron, and the sweet citron; the flowers are reddish, pink, white, and violet. It grows well in narrow valleys where the heat in suminer is retained during the evenings; it grows admirably on the shores of the Mediterranean in almost any soil, and is easily multiplied from slips or cuttings, which are also used for budding or grafting by the dealers and veuders of orange trees.

For California I would recommend raisiug sweet oranges from seed or grafting the seedlings or stocks of the sour orange, the hardiest of all for cold winters.

Observations on pruning.-The flower and fruit are produced on the young rood of the current season generally. The pruning has in view three objects: first, to keep the branches from being too numerous, and thereby making the foliage too thick, so as to exclude air and sun to a great part of the head; secondly, to check those branches which grow too vigorously for the rest of the tree; thirdly, to remove old and bare wood and make way for the young. The weakest branches should also be removed, and the pruning should be done on dry days during the months of February and March. No shoots should be allowed to grow below the head, unless left for the purpose of propagation by layering in pots and thus obtaining young additional urees.

The orange tree spreads its roots close to the surface; care should be taken not to disturb them whon cultivating the soil around the trees.

Nothing is wasted of the orange tree. The leaves, the flowers, and the fruit are all a source of profit; they all coustitute a branch of commerce. On pruning the trees the leaves are gathered from the cut branches, dried, and they sell in the markets of Europe from $\$ 2$ to 84 per hundred-weight. The flowers are sold for the distillers and other purposes in France at 25 cents per pound. Oranges for exportation are gathered in November when their color begins to shange from green to a yellowish; the second gathering for short distances is male in December, and the last for the nearest markets in February aud Mach.

FeLix A. Ma'THEN, Consul.

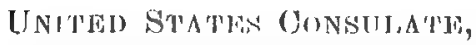
Tingier, thril:2, 18 s. 


\section{CONTINENT OFAMERICA.}

\section{MEXICO.}

\section{GUERRERO.}

REPOHT BT OONSUL SUTYER, OF ACAI'ULOO.

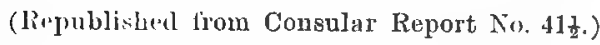

Traricties.-Sweet and bitter oranges, narel oranges, lenions, limes, shaddocks, citrons.

Limes and street oranges are the most valuable. Some 15,000 boxes of limes, representing for the growers a valne of about $\$ 25,000$, are exported anuually per steamers of the Pacific Mail Steam-ship Company to San Francisco. Brought to town, selected, and packed for export, this fruit costs, more or less, $\$ 3$ per box.

Unly swall quantities of orauges are exported to Sau Francisco per steamer from December to February, before the crop from the islands in the Pacific overstocks the market.

Oranges are obtained at $\$ 5$ per thousand, but on account of high rates of freight can not compete in the San Francisco market with the fruit imported from those islands.

Maturity.-Lime trees which are allowed to grow like a bush, with branches rising from the roots, commeuce to bear at the age of four vears, aud are in full bearing when eight years oln; in grood soil and with but very little care the tree will attain the age of fifty years. 'This tree is indigenous, whilst the other varieties of the citrus family are said to have been imported.

Orange trees commence to benr at the age of five years, are in full bearing at the age of ten, and will remain fruitful fully as long as the lime tree.

Propagation.-All the trees are seedlings.

Insect pests.-Ants are the only insects which are injurious to the trees, much more to the orange than to the lime trees; people protect their trees in various wars from ants with more or less success. The ants are destrojed by digging up their uests, or are kept off the trees with fine sand, fire, water, petroleum, etc. Fungous growth and other parasites are not found in such abundance as to serionsly injure the trees.

Planting.-W Most of the trees are planted very irregularly, in selected, favorable spots, which may keep moist all the year round. In a few 
newly laid out lime-tree plantations the distance between trees is 20 feet in every direction.

Situation.-Auywhere, mostly in unoist places along small streamlets or gulches on the hill-sides, in low bottoms along rivers, or near the sea-shore; in sandy lilack loam they yield the best results; the siveetcst aud thin-skinued oranges usually grow on hill-sides, whilst the fruit of lowlauds is generally thick-skinned.

Some orchards are in close proximity to the sea-shore, in sandy black loam, in some instances with lagoons or brackish water on the side opposite to the sea-shore, and give very excellent results. Thus situated there is one, newly, regularly planted, of 8,000 lime trees and 100 orange trees, with room for many thousands more, and with the advantage of cheip trunsportation by water to Acapulco, the port of shipping.

Irrigation.-No system of artificial irrigation is in use; the ground between trees is not cultivated, but merely kept free of undergrowth and weeds, lands being as yet of but nominal value.

Yield.-As the orchards are not regularly planted and the trees are scattered here and there without any regard to economy in land occupied, it is utterly impossible to state even only approximately the yield or cost of cultivation of an acre per aunum.

One orange tree from the age of eight years up to fifty years of age in ordinarily good conditions will yield on an arerage 3,000 oranges every year, worth, picked, $\$ 4$ per thousand. A lime tree from the age of eight years to the age of fifty bears fruit all the year round, and will field about 8,000 per year, worth on the tree, say, $\$ 10$.

Land being but of nominal value, no interest on capital investeci in the same or any ground rent is to be taken in account; nothing is irrigated, consequently the cost of cultivation is very little, say $\$ 150$ per annum for iu orchard of several hundred trees.

'There being no export market for the other varieties of the citrus lamily, they are of comparatively little value, and only raised for home constumption.

UNited STATES Consulatit, JOHN A. SUTTER, JR.,

Consul. Acapulco, February 15, 1884.

\section{SONORA.}

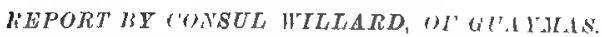

On receipt of circular, I auldresied letters to several of the mange growers in the interior of Sonorn (for at Guaymas but l'w oranges are (nown) and in reply was informed that, as the cultivation of oranges

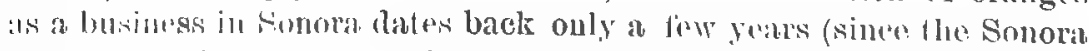
railway has bern in operation, 1882), they dial not lesel competent in yising; , propere report. 
I an told that the first plants or cuttings of oranges cultivated in So. nora were brought by the Jesuit fathers ninety years ago from Italy, and planted at the missious of San Joś de Guaymas and Hermosillo. But little attention was paid to their cnltivation excepting for bome con. sumption, as there was no market for them on the coast (as they are grown from Guaymas to Panama), and no quick transportation existed to take them to a market north. After the Sonora Railway was finished it furnished the means of getting them to a market in the United States, and in 1883 i small shipment was made with good results, and since then orchards have been planted and oranges now figure as an article of export to the United States by rail. In $1888,14,000$ looxes of 200 oranges each were shipped. The fruit is sold on the trees at from $\$ j$ to $\$ 8$ per 1,000 , beiug purchised by fruit dealers through their agents, who pick, pack, and ship the fruit.

The Sonora orange commences to ripen in November, and by the end of December the fruit is nearly all harvested.

Orange trees are grown aloug the sea-coast, and in the interior of the country up to 3,000 feet altitude. Bottom lands have been used for this purpose heretofore, but I am told some orchards have been recently plauted near Hermosillo (iuland 100 miles from Guaymas, ) on rolling liuds and hillsides.

The trees are irrigated throughout the year, particularly in the dry season, which commeuces in October and ends in July.

The trees are raised trom the seed of the sour orange and are set out or planted 30,40 , and 60 feet apart; the second year are grafted or budded with the sweet orange. They commence to gire a small quautity of fruit the thirt year after grafting, and are in full bearing condition in the eighth year, yielding, if well grown, from 1,000 to 1,500 oranges per tree.

No insect pests have appeared as yet to destroy the tree or fruit.

Lemons, fins, and olives are caltivated to a limited extent. These fruits from the lew trees cultivated are. used for home consumption alone, none being exported.

\section{A. WILLARD,}

Consul.

\section{United States Consulate,} Guaymas, Mexico, November 13, 1889.

\section{LOWER CALIFORNIA.}

\section{REPORT BI CONSUL VIOSCA, OF LA PAZ}

Varieties.-The Oastillian orange (Naranja de Castilla) is the best variety known here for profit, supposed to have been introduced by the early Spaniards; of recent years seed aud young trees brought by fruit growers from the States of Sinaloa and Souora have been planted in 
different orange orchards, resulting in quite an improvement in the quality and flavor of the fruit over the old orange-producing trees in the country; other varieties are of limited prodnction, such as mandarin, pear and king orange and not of sufficient quantity for export.

The citrus fanily comprises here six species fruitful and profitable for cultivation. Citron, shaddock (torouja), large lemons, limes (citrus limetta) lima, sweet lime, king orange. The lima chichona, or sweet teat lime, weighs commonly from 12 to 14 ounces and is very delicious. The luing orange is the production of an orange tree, a young shoot grafted into a sweet lime tree and in time from that to a shaddock or toronja, and finally a shoot from this last is again grafted on a common orange tree. Each of the orange fruit weighs from 4 to 5 pounds, and are of very delicate and sweet flavor and also exempt from acid.

Situation.-The locations where the trees grow are San Antonio, San José, and La Paz. San Antonio is 56 miles from the sea; the other places are ports of entry.

Elevation of the first-named town, 1,200 feet; the other two are in a level valley, all fully exposed to the sun.

Level land is best. The soil here is alluvial, sands, and the subsoil within four feet under is of clay and gravel.

Temperatuve. - The average temperature is $85^{\circ}$, minimum $60^{\circ}$, maximum 93०, Fahr. During winter nights are lightly cold, never warm, but quite warin during the day. In snmmer, sultry days very seldom and the atmosphere generally very clear.

Rain commences in July and ends in October, in time to assist the grow th progress of fruit.

Irrigation.-Irrigation is practiced all the year round. The citrus family have to be watered every three or four days, and give them as wuch water as possible.

Cultivation.-Young trees are transplanted in the month of Septem. ber, aud also in February, and the cleaning of trees takes place in December.

Fertilizers.-Cow and other manure is used as fertilizer, but in setting young trees a circular hole is excavated of 4 feet diameter and of 3 or 4 feet depth, and about a 4 -inch layer of old cattle bones is pnt down, and on the top of it avother 6 inches of clay, aud after anotber 6 inches of nanure, and following commou soil. The tree is set on the top of that. The best results have been obtained that way.

Irming.-First remove the inner superfluous shoots living at the expense of the sap of the tree, and cut all otber nunecessiry brauches to allow circulation of air. It is evidently proved that the tree should be allowed its full growth from ground. It is best either to protect it from hot breezes or from the heat of the soil, and even from frost, as zeru. (erally the upper part only suffers, and the rest of the tree is fully protected.

l'ickinl.-The picking of oranges takes place carly in November, 
whence they are just ripe enough for shipping. Oranges are cured by burying them separately under 4 or 6 inches of very dry saud, in a shaded and ventilated place, for a month or two, after that they can be taken out, will look proportionally fresh, and will keep in that condition for six months.

Packing and shipping. - When packed for export the oranges are wrapped in paper and packed in special boxes.

Planting.-Orange trees are planted 20 feet apart, lemons 15 feet, aud limes 20 feet. Orange trees are propagated by seed, shoots from roots, and by branch cuttiugs.

Some orchards are quite large and others are small.

1faturity. - Fruiting begins at tire or six years from the time the seed is planted; when the tree is fifteen years old and upwards it produces the largest crop of fruit. The full maturity of the tree is uncertain.

Insect pests.-Trees here are very seldom tronbled with insect pests, with the exception of some seasons, by an iusect in the shape of a tick, called manteca, which is very easily removed; but sometimes worms in the shape of teredo ou the roots kill the tree beyond cure.

JAMES VIOSCA, Consul.

\section{Unifed States Consulate,}

La Paz, December 21, 1889.

\section{CENTRAL AMERICA.}

\section{GUATEMALA.}

REPORT OF CONSUL-GRNERAL HOSMER.

I have the honor to acknowledge the receipt of the circular submit. ting a list of questions regarding the cultivation of oranges, lemons, figs, and olives.

In reply, I beg respectfully to state that the fruits referred to are of spontaneous growth in Guatemala, aud are not cultivated or exported.

They grow in nearly all parts of the Republic, from the sea-level to an altitude of 5,000 feet above it, and are freely consumed by the population, but without care or effort in their culture.

$$
\begin{aligned}
& \text { JAMES R. HOSMER, } \\
& \text { Consul-General, }
\end{aligned}
$$

United States Consulate-General,

Guatemala, December 9, 1889 , 


\section{SOUTH AMERICA.}

\section{BRAZIL}

\section{BAHIA.}

\section{INTRODUCTORY.}

I have the houor to report the following concerning oranges and lemons, as called for in the circular dated September 28, 1889.

As neither figs nor olives are grown here in the State of Bahia, nothing need be sail of them. Very little attention is paid eren to the cultivation of the orange or the lemon; so.little, that all that are growu are used in the place, none being exported even to adjoining States. The supply is so limited as practically to prohibit exportation, on ac count of the very high price that must necessarily be paid for them.

Should one wish to send a box of selected oranges to a friend in the United States, he must pay for such box of one hundred, packed ready for shipment, $12 \frac{1}{2}$ millreis, equivalent to $\$ 6.12 \frac{1}{2}$, and this in the orange season, too. Therefore, as none are grown except for home consumption, it seems quite useless to answer the questions in the order in which they are submitted.

\section{ORANGES.}

Varieties.-The best variety is called Lavanja de embigo or navel orange. These oranges are seedless. When properly cultivated they grow to a great size and hare a most delicious flavor, being also very juicy. It is not an infrequent thing to find oranges of this class weigh. ing a kilo each, and often a little more, and measuring in circumference from 18 to 20 inches. The orange of this class of ordinary growth measures from 12 to 15 inches in circumference.

The other valieties, not choice, however, are Lavanja de terra, or seville orauge, which has rather a bitter taste, with seeds, and not as large, nor of course as fine a flavor, as the Lavanja de embign.

Another lind is the Laranja de Cravo or tangerine, similar to the tangerine of Florida, with seeds. The fourth and the last class is the Laranja brabo, or wild olange, with pips also.

Whatever cultivation is given time navel orange receives, though some attention is being given to the tangerine.

Situation.-Anywhere along the sea-coast. I bave been informed they may grow anywhere in fact in the State.

As there is no land in the State that is cultivated that has any great degree of elevation, it may be said they will grow at any elevation.

Soil.-Olayey soil mostly about and in this city. Some sandy. In the interior of the State more of an alluvial nature. The character of 
the subsoil is prusumbibly moch the same as the soil. In most cases the subsoil has nerer been turned up. The land is nerer preparel hy plow. ing it. The grass and weeds, when cut away at all, are cut by largo hoes.

Climatic influenes.-Along the coast the merrnry ranges between it and $92^{\circ}$ in the shade. In the interior, especially on the higher eleva. tions, the range is greater. Oool nights and very moist atmosphere. Rain-fall in inches, I do not know. Generally the rainy season begins about April 1, continuing to Novenber 1, thongh there are freqnent silowers in the dry season from November to $A$ pril. Consequently, as the fruit is usually picked from May to August, it ripens in the rainy season.

Irrigation.-There is no irrigation.

Cultivation consists simply in cutting the grass and weeds that spring up whenever needea, and is done, as stater, with a large hoo.

In a very few orchards the ground is seeded with grass, which is cut when green, after which the soil is loosened with the hoe, then animal manure is scattered broadcast through the grove.

Pruning.-Pruning is done after the treereaches its fifth year, or thereabouts, say 4 to 6 feet from the ground. It is then continued every year thereafter, while the tree has growth.

Picking.-This depends on the demand, as they are not shipped. Peo. ple will buy them only when ripe, consequenthy they are allowed to remain on the tree till reaching the stage of ripeness.

Were the oranges to be shipped, the pieking before being ripe, would, of course, depend upon the length of time occupied by the steamer to the place of destination.

Planting.-The trees are planted from 12 to 16 feet apart, and propagated by cuttings in Bahia. The orchards are cery sinall generally.

Maturity.-The trees commence to bear in about five years. If the trees are properiy cared for, largest crops are obtained from the eighth to the twentieth or twenty-fifth year in the life of the tree. Much depends, of course, on the seasous-whether very diy or very wet. They are fruitful for thirty to forty years.

Insect pests. - A sort of white worm, which is destrojed by brushing the trunk of the tree with a mixture of clay and water, or ratber painting it with the liquid mixture.

\section{LEMONS.}

There are but two varieties of lemons in this State. The one called Lima doce, or sweetjuice; the other Limao, an acid, nearly round lime. This lime is abundant, but is not cultivated to any appreciable extent. It is much more acid than the lemon proper, and is known, I believe, by the scientific name of Citrus limetta, the lemon being known as Cit. rus limonum.

As the limes are not shipped there is no curing, no packing. They are picked whenever there is a demand for them and, like oranges, may 
be obtained nearly the entire year, though like the orauges they are best in their season, which is the same as the orange scason.

There are no statistics issued on the subject from any source. Prices of both oranges and lemons depend on the supply. The lowest price for the best quality of oranges is about 4 vintins, equal to 4 cents. The maximum price is about 8 vintins, say 8 cents. Lumons, or limes, may be bought from ten for 1 cent to one for 3 cents, depending on the supply or scarcity.

D. N. BuRKE,

Consul.

United States Consulate,

Bahia, March 1, 1890.

\section{BRITISH GUIANA.}

REPORT BY OONSUL WAITHALL, OF DEMERARA.

ORANGẸS.

Varieties.-The oranges grown in this colony are known as tangierine, bitter, sweet, and myrtle. Under the term "sw eet," sereral varieties are included, which have no distinctive name.

Situation.-The groves are on the coast lands and banks of the rivers, inland from the sea, varying from a few hundred Fards to several or many miles, but scarcely above the sea at all, as the alinvial land lies mainly below the level of spring-tides. The cultivated lands are generally open, with little shade, and almost exclnsively level. The soil is alluvial, forming a stiff blue clay, with a superficial covering of "pegass," or vegetable mould.

Climatic influences.-The year consists of two wet and two dry seasons, more or less irregular in duration. December and January are generally rainy; February and March usually dry; April (in whole or in part), May, June, July, and sometimes August, are more or less wet, May and June being generally very rainy; September and October almost invariably very dry, as is sometimes a part or the whole of No. vember. February, April, August, and November are, Lowever, rery variable and uncertain.

The temperature is singularly uniform. The extremes on the coast are about $70^{\circ}$ and $90^{\circ}$, Fahrenheit. The difference between dis and night is more marked than the variatious of either the day or the night temperature at the different seasons. The mean maximum temperature of the days is about $87^{\circ}$; mean minimum of the nights, about 750 .

'There are not many lays that can properly be called sultry, as good breezes generally prevail at all seasons.

The rain-fall is variable, ranging within the last twenty years from 52 to 108 inches, lut averaging about 85 or 90 inchos. 
Irrigation.-None, except what is merely iucidental. (See reports of the uudersigned, of August 2, 1889, on Irrigation und Urainage, and of November 8, 1889, on Cauals, etc., in British Guiana.) There is practically no cultivation in this eolony of any fruits except plantains and cocoanuts.

Fertilizers.-No fertilizer's are ever used.

Pruning.-No pruning is ever doue.

Picking--Gathered when mature, but while still green. Usually kept dry, but no system of curing followed. None are exported.

Planting.-There are no regular plantations. Therefore there is no system as to distance apart. The trees are propagated exclusively from seed. The trees are usually mixed with other plants, and therefore variable in extent.

Maturity.-The trees begin to bear when from five to seven years old. They mature at the age of from ten to twenty years, which may be regarded as the period of greatest production, although this is largely dependent upon various circumstances.

Insect pests.-Orange scale insects on the coast, and parasol ants in the interior. No treatment adopted as a rule.

\section{LEMONS.}

Very few, if any, lemons are grown in this colony. Limes are cheap and abundant but not systematically cultivated, picked, or cured, and none are shipper.

No statistics issued.

Neither figs nor olives are grown in British Guiana.

W. T. WALthaLL,

Consul.

United States Consulate,

Demerara, February 20, 1890.

\section{ECUADOR.}

REPORT BY OONSUL.GENERAL SORSBY OF GUATAQUIL.

ORANGES.

There is but ono variety.

Location.-The distance from the sea depends upon the sea-level. Elevation above the sea-level 1,000 to 1,500 feet. Exposure to the sun continuous.

Level land is best, soil and subsoil formation; lime and sandy.

Climatic influences.-Temperature $50^{\circ}$ minimum, $88^{\circ}$ naximum, $70^{\circ}$ average. Nights warm and moist; sultry dass in dry season; atmosphere extremely dry. There are two distinct seasons. In the dry sea. son it is never wet, and in the wet it is never dry, the rain.fall for four 
months being very heavy. When rain falls, the growth of the tree and fruit is attained. Irrigation not practiced.

Cultivation.-Plowing during rainy season. No fertilizers usel.

Pruning.-Not resorted to.

Picking.-Picked in the dry season, June and July, mainly, and picked half ripe for export, but ripe for home consumptiou.

Packing and shipping.-Packed loose, and shipped to Peru and Chili exclusively.

Planting.-Distance planted apart 12 feet; propagated by seed; noue but seedlings. The orchards are small.

Maturity.-Age of fruiting begin at five years; age of largest crops at ten years; maturity of trees ten years.

Insect pests.-There is an injurious insect pest known as the Pulgon, which kills the tree.

\section{LEMONS.}

Picking.-The lemon is small, and is picked green both for home consumption and for export, and ripens after it is gathered. There is no method of curing. 'They are picked in the dry season, mainly in June and July.

Curing.-There is no particular process; the fruit is handled, both in gathering, stowing, and shipping, by hand.

Yield. - The best information I can get is that the yield of the orange is about $1,500,000$ per anum, the price being about 80 cents sucre,* or, say, 60 cents gold, per 100 .

It is practically impossible to get the yield of the lemon. There is exported about 60 boxes of 500 each, and the price is about 300 sucre. or 2.10 United States gold per box.

UNITED S'TATES CONSUlate-GENERAL,

WILLIAM 13. SoRsit, Consul-General. Guayaquil, March 10, 1890.

\section{ECUADOR.}

REPORT BY CONSUL BEAOH, OF GUATAQUIL.

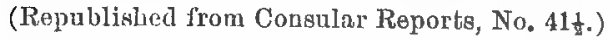

Notwithstanding its very restricted domain, it is probable that no country in the world possesses so great a variation of climate as Ecuador, which rauges from the temperiture of perpetual suow to that of perpetual summer, neither essentially chauging with the alternations of the seasons. The ice and snow at all times cover the summits of Chimborazo and other mountains of great altitule, while in the lower sections the mercury ranges between fro and 850 .

\footnotetext{
"Thes sucro is the monetary unit of Eenador.
} 
The soil is less varied than the elimate in characteristics, though possessing several elements. The lowlands are either loam unmixed, sandy loam, or clay loam. The surface of the uplands, with scarcely th axception, is of volcanic origin-lava, scoria, porphyry, etc. As in some other part of Sonth America, notably Venezin'lid, the exposerl rocks are undergoing a constant decomposition, prodncing a soil every. where in some degree fertile. In Echador even the lava has been so clisintegrated as to form a soil. Those giving attention to botany understand that each of the regetable species needs specific elements to promote germination and conduce to development. Some require elements other than a favorable soil or temperature. A portion of the regetable kingdom matures only after passing through the extremes of heat and cold, and which would not survive under a continuous summer temperature. The cocoanut tre ', as an illustration of the special requirements of many species of plants, may liave a soil and tempera. ture that are favorable, yet it must "breathe" the salt atmosphere in order to exist and thrive.

Ecuador, though having the wide range of temperature before mentioned, does not have radical changes, and therefore does not sustain all of the vegetation that would appear to have a place somewhere in the widle range of temperature noted. Yet there are few countries, if ans, that can sustain a more diversified vegetation than Ecuador. In fruits it produces all that belong to the tropics, usually in great profusion and perfection; and many rarieties not considered tropical, as apples, pears, peaches, and strawherries. In no respect have the proluctire resources of the country been fully developed, and the practices afford a poor instructiou for others to follow. A tescription of the crudities of the practice, and possibilities of the country, may prove of interest in portraying inutilized opportanities, and how not to do it.

\section{ORANGES.}

There are three varieties of oranges grown in Ecuador, viz, thick skin and thin skin, sweet, and sour. The thin-skin variety is in most demind for domestic use. None are exported further than Peru and Ohili. The trees come into bearing at from three to four vears of age, and continue to bear until about twenty years old.

The trees are all seerlings; that is, they comeup and grow naturally.

The fruit while ripening is occasionally afflicted with insects, evidently after the sweet juice.

As a rule the trees are not planted, but grow where they by chance come up. If set out in orchards the trees should be placed at least 40 feet apart, as the frnit requires much air and sunlight to mature well.

The fruit does not produce well immediately on the sea-coast, but 5 miles or more in the interior it does well on any kind of soil, though best on a deep, rich loam. 
The fruit is not irrigated, and the land is not cultivated, not even by cutting down the brush and weeds with a machete.

No expense for cultivation. Trees well matured average a yield of 4,000 oranges per year, which are sold on the tree at $\$ 10$, but which bring in the Guayaquil market from $\$ 3$ to $\$ 4$ per thousand. The home market is usually well supplied, and more luscious fruit is not elsewhere produced.

\section{LEMONS.}

Whe lemon family in Ecuador is of three sorts-large sour, limes, and sweet. The trees come into bearing at from two to three years of age, and continue to bear up to about twenty years of age.

The trees are all seedlings, and come up by chance.

Neither trees nor fruit are troubled with insects.

There are no orchards; but if there were, the trees, to produce well and bear good fruit, should be from 40 to 50 feet apart, for the same reason as given regarding oranges. The trees that come up promiscuously are often transplanted into hedges and set near together, more for the purpose of making a fence than realizing from the fruit, which is of market value.

The trees are not detrimentally affected by sea breezes, and they alppear to thrive anywhere.

The trees are not cultivated or irrigated.

It is difficult to say what the yield wonld be under good treatment, but it certainly would be very large. The price of the fruit is too low to make the business of lemon growing profitable in Ecuador.

\section{Horatio N. BEaCH,}

UNITED S'TATES CONSULATE, Consul. Guayaquil, February 24, 1884.

\section{VENEZUELA.}

REPORT II OONSUL BIRD, OF LAGUAYRA.

ORANGES. - H'om general information and from considerable personal observation, it may be stated that the Valoncia orauge is the only rariety known in Venezucla, the best of which grow in the vicinity of the city of Valencia, Venezuela, 40 miles in the interior and about 1,82 i feet above the level of the sea. They scem to thrive best with moderate expostre to the sun on hilly or undulating lant, on soil composed of blick loam. The arerage temperature best suited to their srowth would alppear to be $77^{\circ} \mathrm{N}$., with extremes of $85^{\circ}$ and 700 . The fruit matures best in a molerate season of rain, bat irrigation in nerer practiced. The caltivation of this fruit is proceeded with after the mosi primitive fishion, being propagated by grafts on seerlling stocks and receiving no fertilizing nor pruning whatevel. 'Tho mbards are of small extent, 
none being rivised for exportation. The trees are set 1.5 feet apart; they suffer little or no injury from insects or fungous grow th ; they come into bearing aftur five years from planting, when they begin to bear average (rops and are thereafter quite neglected. When planted near the coast the orange does not do well, but those raised in the interior are of good size and line flavor.

IAEMONS. - The lemon is not grown in Venezuelit. There is a larger sour-sweet fruit raised here that is, in general appearance, much like the lemon. There is also the smaller fruit called the lime, that is raised in great abundance, but never exprorted. These are the only fruits propagated here that bear any resemblance to the lemon of commerce.

WINIFELD S. BIRD,

\section{UNITED STATES Uonsulate,}

Oonsul.

Laguayra, November 15, 1889.

\section{MARACAIBO}

Oranges and lemons of many varieties grow wild in abundance on our river bottoms but nobody has ever paicl any attention to their cultivation. Figs are also planted, but rery few; they bear in great abundaice. The same may be said of olives; both figs and olives grow in the hot sandy soil of the const as well as in the higher parts of the Cordilleras. There is no doubt that if those fruits would receive proper attention aud were cultivated on a large scale a great export trade could be established.

\section{E. H. Plumacher,}

Consul.

\section{United Sta'tes Consulate,} Maracaibo, December 14, 1889.

\section{PUERTO CABELLO.}

\section{IZEPORT BY OONSUL DE BLANO.}

Relative to the cultivation of oranges, lemons, figs, and olives in this district, I have the hour to report that I have been unable to obtain information of sufficient value to be transmitted to the Department of State. The olive tree is not known in this district; as for oranges, lemons, and figs, they are not cultivated in the proper sense of the term; they grow without any care or attention here and there, and flourish and thrive, or languish and perish, according to circumstances. No lemons, oranges, or figs are exported from this district.

Charles de Blano, 


\title{
BRITISH WEST INDIES.
}

\author{
BERMUDA.

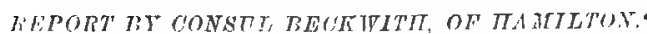

Vurieties.-In Bermuda we have but one variety of sweet orange, which is delicious, large, and juicy. I know of no name for our oranges; they are yellow, somewhat like the Harana and New Orleans oranges, although not oval shape, being round and flat; some measuring 18 inches in circumference. The Mandarin orange and grape fruit are also grown.

Situation.-The trees grow in valleys and are protected by cedar trees and hills. When exposed to the high winds they do not flourish. They are sometimes grown near little bays, and but a few feet from the sea, and very little above sea-level. The trees thrive by exposure to the sun. The valleys are the best where the soil is the deepest, and of a deep-red color.

Soil.-The soil is from 3 to 4 feet in depth, and subsoil is a deepred clay in these valleys, in some places of the depth of 12 feet, but on the sirles of bills not deeper than 6 to 12 inches, and mostly a loamy soil.

Climate-We can grow here all that grows in a tropical climate.

In the summer the average temperature is about $80^{\circ}$, in winter from $65^{\circ}$ to $70^{\circ}$. Night aud day varies very little. Our changes are seldom more than from $3 \circ$ to $4^{\circ}$. The sultry days are in August and September. The moist atmosphere occurs after heavy rains, the ground being porois, and the heat of the sun will then produce a heavy atmosphere; ordinarily alear, bright, and beantiful weather.

Trees of all kinds are becoming fewer on the islands, in conseque:lee of which we do not have as much rain as formerly, but when we hare frequent rains it adds much to the growth of the fruit and trees.

The seed is planted in boxes; thoy are also budded ou the seville orange aud lemon when the bark can be freely removed from the wood.

Cultivation.-Most of the trees are little cultivated; some are planted. in the grounds with the crops, and the only fertilizers are what are used for other crops-sea-weed, stable manure, etc. I find the best fertilizer to be chamber-lye, about 1 gallon to 300 gallons of water, thrown around the roots two or thrce times a montl. Care must be used in not making it too strong, as the albumen forms around the roots aud prevents the water penetrating, and in time all the leares drop, and if the roots are not attended to the tree dies; the remedy is to remove all the soil and use lots of water.

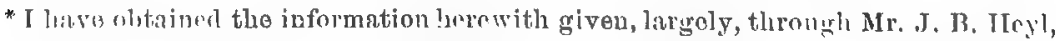

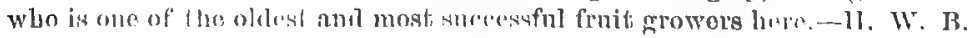


Pruning.-Ouly the dried branches are cutoff fruit-beariug trees, trim while young to a proper shape-then let alone. The height from the ground iu some cases is 30 feet, but a good height here is from 20 to 25 feet. They have always to be protected from the wind.

Picking.-The picking is done in December and at any hour of the day. They are picked when fully yellow-if the negroes do not steal them before.

Curing.-In a dry room for two or three days, sprearl on the floor, numbers too small to ship, home consumption take all.

Planting,-The trees are planted about, 20 feet apart, and propagated by transplanting from boxes-budded and grafted. We have good oranges from seedlings, but know what we are getting when we buil. You can never count on a seedling. The orchards are decidedly small.

Muturity.-A budded tree bears in three or four years; a grafted treo in about fire years; seedlings seren or eight years, sometimes ten. When the largest crops are produced is owing mostly to farorable seasons. There are trees on the islands over fifty years old still bearing.

Insect pest.-Sometime in the fifties (5s or 59) I think, a ressel was brought in here in distress, with a cargo of oranges; one gentleman who had some fifty or sixty very fine trees bought a few boxes of these oranges to plant the seed. In a few months his flourishing trees were corered with an insect which gare the trees the appearance of being whitewashed. This insect fed on the bark of the tree and extracted the yellow sap from the bark, curling the latter up. Every device thought of was tried, but the Island was cleaned of nearly every tree, lemon, oranges, limes, all shared the same fate. I lost mine as well, with the exception of two lime trees and a few lemons in another part of my grounds which led me to look to the cause of their being healchy. Between the two lime trees grew a pawpaw tree, and on looking at the lemon trees I found three or four yawpaw trees. I then visited all the trees I heard of that were living, and wherever I fond a live "tree the pawpaw tree was near it. I also fonnd glycerine a first-rate remedy, half glycerine and half water with a little carbolic acid, applied with a paint brush all over the trunk seemed to keep the atmosphere from the insect, which soon dies (or the carbolic acid may kill it), and the first rain washes off the glycerine, which does not destroy the trees as would oil. I have now some healthy trees grown from seed, with fruit on and last year we had a fair crop; another thing to look after is that your trees do not go too much to wood; the woody roots should be cut off 5 or 6 feet around the tree; they are the roots running from the tree which make the branches, and the fine roots that are close to the tree are the fruit roots and the ones to be nourished.

HENRY W. BEAKWITH,

Consul.

UNITED STATES OONSULATE, Hamilton, November 28, 1889. 


\section{DOMINICA.}

REPORT BY CONSULAR AQENT STEDHAN.

The oranges exported from this island are of the common sweet variety. The trees are not cultivated, but grow promiscuously throughout the island, at altitudes varying from 50 to 1,600 feet, and are most plentiful on the leeward side. The fruit begins to ripen early in Septem. ber, and the crop continues until the end of November- small quantities can be had in December and January.

The Serille sweet orange (which is used principally in making marmalade); the Taugarine and Portugal oranges are also grown to a small extent, but havě nut been exported.

There are a few lemon trees in the island, mostly of a poor description, but the lime tree is cultivated to a considerable extent and in. creasing annually. A small quantity of the fresh fruit is exported, but the great bulk of the crop is compressed and the juice exported in a raw and concentrated form, the latter principally to the Lnited States

The trees are grown at rarious heights, in some places as high as 1,500 feet. The trees are planted at distances of from 14 to 18 feet apart, according to the richness of the soil, and are propagated from seed. The picling begins in July and extends to November, the height of crop being in September. The juice is extracted by passing the. fruit throngh a mill and afterwards concentrating in copper taches.

\section{Wm. Stedman,}

Consular Agent.

\section{United States Consular Agency,} Roseau, Dominica, March 4, 1890.

\section{JAMAICA.}

REPORT BY COYSUL HOSKINSON, OF KINUNTOY.

(Republished from Consular Reports No. $41 \frac{1}{3}$.)

In reference to the fruit circular, I forwarded by last mail a press copy of Dr. Neesh's lecture on orange cultivation. The lecture has siuce been published in onc of the city newspapers, and combines a scientific treatment of the subject with a long practical experience of the writer. Oranges have wever been regulaly planted ont in this island as they are in Floridla, all the orange trees having been self: sown, manly by the seeds being carried by birds into the brush, and when the plant has grown up the thickets have heen cleared away, leaving the young orango trees stauding in irregular groups. No pains is ever taken to improva the variety, and no particular attention of any kind is given to the trees, the cleared land being the main considera- 
tion lor cattle grazing. The doctor says of the introduction of the orange:

When the Inglish landed in this island they found here tho sweet and bitter orange and the lime. The citron and shaddock are of more recent introduction; and at the present timo nearly all the useful kinds of the orange family are eitber widely disseminated or to be foind as growiug specimens in our botanical gardens. The Afgle marmelos, or Bael fruit, is yet scirce; the Japanese orauge, or kumquat, is almost nuknown, and some kinels of lemon, notably the bergamot and lime, are still wantiug.

After speaking at length of the conspicuous and distiuctive characteristics of the orange tree as evidence in the leaf, the flowers, the seeds, and the rind, he says :

The swect oranges grown in Janaica have beeu, up to quito recent years, of no particular or natued variety. They have been grown from seed; and it speaks much for the porfect suitability of tho soil aud climato in most parts of the island that such excellent fruit should have been prodnced under a plan which embodies none of the teachings of horticultural art, under a plan, in short, which is one of neglect or lucky chance, left to take the place of intelligent guidance. The earliest cultivators of oranges in this islond were the euslinved negroes, and the oldest trees yielding the largest crops are only to be found on those parts of estates which were set apart for the cottages and gardens of the slaves. I know of a small sugar estate on which, forts years after emancipation, the fruits of the orange trees planted by the old negroes around their dwellings, were sold to a contractor, without any expense of labor, for $\mathfrak{E} 40$. This was aimost at the commencewent of our fruit trade, and the crop (more carefully handled now than then) is worth more than ionble the money. Our common variety, then, is a mixture of seedlings, some of the fruit being really excellent, of large size, of good flavor, and of qualities which achieve for it a popularity in the Americau market. Naturally, when the cultivators trust only to seedling trees for their crops, the best fruit will be produced in the most highly-favored localities. The orange tree requires a deep, rich soil, a warm climate, with plenty of sun to ripen and sweeten the fruit, and plenty of moisture to keep up its growth. These conditions of soil and climate obtain in the parish of Manchester, which is famous for its oranges, also in the cooler parts of Clnrendon and St. Catheriue and in St. Ann's, from all of which parts the best oranges are exported.

\section{Of the methods for propagating desired varieties he says:}

We owe the large number of varieties to the tendency which the orange has to "sport," as gardeners term the tendency of seedlings to prove different from the parent plant. Whilst this tendency is of some advantage as affording the chance of improvewent, it is a disadvantage, in that it prevents the propagation of the tree by means of seed, for when seeds are sown the resulting trce is much more likely to bo inferior to than it is to eqnal or surpass its parent. Hence the necessity for special means of propagation, as by cuttings, layering, buclding, and grafting. The orange tree is not usunlly propagated by cuttings, but it can bo dono; nor hy layers, and yet, as a matter of fact, a mollification of the method of layering, kuown as layering by elevation, is practiced in the ease of the orange. Alnost everybody is fumiliar with the process of laying down the shoot of a grape-viue. The branch of the vine is simply laid in a shallow trench; it is pegged down in its place, or a stone is placed upon it to keep it down. The trench is then filled up with earth, which should be kept moist, when in about three months a copious supply of roots has been thrown out by the branch in the trench, and the shoot may be cut off from the parent viu" and be planterl in au independent position. Now, in the case of a bigh-growing tree like the orange, we can not bring the branch down to the gromnd, but we can carry 
up the soil to tho branch. It is done in this way: A flower-pot or box is made with a slit in its side, so as to receive a growing branch, which is first of all prepared by wounding or wringing the bark, so as to cause it the more reanlily to throw out roots. The flower-pots or boxes are then filled with soil and secured in their places by cords or props. The earth in the pots is kept moist by frequent waterings; and the result is that in a short time roots are thrown out, after which the brauch may be sawn off below the flower-pot, and it is ready to be planted out. This plan is now greatly resorted to by the Portuguese in the Azores; and I should like to read the following short extract from the account of their method by a visitor to the orange groves of the island of St. Michael. He says:

"The trees are increased in a curious way. The mode of propagation was derived from the Chinese, and has been much in use of late years. A branch of the diameter of 4 or 5 inches is chosen, around which a circularincision is cut. Around this straw matting is wound in tho shape of a funnel, aud filled with beaten earth from the middle of May to the middle of June. Roots soon begin to pusb, and by the following winter it is provided with sufficient to support it when detached from the parent stem. The young plant thus obtained often bears fruit at the end of two or three years."

This mode of propagation has simplicity for its recommentation. By its means the possessor of any good kind of orange tree could soon establish a considerable number of the same lind, and without the exercise of any special skill. But it is a slow process of multiplication compared with budding and grafting, which in fact are the modes adopted by nurserymen. For these modes stocks are necessary. Stocks may be raised from seeds, or full-grown bitter-orange trees, or swent-orange trees of inferior kinds may be cut down to stumps and a bud or graft inserted. For the theory on which budding and grafting deyends I must refer you to horticultural works, and also for the details. Let it suffice here to state that the process is by no means diffioult, and may be acquired by any nersevering grower simply by attending to the directions.

To return to the orange tree and the question of pruniug. The orab́ge tree differs from coffee trees and most fruit trees iu that very little skill or labor in prnning is required. As already stated, the fruit is formed on young sboots of the current year's growtl, and consequently pruning this tree can not exert the same influence as in pruning coffee, which requires ripened wood for the bearing shoot. Fertility in the orange is promoted by manuring, and pruning mas be simply restricted to cutting out dead wood and misdirected branches, or to giving a desirable shape to joung trees. To stimulate a bearing tree to its utmost prodnctiveness, the following plan may be followed: Let a cord be passed loosely round the trunk of the tree, and with the distance of the uttermost branches from the stem for a radius, let a circlo be marked on the ground round the entire circumference of the tree. A deep treuth, fulls a foot wide, should be dug along this line and be filled up with a mixtnre of bone.drst and well-rotted manure; finally, lot the trench be covered by the loosoned soil. The effect of this treatmont will be to stimulate a grow th of young rootlets, which will feed upon the enriched soil of the trench; the result of this will be that a strong growth of young shoots will everywhere take place amougst the branches; and, as a final consequence, the tree will be full of llowor atud fruit. When the season's growth bas taken place, it will be found that the treo has gained in size to the outer dimensions of the trench.

\section{Of the preparation for market he says :}

Within the past fow years great improvemonts have taken place in tho modos of collecting and packing the fruit. At first, in the carly history of our iruit trade, the oranges wero rudely kuocked down from tho trous by neans of long sticks, with no more cars than a pen-keoper's cittle-nam would take in knocking down a lot of bitter oranges as a feed for the pigs. They were carried loose in oarts to the port, and at the 
iv t the oranges were shipped in bulk. With all this bruising and want of care it is not surprising that cargoes on arrival at New York were found to be in such a da maged state as to be next to worthless in value. These early shipmonts indeed seom to have been good for no other effect than to teach the American consignees two things, one of which was the excellence of a Jamaica orange when it happened to reach New York in good condition, the otber was the lamentuble ignoranee of our people of all that pertained to collectiug and packing the fruit. American contraetors next appeared upon the scene. 'These agents had bcen sent out to make purchases of growing crops, and to teach and superintend improved methods of packing. They brought with them hundreds of pairs of small, stout pruning-shears, of to great monetary value, which they gave away to the laborers, whom they taught to cut off the orange fruits by tho stem and to deposit them carefully in a basket. They also taught that the oranges should be carefully laid on shelves and floors for one or two days, theu to examine them for signs of decay, and to wrap up in paper and pack in barrels only those which were sound. These teachings, wherever they were intelligently followed, had a good effect. The extra value of Manchester "stem-cut" oranges in the New York market soon proved that care meant money, while carelessness signified loss. Onr creole middlemen and contractors soon became more exacting as to the careful handling of the oranges they bought from the peasaut proprietore, and the upward tendency of local prices hus steadily gone on as a consequenee. Seven or eight jears ago the wholesale price of oranges in the interior towns was sixpence per 100, aud their value in New York was a thing not to be foretold from the prices-eurrent, for very often the shipment of such fruit entailed a henvy loss. Nowadays the price of a barrel of wrapped oranges is $\$ 3$, and the price obtained in New York fluctuates between $\$ 5$ and \$7. Under the improved modes of packing the trade has steadily gone on increasing, until it is now an established and most important industry, representing, according to the latest returne, an export value of $£ 37,567$, obtained for $34,000,060$ of oranges.

\section{And of the several competitors in the fruit market he says :}

For the possession of our actual and possible future markets we have certain competitors. The principal of these is Florida; next comes Cuba, which ships oranges principally from the port of Havana. The island of Porto Rico is rather a formidable competitor. Mayagnez is the principal port of shipment, and the fruit is so fine that it fetches good prices in the American market. Of Jamaica oranges 400 are taken as the average number contained in a barrel, but of the oranges shipped from Porto Rico a barrel contains on the average 350 ; in other words, seven of such oranges are equal to eight of those sent from Jamaica. They are also said to keep well. The extra size denotes careful cultivation, and the better keeping qualities tell of care in picking and packing. The Babama Islands usually send oranges to the American markets, but this year the growers have been unfortunate, as the crop is reported to have been entirely destroyed by a succession of heavy gales. The other West India Islands must also be regarded as possible competitors, though up to the present they are not actively competing. British Honduras is also a competitor, both in bananas and oranges, and the opening up of a direct line of railway between Mexico and the American frontier, which has justnow occurred, also suggests Mexico as a competitor, if not with Jamaica, at least with Florida. California is even a competitor, but the effect of her competition is simply to supply the markets on the Pacific coast, aud even there California has to struggle against the shipment of oranges from Tahiti and other islands in the Pacific. At present the countries bordering the coasts of the Mediterranean are competitors more for the supply of lemons to the United States than of oranges. The Azores have their principal orange trade with Eugland, and only a limited trade with the United States. In the Azores they have great difficulties of climate to contend agaiust. Westerly gales, sweeping over the wide expanse of the Atlantic, are so violent as to be very destructive to the orange crop. To overcome the disadvantage, expensive structures of high-walled inclosures of small area have to be resorter to in order to provirlo shelter. It need hardly be remarked that all such difficulties and expense are spared in Jallain':

$$
156 \mathrm{~A}-3
$$


Let me add, in conclusion, that Jamaica is admirably adapted for orange cultivation. The soil, the climate, the rapidly increasing steam facilities for transportation, and the cheapness of land seern to me to combine to make of this island an especially desirable field. As I lave said, the fruit actually grows wild, and without other cultication than keeping down the bush. If the same intelligent care and attention were given to the growth of the tree and to the proper packing of the fruit for market that obtains with us in the United States, it would prove a most profitable and pleasant occupation to all engaged in it. But the cultivation is regarded as secondary to the use of the laud for cattle or sheep pasturage, and the care and handling of the fruit is still, as a rule, of the roughest and most careless desci iption. Nearl 550 per cent. of the fruit, on an average, is either spoiled or seriously damaged before it reaches a market, and the greater portion of this great loss is due to rough and careless handling.

Geo. E. Hoskinson,

Consul.

\section{United S'Tates Consulate, Kingston, Jamaica, March 27, 1884.}

\section{JAMAICA.}

\section{REPORT BI GONSUL HOSKINSON.}

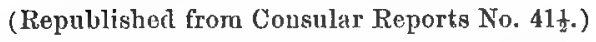

Iu further contiunation of the subject treated of in my dispatch of the 27 th of March, I have now the honor to forward, in a counected form, the uotes of an experienced observer and cultirator of the orange tree.

Geo. S. Hoskinson, Consul.

\section{United States Consulate,} Kingston, Jamaica, April 14, 1884.

[Inclosure.-Coneul Hoskinson's report.]

Parieties. - Of oranges, the varieties principally grown are native seedlings, some of which were prior to the emancipation planted by the slaves near their dwellings and attended to by simple methods of cultiyation. Many of the trees now furuishing fruit for export are the remants of those planted by the elaves, such as the irregnlar groves now to be found on sugar estates and coffee plantations. Some of the trees are wative seedlings spontanoously springing up iu pastures and guinea-grass pieces. Since emancipation the colored perplo have planted orange trees in their amall freeholds in the mountains. This has been done to a large extent in the parish of Mitu"hester, wheresweet oranges of grod quality havo been long grown, and where the

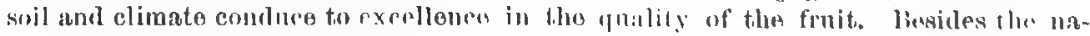

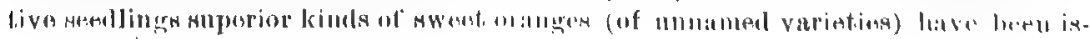


ened from the Botanic Gardens, also Tangerine oranges of a very fine quality. The trees issued from the gardens are budded and grafted. The Tangerines are mostly grafted. It is difficult to say which are the more valuable. The 'Tangerine oranges fetch the highest price in the local markets, but they are notexported. Of the native seedlings those produced in Mauchester are admitted to be the best in the island on account of size, sweetuess, flavor, and for their good keeping 'Iualities. It lias also beeu maintained that they bear handling, packing, and the sea rojage to New York better than varieties grown elsewhere; for example, better than those grown on the worth side of the island. Seedling trees begin to bear at eight, nine, and ten Jears, and are in full bearing at fifteen or twenty years. Grafted or buckled trees come into bearing a little earlier from the time of planting ont. Nothing definite can be stated as to how long the trens remain fruitful further than it must be a long time, as trees dating from the era of slavery and estimated to be fifty or sixty years and perbaps older are still in full vigor, and the writer has seen such trees withont observing about them any sigus of decay from old age. The longevity of the orange tree is well known. but in this island it is difficult to ascertain the age of old orange trees, owing to the fact that their planting was the work of slaves in their own time and not plantation work. Records of old plantation work still exist, but not of the planting of orange trees. The foreign market for Jamaica-grown oranges has only been opened up within ten or twelve years past, and it is only in recent years that methodical planting has been resorted to.

Of lemons, the known varieties are only two, viz, an old-established seedling variety, producing very large fruit, and seorlings obtained about five years ago by the importation of Sicilian lemons from New York, with the object of obtainiug their seed for planting purposes. The frnit obtained from the trees of the last-named variety are of larger size than the fruits from which their seeds were obtainet. The trees referred to have borne good crops this season, the lemon, as is well known, coming earlier into bearing than the orange. There is as yet only a limited production of lemons, aud the trade is principally in the hands of two growers, who send their produce to New York. For local nse, in the preparation prineipally of lemonade, and in cookery and domestic uses the lime takes the place of the lemon. The lime grows spontaneously in most parts of the island. It is of the easiest possible culture.

The trees of all these varieties of citrus, orange, lemon, and lime are principally seedlings. It is ouly latterly, that is, since the development of the export trade, that budding and grafting have been resorted to.

Insect pests.-In Janaica the orange trees have few insect pests, and there are no complaints of attacks of fungus. It is only where orange trees are attempted to be grown in hot and dry localities, as, for example, in gardens in the city of Kingstou, and the ratber arid plain of the Liguavea, in the parish of St. Andrews, that they suffer from coccus and ants. In such localities lemons and limes suffer less than orange trees; but in the locality referred to the climate is admitted to be too hot and dry for the orange tribe. On the plains of St. Catherine, in the vicinity of Spanish Towu, recent attempts at planting orange trees have been made. This plain is an extension of the Liguanea, but the climate is moist and the lands are capable of irrigation by the Rio Cobre Irrigation Works. 'These plantations were recently inspected by a Goverument officer, one of the superintendents of the Botanic Gardens, and in his report he speaks favorably of the appearance of the young trees, without mentioning the ravages of auy pest. However, it is known that the coccus has attacked orange trees in another locality in the same parish, but the attacks havo been subdued by smoaring the trees with a composite lime wash wade by boiling together lime, sulphnr, and tobacco stems in, water. Further in the interior and at a greater elevation the coccus is almost entirely unknown. It has not hitherto been a subject of complaint amougst growers.

Planting.-Most of the trees in pastures and on sugar estates and coffee plantations stand vely far apart: indeed, they may be said to he isolated trees. In close plant:L- 
tions the distauces are between 20 and 30 feet apart. In the small grounds of the peasantry the trees may be observed so closely planted as to be in contact. Wide plauting, however, is preferred by intelligent growers as tending to the best results. 'Iangerine oranges are planted at 22 feet apart, and larger sweet oranges at 25 to 30 feet apart; lemons, 18 to 22 feet.

Situation.-Plantations of orange trees are made principally at elevations above 1,000 feet. In Manchester the olevitious will average 2,000 feet. Undulating valleys aro principally selected on account of the greater depth of the soil to be found on such spots, also on account of its greater richness. The soil principally selected is that of the white limestone formation of Jamaica geology, known as "honeycomb rock." The resulting soil is a strong red eartb, calcareous and ochery, owing to the presence of red oxide of iron. Orange trees yield the best results on the limestone soils, both on account of constituents promoting fertility and on account of the perfect natural draiuage of such soils.

The sea-shore is avoicled. The powerful sea-ioreezes (trade winds) are hurtful to the blossoms and tender branches. At an elevation of 500 feet the sea-breeze ceases to be troublesome. The sea-shore is also too arid, and as a rule the soil of the coast line is sterile and unsuitable.

Irvigation.-Artificial irrigation is only practiced to a limited extent in the plain of St. Catherine, and its application to orauge trees must at present be regarded as experimental merely. The principal crop cultivated between orange trees is guinea grass, but some of the best growers prefer to keep up a clean cultivation, the nunber of such cultivations and cleanings being determined by the growth of weeds. To keep up a clean cultivation in certain low and moist districts would require a cleaning every three weelss; but longer intervals, as of eight or ten weeke, could be taken in drier portions of the year. 'The general practice, however, is to allow the grass to grow and to keep weeds and shrubby undergrowth cut down by means of a cutlass or bush-knife, which is done three or four times a year. In the grounds of the peasantry the whole list of cultivated crops in the tropics might be enumerated as crops cultivated between orange trees. Il maý suffice, however, to mention yams (Dioscorea alata, Dioscorea trifida, etc.), cocoes (Colocasia esculente), bananas and plantains (Musa sapientum aud Mrusa paradisiaca), coffee shrubs (Caffea arabica), papaws (Carica papaya), annatto (Bixa orellana), and small culinary vegetables. "The "yard" or "provision ground" of the peasant is generally a perfect medley of vegetable growth, including besides orange trees almost evergthing else. In such places the cultivation of the orange tres is associated with the stirring and cleaning of the ground necessary for tho smaller crop.

Yield.-Owing to imperfect data it is difticult to give particulars as to yield, proceeds, and cost of cultivation. Undoubtedly the yield conld bo iucreased hy more careful cultivation and judicious manuring. The yield in a tropical climate may be described as more continnous than in a wam temperate or subtropical region. Oraugetrees are observed to be in flower and in fruit at the same time. The tendencr to continuons flowering is so strong that every copious shower ma be said to bo followed by a growth of young shoots with their flowers. This tendency greatly prolongs the season of fruit. It is scarcely an exaggeration to say that sweet oranges may be obtained all the year round, but the priucipal season of fruit is from september to April, This teuclency is even stronger in the case of the liue, which is to be had in pleuty for ten or eleven months of the year. As to proceeds, it is unly when whe orange crop is sold in bulk to a contractor thut the fignes becomo known. This is the general practice on sugar est it tes wherever oranges may be irrowiug. The cost of cultivation has a willo range, from nothing at all where it is negleceled, as is too often the case, to the heavy exprust of maintining a clenu cultivation. In the orange districts nurest Kingston t'le prices obtained ly tho puasunt proprietors (who sell small lots weekly to carters and doalurs) on the supol ringe from 9d. to 1s. per 100

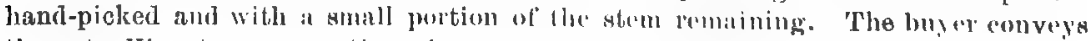

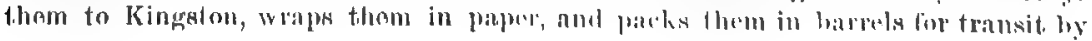


shemere to Now York, Philadelphia, and Baltimore, At this rato the yicld from siugle trees has beeu estimated to rauge from 108 . to 20 s., and even more according to the age and size of the lroe. Growers who pack their own oranges usually obtain 128. a barrel in Kiugston. Latterly, tho tendency of prices has been upwards. Mauchester "stem cut" oranges, carefully wrapped and packed, are worth $16 s$. (\$4) a barrel in the local export market. In New York they are wortl from $\$ 5$ to $\$ 8$ per barrel according to fluctuations in the market. A barrel contains from 350 to 400 oranges. Thus it will be seen that the protits of the large grower greatly exceed those of the persant.

\section{GENERAL REMARKS.}

The spontaneous character of orunge cultivation in Jamaica is a noticoable feature. It is ouly during recent years that a new character is being given to the culture by systematic planting and increased attention. The official count of oranges exported in theyear ending September 30, 1833, is 3 3,000,000. Almost all these were wild oranges or spontaneonsly grown fruits. The climate of Jamaica, in the olevated portions of the interior, is believed to be exceedingly well adapted to the cultivation of the orange, and the soil also. The excelleut seedlings spontaneotisly grown may be ad. duced in support of this belief. When cultivation is bestowed the first effect is to increase the size of the fruit. Manuring is much neglected, but when manures are applied the increased yield and the more rapid growth of the tree are very noticcable. The tree is a gross feeder, and requires lime, potash, and phosphatic and ammoniacal manures. Cow mauure is the compost applied in Jamaica. The orange industry is limited to the export of the fruit to the United States and Canada. No commercial attempts have beeu made to oxtract the essential oils for perfumery.

The length of the season of fruiting in this island is also noteworthy. Those who are experimenting with irrigation entertain the idea that the season may be controlled so as to produce fruit at any desired time of the year by its aid. But this may prove a doubtful advantage, as summer-grown oranges would enter into competition with northern fruits in their own markets. For the same season a summer crop of bananas is not so valuable as the crop prodnced daring the absence of northern frait. The natnral close of the orange season in Jamaica is marked by the fruiting of the Star apple, and then all classes prepare for themselves the tropical dainty which the creoles style " matrimony." This is a mixtnre of fresh orange juice with the pulp of the Star apple, wo which various flavors are added according to taste. Bnt the simple admixtnre is a delicions compound and is universally relished.

\section{TRINIDAD.}

\section{REPORT BT OONSUL SA TFER.}

Orange and lemon trees are attended with good soil and climate in this colony; but they are mostly in a semi-cultivated condition, as, hith. erto, planters bave given their attention to the more important industries. The fruit, however, is of good size and quality, a considerable number being shipped to New York by direct line of steamers. Figs and olives are nseless in this colony, the former being destroyed by frugirorous bats, and the latter do not bear.

MOSES H. SAWYER,

Consul.

UNTTED STATES Consulate,

Trinisal, B. W. I., November 2:, 1889. 


\section{Mr. Hart to Consul Sacyer.}

[Inclosure in Consul Sawyer's Report.]

Varieties.-The St. Michael, or ordinary sweet orange. Citrus aurantium, or tho Mandarin and Sangerine.

Situation.-In sheltered valleys, at elevations from 100 to 1,000 feet above sea-level, and from one-fourth mile inwards. The trees are slightly shaded from the sun. Sheltered valleys are best; soil, loamy, alluvial; subsoil, voleanic (trap).

Temperature.-Meau maximum, 870.5 Fab. Mean minimum, $69^{\circ} .7$. Meau annual, 780.6. Maximum, 910 , September mean for month. Minimum, $66^{\circ} .9$, February mean for month. Range of temperature varies from $21^{\circ}$ to $30^{\circ}$ daily.

Average rain-fall for twenty-tive years, 65.49 inches. Growth takes place during rainy season, from July to December. (Driest month, February.)

Invigation.-No artificial irrigation used.

Cultivation.-Practically the trees grow without attention. (Weed.)

Fertilizers. -No manure nsed, except near a bomestead, when farm-yard manure is very beveficial.

Pruning.-Little or no pruving practiced. Trees would be better for attention in this direction.

Picling.-When commencing to turn yellow, or when "full," to use the local term. Curing.-Simply dried.

Packing.-Packed in cases containing 2 cubic feet, with one division; wrapped in paper.

Planting.--No regular plantations yet exist. Trees are planted irregularly, and all trees are raised from selected seed at Royal Botanic Gardens and distributed thronghout the coling.

Maturity.-Trees begin to bear at five to six years, and reach full naturity at twenty jears.

Insect pests. -Insects common: Brown and white scale, cottong scale; sometimes destructive; cleaned with lime wash and soap solutions. I know of no useful insects but the numerous varieties or species of wasps.

No printed matter available.

Cultings. - Cuttings can be secured through the New York agents of Direct Line Steamers, George Christall \& Co.

$$
\text { J, F. HART, F. L. S., }
$$

Government Botanist and Superintendent of the Royal Botanic Garden, Trinidad.

\section{DUTCH WEST INDIES.}

\section{REPORT BY UONSUL SAITTH, OF CURACHO.}

In regard to the information relative to the cultiration of oranges, lemons, figs, and olives, requested in circular dated the 2sth September, I have to report that said fruits are not cultivated here. In former times, when rains were more regular, a kind of bitter ormges, from the peels of which the Curaçao liquenr is made, was grown here, but is now almost entirely ahaudoned.

I. B. Sиiтн,

United States Consulat'ie, Consul.

Curaçao, W. I., Norember 8, 1889. 


\section{FRENCH WEST INDIES.}

\section{GUADELOUPE.}

IETORT PREPARED BY MR. ST. FELIX OALARDEAU, DIREOTOR OF THE BOTAN. IOAL GARDEN AT BASSE-TERIIE, FOH OONSUL BARTLETT.

The only variety of lemous raised to any extent in this island is the small lime, which is used in Dominica and Montserrat for making concentrated lime juice. In Guadeloupe thus far it is only used for domestic and culinary purposes, but could be raised as well as in the English islauds for making concentrated juice. For many years there has been a disease on the lime trees, but the evil seems now to be passing off.

There are plenty of good oranges in the island; they aro mostly used for local purposes. Very little exportation has been tried from here, Guadeloupe being too distant from the United States to export oranges profitably by sailing vessels. Steamers would succeed and perhaps incite the country people to raise fruits for exportation. There are four or five rarieties of good oranges in the island.

No regular orchards.-The trees are a few in gardens and on different estates, more or less. No large fields of oranges. Grows more luxuriantly on cool mountain sides. Subject also for may years to a blight, caused by a variety of aphis or louse, which attacks the young twigs of the trees.

No special cultivation.

No fertilizers used.

No pruning.

Oranges are ripe from Norember to April. Blooms in March.

Trees are propagated from seeds.

Fruit at five or six years from seed. The variety not always the same from seed. No grafting of orange trees. Trees in full bearing at ten years of age from seed. Live a great many years.

No exportation of oranges or lemons from the island. St. Felix caichdeau.

BASSE-TERRE, March 23, 1890. 


\title{
SPANISH WEST INDIES.
}

\section{CUBA. \\ REPORT BY CONSUL.GENERAL WILIIAMS, OF HAVANA.}

No regular system for the cultivation of oranges and lemons for export is followed in this island. The only plantiugs of these fruits here are made in scattered spots of land about the buildings of small proprietors. The trees seldom receive the care of good husbandry, and whatever surplus arises in this way over local deman il is sold to gatherers who ship it to the United States. Therefore regular and well laid out orange groves, as seen in Florida, do not exist here. But the capacity of this island for the production of these two fruits of superior quality is almost unlimited.

RAMON O. WILLTAMS, Consul-General.

\section{United S'TATES Oonsula'TE-General, Havana, March 24, 1890.}

\section{SANTIAGO DE CUBA.}

\author{
REPORT BY OONSUL REIMER.
}

ORANGES.

Varieties.-The wild orange found all through the mountainous and wooded districts of this island is no doubt native thereto, as it is found in mountains and wildernesses where no human foot has ever trod before; whereas the sweet orange was brought here last ceutury and even earlier by the French and Spaniards, and also the English, from Trinidad and Martinique. Owing to the lack of transporting facilities the oranges are not at all cultivated and trees here and there on coffee and sugar estates enable the people liring in this eity to ocensionally enjoy the fruit. It is a curious fact that oranges planted in the immediate vicin. ity of this eity and also in the immediate vicinity of the coast, no mat ter how sweet they originally were, produce crops of sour oranges. This is no donbt owing to the mature of the soil, which is chiefly composed of decomposed coral rock and contaius consilerible lime. In the rich alluvial soil of the interior oranges suitable for commeree cau easily be grown, but, considering the cost of transporting them to the seat board, their cultivation on a basis sufficiontly extensire to warrant a large export is at the present. ont of the gluestion. 
As to the varieties of sweet, oranges grown liele, I find from les. sonal observation that, whatever its origin, the sweet orange acclimated here takes a good deal of the Havor and character of our Florida oranges, and as no effort is made to scientifically cultivate any particular lrind and species, it is impossible to determine the best variety.

Situation.-Trees producing sweet orauges are found here on sugar and coffee estates from 10 to 50 miles from the coast line and distant from shipping ports and harbors.

As to elevation above sea level, sweet oranges can be produced in rich alluvial soil found at various elevations.

Climate.-The temperature of this island varies from 60 minimum to I00 maximum (FahrenLeit) all the year. The nightsin winter are generally cool, especially when the north winds, most common from December to March, prevail. In the mountainous districts of this province the nights are never sultry, although the days rery often are very sultry. In the absence of any scientific statistics I calculate from personal observation that the rain-fall is about 45 inches per annum.

\section{LEMONS.}

Lemons are not cultivated at all, and in their stead limes, growing wild here and natire to this country, are used.

The lack of laboring men, the few necessities of the natives, and the poor transporting facilities render the success of all agricultural industries, except the cultivation of sugar, almost impossible as a commercial investment.

Figs, although easily grown here, are very rarely found. Olives not at all.

OTTO E. REIMER, Consul.

United STates Consulate, Santiago de Cuba, January 10, 1890.

\section{PORTO RICO.}

REPORT BY OONSUL CONROY, OF SAN TITAN.

(Repnblished for Consular Reports, No. 41 $\frac{1}{2^{\circ}}$ )

In answer to the Department's communication, dated December 4, 1883, requesting information with regard to fruit culture and the extent and value of the fruit industry as conducted in this consulate, I have respectfilly to state that there are no grape vineyards, olive trees, or figs cultivated in this province.

Orange trees grow all over this island. The Porto Rico orange mostly cultivated averages from $2 \frac{1}{2}$ to 4 inches in diameter. The trees average 
from 8 to 30 feet in height, according to the attention given to theil culture. They commence bearing the fourth year and hold their own for fifty years or eveu more. Their fruit is very sweet, with a fiue delicate acid, thin pulp. When taken medinm care of the trees produce abundantly, say 1,000 to 1,500 oranges to each tree. These are planted from seeds, say the pit of the fruit, grafting, or budded, but the seeds give better results. The seed should be dried in the air without expos. ure to the sun or artificial heat. The trees are very seldom troubled with disease, unless entirely neglected, when they are subjected to a sickness called "piojillo," similar to a white mold dampness, which spreads over the leaves, branches, and trunk of the trees. Whitewash, with lime, and ashes at the roots of the trees produce the desired effect.

The trees are planted about eight yards apart. Any closer the trees are not so productive.

This islaud being very fertile, orchards are to be found in all parts of it, from close to the sea-shore, say about a mile distant from the coast, up to the interior, and up the mountains as high as 2,500 feet above the level of the sea. It is noticed that all kinds of trees produce well, and are much fiuer in sandy soils, say about a mile or two from the sea, where the soil consists of black sand, or about three parts of fine sand and one part of black earth, with a bottom of hard clay at from 3 to 4 feet below the surface. Most of the orchards are situated from 2 to 5 miles from the sea-coast.

There is no system of irrigation in use, the periodical rains being quite sufficient. The ground in orchards is often eultivaled with rice, corn, beans, etc., but more of them with grass. The trees are poorly attended in this district, and in all the east end of the island, very little fruit being raised for export. In fact, so little attention is given to the culture that it may be cousidered that the orange as well as other fruits are growing in their wild state.

In the west end of the island, more particularly in the district of Mayagnez, oranges and pineapples are cultivated for exportation to the United States; quite a number of American schooners come out during the months of November and December in ballast from Boston and New York, and load with fruit. I cau not state definitely the yield of the trees, but each tree is calculated to give from 1,000 to 1,500 oranges, which sell readily at $\$ 3.25$ per thousand.

T'he cost of cultivation is very littlo. The crop commences in this district in December and lasts until May. When propere care is takeu, however, it is most conmon to have the trees with ripe and green fruit growing at the same time. Orauges are to be had all the year round, but from May to November in less abundance.

As this island is situated between $17^{\circ}$ and $18^{\circ}$ of latitude north, there is no great change in the temperature. During the winter months it rains almost contiuualy, but the thermoneter seldom indicates less than $75^{\circ}$ Fahr.; so there is no frost ever feared. The want of roals all over 
this province is the great drawback to the cultivation of all fruits that require to be handled with care. The climate is fine and soil very pro. lific. Even in the highest points of the monntains, among the rocks, the orange trees grow wild. Lemons are abuudant the entire year round, but the trees mostly grow without culture; the fruit is small, but very juicy. None are exported.

EDw. ConRoY,

Consul.

United Sta'tes Cónsulate,

San Juan, Porto Rico, January 28, 1884. 


\title{
CONTINENT OF ASIA.
}

\author{
ASIA MINOR.* \\ REPORT BX CONSOL EMMNTT, OF SMYRNA.
}

Varieties.-The best oranges are the "Parakila," so called from the village of Mitylene Parakila, and the "Kaw" trees, so called from their being blood oranges. As for lemons, the "Chio" are the best; none others are cultivated.

Situation.-Valley, hillside, or table land; distance from sea immaterial; elevation above sea-level from 35 to 2,700 feet; exposure to sun immaterial, as the climate is very mild and agreeable here.

They are grown on all kinds of land, but table land is preferable. The soil is calcareous.

Climatic influences.-The climate has great influence upon the orange and lemon trees, which do not thrive in the olen air below $43^{\circ}$ latitude and where the temperature is lower than freezing point.

The temperature in minimum is $32 \circ$, maximum $95^{\circ}$, average $68^{\circ} \mathrm{Fahr}$ enheit; the atmosphere is very heavs, but always variable by winds at night.

\section{Rain-fall.-About 25 inches.}

Irrigation.-No system of artificial irrigation is in use here. When the fruit has the size of nuts, water is necessary; and in abundance, every week once at least.

Cultivation.-The working of the soil is commenced at the end of March; they dig the soil with a spade to the depth of two to three inches in the clear spots, and only 1 to $1 \frac{1}{2}$ inches deep in the vicinity of the trees.

Fertilizers.-At the end of November human manure is largely employed every two years. These manures are buried in the soil at a depth of from 10 to 12 inches round the trees, and remain buried and exposed to the rain until the end of March, when cultivation com. mences.

Pruning.-They prune once at the end of March with very great attention, and they give to the tree a regular, elegant, and graceful form.

* The information here given was obtained from the consular agent at Mitylene, who is axtrnsivaly "ngaged in the cultivation of oliven as well as lamous and oranges. 
Picking and curing.-They pick two or three days after Christmas, immediately after ripeness, which takes place here during December. They are cured by wrapping in tissue paper. For packing and ship. ping the fruit is always packed in tissue paper, and in this manner packed in boxes or baskets containing about one hundred each.

Planting and propagating.-The trees are placed at a distance of about 20 feet from each other if the soil be rich, and at only about 17 feet if it be middling.

The orange aud lemon trees here are budded or grafted; the best varieties are grafted.

There are small and large orchards here.

Maturity.-The trees come into full bearing the fourth year and they reman fruitful about fifty years, but the best crops are gathered from the fifteenth to the thirtieth year.

Insect pests.-Insect pests do not exist.

W. C. EMme'TT,

Consul.

UNITED STATLS Consulate, Smyrna, January 18, 1890.

\section{MITYLENE.}

REPORT BY OONSULAR AGENT FOTTION.

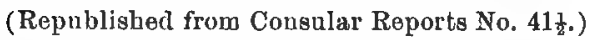

Every variety of orange and lemon tree is grown here, but the most valuable are the Parakila orange trees, so called from the village Parakila: and the Kan orange trees, so called from their blood-red color. The Parakila trees are large, and produce very large fruit, while the Kan orange trees are not large, but their fruit is very sweet. The trees come into full bearing the fourth year, and they remain fruitful about fifty years, according to the climate and cultivation. The orange and lemon trees here are budded or grafted. The trees are not troubled with injurions insect pests or fungus growth, but sometimes are injured by the cold, when the temperature is lower than $0^{\circ}$ Réaumur. The trees are placed at a distance of about 6 meters from each other if the soil be rich, and at only 5 meters if it be middling. Orchards are found in every place, but they yield best results on the sea-coast. The orchards are found very near to the sea-coast. No system of artificial irrigation is in use here. They prune here at the end of March, with very great attention, and thes give to the tree regular, elegant, and graceful forms. As soon as the pruning is finished the working of the soil is commenced, and they dig the soil with a spade to the depth of 25 to 30 millimeters in the clear spots, bnt only 2 or 3 inches deep in the vicinity of the trees. Jater, two or three baskets of mannre are distributed 
around each tree, and at the end of May the ground is irrigated once in every week or two weeks, according to the season, the position, and quality of the ground in summer. Irrigation is suspended during the antumu and winter. At the end of November manure of human excrement is largely employed every two years. These manures are buried in the soil at a depth of from 25 to 30 centimeters round the trees, and, remain buried and exposed to the rain until the end of March, when cultivation begins. The yield proceeds per acre per anum in the best orange orchards is about $\$ 80$, and the cultivation costs per acre per annum $\$ 15$. The principal portion of the orange and lemon product is for home cousumption; the export is insignificant.

M. M. FOT'LLN, Consular Agent.

\section{United States Consular Agendy,} Mitylene, March 12, 188 .

\section{PALESTINE. \\ REPORT BY OONSUL GILLMAN, OH JERUSALEY.}

Oranges and lemons in Palestine are grown chiefly along the seacoast; and the more extensive groves are at Jaffa, which place is now celebrated for the excellence of its fruit. Some groves ou a smaller scale are also found at Gaza. The orange is cultirated in other places in the district, and even in and around the city of Jerusalem, but not in sufficient amount to be worthy of special notice; the fruit grown inland being generally inferior.

Varieties.-The two principal varieties of the orange grown at Jaftil are called the Shamudi and the Beladi. The Shamudi is of an oral shape, in this respect somewhat resembling a lemon, and, owing to its large size, fine flavor, and thick skin, is the sort best suited for exportation. The finest of these are considered the largest orauges in the world. The Beladi has a round form, and is smaller in circumference, and, although more juicy than the Shamudi, is not so much in demaud for exportation, as its thinner skin does not enable it to stand so well a long voyage. The Sidou orange is a small round fruit, much smaller than the Beladi, than which it is also sweeter and more juicy; while the skin, being still thinner, renders it unsuitable for tra nsportation to any great distance. In flavor it is cousidered one of the most delicious of its species. Its cultivation is chietly confined to the place for which it is named. The Tangerine orange, also known as the Mandarin, and resembling the variety of the same name grown in Florila, is also culti. vated at Jaffa to a very limited cxtent; yet it usually brings a higher price than any of the other nimed varieties. There is still another sort of orange, viz, the ungrafted. This is produced on treas raised directly from the seod, but being of small size and merdioner ass to quality it can 
not compete with the fruit of the budded or grafted trees, and is kept for home consuruption.

Of the lemon there are two kinds, the sweet and the sour. The former comes into market in November, and lasts only a short time. Though quite juicy it has but little fluvor. The rind abounds with a bighly tragrant oil, resembling bergamot in odor. The fruit is much appreciated by the uatives; but it is not exported. The sonr or acid lemon attains at Jaffa a very large size, while the acid is less sharp and of a more delicate flavor than that of the lemon of other countries. It is more and more extensively grown each year, with the object of exportation, though in the past chiefly produced for the home market.

Situation.-The distance of the orange and lemon gardens at Jaffu from the sea is from one-fourth of a mile to 3 English miles. Here the trees Hourish, and find altogether an enviromment best adapted to their superior development. The elevation above the sea-level is from 50 to 100 feet. The larger part of the environs of Jafta occupied by these gardens must be considered level, and only a small portion of it can be called slightly rolling land. The trees seem to do best in such a situation, and with sufficient exposure to the sun, which here there is no lack of.

Soil.-The character of the soil in which the trees best succeed is a sandy clay. It is considered that a mixture conducive to the highest results would be 75 per cent. of the beach sand with 25 per cent. of alluvium, and containing a good proportion of alkaline salts. The subsoil is chiefly clay.

Climate.-The arerage temperature at Jaffa is in the daytime, 700 to $71^{\circ}$ Fahr.; and at night, $55^{\circ}$ to $56^{\circ}$ Fabr. The mininum temperature is $32 \circ$ Fahr.; the maximum, $10^{\prime \circ} \circ$ Fabr. The vights are usnally cool, while the days are warm or sultry. The ordinary atmosphere, affected by the sea breezes, is, in general, moist. The lain-fall varies from 17 to 30 inches per anuum. The growth of trees and fruits are accelerated during the "rainy season;" but as irrigation is constantly employed here during the "dry season," the difference is not so perceptible as it would be uncler other conditions.

Irrigation.-Within a circuit of 4 miles around Taffa, the gardens are irrigated. The water is found at deptlis of from 20 to 60 feet below the surface, wells being sunk to these deptbs. The water is raised by water-wheels moved by horse-power. The trees are irrigatel during the entire of the "dry season," which generally lasts from May till November. The flowering of the trees usually begins by the middle of March, and continues till the middle of April. The trees are watered once a week, and during the night, to save evaporation; the quantity of water distributed by the drains may be estinated at about 15 cubic meters to the acre, per diem.

('ultivation.-The soil of the gardens is dug at different times; but at least twice a year, generally in the spring and autnmn. 
Fertilizers.-The fertilizers used are the dung of the horse, and that of the mule and camel, applied mostly in the winter-time.

Pruning.-Little or no pruning of the orange and lemon trees is observed at Jaffi. The trunks are usually left shaded by the lower branches.

Picking.-Oranges as well as lemous are picked from October till May, that is from green to fully ripe. The maturity of the fruit dates from January. After being picked they are left two or three days in storerooms for the skins to dry. They are then wrapped in tissue-paper, and packed in boxes containing from 140 to 200 pieces. These are de. livered in boats to the steamers lying off shore, being always lowered in to the holds. To allow for damage, decay, or other loss, 1,500 oranges or lemons are counted to the thousand.

Planting and propagating-The trees are planted at a distance of from 10 to 14 feet apart.

The orange tree is propagated in the following uanner: I11 July and August suckers or cuttings, 18 inches in length by 1 inch in thickuess, are made of the sweet lemon tree, and planted in beds which are watered twice a day. The second or third sear' the cuttings are budded by making a $T$ incision, and inserting a bud from the Shanudior Beladi orange. When it has taken, the lemon stick is cat off a few inches above the bud, which then grows rapidy, and bears fruit the third or fourth year. Lemon trees are propagated in the same way, using for budding a sour lemon bud on the stem of the sweet lemon.

The best rarieties, as already indicated, are budded.

Tho orchards or gardens vary in size, but ustually contain sereral aeres. Abont 3,000 acres are devoted to this purpose at Jaffid, which are divided into about 600 gardens, all irrigated.

Maturity.-Orange trees contiune to bear truit from the fifth to the twentieth and thirtieth years; lemon trees from the fourth to the twentieth year. Their maturity is from the tenth to the twentieth jear, when the inest and largest crops are borne.

Insect Pests. Uuntil recently, it was supposed the trees were esempt from insect pestis, or disease of any description, the soil aud other conditions at Jaffa being peculially arlapted to the productiou of healthy and vigorous trees; but closer investigation has revealed that, in a good many garlens, there is to be met with some diseased trees, which are injured by a little insect living moler the bark. No treatment, whatever, has been allopter to restrain the propanation of this, as ret, nameless enemy, nor is it known to havo any parasite. Boneticial in. sects have not been spreially observed.

Miscellaneous.-There is no furthor particular information as to the picking and curing lemons before shipping than that already given by une.

There are $n 0$ reports giving inlormation as to processess, prueses, or

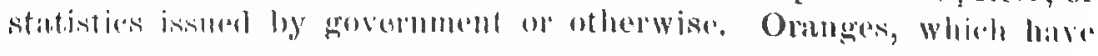


recently been damaged by hail, and will doubtless, therefore, considerably auvance iu price, are now selling at Jiffa at from $\$ 9.50$ to $\$ 10$ per thousand; while lemons bring about half this price. During the month of Jaunary last orauges were shipped at the rate of 5,000 boxes per week. The fruit sent abroad is generally of the best, selected quality.

HENRY GiLlMaN,

Consul.

UNI'TED S'TATHes CONSUla'te, Jerusalem, Februtry j0, 1890.

\section{SYRIA.}

\section{BEIRUT AND VICINITY.}

REPORT BY CONSUL BISSINGER.

ORANGES.

Varieties.--Name of best variety for profit: Belady and Khutmaly. Belady is of two species, rough and smooth. Nawes of other choice varieties wortluy of culture and for profit: Rose or Blood orange, Shammooly, Bizry.

Location.-'The trees that produce the varieties named above are grown on the sea-coast, close to the sea; but in some sheltered valleys a few trees are also grown, the lower the better. Exposure to the sun is necessary.

Soil.-Level alluvial land is the best. Red earth somewhat sandy is the best; black loam.

Climate.-Temperature: Highest, $95^{\circ} \mathrm{Fahr}$; lowest, $45^{\circ}$ Fahr.; average, $70^{\circ}$ Fahr.; nights warm; air withont fogs or mist; some dew is beneficial.

Rain-fall._A verage 32 inches. During rainy season fruit grows, but not trees; these latter grow in the fall and in spring.

Irrigation.-A After the cessation of rain, according to dryness of soil and generally about June 1. In black loamy soil and red earth mixed with sand every six to eight days; lighter soil every ten to fifteen days. The earth in which the trees are embedded is filled with water.

Cultivation.-Plowing either before the beginning of irrigation or after the first irrigation.

Fertilizers.-Goat manure, the best, applied either in the spring or after first irrigation either at base of tree or mixed with the water.

Pruning.-Only the dead wood is cut off in spring and winter.

Picking.-Picking takes place from November 1 to May 1 ; the fruit is picked for home consumption when ripe, for export before it is ripe.

The oranges are rolled in paper and packed in boxes.

Planting and propagating.-The trees are planted 20 to 22 feet apart, and are propagated either by seediug or budded. Bitter orange stock is $156 \mathrm{~A}-4$ 
the best when $\tilde{5}$ inches in cirenmference. The best varieties are the budded. The orchards ar'e small.

Maturity-The trees begin bearing three years after budding; twenty vears of age, best crop.

Insect pests.-Small scale pest; not treated at all.

\section{LEMONS.}

Varicties.-Lemons are of three varieties: (1) Seedlings; (2) grafted; (3) from shoots of a grafted tree put into the ground; the best is the grafted. Whitish, clayey soil is suitable for lemous; it is not the best. "There is a variety of lemon called "sweet lemon" which has the color of lemon and the shaje of a medium-sized orange, but has a sweet, rather insipid taste. Its cultivation is similar to that of the lemou, except that it grows best in soil free from sand. Lemons are picked during all the months of the year. Packed in paper and put in wooden boxes. No information or statistics published by the Goverument.

\section{ERIARD Bissinger,}

Consul.

\section{UNITED STATES CONEULATE,} Beirut, February 19, 1890.

BEIRUT.

REPORT BY CONSUL ROBESON.

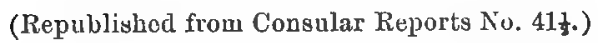

There are three kinds of oranges grown in this country: (1) sour oranges; (2) sweet orauges; and (3) Maudarins. The last are the most valuable. These trees are mature in the seventh year, and remain fruitful forty or tifty years. The sour oranges are raised from seedling, while all the other kinds of oranges grow better by grafting. T'wo kiuds of lemons are cultivated near Beirut-the sweet and sour lemons. The best results are obtained from sour lemons when they are grafted on sweet-lemon trees, as the size of the fruit increases with the age of the tree. Lately a sort of fungus has appeared on these trees, and in some plases small snails attacked them, but as yet no effectual remorly has been found to prevent or cure the same. The orange and lemon trees are planted about 20 feet apart. It is said that they grow best ou the sea-coast. Low sheltered places are, however, to be preferred, as much exposure to the winds proves injurious. Dark or samdy soil suits such trees much better than light. Goats' manure is preferable to any other.

Orauge and lemon trees require to be whiterel during the dry season. The first irrigation is effected in June whon the leaves of the trees begin to curl up from the dry heat. The ground of the ormge and lemon oreh. ards is cultivated three times a your when the soil is thoroughly dry. 
The aunual yield of fruit per acre in the best orange orchards is about 30,000 oranges, the average price of which may be estimated at from $\$ 130$ to \$140. The yield and price of lemons are nearly the same. The lemou trees last twenty five years, while the orange trees, like olives, last for an indefinite period of time. 'The cost of plowing, irrigating, and manuring per acre may be set down between $\$ 15$ and $\$ 18$ per annum. The seeds of orauges and lemons are first sown in a small tract of land. Ifter a year they aro remored and replanted in a larger piece, and at the end of the second year they are again transplanted into groves.

JoHN T. ROBEsON,

Consul.

United Státes Consulate,

Beirut, May 3, 1884.

HAIFA.

REPORT BY CONSULAR AGENT SCHOMAOHER.

Horticulture is carried on in my district in the same primitive man. ner that has been the custom for centuries.

Variety.-Of oranges and lemons there are but a few groves of auy account in my district in the neighborhood of Acca, therefore I cau only answer the questions in a general way. There is only one kind of orange planter, called, in Arabic, bortogan beeladie.

Situation.-The groves are situated 3 miles from the sea. The elevation above sea-level is from 30 to 40 meters. The trees are exposed to the sun without any protection. The soil is sandy, of reddish color.

Climatic influences.-Temperature: minimum, $2^{\circ}$ to $4^{\circ}+$ Reaumur; maximum $33^{\circ}$. to $35^{\circ}+$ Reaumur; average 20 to $25^{\circ}+R$. The vights are generaliy warm about six months; about three to four months a temperature from $12^{\circ}$ to $14^{\circ}+$ Reaumur, the remaining two months $20+$ (only a few nights) to $20^{\circ}+\mathrm{R}$. There are about thirty-five or iorty days of extremely dry atmosphere during sirocco. Moist air prevails during the rainy season, from December to April.

Rain-falls.-'The raiu-fall varies from 1 foot $7 \frac{1}{2}$ inches to 3 feet 3 inches per year; by 1 foot $7 \frac{1}{2}$ inches we call it a dry sear; two feet is about sufficient rain.

Irrigation-Irrigation lasts from May to December. The water is raised by mule-power from wells from 25 to 100 feet deep, and then flows into large reservoirs, from whence it is run out iu small chaunels to the trees. Irrigation lasts from May, at which time the blossom is past, and is carried on until December, when the fruit is about ripe. Each tree receives from 40 to 50 gallons of water, once a week.

Cultivation.-The soil in the groves is thoroughly worked with broad hoes several times a year. 
Fertilizers.-Before irrigation commences the soil is well manured with sheep dung. The manure is spread over the whole soil of the groves and then mixed with the soil.

Pruning.-There is but very little pruning done, and not before the in'ee is four years oul.

Picking.-The oranges and lemons are picked from November to April. Stage of ripeness, January, some nearly, some evtirely ripe. The fruit in my district is not exported, but consumed by the home trade.

Planting and propagating.- The distance planted apart is from 20 to 25 feet; trees are propagated from the seed aud from cuttings. Seedlings which are grafted when two or three years old are preferred. The orchards are various, from 1 to 15 acres.

Maturity.-Age of fruiting the fifth year, the largest crop about in the fifteenth year. Maturity at thirty-fice to forty sears.

Disease.-Since a few years a disease is spreading in some localities awong the orange and lemon trees, similar to the phyloxera in vines, which threatens to destroy the groves, as no remedy has been found yet for this disease, bu the gardens near Acca lave up to now not suffered from this disease.

\section{JACOB SCHUMACHER, Consular Agent.}

\section{United States Constuar Agency,
Acca and Haifa, Hecember 5, 1889.}

\section{HAIFA.}

NEPORT OH' CONSTLAR AGENT' SCHCHA'HER.

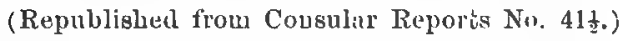

Only one variety of oranges is cultirated in. my district, and is naned, after the city of 1 cca, "Accary." It has the form of the round Spanish orange, with reddish jellowish flesh; it has a fine flaror, and is very juicy. Blood oranges and mandarines are cultivated so little here that there is no rule for their treatment. The orange of my district is about 31 inches in diameter; the skiu is smooth, thin, aud contaius considerable oil.

Several sizes of lemons grow here; the larent is about $4 \frac{1}{2}$ inches long by 3 inches in liameter. The skin of the lemon is thick and cou. tains much oil. At the age of four to live years both orange and lemon trees begin bearing and remain fruitful thirty to forty years.

We have two kinds of lemons, swert and sour; the sour bear as seedliugs; on the sweet the orange is grafted. This manipulation of grafting on sweet lomon trees has lately proved to be tho most profitable, as the size of the fruit increases with the age of the tree, while those wrafter on sour lemon trees become smaller after tiltuen yairs. The trees are 
not troubled with injurious inseets, pests, or fingous growth; want of irrigation checks the growth of the trees.

Orchard trees are planted 10 to 12 feet apart in each direction. Both orange and lemon trees are plinted as surubs in such a manuer that several stems come out of the ground together, although there are some orchards where the trees have but one stem; those, however, planted as bushes protect the fruit better against the influence of the wind. The orchards are planted, as a custom, along the sea-coast, where they yield most abundantly on level land; inland orchards never do so well. As the orchards require a sandy soil, they are planted as vear as one-fourth of a mile up to some ruiles distance from the sea-shore. Every orange or lemon orchard is cultivated by a system of artificial irrigation, irrigated twice or three times a week (in the evening part of the day). The ground in orchards between trees is cultivated twice a year-in the fall before the rain appears and in spring when the rainy season is orer. The value of the yield of au acre per annum of best orchards amonnts to from $\$ 30$ to $\$ 100$; the cost of cultivation amounts to about $\$ 10$. The returns would be much larger if the orange were exported to Europe ; the above statements therefore relate only to home consumption.

JACOB SCHTMGCHER, Consular Agent.

United States Consular Agency, Haifa, February 20, 1894.

\section{MERSINA.}

REPOAT BT COXNELAR AGENT DATSON

Varifties.-The best variety for profit is the bitter orange; the next varieties worthy of culture are lemons aud oranges. The above three varieties are grown at Adana, Tarsus, and Mersiua.

Situation.-Distance from sea: Adana, 13 miles; Tarsus, 15 miles; and Mersina on the sea shore. Eleration above sea-level from 1 to $\tilde{5}$ yards; the trees have full exposure to sun; level land is the best.

Soil.-Rich soil. 6 feet; subsoil gravel.

Climate. - The frost would destroy the trees, and also the dry winds in summer, if not watered. The trees only fear the frost, and the dry. ness of soil ; the heat does not affect them when watered. Cold nights in winter without frost, moist atmosphere.

Rain-fall.-Rain-fall from 18 to 20 inches; the trees are watered by irrigation in the dry season. Rain falls in November, December, March, April, and May. The trees get watered two or three times a week in Jnne, July, August, and September, and until sufficient rain comes.

Irrigation.-For irrigation the water is taken from the Sarus river which passes through Adana, the Cydnus through Tarsus, and the Mer- 
sia river wbich runs close to the gardens. They irrigate two or three times a week until the wet season comes, at which time the fruit is formed to about twice the size of a walnut. In the drs season they open a space of about 3 feet diameter all around the trunk of every tree and 1 foot deep, so as to allow the water to remain in. At the beginning of the wet season they fill up these holes and cover the trunk with earth up to about a foot from the ground with a slope of 3 to 1.

Pruning.-Very littıe pruning is required or done here. They generally clean the trunk of all its branches from the surface of the ground up to the height of about 3 feet where the thick branches start.

Picking.-The picking of the fruit begins end of November. About 15 th of December, the fruit, is nearly all ripe, but they pick it until the end of February, according to the requirements of the market.

Curing.-To get the fruit to last the longest time possible it must be cut with a little stalk attached about 1 inch long.

Shipping.-The bitter oranges are shipped from Mersina to Liverpool, each one wrapped in thin paper, and they are packed in boxes containing $100 \mathrm{each}$, in two rows, which are separated one from the other by a thin board.

Planting and propagating.-The trees are planted from 12 to 14 feet apart. They graft the roung wild trees that come by seed about 3 feet off the ground when they get 1 inch diameter.

The orchards.-The largest orchards here occupy about 20 acres of ground; the smallest. 5 acres.

Maturity.-The grafts give fruit the second year, and the older they grow the more fruit they give. There are trees tifty years old, 14 to 20 inches diameter at the trunk.

Insect pests.-A small insect like a black ant, with wings, attacks the young tips of the new branches. They do not know of any remedy against it. The ants destroy the above insect.

Packing.-Lemons are picked in December; packed each in thin paper and shipped in small boxes of 200 each.

Exports.-A bout 1,000 tons of bitter oranges might be exported from Adana, Tarsus, and Mersina in one season.

No figs are grown in this vilayet for export. There are some olive forests in the vilayet, but in a wild state.

WM. DATSON,

Consulur Agent.

United Statems Consular Agency, Mersina, December 7, 1889. 


\section{SIDON.}

RETORT TI OONSUL RISSTNAER, OF BEIRUT.

Tarieties.-The oblong, thin-skinned, most delicate, but can not be transported. The other variety is thick-skinned, with flat ends, more hardy.

Situation.-On alluvial sea.coast plain of Syrid, within a range of a very fer miles, not more than 5 from the sea, and at an elevation up to 200 feet. Constant sunshine, very few clouds, no fogs.

Soil.-Level, flat lanu; sandy soil, the best and light earth.

Climate.--Even, no sudden changes. Dry and rainy season. Tem. perature, $40^{\circ}$ to $98^{\circ}$ Fahr. ; average, $69^{\circ}$ Fahr. Nights warm. Air withont fogs or mist; some dew is beneficial.

Rain-fall.-From 34 to 40 inches the ordinary range. Trees grow in spring and put forth new shoots in fall if watered when thirsty.

Irrigation.-By channels of running water from river. Irrigation is used when after spring rains the leaf shows a need. Different soils require different periods of irrigation. From six to fifteen days; whenerer the soil is dry then the trees are irrigated-ground flooded. .

Cultivation-Plowed once a year.

Fertilizers. - Best application is to put goat manure iuto irrigating water.

Pruning.-Varies; low trees preferred; less injury to fruit when it falls; in fall dry wood is pruued.

Picking.-Cheap kinds are allowed to fall for home consunption. The fruit is picked, for a near market, fully ripe; for a distance, while green.

Packing.-Wrapped in paper and put in wooden boxes.

Plunting and propagating.-Branches tonch and interlock; from 20 to 30 feet; some are propagated, some are seedlings, but the best varieties are budded.

Maturity-Differs according to land; five to eight sears they bear well.

Disease.-Only a small scale like a freckle on fruit, which dries the tree.

Shipping, pacling, and canning goes on during all seasons of the year. Every week, wrapped in paper and boxed.

\section{SIDON. \\ REPORT BI ('ONSUTAR AGENT ABELA.}

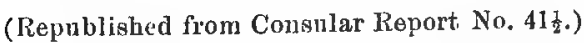

Varieties.-Oranges are distinguished by their shape and contour. Belids, round, flat, ends, rery thick peel, hardy; ripeus late. Shamouts, long like an egg, thin-skinned; ripens early. Bisry, finest flavor; a 
seedling. All these, except the last, ale gralted upou the wild or bitte'l' orange, and in two or three years after grafting begin to bear fruit. No limit is recognized to the period of fruit-bearing, but the trees attain a very old age withont deteriorating. Only one variety grows directly from the seed; the others are all grafted, which is considered a better wethod than budding.

Soil.-The order of the soils best adapted to orange culture is as follows: the best being light red earth, then dark loam, then sandy, and finally clavey.

Pests.-Until the past sear nothiug had troubled the trees except the attacks of moles on the roots of the trees. But now a fungus has appeared, which is spreading rapidly, and seems likely to do great damage. No remedy for it has been discorered as yet.

Position.-All the oranges and lemons of Syria are grown very near the sea-coast, whether at Tripoli, Sidon, or Jaffa; and I know of no extensive successful cultivation more than 4 miles from the sea, and some of the orchards are within 20 rods of salt water. When the trees are set ont they are placed 18 feet apart every way when the soil is good, 16 feet when the soil is only arerage; trees placed behind a shelter, as another line of trees, prosper better than those exposed to severe wind.

Irrigation.-As there is no rain frow May 1 till October 1, irrigation is the ouly means of keeping the trees alive. Each tree is surrounded by a little bank of earth to keep the water about the tree. The trees are left without irrigation till the last of June, till the leares curl a lit. tle, then they are watered three times for periods of seven days, and after this every fifteen days. The irrigation of the river coming from Mount Lebanon is better than that from the wells, as the last has a taste of brackishness.

Yield.-In good orchards it is estimated that the average rield is from 1,500 oranges to 3,000 per tree, and in poor orchards about 600 per tree. The yield is annnal, but every other year the crop is lighter.

\section{Sitibli Abela,} Consular Alfent.

UNITED STATES Consular AGENCY, Sidon, February 21, 1884.

\section{TARSUS.}

REPORT BI AITIYA CONSOLAR AGRYTA V.INIA.

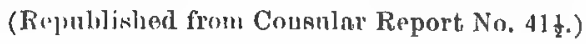

There are four kinds of trees more or less productira : The sour lemons, the sweet lemons, the sour oranges, and the swert oranges. The most yielding of these trees are the sweet lemons, but the most valuable are the sour lemon and the sweet orange fruits, the nkial value of which 
is from 1 to 3 cents each. These trees cone generally to their full bear ing after the tifth year of their plantation, which is first eff'ected in seeds and replanted the next year at a distance of from 13 to 16 feet betweon each ylant. By grafting, these four kinds of trees can be transformed into one, which succeeds perfectly well. Sour lemons and sweet oranges are most sensitire to a cold temperature, especially the former, which are sometimes completely ruined by cold. Thus the duration of these trees depends on temperatnre, and might be prolonged to thirty or forty years. In this country such trees are never troubled with any injurious insect, etc.; severe temperature is the ouly thing that injures them. The orange and lemon groves are generally situated in the interior or on the coast, but always in the vicinity of towns in order to be sheltered from cold. The plain lands are rather suitable for the plantation and conservation of these trees; but the best results are obtained on the coast, where the soil is more or less sundy aud light. Even at a distance of a quarter of a mile from the sea these trees prosper quite well. The system of irrigation used in this conntry is the runuing water. In those places where such water is lacking wells are $\mathrm{dng}$, tue water of which is used for watering the gardens by means of wheels mounted with buckets. Iu the places where the soil of the groves is cultivated watering is necessary in summer and antumn when rains are late, and this is done repeatedly.

It is commonly calculated that the a verage yield of these trees is worth from $\$ 2.50$ to $\$ 3$ each. In this country no exportation of oranges or lemons is made; ou the contrary, large importation is effecter anuually from the coast of Syria for the local consumption.

Elie Avania,
Acting Consular Agent.

Thited S'Tates Consular Agenct,

Tarsus and Versine, March 3, 1884.

\section{TRIPOLI AND VICINITY.}

REPORT BI CONGUL BISSINGER.

Varieties.-The best varieties are, citron, mandarines, the "belady," (indigenous) and Jaffa oranges, after which come the sour and sweet lemous.

Situation.-From the sea to 10 miles inland, with slight elerations. The trees should be exposed to the sin. Low, level land is best. The best soil is red or black, but sandy.

Climate.-The degree of heat is morlerate; from $40^{\circ}$ to $90^{\circ}$ Fahr. Cold nights destroy the blossoms. In warm days and nights the trees have to be watered; moist and ordinary atmosphere is beneficial.

The rain-fall is 36 inches on an average per vear. Abundance of rain is advantageous; frost injures the trees. 
Irrigation.-When the soil is dry, during the months of Iune, Julr, August, and September, ard sometimes October. More or less according to dryness of soil and size of trees-once every eight or ten days.

Cultivation.-In the spriug, when the soil gets ary, the ground should be plowe.l to the depth of 5 or 6 inches; this should be repeated three or four times, $i$.e., once every eight or tan dass; in summer erery eight or ten days after each irrigation. This alternate succession of plowing and irrigation should occur between the 15th of June and 15th of September.

Irrig tion.-Goat manure is the best, cow dnug ranks second, after which, in point of quality, comes horse manure. Half of the quantity is to be used iu wiuter and the other half in summer. The quantity needed is about 84 pounds for each large tree. The first 42 ponnds that are to be used in winter should be placed on the surface of the soil, at a distance of about 10 to 12 inches from the foot of the tree, and the other 42 pounds distributed in two or three equal parts, after being mixed with water during the summer. Simall trees veed only half of this quantity.

Pruning.-Pruning should be confined to the lower branches, but yet sufficiently upward to leare a free passage for a team of oxen when tilling the ground.

Picking.-Citrons, sweet and sour lemons, as well as oranges, must be picked when green, with a yellowish tint, if intended for exportation; if for local consumption, when fully jellow. These fruits fall to the ground as soon as they are perfectly ripe, and should be gathered when dry from dew or moisture. It is of great importance to roll these fruits in thin paper before packing them up in boxes.

Planting and propagating.-The trees are planted from 3 jards a inches to 4 yards 12 inches. Citrons are propagated by seedlings; sweet and sour lemous and orauges by grafting. Oranges prosper well when grafted on sweet lemon trees. Sweet lemons can be grafted on sour lemon trees. The best varieties are budded. Orchards are generally suall.

Muturity. - Trees begin to bear fruit in the fourth or fifth year after being planted. The largest crops are from the serenth year npward.

Insect pests.-No insects infest this kind of a tree except a scalo pest, for which there is no known remely; but the damage caused by it is slight.

Erhard BisNingme,

UNTTED STATES CONSULATS, Comsul. Brint, Februmy 12, 1890. 


\section{ADEN.}

I have the honor to acknowledge receipt of circular dated 28 th Sep. fember, relative to the cultivation of oranges, lemons, figs, and olives in my district, and in reply I regret to state that owing to the barrenness of $\Delta$ rabian soil, the cultivation of the above-mentioned fruits to any extent would be impossible.

\section{DWIGHT MoORE, \\ Consul. \\ Consulatite of United States, \\ November 29, 1889.}

\section{INDIA.}

IEIORT, PREPAIED FOR.VICE CONSUL BODE, OF ROMBAT, DY MR, G. MARSHALL HOODROT, LECTURER IN BOTANY AND ARRICTLTURI' IN THE OOLIEGE OF SOIEXCE, POONO.

ORANGES.

Tarietirs.-The best orange grown in India is the Cintra, a name commouly assuined to be derived from the Portuguese town, but lately de. clared to be a corruption of a Sanscrit word which should be pronounced Suntura. The tree is of upright habit, rarely exceeding 12 feet in height and 8 feet iu expansion of branches. The leares measure $1 \frac{1}{2}$ by $\frac{3}{4}$ to $2 \frac{1}{2}$ ly $1 \frac{1}{4}$ inches. The winged joint in the stalk is very slightly developed. The flowers are tbree-fourths inch in diameter, hace five petals, twenty to twentr-four stamens and nine to ten carpels. The fruit is found in two varieties-one Laving the skin very loose and the otber having a smooth, tight-ftting skiu, as grown at Nagpur. This fruit has been leclired hy people who have traveled mnch, to be the finest orange in the world. The flaror of the two varieties is equal when grown under similar couditious, but the loose-skinued variety bas an imposiug appearance and is rather more easily peelerl, consequently it is the market favorite. The inner skin (endorarp), of both varieties is very delicate and the liths (carpels) cohere so slightly that it is easy to break up for eating. Urdinary market specimens weigh 7 ounces, but examples weighing 10 ounces are common. Well-grown specimens have only two or three seeds, which have several embryos.

The Mozambique orange.-The tree that bears this orange is of a strong growing habit and forms an irregularly globular head. Its leaves measure from $2 \frac{1}{2}$ br $1 \frac{1}{2}$ to $5 \frac{1}{2}$ by $3 \frac{1}{2}$ inches, entire, or very slightly and irregularly toothed and the apex pointed or cut ont. The leaf stalk is three-fourths inch, the wings on ove of the joints attaining one-fourth jnch in width-often less, and sometimes wanting. The flowers are $1 \frac{1}{2}$ inches in dianeter; have five slightly oblique petals which are glandu. lar on the ontside, and twenty to twenty-four stamens. A verage speci- 
mens of the fruit grown in India weigh $S$ onnces, but specimens imported from Mozambique 13 ounces in weight are common. In shape it is globular, slightly compressed vertically. The skin is medium in thickness, tight fitting, marked by numerous small vertical furrows and a circular smooth mark about 1 inch in diameter on the upper end. The pulp is usually pale yellow, but when dead ripe becomes of the brownish jellow that may be called the medium tint of orange pulp. In flavor it is sweet, but withont the piquancy of the best variefies. The inner skin is tough, so that the orange must be cut up with a knife and is only fit to be sucked. Seeds about twenty, with several embryos in each. Two sorts are known, Khaguzee, thin skinned, and Goradiya, thick skinned. Both sorts keep in good condition about two months, although ripe when gathered. The imported fruit must keep in good condition longer, as it is brought from Mozambique by sailing craft.

Ladoo orange of the Deccan.-The tree that bears this variety produces long, straight branches, apt to spread out considerably as the tree attains size, therefore needing to be planted 18 feet apart. The leaves are from $1 \frac{1}{2}$ by 3 to $2 \frac{1}{2}$ by $1 \frac{1}{4}$ with the winged joint of the stalk very slightly developed. The open flowers are three-fourths of an inch in diameter, have five petals, twenty to twenty-fonr stamens, and nine to ten carpels. The fruit attains 8 ounces in weight, is in shape a much depressed globe with a distinct nipple at the stalk, and, within the skin on the upper end, generally has an extra orange about three-fourths of an inch in diameter with fire to seven liths (carpels). The skin is of a dusky yellow color, moderately rough and loose, aud of medium thickness, the inner skin very thin and inclosing juicy sweet pulp of piquant flavor and medinm tint of color. This is a fine orange for eating, but it does not bring a high price on account of its indifferent appearance.

Lall Ladoo of the Deccan.-This fruit I have identified with the man. darin orange of books. The tree resembles the Ladoo in habit, leaves, flowers, and shape of fruit, but the skin of the fruit is of a deep orange color, smooth and loose, and inclosing eleven liths having a stronger inner skin than the Ladoo and about twenty seeds. It is a very haud. some and attractive fruit of good flavor.

Kowla orange.-This is a small-sized, indifferent orange, which becomes yellow on the tree before it is sweet.

The Sylhet orange.-This variety, which is very often to be seen in the Calcutta markets, is grown in the district whose name it bears. It aver. ages 5 ounces in weight, has a light skin and good flaror.

The Malta and $\mathrm{St}$. Michael oranges have been introduced and thrive well, but are not greatly valued where the Cintra can be grown.

Location, etc.-The finest oranges in India and, in the opinion of somein the world-are grown near Nagpur, which lies in north latitude $21^{\circ}$ $9^{\prime}$ and east longitule $79 \circ 11^{\prime}$, about 350 miles from the sea, and at an altitude of 1,025 feet above mean sea-lerel. The orchards are fully ex. posed to the sin, and the gromnd of each orchard nearly level, as they 
are dotted about at intervals in a gently rolling country where the tine soil has been collected from the exposed and disintegrated trap rock. This soil forms a stiff loam from 2 to 3 feet in depth, containing about 7 per cent. of lime and $1 \frac{1}{2}$ per cent. of regetable matter. The subsoil is open, nodular limestone mixed with clay, and gives excellent drainage.

Climate.-The climate of Nagpur is shown in the following table, which is compiled from the Govermment Meteorological Reports. It may be described as comparatively hot and moist from June to Septem. ber, cool and dry from October to February, hot and dry from March to May.

It must be noted that the temperature given in the following table is taken from a barometer shaded from direct suushine and from radiation at night. The increase obtained by exposing the barometer to the sun averages $59.8^{\circ} \mathrm{F}$., and the decrease from exposing the barometer to the open sky at night varies from $12.8^{\circ}$ in January to $2.7^{\circ}$ in July.

Table showing the climate of Nagpur, India, where very fine oranges are grown.

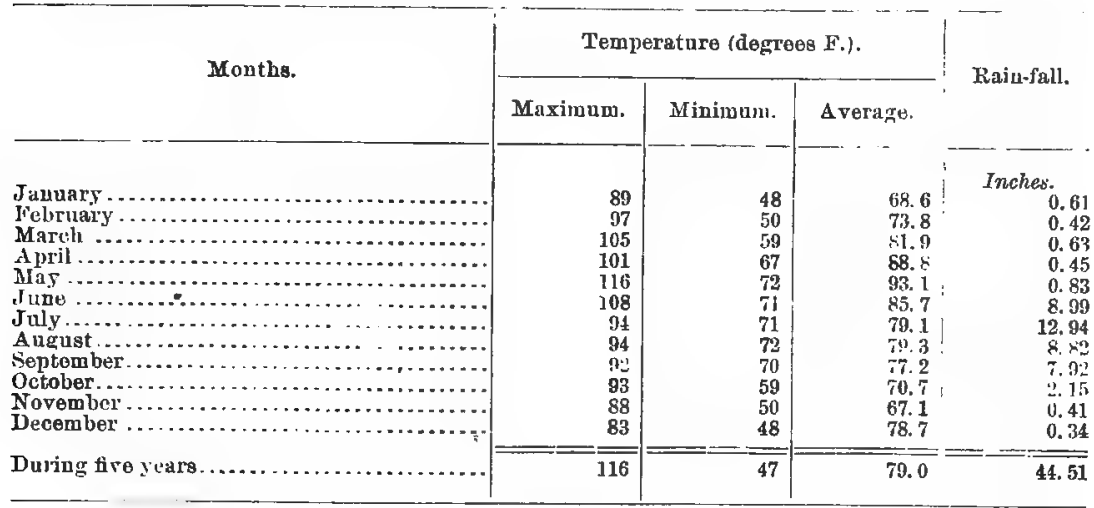

There are two distinct seasons in which the trees will flowerand ripen frnit, and to obtain high-class fruit the cultivator must elect which season he will work a particular break or division of the orchard, because the trees will not bear properly at both seasons, aud the attempt to make trees bear fruit at both seasons has been the destruction of many plantatious in other parts of India. The finest fruit is obtained from flowers that open in June and July. This is on the market from February to May. The other flowering takes place in February and March. This ripens fruit from December to February.

Irrigation.-The trees are kept dry during May or December, according to the season at which fruit is wanted. At other seasons irri. gation is carried on sufficient, with the rain fall, to provide 4 inches of water over the entire surface. The water is drawn from wells 30 feet deep by means of a leathern bucket which coutains about 25 gallons, by a pair of uxen that walk down an incline plane, pulling at rope that passes over a pulley. The cost of drawing water by this means is 1 
anua (say 3 ceuts) per 1,000 gallons for 30 feet in depth. The water is led into small surface channels lsaving a slope of 1 in 1,000 , and from the channels into beds extending round the tree as far as the expanse of the branches. Iuto those berls $1 \frac{1}{2}$ to 2 inches of water is led once in ten days during the absence of sufficient rains, so the soil is kept moist from the fluwering time till the fruit is all gathered.

Cultivation.-The soil is kept clean aud open by plowing or digging with a pick, 4 inches deep, twice yearly. For the crop that ripeus during February -April water is withheld and the soil opened up during April and May. The soil is at the same time drawn away and the roots exposed during fifteen to twenty days. At this time the greater part of the leaves fall off, then 100 pounds weight per tree of old, moist cow-dung is mixed with the soil and the roots covered up and watered heavily, if rain does not fall soon; this callses the trees to burst into bloom and fresh leaves; thereafter the soil is kept moist till the fruit is gathered. The same operation carried ou in December brings ripe fruit during December and February following.

Pruning.-This extends to clearing away suckers from below the graft and cutting out weakly and defective shouts only; excessive pruning must be avoided, as it tends to make the plint run to wood and prevents flowering.

Picking.-The fruit continues to attain full development duriug a month from each break of trees that has beeu started into growth together, and is picked over at intervals of a few days. A faint trace of yellow in the skin of the fruit indicates maturity. When fresh from the tree this fruit has a delightful piquancy that is to a great extent lost by the fruit being packed up closely for a few weeks, but the fruit remaius in good condition about two months if not closely packed.

Curing.-Nospecial curing is given unless the fruit has been gathered unripe. In that case it is packed with the hay and kept close 10 a box for a few days. Such fruit is always inferior.

Packing.-In packiug 30 to 40 pounds weight of oranges are placed in very slin baskets, without any packing material, aud the lid tied down. Nove of the fruit is shipped as merchandise, as the demand in the large cities exceeds the supply.

Planting and propagating.-The trees are planted 12 feet apart each way, except for Ladoo, which is given 18 feet apart.

Grafting or seedliny.-Seeds of Citrus medica, (Jambooree), al large coarse citron of vigorous habit, are sown, and when the stocks are two to three years old are budded. In budding one rertical slit in the bark ouly is made and the branch bent towards the slit so as to make it salue open; into the gape the bud is inserted and the branch released; it then springs back and closes in the bud which is tied with a strip of fiber. Occasionally the sweet lime (Citrus limetha) is used as a stock, and is believed by some to insure more sweetuess in the fruit. The best varieties are invariably budded, as seedlings take so long to pro. duce fruit as to be practically useless in fruit growing. 
Size of orchards-CFrom the naturo of the soil required and the for. mation of the comntry large orchinds can not be planted; from 5 to 10 acres is a common size.

Maturity.-The trees begin to bear at three years from the bud, curry the beaviest crop botweon the sixth and tonth year, and after 15 year's decay rapidly.

Insect pests;-An important insect enemy is the caterpillatr of Erytheo, which strips the trees of the young foliage during July. Hand picking is the chief remedy employed. An undetermined wool boring insect attacks the trees as soon as decay sets in, and is comnonly supposed to be the cause of decay. Severe pruning and burning the affected branuhes is the most effectual remedy. It is donbtful whether any insects are beneficial except in distributing the pollen, but the entomology of Iudian fruit culture is fragmentary as yet.

\section{LEMONS.}

Lemons are not exported. The large coarse citron called Jambooree (Citrus medica) can be produced cheaply in large quantities, but except by dyers for the acid it is but little used and brings a very low price.

The siveet lime (Uitrus limetha) it fruit having a tight, smooth, very thin skin, ultimately of a pale yellow, and eleven to twelve liths, iuclosing very pale colored sweet juice without piquant tlavor and about ten seeds. The leaves attain $3 \frac{1}{2}$ by $2 \frac{1}{2}$ inches, slightly toothed, and thorns one-fourth of an inch in length are developed in the axiles. This fruit is widely cultivated, but not to any important extent in one place. It is chiefly grown from seed.

The common sour lime (Bagdee Limboo).-A globular, smooth, pale sellow fruit weighing about one-tenth of a pound, having pale greenish yellow acid pulp of pleasant flavor inclosed in 10 by 11 liths and numerons seeds having several embryos.

The tree is of a dense growing, branching, thorny babit, bears leaves from 2 by 1 to 2.2 by 14 inches, laring a stalk one-half inch in length, of which the winged joint is one-quarter of an inch. The flower has four petals, is three quarters of an inch in diameter, and has twenty. two to twenty-five stamens.

This is the favorite sour lime. It is used by all classes as a condiment and digestive, and is widely produced throughout the country. The trees are raised from seed, and when cared for properly attain at least fifty years of agee.

The Pati Limboo, or Karna, is a varicty of the above, $3 \frac{1}{2}$ ounces in weight, oblong in shape, and bearing nipples at both ends.

The Popamus or Pumalo, (Citrus decumàna), seedlings of this fruit rary greatly aud a large proportion are worthless, but the grand, thin-skinned, and red-fleshed varieties that are cultivated near Bombay are very delicions and wholesome if eaten in the morning with salt ul sugar. A well-developed speciuen weighs 4 jounds and is 7 
inches in diameter. It has fourteen to fifteen liths ; seeds few, or sometimes nove; embryo one in each seed. The tree thrives in a hot, moist climate and needs the strongest of nitrogenuus manures. Near Bombay slaughter-house offal is freely given as maure. Enarching on to a seedling Pumalo is the means einployed for propagation, and regular irrigation when the rain-fall is below 4 iuches per month is provided.

Publications.-Government of India does not publish prices and statistics of fruit. The Magpur cultivation of the orange, which is by far the most cousiderable in the conutry, was initiated by a Scottish gardener nawed Thompson, who was in the service of the local priuce about thirty-five years ago.

\section{G. MARSHALL WoOdRow.}

PoONA, Larch 3, 1890.

\section{PHILIPPINE ISLANDS.}

\section{REPORT BY CONSUL WEBB, OF HANILA.}

As stated in a previous report, horticulture is in a rery backward condition in the Philippine Archipelago, and, while there are five varieties of oranges aud four of lewons found here, they are not cultivated to an extent that would create a demand for them for export. The natire women, who find the trees growing wi!d in the jungles or encourage a few to grow around their huts, bring the fruit to the cities and towus, selling it about the streets and markets; bnt there are no carefully kept orange or lemon groves, as in other orange producing countries, and no interest whatever is mavifested by the Europeans here in the cultivation of the fruit. The results of this indiffirence and neglect are apparent, as the fiuit is of a very inferior quality. I am quite sure there is not a uative orange or lemon to be found that would compare at all favorably with the ordinary products of Florida and Califoruia. When fit to eat the skin is greeu and has the appeirauce of just begin. ning to ripen, and when it reaches the orange color the pulp is either perfectly dry and tasteless or decayed and unfit to eat. When the pulp is sweet and juicy the skin is usually a deep green.

Varieties.-The following varieties of oranges and lemons are found here:

Citrus Aurantium known to the natives as the "Naraujita." It resem. bles somewhat the ordinary Japinese orange, but is inferior in flavor; the pulp is of a rich, piukish color, separates readily, and when ripe is quite juicy. It usually measures at maturity about $2+$ to $2 \frac{1}{3}$ inches in diameter and is slightly flattenen at the stem and bud ends.

Citrus Aurantium, knowu to the" uatives as the "Cajel;" it is the juiciest and most palatable valiety found. It has a yellow pulp which alings tenaciously together and is difficult to separate from the skiu and the fruit is, therefore, never peeled for the table. The only method 
of eating it is to cut away pieces of the pulp with the rind ardhering to them, leaving the core with the seeds in it in an oblong square piece. The outside pieces are then taken in the fingers and the juice squeezed into the mouth. As a rule the juice has a watery taste although one is occasionally found that yields rich and deliciously flavored juice.

Citrus Aurantium or "Pisong" resembles in shape and flavor the Mandarin or "Kid-glove" orange of China and Japan, but unlike the latter the skin is always green; it can be easily peeled with the fing "rs, and the pulp separates freely and without breaking; it grows plentifully and is very cheap.

Citrus Decumana, called by the natives "Lucban," is generally from 4 to 6 inches in diameter, with skin an inch or more in thickness, and closely resembles the "Pomals," brought here from China, except in the color of the skin. The pulp is white and separates readily, and the juice is quite tart.

Citrus Madurensis, called by the natives "Sua," is an exact counterpart of the Lucban except that the pulp is red and the juice sweet, with a suggestion of tartness.

Citrus Medica or "Limon Real" (royal lemon) is shaped like the Mes. sina lemon but is very much smaller and less juicy. The skin is of a yellowish green color when ripe and the juice is very sharply acid. It is excellent fruit for lemonade, for which it is used almost exclusively.

Citrus Medica or "Limon" is seldom more than an inch or an inch and a half in diameter, is nearly round, and its flavor closely resembles that of the lime. The skin is quite green until it begins to decay.

Citrus Medica or "Limoncito" (little lemon) is seldom more than half or three-quarters of an inch in diameter, and, when ripe, has a yellowish green skin. It is slightly sweetish and is used only by the natives in making preserves.

Citrus Medica or "Calamondin," when ripe, is usually about an inch in diameter, almost perfectly round, and has a very thin bright yellow skin, and red pulp. The juice is very sour and is used for flavoring sauces and for lemonade.

Situations.-The orange and lemon trees are seldom found at a distance of less than 100 meters from the sea and they thrive best at about 200 on high ground and in dry, sandy soil. They are most proluctive on the higher-level lands where they are partially in the shade of larger trees, although they seem to do fairly well even under the blistering rays of the tropical sun.

Climate.-The temperature of the best producing districts varies but little. Last year, which may be taken as a fair average jear, the maximum temperature was 765.33 , the minimum 755 , and the average 759.35 .

The average annual rain-fall is about 3,000 millimeters. The greatest rain-fall since 1865 occurred in 1876 when it reached $3,072.8$ and the least was in 1885 when 905.5 millimeters fell. In September, 1867, 1,110 millimeters fell in three days, being the heaviest continuous rain-fall ever $156 \mathrm{~A}-5$ 
known here. The atmosphere is humid at all times and is very moist at night, so much so that in Manila the belief prevails that a foreigner is almost sure to contract rheumatism, neuralgia, or a low type of fever if he sleeps near the earth. Residences for foreigners are, therefore, usually built with the sleeping rooms from 10 to 12 feet above the ground. The nights are damp and cool and the days warm and sultry during the greater part of the year. During January, February, and March rain rarely falls, and frequently December is also a dry month; the rainy season sets in fairly in June, and for six months drizzling raius prevail with occasional drenching showers.

Irrigation.-Irrigation is never necessary except for the rice fields.

The orange and lemon trees develop more rapidly during the rainy than the dry season, and the fruit is gathered eight months in the year. Under proper eultivation oranges and lemons could probably be had the year round.

Propagation.-Nature is generally allowed to take its own course in regard to fruits of all kinds, but occasionally an unusually euterprising native will undertake to propagate a few orange trees from the seeds or by the following method:

A strong hemp cord is wound several times around a flourishing branch, 2 or 3 feet from the end, and a section of bamboo 4 or 5 inches long and about 2 inches in diameter, is split in halves and bound around the branch, the lower end resting on the cord. Into the bamboo cup is placed some moist earth, which is frequently watered, and into which the branch sends small shoots. When these have developed sufficiently the branch is severed from the tree just below the cord, and, after the latter and the bamboo cup have been removed, it is planted in light, sandy earth, which is kept loose and well broken until the tree fairly takes root; after this its owner pays no further attention to it except to gather the fruit. No fertilizing material is used, nor is any regnlar system of pruning followed. A tree thus propagated will bear fruit the following year, while a tree grown from the seed requires four jears or more in which to develop into fruition. When trees are planted they are usually placed about 8 yards apart. There are no insects that are known to either injure or benefit the trees.

\section{GONCLUSION.}

The principal orange-producing districts are the provinces of Batangas, Bulacan, and Lagnna, on the island of Leuzon, but they are found in almost every province of the archipelago.

Une reason why the natives neglect to cultivate the fruit of the islands is that all who are willing to work can find more profitable employment in the cultivation of hemp, sugar cane, aud tobacco, and the care of the orange trees and the picking and selling of the fruit are left, to the women and children. The foreigners, too, find more profit in hemp, sugar, and tobaceo than they could possibly realize from fruit, wilh a corresponding investment of time and money. 
My limited knowledge of horticult ure leads me to confidently believe that, under a proper system of grafting, pruning, and fertilizing, the oranges of the Philippine could be made to rival those sent here in large quantities from China and Japan, which command a much higher price and are bought in preference to the native fruit by those who can afford to pay for them.

Neither figs nor olives are found here, but I am told that a few trees of both kinds have been raised in the door-yards of Europeans from the seeds, yielding, however, very inferior fruit.

United States Consulate, Alex. R. WEBB, Consul.

Nanila, December, 23, 1889.

\section{NEW SOUTH WALES.}

REPORT BT COMMEROIAL AGENT DAWSON, OF NEWOASTLE.

Referring to circular on the cultivation of oranges, lemons, olives, and figs, I beg to state that $I$ have written to several parties in regard to the matter, but, thus far, I am able to make only a very meager and unsatisfactory report.

In answer to the questions put in the circular, I will take an orangery on the Allyu River as the locality, about 60 miles north of Newcastle. Almost any variety grows well there, and, after deducting expenses, leaves a medium profit in fairly paying seasons. Mandarins, Emperor, thorny, and almost any of the larger sorts are favorites. This is about 6 miles from Vacy, near Patterson, and about 20 or 30 miles from the sea-coast. The elevation is about 100 feet above the sea-level, and the trees are grown in the open hilly country around. But the orangery in question is situated in an elbow of the Ally River, the ground having evidently been formed from time to time by sediment, sand, etc. The country above this point is very ridgy and hilly-the hills, in some instances, being of limestone formation, and probably on this account the orange flourishes, the deposit naturally containing a certain amount of lime subsoil. About 20 feet deeper the soil is of a clayey nature. Other orangeries are in the neighborhood, some of which are on the hills, and all are in a bearing condition; but in the opinion of most people the flavor is not so rich as that of those grown on the alluvial soil, and the rind of the latter is thinner.

The bark disease has lately attacked the trees in this vicinity. The trees grow better in fairly dry seasons with occasional showers, but of course droughts will kill them, or partly so. Very wet weather causes the fruit to drop off or split.

No irrigation is used, and it is questionable if the increase in the yield would compensate for the extra cost. The trees are in all stages 
of growth, from one to twenty and thirty years, owing to new trees being planted in the place of old ones which have died from the bark disease. This disease attacks the roots and the foot of the tree. The bark at that place splits and decays, after which the branches die. Trees are plowed between about $3 \frac{1}{2}$ inches deep. The trees are not pruned very much. They are merely thinned. When in full bearing the foliage nearly reaches the ground. The oranges are picken about from July to September and sold to dealers from the tree, not cured. The dealers cart them in teams to Maitland, abont 20 miles north of here, and then re-sell in smaller quantities.

The trees are planted from 20 to 30 feet dpart, from seedlings, bitter orange or lemon butts grafted or budded. There are from 10 to 30 acres to a grove, and the crop generally increases with the age and size of the trees.

This district is free from insect pests. Nut grass, or Townshend's curse, is the greatest nuisance in the flooded and alluvial soil.

THomas 'M. IAWSON,

Commercial Agent.

\section{United States Commercial Agency,} Newcastle, N. S. W., March 24, 1890.

\section{AUSTRALASLA.}

REPORT BY OONSUL GRIFFIN, OF SFDNEY.

It is perhaps not generally known that citrus fruits, and especially oranges and lemons, will grow to perfection through the whole of the southern part of this great island continent, on the table-lands in the interior and along the sides of the mountain ranges in the far north. In portions of Queensland and of south and western Australia, where the climate resembles that of Spain and Italy, the trees grow luxuriously and bear most delicious fruit. In no portion of Australasia is the cultivation of citrus plants looked upon as a profitable industry, except in the colony of New South Wales, and there only in one or two counties.

The area of orangeries in New South Wales at the end of March, 1889 , is given by the Government statistician as 10,857 acres, against 8,875 acres in 1888 . The attention given to the export of oranges dur. ing the last few years has led to extensive orange-planting. The demand for young trees has been such that it has been found difficult to obtain plants of good varieties, and the price has more than doubled.

\section{AREA OF ORANGERIES $\triangle N D$ PRODUCTION.}

The only colonies which prepare statistics to show the area of land under cultivation with oranges are New South W:les, Queensland, and Victoria. 
The following returns are extracted l'rom the latest Goverument statistical tables published in those colonies:

Area under orop, gross produce, and arerage produce per acre of oranges, in New South Wales, "lleensiand, and Victoria.

NEW SOUTH WALES.

\begin{tabular}{|c|c|c|c|}
\hline Years. & $\begin{array}{l}\text { Area un- } \\
\text { der crop. }\end{array}$ & $\begin{array}{c}\text { Gross } \\
\text { prodnce. }\end{array}$ & $\begin{array}{l}\text { Average } \\
\text { produce } \\
\text { per acre. }\end{array}$ \\
\hline 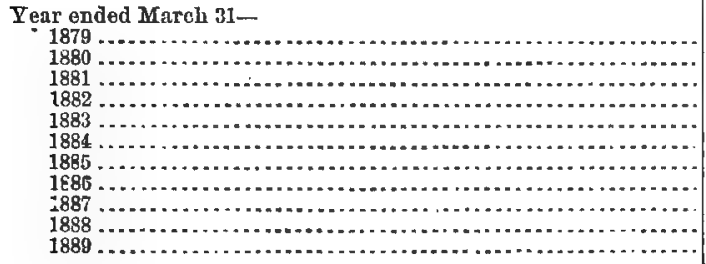 & $\begin{array}{r}\text { Acres. } \\
4,287 \\
5,106 \\
5,939 \\
6,301 \\
6,716 \\
7,268 \\
6,911 \\
7,733 \\
7,920 \\
8,875 \\
10,851\end{array}$ & $\begin{array}{r}\text { Dozen. } \\
3,398,455 \\
2,763,811 \\
3,810,356 \\
5,164,134 \\
4,978,829 \\
8,102,659 \\
4,097,666 \\
8,749,256 \\
6,376,868 \\
8,704,677 \\
19,693,880\end{array}$ & $\begin{array}{r}\text { Dozen. } \\
792.73 \\
541.28 \\
641.58 \\
819.59 \\
741.34 \\
1,101.08 \\
592.90 \\
1,131.50 \\
805.16 \\
980.80 \\
1,722.78\end{array}$ \\
\hline
\end{tabular}

NOTE.-Returns of oranges for years prior to 1889 are understaterl.

QUEENSLAND.

\begin{tabular}{|c|c|c|c|}
\hline 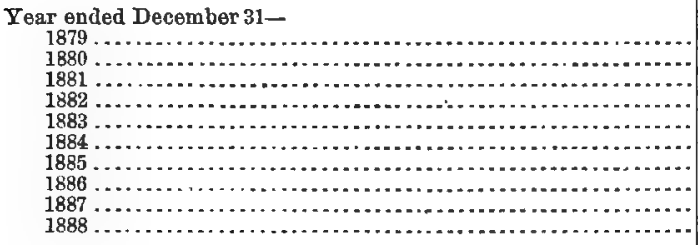 & $\begin{array}{r}219 \\
253 \\
252 \\
383 \\
399 \\
457 \\
633 \\
751 \\
992 \\
1,068\end{array}$ & $\begin{array}{r}92,140 \\
199,461 \\
141,910 \\
164,616 \\
489,344 \\
141,285 \\
658,549 \\
451,777 \\
772,380 \\
742,417\end{array}$ & $\begin{array}{r}420.73 \\
791.51 \\
501.13 \\
429.53 \\
1,227.93 \\
309.16 \\
1,040.36 \\
601.57 \\
778.61 \\
695.15\end{array}$ \\
\hline
\end{tabular}

VICTORIA.

\begin{tabular}{|c|c|c|c|c|c|}
\hline \multirow[b]{2}{*}{ Years ended Mareh 31- } & \multicolumn{2}{|c|}{ Area under crop. } & \multicolumn{3}{|c|}{ Gross produce. } \\
\hline & Olives. & $\begin{array}{c}\text { Oranges } \\
\text { and } \\
\text { lemons. }\end{array}$ & Olives. & $\begin{array}{c}\text { Olize } \\
\text { oil }\end{array}$ & $\begin{array}{l}\text { Oranges } \\
\text { and } \\
\text { lpmons. }\end{array}$ \\
\hline
\end{tabular}

It is probable that when the returns for $\mathbf{1 8 5 9}$ for Victoria are available they will show a very large increase, for since the inaugaration of irrigation colonies there, large areas of orangeries have been planted at Mildura and elsewhere. The orange and lemon tree is also being planted on a large scale at the newly established irrigation colonies in South 
Australia. Much attention is being paid to citrus culture in New Zealand, where the soil and climate, particularly in the north island, are well adapted to the industry. The oft-repeated statement that only sour oranges mature in that colony is due to the fact that heretofore the oranges were protuced from the seedling and that the best grafted varieties have only been recently introduced.

The orange was tirst planted in New South Wales by Captain Hunter, who accompanied Capt. Arthur Philip and the early settlers to Australia in 1788. The ship which conveyed them, while on the voyage stopped at Rio, where orange plants and seed were obtained. I learn from Captain Hunter's journal of transactions at Port Jackson (Sydney) that some of these plants were taken to Norfolk Island. There is a reference to the latter fact in the journal of Lientenant King, $R$. N., who says:

Two orange trees which I brought with me from Sydney were kept in tubs until I could find a sheltered situation in which $I$ could plant them.

In another part of the same journal it is recorded that " the orange trees were in a thriving state." The fine appearance of the orange groves and the superb flavor of the fruit in new South Wales are frequently mentioned in the early records of the colony.

Flourishing orange groves are, in the present day, to be found almost everywhere within a radius of 50 miles from the city of Sydney, the oldest trees being found about Parramatta, Lane Cove, and Central Cumberland; while in the valleys of the Hunter, the Hawkesbury, Manning, Nepean, Richmond, and Clarence Rivers are flourishing groves. It would be difficult to find in any part of the world groves more beautiful or luxuriant than those around Parramatta. There can be seen trees laden with blossoms and fruit in every stage of growth.

BEST VARIETLES FOR PROFIT.

There are many varieties of oranges and lemons in New South Wales, all of which are more or less profitable. Every grower las his favorite, and it would be difficult to select any particular kind as yielding larger profit than another.

It is probable, however, if a census of opinion were taken that there would be a majority in favor of the Parramatta orange (citrus aurantium variety) brought originally from Brazil in the early days of the colony. This kind is met with in the markets more often and in greater number than any other variety of orange. The skin is usually thick, but there is nothing coarse about the fruit. Many of the oranges are said to be fruits of seedlings, and I aw informed by Mr. Charles Moore, the director of the Sydney botanic gardens, that, as a rule, seedlings do not produce the same quality of fruit as that from which the seeds were taken; also, that resort must be lad to budding, grafting, or lajering in order to produce really good fruit. 
There is a great deal said about thin-skinned oranges, but in reality the quality of the soil has most to do with the texture of the skin. New land produces coarse fruit, but as the soil becomes somewhat impoverished by the action of the roots the skin becomes finer. Any grower can produce thin.skinned oranges by allowing his land to become exhausted, but he soon finds out that it will not pay to do so. The most experi. enced growers pursue a medinm course. Thick-skinned oranges, being more porous, are not suitable for export.

The Australian nanel or Bahia."-This is a remarkably fine orange It often measures from 15 to 16 inches in circumference. It is rich. juicy, and delicious; it is seedless, or nearly so, and commands a high, price. The tree is liable to become a shy bearer. It likes a deep, loamy soil, and plenty of water. The best specimens are grown on the Hunter, Manning, and Richmond Rirers. Great care, however, is necessary with its culture. In my report on fruit transmitted in June, 1887, I mentioned that this orange was identical with the Washington Navel in California, and that it came originally from Brazil, and was introduced into California from Australia. Since the publication of my report W. B. M. Lelong, secretary of the State Board of Horticulture, has expressed the opinion that the Australian tree does not resemble the Washington Navel in its habit, and that the resemblance in foliage has led to its mistaken identity. In a work entitled "A Treatise on Citrus Culture in California," published in 1888, Mr. Lelong thus describes the Australian Navel:

The fruit varies greatly in size, all sizes generally being found on the same tree. A very shy bearer; blooms profusely, but very few of the blooms set; often the trees are loaded with fruit, and after having attained the size of marbles drop to the ground withont ans apparent cause whatever; it also has a lendency to split at the navel. The navel is usually large and prominent, unlike that of the Washington Navel, which is rond and generally small. This variety was first introduced into California by the late Lewis Wolfskill. The trees were imported from Australia in 1874.

It is maintained here that the Australian Naval was introduced into California at a much earlier date than 1874. Both the tree and fruit are easily recognized by Mr. Lelong's description, but the difference in the so-called varieties is not so marked as Mr. Lelong states. The truth is the fruit varies greatly even in the same orange groves. Trees planted at the same time and in the same kind of soil often differ materially. Some of these will be prolific, while others will bear scarcely any fruit. This peculiarity has led many to believe that there are two varieties of the Australian Navel, one a prolific and the other a shy bearer. Closer observations on the part of experts to this delicious fruit would soon enable them to settle the question.

According to Mr. H. E. Van Deman, Chief of Division of Pomology, Washington, the trees known as the Washington Navel

were first imported by Mr. William Sannders, of the United States Department of Agricultnre, from Bahia, Brazil, in 1870. They were twelve in number, supposed to

" See report of Consul Burke of Bahia relative to this orange. 
be all alike, having been propagated and grown in Brazil especially for the Department and under the direction of the Commissioner of Agriculture. They were named by Mr. Saunders Bahia, in honor of the place from which they came. Two trees propagated from these were sent to Mrs. S. C. Tibbetts, of Riverside, Cal., in 1873. When these trees fruited and their superior quality was ascertained they were called by the orange-growers of California the Washington or Riverside Navel, to distinguish the variety from the Australian Navel, then commonly grown.

Mr. Van Deman also mentions that this variety of orange, bearing excellent fruit, has been growing for several years in Florida. He has devoted much study to the origin, manner of introduction etc., of the navel orange, and he states

that most of the oranges named constitute distinct varieties, although some still hold to the opinion that these differences are in a great measure caused by peculiarities of soil, climate, and treatment.

\section{He further says :}

After examining specimens of fruit from many places in Florida and California under all of these synonpms and those grown on the original trees hers, and having read what has been published in the papers on the subject, I see no reason for believing that all of the twelve trees imported from Brazil are not all of one variety.

M. J. Harold, agricultural and horticultural reporter for the "Sydney Town and Country Journal," who bas had much experience with citrus fruits both in California and Australia, is of opinion that the Australian Navel and the Wașhington or Riverside Navel are essentially the same. In a recent interview with me he said be had compared very carefully the variety grown in each countrs, and that he was fully satisfied there was no difference between them. In regard to the statements made by certain pomologists that the narel or central depression on the Australian variety was larger and not so round as that on the California orange, he said such statements could only hare been made after imperfect observation or from the examination of one or two specimens.

There is no decided difference in the size or shape of the navel, and the difference, if any, is only what might be expected in oranges of different size even off the same tree. The fruit grows alike in both countries and is apt to split in the same way. When the trees are nine or ten years of age the fruit often grows to about the size of a small marble or hickory-nut and then falls off.

Mr. Harrold further said that he would be very glad to know that the California nurserymen possess a new variety of Navel or Bahia orange, but his experience and that of his friends, both in Australia and the United States, will not warrant any such conclusion. No harm, however, can result from experimenting in this direction with the Navel orange.

Mr. J. Beresford Cairnes, vice-president of the Fruit Growers' Union of New South Wales, informs me that he has imported from California a large number of the best varieties of orange trees on account of fruitgrowers near Parramatta. The Messrs. Ohaffis Brothers have also planted a considerable area with California orange trees at their irriga- 
tion colonies on the banks of the Murray River, several hundred miles inland, and all their trees are in a flourishing condition, thus disproving the coutention that the orange will not grow away from the influence of the oceay.

Mr. Angus McKay, agricultural and horticultural instruetor at the Tecnological College, Sydney, says that the best results are obtained on land from 10 to 20 miles from the coast, and Mr. D. A. Crichton states that the orange thrives and bears excellent fruit in the inland districts. Be says in a pamphlet published at Melbourne during the last year:

Having had an extensive experience in the enltivation of citrus fruits in Australia I can say there is no foundation for the belief that the orange will not grow and do well away from the influence of the ocean. I am certain that both the orange and lemon may be grown successfnlly in many districts north and south of the Murray, provided the trees receive the attention they require. "In fact I believe that the cultivation of the citrus fruit will rank among the most profitable of our industries, as there is a rapidly expanding home market for them and any surplus that can be produced can be sold to advantage in other parts of the world.

The Siletto (or cluster orange).--This variety is much liked in Australia and is a great favorite with gro wers. The fruit is line, large and delicious, and is something like the Mediterranean sweet, but better suited to the soil and climate of Australia than the latter variety. The Siletto as its name implies, grows in clusters and some of the longest and finest I have ever seen may be found in, the orange groves of New South Wales.

The St. Michael.-This orange is also a great favorite both with growers and consumers. It is sweet and thin-skinned when grown under proper conditions. It is said, however, not to be a hardy tree and to require very great attention and experience to cultivate it properly. Mr. D. A. Crichton says that it should have a sheltered situation, for, like the Navel, if circumstances are not favorable, it is a shy bearer and the fruit is apt to lose its high character.

The hardier varieties of the orange will ripen at an elevation from 50 to 2,000 feet above the sea, but they must be kept from frost. The Navel, St. Michael, and some other varieties are more easily injured by the hot winds than the Paramatta, Rio, or common orange.

The Seville, or bitter orange (citrus vulgaris), is also grown in this colony, but only to a limited extent. It is one of the best varieties for marmalade and for the manufacture of perfume.

The Mandarin orange (citrus nobilis).-This forms an interesting group in Australia. The group embraces the Canton, the Emperor of China, the Thorny, and the Kumquat. The first three are valuable, and especially the Canton. The fruit is thin-skinned, swetet, and delicious. The Emperor is equally sweet, juicy, and fine flavored, but smaller in size than the Canton. The Thorny is also a sweet and juicy fruit, but is smaller than the Emperor. Mr. S. W. Pye cultivates with fair suecess two new varieties, the Capera and the Rulsy.

Of the different varieties of the lemon (Oitrus lemonium) grown in 
Australia, the Lisbon is the most popular ; but there are several kinds of Lisbons, the best known of which are the variegated and the thornless. The common lemon is also cultivated, but the fruit is small and inferior, when compared with the Lisbon. Mr. George W. Knight, whose testimony was taken by the Royal Commission of Victoria on vegetable products, states that the lemon will not stand the warm, dry climate of the northern part of Victoria and that its leares do not attain half the ordinary size there.

The lime (Citrus limetta) is cultivated more or less in various parts of Australia, and will thrive almost anywhere when the thermometer does not fall lower than 20 degrees above zero. The best kinds are the Lemon lime, the Bergamot, the Mela Rose, and the small Naples lime. All thesé will grow luxuriantly over a large extent of country. They are found on the Blue Mountains and on the table lands of the New England district in New South Wales. They are not partial to a high temperature and especially where the sun is hot enough to scorch them. They like a little frost and what is called a dormant climate. In Queensland both the orange and lemon trees have an inclination to form into a crown at the surface and branch out in long luxuriant branches like the bamboo.

The largest orange and lemon trees in Australasia are to be found in the county of Cumberland, in Mr. S. N. Pye's grove at Rocky Hall, Paramatta. They are the oldest trees in this part of the world, having been planted nearly a century ago. Some of the trees are over 40 feet in height and have a diameter of 22 inches. They have been mentioned in various reports I have made as yielding as many as 10,000 oranges per tree in a single season.

\section{SOIL FORMATION.}

The soil in the orange-growing district about Paramatta consists principally of Wianamatta shales overlying sandstone. The soil around Lane Cove, also in the Paramatta district, has been carefully analyzed by Mr. W. A. Dixon, F. I. O., F. O. S., instructor in chemistry, Sydney Technical College, for Mr. Angus McKay, instructor in agriculture at the same college.

\section{Mr. Dixon remarks with reference to soil analyses :}

It may be said with truth that the greater number by far of the soil analyses which have been published are of little value, for these reasons: (1) Sufficient care has seldom been taken to obtain uniform samples of the soil for analyses; and (2) the analyses have not been conducted with sufficient refinement to secure the object in view The former condition can be easily attained, but the latter can only be secured by years of practice, which is often wanting in those to whom the work is relegated.

I have not been able to obtain analyses of the soils in the different orange-growing parts, but such as I have obtained have been made by Mir. W. A. Dixon, and it is worthy of note to quote his explanation of the manner in which his aualyses are made:

In selecting a sample, it is commonly the practice to dig up some soil in one place and mix up ten or twelve pounds of it for a sample. If we consider that the excrement of a bird containing ten grains of nitrogen mixed with a sample so taken would be 
equal to 0.014 per cent. of nitrogen or 1,568 pounds per acre, and that the urine of an animal spent a year before might similarly increase, not only the nitrogen but the phosphates and other ash constituents of plante gathered from far and wide, it is evident that such a mode of sampling is liable to error and stands condernned.

The samples of soil analyzed by Mr. W. A. Dixon were taken as fol. lows:

A piece of sheet iron was bent into a tube, $1 \frac{1}{2}$ iuches in diameter, leaving a slit oue-quarter of an inch wide down one side, and one end of this was fastened to a convenient handle. The ground was gone over at regular intrrvals of about a chain apart, when the tube or scoop was screwed into the soil, and this being relieved by a sparle the section of soil could easily be removed by passing a knife throngh the slit. The different sections allowed to dry and thoroughly mixed and sifted must give a tolerably average sample of the soil of the area operated on. This may seem $i$ tedione operation, but withont this preliminary care the work of analysis is not only use. less but often misleading-which is worse.

To arrive at the degree of exactitude which is required in soil analyses to be of value, we should consider the quantities of concentrated manures which are found practically of value in agriculture and determine the quantity of the same constituents in the soil to within such limits at least. If we take the weight of an acre of soil at 1 foot deep as 5,000 tons, it will not be far from the truth as an average, and this depth may be taken as that at which, being subjected to tillage, crops derive the bulk of their nutriment. On this basis 0.001 per cent. of any ingredient would represent 112 pounds per acre. Again, if we take the quantities of concentrated artificial manures which are applied as top dressing and otherwise, we find that a soil analysis requires to be carried to the third place of decimals with certainty to be comparable with practical results, for some substances at all events. For my part I think that this third place is about the limit to which analyses can be carried with any degree of certainty, and to do this it is necessary to carry ont to the fourth and take the nearest number in the third, and this requires that large quantities be operated on, which require much care and patience.

The constituents determined are those soluble in cold concentrated hydrochloric acid by agitation during forty-eight hours, and this solution may be fairly assumed to contain all the constituents of the soil at all readily available as plant food. Ordinary commercial hydrochloric acid was used containing already iron and sulphuric acid, and to it were added small quantities of bone ash dissolved in acid sulphate of magnesia and chloride of potassium. A similar quantity of this prepared acid was put through all the processes used in each determination, and the quantities present weighed, so that the numbers obtained for the soil are the differences between it and the hydrochloric acid used. This, to a great extent at all events, eliminates errors due to the solubility of precipitates in water and the re-agents used.

The first soil dealt with was taken from Mr. H. Heard's property, where the agricultural classes had been taken for the purpose of studying how well-ordered orcharding can be carried on with profit.

The soil on Mr. Heard's property is typical of a very large area of the shale series. It is described by Mr. McKay as of a decided red color, due to the presence of iron. It is a good, sound loam, seeming to be more clayey in composition than the analysis actually shows. It is the virgin soil. The geological formation here is Hawkesbury sandstone, under shale beds, which vary in quality. 


\section{The following is the first analysis :}

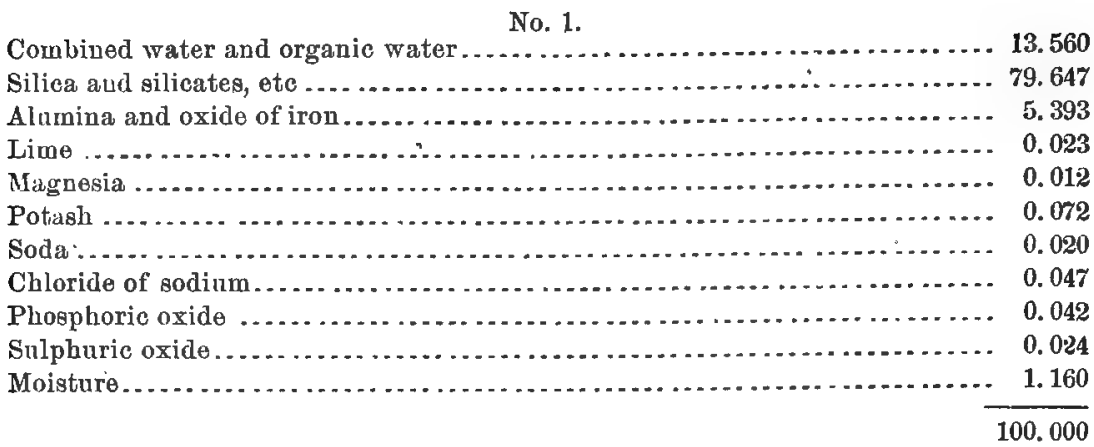

Nitrogen=ammonia 0.163.

Capacity for absorbing and retaining moisture

Mr. McKay states that the small proportion of lime in this soil is its greatest defect, and that it would require to be enriched with bone manures.

The next analysis is from the same property, but from garden land, where cultivation has been canried on during many years and which bad received careful manuring in a manner suitable for shale soils:

No. 2.

Organic matter and moisture (of the whole bulk).

Clay, or alumina, and iron (of the whole bulk)

Carbonic acid

Lime (of the whole bulk)

Chloride of sodium (of the whole bulk) ..............................

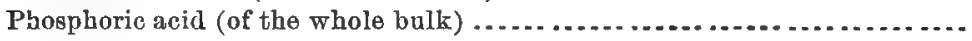

Sulphuric acid.

0.01

Loss by water, etc., (of the whole balk)

Traces.

Nitrogen $=$ ammonia 0.25 .

Capacity for absorbing and retaining water

With reference to this analysis Mr. McKay remarks that the soil could be limed heavily, with advantage.

The next analysis is from the old orange country, natural soil formation, from location about 3 miles northerly from the town of Paramatta:

No. 3.

Organic matter and water.

Sand or silica

Clay, or alnmiua

Carbonic acid

Lirne Trace.

Magnesia

Potash

*Capacity for absorbing and retaining moisturo.

"All the foregoing soils are absorbent of water and retentive of it, in proportion to the state of cultivation. The cultivated land No. 2 stande best in this respect and is rated as 8, as a standard for the analyses. 
Mr. McKay says of this soil:

It is richer in organio matter than No. 1. The formation is the same. It needs lime, or marked fulling off in crops must follow as the land is worked.

Mr. S. W. Pyc, to whom I sent a series of interrogatories in regard to the soil in the orange districts is of opinion, that a rather poor, loamy, sandy soil is best suited to the citrus fruits, but fully 3 inches of the seed-bed should be very rich in compounds of light pature to prevent the surface becoming compressed by constant watering. The substances most suitable for this purpose are thoroughly decayed bush leaves, especially those of the forests, rotten grass, roots, the surface of virgin soils, and well-rotted inanure. Fresh manure is objectionable. If the soil is of virgin nature it should have a dressing of lime, to enconrage the decomposition of organic matter in the soil and to destroy all insect life.

The largest orange and lemon grove in Australia is located at Seven Hills, in the county of Cumberland, it being a little over 200 acres in extent. The soil there is of a rich black and brown color, from 12 to 24 inches deep. The subsoil is principally clay. The water in the creeks is slightly brackish. This district produces the finest Navel orauges in Australia.

\section{CLIMATIO INFLUENCES.}

The climatic iufluences are exceedingly favorable to the growth of fruit. The highest range of the thermometer in the Cumberland district is $106^{\circ}$ and the lowest is $42^{\circ}$.

The editor of The Year-Book of Australia-a most valuable publication-Mr. Edward Greville, has favored me with the following tables relating to the temperature and rain-fall of the six chief cities in these colonies. It is around these cities that the chief fruit-growing districts are to be found:

SYDNEY, NEW SOUTH WALES.

[146 foet above sea-level.]

\begin{tabular}{|c|c|c|c|c|c|c|c|c|c|c|}
\hline \multirow{3}{*}{ Month. } & \multicolumn{3}{|c|}{$\begin{array}{l}\text { Barometer (reduced } \\
\text { to } 32^{\circ} \mathrm{Fah.} \text {. }\end{array}$} & \multicolumn{3}{|c|}{$\begin{array}{c}\text { Temperature (in } \\
\text { sbade). }\end{array}$} & \multicolumn{4}{|c|}{ Raiu-fall. } \\
\hline & \multirow{2}{*}{ Mean. } & \multirow{2}{*}{$\mid \begin{array}{l}\text { Highest } \\
\text { reading. }\end{array}$} & \multirow{2}{*}{$\begin{array}{l}\text { Lowest } \\
\text { reading. }\end{array}$} & \multirow{2}{*}{ Mean- } & \multicolumn{2}{|c|}{ Extremes. } & \multirow{2}{*}{$\begin{array}{l}\text { Total } \\
\text { fail. }\end{array}$} & \multirow{2}{*}{$\begin{array}{l}\text { No. of } \\
\text { days. }\end{array}$} & \multirow{2}{*}{$\begin{array}{l}\text { Greatest } \\
\text { fall. }\end{array}$} & \multirow{2}{*}{ Date. } \\
\hline & & & & & Max. & Min. & & & & \\
\hline 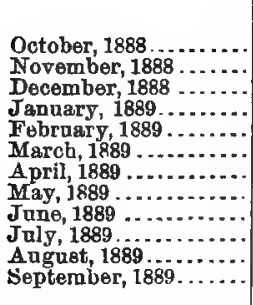 & $\begin{array}{l}\text { Inches. } \\
29.931 \\
29.831 \\
29.806 \\
29.802 \\
29.803 \\
29.953 \\
30.012 \\
29.982 \\
29.702 \\
30.070 \\
29.975 \\
29.885\end{array}$ & \begin{tabular}{|l|} 
Inches. \\
30.260 \\
30.276 \\
30.130 \\
30.122 \\
30.145 \\
30.348 \\
30.345 \\
30.454 \\
30.065 \\
30.377 \\
30.488 \\
30.210
\end{tabular} & $\begin{array}{l}\text { Inches. } \\
29.426 \\
29.371 \\
29.270 \\
29.360 \\
29.365 \\
29.413 \\
29.521 \\
29.553 \\
29.160 \\
29.702 \\
29.401 \\
29.410\end{array}$ & $\begin{array}{l}\circ \\
62.6 \\
69.0 \\
70.4 \\
71.9 \\
71.3 \\
69.9 \\
65.4 \\
61.1 \\
55.9 \\
52.5 \\
54.7 \\
57.4\end{array}$ & $\begin{array}{c}\circ \\
85.5 \\
92.9 \\
85.8 \\
102.8 \\
96.6 \\
91.5 \\
77.0 \\
75.8 \\
68.0 \\
64.4 \\
69.7 \\
83.7\end{array}$ & $\begin{array}{l}\circ \\
49.6 \\
56.8 \\
57.8 \\
58.3 \\
57.6 \\
59.2 \\
53.6 \\
49.4 \\
44.1 \\
41.6 \\
42.2 \\
44.1\end{array}$ & $\begin{array}{r}\text { Inches. } \\
1.613 \\
0.529 \\
7.089 \\
2.098 \\
2.696 \\
1.128 \\
3.578 \\
20.868 \\
1.128 \\
8.914 \\
4.113 \\
4.31\end{array}$ & $\begin{array}{r}12 \\
10 \\
18 \\
16 \\
9 \\
17 \\
13 \\
17 \\
12 \\
20 \\
18 \\
19\end{array}$ & $\begin{array}{r}\text { Tnches. } \\
0.815 \\
0.123 \\
2.751 \\
0.556 \\
2.196 \\
0.275 \\
1.487 \\
8.363 \\
0.380 \\
2.237 \\
0.905 \\
0.916\end{array}$ & $\begin{array}{lr}\text { Oct. } & 8 \\
\text { Nov. } & 29 \\
\text { Dec. } & 1 \\
\text { Jan. } & 4 \\
\text { leb. } & 8 \\
\text { Mar. } & 10 \\
\text { Apr. } & 1 \\
\text { May } & 28 \\
\text { June } & 25 \\
\text { July } & 26 \\
\text { Aug. } & 6 \\
\text { Sept. } & 19\end{array}$ \\
\hline $\begin{array}{l}\text { Sums or means } \\
\text { Or extremes.... }\end{array}$ & $\begin{array}{c}29.896 \\
\ldots \ldots\end{array}$ & $\begin{array}{l}30.268 \\
30.488\end{array}$ & $\begin{array}{l}29.4 ! 3 \\
29.160\end{array}$ & $\begin{array}{c}63.5 \\
\ldots \ldots . .\end{array}$ & $\begin{array}{r}82.8 \\
102.8\end{array}$ & $\begin{array}{l}51.2 \\
41.6\end{array}$ & 58.081 & 181 & 8.363 & May 28 \\
\hline
\end{tabular}


BRISBANE, QDEENSLAND.

\begin{tabular}{|c|c|c|c|c|c|c|c|c|c|c|}
\hline \multirow{3}{*}{ Mouth. } & \multicolumn{3}{|c|}{$\begin{array}{c}\text { Barometer (reduced and } \\
\text { corrtected). }\end{array}$} & \multicolumn{3}{|c|}{$\underset{\text { Temade). }}{\text { Temperature (in }}$} & \multicolumn{4}{|c|}{ Rain-fall. } \\
\hline & \multirow{2}{*}{ Mean. } & \multirow{2}{*}{\multicolumn{2}{|c|}{$\begin{array}{l}\text { Higheat Lowest } \\
\text { reading. reading. }\end{array}$}} & \multirow{2}{*}{ Mean. } & \multicolumn{2}{|c|}{ Extromes. } & \multirow{2}{*}{$\begin{array}{l}\text { Total } \\
\text { fall. }\end{array}$} & \multirow{2}{*}{$\begin{array}{l}\text { No. of } \\
\text { days. }\end{array}$} & \multirow{2}{*}{$\begin{array}{c}\text { Greatert } \\
\text { fall. }\end{array}$} & \multirow{2}{*}{ Date. } \\
\hline & & & & & Max. & Min. & & & & \\
\hline 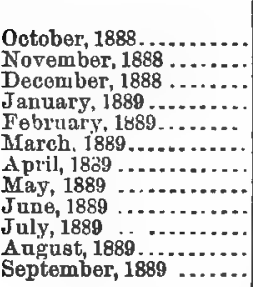 & \begin{tabular}{|c|} 
Inches. \\
30.100 \\
30.015 \\
30.001 \\
29.900 \\
29.989 \\
30.065 \\
30.163 \\
30.129 \\
29.983 \\
30.142 \\
30.125 \\
30.060
\end{tabular} & \begin{tabular}{|l|} 
Inches. \\
30.335 \\
30.329 \\
30.214 \\
30.255 \\
30.189 \\
30.348 \\
30.349 \\
30.538 \\
30.250 \\
30.383 \\
30.517 \\
$\mathbf{3 0 . 2 8 3}$
\end{tabular} & $\begin{array}{l}\text { Inches. } \\
29.804 \\
29.713 \\
29.550 \\
29.567 \\
29.624 \\
29.772 \\
29.851 \\
29.714 \\
29.580 \\
29.654 \\
29.623 \\
29.781\end{array}$ & $\begin{array}{l}\circ \\
69.2 \\
\mathbf{7 3 . 4} \\
\mathbf{7 5 . 3} \\
\mathbf{7 6 . 5} \\
\mathbf{7 7 . 7} \\
\mathbf{7 4 . 6} \\
69.9 \\
65.7 \\
59.1 \\
58.9 \\
60.5 \\
\mathbf{8 5 . 1}\end{array}$ & $\begin{array}{c}\circ \\
90.4 \\
99.3 \\
94.5 \\
96.0 \\
94.6 \\
91.5 \\
85.9 \\
82.8 \\
75.5 \\
76.0 \\
78.6 \\
85.7\end{array}$ & $\begin{array}{l}\circ \\
54.6 \\
51.9 \\
59.4 \\
61.8 \\
61.8 \\
61.8 \\
55.6 \\
53.0 \\
41.6 \\
37.2 \\
41.5 \\
45.5\end{array}$ & \begin{tabular}{|r|} 
Inches. \\
0.771 \\
3.485 \\
6.008 \\
1.232 \\
2.002 \\
4.288 \\
6.047 \\
3.346 \\
0.717 \\
8.464 \\
3.832 \\
3.307
\end{tabular} & \begin{tabular}{r|}
10 \\
9 \\
13 \\
5 \\
8 \\
19 \\
21 \\
17 \\
3 \\
12 \\
12 \\
10
\end{tabular} & $\begin{array}{r}\text { Inches. } \\
0.248 \\
1.560 \\
1.482 \\
0.430 \\
0.940 \\
1.113 \\
2.940 \\
0.638 \\
0.498 \\
3.542 \\
0.367 \\
1.603\end{array}$ & $\begin{array}{lr}\text { Oot. } 17 \\
\text { Nov. } 28 \\
\text { Dec. } 14 \\
\text { Jan. } 21 \\
\text { Eeb. } 23 \\
\text { Mar. } 25 \\
\text { Apr. } \mathbf{1 7} \\
\text { May } 7 \\
\text { Jane } 6 \\
\text { July } 16 \\
\text { Aug. 14 } \\
\text { Sept. 21 }\end{array}$ \\
\hline $\begin{array}{l}\text { Sums, means, or } \\
\text { extremes } . . . . .\end{array}$ & 30.056 & 30. 538 & 29.550 & 68.8 & 99.3 & 37.2 & 43. 499 & 139 & 3. 542 & Jaly 18 \\
\hline
\end{tabular}

MOLBOURNE, VICTORIA.

[91 feet above meq-level.]

\begin{tabular}{|c|c|c|c|c|c|c|c|c|c|c|}
\hline \multirow{3}{*}{ Month. } & \multicolumn{3}{|c|}{$\begin{array}{l}\text { Barometer (reduced } \\
\text { to } 32^{\circ} \text { Fah.). }\end{array}$} & \multicolumn{3}{|c|}{$\begin{array}{l}\text { Temperature (in } \\
\text { ghade). }\end{array}$} & \multicolumn{4}{|c|}{ Rain-fall. } \\
\hline & \multirow{2}{*}{ Mean. } & \multirow{2}{*}{$\begin{array}{l}\text { Highest } \\
\text { reading. }\end{array}$} & \multirow{2}{*}{$\begin{array}{l}\text { Lowest } \\
\text { reading. }\end{array}$} & \multirow{2}{*}{ Mean. } & \multicolumn{2}{|c|}{ Extremes. } & \multirow{2}{*}{$\begin{array}{c}\text { Total } \\
\text { fall. }\end{array}$} & \multirow{2}{*}{$\begin{array}{l}\text { No. of } \\
\text { days. }\end{array}$} & \multirow{2}{*}{$\begin{array}{c}\text { Greatest } \\
\text { fall. }\end{array}$} & \multirow{2}{*}{ Dute. } \\
\hline & & & & & Max. & Min. & & & & \\
\hline 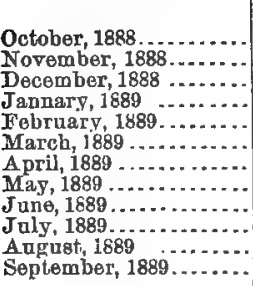 & $\begin{array}{l}\text { Inches. } \\
30.046 \\
29.911 \\
29.884 \\
29.862 \\
29.887 \\
30.015 \\
30.042 \\
30.082 \\
29.758 \\
30.158 \\
30.020 \\
29.037\end{array}$ & \begin{tabular}{|l|} 
Inches. \\
30.371 \\
30.349 \\
30.196 \\
30.191 \\
30.237 \\
30.389 \\
30.450 \\
30.640 \\
30.246 \\
30.473 \\
30.582 \\
$\mathbf{3 0 . 3 2 9}$
\end{tabular} & $\begin{array}{l}\text { Inches. } \\
29.433 \\
29.507 \\
29.374 \\
29.413 \\
29.570 \\
29.439 \\
29.501 \\
29.547 \\
29.218 \\
29.656 \\
29.403 \\
29.461\end{array}$ & $\begin{array}{l}\circ \\
56.1 \\
62.7 \\
66.7 \\
67.7 \\
65.9 \\
64.4 \\
60.5 \\
55.6 \\
52.5 \\
47.8 \\
50.1 \\
52.3\end{array}$ & \begin{tabular}{|c|}
0 \\
88.0 \\
102.0 \\
96.4 \\
99.2 \\
96.0 \\
96.0 \\
87.9 \\
78.1 \\
66.0 \\
62.1 \\
68.0 \\
74.5
\end{tabular} & $\begin{array}{l}\circ \\
35.1 \\
38.1 \\
47.2 \\
49.7 \\
45.5 \\
43.0 \\
37.2 \\
39.4 \\
37.6 \\
31.3 \\
32.1 \\
32.1\end{array}$ & $\begin{array}{r}\text { Inches. } \\
1.35 \\
0.62 \\
2.72 \\
4.22 \\
1.50 \\
0.24 \\
3.60 \\
0.94 \\
2.78 \\
1.64 \\
2.06 \\
1.51\end{array}$ & $\begin{array}{r}8 \\
6 \\
9 \\
11 \\
11 \\
7 \\
5 \\
7 \\
11 \\
11 \\
16 \\
8 \\
15 \\
14\end{array}$ & $\begin{array}{r}\text { Inches. } \\
0.54 \\
0.20 \\
1.10 \\
1.80 \\
0.78 \\
0.12 \\
1.63 \\
0.32 \\
0.65 \\
0.62 \\
0.31 \\
0.35\end{array}$ & $\begin{array}{lr}\text { Oct. } & 7 \\
\text { Nov. } & 12 \\
\text { Dec. } & 31 \\
\text { Jan. } & 3 \\
\text { Feb. } & 6 \\
\text { Mar. } & 18 \\
\text { Apr. } & 7 \\
\text { Mas } & 13 \\
\text { June } & 13 \\
\text { Jaly } & 2 \\
\text { Ang. } & 31 \\
\text { Sept. } & 23\end{array}$ \\
\hline $\begin{array}{l}\text { Sums, means, and } \\
\text { extremes } . . . . .\end{array}$ & 29.967 & 30.582 & 29.218 & 58.5 & 102.0 & 31.8 & 23.18 & 117 & 1.80 & Jan. 3 \\
\hline
\end{tabular}

Average yearly rain-fall for the last, thirty-one years, 25.75 inches. 'Average number of rainy days for the last thirty-one years, 135 . 
ADELAIDE, SOUTH AUSTRALIA.

[From Ootober 1, 1888, to September 30, 1889.]

\begin{tabular}{|c|c|c|c|c|c|c|c|c|c|c|}
\hline \multirow{3}{*}{ Montl. } & \multicolumn{3}{|c|}{$\begin{array}{l}\text { Barometer (reduced to } \\
32^{\circ} \text { Frah. menn sea-lovel). }\end{array}$} & \multicolumn{3}{|c|}{$\begin{array}{l}\text { Temperature (in } \\
\text { shado). }\end{array}$} & \multicolumn{4}{|c|}{ Kain-fall. } \\
\hline & \multirow{2}{*}{ Mean. } & \multirow{2}{*}{$\begin{array}{l}\text { Highest } \\
\text { roading. }\end{array}$} & \multirow{2}{*}{$\begin{array}{l}\text { Lowest } \\
\text { reading. }\end{array}$} & \multirow{2}{*}{ Mean. } & \multicolumn{2}{|c|}{ Extremes. } & \multirow{2}{*}{$\begin{array}{l}\text { Total } \\
\text { fall. }\end{array}$} & \multirow{2}{*}{$\begin{array}{l}\text { No. of } \\
\text { days. }\end{array}$} & \multirow{2}{*}{$\begin{array}{c}\text { Greatest } \\
\text { fall. }\end{array}$} & \multirow{2}{*}{ Date. } \\
\hline & & & & & Max. & Min. & & & & \\
\hline 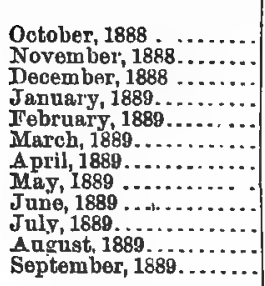 & $\begin{array}{l}\text { Inches } \\
30.181 \\
30.011 \\
28.972 \\
29.984 \\
30.004 \\
30.109 \\
30.144 \\
30.174 \\
29.988 \\
30.274 \\
30.134 \\
30.068\end{array}$ & $\begin{array}{c}\text { Inches. } \\
\mathbf{3 0 . 5 0 0} \\
\mathbf{3 0 . 3 5 2} \\
\mathbf{3 0 . 2 5 6} \\
\mathbf{3 0 .} 268 \\
30.365 \\
30.416 \\
30.543 \\
30.610 \\
30.507 \\
30.685 \\
30.662 \\
\mathbf{3 0 . 4 7 9}\end{array}$ & $\begin{array}{l}\text { Inches. } \\
20.721 \\
29.610 \\
29.615 \\
29.520 \\
29.570 \\
29.640 \\
29.432 \\
29.654 \\
29.387 \\
29.760 \\
29.572 \\
20.560\end{array}$ & $\begin{array}{l}\circ \\
62.8 \\
71.4 \\
74.8 \\
75.2 \\
73.4 \\
70.9 \\
63.0 \\
57.0 \\
53.8 \\
50.5 \\
53.1 \\
55.2\end{array}$ & $\begin{array}{c}\circ \\
91.9 \\
105.8 \\
107.5 \\
109.0 \\
100.4 \\
102.0 \\
82.5 \\
75.5 \\
68.3 \\
65.9 \\
71.3 \\
76.7\end{array}$ & $\begin{array}{c}0 \\
41.5 \\
46.4 \\
48.9 \\
54.1 \\
53.5 \\
49.6 \\
49.6 \\
37.5 \\
38.5 \\
36.3 \\
38.0 \\
38.5\end{array}$ & $\begin{array}{r}\text { Incheg. } \\
0.306 \\
0.655 \\
0.278 \\
2.084 \\
0.231 \\
0.813 \\
5.654 \\
4.086 \\
4.752 \\
1.211 \\
3.589 \\
1.504\end{array}$ & $\begin{array}{r}5 \\
8 \\
8 \\
8 \\
2 \\
8 \\
15 \\
14 \\
22 \\
14 \\
20 \\
16\end{array}$ & $\begin{array}{r}\text { Inches. } \\
0.229 \\
0.156 \\
0.1 \% 4 \\
2.299 \\
0.128 \\
0.206 \\
2.207 \\
1.643 \\
1.362 \\
0.210 \\
0.915 \\
0.226\end{array}$ & $\begin{array}{lr}\text { Oct. } & 4 \\
\text { Nov. } & 13 \\
\text { Dec. } & 29 \\
\text { Jau. } & 2 \\
\text { Fob. } & 2 \\
\text { Mar. } & 7 \\
\text { Apr. } & 2 \\
\text { May } & 20 \\
\text { June } & 13 \\
\text { July } & 31 \\
\text { Aug. } & 7 \\
\text { Sept. } & 27\end{array}$ \\
\hline Sung or meaus .. & 30.083 & 30.685 & 29.387 & 63.4 & 109.0 & 36.3 & $\overline{26.068}$ & 140 & 2.299 & Jan. 2 \\
\hline
\end{tabular}

Average yoarly rain-fall for last thirty-twa years, 20.083 inohes. Average number of raing days fo sst thirty.two years, 128.

PRRTH, WFSTERN AUSTRALIA.

[Lat., $31^{\circ} 67^{\prime} 10^{\prime \prime}$ S.; Long., $110^{\circ}$ 62' E. Altitude, 67 feet.]

\begin{tabular}{|c|c|c|c|c|c|c|c|c|c|c|}
\hline \multirow{3}{*}{ Month. } & \multicolumn{3}{|c|}{$\begin{array}{c}\text { Barometer (rednced to } \\
32^{\circ} \text { Fah.). }\end{array}$} & \multicolumn{3}{|c|}{$\begin{array}{c}\text { Temperature (in } \\
\text { shade). }\end{array}$} & \multicolumn{4}{|c|}{ Rain-fall. } \\
\hline & \multirow{2}{*}{ Mean. } & \multirow{2}{*}{$\begin{array}{l}\text { Highest } \\
\text { reading. }\end{array}$} & \multirow{2}{*}{ Lowest } & \multirow{2}{*}{ Mean. } & \multicolumn{2}{|c|}{ Extremes. } & \multirow{2}{*}{$\begin{array}{l}\text { Total } \\
\text { fall. }\end{array}$} & \multirow{2}{*}{$\begin{array}{l}\text { No. of } \\
\text { days. }\end{array}$} & \multirow{2}{*}{$\begin{array}{c}\text { Groatest } \\
\text { fall. }\end{array}$} & \multirow{2}{*}{ Date. } \\
\hline & & & & & Max. & Min. & & & & \\
\hline 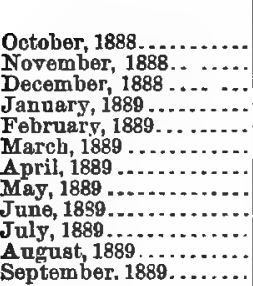 & $\begin{array}{l}\text { Inches. } \\
30.112 \\
29.984 \\
29.990 \\
29.923 \\
29.991 \\
30.076 \\
30.122 \\
30.110 \\
30.095 \\
30.231 \\
30.191 \\
30.128\end{array}$ & \begin{tabular}{|l|} 
Inches. \\
30.438 \\
30.303 \\
30.230 \\
30.205 \\
30.170 \\
30.319 \\
30.397 \\
30.447 \\
30.426 \\
30.518 \\
30.478 \\
30.572 \\
\end{tabular} & $\begin{array}{l}\text { Incher. } \\
29.909 \\
29.725 \\
29.773 \\
29.580 \\
29.778 \\
29.848 \\
29.825 \\
29.839 \\
29.611 \\
29.812 \\
29.662 \\
29.704\end{array}$ & $\begin{array}{l}0 \\
64 \\
69 \\
72 \\
73 \\
74 \\
76 \\
67 \\
59 \\
57 \\
54 \\
54 \\
58\end{array}$ & $\begin{array}{r}0 \\
95 \\
97 \\
102 \\
105 \\
101 \\
104 \\
91 \\
79 \\
75 \\
70 \\
73 \\
84\end{array}$ & \begin{tabular}{l|}
0 \\
45 \\
46 \\
55 \\
52 \\
56 \\
56 \\
47 \\
41 \\
39 \\
38 \\
34 \\
38
\end{tabular} & $\begin{array}{r}\text { Inches. } \\
3.05 \\
1.37 \\
1.11 \\
0.00 \\
0.01 \\
0.68 \\
1.72 \\
4.02 \\
4.87 \\
3.23 \\
5.69 \\
2.08\end{array}$ & $\begin{array}{r}12 \\
10 \\
6 \\
0 \\
1 \\
3 \\
10 \\
15 \\
18 \\
17 \\
14 \\
11\end{array}$ & $\begin{array}{r}\text { Inches. } \\
0.27 \\
0.32 \\
1.72 \\
0.00 \\
0.01 \\
0.47 \\
0.88 \\
0.81 \\
0.74 \\
0.87 \\
1.69 \\
0.72\end{array}$ & $\begin{array}{l}\text { Oct. } 3 \\
\text { Nov. } 8 \\
\text { Deo. } 1 \\
\text { Feb. } 19 \\
\text { Mar. } 23 \\
\text { Apr. } 16 \\
\text { May } 2 \\
\text { June } 27 \\
\text { July } 6 \\
\text { Aug. 15 } \\
\text { Sept. 16 }\end{array}$ \\
\hline & & & & & & & & & & \\
\hline
\end{tabular}

Barometer mean for twelve previous years, 30 _ inches. A verage jearly rain-fall for twelve previous years, - inches. Average namber of rainy days for twelve previvus years, —. Average temperature for twelve previous years, - 0 .

HOBART, TASMANIA.

\begin{tabular}{|c|c|c|c|c|c|c|c|c|c|c|}
\hline & Inches. & Inches. & Inches. & & & 0 & Inches. & & Inches. & \\
\hline October, 1888 & 29.985 & 30.393 & 29.420 & 52. 7 & 80.3 & 34.0 & 1.59 & 19 & 0.28 & Oct. 5 \\
\hline$r, 1888$ & 29.871 & 30.441 & 29.082 & 57.4 & 98.0 & 39.7 & 2.23 & 10 & 0.84 & Nov. 15 \\
\hline December, 1888 & 29.947 & 30.347 & 29.458 & 61.7 & 91.3 & 39.0 & 1.45 & 6 & 0.54 & Dec. 20 \\
\hline January, 1889 . & 29.875 & 30. 370 & 29.298 & 63.3 & 91.5 & 44.0 & 2.36 & 13 & 0.75 & Jan. 14 \\
\hline February, 1889 & 29.854 & 30.340 & 29.348 & 62.5 & 95.0 & 44.7 & 1.57 & 12 & 0.48 & Fob. 5 \\
\hline 1889 . & 29.991 & 30.452 & 28. 960 & 60.1 & 89.0 & 42.2 & 0.72 & 12 & 0.25 & Mar. \\
\hline April, 1889 . & 30.043 & 30.474 & 29.528 & 57.3 & 77.7 & 36.8 & 2.78 & 14 & 1.57 & Apr. 8 \\
\hline 10000 & 30.100 & 30.630 & 29.482 & 52.6 & 72.0 & 36.2 & 0.96 & 15 & 0.32 & May 22 \\
\hline June, $1889^{\circ}$ & 29,698 & 30.293 & 29.107 & 48.4 & 60.0 & 33.8 & 8.15 & 21 & 4. 11 & June 14 \\
\hline July 1889 & 30.136 & 30.505 & 29.425 & 47.3 & 60.3 & 33.5 & 1.90 & 7 & 0.93 & July 2 \\
\hline August, 1889 & 29.976 & 30.716 & 29.370 & 48.4 & 66.8 & 32.2 & 0.96 & 13 & 0.24 & Aug. 13 \\
\hline September, 1889 & 29.880 & 30.375 & 29.264 & & 70.2 & 33.7 & 113 & 16 & 0.18 & Sept. 1 \\
\hline Sums or noa & 29.942 & 30.716 & 28.960 & 55.13 & 98.0 & 32.2 & 25.89 & 158 & 4.11 & June 14 \\
\hline
\end{tabular}


PLANTING.

Planting in New South Wales generally takes place between the middle of March and the end of April, although it may be done at other times. It must be remembered that the seasons here are the opposite to those in America. Trees planted early in the Australian autumn (in March) begin quickly to take root, as the ground at that period contains considerable warmth. The plants soou recover from the check caused by removal and are fairly established before the winter sets in. If trees are planted in the Australian winter, say in June and July, the growth is necessarily less active and the plants are liable to suffer from the effects of the winds and frosts, where frust occurs. When it is not convenient to plant in autumn the leading authorities say it is better to wait until spring (September) rather than put the trees iu during the winter months. As a rule trees should not be shifted after their spring growth has fairly siarted or before their summer growth has matured. Mr. D. A. Crichton, in urging this plan, says :

It must be clearly understood, however, that though I advocate autumn planting where practicable, it is essential that the trees are in a fitting condition for shifting. As a matter of fact the summer growth, very frequently, does not mature early enough for the trees to be shifted in the autumn.

The same authority is very averse to planting trees close together. He says that the intervening space ought to be fully 24 feet from tree to tree, except in the case of the smaller varieties. The Mandarin, being less rohust than other kinds, may be planted out at distances from 15 to 18 feet apart, according to growth or variety.

PRopagation.

Opinion is divided here as to the best method of propagation, but the most successful growers prefer grafting to budding. Most of the trees sold by nurserymen are raised by grafting, but some cultivators mention that the budding process is the best, as grafted trees go off through the bark, decaying at the place where the scion was united to the tree. As to the best kind of stock, many favor the lemon for the reason that it is not only more vigorous and hardy, but less apt to be injured by removal.

The late James Pye, who had more than fifty years' 'xperience with Citrus fruit cultivation at Paramatta, preferred to graft on the orange stock instead of on lemon stocks. He was also a strong ad̀ vocate for cultivating seedlings and grafting upon them instead of the lemon stocks. He said:

I commenced grafting upon the bitter orange stooks alont five years agro. I find them free from all insects and looking healthior thm any other kiud.

Mr. Charles Moore, director of the Botanic Gardens, Syduey, when he visited the orunge-growing countries some yours ago, observed that 
this method was used by the orange growers in Spain to propagate their trees. Mr. James Pye, in connection with this matter, said:

I have no objection to one cross with the common lemon; but if you go on crossing year after year, it deteriorates the quality of the fruit (more particularly tho keeping quality) as well as incroases the rod scale. Thero is no treo so subject to the red scale as the lemon tree, and there is none of the orange family so free from it as the bitter orange.

\section{IRRIGATION.}

Irrigation, for fruit-raising, has not been sufficiently tested in Australia to enable an opinion to be giren as to its effect by any well-defined results so far as orangeries are concerned. The truth is, irrigation is not practiced systematically in New South Wales. In Victoria, and South Australia, where irrigation colonies have been started, the trees are too young to bear fruit; but their healthy condition is au evidence of what may be expected in the near future. It is very generally understood by farmers that no other class of fruits require irrigation so much as those of the Citrus family. Crops can not be dependerl upon during seasons of dry weather unless supplied with water by artificial means. The trees are always in an active state of growth and require a great deal of moisture; therefore this moisture unst be supplied from some source or otherwise root-actiou is interfered with more or less and the trees will suffer. Mr. D. A. Orichton points with pride to what has been done by the irrigationists in Victoria. He does not, however, propose any precise rules to be followed other than not to allow the trees to flag through lack of moisture at the roots. Care must also be taken not to supply water too freely, as that will make the fruit coarse, want. ing in flavor, and too tender for packing and keeping. The best land is drained and trenched, and by the time the trees come into bearing, the expenses have often amounted to considerably over $£ 100$ (\$187) per acre. The fertilization at Paramatta cousists principally in the use of nitrogenous substances.

\section{PRUNING.}

Many growers recommend great care to be taken in pruning, from the fact that it is often productive of more harm than good. No more cutting ought to be done than circumstances render necessary. In the case of trees which hare arrived at full bearing age little is required in the way of pruning. The removal of rank shoots, dead or diseased wood, and the thinning out of branches when overcrowded, so to allow the air to circulate freel $\tilde{y}$, are about all that is necessary. The case is different with young trees, for there the object of the cultivator is the development of a strong growth of wood in a particular direction. The knife in that case must be used pretty freely. Young trees should have suffcient, lateral shoots left to balance the plants in each direction and form the heads. Shoots not required for the development of the tree should be cut away. It is better, however, to leave a few more shoots than those which will be ultimately required to form the trees, in order to $156 \mathrm{~A} \longrightarrow 6$ 
afford the stems the necessary protection from the sun, removing them as the trees iucrease in size. In training trees of the citrus family, it is desirable that the branches hang to within about 2 feet of the ground, so as to protect the trunks from the heat of the sun in summer. It is not an uncommon thing for trees to be trained high, so that horse-power cultirators can be ased close to the stem, but. Mr. Crichton says the practice is bad, and he is of opinion that the cracking or discoloration of the bark, which is so common in this part of the world in orange and other fruit trees, is caused by the sap fermenting through the action of the sun. By training the head low there will be no trouble caused by the exposure of the trunks. Besides, trees with low heads are less liable to suffer from high winds. It is not advisable to let young orange trees bear too freely. The growth of wood in joung trees is the chief consideration. Trees should be five years old before they are allowed to bear heavy crops, as by that time they will have attained a fair amount of growth.

It is said to be highly important that the trees should be placed in a position where their roots will not be subject to extremes of drought or excessive moisture or to sudden changes in temperature. The remedy for this is first by trenching and draining the ground thoroughly so as to secure the most perfect root bed, and then by mulching the surface soil, so as to shelter it from the full power of the sun and drying winds. The temperature in deeply-worked and well-drained land is higher in winter and lower in summer than in shallow or undrained soil. Nor is the land so readily affected by atmospheric changes.

\section{PICKING AND PAOKING.}

Oranges and lemons are picked from April to November. The plan is to leave them on the trees until they are ripe, or nearly so. The most experienced growers cut them from the stems instead of pulling them, although the latter nethod is mostly pursued. Uare is taken not to pick the fruit in damp or wet weather, and not to pat them in boxes until they are free from moisture. The oranges packed by Mr. E. B. Cairues at Paramatta for the London market turned out rery well for trial shipments. The fruit was wrapped in tissue paper, put in boxes of uniform size, and subjected to but little pressure in nailing on the covers.

Mr. Cairues states that before the export of fruit can prove a profitable iudustry for long distances better provisions than exist at pres. ent will have to be made for the care of the fruit during the royage. Even temperature is required while in transit, and the fruit ought not to be subjected to either extreme of beat or cold.

\section{OURING.}

Very little has been done in the way of curing citrus fruits in Australiu. Citron is not put up for sale, and the small quantities made are only for families for their own private use. 


\section{SIZE OF ORANGERIES.}

The orange groves in Australia vary in size from 1 to 200 acres. Orange and lemon trees are seldorn however planted so as to form groves of either of these trees exclusively other fruit trees are interspered, called here "summer truits," such as peaches, apricots, passion, and other fruits. The average holdiugs vary from 6 to 20 acres in extent.

\section{AGE OF FRUIT TREES.}

It is said orange and lemon trees do not come into full bearing until ten or twelve jears after they are planted, although they may commence bearing in the fifth year.

\section{INSEOT PESTS.}

Mr. Charles Moore, director of the Botanic Gardeus, Sydney, informs me " that the insects that attack the orange tree are the common small white scale, the brown scale, and the smooth surface white coccus." These insects have at times made great ravages among the orange groves and orchards. Experienced growers keep their trees comparatively free from these insects. It is very generally believed that the ravages of these pests are due to defective cultivation. Mr. C. Moore states that various remedies. have been employed in Anstralia to get rid of the attacks of insects,

The principal remedy leing Fishurst's compound, but the results have not been commensurate with the cost attending the use of such compounds. There is no doubt many of the compounde will destroy the insects, but their use in a large way is impracticable. The best remedy in my opinion is to improve the cultivation, as healthy plants will throw off all pests.

Mr. Orichton recommends that care be exercised in preparing and draining the ground before planting the trees. His experience is that when this is done and the trees are fed well and mulched before dry weather sets in disease, insects, and fungoid pests seldom cause trouble in an orangery. According to the same authority the remedies generally employed for scale are lime, sulphur, soft soap, whale-oil soap, kerosene, tobacco water, and various patent insecticides; also quassia water is safe and good.

He recommends the following remedies as affording better results than any others hitherto tried: (1) Arsenical compounds; (2) petroleum, and (3) pyrethrum, and says:

The first acts through the stomach, and is effectual chiefly against mandibular inoects; the second and third act by contact, and are therefore of more general application.

Mr. Charies Moore does not think that the fluted or cottony cushion scale, which has proved so destructive to orchards in California, has attacked the orange and lemon trees to any great extent in this colony, and this opiniou he also expressed in 1886, and which was reported by 
me to the Department of State in my dispatch No. 89, of 23d January, 1886. Prof. F. M. Webster and Mr. Albert Koebele, of the Department of Agriculture, Washington, D. C., who visited Australia during the year 1888, are of opinion that the absence of the cottony cushion scale, Tcerya, is due to the prevalence of the Australian lady-bird, Vedolia cardinalis, which not only feeds upon the scale itself, but deposits its eggs beneath them, and the young larvæ of the lady.bird burrow into the egg masses from below and feed upon the eggs of the Iceryas; later they attack the Iceryas of all sizes.

During the last two years a number of Australian lady-birds have been introduced into infected orchards in California with the most gratifying results. Prof. D. W. Coquillett, of Los Angeles, Cal., has very carefully studied the life-history of the lady-bird, and an account of them is contained in Professor. Riley's Annual Report for 1888. In Insect Life, volume 2, No. 3, 1889, page 70, published by authority of the Secretary of Agriculture, Washington, Prof. D. W. Coquillett states that the Australian lady-birds have been distributed through many orchards on the Pacific slope of the United States, and that they have spread very rapidly. Mr. J. R. Dobbin, of St. Gabriel, Cal., stated, in July, 1889, that the Australian lady-bird had multiplied and spread over 3,200 trees in his orchard, and that the cottony cushion scale was rapidly disappearing. He says :

I made a public statement that my orchard would be free of Icerya by the first of November, but the work has gone on with such amazing speed and thoroughness that I am to-day confident that the pest will have been thoronghly exterminated from my trees by the first of August. As the lady-bird has been extensively distributed, I feel positive from my own experience that the entice valley (San Gabriel) will be practically free from the Icerya before the advent of the new year.

Citrus trees are affected with what is called the lemon-tree borer, AEmona hirta, in both Australia and New Zealand. In some districts the trees are completely riddled by this pest. Mr. A. T. Urquard of the Karaka in New Zealand, forwarded specimens of these insects to Prof. T. Kirk, F. L. S., of New Zealand, in the pupa state, enabling the professor to identify them with the Amona hirta of Captain Brown's "Manual of the New Zealand Coleoptera." Mr. Urquhard stated that he had observed this insect for several years in connection with the fertilization of the Yucca fiber plant, but its identity with the lemontree borer has not hitherto been suspected.

Professor Kirk says that the best way to stop the inroads of the borer is to prevent the deposition of eggs; this he says, however, can not be done effectively until its habits are more widely known. He recommends that all wounds should, as far as possible, be covered with tar or some substance calculated to prevent the deposition of eggs; also, probing the galleries with a wire and perforating the larra would be found effective. Soft soap dissolved in boiling water containing a little carbolic acid injected into the galleries by means of a syringe is said to dissolve the larva. Professor Kirk says a weak solution of caustic potash would prove equally effective. 


\section{FRUIT TRADE.}

The seasons in Australia, as stated before, being directly opposite to those in California, there is of course a strong demand for fruit in one country when most abundant in the other. The want of quick and frequent steam service between the two countries is the principal obstacle in the way of the development of the fruit trade; at least that is the case as far as the imports of American fruits into this country are concerned. There is only one steamer per month plying between the cities of San Francisco and Sydney and there is no direct steam communication between Melbourue and San Francisco, while no steam service exists between these Australian cities and New York or other cities on the Atlantic coast of the United States.

The voyage from San Francisco to Sydney occupies twenty-five days. The revolution which has taken place in steam-ship construction within the last decade has rendered the vessels at present plying between the two ports obsolete, so far as cool storage accommodation is concerned. The owners of the line, Messrs. Spreckels \& Co., have, however, expressed their determination to replace the Alameda, Mariposa, and Zealandia by vessels of the most modern build. When this is accomplished, as a natural result the fruit will always be in the best condition when it arrives. The weather, especially when crossing the equator, is extremely hot, and without cool chambers and other modern facilities for properly storing fruit it is hardly to be expected that it could make so long a transit without injury.

At present the trade is small and is confined principally to the imports of fruits from California. The fruit export to San Francisco thus far has been only a few trial shipments. The truth is, the cost of getting the fruit from the country districts to Sydney is too great to induce the farmers even to bring it to market except in small quantities, much less to think of exporting it to America.

The railway freights from the fruit-growing centers to Sydney are from 75 to 100 per cent. higher than in the United States. There is a strong agitation on the part of the public press and people to have these ligh charges reduced.

G. W. GRIFFIN, Consul.

\section{United States Consulate,}

Sydney, N. S. W., January 21, 1890. 


\section{FIJI.}

Very few oranges are grown, and those only by occasional planters, who plant a few trees for their own use; no particular rariety is sought after. The tree is grown as much for the shade it affords as for the fruit it bears.

Lemons are not cultivated. There is a lemon or citron that grows wild in the bush, but as jet is not considered of importance enough for export. It is a prolific bearer, and grows abundantly everywhere in this colony. Were it properly developed by scientific cultivation, I think it would prove a valuable addition to the varieties grown in our own country.

$$
\text { ANDREWS A. ST. JoHN, }
$$

Commercial Agent.

UNITED States Commerdial AGENCT,

$$
\text { Levuka, January 10, } 1890 .
$$




\section{CONTINENT OF EUROPE.}

\section{FRANCE.}

REPORT BY OONSUL BRADLEY, OF NIOE.

\section{ORANGES AND LEMONS IN THE RIVIERA.}

Varieties.-Among the hundred and over varieties of citrus growu on the Riviera, it is impossible to specify any one or two as most profitable. The oranges are not only exported as fruit, but orange-flower water is distilled from large quantities of their flowers (one firm alone using 700,000 pounds of flowers). Tons are candied green. Neroli, so much used by the perfumer, is extracted from other varieties, and from the dried peel curaçoa is manufactured.

From recommendations given I have selected eight varieties of oranges as among the most useful.

ORANGES.

Orange franc (Citrus aurantium vulgare).-Stem straight and vigorous, bark gray, head hemispheric, whose branches, numerous and confused, are covered with thorns. The young sprouts are angulous and of tender green color. The lower leaves thick, oval, lightly notched, light green ; upper leaves oblong, darker green, glossy, entire, on a long stem, less winged than the under leaves. Flowers axillary and terminal, white petals, ovary often striated at the base. Fruits, average size, rounded, globulous, sometimes slightly concave at top, where the place that the style occupied is always apparent. The stem end frequently shows the striæ noticed in the ovary. Skin golden yellow, slightly rongh, and covered with vesicles. The pulp is divided into eight or ten compartments, full of large vesicles nearly as yellow as the skin, which hold a juice abundant, palatable, and sweet. Seeds large, oblong, unequal, each inclosing three or four perfect germs. The tree grows here to be 24 feet high, its head, say, 27 feet in circumference; in warmer climates a little larger. It commences bearing at eighteen or twenty years of age. The fruit grows sweeter as the tree grows older. It ripens early and resists cold better than any other variety; not much cultivated on account of slow growth, and because the fruit is much of it spoiled for transportation by the thorns, but the stocks are much used for grafts of other varieties. 
Orange de Nice (Citrus aurantium nicense).-Differs but slightly from the above; it is a favorite because of the keeping qualities of the truit, and the readiness with which a graft from it starts.

Orange de Malte (Citrus aurantium Melitense).-Skin dark gellow, shading into red; the pulp may be red in part or wholly. It is considered to be a hybrid between the Franc and some East Indian species.

Orange a pulp rouge (Cilrus aurantium Hierochunticum).-The skin of this orange is always yellow, never red, but the pulp is dark red. This variety difters little from the preceding in appearauce and form.

Mandarin (Citrus madurensis or Citrus deliciosa).-Already well known in California. Here it is one of the hardiest varieties.

Orange bigaradier Franc (Citrus bigaradia) - Root long, branchy, bearded, light colored outside, yellowish within. Trunk straight, gray. ish, branches bushy, covered with long greenish thorns. Young sprouts are pale green, angulous, like most of the genus; leaves elliptic or ob. long, narrow, acuminate, lightly notched in the upper part, wavy, a fine green, and carried on stems more or less winged. Flowers in clusters, liave calix angulous, five petals, taste slightly bitter, from thrty to thirty fire stamens partly adherent at the base. Ovary round or striated, surmounted by a style, terminated by a tuberculous stigma. The fruit is of average size, round or slightly elongated, smooth or sometimes rough, flatteued at the end, yellow to reddish orange color. The peel is bitter, very tragrant, clinging to the pulp, which is yellow and divided into twelve or fourteen parts; its juice is not very palatable, bitter acid taste. The seeds are oblong, sharp, and yellow. The tree grows here to the height of about 27 feet; flowers in May and sometimes in autumn; fruit ripens slowly. Neroli is distilled from its flowers, and from its dried peel the liquor curaçoa is made.

Orange de Chine, bigaradier, or Chinois (Citrus bigaradia sinensis).-A valuable dwarf variety, about 12 feet high ; resists the cold well. The orange is used for preserves or candied fruit and a water is distilled from its flowers.

Bergamotier ordinaire (Citrus Bergamia vulgaris).-The bergamotier is naturally lofty, plenty of branches, but the branches are so brittle that the head of the tree is rarely well-filled out or regular. Its leares are oval, oblong, some pointed, others obtuse, average size, green, the lower surface whiter than any other orange leaf, leaf stems long and winged. Flower white, small, fragrant, scattered or united in clusters, borne on very short stems. Fruit good sized, usually pyramidal, rarely round, yellow, smooth, glossy. It has an agreeable fragrance peculiar to itself, peel thin, pulp yellowish green. This variety is chiefly valuable for the essential oil obtained from its flowers and peel.

\section{IJMONS.}

Jemons being generally seedlings, a very large number of varieties are produced, which even proprietors of orchards do not try to distin. guish. Twenty or thirty varieties have been classified. 
The following are said to be among the most valuable: Lemonier ordinaire (Oitrus limonum) rulgare; lemonier imperial (Citrus limonum) imperial ; lemonier bignette (Citrus limonum) bignetta; lemovier perette spatafore (Oitrus limonum) peretta spatafora. This last excellent in damp situations.

The lemons thrive only in the sheltered nooks within a mile or two of the sea, where every deep warm valley has its small orchard ripening, not only from the direct rays of the sun, but from the warmth thrown back by the cliffs around them. The oranges more hardy can be found 10 miles from the coast among the mountains as high as 200 or 300 yards above the sea. Our only level land is in small valleys among the Alpes Maritimes which cover all this district. It is generally noted that this fruit ripens earlier on hill-sides where water can be brought to it.

The soil best adapted to them here is a silico-argilaceous or argilocalcareous soil, the latter, when not too damp, but any good mixed soil seems to answer, as they are not difficult.

In regard to temperature M. J. Tesseàre gives observations taken by lim covering twenty years. The minimum during that time being $26^{\circ}$, maximum 92.5, arerage $60^{\circ}$ Fahrenheit in the shade. These observations were taken three times daily, sunrise, 2 p. m., and at sunset. In the sun at 2 p. m., the thermometer marked minimum $99 \circ$, maximum " $135^{\circ} .5$, averaging 112.1. Lowest night temperature $26^{\circ}$, highest $79^{\circ}$. There are but few sultry dajs. During the twenty rears there were 4,385 days almost or entirel s cloudless, 1,547 clouds days, 1,348 days more or less rainy, 28 days withont observation. This would give in one jear 219 sunny days, 77 cloudy, 67 rainy. The hygrometer of Saussure gives minimum of 23 , maximum 77 , average 61.4 .

For the five years $1870-74$, the minimum rain-fall was in $1874,24.3$ inches; the average for the five years was 35.1 inches. The peculiarity of the rain-fall is the tropical intensity of each shower and its short duration; so that while we have actually more rain than London, England, we have very much fewer rainy or cloudy days. During the long summer, from June to September, the trees are irrigated with water brought in canals from mountain streams, which is generally tempered by storing in large private tanks for some time before being applied, which it is at intervals of one or two weeks. This is done in summer, between sunset and sunrise; if necessary in antumn it is done in the morning. Gardeners watch the leaves of the tree for indications of need of water. The orange needs less water than the lemon.

The earth is worked over twice a year. In the spring after pruning, at least a foot deep, again in the autumn not quite so deep. The tool used for this work is always tined, as a blade might injure the smaller deep roots. It is considered desirable to cut away the roots which lie near the surface, as they are injured by becoming too dry and the tree suffers. The deeper growing roots are better for the tree to draw sustenance from, as they keep moist longer.

Fertilizers are used for two definite purposes and at two different 
epochs: First, to press the growth of the young tree with manure speedily decomposed, which will furnish strong nutriment at once to the roots, such as oil-meal cakes, guano, dried blood, stable manures. Second, for the support of the mature tree with manures of slower decomposition, such as horn shavings, bones, woolen rags, hair, hide, and even leather. These are placed arouna the tree as far from the trunk as the roots extend during the autumn, and covered with earth to the depth of a foot.

The object aimed at in pruning is to bring the greatest surface possible of the tree to direct action of air and light. The spherical form is considered best. To keep this form shoots are pinched off in June each year. In the early spring weak and dead wood, forgotten useless shoots, are cut out to let light and air in among the branches; a sharp knife must be used.

Oranges are picked first when just beginning to turn yellow, in October, for distant shipment, next in December for a nearer shipment when half yellow, finally in the spring when fully ripe for home market. They are sold by the thousand, the caisse or patronne. The best are wrapped in gray paper and packed 360 in a box, and called caisses flaudrines. The second quality are packed in the same way, 500 to the box, and called simply caisse. The third quality packed the same way is called caisse de Menton. The fourth quality are called Patronnes de Magasin, and the fifth Patronne de barque. These latter are shipped by boat in bulk. Those poorer than the above five qualities have no commercial value, excepting for the peel, which is taken off and dried. Oranges as a rule grow sweeter with the age of the tree.

Lemon trees blossom from the earliest spring to late fall, and even during the winter. From the few fertile flowers of late winter comes a large thick-skinned fruit with but little juice, called Testassa. The early spring flowers from which good fruit ripens in about six mouths or in October and November are the ones most depended on for a crop. These lemons are called here Primo Fiore or Maraviglia. The next flowers of May and June only ripen their fruit after ten mouths which are called Secundo Fiore or Granetta. These are generally inferior to the primo but if for any reason those fail, nature tries to make up for it by putting all the good qualities lost with primo into the secundo, The flowers of July and August mature the following April and produce the Verdame which is said to keep well for shipment. After the rain of September and October, a few flowers are fertile and give a coarse fruit called Septombrine.

The fruit, carefully picked, is spread on straw, where the different commercial qualities are selected. They are wrapped in absorbent paper and packed according to size and given the following commercial names: Caisse Flandrine, 400 of the best size in a box; Caisse Lyonnaise, 500 in a box, and Petites Oaisses, where three boxes hold 1,000 of the sinaller ones. The lemons of the first class in size must be at least 55 millimeters in diameter. 
The plants are propagated by seed, grafting, cuttings, and layering, principally by the two first methods. When planted in the orchard the distance apart is moditied, first, by the kind of culture whether in large orchards, when other plants are to be cultirated between the rows and nature allowed to take its course, or in small gardens, where a system of forcing is used ; second, the quality of the soil, and, finally, the form in which they are to be set out, whether in one row, in squares, etc. In a general way from 15 to 24 feet is near enough for trees of standard size.

The trees begin to bear flowers and fruit at five years, give a reasonable crop at fifteen, but increase in productiveness up to forty years.

\section{INSECT PESTS.}

The following insects are hurtful to both orange and lemon trees, but as the lemon tree is always in flower and is more frequently watered, the Lepidoptera in the larva state is more injurious to it than to the orange :

Coccides.-Dactylopius citri (BoisDuval).-This insect with soft tegument is very common on both orange and lemon trees of the Riviera. Its body is a red brown; about it are numerous cottony appendices, 17 on each side; at the end of the abdomen are two mucb longer than the others. The insect is entirely covered with white dust. Its length is $0 .{ }^{\mathrm{m}} 003$ to $0{ }^{\mathrm{m}} 004$, breadth $0 .{ }^{\mathrm{m}} 002$. The antennæ of the female are 8 jointed. The tarsis is half the length of the tibia; the thread-like feet are very long. Web pores are plenty; the genito-anal ring large, with 6 bristles; the larva has antennæ 6-jointed; the abdominal web pores are less numerous than in the perfect insect. The male is long, brown on head and thorax, abdomen yellowish; the feet and antennæ darker in color; these latter have 10 articulations. Thorax narrow; elytron very long, grayish white; abdomen very long, with web pores on the edges; sexual organs tuberculous in form, quite large, terminated in a rounded point; feet long; tarsis longer than the thighs.

This insect, a veritable scourge, forms upon the young fruit and leaves cottony and sticky heaps, contrasting strongly by its whiteness with the color of the fruit and the black layer of the "Morphée," which al. ways surrounds them. Breaking off these living heaps, some of the insects will be crushed, yielding a reddish liquid; in them will be found insects in different stages of development, and besides this the larræ of the coccinella and the caterpillar of a little Lepidoptera, the Ephestia gnidiella.

The Dactylopius citri seeks sheltered spots where the trees, too closely planted, lack air and light. It hurts the growth of the trees by stopping the leaf pores. It unites with the Lecanides and the Aphides to propagate "Miellat" and "Morphée."

Aspidiotus limonii (Signoret).-This Coceus with hard tegument, 
which is found particularly upon the young branches, has, according to M. Signoret, the lobes at the abdominal extremity detached and apparent and the finabriate scales long; the last abdominal segment is elongated. The shell of the adult female is spherical, yellowish white in color, with iuternal organs rellow, and a large quantity of eggs. The shell of the male is more elongated. Raising the shell of the mother when the little ones are being hatched, numerous small white larvæ running quite fast among the eggs, yet unopened, can be seen. These resemble the Phylloxera, excepting in color. The male is quite common, his head is notched in front, the antennæo are long, thorax rounded and broad.

Lecanium flesperidum (Auctorum).-This insect is clothed with a solid cuirass. It is elongated in form; its color a yellow brown. It adheres firmly to the leaves and is difficult to distinguish from them. Its antennæ have six articulations, legs slender, claws very long, genito anal rıng surrounded by six bristles. Larva long, with six articulations in each of antennæ. The male has not been described. Examinations of the female show embryo but no eggs, which gives rise to suggestion that she may be viviparous.

Lecanium olece (Bernard).-Brown, with deep body and two raised transverse lines on the back, almost heart-shaped; the antennæ have eight articulations; yellow at first, they become black. The female lays her eggs and shelters them under herself in great quantities.

The methods in use by the best gardeners for the destruction of this form of pest is to powder the tree with a mixture of sulphur and plaster from April, and to brush trunks, branches, and fruit during the winter. Washing with waters, saline, alkaline, or acid, which might harm the plant, are given up; syringing with medicinal liquids is also discouraged. Carbolic acid, turpentine, or petroleum dilutions are preferred for brushing on, the latter as the cheapest with water in proportions of 1 to 30 . These should be applied at night in spring. It is also recommended to wash the trunk with lime water and to cut off and burn on the spot at night the small branches too much attacked to be cured. Another author advises the use of nitrobenzine, but the essential things seem to be plenty of light and air through and among the trees, and, above all, protection from wild birds.

Lepidoptera.-Acrolepea citri (Millere)._Tincida described by Milliere and Rangouet. The female probably lays her eggs, which are round and of a bright yellow color, near the bud. The joung larva soon hatches; it is at first to the naked eye a yellowish white, and retains this color some time; at the moment of its final transformation, when it is largest, its body is yellowish green in color, which is particularly noticeable in the hollow of each ring and on the under parts. The head, dark brown, has antenna, or horns. The eyes are very apparent. A marked distinction between this insect and the Prays-oleellus is that the latter has upon the first thoracic ring two bright black spots, which are 
wanting in the Acrolepea citri, whose first ring is simply a darker shade. The body of the larva is a yellowish-green color, and has six brown feet armed with little claws darker brown. The false feet to the number of eight are placed under the sixth, seventh, eighth, and ninth ring. 'They are provided with an apparatus with short filaments, which allows them to adhere or cling strongly to any object. The last abdominal segment is conical and notched at the anal extremity; it is provided with the same apparatus as the false feet, commencing with the first thoracic ring; the covering is delicately marbled with a reddish color. Preserved in alcohol the larva, which has lost its greenish tints, becomes yellow, the back a darker shade, the eyes and mandibles are very black. Very lively, it burrows in the bud whose covering it has pierced, and leaves a round hole very apparent. Once settled in the bud it commences by devouring the base of the stamens, then it attacks the embryo of the fruit. It is found sometimes at the bottom of the calyx en. veloping the base of the fruit, still very small, with its rings, trying to get into it; moving from place to place, it emits thread, which binds the stamens together and encloses its excrements. When the flower attacked opeus, the stamens are seen to be upset and the young fruit, pierced at several points, soon blackens and dries up, even before it is as large as a grain of wheat. If the larra is disturbed, it quickly leaves the inside of the flower and crawls about the outside of it; then if there seems to be danger it tries to reach another branch or the ground, dropping down by the thread spun from itself, by which it climbs up again when the danger seems past, absorbing the thread into itself as it goes up. The larva being fully developed, it prepares to spin its cocoon in the calyx of the flower.

The cocoon is a gray-brown, meshes so loose that the phases of transformation can be easily followed; once really shut in, the caterpillar shrinks rapidly. Larvæ commencing their cocoons 20th and 21st of September yielded a butterfly the 26th or 27th following. Its sleep then lasts but six or seven days. At first the little chrysalis, in its cocoon, is a greenish color on its under parts, the upper parts, and a line upon its front red. After this the green and red fade and it becomes a light brown, verging toward green, which darkens more and more. At its birth the butterfly is almost black; it is ouly later that it pales and the varied designs appear upon its dress. It is motionless, antennæ stuck to its body, legs drawn up under it, looking like a small black spindle; when well dried it straightens its antennæ, which it carries pointing forward, aud always in motion. It raises its head, stretches out its legs, and makes its toilet; at the slightest alarm it changes its place with a jerky little flight. The designs on the wings of these butterflies vary much and sometimes disappear completely to give place to a general mouse-gray color, more or less silvery.

$\Delta$ general description of a good specimen of this insect would be as follows : 
The body mouse-gray, under part silvery; head the same color, eyes are large, the dark antennæ half the length of the body.

Examining with care, a black line forming a half crescent is apparent, at the commencement of the prothorax, near the center of the folded wings, or in the front third; a second black spot appears resembling the letter A, with top flattened and lacking the trausverse bar. The top points toward the head of the insect, the sides are on the two wings. Further back is a third black spot similar to the second, but very much fainter, and the final point of the wings, a darker gray than the rest, makes a last noticeable spot. The specks on the wings are too small to be called spots. The three pairs of legs are of different lengths; the second pair has one spur, the third has two. In color they are gray, with black rings.

I have only studied these insects during the blossoming seasen of August. Professor Penzig, who has made longer studies of them, says that there are three generations in each Jear; the first in April and May, the second in August, and the third in October and November; according to him the winter is passed as an egg from this last generation. The first generation in the spring from these eggs is not strong or prolific, and not so harmful. The August generation is the most mischievous. They were first noted as hurtful in Corsica, later in Sicily by M. Panizzi. The methods of destruction used against this insect and the next two are to pick up and burn the flowers attacked and to gather all grass and weeds growing near the trees, dry them and burn them in heaps under the trees at night-fall. A great many butterflies attracted by the light are destroyed, besides other forms of iusect life, under the burning heaps.

Ephestia guidiella (Milliere).-A Phycide described by M. Milliere, of Cannes, who gave it this name because he first found it upon a Daphne gnedium, a shrub quite common on the hills. It seems to be polyphagous, however, as it is found on many plants; besides this they are found under the whitish, sticky, cottony heaps deposited on fruit and leaves by the Dactylopius eitri.

It has the form but is a little larger than the Acrolepid. It differs from the latter in color, being blackish, with a band of darker shade on each side, dotted or marbled. The larva is hairy; there are hairs even around its eses. Its head and first thoracic ring are a brighter color. Placed iu alcohol it is a lighter shade, becoming a chestnut, the band on the sides very marked. It is very lively, seems to flee the light and is longer in preparing for its transformation than the Acrolepia. It first makes a loose shelter, in which it spins a cocoon impenetrable and whiter than that of the other, aud while longer in preparing the cocoon, it is at the same time longer in chauging from chrysalis to but. terfly, wine days instead of six. The butterfly is larger and a dark gray. Its wings, iustead of being folded in a spindle-shape, are folded more in the shape of an acute-angled triangle. The body is mouse- 
gray beneath, a little darker above, the abdomen is well furnished with hairs, the under part of the wings is a brilliant ash-gray. The upper wings are fringed only at their extremity and on the inver side. Their general shade is lees of wive, with metallic luster, two light designs cross them. When its wings are spread this color is brighter, but the design fades and nearly disappears if the insect is long on the wing. The under wings have a darker shade above than below, their fringe is long, especially the outer edge, adark line separates the fringe from the rest of the wing. The legs are an even gray, something the shade of the under part of body and wings; with wings spread the Ephestia guidiella measures about $0^{\mathrm{m}} .015$, while the Acrolepia citri measures but $0^{\mathrm{m}} .010$ or $0^{\mathrm{m}} .012$. Professor Penzig thinks it has but two generations. The discovery of the larvæ of these insects in the beaps made by the cocci raises the question, yet uusettled, whether they feed upon the latter, and so are not wholly harmful.

Eupithecia pumilata (H. G.).-A geometride larger than the Ephestia. As the butterfly varies in its markings so the larva of this insect vary so much is to make detailed description difficult Its body is cylindrical; six true legs appear, but those on the tenth ring and on the twelfth and last are false. The body is yellow-green, with black lines on the sides. In the middle of the back a longitudinal line from which, on each ring, a line runs at right angles down the sides; the body is corered with thinly-scattered hairs. The chrysalis, jellow-brown, is quite slender.

The specimens of the butterfly that I have raised are a grey-sellow color, brighter beneath than above. The eyes are large and greenish. The under wings are marbled, with little irregular blackish spots. They are notched in the back part and have a darker line serring as base to the fringe. The upper wings, larger and darker, have the same dark line. On their field there are, besides the spots which the under wing bears, designs lighter and darker.

The diptera are represented by one small $\mathrm{fl} 5$, in color blue, striped with yellow, which lives in its larva state in the pulps of the oranges. It is the cerutitis hispanica (B). M. Peragallo could find nothing more detailed than this fact noted by Colonel Goureau.

Of coleoptera, the curculio-otior-hynchus meridionalis, which attacks the young shoots of the olive, is equally fond of the orange-tree, and all lemons which fall on the ground in damp places are pretty sure to contain more or less of the dark yellow carpophilus mutilatus, and to show the small, round hole in its skin by which entrance was effected. To obtain a specimen, it is only necessary to squeeze the lemon, and the carpophilus comes out with the juice, but not wet by it.

The Morphèe or Fumagine.-After jears of study and discussion of this disease, which gives the leaves of a grove the appearance of being coated with soot, scientists have united in the belief, well founded, that it is due to the liquid excrement of one of the cocci in which germs of 
mushrooms find congenial soil for growth and do grow very rapidly. To prove the power of this insect to eject to some distance its excrement, M. Peragallo confined in a glass insect-case several live specimens of the cocus on orange tree leaves already affected with fumagine. Within twenty-four hours the glass was sprinkled with tiny drops of a viscous liquid, white and transparent, which had evidently been produced by the insects, and which were soon covered with fumagine from germs in the air. For its cure, the abbe Loquez says:

Have no excess of humidity, plant arther apart, give the trees air, let them grow tall, be mocierate with irrigation-water gives fruit but is liable to injure the treefinally, burn the infected branches.

M. Riviere suggests lime-water washes, fumigating with tobacco, washing and brushing the leaves, branches, and fruit. Dr. Signorel adds hanging wisps of straw soaked in coal-tar under the trees. At Mentone petroleum and vinegar-water are both used as washes.

Two methods are given in the record of the Entomological Society of France for 1883; the first from Greece, the second from Sicily:

(1) Prune well and syringe the trees with the following mixture: Eight parts water with one each of petroleum and quick lime finely powdered.

(2) Powder the trees while damp with dew with fresh or unleached wood ashes.

To sum up, keep the trees healthy, do not plant in low places or where there is much fog, cut off sickly branches, and destroy by hand as many insects as possible.

"Gum" shows great weakness and probable death of the branch on which it appears; it is considered to be a cryptogamic disease. M. Peragallo gives the following insects which seem to be friends of the orange and lemon trees:

Syrphus hyalinatus (de Fallen).-From larvæ found at Mentone and Roqueburne, in whose neighborhood were quantities of the larra of Acrolepia citri, black and dried, were developed in his breeding cases a diptera already known as destructive to the coccide, identified as the Syrphus by alinatus (de Fallen). This insect is considered by M. Peragallo as one of the most useful parasites of the lemon trees, living as it loes on different kinds of insects hurtful to the tree and being quite common in some sections. He has found also in the chrysalides of Microlepidoptera larvæ which gave birth to tiny Hymenoptera as yet unnamed, and in one case records the birth of a Hemerobius chrysops from the chrysalis of a Eupithecia pumilata; these latter cases being more truly in the nature of parasites than the Syrphus hyalinatus.

\section{ACKNOWLEDGMENT.}

Besides personal observation I am indebted to the following works for information on the subject. In some cises, particularly concerning the insects, I have made free translations: 
Histoire et Culture des Oranges. A. Risso, A. Poiteau, revised by M. A. clu Breuil. Nice pratique, etc., A. La Costa.

Les Primus u'bonneur. Ministère de l'Agriculture.

Statistique Agricole. Ministère de l'Agriculture.

Arbres, otc., daus la région comprise entre Cannes et Menton. F. Forckel, head grardner at Monte Carlo.

Etudes sur les Insectes nuisibles ì l'Agriculture. M. A. Peragallo.

M. Gos, Chief of the Bureat of Agriculture for the Department.

List of oranges and lemons grouen on the liviera.

Cillens Aurtuliun-

Vulgare,

Sinense,

Depressum,

Pyramidale,

Ilicifolium,

Crispun,

Piriforme,

Latifoliun,

Genuense,

Duplex,

Nicense,

Microcarpum,

Minutissimun,

Gibbosum,

Corniculatum,

Melitanse,

IHierochnuticum,

Balearicum,

Sigillatum,

Mammiferum,

Limetiforme,

Oblongum,

Ellipticum,

Oliveforue,

Torulosum,

C'arnosuw,

Rugosum,

Ruginosum,

Pomutu Adami l'arisiorum,

Nobile,

Longifolinu,

Multifloruu,

Angustifolinw,

Tardum,

Aspermum,

Grassense,

Coniferum,

Imbigum,

Lusitanicum,

Otaitense,

Mutabile,

Lunatum,

Loursiro.

, $156 \mathrm{~A}-7$ ('itrus Bigaradia-

Corniculata,

Sulcata,

Fetifera,

Canaliculata,

Cyathifera,

Caliculata,

Crispifolia,

Multiflora,

Violacea,

Duplex,

Spatafora,

Mamillata,

Longifolia,

Volcameriani,

Racemosa,

Neapolitaua,

Asperrua,

Itau,

Sallesiana,

Macrocarpa,

Hispanica,

Florentina,

Coronata,

Glaberrima,

Dulcis,

Salicifolia,

Simensis,

Myrtifolia,

Fasciata,

Bizarria.

Citrus Bergamia-

Vulgaris,

Torulosa,

Parva,

Mellarosa,

Mellarosa Plena.

Citrus Limetta-

Vulgaris,

Parva,

Acris,

Hispanica,

Romana,

Tuberculosa,

Auraria,
Pomum Adami.

Cilrus Pompelmos-

Decumanus,

Vulgaris,

Crispatus.

Chadock,

Ragemosus.

Citrus Lumia-

Dominica.

Rhegina.

Conica.

Ollula formis.

Valentiua.

Gallitia.

Dulois.

Saccharina.

Aurantiaca.

Rubescens,

Limeta.

Citrus Limonun-

Sylvaticum,

Incomparabile,

'I'enue,

Striatum,

Pusillum,

Calabrinum,

Caly,

Bignetta,

Bignettia Juikgu,

Hardonium,

Rosolinum,

Asperuum,

Ponziunm,

Duplex,

Ligusticum,

Roseum,

Barbadorus,

Neapolitanum,

Globosum,

Parvum,

Hispanicum,

Balotiuum,

Mellarosa:

Peretta,

Peretta Spatafora, 
List of oranges and lemons grown on the Riviera-Continued.

Ciirus Limonum-Continued
Peretta Striata,
Peretta Florentina,
Peretta Longa,
Vulgaris,
Ceriescum,
Cajetanum,
Fusiforme,
Oblongum,
Canaliculatum,
Imperiale,
Lauræ,
Racemosum,
Rheginum,

\begin{tabular}{ll} 
Sancti Remi, & Cornuta, \\
Nicense, & Salodiana, \\
Paradisi, & Plena, \\
Ferrari, & Duleis, \\
Amalphitanum, & Florentiua, \\
Chalcedonicum, & Elongata, \\
Bimamillatum, & Rugosa, \\
Digitatum. & Romana, \\
Vulgaris, & Sulcata, \\
Cueurbitina, & Costata, \\
Tuberosa, & Glabra, \\
Maxima, & Simoniformis, \\
\hline
\end{tabular}

William Harrison Bradley,

Consul.

\section{United States Consulate,}

Nice, May 5, 1890.

\section{CORSICA. *}

REPONT BY CONSULAR AGENT DAMTANI.

Situation.-Trees of the orange species thrive in Corsica if cultivated at an altitude of 200 to 400 meters above the sea-level; below that they are $\mathrm{dwarfed}$ in their growth, and above 400 meters they are affected by the cold. The tree requires a deep, fertile, and pervious soil, irriga. tion during the heat of summer, and shelter from high winds. Damp and compact soil does not suit; but it thrives best in a clayey siliceous clay limestone, or a pervious, siliceous, clayey soil. On a damp soil the roots are soon injured. The ground must not only be wholesome and pervious to water, but it must also be rich in mold.

Cultivation.-Both the orange and lemon trees require much attention if they are to yield abundantfruit every year. If planted on ground exposed to the north wind, they must be sheltered by triple rows of the pyramidal cyprus or the Eucalyptus globulus. Twice a sear, in spring and autumu, the ground at the foot of the tree is dug up, and in September and October, or in February and March, well manured with all kinds of manure, according to the season; generally, before wiuter, vegetable manure, more or less decomposed, and the refuse of farms is used.

Pruning.-The cutting or pruning does not differ from that of other fruit trees. It is done at the end of the winter when it is dry; the top is rounded and the inside is curefully exposed to the influences of the . sun and air.

Climatic influence. - The orauge tree ('an not support cold beyond $5^{\circ}$ or bo contigrade below zero. The lenou is cren more delicate and will only 
thrive in localities where the thermometer does not fall below $2 \circ$ or $3^{\circ}$ centigrade. It must be planted on hills exposed to the south and well sheltered against north and northeast winds by elevations or artificial means. It must be irrigated by running water, by trenches, every fourteen or twenty days and must be placed in holes having 1 meter or 1.30 centimeters square in depth, or the ground must be dug to a depth of 90 centimeters, which is preferable. The trees must be 5 or 7 meters distant from one auother, according to the fertility of the soil.

Insect pests.-The lemon is also liable to be injured by winter frosts, by jaunisse or chlorose, or by excessive humidity. It is also attacked by kermes or the white louse (Dorthesia citris), the cochineal (Oocus citris), and by fumagine. The jaunisse and decay of the roots is arrested by draining the ground, the multiplication of insects and fumagine is stopped by syringing the branches and leaves with hyposulphate of lime in March and April.

Maturity.-The lemon and orange begin to bear fruit the third year after grafting, but do not produce abundantly till the fourti or fifth year. They are generally best from the ninth to the twelfth year and yield on the average 3,000 fruit. The lemon tree yields even more. The fruit is gathered with much care and after the disappear. ance of the dew. They are packed in cases and in rows, after being wrapped in thin paper. Each case contains about 500 or 380 to 400 oranges.

Varieties.-The kinds cultivated in this locality are-

Oranges: The Sweet Fruit of Brazil (Brasiliculis), the Blood Red (Hiero chuntisum), the Sweet Portugal (Lusitanirum), the Sweet Malta (Meliteuse), the Otaite (Otaiteuse), and the Mandarins (Nobilis.)

Lemons: Bignette of Genoa, the most productive; Bignette of Valence, without pippins (Citrus aspernum); Bignette of Spain (C. hispanium); Bignette of Malta (C. meliteuse); Bignette of Vulgare (ordinaire).

Simon Damani, Consular Agent.

United Stapes Consular Agency, Bastia, February 6, 1890.

\section{MARSEILLES.}

REPORT BY CONSUL TRAIL.

In this consular district orange and lemon trees are only cultivated to any extent in Corsica.

The climate in the region around Marseilles itself is not temperate enough for these two trees. Up till about thirty years ago there were plantations still in the plains of Toulon and Hyères, but even these. have loug since been conferted in to market gardens. 
They are now only to be fonnd towards the eastern bouudary, and here only chiefly orange trees that are cultivated more for their blossom than for their fruit, orange blossom being used in large quantities in the distilleries in Grasse, Canues, Nice, and other centers of the perfumery industry.

Charles B. Trail,

Consul.

Marseilles, A pril 30, 1890.

MENTONE.

REPORT BI CONSULAR AGENT OLERICY.

Darieties.-The names of the best qualities are (1) Fleurs, (2) Cé. riesche, (3) Granetti, (4) Verdame.

Situation.-There is not any special situation for those qualities; they are corresponding to the four blossomings of the tree. Orange and lemon trees grow near the sea as well as upon the hills, but exposition to the sun is to be preferred; so also is hilly ground when there is water, but level ground is good too.

Soil.-Calcareous and permeable soil is best.

Climatic influence.-A mild and temperate climate has a great influence on the growth of the trees.

Temperature.-They grow well in a high temperature, $32^{\circ}$ centigrade; they freeze under $3^{\circ}$ centigrade. Cold and damp nights are injurious; those warm and with an ordinary atmosphere are favorable.

Rain-fall.-In Mentone the rain is generally calculated at about 85 cubic centimeters per year. Spring and autumn rains are the best.

Irrigation.-One irrigates in summer from June 21 until August 30 with water gathered in the hills and kept for the purpose; after the blossoming and three times during the summer at iutervals of a wouth, 500 liters every time.

Cultivation.-The orchards are plowed twice a year.

Pruning.-The trees must be pruned every year and according to the plantation.

Picking and curing.-Lemons are gathered in Mentove four times a year; oranges twice, January to April. Lemons and orauges must be firm and not too ripe when they have to be exported.

Planting and propagating.-The trees are planted at a distance of 5 or 6 yards to have a regular plantatiou. Isemou trees are propagated by grafts on bigaradiers or bitter Jewou trees. Orauge trees from seeds are better but less resistant.

Maturity.-The trees are grafted when four years old; they do not give a very good gathering before being fifteen years old.

Insect pests.-The morphée and the fumie are the two diseases of the orange and lemon trees; the former is an insect, the latter a mush- 
room; no remedy has yet been found. All birds destroy the injurious insects.

Fertilizers.-Farm manure is the best; it lasts two vears. Rags, horn scrapings, and sesamum are also used. The manure is placed at the foot of the tree in Norember; 100 kilos of dung, 30 kilos of rags, 15 kilos of sesamum or horn scrapings ; the quantity of manure is according to the strength of the trees.

United States Consular Agency, Aughe Oluerioy, Consular Agent. Mentone, May 15, 1890.

\section{ITALY.}

CARRARA.

REPORT BT GONSOL RIOE.

[From statistics supplied ly the conenlar agent at Carrara.]

ORANGES AND LEMONS IN CARRARA.

Varieties.-There is no special nomenclature for the oranges grown within this district; the only ones differing from the common ones are the red ones called sanguigni. The mandarins and citrons are raised but on a limited scale.

The lemons grown within this district are divided into two classesthe sweet lemons with the thick rind, and the bitter ones with a thin one; the latter are much smaller, but contain more juice and are better for preserving, therefore more in demand.

Situation.-Lemons and oranges are produced, but not extensively; generally cultivated about 4 kilometers from the sea, with about 50 to 100 meters elevation, the most preferable position being one with a southern warm aspcet, but bearing in mind that there is always an undersoil of grarel.

Climate.-The maximum temperature is 30 degrees centigrade, minimum, .05. Medium annual fall of rain, 395 millimeters, the greater part of which falls daring the months of October, November, December, and January.

Irrigation.-The irrigation is done two or three times a year, from July to September, that is, during the ripening of the first crop of lemons and when the second crop is in blossom.

Fertilizers.-The plants are manured and hoed once a year, usually during the winter. The manures used are generally stable manures, and in the spring they are also enriched with liquid sewage.

Pruning.-The plants are proned almost to the very top every two years.

Pioking.-Lemons are gathered at various turns during the year and 
on an average every three months. Oranges are gathered during the months of December and January. After gathering they are placed in baskets and sent to the different markets in Tuscany either by rail or by wagon; none are exported.

Propagation.-Plants are propagated from the seed of the bitter oranges or lemons, and are after grafted by the usual process. For the oranges the sweet seed is preferred, it giving finer plants, bearing better fruit; these, lowever, bear much later and are more liable to be attacked by the disease called "gommosi" or "gummy."

Maturity.-The plants bear fruit when about seven to ten years old and live for many years-some plants have record of one hundred years.

Insect pests.-The only insect which damages the orange plant is a sort of black ant, which breeds an insect that sucks the juice of the tender sprigs, thereby impoverishing the parent plant.

United States Consulate, WiLliam T. RICE,

Leghorn, May 23, 1890.

Consul.

\section{GENOA.}

REPORT BY OONSUL FLETOHER.

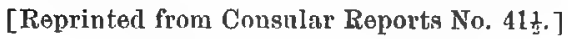

ORANGES AND LEMONS.

The genus Citrus for economical cultivation is divided into three classes-the orange, citron, and lemon.

Varieties.-The varieties of oranges generally cultivated in this province are:

(1) Citrus Bigaradia dulcis, or sweet orange.

(2) The Melangolo of China, or .Citrus Bigarradin cenensis.

(3) Citrus deliciosa, or Mandarin orange, aromatic and saccharine.

Two kinds of citron are cultivated :

A. Citrus medica rugosa, wrinkled fruit, very gool andied or otherwise preserved.

B. Citrus medica cedrato, a very precions and aromatic fruit, the shell of which is also candied.

The following are the varieties of lemon raised here:

A. Citrus limonum, a lemon very good for its acid and unedicinal virtues.

B. Citrus limonum tenno, a lemon of gentlo rind, fruit rich in acid, but too tender to stand transportation.

C. Citrus limonum oblongum, an oblong lemon, considered very valuable on account of the quantity of acid it contains.

These three varieties are ranked as the best, and therefore are cultivated the most in this vicinity.

Prontuctine "ge.-Sharp fruit tress gives full crops when about, say, from sixteen to twenty Jasm old, wud hey keep yiehdiw excellent crops 
for many years afterwards. It is not often that these varieties becorne very old, say, not over one hundred years. The foliage expands to a remarkable degree, and an average plant will usually produce 5,000 fruit per annum; especially can this be said of the lemon tree.

Planting.--Before the malady gomma (gum) manifested itself it was preferred to multiply the trees by burying the ends of shoots in the ground at proper distance; these shoots soon took root, but now the seed of Melangolo is planted, into which, when grown to a certain size, the qualities desired are grafted. The Melangolo tree up to the present time is in a very healthy state and forms a good trunk in which to graft all varieties required. Sharp fruit trees are planted at a distance of about 17 feet apart on flat land and from 13 to 14 feet apart on hill-sides. The shade of one tree on another is injurious to the blossoming of the latter, therefore care should be taken that fair space be given all the plants in order to have nature do its best for man. The average number of trees in a hectare of land (or 2.471 acres) is 490, and with this number as a basis from whlch to calculate it gives a space of about 20 square meters for each tree.

Situation of orchards.-Orange and lemon orchards in Liguria are all on the sea-coast. Flat and hilly lands in orchard are alike protected by lofty mountains from northern winds. This state of affairs appears necessary; the temperature must be constant, for even the slightest frost damages the lymph of the plant and juice of the fruit. Orange and lemon groves can be, and are, cultivated inland, but the temperature in such places must not reach higher than $40^{\circ}$ centigrade and not lower than $2^{\circ}$, or by Fahrenheit scale, $104^{\circ}$ and $32^{\circ}$. Inland orchards usually do well around lakes on account of the constant climate. (iroves are also to be seen on table-lands, but always on the south side of mountains; in such localities the temperature is as given above. Sharp fruit trees need a damp soil, and if the land does not contain sufficient moisture it is impossible to obtain a good crop. On naturally dry soil, therefore, water near by is of great value.

Orchards in this province and in all Liguria are near the sea and protecter from the cold northern winds by mountains. Many small groves can be seen beside stone walls, to which the branches eling, particularly the lemon. The land throughout this province being so mountainous, it must be taken for granted that but few orchards can be seen on socalled flat lands.

Cultivation.-Orange and lemon groves, on account of the irregular formation of the surrounding country, are necessarily small, and they are owned by about as many people. On account of this natural ab. ruptness and irregularity, added to the fact that the orchards are not large, it is the opinion of the owners that irrigation is too expensive. Further, the soil on which groves are planted is what the Italians term strong, and it is claimed for it that it retains moisture for a long time. Again, an idea prevails among the people that springs are of no great depth here, and consequently the water therefrom courses through the 
earth, and at no great distance from the surface, and that such an existence waters the roots without the aid of man. A happy belief! Certain it is, however, that at Nervi, a few miles along the coast from Genoa, orchards thrive with but little irrigation, and this state of affairs is noticed even in the dryest seasons. Unless groves have strong soil, as above mentioned, and are moistened by an unseen water-course, they will prove unprofitable if the owners do not nourish the dry roots as often as, say, once in eight days. In the first four or five years cul. tivation between the plants is possible, but when the tops of trees reach a certain expansion cultivation wonld seem impossible, or, at least, improbable.

Produce and expense.-When the tree reaches between the ages of fifteen aud twenty years each one is expected to yield abundant fruit, the orange from 400 to 600 , and the lemon from 600 to 1,000. On strong soil and with proper care as the orchards advance in years it is said that a lemou tree will zield from 3,000 to 5,000 fruit per year. The ground is manured like unto the olive groves, some kind of compost, etc. The expense is estimated as about the same, namely, $\$ 05$ per hectare (2.471 acres) per annum.

\section{SUMMARY.}

Oranges and lemons are not raised in such quantities in this consular district as to admit of large exportation, but the trade in olive oil is a big item.

The following table is copied from advanced sheets of what is designed as an accurate report of the importation and exportation of olive oil, oranges, and lemons for the year 1883 , to be soon issued by the chamber of commerce of this eity.

IEXPORTS O] LEMONG AND ORANGES.

La Plata States ......................................... 39,102

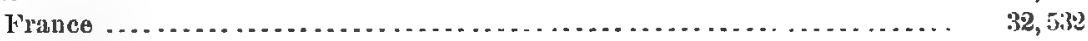

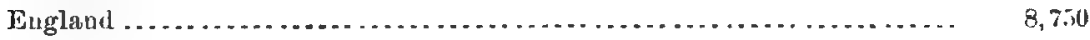

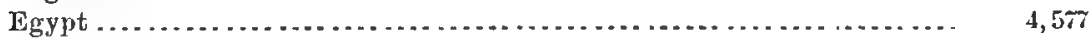

Total .............................................. 84,961

IMPORTS OF LEMONS AND ORANGES.

France................................................ bis

Tripoli and other African portis....................... bit. 15.

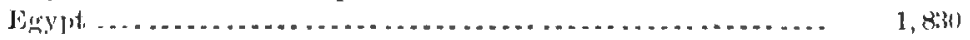

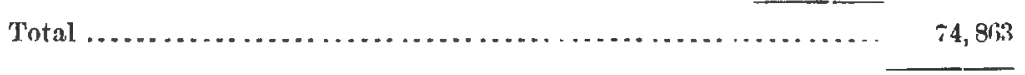

Total exports over over importa........................ 10,0...

JAMW Fri'TCHER,

Comsul.

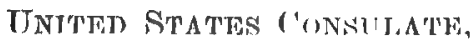

Gcuor, Ilaly, Ih!y 1, 1884. 


\section{MESSINA.}

REPORT BY GOUNSEL, JONES.

ORANGES AND LEMONS.

Varieties.-Best variety for profit, the citrus lusitanicum (orange); citrus lusionium and citrus fusiforme lemon. Other choice varieties worthy of culture and for profit are the citrus bergamia (bergamot); citrus deliciosa (mandarin); citrus luiretta. There are some thirty other varieties of less note.

Location.-The finest lemon-groves are in the neighborhood of Briga, Pezzuolo, Giampilieri, Santo Stefaro, Saponara, Rometta. The finest orange groves at Francavilla aud Rouella, in the valley of the Alcantara.

Distance from sea.-Lemon trees do better nearer the sea than orange trees; they thrive at from $\frac{1}{4}$ to 2 miles from the shore; orange trees from 2 to 6 miles.

Elevation.-The greatest elevation at which lemon trees do well is 1,500 feet. Orange trees do well at 2,700 feet above sea-level.

A southern exposure is best; but it requires the most water. A northern exposure is generally too cold. An eastern exposure exposes the trees to April frosts. A western exposure is always damp.

The lemon, like the vine, delights in hill-sides, facing south. Plains, as well as hill-sides, are well suited to the orange.

Soil, etc.-In this district the finest lemon groves are on argillo-calcareous soil of the Tertiary period, and on calcareo-argillaceons soil of the Quaternary period. These two soils are the best for both oranges and lemous. Sandy soil is not well adapted to orange and lemon culture, as it is too thirsty. When grown on sandy soil these trees are small and their late fruit (fruit from the last June blossoms, which at latest must be gathered in February and March) is spongy and nnfit for transportation. Oranges do better than lemons on sandy soil.

Climatic Influences. - The climatic influences in this district are seldom injurious to orange and lemon trees. The lemon requires an equable climate to produce perfect fruit. The orange and mandarin are hardier and suffer less from sudden changes of temperature; they do well at a higher elevation than the lemon and at a greater distance from the sea.

Temperature.-The temperature in this orange and lemon district ranges from $34^{\circ}$ to $100^{\circ}$ Fahr.; should it, however, exceed those limits for a few hours only the trees soon rally. During the winter of 1887 the mercury fell to $22 \circ$, and the tender twigs were frozen; these being at once cut away, the trees were none the worse for the cold. During the summers of 1888 and 1889 the mercury rose to $103^{\circ}$; an extra supply of water soon made the trees look as green as ever. 
The average temperature is $96^{\circ}$ in summer and $42^{\circ}$ in winter; mean annual temperature $70^{\circ}$. Nights cold or warm, sultry, moist, ordinary atmosphere.

Spring and autumn the nights are frequently cold, and still always above freezing-point, however, and do no damage.

Warm nights increase the evaporation but do not injure the trees. In March and April the cold at early dawn sometimes blights the blooms, which would otherwise produce the "bastard" or late fruit.

During the summer the atmosphere is seldom if ever dry. In winter the air is dry when the wind is north, which rarely happens. West and northwest winds are damp. The prevailing wind is the sirocco (southeast); it is generally warm and moist.

The average moisture of the atmosphere is 0.025 millimeters; quite inadequate to the successful culture of the orange and lemon. Only groves of the stiffest clay or calcareous soil with a wet subsoil can dispense with irrigation. Oranges stand drought better than lemons.

There are but few sultry days except in the early spring, when the atmosphere is saturated with moisture; at this period rain is not wanted, and often proves destructive to the crops.

The average annual rain-fall is 22 inches. From April to September it seldom rains, but pours in torrents in September and October, causing great damage. The heavy rain during the night of October 1, 1889, destroyed a number of groves. Light, steady, and constant rains occur in March and April.

Rain in May and June damages the blooms. Rain in September helps to develop the bastard fruit. Too much rain canses the trees to become chlorotic, and predisposes them to the "gum;" it also makes the fruit watery and destroys its keeping qualities.

Irrigation.-Generally speaking, throughout Sicily, orange and lemon culture is impracticable without irrigation. There are a few exceptions to this rule, however, in certain favored localities.

The trees are watered for the first time in June, when the fruit from the early hlooms is the size of a pea and the trees are still in bloom.

The amount of water required to the acre depends upon the age of the trees, the nature of the soil, altitude, exposure, etc. On an average, each lemon tree, on moderately moist soil, requires 200 liters of water at each watering; 2,000 liters of water a year.

Oultivation.-Vegetables are planted between the rows until the trees are large enough to shade the ground. Young trees are in consequence worked six times a year. When the trees have attained their full growth they are worked but seldom.

The first working of a full-grown grove takes place in October or November. after the autumnal rains havंe made irrigation unnecessary. A grubbing-hoe is used to stir the soil, cover the weeds, and draw away the earth from the foot of trees. The second working is in March, when the earth is thrown back to the foot of the trees. The third work- 
ing is in April, after which the land is trenched and a basin is made around each tree.

Fertilizers.-These groves are badly fertilized, as there are no good fertilizers bere. Stable manure is so mismanaged that it furnishes but little plant-food.

Fifty-five pounds of stable manure are applied annually to each young lemon tree. These gardeners are now finding out that this amount is too great, although the manure is of an inferior quality.

Lemon groves in bearing are manured every three or four years; 55 pounds of cow or stable manure to the tree.

Some gardeners put the manure in the irrigation trench, and let the water spread it around the trees; others scatter the manure around the trees, turn it under, and then irrigate. Experiments are being made with sulphate of am monia.

The best time to fertilize orange and lemon trees is from April to May. To obtain bastard fruit the trees are fertilized in October.

Pruning.-A tree is never pruned until it is four years old ; its suck. ers and badly placed branches only having been cut away up to that time. Trees are generally pruned in March, after the crop has been gathered, but no precise date can be given. These trees are always pruned high from the ground; their lowest branches are at least 7 feet above the soil, except when they are directly exposed to winds from the sea, in which case they are kept low that they may escape, as much as possible, from the salt spray. Pruning should not be-practiced in sum. mer, as, at that season, the wounds are hard to heal and are apt to predispose the trees to gangrene and other diseases.

Picking-Lemons are gathered from October to August; oranges from November to April. Lemons are picked whilst immatare for foreign markets, and should not weigh less than 80 grams each. Lemonjuice and essence are extracted from inferior lemons. The greatest care is necessary in gathering the fruit not to bruise it. After the stems have been cut close the fruit is wrapped in tissue-paper and carefully packed in boxes containing from 300 to 360 lemons and from 160 to $200,240,300$, and 360 oranges.

Planting.-One hundred and sixty-two trees are planted to the acre. Propagating.-The lemon is now budded on the bitter orange stock (Citrus bigaradia). Prior to 1870 the seedling only was budded, but this tree having been destroyed by the gum the hardy bitter orange stock has taken its place. The several varieties of oranges grown are also budded on the bitter orange stock.

Varieties.-The best varieties are budded; seedlings never reproduce their own variety.

Orchards.-The orchards are generally small, averaging from five to seven acres. The high prices that ruled a few years ago induced small land.owners to plant out orchards, but prices having fallen and diseases 
having made their appearance many of these orchards have been aban. doned.

Maturity.-Trees begin to bear at six years of age and are most prolific at twenty. The greatest age of the average tree is fifty years. Orange trees sometimes last eighty years.

Insect pests.-A number of insects attack orange and lemon trees: The Coccus hesperidum, Kermes aurantiis, ants, Mytilaspis fulva, Secanium hesperidum.

The most troublesome of the parasites is the coccus, which belongs to the order of the hemiptera and to the suborder of the homoptera, and is vulgarly called the scab. In the spring it propagates rapidly in damp, warm weather. It prefers the lemon to the orange. This is very detrimental to trees that are overshadowed by taller trees or that have not had their heads opened ont to let in light and air. Remedy : a solution of lime.

The Kermes aurantii is partial to the orange and panctures its leaves Remedies: Solution of lime, solution of sulphate of copper, kerosene, infusion of tobacco.

The best way to get rid of ants is to destroy their hills in Fobruary with kerosene; fumigations of sulphur are also resorted to.

The Mytilaspis fulva; remedy, solution of phenic acid. The Secanium hesperidum; remedy, sulphur fumes.

Beneficial insects. - The coleoptera (of the cochineal family) and the hemiptera, above mentionet, feed on the aphides.

Parasites.-There are no known parasites of the injurious insects. Small birds, if preserved from ruthless sportsmen, would prey upon these destructive insects.

Picking and curing.-The fruit is gathered in baskets, lined with cloth, and piled at the foot of a tree, where expert workmen trim the peduncles close to the fruit and examine each orange and lemon, selecting the choice ones for exportation. This fruit is then carried in large bas. kets to the warehouse, where, after a second careful inspection, women wrap it in tissue-paper. The fruit contained in each box must be of the same size. These packers are most expert in classifying the fruit. Sight and touch are the only sizers used. If the boxes are kept for any length of time in warehouses, they are opened once evers three weeks that their contents may be carefully re-examined, and the damaged fruit removed. Time is the only curing process for both oranges and lemons.

WALLACE S. JONES, Consul.

Unitho States Consulate, Messina, January 27, 1890. 
MESSINA.

REPORT OF OONSUL JONES.

[Republished from Consular Report No. 102.]

ORANGES AND LEMONS.

In Sicily lemon culture is 30 per cent. more profitable than orauge culture; lemon trees are more prolitic than orange trees. Prices for lemons are higher than for oranges. The prorince of Palermo is the great orange district of Sicily. Throughout the province of Messina the orange was exterminated in 1865-1870 by the "gum," and the lemon budded on the wild orange has taken its place. To defy the ravages of the gum the bud must be put in the wild orange stock at least 3 feet from the ground.

\section{ORANGES.}

The bulk of oranges shipped from Messina comes from the province of Reggio on the main-land. In Calabria they begin gathering the orange in October; their fruit is hard, sour, and of a whitish appearance ; it is shipped to England. Shipments of oranges to the Dnited States begin in December. They begin gathering oranges in Sicily in November, if we except small shipments to London of unripe and undersized oranges from Milasso, 30 miles to the northwest of Messina. This poor fruit is quoted at about 70 cents a box in October; deducting 20 cents for cost of box, leaves 50 cents for the fruit and handling. These oranges are bought by confectioners.

The climate of southern Italy being warmer in summer than that of Sicily (Sicily, surrounded by the deep waters of the Mediterranean, is cooler in summer and warmer in winter than the province of Reggio), and the oranges being generally grown on a light, sandy soil, account for their maturing earlier in Calabria. As just stated, the first gathering of oranges in Sicily occurs in November, but most of the crop is gathered in December and January. The Sicilian grower prefers running the risk of damage by frost (but two crops have been injured by cold during the last twenty years) to gathering his oranges when they are still too immature. Sicily oranges, which are, of course, not fully ripe when gathered, keep well for forty days. Frequently the fruit when gathered is allowed to sweat in the groves from two to three days, piled on the ground and covered over with tarpaulins; it is then wrapped in tissue paper, boxed up, and sent to the city. Fruit is also sent directly from the groves. All fruit upon reaching the exporters' warehouses is carefully inspected, selected, and wrapped in fresh tissue paper, and repacked. Exporters ship their oranges as soon as packed.

\section{COST OF PACKING-SHIPMENT.}

During the shipping season large tirms in Messina employ as many as three huudred womeu and girls, paying them 20 to 25 cents a day- 
nine hours' work. The women select and wrap up the fruit. Men are employed to pack the fruit and handle the boxes; they get from 40 to 50 cents a day. The stevedores handle the boxes with great eare. The steamers give all possible ventilation to the fruit during the voyage. Fruit possessing the greatest keeping qualities is sent in sailing vessels to the United States. The duties paid on oranges and lemons entering the United States are as follows: On oranges in boxes, capacity not exceeding $2 \frac{1}{2}$ cubic feet, 25 cents per box; half-boxes, capacity not exceeding $1 \frac{1}{4}$ cubic feet, 13 cents per half-box; bulk, $\$ 1.60$ per thousand; barrels, capacity not exceeding that of the 196-pound flour barrel, 55 cents per barrel; packages not especially enumerated or provided for, 20 per cent; ; on lemons in boxes, 30 cents per box; on half-boxes, 16 cents; in bulk, $\$ 2$ per thousanil; in packages 20 per cent.

Exporters frequently buy the fruit on the trees. Below is given the cost of preparing and shipping a box of oranges or lemons:

Cutting, selecting, and packing in the groves......................... $\$ 0.15$

Box, paper, nails, and hooping ................................... $\quad .30$

Transportation to Messina (average) ............................... . 20

Repacking, shipping charges, store rent, and hrokerage ................ .14

Freight, per box, by steamer to New York ........................... .30

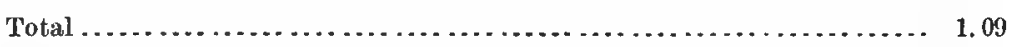

A few tirms export fruit to the United States on joint account. Fruit is generally shipped on consignment. Consiguees' commissions and auction fees are 6 per cent.

Years ago oranges were proserved in sand for from four to five months, merely for family use. This practice no longer prevails; it would not pay on a large scale, such enormous warehouses would be required and so great would be the expense of handling the fruit. Preserving oranges in bran has been tried; it proved too heating. I have heard of a successful shipment of oranges packed in beech sawdust. The vessel carrying the cargo left Messina in December and reached St. Petersburg in May. Spanish grapes packed in cork-tree sawdust keep from September to March. Preserving oranges by the fumes of sulphur has never beeu attempted here, lest the fumes might cause the fruit to dry up.

The maturing of oranges and lemons is affected by the altitude, latitude, excessive leat in certain localities, irregular rain-fall, and the nature of the soil.

Sicily is mountainous in character, and is agronomically divided into three zones:

(1) Marine zone, in which fruit ripens earliest.

(2) Middle zone, extending from 1,500 to 3,000 feet above the sealevel.

(3) Mountaiu zone, where the temperature is too low and tha climate too dany for citrus culture. 
The soil has a great influence upon the maturing and keeping qualities of the citri. The fruit ripens earlier on light, sandy soil than on clay soil. Fruit grown on light, sandy soil can not be left long on the trees withouc its deteriorating in quality-becoming dry and spongywhereas on stiff clay it can remain with impunity until the end of April. The latest fruit to ripen is that produced on the upper limit of the middle zone-the trees growing in stiff clay soil-which can remain on the trees until the end of June without its drying up or its skin becoming hard and spongy ; it must, however, be gathered in July, for should it be left longer on the trees it would injure the new crop.

Fruit grown on a light, sandy soil is small and of a pale yellow, and is of comparatively short keeping. That grown on a clay soil is large; it keeps well and is of a reddish brown. Trees on clay soil resist a drought much better than those on sandy soil. The groves to the southwest of the Palermo district produce much more highly-prized fruit than those on the northwest, the sole difference between them being their clay and sandy soils. As "in the neighborhood of Palermo, so in other districts of the province, even where the climatic differences are great.

Fruit in Sicily is known as "mountain fruit" and "sea-coast" fruit. Merchants further classify the fruit according to the soil on which it grows. Fruit grown on a clay soil brings 30 per cent. more than fruit produced on a sandy soil. Mountain fruit is firmer and keeps better; its superiority is attributed to the nature of the soil and not to the influence of the climate. Fruit produced in the plain of Portello, the soil of which is clay, brings the same as that grown on the heights of Moureale:

The fine large oranges that bring a high price in Palermo in summer are allowed to remain on the trees until the end of May, when they are stored iu subterranean grottoes. They are produced on clay soil abounding in alkalies and well.decomposed organic matter. In the sides of the mountains, near Palermo, are many grottoes that are cool and well ventilated, in which oranges keep nicely during the summer; they are spread two layers deep upon large mats, placed at convenient distances one above the other. Every day or two the fruit is turned over and all the defective oranges are removed. This fruit finds a home market.

The principal orange and lemon groves are on the northern and eastern coasts. The mountains along these shores rise in bold headlands from the sea, having but a narrow strip of land-the marine zone, of a sandy character-at their base. The soil of the hill-sides-the middle zone-is generally clay. For lack of water for irrigation, oranges and lemons are not grown to any extent on the southern and western shores.

LEMONS.

The well-known variety of lemon called the "lunare"-Iunar, or everbearing, produces blossoms and fruit every month in the year. When, 
however, during the Indian summer, rainy days are succeeded by dry, clear weather, lemon trees of different varieties immediately put on blooms, and if, owing to the mildness of the season, the fruit sets at the beginning of winter, it will come to maturity in midsummer.

Lemons are divided into two classes, the true lemon and the bastard lemon. The true iemon is produced by the April and May blooms; the bastard by the irregular blooms of February, March, June, and July, which depend upon the rain-fall or regular irrigation and the intensity of the heat during the summer and winter seasons. The true lemon requires nine months to reach maturity, from the bloom in May to the mature fruit in January. There are but three harvests of the true lemon. The first is the November cut, when the lemon is green in appearance and not fully ripe. Lemons of this cut are the most highly prized; they possess remarkable keeping qualities, and are admirably preserved in boxes in warehouses from November until March, and sometimes as late as May, and then shipped. The second cut occurs in December and January. Lemons of the January cut must be shipped three weeks after gathering. At this date the lemon has acquired a yellowish appearance. The third cut occurs in March and April. This fruit is shipped as soon as gathered, spring prices being always high. The uniformity in size of lemons, as we meet them in the trade, is due to the monthly harvestings from Uctober to March. No sizer is used or even known here.

Bastard lemons present well-characterized peculiaritios in shape and appearance; their inner skin is fine and adheres tenaciously to the meat; they are hard, rich in acid, and seedless. The bastard lemon, produced from the bloom of June 1, is still green the following April, and ripens only towards the end of July. It remains on the tree over a year, and sells well in summer. Besides the March and June bastards, there are yet others that remain on the trees from twelve to eighteen months. The true lemon can be left on the tree until the end of May or the first week in June, but it interferes with the new crop, drops off from overwaturity, and is liable to be attacked by insects. The bastards, on the contrary, withstand bad weather and parasites, and they mature from June to October. It is estimated that four times more oranges than lemons are lost in the groves aud warehouses. Good drainage is, of course, most essential in orange and lemon culture.

Table A shows the mean annual price per box of oranges and lemons at Messina for the years 1870 to 1886 , inclusive, the figures being official.

ESSENCES.

With three strokes of his sharp knife the eutter peels the lemon length wise and lets the peel fall into a tub nuder the chopping-block. He then cuts the lemon in two and throws it from his knife into a bucket. $\mathrm{He}$ works with wonderful rejpidity and fills from ten to twelve tubs with 
peel a day and is paid 5 conts a tub, weighing 77 pounds. His left hand and right index are protesterl with bands of osvaburgs or leather. Decayed fruit is not peeled, as its oil cells, being atrofied, yield no essence.

Fresh peel is soaked in water fifteen minutes before tho essence is extracted. Peel that has stood a day or two should remain in soak from thirty to forty minutes, that it may swell and offer a greater resistance against the sponge. The operative holds a small sponge in his left hand against which he presses each piece of peel two or three times, simple pressure followed by rotary pressure. The women employed in this work run a piece of cune through their sponges to euable them to hold them more firmly. The outside of the peel is pressed against the sponge, as the oil glonds are in the epicarp. The crushing of the oilcells liberates the essence therein contained. The sponge, when saturated with the essence, is squeezed into an earthenware vessel the operative holds in his lap. $\mathrm{He}$ is expected to press the peel so thoroughly as not to overlook a single cell. This is ascertained by holding the pressed peel to the flame of a candle; should it neither crackle nor diminish the brilliancy of the flame the cells are empty. This process yields besides the essence a small quantity of juice and feccia (dregs). The separation of the essence, juice, and feccic soon takes place if the vessels are not disturbed; the oil floats on the juice and the dregs fall to the bottom. These three products derived from the peel hare no affinity with each other. As the essence rises to the surface it is skimmed off, bottled, aud left to settle for a few dass. It is then drawn off with a glass syphon into copper cans which are hermetically sealed. After the essence has been expressed a small quantity of juice is pressed from the peels, which are then either fed to oxen or goats or throwu on the manure pile and well rotted, or they would make too heating a fertilizer.

The yield of essence is very variable. This industry is carried on five months in the year. Immature fruit contains the most oil. From November to April, in the province of Messina, one thousand lemons yield about 14 ounces of essence and 17 gallons of juice. An operative expresses three baskets of lemon peel (weighing 190 pounds) a day, and is paid 20 cents a basket. The essence is so valuable that the operatives are closely watched; they are most ingenious in secreting it about their persons. Six men work up 8,000 lemons a day; two cut off the peel while four extract the essence, and obtain 136. gallons of lemonjuice and 7 pounds of essence. In the extraction of essence defective fruit-thorn-pricked fruit blown down by the wind or attacked by rustis used. This fruit is sold by the "thousand," equivalent to 119 kilos or 260 pounds, and thus classified : First, mixed lemons, as they come from the groves during December and January, of good quality but not always marketable, often from top brauches; second, lemons from March blocms; third, lemons refused at the packing-houses ; fourth, dropped fruit; fifth, shriveled or deformed frnit.

$156 \Lambda-8$ 
Prices do not depend exclusively upon the classification of the fruit; the locality where it was grown is taken into consideration as well. Lemons grown on clay soil yield more essence and juice than those grown on sandy or rocky soil.

Dealers sometimes adulterate their essence with fixed oils, alcohol, or turpentine. Adulteration by fixed oils is detected by pouring a few drops of essence on a sheet of paper and heating it. Upon the evaporation of the essence a greasy spot will remain. Alcohol is detected by pouring a few drops of the essence into a glass tube in which a small quantity of chloride of lime bas been dissolved. The tube is then heated and well shaken, and its contents being allowed to settle the essence will float in the denser liquid. To detect turpentine pour a fow drops of essence on writing-paper and a strong smell of turpentine will remain after the essence has evaporated. The essence of sour orange, mixed with the essence of lemon, produces an aroma similar to that of the essences of bergamot; the latter is much used by confectioners in flavoring ice-creams, etc.

Equal parts of lemon essence and spirits of turpentine, well mixed (mixture known as essenza vestrincutale), remove stains from linen and silk fabrics.

In a bergamotessence establishment at Reggio, on the main-land, is to be seen in operation a hand machine for extracting essential oil. The skin of the unpeeled bergamot is punctured by a system of revolving knives and then gently pressed. It should be borne in mind that the bergamot is spherical in shape, and this machine could not be used on the lemon on account of its shape. A thermo-pneumatic essence extractor, worked by steam-power, has also been invented, but the old system is still in general use in Sicily on account of abundant and cheap labor. The method employed for the extraction of essential oil from the lemon (as given above) applies as well to the sweet and sour orange, to the bergamot, and to the mandarin. But a very small quantity of essence of mandarin is made, and but slight attention is paid to the extracting of essence from the orange flower. The essence extracted from the flower of the bergamot is called neroli, and is worth $\$ 35$ per pound.

Table B shows the total quantity and value of essences exported from Messina for the last eighteen years-1870 to 1887 .

Table $\mathrm{C}$ shows the value of the essences exported from Messiua to the United States for the last ten years-1878 to 1887.

Table D shows the mean annual price per kilogram at Messina of the essence of bergamot, lemon, and orange for the years 1870 to 1886.

\section{RAW AND CONOWNTRATED LEMUN-JUICE.}

When lemons have beren peeled and ant in two, as above stated, they are carried to the press and thrown into large wicker bags, circular in form, made al bulnushes, and are pressed in these bags. If the juine 
is to be exported raw only perfectly sound lemons can be used; but if the juice is to be boiled down, one-fifth of the lemons may be of an inferior quality and two fifths of them pretty well decayed. The juice from sound lemons is yellowish in color, and gives a pleasant aroma; its density decreases with age. With all classes of lemons the gield of juice and its acidity varies considerably from month to month. The amount of juice increases from October to April, its acidity and density decrease, and the same is the case with the deusity of the essence, owin to the winter rains.

The manufacturing of essential oil and lemon-juice is quite lucrative, but manufacturers, to avoid being taxed on their business, are reticent as to their profits.

An addition of 5 per cent. of alcohol will prevent raw lemon-juice from spoiling. Lemon-juice is adulterated with salt or tartaric acid. Raw and concentrated lemon-juice is exported in casks of 130 gallons capacity. It requires 1,500 lemons to yield 26 gallons ( 1 hectoliter) of raw juice, while it takes 2,500 to yield the same quantity of concentrated juice, and 200,000 , more or less, according to their acidity, to give a cask. Experience has shown that the lemons of the Province of Messina, especially from the easteru shore, contain more acidity than the lemons grown elsewhere in Sicily.

The value of lemon-juice is governed by its acidity. The rule is that concentrated lemon juice shall show 60 degrees of acidity (the juice excracted from the bergamot or the sour orange must show 48 degrees, or one-fifth less than that derived from the lemon; it also sells for onefifth less than lemon-juice). Formerly a sitrometer, known as Rouchetti's gauge, was used to ascertain the per cent. of acidity; now, however, resort is had to chemical analysis, which is more satisfactory both to seller and buyer.* Lemon-juice is used in the printing of calicoes.

Table $\mathbf{E}$ shows the mean annual price of concentrated lemon-juice per cask of 130 gallons, and of raw lemon-juice per hectoliter of 26 gallons, from 1870 to 1886 .

Table F shows the export of lemon-juice from Messina from December, 1884, to December, 1887.

Of late years a new article, known as vacuum-pau coucentrater natural juice of the lemon, has been manufactured here. The juice concentrated by this method contains 600 grains of crystallizable citric acid for every quart. It is exported in casks containing 112 gallons, in half and quarter casks. It is also shipped in bottles of 500,300 , and 150 grains each. This concentrated juice is as limpid as first-quality oil.

There is an establishment here, probably the only one of its kind in Italy, that prepares crystallized citric acid. It takes from three huodred and forty to three hundred and eighty lemons to make a pound of citric acid, which sells at about 43 cents.

*'The last two par:igraphs are quoted from my report accompanying dispatch 51 , datid April :20, 1888. 


\section{FRUI'T IN BRINE.}

Large quantities of souud but unmarketable lemous and sour oranges are packed in brine. The remarks referring to the shipment of citrou in brine, contained in my report published in No. 61, Consular Reports, February, 1886, are equally applicable to the packing in brine of lemons and sour oranges.

$A$ cask of sour oranges in brine is worth here about $\$ 10$ at this time. Small lemons in brine are worth about $\$ 8$ per cask, and good-sized ones about $\$ 12$. While the custom-house keeps a record of the quantity of citron in brine that is annually exported, singularly enough it keeps no record of the large shipments of other fruits in brine. Fresh and salted fruits are included in the same figures.

WALLACE S. JoNes,

\section{United STates Consolate, Messina, January 8, 1889.}

TABLE A.-Mean anual prices at Messina per box of lemons and oranges for the years 1870 to 1886 , inclusive.

\begin{tabular}{|c|c|c|c|c|c|}
\hline Trats. & Lemons. & Oranges. & Years. & Lemons. & Orauges. \\
\hline 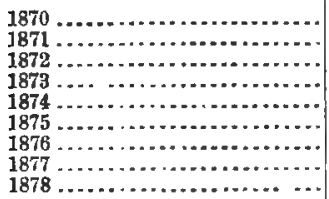 & $\begin{aligned} \$ 2.15 \\
2.25 \\
2.48 \\
2.93 \\
3.26 \\
3.08 \\
2.33 \\
2.10 \\
2.43\end{aligned}$ & $\begin{array}{r}\$ 1.86 \\
1.62 \\
1.71 \\
1.41 \\
1.70 \\
1.53 \\
1.36 \\
1.19 \\
1.07\end{array}$ & 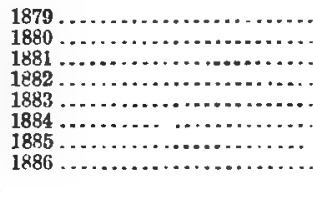 & $\begin{array}{r}\$ 1.93 \\
2.30 \\
1.94 \\
1.83 \\
1.44 \\
1.22 \\
1.36 \\
2.00\end{array}$ & $\begin{array}{r}\$ 1.23 \\
1.30 \\
1.01 \\
1.30 \\
1.10 \\
1.17 \\
1.12 \\
1.14\end{array}$ \\
\hline
\end{tabular}

TABLE B. -Quantity and walue of essenres exported from Messina to the whole world during the years 1870 to 1887 , inclusive.

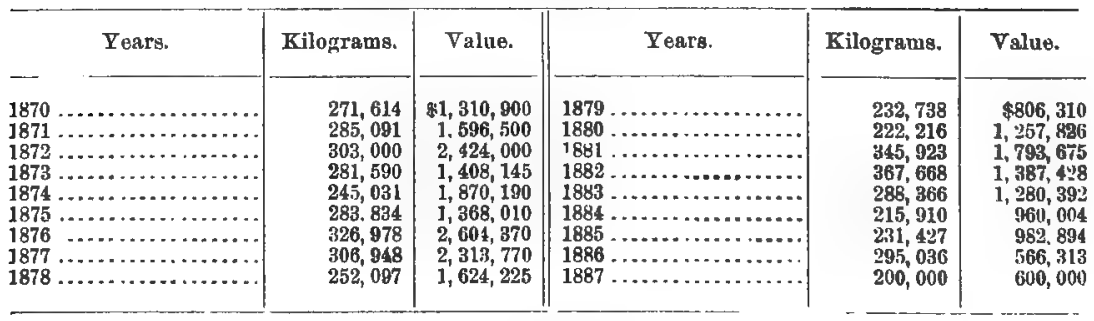

'IABLte C. - Value of essences exported from Meseina to the Inited States from lire to 1887, imlusine.

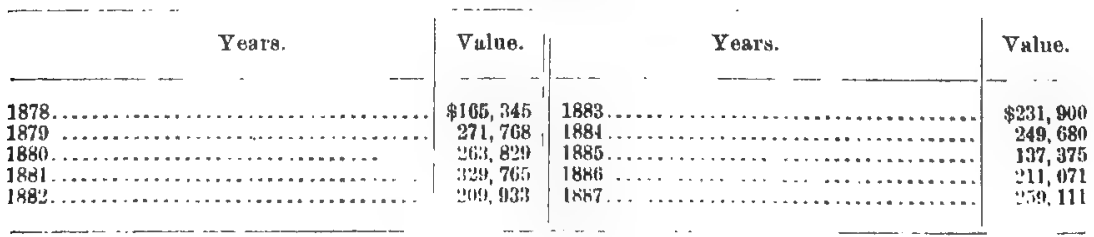


I'ABLE D. Mean annual prices of ersonces at Messime for the year8 1870 to 1886 , inclusice.

\begin{tabular}{|c|c|c|c|c|c|c|c|}
\hline Yeare. & Bergamot. & Lemon. & Orange. & Tears. & Bergamot. & Lemor. & Orange. \\
\hline 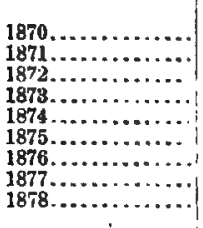 & $\begin{array}{r}\text { Per kilo. } \\
\$ 6.10 \\
6.35 \\
8.10 \\
9.61 \\
11.52 \\
10.00 \\
7.56 \\
7.16 \\
5.83\end{array}$ & $\begin{array}{r}\text { Per kilo. } \\
\$ 5.14 \\
6.53 \\
8.50 \\
7.50 \\
6.45 \\
5.23 \\
5.00 \\
4.35 \\
3.56\end{array}$ & $\begin{array}{r}\text { Per kilo. } \\
\$ 2.65 \\
\text { 3. } 35 \\
5.86 \\
3.87 \\
2.95 \\
2.43 \\
3.18 \\
3.12 \\
3.22\end{array}$ & $\begin{array}{l}1870 \ldots \ldots \ldots \ldots \\
1880 \ldots \ldots \ldots \ldots \\
1881 \ldots \ldots \ldots \ldots \\
1882 \ldots \ldots \ldots \ldots \\
1883 \ldots \ldots \ldots \ldots \ldots \\
1884 \ldots \ldots \ldots \ldots \ldots \\
1885 \ldots \ldots \ldots \ldots \ldots \ldots\end{array}$ & $\begin{array}{r}\text { Per kilo. } \\
\$ 5.10 \\
5.52 \\
4.10 \\
4.22 \\
3.50 \\
2.78 \\
2.51 \\
2.00\end{array}$ & $\begin{array}{r}\text { Per kilo. } \\
\$ 3.86 \\
5.23 \\
4.23 \\
4.60 \\
2.73 \\
1.77 \\
1.70 \\
1.75\end{array}$ & $\begin{array}{r}\text { Per hilo. } \\
\$ 3.04 \\
4.32 \\
3.47 \\
3.88 \\
3.47 \\
1.05 \\
1.80 \\
1.87\end{array}$ \\
\hline
\end{tabular}

TABLE E.-Mean anual prices at Messina for concentrated lemom-juics and raw limonjuice for the year's 1870 to 1886 , inclusive.

\begin{tabular}{|c|c|c|c|c|c|}
\hline Years. & $\begin{array}{l}\text { Concentrated } \\
\text { lomon-juice, } \\
\text { per cask of } \\
130 \text { gallons. }\end{array}$ & $\begin{array}{c}\text { Raw lemon- } \\
\text { juice, per } \\
\text { hectoliter of } \\
26 \text { gallons. }\end{array}$ & Years. & $\begin{array}{c}\text { Concentrated } \\
\text { lemon-juice, } \\
\text { per cakk of } \\
130 \text { gallons. }\end{array}$ & $\begin{array}{l}\text { Raw lemon. } \\
\text { julce, per } \\
\text { h-ctoliter of } \\
\mathbf{2 0} \text { gallons. }\end{array}$ \\
\hline 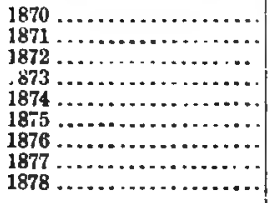 & $\begin{array}{r}\$ 133.40 \\
167.10 \\
268.00 \\
332.80 \\
697.30 \\
213.33 \\
163.10 \\
158.15 \\
144.72\end{array}$ & $\begin{array}{r}\$ 2.30 \\
2.50 \\
3.60 \\
5.33 \\
5.13 \\
4.10 \\
3.00 \\
2.63 \\
2.30\end{array}$ & 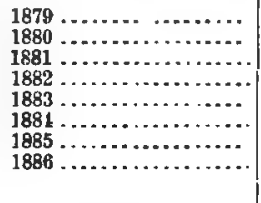 & $\begin{array}{r}\$ 115.00 \\
161.00 \\
159.50 \\
124.43 \\
101.50 \\
81.20 \\
98.15 \\
143.43\end{array}$ & 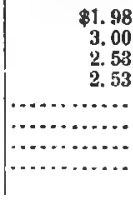 \\
\hline
\end{tabular}

TABLE F.-Exports of lemon-juice from Messina to the follouring plaecs during the years 1885,1886 , and 1887.

\begin{tabular}{|c|c|c|c|c|}
\hline & Places. & $\begin{array}{l}\text { Dec. } 1,1884, \\
\text { to } \\
\text { Nov. } 30,1885 .\end{array}$ & $\begin{array}{c}\text { Dec. } 1,1885 \\
\text { to } \\
\text { Nov. } 30,1886 .\end{array}$ & $\begin{array}{l}\text { Dec. 1, 1886, } \\
\text { to } \\
\text { Nov. } 30,1887 .\end{array}$ \\
\hline & & Pipes. & Pipes. & Pipes. \\
\hline Give & & 184 & $2<0$ & 400 \\
\hline Moscow ....... & & 8 & 2 & 3 \\
\hline Dnited States & 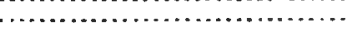 & 241 & $39 \overline{3}$ & 398 \\
\hline Marseilles........ & .. & 164 & 254 & 485 \\
\hline $\begin{array}{l}\text { Genoa...... } \\
\text { Trieste.... }\end{array}$ & & & & \\
\hline Hamburg ..... & ….......... & 107 & 152 & 132 \\
\hline $\begin{array}{l}\text { Russia } \\
\text { Othe.... countries ... }\end{array}$ & (n............... & & 154 & $\begin{array}{r}231 \\
96\end{array}$ \\
\hline Total. & ......... & 3,440 & 2,353 & 4,438 \\
\hline
\end{tabular}

NAPLES.

REPORT BT OONSUL CAMPHA USEN.

ORANGES AND LEMONS.

Varieties.-The names of best variety for profit are the Palermo oranges and Sorrento lemons. The other choice varieties worthy of culture and for profit are the Gargaño, Majori, Amalfi, and Sicilian oranges and lemons.

Location.-The trees are planted on rich soil, where the temperatnre 
is not high, and where they are protected from cold winds. Distance from sea, 30 meters ( $97 \frac{1}{2}$ feet); elevation above sea-level, from 25 to 3,000 feet; southeru exposure to sun, level land; clayish and damp soil is best.

Climatic influences-Minimum 0 , maximum 180 centigrade. The nights are warm, days variable.

Rain-fall from December to February is very beneficial to all fruits, making them grow better, and improving also the growth of the tree The rain-fall in inches can not be ascertained, as there is no record kept by any person as far as $I$ can ascertain. At some of the observatories records are perluaps kept but it is difficult to obtain information from them.

Irrigation.-Irrigating is practiced from May to September, and until the soil is soaked through; in summer every week.

Cultivation.-By stirring the ground every two years and frequently during the scason. Fertilizers are not used.

Pruning. - In the month of April, about three feet from the ground, in the usual manner.

Picking.-As soon as they become yellow the oranges and lemons are picked, wrapped in thin paper, put in boxes, and shipped.

Planting and propagating.-The trees are planted 15 feet apart, and propagated by graftings and planting the seeds.

The best varieties are from seedlings-wild oranges grafted into sweet oranges and lemons. Most of the orchards are large.

Maturity._At the age of four years they begin to bear. The largest crops are obtained when the tree is twenty years old. They mature at from fifty to one hundred years.

Insect pests.-The louse; no remedy has been found or discovered to destroy it. There are no beneficial insects.

Tidward camphausen,

Consul.

United States Consulate,

Naples, Jrnuary 31, 1890.

\section{PALERMO.}

REPORT BY OONSUL OAKROLL.

Varieties.-The following are the best varieties cultivated in Sicils, vi\%: Citrus bigaradia macrocarpa, Riss ; Oitrus bigaradia coronata, Riss; Citrus bigaradia glaberrima, Riss; Oitrus medica glabra, kiss; Citrus medica florentina, Riss; Citrus bergamia (variety Vulgaris), Riss; Cìtrus bergamia (variety NIellarosa), Riss; Citvius aurantium piriforme, Riss; Citrus aurantium precox, Riss; Citrus deliciosa, Ten.; Citrus limonum fusiforme, Riss; Citrus limonum oblongum, Riss; Citrus limonum calabrioum, Riss.' 
The following varieties are also cultivated, each having its special merits, viz :

Variaties.

Citrus bigaradia ................................................... 21

Citrus limetta..................................................... 7

Citrus lumia ........................................................ 1

Citrus medica ....................................................... 8

Citrus bergamia....................................................... 2

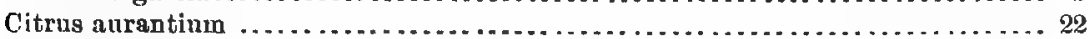

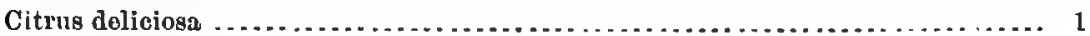

Citrus limonum ................................................ 19

PLANTING AND PROPAGATING.

Orange trees are planted 5 meters apart, and lemon trees from 5 to 6 apart, depending on circumstances.

The old lemon and orange gardens in this vicinage are generally either the result of certain succulent slips, which were cut from the trees and buried or planted two-thirds of their length in moist friable ground, or curving or bending a live branch, without detaching it from the tree, and inserting it to a depth of about 30 centimeters in rich, soft friable soil. At the end of about tivo years, or when sufficient roots sprouted from the branch thus hended in order to enable it to live without the mother tree, the branch in question was detached therefrom and allowed to proceed, in growth, on its own account.

This method of propagation has become almost extinct. There are certain cases, however, in which it is still resorted to because of the rapidity with which the trees develop and which make it preferable to any other, as well as on account of the abundance of the yield of trees thus propagated. But the fact that such trees are susceptible of attack by male della gonma and readily destroyed thereby in a few years, has convinced even the most steadfast adherent of the method that it should be abandoned and a resort had to propagation through the several varieties of melangoli seed, called bere aranci arrari (Citrus bigaradia) and the trees thus derived grafted with the varions varieties, as they resist the malady in question with much more vigor. In fact, the orange and lemon trees of Palermo, which are generally ob. tained by the seed of the melangoli, have resisted the male della gomma much better than those of Messina which were formed from plants de. rived from lemon branches. The best varieties are bndded.

The orchards in Sicily are very large and are, in view of the great profit ensuing therefrom, increasing rapidly.

Fructification.-They fructify at the age of three years, the yield being largest thereafter, from jear to year, up to the twentieth, when they are becoming old and subject to all diseases. At this period they are denuded of their branches and a new graft resorted to.

Insect pests.-The most troublesome insect, and that which injures the orange and lemon trees most, is called Coccus hesperidum lin or Coccus citry. 
The facility with which this insect propagates itself, and the rapid increase consequent thereon, result, in a comparatively short time, in the death or serious injury to the trees. The mode of attack of this insect is by eating a hole iu the tree from which soon exudes a protuse flow of juice, resulting in death or serious injury thereof, as stated.

The coccus citry lodges in trees having thick leaves, and especially in those shaded by larger trees or plants. In this contingency pruning is resorted to, with a view of letting in light, and thus causes the insect to seek another refuge or die. No specific is known to combat this insect, but the usual mode of relief therefrom is by washing the trees with lime water.

Other very injurious insects abound such as the Kermes coccineus, Kermes hesperidum, Kermes aurantii, Lecanium hesperidum, and Pidocchio, which prefer the orange to the lemon trees. These, too, are destroyed by lime water, solutions of copper, sulphate thereof, etc., petroleum, snuff, etc.

Beneficial insects.-Terrestrial formicas or ants destroy other destructive insects and their eggs, but in their absence they gnaw the tender branches and leaves, thus causing them to atrophy. Therefore all efforts are made to destroy the ants as in the case of other insects, hoeing the ground in winter being resorted to as a means to that end, thus exposing them to inclement and cold weather, death generally ensuing as a consequenee.

Parasites.-The litchens, which attach themselres to old trees, those attached by male della gomma. Shady and moist places favor the .development of litchens. Sea water is used as a wash to get rid of this parasite.

The fumagine evoluting from the agglomeratiou of microscopic plants, technically called capnodium or Frumago citry. The fumagine attacks all varieties of oranges and lemons and canses grave damage. The trees attacked suffer greatly, the yield thereof being very small. The fumagine attacks the trunks, branches, leaves, and fruit. Only the epiclermis or outsite of the fruit is attacked. This parasite is destroyed hy means of pruning and manuring in January.

\section{LEMON $\triangle$ ND ORANGE GROVES.}

The trees that produce the varieties named at the beginning of this report are grown in Sicily.

Distance from sea.-There is no fixed distance from sea for planting orange and lemon trees. There are many orange and lemon gardens in the vicinity of Palermo, bordering on the sea, some of which prosper better than those situated more inland. This, however, obtains ouly when the gardeuers are skilled meu aud give particular attention to the ground and adopt proper means with in view of protecting the trees from strong sea-winds. 
Elevation above sea-level.-It is impracticable to determine with accuracy the elevation at which orange and lewon trees can be cultivated, the latitude and certain special conditions influencing this. In Sicily, for instance, oranges and lemons are profitably cultivated along the seacoasts at an altitude of from 100 to 500 meters above sea-level, and often much better crops are obtained where the elevation is from 500 to 1,000 meters.

Exposure to sun.-It is of great advantage when the gardens have i southern exposure, or when the sun beams down upon them from sunrise to sunset. This exposure is recommended by gardeners here.

Position of orchards.-Orange and lemon trees are indifferently planted in the vicinity of Palermo, in lilly, rolling, or level land. The nature of the soil, climate, exposure to sun, attention to the soil, trees, etc., seem to be the principal requisites; elevation, all other things favorable, having little or no influence, save as to quality. Fruits produced on hilly land are more appreciated, and generally command higher prices than those produced on rolling or level land. There are exceptions to this, however. In Palermo, for instance, fruits produced on certain level lands command as high prices as those produced on hilly land; with this exception, however, the land best adapted to the cultivation of oranges and lemons is generally hilly. In fact, the fruit-dealers mark their fruits with an "M," which signifies "Montagna" or "Mountain," which enhances their price, as seen from the following comparison, viz:

Fruits produced on hilly land, 25, 50 lire per thousand; on rolling land, 21, 27 lire per thousand; on level land, 17 lire per thousand.

Soil.-Considerable attention has been given of late years to the character of the soil, subsoil, etc., best adapted to the cultivation of the fruits in question, as well as to the chemical composition of oranges and lemons which has resulted in the belief that calcareous land, containing certaiu other material necessary to the life of all vegetation, is the best, in order that they may contain the requisite amount of lime, potassa, soda, etc. The soil best adapted to the cultivation of oranges and lemons is at least one meter in depth and devoid of rocks, and accessible to water for irrigation, else the trees die.

Deep, clay land, open and exposed to the rays of the sun, accessible to water, abounding with alkaline salts, minus rocks or stones, little or no grass, not exposed to strong winds, rains, or frosts, etc., is deemed to present the best advantages in all respects.

\section{CLIMATIC INFLUENCES.}

Temperature.-The temperatnre in the adjacent territory of Palermo, in summer, does not ordinarily exceed $35^{\circ}$ centigrade, and rarely falls lower than $20^{\circ}$, and in winter the maximum is $23^{\circ}$, and the minimum $10^{\circ}$. Consequently, the average summer temperature is $2 \tau_{2}^{\circ}$ and that of winter $162^{\circ}$, the average annual temperature being $22^{\circ}$. 
Neither cold nor warm nights, in the territory conterminons to Palermo, seem to wield an influence upon the result of the cultivation of oranges and lemons therein. Sultry days, although frequent in summer, and occasioual warm or cold spells, appear to exert no detrimental influence upon either lemons or oranges. For instance, the fruits in question flourish quite well where the thermometer does not fall below $+3^{\circ}$ centigrade, in winter, nor rise above $34^{\circ}$ in summer. It has been observed in Palermo on varions occasions that the orange and lemon trees resist a summer sultry temperature of $40^{\circ}$ centigrade, and that of -20 in winter without any apparent detriment, while many other plants or trees were destroyed or damaged.

The atmosphere in and conterminous to Palermo in winter is almost invariably humid or moist, while the climate is mild. In summer the atmosphere is very warm with little moisture, save immediately on the sea-coast, the scirocco which often obtains making life of all kinds perilous. During this period irrigation is lavishly resorted to in order to keep the trees alive and preserve the fruit.

Rain-fall.-The conditions of temperature and climate in Sicily aro exceptional, compared with other parts of southern Italy. The strong, constant winds which prevail in winter condense and accumulate the vapors, over which they traverse, into a small compass, and as a result the rain-fall is often so copicus as to inundate entire localities. Rain commences about the latter part of September and ends in April, 22 inches falling within the interim named.

When rain falls in large quantities the trees are damaged; but in small quantities it is advantageous to them.

Irrigation.-The cultivation of oranges and lemons, in Sicily, generally can not be undertaken, unless the trees are irrigated from spring to autumn, or when the land is not adjacent to springs, the drippings from which serve therefor, or when springs do not exist in the subsoil, the filtration of which sufficing to maintain the ground in a moist state during summer. The custom of opening canals parallel to the rows of orange and lemou trees into which water, accumulated in an elevated reservoir, is allowed to flow, thence into and between the openings or small depressions between the rows of trees, until the ground is thoroughly saturated, the more remote points from the source of the water being irrigated first, until finally the irrigation water and its source coalesce or meet, obtains here.

In the best conducted orange and lemon gardens in the vicinity of Palermo, irrigation is resorted to every eight days during the first year of the growth of the trees; every trelve days during the second and third years; every fifteen lays during the years from the fourth to the eighth, inclusive, and from the eighth year forward invariably every twenty-two days.

Orange and lemon gardens require, on an average, 350 cubic meters of water for each irrigation to the space of one hectare of land in good condition. 

Great attention is necessary as to the amount of water required. If too much is used the trees are subject to a disease called "male della gomma;" literally translated, "gum disease." If too little, derelopment is delased and eren their death may ensue.

Oultivation.-April and May are the best months in which to cultivate orange and lemon trees, the inclement weather having terminated, thus insuring the safety of the buds.

Oranges and lemons are cultivated from the dry seed, which costs lire 1.80 per kilogram, or from fresh plants containing the seed, the latter requiring more attention than the former.

Planting or sowing, as the case may be, commences in April, as stated, or later, in order to avoid white frosts, the ground being previously prepared.

Trees resulting from dry seed are generally good and strong, and attain a height of at least 1 meter, before being grafted with a view of propagating the varions rarieties desirel.

The gardeners of the Province of Palermo recommend that a distance of about 5 meters should intervene between each orange tree when the ground is level, aud about 4 meters in undulating, rolling, or declivitous land. Lemon trees are recommended to be from 5 to 6 meters apart when large trees are expected, or desired, as is the case with all trees derived from "cerlrangoli amari," (Citrus bigaradia, Riss.)

The best mean $\mathrm{s}$ of planting trees is in placing them in parallel lines from north to south, in orter that they may be equally exposed to the sun's rays throughout the entire day, and so placed as to form a series of equilateral triangles, with a tree on each angle, as per drawing herewith. To this method of planting the name Losanga has been given.

It is customary during the early stages of the growth of lemon and orange trees to alternate them with other plants, such as vines, cotton, etc., in order to give them strength and nutrition, as well as to utilize the necessarily large vacant spaces of ground.

At the expiration of ten years, howerer, or when the orange aud lemon trees have become so large and tall as to obscure the plants in question with their branches, etc., they are taken up and ntilized in a new field.

Fertilizers.-Alkaline substances are better adapted than any other materials for fertilizing. Gardeners in the vicinity of Palermo formerly used sea-weed, mixed with the excrements of horses and cows or stable accumulations.

Fragments of dressed leather, woolen rags, scrapings from horns, and certain other remains of old or cast.riff manufactures, as well as decayed fruits, are regarded as the best admixtures of fertilizers for oranges and lemons. The materials or substances in question are stratified in proper places with a view to their fermentation before leing used.

When trees are planted they are abundantly maured, and after one 
year the ground around them is cleared away to a depth of 40 centimeters, forming a circular ditch with a diameter of two meters into which two baskets of manure, or about 20 kilograms, are deposited, whereupon the ditch is covered with the earth previously removed, placing it so as to form a shallow ditch around the tree. This operation is resorted to in January and February. Small trees are manured twice a year, for the first five years, viz, in March and Angust.

Ordinarily, however, when trees prosper, manning is resorted to only every three years, the quantity used being about 40 kilograms to each tree.

Pruning.-The first pruning is made after the expiration of the third year. The height from the ground depends on the quality of the land in which the trees are planted, as well as the desire for either high or low trees. When the land is exposed to northern and southern winds it is better that the trees should be low, but inversely should this exposure not obtain.

In Palermo, as in all Sicily, the orange and lemon gardens are pruned from December to June, while the trees are devoid of fruit, the process being governed by the gardeners' interests and experience rather than by any theoretical suggestions.

Gardeners take care to clip or clean the trees yearly, cutting off all old and useless branches. Pruning is resorted to every three years.

\section{PICKING AND CURING.*}

Oranges are picked from November to March, and lemons from November to August. The first picking is generally made in November, the second in December or January, and the third in March or April. During the summer months, however, snch as are verging on maturity are picked from time to time.

Oranges and lemons for export are picked prior to maturity, and thas shipped to ripen on the voyage.

Oranges and lemons for export are not cured, but simply selected with a view to bearing the long voyage. Those not shipped, and for which a sale is not readily found in the markets of Palermo, are preserved from March to Angust, in well ventilated caves or grottoes, to be sold to ice cream dealers for the purpose of making ice-cream, jellies, lemonade, etc.

"In a subsequent dispatch Consul Carroll says that, " in connection with preserving oranges and lemons afler being taken from the trees, it muy be proper to say that this consulate is often applied to for information as to the supposed or alleged means resorted to here for that purpose by California aud Florida fruit growers, and to repeat, for the information of fruit growers in the United States, that there is no process resorted to nor known here to preservo the fruits in question other than folding them in fine tissue-paper, which is changed from time to time, and the fruit examined and all contaminated oranges aud lemous eliminated from the baskets or boxes in which, for the time being, the fruit may be placed. Precaution is also taken to place or keep the fruit in question in a dry equable tamperature.

"Oranges amel loums are geuorally picked lofore maturity." 


\section{PACKING AND SHIPPING.}

When oranges aud lemons are picked they are carefully selected and wrapped in tissue-paper, packed in open boxes, and placed in the warehouse. Again, before shipping, they are carefully selected, newly wrapped, and packed.

Generally speaking lemons can be divided into two categories, viz, normal lemons and abuormal or anomalous lemons. The normal are those that bloom in the months of April and May, and the abnormal or anomalous those derived from the blossoms of February, March, June, July, and other successive months, and which depend on waterfalls, to a more or less degree, during warm weather, for irrigation.

The normal lemons arrive at maturity in about nine months-that is, from May to January, inclusive-the picking thereof being commonly made in three successive periods, riz, from November onward. The lemons picked in the first period are green, and those picked in the third period more mature. They are picked according to the requirements of the purchasers. The first and third pickings are more valuable than those of the second, consequent upon fruits being more abundant during the latter period.

The fruit under consideration is believed to be the best, and by gardeners is classified as first.class fruit and sold at very high prices.

The fruit picked at other times is called anomalous.

Lemons are picked by men who, if the trees are too high to permit their doing so from the ground, climb up and detach them, taking care to leave a piece of stem, placing them in baskets lined with linen, on the handle of which is a wooden hook tied in order that the basketsmay be hung on the branches. So soon as a basket is full it is lowered from the tree by means of a rope, provided with a knot, and exchanged for an empty one by a boy knowu as "panieraio," or, literally, "basketmaker," whose duty it is also to empty the baskets in the place desig. nated by the "taglia piedi" (peduncle cutter). This is an expert workman in his line, who performs two offices at the same time, viz, cuts the peduncle of the lemons close to the crown, and afterwards separates the good from the bad lemons, depositing them in two separate heaps. Small lemons, although they may seem to be good, if of less weight than 80 grammes are, as a rule, not exported.

It is estimated that out of the total lemon crop about two-thirds are considered fit for export, the remaining third being utilized in the manufacture of acid, essences, elc.

The "taglia piedi" (peduncle cutter) places the lemons on a straw bed, in order to protect them, during the voyage, from damage.

When lemons are classified, girls place them in baskets lined with liuen. Each girl places in her basket 208 lemons, 4 lemons at a time, thus making 52 operations or movements, and when completed places the baskets on her hoad and conveys it to the warehouse. 
In the warehouse good lemons are placed in flat lots 1.30 meters high, where they are allowed to remain from five to eight days, in order to determine their strength, at the end of which any decayed or dam. aged lemons which may be found are picked out. This is not, however, general, especially when the producer of the fruit is not the shipper and has no interest in the shipment thereof. It is only done in cases where the shipper has purchased the fruit or the producer ships it on his own account.

In the warehouse, near the gardens, the lemons are wrapped with tissue-paper, placed in boxes, the interior of which is lined with paper of the same kind. The boxes so prepared arecarried into the city warehouse, where the lemons are taken out of the boxes and a new assortment made, and in order to ship them the above operation is repeated.

Should the boxes not be promptly shipped for any cause, and remain in the warehouse some time, then it is in the interest of the person on whose account the fruit is to be shipped to assort them, in order to ascertain if there are any damaged fruits among them.

The fruit is shipped in boxes of the following dimeusions, viz:

Centimeters.

Breadth .......................................................... 29

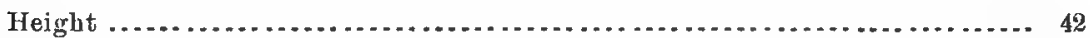

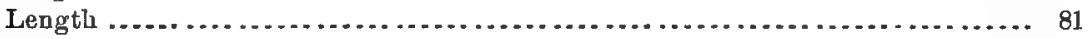

The number of lemons which each box contains depends on their size, and in order to be exact the fruit is divided into four categories, as follows, viz: 200 if of the first category, 240 if of the second category, 360 if of the third category, 4.20 if of the fourth category.

Boxes are divided into two compartments, each containing half the number stated above, placed as follows, viz:

First category, in 4 strata, 25 per stratum; second category, in 4 strata, 30 per stratum; third category, in 5 strata, 36 per stratum; fourth category, iu 5 strata, 42 per stratum.

Philip OARRoli, Consul.

United States Consulate, Palerimo, March 7, 1890.

\section{SICILY.}

REPORT BY DONSUL LAMANTLA, OF CATANIA.

Varietie8.-The names of the best varieties of oranges for protit are: The common orange (a round fruit); the calabrese (a long-keeping fruit); the sauguigno (a blood-red orange); the oval (a late, sweet, and good keseping); the mantarino (mandarine, the largest one). 
The names of the best varieties of lemons for profit are: $I$ limone comune (common lemon for trade); Il bergamotto (for making essences); Il cedro vero (citrus medica, for preserving).

Situation.-The same are located in low and bigh land, as well as all around Mount $2 \mathrm{tna}$, at a distance from 300 to 600 meters from sea, at an elevation from 500 to 600 meters above sea-level, exposed to sun, on level lands, because it is better, and ou rich calcareous soil.

Climate infuence.-The minimum temperature in January is $5^{\circ}$ Centigrade; the maximum is $35^{\circ}$ Centigrade in August, and the average $17^{\circ}$ in May.

Nights in summer are rather fresh, and cool in winter. Days generally clear, seldom moist, and good atmosphere.

Rain-fall from 25 to 30 inches per year, and rain in proper season helps the growth and the fruits greatly.

Irrigation.-Irrigation is done by spring and stream water, and by well-water elerated by steam or horse power.

The groves with said water are generally irrigated at option, and whenever needed, as lemon trees bear all the year.

Cultivation.-The following information $I$ have been able to gather by personal visits to the owwers of the beautiful large groves of orange and lemon trees, the production of which forms one of the principal resources of the country, viz: When it is wished to plant a new lemon grove, the gardener from November to April prepares in the best spot of his garden a well-manured seed-plot of 2 square meters, whereon he sows a quarter of a gallon bitter-orange seed, and covers the same with about 2 inches of fine earth. Two months later you see the young plants out of the ground, and on the coming summer the seed-plot is to be watered at least every four days. After one year the young plants are at a height of 18 inches, and then the gardener prepares a larger seed-plot to plant the same, at a distance of 18 inches apart, where they are left till another year. The new ground is hoed about $2 \frac{1}{2}$ feet deep, and divided in square compartments of $1 \frac{1}{2}$ feet each side, in the corners of which are located the largest seedlings taken out from the seedling bed, leaving there the smallest ones, to be replanted later on.

This method of planting is called by these gardeners mettere a casella (planting in cell). There they are kept for the second year, with good care, the stems being fastened to sticks driven in the ground along-side, in order to grow straight and to protect them from the wind.

On the third year the seedlings are already grown sufficiently to be replanted in another larger place, in order to give them more ronm. Consequently half the largest ones are again dug up and planted in another prepared bed.

This second method is called planting in piantonaio. Here the plants are left until the fourth year. In January or February of the fifth year the grower divides all his grouud, already prepared during the previons fill, in sefuare compartments of 14 feet long each side, and in the cor- 
ners of each one he digs out round ditches, with some well-manured animal compost, mixed with the earth. It is proper, however, to note that the young trees arealways to be kept free from sprouts, and watered and manured diligently. This operation is done as follows:

Every fifteen days the ground is removed from the bottom, and the grower around the tree forms two circles, one of a foot and the other of two feet in diameter. Then he removes the ground from the base of the tree about 5 inches deep and fills it with manure, covered with the same ground. This operation is also recommended for large old trees.

In the fifth year the said trees of bitter-orange seedlings are grafted iut , lemons, or oranges if desired.

Fertilizing.-A lemon grove must at least be dug three times a year; that is, on the first of January, pretty deeply, and the ground mauured, if possible, in all its extension; (2) in the month of April for forming the conche (compartments) and gutters for watering in the hot summer; (3) in the middle of June, for weeding. In the fifth year, the young bitter orange trees will be grafted.

Grafting.-Although no inquiry is made about grafting, yet I may give some details of the methods nsed in Sicily. Grafting is done in becco di flauto (beak of flute), by spacco (splits), or by scudo (shield). This last one is generally practiced in this island, and the proper season is in the montl of October or May. The first method is called "ad occhio dormente" (sleeping eye), because it is necessary to await the coming spring season to see whether the grafting has turned out well. The second is practiced by smarter agriculturists, and is called occhio vivente (living eye), for the reason that should it fail, in the coming fall it is operated again. The shoots are to be chosen from the best and most vigorous adult trees, and so at the end of the serenth year you will have a good producing young lemon grove, fruiting all the year around.

A fifteen-year old tree generally produces 500 lemons, while at twenty it yields over 1,000. Professor Cassella states that he has seen several very large old trees producing as many as 10,000 fruits per year.

Pruning.-Pruning is done according to the growth of the tree. The method used in Sicily is a tronco rovesciato (capsized cone.) This form is practiced from the time the tree is young by cutting the maiu trunk, and letting the lateral branches grow, in order to have free ventilation and free sunlight, and to effect the fruits to maturity.

The height of the trees varies according to locality and usage of the country. In Messina, for instance, they are left pretty high, while in this province they are kept low, on account of strong winds, which sometimes prevail around Mount Ltna.

Picking.-The regular season for picking lemons in this district commences from October in low lands, and in November on high lands, up to the cull of January. That is called 11 mimo trglion (first cut), and the 
fruits are considered as the best for quality and long-keeping. The second cut, larger than the first one, begins in March and lasts until the end of April, and the last one, or third cut, known as verdelli, from May to the end of September. Finally lemons bear all the year arouud.

Orange picking commences in low land in November, and on the montagra (mountain) from January to April. These are the best fruits, and durable, fit for packing and shipment. The same are always picked a little greenish, and not in full maturity; but they acquire their natural bright color after they are wrapped in tissue paper and boxed for shipping.

Before shipment, however, they are chosen into four different sorts; that is, first and second choice the fruits are thoroughly examined to be entirely free from thorn touch or any disease, and they are shipped for farthest markets. The third choice are sent to near markets, and with the fourth one is made essence and agro cotto.

The fruit is gathered with care, the stem is cut with a very sharp round-bladed knife, and left to the eye to prevent decay.

Planting and propagation.-The distance planted apart must not be more than $\mathbf{1 6}$ feet, for the reason that if trees are allowed to grow too large they can not stand to support the lateral branches overloaded with fruit, besides preventing free ventilation, without which disease is generated.

As before stated, trees are propagated br seedlings.and grafting. The best varieties are of course obtained from seedlings, and then grafted to the desired kind.

The orchards are pretty large in some localities and small in others.

Maturity.-The age of fruiting is at 8 years, giving the largest crop at 20; the maturity of trees is from 70 to 100 jears, and according to the soil, exposure, locality, and culture of same.

Insect pests.-The insects damaging this beautiful plant are: $\Pi$ pidocchio del limone (lemon louse) and $I l$ pidochio dellearancio (orange louse). .

The first one is an insect of a whitish color, which attacks both leaves and fruits. It made its first appearance in Sicily in 1862, and notwithstanding the several efforts to destroy it, nothing has as jet been accomplished to succeed.

The second, pidocchio (lonse) of orange, is another insect of a dark brown color, and a very injurious one to both orange and lemon, by infesting the tree bark, leaves, and fruits.

Another insect, supposed to be the cossus aurantii and a crittogama, called nero degli agrumi (black disease) first of a whitish color and then black. Both of them attack, also, the bark and branches of the tree, propagating on the leaves, blossoms, and fruits, causing the former to stiffen, turn yellow and dry, while the latter grow very little, turning black, and never acquire the natural color of the ripe fruits.

If the parasite develops early in the season the plant will thoroughly $156 \mathrm{~A} \longrightarrow 9$ 
be covered with the disease, the fruit stops growing, gets black, and falls. It is said that petroleum sprinkled on the trunk and on the branches has proved somewhat of a remedy.

The mosca (fly) is another pest damaging both kinds of fruit. It generally appears in the beginuing of summer, stinging the fruits and depositing therein its eggs, which develop into grubs which destroy the fruit.

The gum disease.-Besides those insects, there is also il male della gomma (gum disease), which greatly injures the whole tree, if not prevented in time. It makes its first appearance with a small spot on the trunk gradually enlarging to about one inch wide, and, in the course of four days, causes a crack on the bark, wherefrom a white yellowish liquid, like milk, drops out. Said liquid becomes thick and thicker like small gum drops, and in a few days later they look like transparent jellow pearls.

According to Professor Cassella's experiments in his grove, where he has saved a great number of trees, to destroy and preserve orchards from such a disease, it seems the following methods are highly recommendable, viz:

(1). When a plant has been attacked, all the infested parts of the bark and wood are to be cut out and care taken to destroy all the tissues affected by the discase, then take some quicklime, and while it is still warm rub all the wound aud especially the parts mostly infected. This done, cover the same to about one-third of an inch thick with the same lime, but cold, and cover the whole with paper or something else. Two mouths later take everything off and you will find the wood without any alteration.

(2) To preserve the tree from the disease, mix 9 parts of lime and 1 part of ashes, and dissolve the same like whitewash. Then dig a ditch around the tree, about 3 feet in diameter, by unearthing the largest roots of the tree, and pour into the ditch about 30 or 40 liters ( $7 \frac{1}{2}$ or 10 gallons) of the cuiupost stuff, and with such a proportion for large, adult trees, treat the others according to age and size. In conclusion, to avoid such disease, for new groves, bitter-orange seed is recommended for planting, and then graftiug at pleasure, as above stated.

Replanting.-On replanting young trees for final stay, as per experience had by several orange and lemon growers in this distriet, I understand that one of the most interesting points is the secret that when said planting is to be done, it is necessary to cut the end piece off the main root, about 3 inches lung, for the reason that, if left on, it would draw all the humor from the ground, and would ilso prolong the growth and the trees to bear fruits. I may here give the totill production of this fruit in the whole Kingdom of Italy. Ont of the twelve agrarian regions into which Italy is divided, only in two of them the acid fruit tree is not cultivated, that is, in Piodmont, Emilia, and a part of Lazio. 
According to a statistical report in 1880, by Professor Cassella, it se'ms that the total production of said fruit amounted to as follows, viz:

Regione meridionale Adriaticn............................... 85, 000,000

Regione meridionale Mediterrane:t ............................ $725,000,000$

Regione meridionale Sicilia............................... 1, 622, 000,000

Total firuits

$2,4: 2:, 000,000$

VINGENT LAMANTta,

United States Consula'le,

Consul.

Catania, January 22, 1890.

\section{SICILY.}

REPORT BY CONSUL JONES OF MESSINA.

\section{KEEPING QUALITY OF SIOILY LEMONS.}

Properly speaking, no process for curing lemons is employed by the fruit-growers of Messina. That lemons grown in the Messina district keep perfectly for months before being put on the market is due to the great care in gathering, handling, and packing the fruit; to their keeping qualities derived from the nature of soil on which they are grown, climate, and variety cultivated.

First. The lemons are gathered with great care, the peduncle being cut (not broken) off smoothly near to the lemon. The fruit is carried to the warehouse in baskets lined with cloth, where it is spread out on the floor (if of wood) or on large mats (if the floor be of stone) and allowed to dry from twenty-four to forty-eight hours-even longer if there is sufficient room in warehouse-but never more than six days. If lemons piled, say, 4 feet deep are left for any length of time, the first layers become greatly beated, aud soon spoil. The fruit, having been carefully selected, is next wrapped in tissue-paper and packed in boxes. Upon reaching the city warehouses the exporters, before shipping, have the boxes re-inspected; the least defect in the fruit causes its rejection. When packed for the last time, prior to shipping, care is taken to pack each lemon with.its nose down. . If the boxes are kept ans length of time in warehouses, they are opened every three weeks and each lemon carefully examined. A lemon with a blemisb; so slight as to be noticeable but to an expert, is thrown out as unfit for exportation. Lemonjuice and essence are extracted from these rejected lemons. The fruit contained in each box must be of the same size; an easy matter, owing to the monthly harvestings. Sizers are unknowu here.

Lemons are gathered from October to August; they should not weigh less than 80 grams each or average more than from $2 \frac{1}{2}$ to 3 inches in diameter wheu gathered. 
There are three harvests of the true lemon-the November cut, the December-January cut, the April-May cut. The true lemon is produced from the A pril-May bloom; ;he bastard lemon, from the irregular bloom of February, March, June, and July. The true lemon requires nine months to attain maturity. The true lemon keeps much better than the bastard. Lemons gathered in November are of a deep green color; after remaining in boxes from six weeks to two months they turn light yellow. Lemons cut and packed in November show 300 to the box; the same lemons (having shrunk) when repacked in Jaunary show 360 to the box; later shrinkage is scarcely noticeable. The November.cut lemon keeps better than that of any other cut; shipments of this lemon are frequently made as late as May to New York. Lemons gathered in January are of a bright yellow color and are not kept more than a month in the warehouses here before shipment.

Second. The soils best adapted to the lemon are the argillo-calcareous and the calcareo-argillaceous. Sandy soil is not well adopted to lemon culture, as it is too thirsty, etc. The lemon requires an equable climate to produce perfect fruit; in this district climatic influences are seldom injurious to the fruit. The lemon does best on hill-sides, facing south. It thrives at from one-fourth to two miles from the sea-shore, and at an elevation of 1,500 feet.

Little or no chemical fertilizers are used in these groves, and stable manure but sparingly. Water is the great fertilizer on this island.

Mas not our fresh soils and chemical fertilizers affect the keeping qualities of California and Florida fruit?

WALLACE S. JONES,

Consul.

United States Consulate, Messina, May 30, 1890.

\section{SICILY.}

REPORT BY OONSUL WOODOOOK, OF OATANIA.

(Republished from Consular Report No. 41ㄴ.)

\section{ORANGES AND LEMONS IN SIOILY.}

In answer to the circular of the Department relative to the culture of the orange, lemon, olive, fig, and raisiu, I have the houor to report for my district as follows:

The Catania consular district comprises the southeast third of the island of Sicily and lies between $36^{\circ}$ and $35^{\circ}$ north latitude, and between $11^{\circ}$ and $13^{\circ}$ east (Greenwich) longitude.

The province of Catania takes in the volcano of Etna and the rich zone of lava soil that surrounds it. The general trend of the land is from the sea-shore upward to the summit of this mountain, which rises 
to an altitude of 10,872 feet, being over two miles high. The soil is composed of disiutegrated lava, and is among the richest and most productive of the world. This inclined plane is habitable to within 94 miles of the crater, and is densely populated, the population being 1,424 to the square mlle, exceeding that of any other part of Italy. The climate is semi-tropical, temperate, or frigid, in accordance with the altitude, the different zones being represented in the vegetable kingdom in the ascent from the sea to the top of 2 Etna.

The climate is here (Catania) in winter mild and salubrious. I have been here since the 1st of October last. Frost is seldom known in this lower altitude. We had none during the past winter, though the citizens called it a cold winter. I am forcibly impressed with the similarity of this climate to that of Southern Oalifornia, having passed several months in that part of the State.

From the sea upward to an altitude of from 700 to 1,000 feet the landscape is beautified by groves of orange, lemon, fig, and olive trees, and vineyards of grape, all of luxuriant growth.

Oranges and lemons are here designated as "marina" (sea coast), growing in the lower altitudes near the sea, and "montano" (of the mountain), growing in the higher altitu(ies. The "montano," or mountain fruit, is the choicest, and commands the best prices in the market, but the crop is not so sure, owing to the frost. The marina orchards bear more abundantly, and the crop is considered a certainty. Of the fruits there are two kinds, the oval and the round. The trees that bear the oval fruit are preferred. Those trees that blossom several times during the year are a specialty because of their producing fruit at different periods of the season.

Of oranges there are four rarieties, the round and oval (as above mentionerl) and the mandarin and bitter. Of these the oval is preferred for commerce, being more durable. The round is sweeter and larger. These two kinds are the fruit of export. The mandarin is a small orange of excellent flavor, but being more perishable than the other varieties, it is used more for home consumption than export.

The bitter orange is very liard 5 , and is adapted to this climate; it is grown for the purpose of propagating the uther varieties by budding or grafting them upon its stock. Its fruit is used in the manufacture of preserves. The round orange begins to ripen in December, the oval in January.

Orange aud lemon trees begin to bear full crops when they are from ten to fifteen years old. The time of full bearing depends much upon the climate (altitude), cultivation, and fertility of the soil. As to the length of time the trees will remain fruitful, I find a diversity of opinion. Some say that varieties of the orange and lemon budded upon the bitter orange stock will remain fruitful from one to two centuries; others say from forty to a hundred years. When not thus budded upon the bitter orange stock, but raised from the seed, the trees are short-lived. They 
become diseased; a gnmmy substance exudes from them; a disease cankerous in nature attacks the wood and they soon die. The bitter orange tree will, without doubt, continue to bear fruit for two centuries. The budding process is generally in practice. Grafting is but little resorted to.

The process of starting an orange or lemon orchard is as follows:

(1) The seed of the bitter orange is planted. When the young plants are a year old they are transplanted. When they have grown to be about one inch in diameter (three or four years old) they are again transplanted and set in the place in the orchard where they are to remain. The top of the young trees are then cut off about 4 feet above the ground. When they become well rooted and growing, the best varieties of the orange and lemon are budded upon the stalk. Two buds are generally inserted, and upon opposite sides of the plant. From these buds branches shoot out, and when a quarter of an inch in thickness become of a reddish color.

The trees of the orange and lemon are subject to various diseases. A parasitic growth of fungus nature frequently appears upon the bark of the trees. The lemon tree is more subject to this than the orange. This growth after a rain (or being soaked with water) is removed by scraping. An insect of a dark brown color called the orange louse is very injurious to both the orange and lemon by infesting the bark, leaves, and fruit. A similar insect of a whitish color, known as the lemon louse, attacks the leaves and fruit of the lemon, but not the orange. The fruit of both the orange and lemon are sometimes injured by an insect called the fly. This insect makes its appearance in the beginning of summer, and commences its devastation by stinging the fruit and repositing therein its eggs. These eggs develop into grubs, which destroy the fruit. Plents of suulight and good veutilation are requisite for all these diseases. Tar-water, and water slightly tivctured with kerosene are used as a wash for the leaves and fruit, being applied with a sponge. Soda-ash is also used. When the fly first appears the fruit must be frequently washed.

These remedies are only of temporary benefit. No remedy has yet been discovered for the permanent destruction of these enemies of the orange and lemon, especially the louse.

The distance between the trees to be maintained in planting in the orchard depends much upon the situation of the ground, the quality of the soil and the climate. The distance varies from 4 to 6 meters (13 to $19 \frac{1}{2}$ feet).

When the soil is loose, rich, and easily cultivated the lemon trees shonld be planted at least 6 ineters (191 feet) apart, becanse, under these circum. stances, the trees grow luxuriantly and become large. When the situation of the ground is such that ventilation will not be good the trees should be 6 meters ( $19 \frac{1}{2}$ feet) apart. Where the soil is poor and the climate cold, so that the trees cuu not grow large, they may be planted 
nearer to each other. The distance to be maintained between orange trees is from 4 to $4 \frac{1}{2}$ meter's ( 13 to 14 feet). The distance must vary in accordance with the situation and quality of the soil, as in the case of the lemon.

Orange and lemon trees make beautiful the upland and mountain side with their vivid green. They grow luxuriantly in the valleys, and fringe the sea-coast almost to the water line. Those orchards rield the best results which are most distant from the seil and are not of such an altitude as to be affected by the frost. The rich valleys above the sealevel, where an abundance of water can be had for irrigation, abound in the best orchards. Some orchards here reach down to the sea, within 330 feet of the shore. Such a location is of course not desirable for the culture of this fruit. The trees so near the sea are more liable to disease, and the quality of the fruit is not so good as that of the orchards more distant.

Artificial irrigation is necessary in this climate. Streams that tumble down from tna are utilized for this purpose. Where this is impracticable, water is elevated from wells by steam or mule power.

The ground of the orchards between the trees must be cultivated. It is necessary that the ground be kept perfectly clean. The soil should be worked at least five times a year, commencing in March and ending in October. When the trees are young and small it is not customary to work the soil. It is thought that the vegetable growth protects the young plants from the too-powerful rays of the sun.

Many sections raise crops of vegetables between the trees. This practice, however, is condemned by the best fruit culturists.

The cost of cultivation in the best orchards per annum per hectare $\left(2 \frac{471}{1000}\right.$ acres $)$, on the average, is about 650 lire $(\$ 125.45)$; but where extraordinary outlays must be made for streets through the orchards (as is often the case in this lava-covered soil) and steam power for irrigation, the cost per annum per hectare $\left(2 \frac{47 x}{1000}\right.$ acres $)$ may be 2,000 lire $(\$ 386)$.

On the average a lemon tree here produces 1,000 lemons per annum; an orange tree 600 oranges. There are cases where trees produce ten times this number.

The Sicilians regard the best time for gathering the fruit for export is in the month of November. The fruit is carefully picked from the tree by hand, caution being exercised not to injure the same by the thorus of the tree or rough handling. The fruit is not rudely thrown into a box, but gently placed in a basket lined with cloth. The stem is left on the fruit, cutting it about a quarter of an inch from the surface of the fruit.

Prior to boxing, the fruit is cleaned of insects or other injurious matter. The box used here generally is capable of bolding from 250 to 360 of the fruit, there being a partition in the center. It is lined with common silk paper. Each individual fruit is encased in the same kind of 
paper prior to boxing. Care is taken that no nail protrules in the box to injure the firuit prior to placing it therein. The boxes are not made air tight, but interstices are left between the boards for ventilation.

Lemons gathered in the month of November and thus boxed are supposed to keep without spoiling for six mouths. Oranges will not keep so long. The boxes should be occasionally opened, and any infected ones removed therefrom; especially should this be done just prior to shipment.

During the year 1882 there were exported to the United States from Catania of oranges and lemons 241,107 boxes, of which the invoiced value was $\$ 441,227.72$.

During the year 1883 there were exported to the United States from Catania 228,857 boxes, invoiced at $\$ 324,284.84$.

For much of the information relative to the culture of these fruits I acknowledge myself indebted to our worthy vice-consul, Mr. Augustus Peratoner, who owns several fine estates upon which are splendid groves of orange and lemon.

ALBERT WOODCOOK, Consul.

\section{UNited States Consulate,}

Catania, May 21, 1884.

\section{VENETIA.}

REPORT BT OONSUL NOYES, OF VENION.

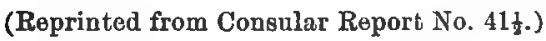

\section{LEMON OULTURE IN VENETIA.}

Although the principal ceuter of exotic culture is not found within the consular district of Venice, some account of the circumstances and methods connected with its practice in the province of Verona may be of interest to fruit-growers in answer to the inquiries of the Department.

The Lake of Garda, the largest of the Italian lakes, while penetrating with its northern extremity far into the mass of the Great 1lps, opens out into the plain to the south with barely the difference of level necessary to contain its waters, and the more completely it allows the warm alr of the plain to penetrate into its deeply embedded mountain recesses the more completely is the tepid element sheltered and isolated from the colder currents of the north. Bathed in this genial atmosphere, the precipitous shores form a range of natural espaliers, exposed to the southern sun in all its course and enjoying a climate of their own, on which the cultivation of oranges and lemons has been a profitable 
industry for several centuries. It is on the western shore of the lake, in the region of Brescia, that both fruits are produced with success; while to the east, and properly within the Venetian territory, the lemon only, being the more hardy, is cultivated to any extent for commerce, the orange being more rarely planted, except for experiment or ornament; its fruit does not generally come to maturity.

Cultivation.-The lemon is cultivated in the open air and succeeds perfectly, though requiring the nicest care and attention. It demands a soil sufficiently loose and fresh to permit the free passage of solar heat without baking or shrinking, and largely composed of the substances most suitable for the formation of acids, of sweet and aromatic juces, such as the alkalies, and particularly those of potassa and lime.

Analysis.-An analysis of the trunk and fruit of the lemon shows in the fruit the presence of 47.48 per cent. of potassa, 22.82 per cent. of lime, and 11.57 per cent. of phosphoric acid; in the trunk, 55.13 per cent. of lime, 17.09 per cent. of phosphoric acid, and 14.76 per cent. of potassa, with smaller proportions of other substances.

Manures.-The manure should be of a nature to complete the natural resources of the soil, by still further additions of alkaline and azotated substances; stable manure, mixed with leaves and sea-weed, and left to decay together till they form a loam, to which may be added powdered lime or plaster of Paris and night soil ; some cultivators use also the refuse of the wine and oil press.

Propagating.-For propagating the plants, a nursery is generally formed in some spot particularly favorable for soil and exposure, and here the plantation may be made in various ways-with the seed simply, with a portion of root which has already given a sprout, with slips buried till they commenced taking root. From the seed sown in spring the plants are more robust, but such plants always require to be grafted later, which is done sometimes in the simple split, but oftener by the insertion of a bud on some thrifty shoot from one of the lower branches.

The young plants remain for six years, more or less, in the nursery, and here, or in the pots or cases to which they are sometimes transferred, they receive the care necessary to bring them to a certain degree of vigor and solidity, as well as the pruning and shaping generally to the form of a sphere or hollow vase.

Transplanting.-When ready for transplanting, the ground is prepared by digging a bruad ditch the whole length of the proposed line of trees, taking care to break the earth as deeply and widely as possible to give free passage for warmth and moisture, and clearing of any stones or large pebbles. The plants are removed from the nursery or case, with the mass of earth adhering to their roots, and set in the earth 9 or 10 inches deep. Care should be taken at the same time to separate and spread any roots too closely grouped together, or tending too much inward or downward. In refilling in and around the roots manure should be used liberally, and a slight elevation of earth raised around the spot 
to retain water. The plants are sometimes grafted before this transfer, sometimes only a year or two after. Each plant should have about $2 \tilde{j}$ square yards of open ground around it; in these intercening spaces, however, small shoots are sometimes cultivated for sale or transplantation, but in all cases the earth should be well spaded during the first year at least, lopping the roots which come too near the surface. The young trees are sheltered during the winter, and the ration of manure for each is prepared beforehand and placed under cover near it for protection from cold, to be well worked into the ground with the first spad. ing, which takes place at the commencement of vegetation in spring.

At the same time the tree should be pruned of its dried or weakly branches and leaves, which would become points of attack for mildew or insects, as well as to maintain its compact and advantageous form; and this cleansing operation, after being carefully attended as soon as the advancing season offers some security against returns of cold, should be renewed towards the 1st of July, when the first period of vegetation has well marked the relative vigor and promise of the young shoots.

The plants should be watered according to the requirements of the season, using for the purpose water from which the chill has been removed by standing in the sun. This is done here mostly by hand with the simple old-fashioned watering-pot.

Where the plants are kept in pots or cases, here as elsewhere, they are more for ornament than profit, and in this case the filling is entirel r of manure, and should be renewed every three years. At a certain stage of growth, also, it is necessary to transfer the plant to a larger recipient, though one change of the kind is generally sufficient, a case of 2 to $2 \frac{1}{2}$ feet in diameter being large enough for it at almost any age. The operation should not be executed without due precantion. The plant, enveloperl in cloths or rags, and lifted gently by ropes and pulleys, should suffer no violence; while suspended, the smaller and too extended filaments of root trimmed away, and lowered with its mass of earth undisturbed into its new receptacle on a stratum of fine gravel prepared for it, the empty spaces filled as before with manure and loam well worked into the roots. The plant should then stand in the shade for about eight days, guarded, as far as possible, from sudden changes of temperature, and copiously watered, admitting, howerer, the external air if in the greenhouse, when the weather permits it.

Finally, and to prove that after all Italy is not the natural home for these delirate products, even with all these precantions, the orange and lemon plants, which thrive here in the open air during summer, can not risk the winter withont protection, either in the greenhouse or under provisory sheds of light planking, provided with stores and couducting tubes sufficient to maintain a certain unitormity of temperature in every part of the inclosure. Many cultivators regulate their practice in heating by the simple expedient of placing a rossel of witer nenr the plant, and light their stoves when the water begins to freezo. This, 
however, is considered dangerous, as the injury may be already done before the signal is given or observed, and the plant once attacked by frost is bejond remedy. More careful gardeners uso the thermometer, and begin heating when it marks $6^{\circ}$ or $7^{\circ} \mathrm{Fahr}$. above freezing point, particularly if the weather is clear and dry.

With all these risks and precautions the cultivation can not but be regarded as exotic and artificial, and the fruit, though large and handsome, is watery in quality, with much of its substance taken up by the disproportionate thickness of the rind; nor has it the concentrated acid of the lemon produced in more congenial climates. The yield, also, is very precarious, and always liable to be prostrated by any extra. ordinary severity of the season. It is estimated for the average year at 500,000 lemons of various sizes, with an average value of 15,000 francs $(\$ 3,000)$.

MoWALLeR B. Notes, Consul.

\section{United States Consulate,} Venice, March 3, 1884.

\section{PORT UGAL.}

\section{THE AZORES.}

REPORT BY OONSULAR AGENT MOREIRA, OF ST. MICHAEL'S.

Varieties.-The name of best variety for profit is the common orange (Citrus aurantium), or China orange, which is the orange exported.

Names of other choice varieties worthy of culture are: the " selecta" (selected) without pips, which never attains a deep color and does not ripen well till March or April; the tangerine, a variety of mandarin, a delicious small orange, but not cultivated to ans great extent; a few boxes are shipped, but of the "selecta" hardly a package is exported.

Situation.-The trees that produce the varieties above-named are grown in almost all situations of the island; distance from sea, from one-half up to three miles; elevation above sea-level, from 80 to 400 feet; for exposure to sun eastern aspect desirable; they grow in all lands, but level land is preferable.

Soil.-Light soil and also argillaceous mixed with pumice-stone.

Climate.-Generally moist.

Temperature.-Winter months, minimum, $48^{\circ}$, maximum, $75^{\circ}$; aver-

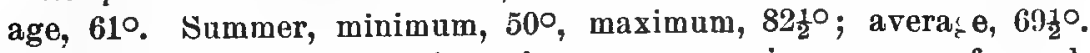
Nights generally cold in winter but very warm in summer; few sultry days; atmosphere moist.

Rain-fall averages 40 inches per annum on the lower grounds, but on the higher lands probably 60 inches. Our soil is porous, the rain soon sinks into the ground, and the soil soon dries up, therefore genial 
showers in summer are very beneficial. In some years there are droughts in summer, and the fruit trees suffer much; consequently the fruit is small and frequently rough.

Irrigation.-Irrigation not required.

Oultivation.-There is no particular method of cultivation.

Fertilizers.-About February lupin is sown broadcast, and when about 2 feet high is dug into the ground; some people (but very few) sometimes use farm-yard manure, and guano has sometimes been applied.

Pruning.-Pruning is not generally practiced before the trees attain an age of seven years, and then at about 4 feet from the ground.

Picking.-Picking begins about the 15th of November and continues up to March ; the fruit is rot properly ripe until January.

Curing and.packing.-There is no system of curing. The fruit is packed in boxes containing from 400 to 500 oranges, according to size of fruit, wrapped in Indian-corn leaves.

Planting and propagating.-Distance from plant to plant, in rows, 15 to 20 feet. If planted closer, which is sometimes done, the trees shoot up too high and the branches touch one another, preventing the sun from shining into the trees as much as desirable. The trees are now mostly propagated by selecting a healthy branch about half an inch in diameter, takking off the bark all round about an inch in height, then putting round it some sifted soil. When it begins to throw out roots it is cut off from the tree and planted out in beds till it attains a height of at least 3 feet, and then it is ready to be transplanted. They are also propagated by layers, that is, by pegging down the lower branches and grafting in the ordinary way. From seedlings the oranges are better than from layers, but they take a long time before they produce any fruit. Sometimes also the trees are budded. The orchards are from one-third of an acre up to 20 acres in size.

Maturity.-The trees will produce in seven years, not however in large quantities, but the largest crops may be expected when they attain the age of twenty years up to forty years, at which latter period they begin to produce less.

There are no insect pests.

Many years ago there was a fair quantity of lemons and some were shipped, but now there are very few. Nobody ever thinks of planting lemon trees except for their own use, or for sale in the market, where sometimes 5 cents are given for one. None are now shipped.

$$
\begin{aligned}
& \text { Augusto S. Moretra, } \\
& \text { Acting Oonsular Agent. }
\end{aligned}
$$

\section{United States Oonsular agenot,} St. Michael's, Azores, December 31, 1889. 


\section{THE AZORES.}

REPORT BY OONSUL DABNEY, OF FATAL.

[Repuplished from Consular Report No. 41\}.]

ORANGES AND LEMONS IN THE AZORES.

The lemon, never raised in large quantities in these islands, probably because its quality diu not make it a favorite, has become quite extinct as an article of trade in consequence of the liability to disease of the tree roots. The orange of the Azores, the China orange, is a fine fruit, but of so perishable a nature as to be incapable of resisting a long voyage. In Fayal and Terceira it has ceased to be exported, not being able to compete in price with oranges sent from other countries in the markets of England, the only markets really within the reach of so delicate a fruit. At the island of St. Michael, which has always been immensely in advance of the others in point of quantity produced and exported, the trade, for the same reason, although yet an important one, has diminished very seriously. From the United States consular agent at that island I have obtained the most of the following information regarding the orange culture. The varieties preferred are the "selecta" and the "navel" orange, the Latin names of which he could not obtain. The trees come into full bearing at the age of eight or ten years, and continue to bear uutil forty or upwards-in by-gone times to a much greater age. They are obtained from seedlings, on which at the proper age the best varieties are grafted, and also by the system of layering; the former are naturally longer-lived trees.

The orange tree at $\mathrm{St}$. Michael appears to be subject to a drying ap of the branches without any apparent cause and without the presence of any insect or fungus. No remedy has yet been discovered for this, I am told (may it not be from exhaustion of the soil, probably?). It is customary to set out orange trees abont twenty-five feet apart. The best orange gardens are some 2 miles from the coast-line. The spaces between the trees are sometimes filled with corn or vegetables, but the more sagacious cultivators abstain from this. Where the garden is devoted exclusively to oranges it is hoed twice a year, but as a rule not manured; never irrigated. The cost of cultivation is estimated at $\$ 20$ per acre.

An acre yields abont 40 boxes of a size to contain some 400 oranges; the value at the present time problematical, as the exportation is done by the garden proprietors banded into large companies. Formerly, when more or less of the fruit was bought by speculators on the treesall expenses being for this account-it was sold at from $\$ 1.50$ to $\$ 2$ the " English box," a package equivalent to three Sicily boxes, or containing from 600 to 900 oranges, according to size of fruit. In a good year as many as 250,000 or 300,000 of such boxes were exported from St. 
Michael, conveyed by small fast-sailing schooners, carrying from 600 to 1,200 boxes of that size. Of late years the carrying has been done by steamers.

The Azorean orange has been with few exceptions packed in corn husks, it being found that, liable as it is to decay, the husk, being thicker and firmer than paper, protects the sound ones more effectively from a decayed comrade.

The soil of these islands, though generally thin, is fairly productive if rain does not fail too much during the summer unonths, and it is observed that the best oranges are raised on rather a sandy soil ; those from richer ground being thicker skinned and deficient in flavor. The climate is decidedly a damp one, but equable in temperature. The mean annual temperature, deduced from three daily observations of a Fahrenheit thermometer properly placed in the shade, I found to be $62^{\circ}$; the maximum observed being $80^{\circ}$ and the minimum $41^{\circ}$.

S. W. DABNEY,

Consul.

\section{United States Consulate,} Fayal, April 24, 1884.

\section{SPAIN.}

REPOR1 BY CONSULAR AGENT LOEWENSTEIN, OF GRAO.

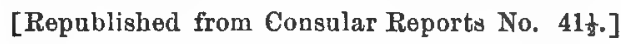

CULTIVATION OF THE ORANGE TREE.

I have the honor to forward to you herewith a report on the cultivation and propagatiou of the orange tree in this province. It was made out after consulting the most eminent cnltivators and authors, and my fervent desire is that this paper may be useful to some of the lesserinstructed cultivators of this tree in the United States.

\section{OLIMATE.}

The orange tree does not thrive in the open air except above $43^{\circ}$ latitude, and then in sheltered spots, where the earth always preserves a temperature above congealment at a depth of $0.02^{\mathrm{m}}$ to $0.03^{\mathrm{m}}$. In these cases the sap of the roots, which is always in morement in the trees of permanent leaves even in winter, defends the exposed parts of the tree from congealment. The thermometer has been known as low as $10^{\circ}$ Rèumur without the orange tress perishing, because such temperature was not sufficieutly continuous to penetrute to any depth in the soil, besides which the thaw that succeeded was accompanied with a clouly sky. In short, the orange tree can be cultivated with perfect security in the open air where the temperature is not lower than $3^{\circ}$ 
Réaumur. In the spots most favored this condition is not met with at a greater altitude than that of 400 meters. When the average temperature reaches from $15^{\circ}$ to $16^{\circ}$ the apparent regetation of the orange tree commences, which, as a rule, takes place in the month of March. T'ie blossoming requires a mean temperature of $18^{\circ}$ centigrade, Rèaumur, the first flowers appearing in April and frequently continuing throughout the whole of May. The blossoms are found on the secondary branches, but principally on the tertian ones, or in general those formed during the previous year; but this rule, which is the most regular, is not the same everywhere. Selling the fruit too late, and the cousequent working and manuring of the grounds (by reason thereof) out of the proper time for so doing, besides which, in consequence of the scarceness of irrigation in summer for want of water, a great disorder in the natural course of vegetation is occasioned. With reference to the height above sea-level, the majority of the orchards range between 4 and 30 meters. The temperature of this province, Valencia, is very mild, and while it seldom reaches as low as zero, many parts are protected from north winds by different mountains.

The climate of the districts where the orange tree is cultivated in Valencia is, as aforesaid, benign, as is shown by the fact that the orange, lemon, citron, palm, locust bean, and various other trees, as also shrubs, all of which are delicate, thrive freely in the open air. Further, the jujube, fig, pomegranate, almond, and olive trees, the vine, and the sugar cane, also flourish here luxuriantly. The dwarf fan-palm grows spontaneously.

The résumé of the meteorological observations made and published during the year from 1st December, 1881, to the 30th of November, 1882, at the Observatory of Valencia, is as follows (barometer being in millimeters and at zero, thermometer of Réaumur, centigrade):

\section{Meteorological observations.}

Millimeters.

Average pressure of barometer $\ldots \ldots \ldots \ldots \ldots \ldots \ldots \ldots \ldots \ldots \ldots \ldots \ldots \ldots \ldots \ldots \ldots \ldots \ldots \ldots \ldots$
Maximum pressure of barometer $($ January 17) $\ldots \ldots \ldots \ldots \ldots \ldots \ldots \ldots \ldots$

Minimum pressure of barometer (October 27) . . . . . . . . . . . . . . . . . . . . . 745.94

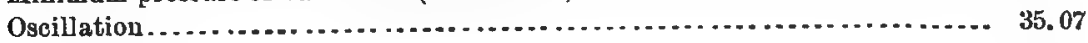

Degrees.

Average temperatare.............................................. 16.2

Maximum temperature in the sun (September 30 ) ...................... 43.0

Maximum temperature in the shade (July 10) ... ...................... 36.0

Minimum temperature in tho air (December 27 and January 6 ) .......... 1.1

Minimum temperature in the reflector (December 27 and Jauuary 6 ) . ....... 0.0

Average oscillation of temperature . . . . . . . . . . . . . . . . . . . . . . . . . . 13.3

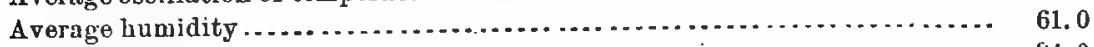

Maxinum of humidity (May 17) ... . . . . . . . . . . . . . . . . . . . . . . . 94.0

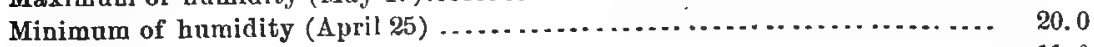

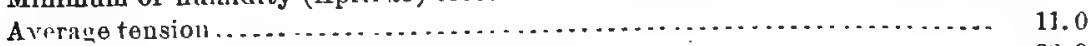

Maximum tension (August 19) ... . .............................. 23.9 


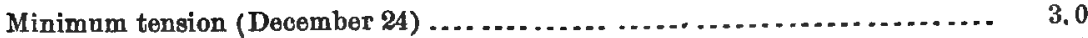

Average evaporation ............................................ 9.1

Maximum evaporation (July 8) ................................. 24.0

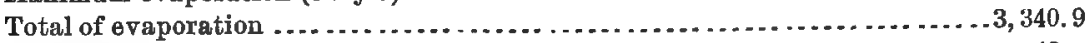

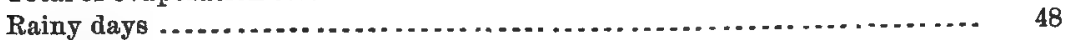

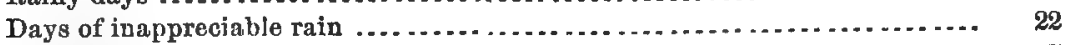

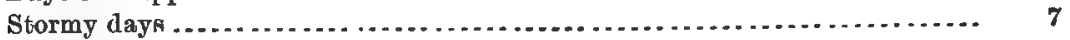

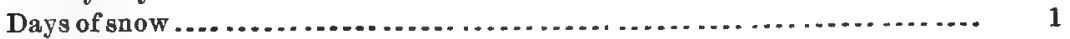

Rain-fall during the jear.......................................... 420.5

Rain-fall, maximum (September 7) ................................ 92.0

Kilometers.

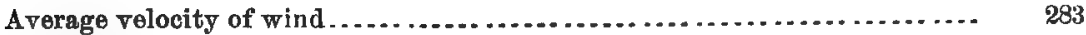

Maximum velocity of wind (February 26) ............................ 962

Minimum velocity of wind (Jannary 1 and August 30) ................. 40

Erequency of the winds. (Observed twice during the year.)

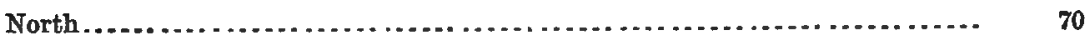

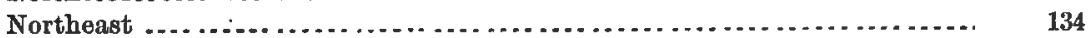

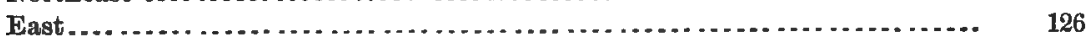

Southeast. . . . . . . .

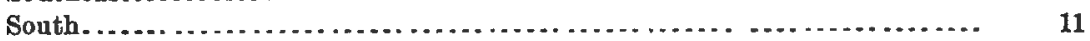

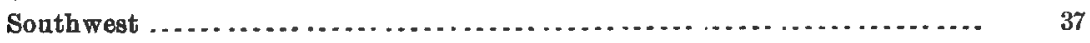

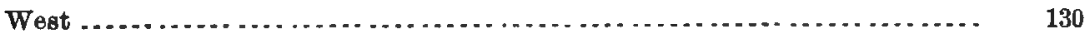

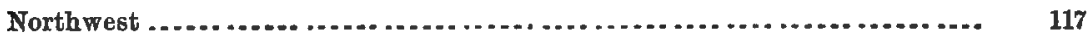

Atmospheric state.

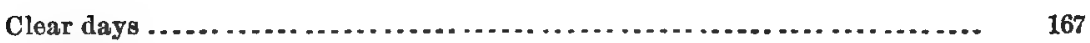

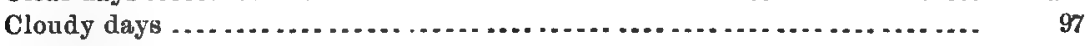

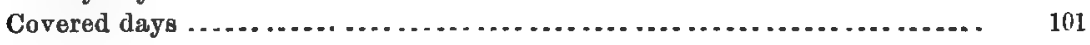

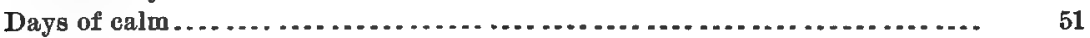

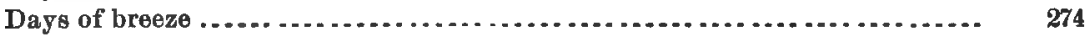

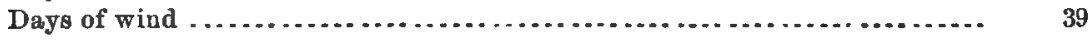

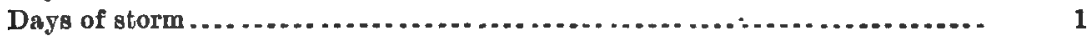

The rain when the weather is not stormy is nearly always accompanied by south or southeast winds, and the rainiest months of the year, or at least those when the rains which are most beneficial for the soil occur, are November, February, and April, although in consequence of the great felling of trees, which has taken place during the present century, as also owing to unknown causes, the rains are much less frequent than they were last century. In this province electricity exists to a very great extent in the atmosphere by reason of the dryness of the climate and the pureness of the sky, especially in the mountainous districts.

\section{SOIL.}

The greater portion of the soil in this region is tribasic, cretaceous, and tertiary, and contains a large proportionate admixture of clay, sancl, and lime, which is the true reason why the earth in this province is so very fertile, as is proved by the luxuriant vegetation, the 
variety of produce, and the richness of this fortune-favored district. The color of the earth in the parts where there is no irrigation is, in general, red, but this changes to gray when irrigation commences and manure is employed. In parts where vegetable refuse and abundance of farm manure form the greater portion of the soil, the color inclines to black.

The soil should be at least one meter in depth and should be subject to irrigation. It should further be of a middle consistence, siliciousargillaceous, or argillaceous-calcareous, rather damp, but without being humid. Chalky soils, more or less pure, those completely silicious, and those which are compact argillaceous, with constant humidity, are useless. In the two first the manures decompose rapidly before being of service to the roots, and they require excessive irrigation, which weakens the soil and exhausty it. In the latter the excessive humidity which is constantly retained deprives the roots of atmospheric influence and causes putrefaction. A soil composed of clayey marl or a light clay mixed with sand is most suitable for the cultivation on a large scale of orange, lemon, and other trees of the same family. The soils where the orange.tree thrives well are of very distinct composition, as there are as many orangeries on sandy as on clayey ones, but those most compact should not contain more than 65 per cent. of fine earth (with less than 0.005 millimeter diameter), and on reaching this limit they should have a sandier earth for subsoil. The same extreme limits which the orange-tree admits in its physical composition are also admitted by the soil with regard to the quantity of lime contained in it, for while in certain districts (Benifay6) the earth contains no carbonate of lime, in other parts 18..9 per cent. is found, and recently a calcareous earth has been examined, the same being of great depth, and has been found to contain 57.22 per cent. of said carbonate; notwithstanding the same, the orange-trees thrive well. These earths are also rich in potash, and contain this matter in an exceedingly large quantity in a form that may be considered as assimilable with the tree, so that in such districts there is no necessity of employing potash for manure. Of the other alimental principles of the plants, there is in general a limited quantity of phosphoric acid, and in some parts an addition of magnesia.

The extraordinary foliage acquired by the orange-tree in a loose soil, which at the same time contains what is necessary for its proper development, may be fully appreciated in the districts of Alcira and Carcagente, in this prorince, which districts are the center of production, and the soil in which is loose and of great depth. A simple analysis of a sample of earth taken from Carcagente showed that it did not effervesce with acids, whilst a sample from Alcira did, and abundantly. The analysis of 100 grams of earth from Alcira gave, salt of lime (carbonate), 20 per cent.; sand (silicate), 70 per cent.; clay, 10 per cent. This analysis, which was lightly mare, is sufficient to give an idea of the soil iu "which the orange-tree thrives to perfection.

$156 \mathrm{~A}-10$ 
Thus it is that in other parts (Castellon de la Plana), where the soil is most compact, the growth is slower; in years when there is a scarcity of water and the orchards are not irrigated at the proper season, the earth becomes so compact as to prevent the growth of the small lifegiving roots, besides depriving them of the beneficiul effect of the atmospheric air, and as these roots cannot then properly nourish the trees, the latter, little by little, harden, or, in other words, the trunk and branches lose the green color they should have, which manifests the abundance of sap contained by them, and which is what preserves them tender, a thing so necessary for their growth.

From the preceding it will be seen that it is uecessary to well examine the soil (should one have the idea of converting it into an orange gar. deu) before incurring any expense, not only examining the surface, but also the subsoil, as there may be some parts where the soil is loose and of good quality on the surface, but very compact and bad beneath, or vice versa. By attending to this the proprietor will know what may be expected from said ground and to what cultivation it would be advisable to dedicate it.

\section{PROPAGATION.}

Orange trees may be propagated the same as any other fruit tree, either from seed, whichis the natural way of multiplication, or from cuttings, which is artificial. The first system, viz, from seed, perpetuates the species and gives origin to new descriptions, afterwards improved by cultivation. The second method, either from shoots, cuttings, or grafting, continues the raceand at the same time accelerates the fruitage, which is always later with the trees produced by the firstnamed system, but in exchange the trees raised from seed are more ro. bust and live to a much greater age. The oldest orange trees found in this province clearly demonstrate that the primitive trees were raised from seed. The sweet orange does not thrive well when raised from shoots, and in order to obtain a good result it is necessary to recur to tightly bandaging them so as to favor the accumulation of juices, which contribute to the acceleration of the unfolding of the underground shoots. The bitter orange is more easily cultivated.

The following means have been employed, and are still being used, as by the same frondose trees, bearing a large quantity of fruit, and this of good quality, are obtained. Said means are these: First, a flowerpot is obtained, composed of two pieces, which can be ensily fastened together either with wire or strong twine passed round them at the top and also at the bottom. 'Then some straight branches of about the thickness of two fingers must be selected, and if said branches are very long they should becut down to the length of $1 \frac{1}{2}$ meters; then the part that has to be placed in the center of the flower-pots is barked all round for about $1 \frac{1}{2}$ inches, and inmediately bound up with esparto-grass cording. As soon as this is done the flower-pots are put together and filled 
with earth and stable manure, well mixed together and watercd; after this they are watered once a week. At the end of a year the roots that have formed fill nearly the inside of the flower-pots, and then the branches at the lower exterior part of these are sawn off and the new orange trees taken to the spot where they are to be planted. For planting them there is only to cut the wire or string holding the flower-pots together, and if thes are well looked after they will commence bearing fruit at the end of two years.

The slips of the sweet-orange tree rarely strike root, or at least such is the experience of farmers here who have tried it.

Till the disease of the orange tree occurred some years back, the propagation was generally effected by grafting the orange on a slip of lemon tree, but since then cultivators have only directed their attention to obtaining vigorous plants from the seed, on which are afterwards grafted cuttings; and the seed most preferred are Niranjo dulce franco, Bigarado franco, and Bigarrado Gallesio; further, should short shoots be required, the trunk should be raised from the seed of the sweet orange. Those raised from the seed of the bitter orange, either franco or that called Gallesio, are more vigorous, more luxuriant, and of longer duration, besides which they better resist the cold, for which reason they are preferred and chosen for the trunks of the trees of tall growth. The fruit of the first named is considered the best.

The last system of propagation, being that adopted in this province, viz, grafting on a franco trunk, a series of operations takes place, such as the establishment of a nursery for raising plants from the seed, a plantation of young trees, grafting, and transplanting.

\section{NURSERIES.}

The soil where this is effected must be of good quality, free from creeping herbs or weeds, and it must be in a good position so as to receive the sun in all parts, besides which it must have an abundance of water for irrigation. All seeds are sown in flat plots, and if they are delicate the soil is manured with a small quantity of wellrotted dung finely minced so as to allow of its better distribution and at the same time produce more beneficial effects; the soil is also excavated and loosened so as to give the plant greater freedom for growing. These plots, when prepared, are opened out in parallel rows of about four inches deep and one foot distance between each.

The means generally adopted in this province for the establishment of these nurseries are as follows: The raising from seed, when on a small scale, is done in large boxes, but when on a scale of any importance it is done in the soil. This last is greatly preferred, because the plants have more roots on account of baving more space for development. Although the temperature of this zone is very benign, it is nevertheless necessary to splect a sheltered spot for the nursery, taking care that the soil be rich, uulritive, of sufficient depth, and possessing 
means for irrigation. Having everything prepared, the next thing is to obtain the quantity of seeds required for sowing when the proper time comes around. The general method is to divide the orange with a knife, takiug care not to cut it so deeply as to tonch the seed, so as to in nowise injure them; these are then picked out and placed in the shade to dry, after which they are preserved, either in paper packets or earthern ware pots, in a dry place. Other methods for obtaining seed are adopted, but the preceding is considered as the best. Once the seed is perfectly obtained, should it not be required for use within a short time or period, it should be placed in layers in sand, so as to prevent its getting too dry and opening. A thing of the greatest importance is the selection of the orange from which to obtain the seed. Some nurseries have been planted with seed obtained from the November orange, and but few trees have been obtained, only a small quantity of seed germinating. The seed of more seasoned oranges come up in greater number and with more strength, in addition to which the plants are much more vigorous. Nurseries may be created with the June orange, the fruit at said period being perfectly seasoned, bnt this is considered too late, and the frost or cold would catch the plants whilst still very tender. The average season for planting the nurseries is from the middle of February till the middle of April, thus conciliating everything : first, because the seed then obtainable is good; and, sccondly, there is sufficient time for the young plants to acquire sufficient strength to resist the cold weather ere the winter sets in.

As the time approaches when the seed should be sown, the soil where such is to be effected is properly prepared, being watered and, when in fit condition, well dug up. If the earth is very compact and composed of hard lumps, these are well broken up and smoked, and made up in hormigueros, which are heaps of dry vegetable refuse covered over with earth, having a small opening near the ground in which is introduced a wisp of straw. On setting fire to the straw the whole mass gradually consumes itself, forming a small heap of vegetable ashes and earth. The ashes of the hormigueros are equally distributed over the surface of the soil, and immediately afterwards this is manured with stable dung, which should have been left to rot in sand, and which must be old and as fine as the sand. This has first to be watered to keep it moist, and when the proper season arrives a good watering has to be given it, after which it is spread over the surface. When the space to be cultivated is limited, the mixture of stable dung and sand is per. formed with a spade, and the ground is not plowed. The ground has to be divided in long and narrow plots, having small irrigating canals between each, which must be sufficiently deep so as not to allow of the water reaching the superficies of the rows, as should it do so it would have the effect of hardening the earth, which should always be loose, so as to obtain a good result.

The seed should be soaked-in water for a couple of days, and after- 
wards thickly sown, to provide against the eventuality of some being defective and not germinating.

There are some who immediately cover the seed with a coating of fine manure of about $1 \frac{1}{2}$ to 2 inches, while there are others who employ a mixture of river sand and stable dung; but experienced cultivators say that the sand often iujures the stalk of the tender shoot. It seems that in order to obtain the most favorable result a covering is made of earth from a pine forest, virgin earth, the greater portion dung. When this is not obtainable, then dry, arable ground which is very loose. Having arrived so far, two things are necessary, viz, that the soil be always damp, and that the earth covering the seed be loose, not offering any opposition to the unfolding and shooting of the tender plant. This is obtained by watering the nursery every two or three days after sunset, and still better by doing so before sunrise, using a watering-pot with a long spout.

When the orange trees are about 2 inches high or more, then irrigation by means of the canals at the sides of the rows will suffice.

The young plants are from four to six weeks before appearing above the surface, and sometimes more, and the plants are kept in the nursery for one or two years, according to the state of their development.

The chief things to be observed with the seedlings are: (1) The earth should always have a certain amount of humidity. (2) The plant should be kept perfectly clean, and should weeds spring up these should be rooted out with a small weeding-hook. (3) When the young plants come up close together they should be separated so as to admit the proper development of those which give promise of thriving, and allow those separated to thrive in other spots where transplanted. (4) If the ground is sufficiently manured the young plants have sufficient nutriment until reaching the height of about 10 inches or even more.

If the soil is not properly manured, then it is uecessary to assist the plant by using Peruvian guano, and for doing this various growers dissolve a small quantity of guano with the water in the watering-pot, and thus apply it to the plants; but should the watering take place by means of the small irrigating canals, the guano is placed at the entry of the water into said canals, and is thus conveyed all over the nursery.

Planting.-As soon as the young plants have acquired a certain development in the nursery, which sometimes occurs at the end of one year and sometimes at the expiration of two, the plantation has to be commenced. This generally takes place from the middle of February to the beginning of March, according to the condition of the plants. It is cowmenced by arranging the soil in the same manner as for the nursery, and when this is done the nursery is well watered, so as to enable the young plants to be rooted out without injuring them.

Some cultivators advise the taking up of the young plants with the earth adheriug as thick as mud, while others connsel that they should be trausplauted with a ball of earth attached to the roots, although 
said ball be of small size, so that the plants should lose less. With a mountain knife, or other similar garden tool, a series of holes are made of superficial depth, to admit the roots of the young plants, which are placed in same conditions as they were in the nursery. The orange trees are planted in the plantation at a distance of from 40 to 50 centimeters apart, if wished to be of short trunk; but should the contrary be desired, they are planted at a greater distance from each other. On transplauting the young trees, a series of light beds are made and the trees are planted at the base of the same and in regular files, but on the opposite side of the beds to that where they are irrigated, thus preventing the water from reaching the voung shoots.

Now and then the top soil is loosened with a weeding-hook, and thus the beds gradually get lower, until at last they are level with the surrounding earth at the time when the plants have taken firm root and are flourishing. The plantation is irrigated once in every three weeks in ordinary weather, but oftener should it be very dry ; and about at the end of two or three months after transplanting, say in $\mathrm{July}$ or August, a small quantity of guano or of rotten dung may be applied. At the expiration of a year in the plantation, the young trees are sufficiently advanced for grafting, shonld they have been tended with great care and are required for trees of short trunk; but should they be required to be of long trunk, every means should be availed of for favoring the developenent of the terminal bud. To this end, every year, about June, by means of nipping, the too forward growth of the lateral buds is checked. In April, branches, leaves, and thorns on the lower half of the stem are cut off, as are also the lateral branches above the same which are vigorous.

This same care is bestowed every year until the stem, straight and devoid of knots, reaches a height of from $1 \frac{1}{2}$ to 2 meters, when grafting is effected ou its upper part. Should any of the plants take a crooked. directiou, they are cut off in April of the second year at abont 10 centimeters from the surface of the soil, when they shoot afresh during the summer, and when the shoots have reached a height of about 20 centimeters the most vigorous are selected and the rest done away with. In this province, trees of short trunk are those invariably grown, consequently this last plan is but little, if at all, availed of.

\section{GRAFTING.}

This is one of the most important means for the propagation of the orange tree.

Grafting consists in the insertion of a branch or entting of one plant into another, which operation has to be carefully done, so that both may unite and ultimatel, form a single plant growing on the same stem. Grafting is also done on a plant with some of its own shoots.

Grafting is principally performed with tho object of procuring thuwers, leaves, wood, or fruit of superior quality or more merit than that previously obtained. 
Grafting also serves for the propagation of many trees and bushes, both exotic, rare, and delicate, by employing specimens of wild, rustic, and strong plants that nay be analogons, or of the same family, so as to improve the budding of the branches of a plant which has become stripped of same (in the regions where the cultivator wishes to augment the growth and reproduce the species), and also to unite on a single branch the male and female flowers of vegetables normally "diacians," which are thus converted into "monoccians," and their fertilization vastly improved. The "graft" is the name given to the shoot, or branch, etc., inserted in another, and "parent" is that in which it is grafted; and the plant obtained is called "franco" when both are raised from the same class of seed, and "bastard" when from different species. With all grafting it is necessary to put similar textures in contact, and above all the generating layers or vegetative zones of both parent and graft, and at the same time impede the access of air and light to the uncovered part, or the wound. It is not, as it is generally believed, the joining of the bark which contributes to the perfection of the grafting, but rather of that generative texture or cambium which exists between the white wood and the bark, by which is effected the growth in diameter of the dicotlidonéos, vegetable substances.

In order to obtain a successfal result, the operations should be performed in fine and temperate weather. The parent plants should be carefully selected, not too young, as although the grafting might be successful, they would be long in bearing fruit, notwithstanding that they would be frondose; neither too old, becanse although giving fruit sooner, they are of little duration ; further, those selected must be perfectly sound, well formed, and possessing a clean bark. There are four seasons when the operation of grafting may be performed, viz, at the impulse, at the time of shooting, at the time of vivifying, and when sleeping.

Grafting at the impulse is done when the morement of the sap commences and the buds begin to wake out of the lethargic state in which they had been all the winter, but before they have unfolded. The season for doing this is from the middle of February till the commencing of April, and it is done by grafting twigs of the previous sear.

Grafting at time of shooting is when the sap is at its greatest activity and when the shoot has attained half or three-quarters part of its definite growth. This system is generally carried into operation from the commencement of April till end of May, and the ingrafted shoot availed of is a tencler shoot of the same vigor as that of the portion of the parent plant where it is to be ingrafted.

Grafting at time of vivifying is so called because it is done at the solstice and when the shoots commence to put forth their second spronts, which occurs from about the end of May till the end of June. The cuttings for grafting on virifying are selected from twigs of the same jear.

Grafting when sleeping is done at the equinox in September, and only 
differs from the previous system in that the graft on vivifying commences immediatly to shoot, whereas that grafted whilst sleeping does not commence to move until the following spring. The system may begin to be adopted from the end of Angust till about the middle of October.

A successful result greatly depends on the intelligence, skill, and care of the grafter, as also on other conditions that may be possessed by him. The young shoots to be gratted are frequently spoilt by workmen whose hands perspire copiously, and the same also occurs from bad breath either from disordered stomach or smoking to any extent, in the cases where the grafter is accustomed to hold the ingrafted shoots and buds between the teeth whilst preparing the patron.

The object of the ligatures is to subject and fasten the graft to the parent tree, and those are best which possess sufficient elasticity not to either tighten or loosen too much, as also suffer but little from atmospheric influences, and further they should be of slight cost and easy acquirement, preference being given to those belonging to the animal kingdom, such as raw and carded wool, worsted, silk, or horse hair. Of the vegetable kingdom the following are best: hemp, flax, esparto, enea, reed-mace, various flexible barks, and the leaves of certain trees possessing the same property.

With the graftings it is necessary that the cuts and wounds in the patron should be properly covered and protected with substances suitable for said purpose, and which ought to combine the advantages of slight cost, easy manipulation, shortness in preparation, duration, and perfect protection. The materials most generally employed are the following: Grafter's clay, which is of ancient use, and is composed of twothird parts of clayey soil and one-third of cow dung, well mixed together; and to this are sometimes added dry herbs chopped very fine, and by some a small portion of salt, is also employed in the mixture. Softened pitch is also made nse of, not alone, as it would dry and peel off, but melted with a corresponding quantity of wax or tallow, or of resin and tallow, to which is added red earth or brick-dust.

A good receipt for this mixture is as follows:

Kilos.

Resin

1. 250

Pitch

0. 750

Tallow

0.250

Earth

1. 500

This composition should be applied tepid, but not very warm, as in this case it would injure the plant.

When a good variety has been obtained from seed, it is so subject to injury or loss from any casualty that the plants are generally grafted in order to preserve them. When the cultivator wishes robust and bushy trees of long vitality, the grafting is done with trees of the same species, but should he wish to obtain trees less robust and either of medium size or dwarf, he does this (although at the expense of obtaining a tree 
of lesser duratiou) by grafting on analogous parent trees of a distinct species to the grafts, on account of such grafts requiring a greater quantity of sap than can be given them by the respective parent plants, for which reason they remain small, have but few branches and roots, and the buds are of but brief duration.

As a geuerul rule two cuttings are grafted on the same trunk, some times with the object of greater certainty, and sometimes for the purpose of the trees sonuer forming their top. With reference to the numerous buds that appear when the graft commences moviug, all are suppressed except those nearest to where the gratting was made in order to draw the sap towards sald point. Should they develop too much, the points are cut off, which is done when the graft attains a length of $0^{\mathrm{m}} .15$.

The universal system employed in this proviuce for grafting of orange trees is the following: If the nursery has been well cared for, at the end of a year the swall free orange trees are grafted, whilst those which from some special circumstances have not sufficiently developed are left for the following jear, and it is recommended that the grafting should be done in that part of the nursery where the plants are thickest, as being very close together impedes the moisture from disappearing from the soil, the sun not being able to penetrate through the plants to evaporate the dampness, as it can when the plants are scattered or isolated. This should be greatly studied in those parts where water is scarce in summer, and it is the plan followed by the majority of cultivators who have nurseries.

Nearly all systems of grafting may be employed with orange trees, but in this province the only one now universally adopted is that of the grafting of a bud, which gives excellent results, giving preference either to the method of jouette (á ojo velando) or to that of vidry (de ojo dormido), according to the season when the graftiug is effected, viz, the first from April till end of June and the second from August to October. One of the most intelligent cultivators of orange trees in this province grafts when the sap is moving, doing so from the time it commences to move until St. Peter's day (end of June), and also when the sap is dormant, which is from Angust till October, cutting the shoot in February. The buds for grafting are taken from the center of the tree, as it has been found that if taken from the lower part the branches of the tree produced always incline towards the earth, and young twigs are not liked, as they produce large trees bearing but little fruit. The buds for grafting are selected from those of the previous year and of the June shooting, and, according to the size of the parent stem, one, two, four, etc., are placed, for should the parent stem be thick and have only one bud grafted on it the excess of sap woald suffocate it. On placing the buds, the parent stem is probed and they are applied to the most salient parts which this may present, because it is considered that it is here where there is the greatest quantity of sap, and it should be done when possible in the part facing the north, so as to suffer less from 
the heat of the sun, besides which one can work better. The grafts should be tied with esparto grass, this being found much better than other strings or cords by reason of the less damage it causes to the bark, besides which it better protects it. It remains in this state for twenty-one days, and if at the end of this time the bud continnes green the grafting is correct, in which case the shoot is cut off about four inches above, and it at once moves if it has dried. Sometimes it commences moving before the grafting has thoronghly taken place, in which case it is immediately cut, although the twenty-one days may not have expired. As soon as the shooting commences, cut the esparto on the opposite side if there is only one bud, or at the sides if there are two, but do not take it off. It is calculated that about three hundred can be grafted daily, and when the grafting is done in fine weather it is much better, but it does not matter if done when raining, as neither through rains nor irrigation have the grafts been lost, although there are some who do not irrigate until at least twelve days after grafting. The four inches of stem which remain above the graft, and which served as a support for the growing shoot, are cut off at the end of a year and before removing the plants from the vursery.

The proprietors taking but little care in providing themselves with good seed on grafting, and the grafter, whose only aspiration is to obtain his day's pay, taking everything that comes nearest to hand and costs him least trouble, it frequently happens that fatal results are the consequence. The same recklessness is noted with those who purchase orange trees already grafted and who tako no trouble to ascertain their origin, etc. For the preceding reasons it is not surprising to see sickly orauge trees in all directions, aud others, although sound, producing but little fruit and this of bad quality, thus occasioning a heary loss to the imprudest and carelcss proprietors, which they could have easily prevented if they had not overlooked that the grafts inherit the good and bad qualities of the tree which produced them, as also of its state of sickness or disease as also of its healthy condition; thus it happens that in a small field of only six hanegadas of loose earth, and the whole subject to the same cultivation, in which, by reason of the carelessness of the owner, there are three descriptions of orange trees, each of different merit, there are some that give a flat fruit with a fine skin or peel ; others that are round and with a finer peel than the preceding; with abundant flesh and as juicy as the former but sweeter'; and, lastly, there are others the oranges of which are very coarse and less esteemed by exporters.

\section{TRANSPLANTING.}

The tree lives, strikes root or the contrary, is more or less well formed, gives better or worse fruit, according to how the plantatiou may have been more or less carefully atitended to, the health and duration of the plant being also subordinate to this operation. T'Le 
outcome of the plantation does not only depend on the nature of the soil, but also on the age of the trees transplanted, as the younger they are there is much greater probability of their taking root. A soil well broken $u p$ is better for a plantation of trees than any other; but very few persons take this trouble, contenting themselves with opening holes at regular interrals in a slightly worked soil. The trees with horizontal branches, or curved at the tip, give fruit sooner than those that have vertical or nearly vertical ones. As a general rule the holes made in virgin earth and of the best soil are about a meter in diameter by one in depth, but in dry and hot soils they should be two meters in dianeter by 1.30 in depth. These are made the winter previous to plantivg, in order that the earth extended and deposited round the edges, as also the sides of the holes, may improve from the action of the air; and in the neighborhood of each bole is placed about a cubic decimeter of wellrotted manure, or, should this not be obtainable, it may be substituted by 4 pounds of dried and pulverized blood or 6 pounds of guano. Should the soil where the planting is to be effected be of bad quality, the half of the earth extracted from the hole is replaced with a similar quantity of clayey silicious or chalky clay soil. The manure must be perfectly mixed with the half of the best earth extracted from the holes, and the half of this is deposited at the bottom of the hole in the form of a spreading cone. The tree is then placed on said conein such a manner that the neck of the root when the hole is filled in will not be deeper than it was in the nursery, as should that limit be surpassed the root, being deprived of the action of the air, would only work imperfectly. The only exceptions to this rule are the transplantatious to dry, arable grouni, and in this case the neck of the root is placed at about 5 centimeters below the surface. Being thus placed, the roots are covered with the remaining earth that had been extracted, and the holes should be so filled up that the soil thrown in them should reach the height of six or eight centimeters above that of the surrounding surface, so that on settling down and becoming firm there should be no profundity at the foot of each tree, and the earth thus raised is arranged in a hollow. Wheu the plantation is thus made it should be immediately irrigated, so that the earth should remain in immediate contact with the whole of the roots, and this irrigatiou should be several times repeated during the months of April and May, conformably as the weather may be more or less dry.

In this province the custom is to make the holes at the time of transplanting, there being few that anticipate this operation, and then the holes are only made of sufficient size to conveniently plant the young trees, for, the soil not being virgin, it is neither necessary to work it so much nor for the soil or hole to receive the beneficial effect of atmospheric influence, as in the first case, which is indispensable. According to experts, orange trees do not require very deep holes, it being preferable for their roots to be near the surface. Plantations of little 
depth thrive better; they give more fruit and are healthier; thus, placing the young trees the same as when in the nursery, and taling care that the grafts are from about 4 to 6 inches above the surface, the planting is well done. After having completed everything necessary for the transplantation, the nursery is well watered and the young trees are dug out with a large spade, with a good quantity of earth adhering to the roots, which earth is surrounded with rotten or dried leaves and tied round with cords; and it may be mentioned, the speculating dealers take as little earth as possible from the nurserv, so as not to imporerish the soil. When the orange trees are conveyed to the spot for planting the first thing done is to line the botton of the holes with the earth first taken out until it is calculated that on planting the young tree it will be, after irrigating the soil, at about the same depth as when in the nursery, and as soon as the tree is placed in position the virgin earth remaining around the sides of the hole is thrown in. There are some who throw in a basketful of burnt earth and vegetables, taking care that the same does not come in contact with the capillary roots, which form what are vulgarly called cabellera 6 barbada (false hair, or bearded). If the planting is done in November, there is no necessity for emplosing more manure, that already made use of being sufficient; but in February, when the time for budding or sprouting approaches, a certain quautity of manure is mixed with the soil at a little distance from said capillary roots to oblige them to go in search of it, by which means they enlarge and gain strength. Before closing up the hole about twenty liters of water should be thrown into it if there is a probability of irrigativg the orchard within a few days; but should the contrary be the case, a small quantity of earth is thrown on top of the twenty liters of water, after which a similar quantity of water is added. It is a matter of importance that the proprietor. should be present when this is done, as it frequently happens that the water is thrown in so-hurriedly that it does not reach the bottom of the hole, thus the roots of the orange tree do not come into contact with it and are consequently either longer in developing or else dry up and die. Un planting it is alssolutely necessary that the earth around the roots should be like mud, so as to prevent any contretemps, and later on, when the time for irrigation arrives, the whole surface is watered and now and then is dug up, the condition of the soil being improved little by little by fresh tillage, the grouud around the trees being kept well free from weels. The soil should be liept sufficiently damp, and the oruhard should be irrigated at least twice a month should the weather be dry. There are some who plant the young trees just the same as when taken from the nursery, while there are others who lop off the branches and cut off about 9 inches of the tree in order that it may sooner commence budding; but this it is not always necessary to do. If on rooting up the young trees some of the roots are injured and have to be cut off, if there are many some of the branches should also be done away with, there being an intimate rela- 
tionship between the roots and branches; hence it is easy to understand that if on transplanting a young tree the roots are liearly intact there is scarcely any necessity for cutting off or reducing the branches, while, on the contrary, if a portion of the roots has to be cut off, the branches should be proportionately reduced.

\section{OULTIVATION.}

The orange, the same as all other fruit trees, may be submitted to two different systems of cultivation; extensive or large cultivation, which means planting the trees at a good distance from each other, and availing of the intermediate soil for other crops, and intense, which is the cultivation in gardens, where the trees of short stefns are planted close to each other and subjected to very careful operations. This latter system of cultivation is more costly than the former, but the results obtained are more certain, better, and more abundant. For extensive cultivation, plants of about the height of from 1 meter 50 centimeters to 2 meters, and a diameter of about 3 centimeters at a distance of a meter from the surface, are selected, and if only a single row is to be cultivated there is no need to trouble about how the trees are planted. Shonld the plantation consist of various rows close together, either the threefold system is adopted, each three trees forming an equilateral trian. gle, or else that called marcoreal, which is when each four trees form a per. fect square. Employing the first system, more trees can be planted per hectare, and the soil can be tilled in three different directions, while in the second case it cau only be tilled in two. - When only one row is planted, the trees are placed at a distance of about 6 meters from each other if the soil be rich, and at only 5 meters if it be middling. Should intense cultivation be adopted, the trees are planted at a distance of from 3 to 5 meters from each other. In many parts of the province of Valencia the marco real of 6 meters is adopted, 276 trees being planted per hectare.

Cultivation during the first years. - As soon as the transplanting has been effected, which generally occurs during February and March, the formatiou of a garden should he atteuded to without delay, so as to bave the plants in a productive state. The rule observed by cultivators in this country is so notably different as to confound the most practical gardener, but that which has been adopted by various intelligent cultivators and which has obtained the best results, is the following:

First year.-Ridges are formed at the sides of the rows of orange trees at about the distance of 75 centimeters from the trees. In the month of April the trees are each manured with one or two pounds of guano, or else with stable dung, or serwage, at the distance of about 50 centimeters from the trunk, to which a trench is dug around it, in which the manure is placed and afterwards covered over. The orange tree thus receives the irrigation from the space between the ridges, the rest of the earth remaining intact; thus the trees are prevented from 
getting dirty, and both work and money are economized. When the seasou for irrigation arrives a thorough weeding takes place; thus the soil is cleared and continues clean. The irrigation is continued at its proper time, in order that the trees may. not suffer, after which the corresponding weerling is effected.

Second year.-In February, previous to the moving of the trees, two or three pounds of guano, or stable dung, is given to each tree as aforesaid, but placed at the distance of 75 centimeters from it, or, in other words, at the edge of the ridges. Later, one or two baskets of any kind of manure are distributed around each tree; this may be done in April, which is the best month for doing it, bnt at any other time it may also be effected. The necessary irrigation and weeding must be strictly attended to, so as to preserve the orangery in good condition, and should any tree bear fruit, this should be plucked.

Third year.-In this year the young roots of the orange trees have reached as far as the ridges and the trees commence bearing fruit, which should be plucked as soon as salable, before Christmas, if possible, so as to be able to work the soil in February. There are some who counsel the plucking of the fruit as soon as it appears on the trees, without waiting to derive pecuniary advantage from it, leaving this for the following year. The ridges are now broken down, the whole superficies irrigated, and hormigueros are made. At a distance of a meter from the trunk of each tree small holes are dug with a spade, aud after placing 2 or 3 pounds of guano in each they are corered up. After doing this the hormigueros are spread over the surface, the soil is irrigated, and at the opportune moment the ground half way between the trees is plowed, great care being taken that the plow does not touch the roots; the earth all round the tree must be well weeded and loosened to about the depth of 2 inches. Watering, plowing, and weeding throughout the year.

Fourth year.-From the previous year, the cultivation to be given to the orange tree when in a state of production has already commenced. The fruit is plucked as soon as possible. Hormigueros are not made this year. The soil is dug up or plorred from twice to four times, and is manured. The principal manure employed is guano, of which abont 36 kilograms per hanegada are used. But should stable dung be employed, about six basketfuls are given to each tree, and it may be mentioned that there are some cultivators who use more manure dur. ing these first years. Pruning the orange trees is now commenced, the same being confined to a cleaning, and this should bo effected between Febrnary and May, preference being wiren to the earlier months of this period. This is henceforward repeated every year, and, in order that the wounds occasioned to the tree may be of eisy healing, the branches or shoots pruned off are always the thinnest or most delicate. Should the trecs he required to be low and wide, the cultivator limits himself to checking their upward growth and favoring their spreading. 
Certain intelligent obserrers maintain that it does not in any way prejudice the tree to lop off all the lower brauches, which there is a cer. taiuty that if allowed to grow will rest on the ground as soon as they commence bearing fruit, thus impeding the necessary tillage. With reference to the remainder, it is prudent that they should be respected, and eren the whole of them left, untouched shonld it be noted that the tree does not suffer in its growth from an excess of branches, as said brauches will later on distribute themseives, being obliged to do so from the weight of the fruit on them, and then a fitter pruning can be effected and the trees left in the condition in which they ought to be, the branches prejudicial either to the tree or its development being easily removed. The want of attention to this is the canse of various pruners finding their trees when least expected with fewer branches than the trunk could nourish, and consequen tly yielding less fruit than they ought to do.

The pruning is another of the most important operations of arboriculture, and very important in the cultivation of orange trees, for the following reasons, which it has for object, viz:

(1) To give the tree a regular, elegant, and graceful form, with relation to the spot where planted and the space occupied by it.

(2) To obtain from the whole of the principal branches a series of smaller secondary ones, bearing floral or fruitful buds.

(3) To make the fruitage more equal and at the same time proportionate to the strength of the tree, care being taken to avoid intermission.

(4) To augment the bulk of the fruit and contribute towards the same being more savory, on account of its juices being obtained with greater care and more completely.

Oultivation when in full production.-As has been seen, little by little many modifications have been introduced in the cultivation of this tree as it goes on developing. When the tree is in full production the cultivation is as follows: If the orchard is small, hormigueros are made one year, and the following one manure is employed ; but should it be large, hormigueros are made in one half and the other half is manured. The following year the part where the hormigueros were made is manured, and in the other part where the manuring was effected hormigueros are made, and this system is successively continued alternately. Should the fruit be sold at Christmas, the soil is worked in February and Iarch; but should the fruit not be sold at said period, the only thing to be done is to wait till it is plucked and then work the soil when possible. As soon as the tree is bare of fruit, the pruner commences his work, the best time for this being the end of February and during the whole of March. All dry branches are cut off, as are also all rickety shoots and the crooked branches which cross one another, and some of those from the center, when there are many close together; in short, all those branches that are calculated to prejudice the tree. The orange 
trees must have sufficient space between each to allow of good ventilation, and they must be properly protected to enable them to resist the abrupt changes of temperature and at the same time give the full quantity of fruit they ought to yield. An excess of wood is prejulicial to the luxuriance of the trees, as likewise to their production, for which reason cultivators endeavor by pruning to widen the scroun of the tree, and check its growth in height. In September, before the trees begin to bud, they should all be well examined to remove all theyoung twigs that may have formed, only leaving such buds as are well placed for forming brauches in the empty spaces there may be. This custom is very much neglected, for which reason trees are very frequently seen with twigs which have rendered useless the principal branches, thus disarranging the good order these should have in their proper distribution. One thing the pruner of orange trees must bear in mind is the following, viz, that the branches of these trees bear a heavy fruit, which makes them incline to either side; bnt there are some who do not take this into account and prune some of the branches that ought not to be touched, only fixing their attention on the place they occupied at the time of pruning, which was different to that where they previously were. Those who are not partisans of low trees, like the cultivators here, allow the orange trees a greater development and do not punish them so much in the pruning.

As soon as the pruning is finished the working of the soil is com. menced. This is watered and dug up, and hormigueros made where they correspond, which last work should be carefully attended to, otherwise the farmer will spend both time and money uselessly. The hormigueros gire very good results in strong and damp soils, but they are of little use in those that are sandy and dry A sufficient quantity of combustible should be employed and the earth so burned as to be neither too much nor too little so, but at the same time be blackish. This opera. tion must be effected slowly and with great care. In the orchards where guano is employed, which is thrown round about the trunk, the hormigueros are made in the parts where said manure has not been used, so that the same may benefit thereby.

In the orchards manured with stable dung, which manure cultivators are accustomed to throw down in every row between each orange tree, the hormigueros are made in the clear spots that have not been manured. The part of the orangery that is manured is worked as follows: Soine farmers irrigate the ground and when the proper season arrices throw down the manure, digging up the soil with a spade to the depth of 25 to 30 millimeters in the clear spots, and only 2 or 3 inches deep in the vicinity of the trees. As this is being done, unen go belind and level the surface with a species of narrow hos, in order that the earth may be more united and better preserve its seasoning. Other cultivators commence by making a string of ridges from one to the other side of each row of orange trees at the distance of the extremity of the branches, 
and when this is done they throw down the manure, which, if in small quantity, is spread from the outside towards the trunk, or, if in large quantity, all over the space between the ridges. As soou as the manure is properly distributed the ground is irrigated, care being taken that the water enter gradually and equally, so as not to wash or carry away the mannre, but let it remain where put. At the proper season the earth is burned over, and all thus mixed together. This latter sys, tem is preferable to the former, inasmuch as the water commences to dissolve the soluble portion of the manure, which thus at once penetrates the soil, and, the insoluble part being well soaked, is better mixed afterwards with the earth.

With reference to the first system, it frequently happens that the manure is spread over spots not yet properly seasoned, and in this case the surface manure or that at a small distance from the superficies is destroyed by the rays of the sun, a loss which is avoided by employing the second method.

At the expiration of a month or month and a half, should it not have rained and the weather continue fine, the orangery is again irrigated. After watering at the proper season, two plowings are given to the soil between the extremities of the branches of one tree and another, care being taken tbat the plow does not touch or injure the branches, and a good weeding is given to the grouud round the trumk and pnder the branches. There are some orangeries where the plow can not be used on accont of the trees being so thickly planted, the branches of one tree almost touching those of its neighbor. In these cases the soil is slightly dug up with a spade. This cultivation is continued throughout the year till the month of October, when the orange (fruit) begins to turn yellow, and then the plowing work is suppressed by many, who only keep ou weeding to keep the surface clean. At this period of the sear great care should be taken of the capillary roots, for if cut, the tree suffers and the fruit falls off.

The person who bas to direct the cultivation of an orangery must always be on the watch, both as regards the weather and the state of seasoning of the soil. Should the carth be sufficiently moist, and there be signs of wet weather, or it be thought that the grouud cun pass some time louger without irrigating, this is not effected, and thus the cultivator economizes the cost of the labor necessarily attendaut after each irrigation. Should the weather be cold the orchard is irrigated if possible, and thus the trees do not suffer so much from it. Should a period of dry weather be followed by a lowering of the temperature at the time when the orange trees are not fully seasoned, the fruit is likely to get frozen, and, to however little an extent this may occur, the orange is useless for shipment. It is always advisable for the proprietor of an orangery to have the irrigation done by a person that thoroughly understands it, so that the water mas ouly enter the field with the required currept, in order to prevent any of the surlace soil being swept awa $156 \mathrm{~A}-11$ 
as also to avoid the formation of any pools, especially about the foot of the orange trees or in close vicinity to them, the same being exceedingly prejudicial. $\Delta$ ccording to the opinion of many experienced cultivators the orchards about Valencia may pass from four to fire weeks during the summer season without being irrigated, but this should not be delayed longer, as it would only redound to the detriment of the fruit, which wonld not thrire as it shonld do. In the winter the gardens can be well left for eight or nine weeks without irrigating.

Water is so scarce in some parts in summer that frequently two months or even more pass without it being possible to irrigate the orangery, in which case the orange trees suffer a great deal and the fruit is small, thus causing a loss of importance to the grower. By giving a much deeper tillage the evil is in great part avoided, but exceeding care must be taken not to eut any of the roots, or should such occur that it should not be to the extent of causing the trees to suffer therefrom, for which reason it is best to perform the tillage gradually and by piecemeal. There are some plantations so exceedingly superficial as not to admit of deep tillage; thus the seasoning only prodnces effects of short duration, and when it rains said plantations scarcely benefit from the nutritive elements washed down and deposited by the rains on the surface, for as soon as the sun shines the greater portion are rapidly evaporated, having penetrated but such a short depth into the soil. These do not admit of any improvement; but it must be borne well in mind that the greater the quantity of earth turned over on planting, the tree to be cultivated has more nutritive elements, and, at the same time, requires less water for thriving.

Although all the trees of this species greatly love water, so much so that without it they can not live, still great care must be taken not to let them have too much, as, unless graduated with the greatest rigor, it does them harm; consequently it has to be arrauged according to the season and the position and quality of the earth, so that on an average and reckoning on soil suitable for the regetation of these trees it will be sufficient to irrigate the gardens once in every twents days in summer and suspend it during the antumn and winter. Should the earth be at all compact it is only irrigated occasionally, but should it be loose it requires it oftever. In general, the desree of watering given to the soil should be sufficient to maintain the leares smooth and straight withont being twisted; should the irrigation be carried be. yond prudent limits it is detrimental to the tree, and it may be easily known when the waterings are too frequent or exceel the necessities of the tree, as the leaves commence turuing yellow.

Hormigneros.-All cultivators are manimons in agreeing that the hormigueros give exeellent results in the cultiration of the orange tree in this zone. The ormge tree itself shows by its wider and derper colored leaf how much it benefits from the hormigures, and there are many who believe they contribute in giving consisteuce to the fruit. 
For the preceding reason the owners of vineyards preserve the cuttings of their vines, preferring the ashes of these to those of other vegetables. By these means the physical properties of the earth are greatly and favorably improred, and in addition to the seeds and roots of weeds being destroyed so are also various insects and their grubs, besides which a quantity of vegetable ash is obtained, the use of which has always been greatly recommended, as amongst other elements the earth receives a quantity of potash, which is of great importance to plants. Notwithstanding the preceding the system of hormigreros is not suitable for all classes of soils, but it is to be preferred for those which are argillaceous, and the result will be much better with those which are red and humid.

The application of hormigueres to light, sandy soils, which are naturally acrid and poor in organic substances, always produces fatal results; but, nevertheless, there is an exceptiou to this general rule, for chalky soils may be improved by the use of hormigueros when done with prudence, as by the action of combustion a portion of the chalk is converted into quicklime, and the same result is obtained as if the earth had been calcined, but in this case it is necessary that the maure should be applied previous to the hormigueros, which is the method adopted in various parts of this country.

\section{FERTILIZERS.}

This manure is largely employed, as by the use of it the terelopment of the orange trees is alvanced, and they give a larger yield. Its use gives excellent results in the young gardens where the trees are weakly, but in the orangeries where the ground is in itself rich it contributes towards the fruit being swollen or blown. The quantity of guano employed raries according to the state of the orchard. In general, a bag containing from 60 to 70 kilograms is used per fanega, but there are some cultivators who use double this quantity. The number of trees planted per hanegada varying so much, some growers have adopted the rule of putting about $4 \frac{1}{2}$ kilograms to each tree; thus the manure of each costs about 5 or 6 reals. If the guano is thrown down dry, small trenches are dug round about each tree, in which the guano is placed and afterwards covered over, but should there be a good supply of water at hand the guano is strewn over the earth under and round about the tree, and the garden is immediately irrigated.

The composition of the principal guanos may be, on an average, represented as follows:

\begin{tabular}{|c|c|c|c|c|}
\hline Guano. & Ammonia. & Phosphates. & Azoe. & Nitrates. \\
\hline $\begin{array}{l}\text { Chinoha Islands } \\
\text { Tobabo Islands } \\
\text { Chilian } \\
\text { Patagonian } \\
\text { Baker's Islands (Pacific) }\end{array}$ & $\begin{array}{r}17 \text { to } 18 \\
7 \text { to } 8 \\
5 \text { to } 8 \\
2 \text { to } 3 \\
\end{array}$ & $\begin{array}{l}24 \text { to } 26 \\
30 \text { to } 32 \\
37 \text { to } 40 \\
44 \text { to } 46 \\
78 \text { to } 85\end{array}$ & $\begin{array}{r}15 \text { to } 16 \\
8 \text { to } 10 \\
6 \text { to } 8 \\
6 \text { to } 8 \\
0.3 \text { to } 1.2\end{array}$ & $\begin{array}{r}\text { Per cent. } \\
\text { 4. } 70 \\
\text { 4. } 70 \\
6 \\
6 \\
\\
3.5\end{array}$ \\
\hline
\end{tabular}


It will be seen from the preceding there are some guanos which are very rich in phosphoric acid and contain bat little ammonia, whilst in others the ammonia predominates, and the phosphoric acid is much less. Potash is found in but very limited quantity, and in some gnanos there are no traces of it, as happens with the guano from the Lobos Islands. Magnesia is also met with, but in small quantity.

The organic substances are of easy decomposition, and cause the formation of carbolic acid, which, decomposing the silicit of potash in the soil, liberates both the silica and the potash. Should the soil be poor in potash and magnesia, it soon becomes barren, although the quantity of guano may be increased. This should be well borne in mind in the cultivation of orange trees, rice, and sugar-cane.

Guano can not by auy means replace good stable manure, but it is one of its best complements, its action being immediate, due to the great solubility of its principal fertilizing elements. Owing to the preceding the action of guano is of but short duration, and unless alternated with other manures, such as vegetable ashes, phosphates, stable dung, etc., the soil soon becomes exhausted. It is a very good custom to mix the guano with stable manure, as, in addition to economy and the facility and equality with which it can be spread in this manuer, the results obtained are more beneficial, because, withont lessening its efficacy, it neither burns nor destroys the young plauts, although these might come in contact with it. By means of practical trials it lias been found out that 10,000 or 14,000 kilograms of stable dung mixed with 150 or 200 kilograms of guano produce much more satisfactory results than 30,000 or 40,000 kilograms of stable dung used alone, and that the earth afterwards remain in a better condition for later culture. It has been proved that a ton of guano (1,000 kilograms) is equal in fertilizing effects to $33 \frac{1}{2}$ tons of stable manure, to 21 tons of horse dung, to $33 \frac{1}{2}$ of cow dung, and to $14 \frac{1}{2}$ tons of human excrement mixed.

One of the most perfect known manures is human excrement. In this is found all the elements required by vegetaloles, and in such a state that their assimilation takes place with rapidity, their effects being equal. Fecal matters are required as much for strong as for light soils, but mevertheless a distinction should be made, viz, when the excrement is in a desiccated state it is applied to argillaceous soils, and when fresh the preference is given to light ones. The fecal matters ar'o very ener. getic, and their action on the vegetation is rapid, brisk, and of short duration, but whilst contributing powerfully to the first development of the plants they weaken the strength of them chuing their latter period. In short, it is a manure which quickly gives what it has to give, leaving little or nothing behind it. That human excrement is one of the most perfect manures is proved by its composition. According to Boussin. gault, 100 kilograms of humas excrement in an ordinary condition contain 75 kilograms of water and 24.90 kilograms of dry matters, the principal elements being : 
Oxygen, hydrogen, and carbon .................................. 20. 10

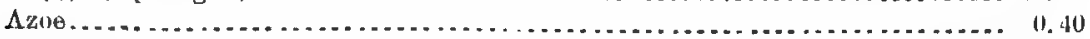

Pbosphntic neill..................................................... 0.20

Putash and soda................................................. 1.50

Lime and magnesial. ........................................... 0.70

Silica and other substances........................................ 2. 00

On evaporation of the water, an inert matter of which it is despoiled as soon as possible, and considering only the dry uatter contained in it, its composition is as follows:

Orgavic matter per 100 kilograms ...................................... 80.14

Mineral matter per 100 kilograms....................................... 19.85

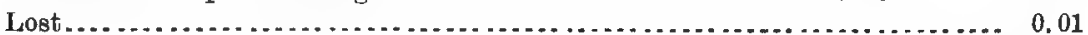

The organic matter contains 78.66 carbon, oxygen, and hydrogen, and 1.45 azoe. The mineral matter contains 0.82 phosphoric acid, 11.00 alkaline salts, potash, soda, and lime, and 8.04 of silica and loss-in short, all the substances that euter into the composition of vegetables; above all, the azoes, soluble phosphates, and alkalies, especially potash.

According to the experiences of Hermsbtael and Schubler, it has been proved that the soil without manuring of any description can produce the seed 3 times, but if manured with vegetable manure, 5 times, and if manured with common stable manure, 7 times, and if manured with pigeon dung, 9 times, and if manured with horse dung, 10 times, and if maunred with human urine, 12 times, and if manured with solid excrement, 14 times.

The employment of manures is indispensable for activating the development of the orange tree and maintaining its fertility. Without them its growth. would be slow, and it would soon be loaded with fruit of small size, which would exhaust the tree by reason of its abundance, and cause it to succumb long before giving its maximnm produce.

The orange tree requires to be manured at two periods of its existence. During its first development it should receive it in abundance, so as to activate as much as possible the formation of its branches and at the same time obtain its maximum production. Aftorwards, during the remainder of its existence, only the necessary quantity for its proper preservation and nourishment should be giren it, its state of regetation indicating the frequency with which it should be manured and the quantity to be giren it. In the first period of vegetation of the orange trees manures of rapid decomposition should be employed, so that they may immediately proportion to the roots, and in abundance, the nutritive elements required by them. Such manures are the following, viz, wellprepared dungs, pigeon manure, the skins and refuse of oily seeds, guano, desiccated blood, and fecal matters. In the second period the manures of slower decomposition should have the preference, and these are horn raspings or scrapings, crushed bones, old woolen rags, horse hair, and the hair, tendons, and waste of tanning factories. The effect of these last manures endures for from five to eight years. Both classes of manure are distributed over the surface soil supposed to have roots 
underneath, and particularly over the parts reached by the radical extremities, which is to say within the circumference covered by the brauches of" the trees. These manures are buried in the soil, about the end of October, at a depth of from 25 to 30 centimeters. Liquid manures are also sometimes employed, such as fecal matters, skins, and refuse of oily seeds, and guano, the whole mixed together with a sufficient quantity of water, but the effect produced is immediate and of short duration. These should not be made use of except during the heat of the summer and at the moment wheu the vegetation is most active, for if applied during the winter they might lead to the putrefaction of the roots. In general, they are not resorted to except for such trees as appear languid and seem diseased, and a trench of about the depth of 5 centimeters is dug around the spot where this liquid manure is to be placed, which is afterwards covered orer. In order that the earth may be fertile, it should coutain all the necessary elements required for obtaining the proper development of the plant that has to be cultivated in it, and these must be in a perfect state of assimilation, but compost and vegetable and animal remains that may be added to the earth in the shape of manures do not return to it the principles lost by it yearly with the crops raised; and Liebig, seeing that in all countries the agricultural production was diminishing, commenced a series of studies to ascertain the cause thereof, the result being such as to clearly demonstrate what was taking place. He found out that all plants required to assimilate a greater quantity of phosphoric acid than that contained in compost, and consequently proposed the employment of bones and natural phosphates, as also mineral phosphates, coprolites, etc. Hence the necessity of mixing or alternating complete with incomplete manures, so that the earth may always retain its fertilizing properties.

The method for calculating the substances which in the shape of manure should be given to the soil as a necessity, after the collection of each crop, is as follows:

1. The cultivator should avail of all the vegetable manure obtainable from the refuse of each crop, to which should ouly be added the fixed principles of the fruit, the nitrogen required by it being supplied by the ammonia in the air, as also that remaining on the surface soil after being washed there by the rains. To ascertain, in this case, the quantity of nutritive principles required to be incorporated with the soil, the probable average weight of the fruit to be produced each year should be calculaterl, baving ascertained which, abl taking into account the weight of ashes, this problem is easily solved. Knowing the weight of the ashes of 100 parts of the fruit, a proportion is established which will give the required result.

2. Should the cultivator not ivish to arail of the vegetalle refuse of each crop, he should add, first, the fixed principles of the fruit, and, secondly, the fixed principles of the brauches and leaves. An analo. gous calculation to the preceding will give the sum of nutritive principles to be added to the soil in the shape of manures. 
3. The case where the cultivator only utilizes a portion of the vegetable refuse. Knowing the total quantity of leaf and branches obtained with each crop, by difference may be ascertained the quantity of leaf and vegetable refuse that is not returned to the soil, and with this datum may also be calculated the nutritive principles that should be adminis. tered, which will be:

(1) The fixed principles of the fruit.

(2) The fixed priuciples of that part of the leaves and branches that are not utilized as manure.

(3) The quantity of nitrogen coutained in the leaves and branches which is not availed of for manure.

The study of the orange tree has determined by analysis that its ashes give the following results per cent., viz:

\section{Composition of the ashes of the fruit.}

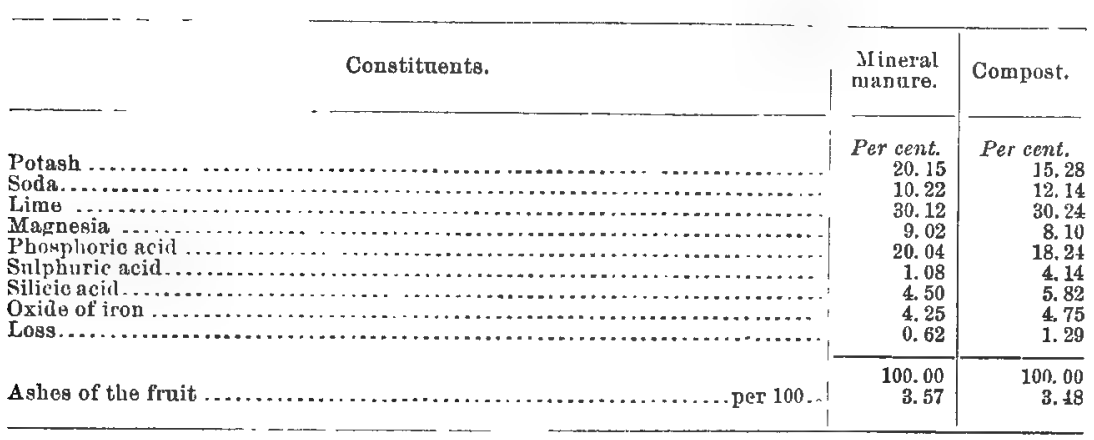

Composition of the trunk, branches, and leaves.

\begin{tabular}{|c|c|c|}
\hline Constituonts. & $\begin{array}{l}\text { Trunk and } \\
\text { branches. }\end{array}$ & Leaves. \\
\hline 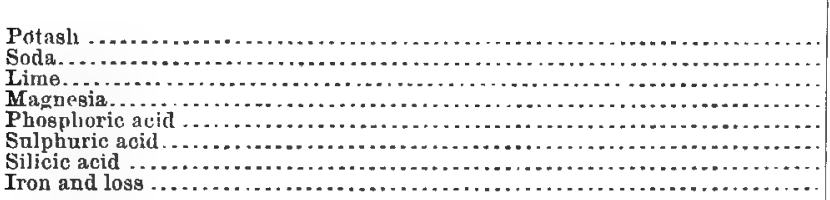 & $\begin{array}{r}\text { Per cent. } \\
14.15 \\
10.67 \\
31.57 \\
10.64 \\
18.82 \\
4.89 \\
2.82 \\
6.44\end{array}$ & $\begin{array}{r}\text { Per ecnt. } \\
10.18 \\
10.82 \\
41.22 \\
6.54 \\
19.47 \\
4.53 \\
5.18 \\
1.76\end{array}$ \\
\hline $\begin{array}{l}\text { Azoe of the leaves } \ldots \ldots \ldots \ldots \\
\text { Ashes of the leaves } \ldots \ldots \ldots \ldots \ldots \ldots \ldots \ldots \\
\end{array}$ & $\begin{array}{r}100.00 \\
1.57 \\
6.32\end{array}$ & $\begin{array}{r}100,00 \\
1.60 \\
6.20\end{array}$ \\
\hline
\end{tabular}

The orange trees analyzed were from Alcira (Valencia); some manured with compost and others with mineral manure. The proportioual dif'ference noted between the assimilative nutritive principles is not to be wondered at, for, as has been observed, this varies with the same plant according to the nature of the soil and the manure employed. 
DISEASEN.

The development of disease in the orange trees is greatly contributed to by atmospherical phenomena, various insects, and parasitical plants, as also the neglect or limited knowledge of the cultivators..

The effects of coli, snow, humidity, dews, frosts, hail, wind, burning rust, chlorosis or yellowing of the leaves, and withering are as follows:

Cold.-This commences by destroying the tender shoots of the trees, followed by the drying up of the blossoms, after which takes place the aisorganization of the fruit and afterward that of the leares, uranches, trunk, and finally roots; crevices open in the branches, which bend and turn black, the leaves wrinkle, roll ap, and die; the flowers become blackened and disorganized ; the fruit loses its brilliancy, dissipates its odorous principles, loses its juice, and tecomes bitter, falls off the tree and rots; or, if the cold has not been very intense, the fruit is half frozen and remains on the tree till th" following spring.

Snow.-This injures the trees botl from cold and its weight. Should the storm be heary and the fall great, this bears down the lortnches and in mauy cases breaks some. As regards the cold occasioned by it, this does not always do harm, but when it does do so it is very frequently confined to the roung shoots. Should the weather be fine both before and after a snow-storm, the colil water produced on thawing proiluces its effects on the young branches, for which reason no time should be lost in shaking all the snow off them before niglitfall, for should it be condensed on them the harm occasioned would be of much greater importance. The system of placing herips of damp straw at fixed distances between the trees, so that on setting said heaps on fire in order to obtain a smoke between the sun's rays and the trees has produced a magnificent result. If after snowing the weather continues threatening, or there be heavy clouls floating about, weither the trees nor the fruit will suffer any harm, although the thermometer might be below zero.

Humidity, deus, and frost. - An excess of humidity in the atmosphere during the fecundation of the blossom generally produces bad results, especially in such places where the rentilation is limited, should the temperature at night decline to any extent. Frost with an east wind occasions a deal of harm, but should the wind be from the north it is not so bad. Little that is economical can be availed of in large orchards, but in reduced ones the harm is lightened at suall cost by a vail. ing of certain materials for shelter, of little value, which in certain dis. trists are plentiful.

Hril.- This causes a deal of damage to the fruit. Should the storm be of short duration and the wounds occasioned by it be of slight pro. fundity, these will soon hal up and ererything continue well, but certain black stains will remain, which reduce the valne of the fruit. Should the storm be heavy, it completely destroys the orange, which quickly enters into a state of putrefaction.

Wind.-This exercises its influence on the orauge trees in two differ. 


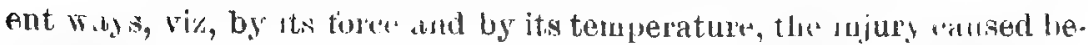
ince greater or less according to the position in which the orchards may lie. Ninth, northwest, and west-north west winds are the most dangerous in certaiu places on ateount of their temperature, for as a rule they dry up the extremes of the branches exposed to their influence, besides which the shoots of certain species become unsond. Those that cause most harm in the south of Europe, by reason of their impetuosity, are the south, south-sonthwest, and sonth-sontheast, according to the position of the valleys. All these winds come with puffs of extraordinary strength and destroy the branches unable to resist them. The only remedy in these important occasions is to cut off everything that has been destroyed and dried up. With tho object of partially avoiding these misfortunes, the custom of producing trees of shortened growth has of late years vastly extended.

The burning and rust.-The disease known as burning is due in great part to the too abnudant dews that fall here, which are evaporated with an excessive rapidity by a bujning sun. 'To the same cause may be traced the disease vulgarly called "rust," or a class of mildew on the leaves of the orange trees. This manifests itself on the fruit by a red stain, which as it increases becomes much darker, and finishes by disorganizing the pulp and rotting the fruit. The cleaning and pruning of the trees is the best known method against this evil.

Chlorosis.-The chlorosis or yellowing of the leaves, and also the withering, are generally attributed either to the superabuudance of hu. midity in the soil, to an excessive quantity of branches having but little ventilation, to the want of irou in the earth, to a species of torpor in the absorption of the mineral matters existing in them, and to the alteration of the roots if old. The remedy to be employed to combat this evil is distinct according to the cause by which it is produced.

\section{INSECT PESTS.}

These attack the roots, trunks, blossoms, and fruit, consequently they are organical beings most pernicious to the trees, frequently causing exceeding harm on account of their extraordinary multiplication. Of this numerous class of insects, the only descriptions which up to date have proved enemies to orange trees, lemon trees, and others of the Auranciacea family, which are cultivated here, are the coleopteral, hemipteral, and dipteral.

Colenpteral.-This description contains more than fifty thousand species, and only one is injuriuus to the orange tree, the same being called Othiorhynchus meridionalis. This devours the leaves aud tender shoots of the orange tree, and is a class of beetle or winged insect. The young insect is sufficiently perceptible, being about a centimeter long, of reddish-black color, and with grooves on the elytron. During the daytime it hides itself in the earth, where it should be hunted and de- 
stroyer, and at night it climhs the trunks, crawling up to the extreme height of the trees in search of the young leaves and tender shoots, which it devours. In general, it is not one of the most terrible enemies, on account of the facility with which it can be found out at the foot of the trees and exterminated.

Hemipteral,-Of this numerous family there are six which are enemies of the orange tree, namely, Aphis auranti, Chermes hesperidum, Chermes oleo, Chermes aurantii, Chermes coccineus, Cocous citri.

Aphis auranti-A kind of small vine-grab of green color varied by black, and with loug feelers, and small green horus black at their points. It is generally seen in the orange trees in the month of September, and when the trees commence to bud it usually fixes at the extremities of the young shoots a quantity of black puceron, which occasions a vast deal of damage to them, iuasmuch as by reason of rendering them useless their growth is greatly retarded. By applying sulphur to the shoots with great promptness the evil is soon and perfectly overcome.

Chermes hesperidum.-This gall-insect, called by gardeners the louse of the orange tree, is not confined to the same, being also found on other trees, such as the lanrel, myrtle, pomegranate, and others. It is found in the shape of an oval body nearly hemispherical, of brown color, somewhat lucent. It prefers the under part of the leaves, but is frequently found on top of them in a line along the center nerve or stalk, being met in great number on the young branches, and when numerous they occasion the loss of a large quantity of sap, which exhausts the trees already languid from iny other cause. Fumigations of sulphur or tobacco are not at all efficacious with these insects; the only true means for diminishing the quantity of kermes consists in simply cleaning the plants with a brush or horse-hair glove, for once that the insects are separated from the brauches or leaves, they do not climb up again, and shortly die. In the orchards carelessly cultivated, as also the spots having but little ventilation in which the orange trees are thickly planted and where the sun scarcely penetrates, is where this iusect is principally found.

Chermes oleo.-This insect, although more natural to the olive tree, is also found attacking the orange tree. The small shell of the femile is semiglobose and of a grayish-brown, more or less dark in color. The superficies is marked with two thick transverse corrugitions, which make it seem rough.

Chermes aurantii is big, oval, very loug, and of a blatkish-brown color.

Chermes eociners.-C'Lis is callel the red kermes, its body being round and of a bright red color. It has two loug feelers, very movable, and six white feet. This gall-insect lives on top of the leares, where it deposits from ten to fifteell eggs, producing a corresponding number of young insects of pearly-white color, which insects on growing to the length of half 's millimeter turn red. The existence of this insect is in. dicated by the appearance on the under part of the leaves of the orange 
trees of some yellowish and concave spots, in which concavities they are found, and should they be allowed to spread much the tree greatly suffers from loss of sap.

Coccus citri (orange cochineal insect). - This is an hemipterous homopterous with an oval-oblong body, convex on the top and slightly swollen underneath. The color is an ashy gray approaching a pale yellow, and it is covered with il cottou-white powder; at the sides are some appendices, and the hind legs are longer than the front ones. The great fecundity of these insects causes the damage occasioned by them to be very considerable, on account of the infinity of their bites, which accelerates the perspiration of the trees. Amongst the various methorls employed for its extermination, the only one which, up to date, has given good results lias been the employment of slaked lime squirted over the branches and leaves by means of a gardener's syringe or small hand pump, taking care that all parts infected are touched. This operation is effected when the regetation commences, which is when the iusect takes up its berth. The trees attacked should be immediately pruned and cleared so as to augment the ventilation and allow the sun to penetrate in every direction.

Diptera.-There is also a dipteran which is an enemy of the orange trees, known by the name of Ceratitis hispanica, or orange fly. This iusect in grub state lives in the pulp of the fruit, which it alters pro. foundly, and causes the same to fall off from the tree before its maturity. The insect is one-half of a centimeter long; of a black color in the ground, although with some yellow-whitish spots and lines; the wings are transparent and crossed by four yellow and black ribbons; the belly peduncular and round behind. The female possesses a borer with which it pierces the skin of the fruit to place an egg in the hole thus prepared. This egg produces a grub which disorganizes the pulp of the fruit and makes it fall to the ground, where it suffers its last metamorphosis. The female deposits her egg when the oranges are still small. By the time the putrid orange falls down, the grub has already arrived at its complete development, and left the same, penetrating in the earth to proceed to its transformation. This winged insect appears in the beginning of the spring. The grub does much harm to the orangeries of the South.

Ants and spiders.-Ants not only injure the fruit but impart to it a somewhat disagreeable smell and flavor; they frequently establish themselves at the foot of the trees and form galleries in all directions amongst the roots, causing such trees as are attacked to languish and ofttimes to perish from the formic acid spread around them, which acid burus the young roots. In this case it may occasion damage to the trees. When an ant-hill is found in the neighborhood of a tree, the following is recommended as an excellent remedy, viz, to take a flower pot, closing the bole in its bottom, and placing it upside down at the side of the hill. The ground is then well watered, and the ants, finding 
this couvenient, shelter, shortly shift their quarters ther'e, taking with them their wives and grubs, so as to keep them warmer. By repeating this operation two or three times they disappear.

Spiders are carnivorous and feed on the blood of the insects they may catch, for which reason they occasion littlewr no damage to the orange tree.

\section{PARASITIC PLANTS.}

(1) Demathium monophyllum or Carbon. This is the most common, and, at the same time, most dangerous. The unseen stamens and pistils of these plants, although but slightly adherent to the vital parts of the orange tree, multiply with an inconceivable facility. Some call it fumago citri on account of the smoky appearance presented by the shoots attacked by the disease. Its appearance is that of a black powder, the congregated particles of which extend sidewise and form a species of very thin crust, which finishes by covering the trunk and branches. An infinity of small and fine peduncles grow out of said crust, bearing on their apex a cellule or black spongy substance, which contains the spores or seed. It is a true arthrosporic excrescence, in which the reproductive organs appear in abuudance and confounded with those of the regetation of the cryptogamia. This fabulous quantity of germs naturally causes the reproduction of the parasite to be exceedingly rapid, especially in damp and shady spots, but it must be borne in mind that it but slightly adheres to the sides of the orauge tree. The aspect of an orchard infested by this parasite is sad and disconsolate; the bright and cheerful verdure of the brilliant leaves of the orange trees completely disappears; the branches and foliage acquire a blackish and dark shade, and the fruit loses its yellow or golden color, being also covered with a dark incrustation, or black smut, and falling off the trees entirely altered.

(2) Lichen aurantii. This is the other cryptogamia, equally parasitic, and likewise occasions much damage to the orange tree. It presents itself in the form of a thin substance, not thick in growth, and of a whitish gray color, covered with small protuberances, which have the appearauce of organs of fructitication. This plant is really more detrimental and daugerous than the other, in conseqnence of the tenacity with which it fastens itself on the different parts of the orange trees, but it is fortunately rarer, and the late years of dry weather have caused it to disappear from various gardeus of the Mediterranean littoral, which were infested with it.

For the destruction of both pardsites, slaked lime is recommended, but the better system for destroying not only these but also all other lichens, existing like palasites, which fix themselves on the trunks and branches of trees, paralyzing the functions of same aud rendering them unfit to produce an ordinary crop, is to well prume the trees, so that the air, wind, light, and solir rays may thoroughly penetrate them. In such 
gardens, where the trees are very numerous and where the trunks are very close together-above all in such spots as the hollows of valleys or humid plains-the trees should be thinned out in such a manner that the branches of the trees can not interlace, and that the atmospheric fluids may have free access on all sides.

Ulcers.-When a tree receives a wound penetrating to the ligneous part and leaving the same exposed to the air, atmospherical humidity, and rain-water, it alters the exterior coats of whiteness and promotes the spilling or wasting of a dark liquid of much acridity. This spilling or wasting impeles the formation of small excrescences on the edges of the wound, which are the commencement of its cisatrization, so that instead of the wound closing up, it continues opening more, little by little, gradually chauging the bark around it and the ligneous part of the tree. Such a round may cause the death of the tree. This disease is known by the name of "Ulcer" or "Gutter." The ulcers are produced with much greater facility when the wounds present a less united superficies and are more separated from the vertical, as in such cases the rain-water is better retuined in them. The most efficacious remedy to be employed in such cases is as follows: Commence by remoring all the altered part until a perfectiy clean wound is presented, which shonld be left in this state and in contact with the air for one or two days to dry it up, after which it should be completely anointed with ointment. Sereral ointments have been proposed as effective, viz, first, the "Ointment of San Fiacre," composed of clayey soil, cow dung and goats' hair or wool, and afterwards a grafting mastic, which should be composed of substances not liable either to melt under the influence of the sun, or crack from frost. One of the best compositions is the following:

Per cent. of weight.

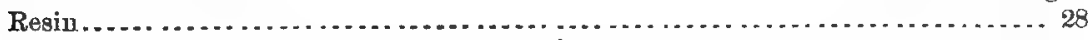

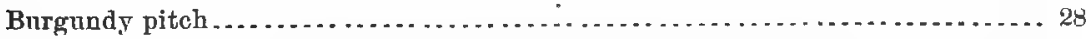

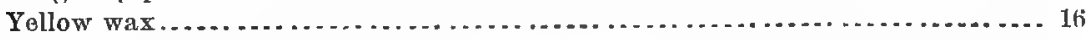

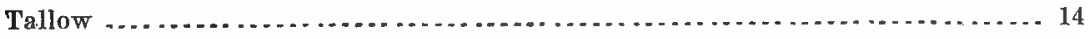

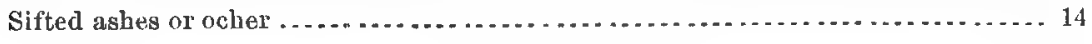

This mixture should be applied sufficiently warm as to be in a liquicl state, but not so much so as to effect the texture of the trees, applying it with a brush. This ointment shonld be preferred to those which become defective through heat and are washed off by rains.

The disease of the orange tree, known by the name of Mal de Goma, is the most to be feared, as it causes such immense losses to cultirators. This disease consists of a gummy oozin a, generall! occurring either in the spring or in the autumn. It attacks either the trunks of the trees just above the surface of the soil, or else the roots themselves. This disease commencas to show itself by some drops of gum appearing ou the trunk, which still appears sound, but this spilling continues increasing, the bark is perforated, and the flow of gum augments, being fluid, 
turbid, grayish in color, and of bad smell; the bark then raises, drying or rotting on the roots, and the plant, which commences turning yellow, weakens and dies.

Recent studies of this disease have proved that its existence is to be attributed to a microscopic fungus belonging to the group of spheroids. Where this fungus does not exist there is no disease; where the germs of it do not reach the disease can not unfold itself; and where the conditions of life are wanting for this small vegetable, whether proceeding from nature or occasioned artificially, the fungus dies and the disease is extirpated. The fruit of this fungus forms itself about the end of July or August, being preserved during the wiuter for propagating its spores in the spring.

The best remedy against this disease, and which from experience has given the best result, is sulphurous acid, mixing 15 bulks of sulphurous acid, concentrated at $66^{\circ}$ Baumé, with 100 liters of water.

Method of application.-Remove the earth round about the tree for the circumference of a meter or so, until no diseased roots are met with. The hole should then be dug deeper, but with great care, so as not to injure the sound roots near the trunk, to about the depth of half a meter if possible. The earth extracted should be piled up to burn it in a hormiguero. All the roots that have completely lost their bark should be cut off, as also those which are in a state of putrefaction, and these roots should be burned. Afterwards all the sickly portions of the trunk, until the bark is saturated, are well moistened with the prepared liquid, as are likewise the diseased parts of the roots that may be met with in such conditiou. It is estimated that about five liters are sufficient, and another five liters for irrigating in the vicinity of the tree. The hole is then filled up either with the burned earth or with new soil, and afterwards watered lightly.

Ten liters of this water saturated with sulphurous acid are more than sufficient for a tree somewhat grown, but practice will teach the greater or less quantity that should be employed.

RICHARD LOWFANSTEIN, Consular Agent.

United States Consular Agendy, Girao of Valencia, June 30, 1883.

\section{WESTERN ANDALUSIA.}

REPORT BY OONSUL OPPENHETM, OF OADIZ.

(Repnblished for Consular Reports, No. $41 \frac{1}{\text {. }}$ )

ORANGE CULTURE IN WHSTERN ANDALUAIA.

In pursuance of instructions containes in Department circulars, dated Washington, December 4, 1883, I have the honor to inclose herewith 
a report upon orange culture in this district. I have also prepared a report on olive culture. Raisins are not prepared within my consular jurisdiction, this branch of fruit culture being localized on the Mediterraneall coast of Spain, and I have therefore omitted that subject. The same will apply to lried figs, which are not produced here. Though the fruit is raised largely in Cadiz aud neighboring provinces, it is generally eaten fresh, and the very small pereentage which is dried turns ont rery mediocre in qualit, and hardly enters into commerce at all.

Varieties and maturity. -The leading varieties of oranges prorluced in Western Andalusia aro: 1st, the Chinese orange (Naranja china legitimas), of which the pulp is very sweet and juicy, with thin and smooth rind; this variety is the most highly prized; $2 d$, the common orange (Naranja comun), haring sweet but not very juicy pulp, the rind rugose, very thick, and easily detached; 3a, seedless oranges, of excellent quality, first cultivaterl by Carthusian monks at Seville; 4th, the sour orange (Naranja agrin), having a somewhat bitterish acid flavor; 5th, the sour-sweet orange; 6 th, the Mandarine orange, a very small fruit of reddish pulp and exquisite taste and flavor; the last is not extensively cultivated.

The orange tree, when raised from a cutting (which is the most usual mode), comes into bearing fire years after planting, though the acme of prodnctivity is not reached with most varieties before some ten or twelve years more. How long they remain fruitful is an undetermined question; that is to say, when the trees are in favorable environment and well cared for. There are in the garden of the Alcazar, at Seville, several orange trees yet in bearing to which very old age is attributed, one being said to have been planted at the time of King Pellro I, about 1350 to 1366; several others dating from the time of Charles I are in a better state still, and, although the trunks are hollow, the foilage is Iuxuriant, and they rise to a height of from 13 to 15 meters. Their trunks measure from 1.24 meters to 1.40 meters in circumference, and the age ascribed to them is about three hundred and forty years.

Planting.-The trees are occasionally raised from seed, but this mode although practiced by careful growers is not generally resorter to in this district, on account of the longer time required in briuging the or. chards into bearing. The best time for putting the seed into the ground is the month of April, when the mean temperature is about $15^{\circ}$ centigrade. With this temperature and the proper conditions of humidity the orange seeds germinate in less than a fortnight. In Seville and adjacent provinces the seed of the sour orange is preferred to all others. as it appears to develop more rapidly, the trees thus raised being later on grafted with any variety desired. Some experts (Riso) hold, however, that the plants raised from the seed of the Chinese variety, although of slow growth, are of a more robust habit and withstand cold weather more successfully. When raised from seed, the usual mode is to keep the shoots in the seed-boxes or hot-beds from four to five vears, 
when the grafts are inserted; the plants are then kept four to five years longer in the nursery, thus taking from eight to ten years before the tree is permanently located in the orcbard.

The general mode of propagation is by cutting. Large fine twigs of last summer's growth are plauted, either in November or in February. In Western Andalusia the eutting is originally chosen from the variety which it is desired to reproduce, and of course no further operation is necessary. In Valencia, however, and adjacent districts, the cuttings are chosen in reference to other points (they are often taken from the lemon tree), and then grafting or budding is resorted to, the graft or bud being of the variety it is desired to raise. Theoperation is usually performed during the winter of the following year, and the grafts are inserted at a height of about 10 centimeters above ground.

Insect pests and fungous growth.-Orange trees are exposed to the attacks of both insects and of parasitic growths. The latter are, in this section at least, considered as by far the most formidable, and will therefore claim our first attention. These parasitic growths are all low cryptogamic plants, and may be roughly divided into two classes. riz, those attacking the roots, and such as confine their action to the exposed parts of the tree.

Among this class the most frequent is a species of white mold, belonging to the genus Byssus, which surrounds the roots of the tree with its mycelium. The white filaments of which it is composed form a dense network around the roots, and have given it its popular name of blanco de las raices (Anglice, "white of the roots"). A well-known Spanish carpologist writes about this pest in the following terms :

This parasite surrounds, exhausts, and cries up the roots of the tree, which, however, does not greatly alter in appearance during the wet season, but when the rising of the sap takes place in the spring (and in a few cases somewhat later) the affected trees quickly succumb. Indications of the evil are a certain backwardness in budding and blossoming, accompanied by pallor of the leaves and yeneral regetative weakness. This shows that the Byssus has attacked the roots. In ordor to connterict its effects it is necensary to complotely expose the roots of the affected tree, remove the filaments of the fungus, and cover the roots with fresh soil. A hole should be dug around the tree nntil the roots are laid bare; the moldy surfaces should then be carefully and thorougbly scraped, and such parts as show deep injury or have leegun to putrefy are to be cut off. The usual practico has been to wash or bathe the rlisanserl roots in water strongly chargod with cow-dung, but in Valencia excellent i uls have been obtained from the nse of hydrosulphide of limo, of a solution of sulphide of copper, and also of protoxide of iron. When refilling the cavity around the tres the fresh soil should be carefully screesed, iu order to oliminate all fragments of dear roots or of rotten wood, as it is npon suleh matter that the Byssus devolops nost readily. It is furcher advised to piace upon thm roots thus oleansol and treated a small ynimtity of well-rotted cow-manure, and above this fresh eartb, mixed with salt, lixiviatod ashes, and pulvarizul bones.

There are undoubtedly a number of the noxious fungoid growths to the attanck of which the roots are exposed, but the generd features, both of the development of the parasites and of the approved mode of combating them, are, in the main, as described above. Ono of them, 
however, deserves special mention, as it proved extremely destructive in the Spanish provinces of Valencia and Castellon (in 1867-'69), aud is believed to be identical with the parasite that destroyed nearly half the orange trees on the Hyères Islands in 1849-51. This parasite is now known as the Sphorium Wolffensteiniani, in honor of a distinguished mycologist who published an exhaustive monograylh on the subject in 1878. At the time of the first appearance of this parasite-or orange disease, as it was then called-in the Peninsula, the Spanish Govern. ment appointed a commission to investigate the disorder. The recom. mendations embodied in the report of said commission were, in the main, similar to those mentioned above. The roots are to be uncovered, all the attacked parts removed and buried; copious irrigation is to be avoided, as also the use of all manure not thoroughly rotted, and especially its application close to the roots. If the soil is humid-and this seems a strongly predisposing cause-thorough draining is necessary. As efficacious remedies are mentioned tar, soot, aud protosulphate of irou, which act as antiseptics; also, powdered lime and sulphate of copper. Otto Wolffenstein, the mycologist above referred to, gives it as his opinion that the most efficient curative agent is a solution of hydrated sulphuric acid, which, according to said writer, nuites the following desiderata: First, it kills all the spores; second, it penetrates the soil to a sufficient depth without oxidizing; and third, it does no injury whatever to the roots. Ten liters of the solution is stated to be sufficient for a tree of a fair size; the solution to be applied in the month of November, as this is the timo when the spores are most easily stamped out.

There does not appear to be any consensus of opinion as to the greater or lesser liability of the different varieties to the attacks of these parasitic pests, nor does such consensus exist upon the comparative resistance of seedlings and the grafted or budded trees. It. is, however, conclusively established that low ground, lack of proper drainage, and insufficieut sultivation are the most favorable conditions for the development of the fungous parasites of this class.

The most widely spread and probably also the most damaging parasite of this class is the Demathium monophyllum, believed to belong to the genus Torula (Persou), and commonly called tizne (Anglice, smut) in Spain. It looks somewhat like black dust or soot, extending in parallel lines and forming a thin crust or coating over the stems and branches. From this crust soon arise an incalculable number of minute pedicles, each one bearing its black sporangium filled with seed-spores. The reproduction of this parasite is incredibly rapid and vigorous, but fortunately it does not adhere strongly to the tree, heuce its removal is not attended with great difficulty; the important thing is not to allow it to get too much headway. The treatment after the removal of the mold is to cover the affected parts with a solution of lime, which may best be applied with a brush. Another cryptogam, called by Du Breuil Lichen $156 \mathrm{~A}-12$ 
aurantii, attaches itself chiefly to the trunk and larger branches. It forms a thin coating, grayish or yellowish-white in color, with numerous small protuberances that appear to be the reproductive organs of the plaut. This parasite is not common, but it is considered very danaging on account of the great tenacity with which it adheres to the trees. There are, however, a uumber of lichens which attach themselves to the trunks and limbs of the orange tree without causing any apparent injury to its growth or to its bearing power.

Great humidity of the atmosphere, want of light and of ventilation, are known to favor the developinent of all these cryptogamic forms, and orchards most affected by them are such as occupy low, close situations, and do not have the trees placed at sufficiently large interrals. A sufficiency of space for the free circulation of air and the free admission of sunlight is, therefore, along with proper cultivation, the best preventive.

A species of phylloxera, first observed on the islands of Naxos and Paros, is known to attack the roots of the orange tree, but this pest las not up, to now made its appearance in the Spanish orchards. Lauderer, the writer who first described this microscopic parasite, recommends the use of a solution of carbolic acid, and of a mixture of sulphur and lime, the latter to be spread around the tree.

The insects causing most damage to orange orchards are several Hemiptera, one of the Diptera, and a few Coleoptera.

Among the Hemiptera the chief varieties are the following:

Chermes herperidem (Linu.). This insect is oval in shape, with hemispherical hack, and is of a glossy lorownish bue. In the spring the shell of the female coutains a large number of egg's resting upon a layer of whitish dowuy matter: The eggs hatch rapidy, and the small harve atre turned loose upon the twigs, leaves, and buds, feeding upon the juices of the tree. They finally attach themselves permanently (usmally to the lower surface of the leaves), remaining there until the following spring, when a new generation is produced.

Chermes olea (Ber.). This species is found upon the orange: tree, Hlthough its more usual habitat is the olive. 'The shell of the female is hemispherical, of a grayish brown, and has two deep transversal furrows, giving it a roughened appearance.

Chermes aurantii (Du Breail). Has been chiefly noticed in Sontheru Frauce aur in Algeria. It is a large insect, in the shape of an oval, and of a brownish-black hue.

Chrmes socoineus (Dn Breuil) is bemispherical in shape, of a vivid red color, has two largish antennic of great mobility, and six white legs. This insect confines itself to the leaves, upon which it lays from 10 to 15 small eggis, that produce an equal number of small Jarvie of a pearlywhitish color. When they have reached a length of about half a millimeter, the insects assume the red coloring; they are frequently moving alout with great rapidity in the vicinity of their meeting places, and are usually found in surall swarms or colonies. 
For the destruction of all the abore-mentioned insect pests the liberal application of powdered sulphur is recommended, such application being probably most thoronghly affected by using bellows. In many districts, however, the method usually followed is to thoroughly scrape and cleanse the attacked branches, removing the badly-damaged parts, and thereafter applying to the affected surfaces a solution of lime (as advocated by Du Breuil) or strong vinegar (according to M. Goreau), using a brush for such applications.

Aphis aurantii (Blanchère) and Aphis citris (Du Breuil) are by some thought to be identical. This is a very large group, and exact scientific identification is therefore difficult. The most common variety encountered here is the pulgon del naranjo (Anglice, flea of the orange tree), which is a small insect, green in color, with black stripes, having large antennxe and black extremities. They are most plentiful in Septembèr. During spring and summer they multiply rapidly, usually taking their staul upon the distal ends of tender shoots, where a certain number remain during winter in a lethargic state.

For the destruction of the Aphis, Du Breuil strongly urges fumigation with tobacco, for which the bellows may be used with advantage. One thorough fumigation ought generally to be sufficient, but if this is not found to be the case the process may be repeated until the insect is extirpated.

Amongst the noxions Coleoptera the most generally known is the Othiorhynchus meridionalis (Schoeul). This insect is about one centimeter in length, of a reddish-black hue, and has striated elytra. During the day it hirles on the ground uear the trees, where it is most easily pursued and destroyed; at night it climbs upon the tree and ascends to the highest parts, usually seeking for the most tender buds and leaves.

All of the above-mentioned species limit their ravages to the branches, leaves, and buds. There are, however, some insects not less noxious which chiefly attack the fruit of the orange tree. The most dreaded of this class is the cochineal bug (Coccus citri). This insect is of a lengthened oral shape, with convex back and somewhat rounded abdomeu; its color varies from an ashy grey to a pale yellow, and at certain times it is covered with a white, fluffy dust; it has peculiar prolongatious or processes on the sides, and the posterior extremities are longer than the others. The male differs from the female in having two large transparent wings. The female secretes a whitish, cottony down, wherein yellowish eggs, varying in number from 150 to 400 , are deposited. . When the larvæ are liberated they attach themselves to the tenderest buds and shoots. There does not seem to be a fixed season for the liberation of the larvæ, further than that the batching process is most abundant during periods of high temperature. The damage caused by this insect is noticed more especially by the great loss of fruit, amounting in some cases to half or even two-thirds of the usual harvest. In the French departments of the Var and Alpes Maritimes, as well as in Mentone, 
this pest has been especially severe. A French entomologist, M. de la Blanchère, has observed that this cochineal bug bas itself au enemy or parasite in a species of Syrphus, which places its larra near the uudeveloped bugs, upon which the larvæ feed. To this valuable auxiliary the same author attributes the disappearance of this pest from certain parts of the Mediterranean coast. De Breuil recommends sprinkling the trees attacked by the cochineal bug and larvis with a solution of lime.

Among the Diptera the only known dangerons enemy of the orange grower is the Ceratitis Hispanica, commonly called mosca del naranjo (Anglice, fly of the orange tree). This fly deposits it larvie in the pulp of the fruit, which is thereby prevented from developing, and generally drops from the tree in an immature state. The full-grown insect is about one-half centimeter in length; it is black in color, having, lowever, yellowish-white spots and striæ; its wings are transparent and crossed transversely by four yellow and black bands; the abdomen is pedunculated and spherical at the posterior end. The female is provided with a "borer," with which it pierces the rind of the fruit, in order to deposit its ova therein; the larva feed upon the pulp, and cause the fruit to fall off and decay. The orange grower cau only protect himself against this insect by great watchfulness in at once removing all the attacked fruit, and thereby preventing excessive propagation of the pest.

Laying out the orchards. - In the province of Seville, and Western Andalusia generally, the usnal distance between the trees is 8 meters. In localities where the trees reach a good size it is advised to enlarge the distance to 9 , aud even to 10 meters. Of course, with small or d warf

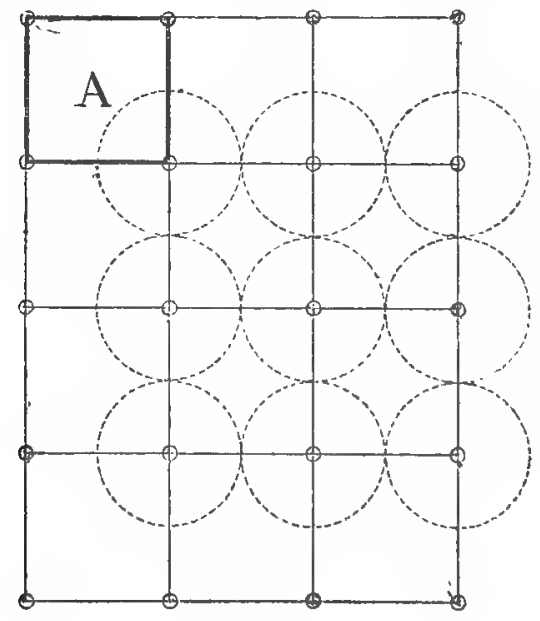

Marco real.

varieties the intervals may holecreased. In Vallencia and Oastellon b metres is the usual liatance. At intervals of 8 meters there will be 150 
trees per hectare $(1$ hectare $=2.4711$ acres $)$, and allowing only b ineters the number will be 276 . The mode of planting usually resorted to is in parallel limes (here called "marco real"), the distance between such lines being cqual to the interval between the trees, thus causing each four trees to occupy the four angles of a perfect square, A, as shown in the diagram. The objection to this mode is, that supposing the roots to exteul in circles, it leaves between each such four circles a large space unntilized save by roots of a length greater than the radius of the circle. In order to reduce this loss the "diamond" plan is resorted to (tres bolillo), which the second diagram illustrates. The equilateral

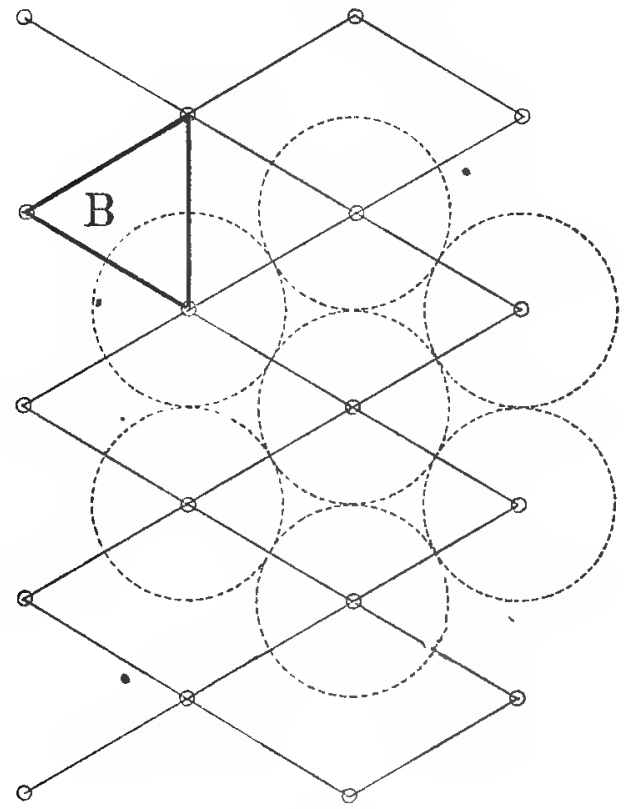

Tresbolillo.

triangle $B$ serves as a basis in this plan, and it is evident that the spaces between the circles are considerably reduced, as compared with the arrangement in squares.

Sites and soils.-The orange tree, which in the interior of Andalusia is hardly found beyond latitude $37^{\circ} 30^{\prime}$, thrives on the Mediterranean coast of Spain up to $42^{\circ}$. This is explained by the well-known moderating influence which the vicinity of large bodies of water has upon the climate. It is generally admitted that orange culture can not well be carried on where the mean winter temperature is much below $9 \circ$ to $10^{\circ}$ centigrade, or where a fall below -40 centigrade is experienced. The trees are injured by lengthened periods of cold weather, especially when accompanied by frost and snow. These facts would of themselves afford the grower some guidance in the selection of a proper situation. There 
are some rery fiue prolitic orchards in the rear of Tarifa, on the Straits of Gibraltar, us well as on the delta and the lower reaches of the Guadalquivir. On hillsides or uplands the trees thrive well, provided the altitude is not such as to act virtually in the sense of Iatitude. It is not common, I believe, to find productive orchards in this section at an altitude exceeding 250 meters above sea-level. It is also con. sidered desirable to have the trees sheltered from very strong winds from any quarter. In Andalusia winds from the north and east are the most prejudicial, the first as being coid and raw, and the east wind as having a desiccating, withering effect. Very steep hillsides are an undesirable location on account of the insufficient retention of moisture; very low grounds are open to the contrary objection, and though large yields are frequently made in such localities, the trees are liable to suffer in wet seasons, and expensive drainage is usually imperative. Of more importance far than the merely topographical features of the soil is its composition, which will be treated further on, as also its stratification. It should be borne in mind that the orange tree extends its roots primarily in a vertical direction, thus requiring a permeable subsoil. Whenever an impervious stratum is reached whilst this vertical development of the roots is still going ou, the trees suffer, and in many cases perish. Fine orchards, composed of trees of from thirty to forty years of age, have been known thus to waste away.

These few remarks are sufficient to show that categorical information as to the influence of topography upon yields is most difficult to give. Vicinity to the sea seems to be anything but iujurious, though $I$ do not recollect ever having seen orchards in immediate proximity to the sea without some natural or artificial shelter. Iu the valley of the Guadalquivir, both above and below Seville, very fine onuge crops are raised, the altitude probably not exceeding 80 meters above sea-level. The soil of one of the best orchards of that section, on being subjected to levigation, was found to be composed as follows:

Sand ......................................................... 43

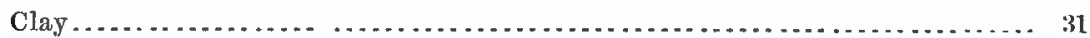

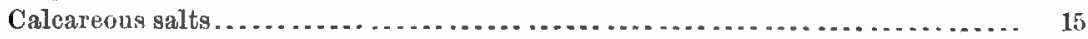

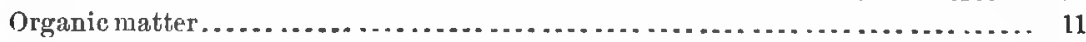

100

Soil of this character, or of somewhat similar type, when accompanied by permeability of the subsoil, may be looked upon as well adapted to orange culture. Soils having imperrions subsoil, or such as are watersoaked or difficult to drain, are especially to be avoided; in snch situations the upper layer of soil is frequently very rich, and on that account an orchard may appear to thrive luxuriantly at first, but as soon as the roots strike deoply, disaster will overtake the trees.

Irrigation and cultivation.-Orange groves in Western Andalusia require irrigation during the hot season at intervals virying from ten to 
fifteen days, according to the greater or lesser porosity of the soil. Tho first irrigation commonly takes place after the dropping of the blossoms, though many practical growers recommend not to begin before Jaly, alleging that irrigation before that period is generally hurtful. It seems, however, a fair presunption that the conditions of humidity prevailing during the previous spring are a factor to be considered in this respect. Irrigation is to be discontinued in October. The system nost in vogue is to have circular excavations surrounding each tree, said excavations being connected by small gutters or canals, into which the water is allowed to flow. This is the most economical method, and that is its strong point in a country like this, where the rain-fall is light. Some of the more careful orchardists are, however, opposed to this mode, arging that the practice snpplies an excess of water to the main roots (which leads to asphyxia), whilst the eccentrie rootlets are insufficiently, or rather, not supplied at all. Where there is no scarcity of water it, would certainly be rational to experiment upon the effects of irrigation upon the entire surface of the orehird, thas supplying the ontlying rootlets with the needful humidity.

March is the month when plowing is first applied to the orchards, at which time the irrigating ditches are restored or renewed. This is also the proper time for putting on manure, which should be placed around the trees, in zones of 1 to 2 meters in radius, this being done before plowing has begun. Where the trees are planted in squares (marco real) cross-plowing at right angles is in order; where the "diamond" (tres bolilla) plan is adopted, the first furrows may be crossed and recrossed with advantage. The second plowing takes place at the end of May. A plow making a furrow of from 20 to 30 centimeters in depth is generally used. In August the soil should be hoed thoroughly; this process to be repeated in September or October. The best growers affect the use of the harrow after each plowing, as it leaves the soil in a mellower condition, breaks up the clods, and destroys the weerls.

Before the orange trees have attained their full size (usually for five or six years after placing them in the orchard) it is not uncommon.to raise some leguminous or root crop on the land, taking care, however, to leave a circle of one meter in radius around each tree unoccupied.

Fertilizers. - The raising of successive orange crops year after year must necessarily end in withdrawing from the soil all available material for such cultnre, hence the attention of agronomists has been long devoted to devising means for ascertaining the exact uature of the constituents withdrawn, as well as the best mode of resupplying the soil with such constituents or their equivalents in an assimilable form. The following analyses taken from a recent treatise by a well-known Spanis agronomist, ${ }^{*}$ show what these coustituents are and their relative quantitative proportions:

"Don Luis Maria Utor, "La Agricultura moderna." 
Composition of the ashes of the fruit of the orange tree.

\begin{tabular}{|c|c|c|c|}
\hline & Constituents. & $\begin{array}{c}\text { Analysis } \\
\text { No. } 1 .\end{array}$ & $\begin{array}{l}\text { Apalysis } \\
\text { No.2. }\end{array}$ \\
\hline 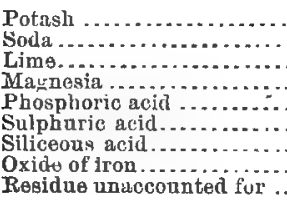 & 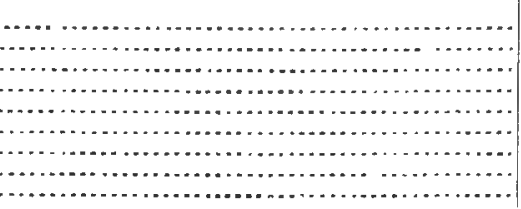 & \begin{tabular}{r|}
20.15 \\
10.22 \\
30.12 \\
9.02 \\
20.04 \\
1.08 \\
4.50 \\
4.25 \\
0.62
\end{tabular} & $\begin{array}{r}15.28 \\
12.14 \\
30.24 \\
8.10 \\
18.24 \\
4.14 \\
5.82 \\
4.75 \\
1.29\end{array}$ \\
\hline & & 100.00 & 100.00 \\
\hline
\end{tabular}

Weight of the ashes of 100 kilograms of fruit: Analyais No. 1, 3.57 kilograms; analysis No. 2, 3.48 kilograms.

Composition of the ashes of the trunk, branches, and leaves of the orange tree.

\begin{tabular}{|c|c|c|}
\hline Constituents. & $\begin{array}{l}\text { A nalysis No. } \\
\text { 3. Trunk and } \\
\text { branchos. }\end{array}$ & $\begin{array}{l}\text { Analysis No. } \\
\text { 4.-Leares. }\end{array}$ \\
\hline 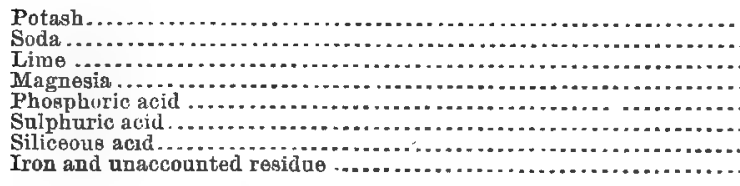 & $\begin{array}{r}14.15 \\
16.67 \\
31.57 \\
\text { J0. } 64 \\
18.82 \\
4.89 \\
2.82 \\
0.44\end{array}$ & $\begin{array}{r}\text { 10. } 18 \\
10.82 \\
41.22 \\
6.54 \\
19.47 \\
4.53 \\
5.48 \\
1.76\end{array}$ \\
\hline & 100.00 & 100.00 \\
\hline
\end{tabular}

Weight of ashes per 100 kilograms: Analysis No. 3, 6,32 kilograms; analysis No. 4, 6.20 kilograms. Nitrogen: A nalysis No.3, 1.57 per cent.; aualysis No. 4, 1.60 per cent.

Leaving out of account the material required for the yearly production of leaves and buds, as to which precise data are wanting, and taking analysis No. 1 as a basis, the cropping of 16,000 kilograms of fruit from one hectare will withdraw from the soil 571 kilograms of miueral constituents, in the following proportions:

Potash

Kilograms

Sorla 115. 06

Lime 58. 36

Magnesia 171. 99

Phosphoric acid

Sulphuric acid

114. 43

Siliceous acid

Oxide of iron (and residue)

25. 69

$27 .-0$

Total

571.00

Nitrogen,* 0.85 per cent. of 16,000 kilogrmms.

The absoluto and proportional percentage of the mineral constituents of stable manure is of course extremely variable. The following tigures

" Ganpariu, an eminent l'rench writer on orange culture, allows 1.19 kilograms of nitrogen per 1,000 orauges. Taking the average weight per thousand at 140 kilo* graus, as crop of 16,000 lkilograms of fruit will require 136 kilugrams of nitrogen, equal to about 0.85 per cent of the weight of crop. 
are given as the quantity of such constituents usually contained in 30,000 kilogranss of what may be called stable manure of the normil type:

Kilograms.

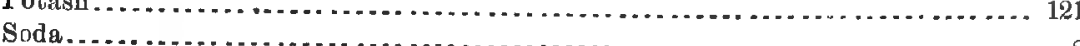

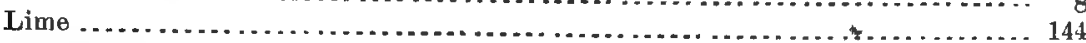

Magnesia ........................................................... 60

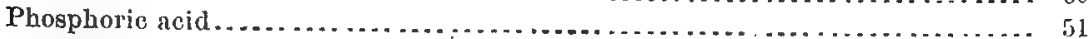

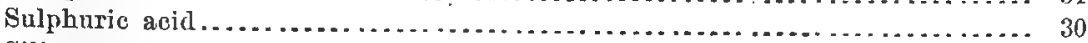

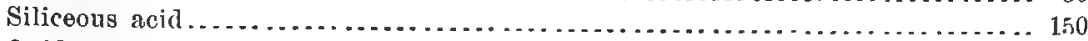

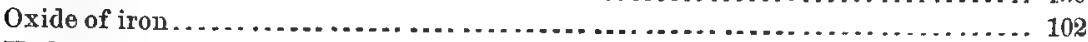

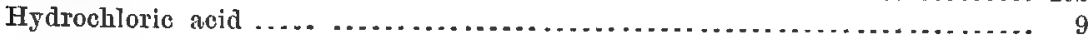

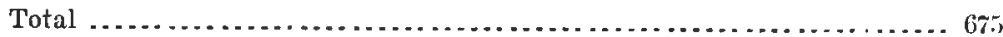

The general composition of these 30,000 kilograms of stable manure may be summed up thus:

Kilograms.

Mineral constituents............................................ 675

Nitrogen....................................................... 120

Carbon, hydrogen, and oxygen.................................. 5.205

Moisture..................................................... 24, 000

30,000

Suppose 30,000 kilograms of such manure to have been applied to one hectare of ground from which a crop of 16,000 kilograms of fruit has been raised, let us see what mineral constituents bave been replaced and what proportion is still wanting.

\begin{tabular}{|c|c|c|c|}
\hline Constituents. & $\begin{array}{c}\text { Contained in } \\
\text { crop. }\end{array}$ & $\begin{array}{l}\text { Supplied by } \\
\text { manure. }\end{array}$ & Deficiency. \\
\hline 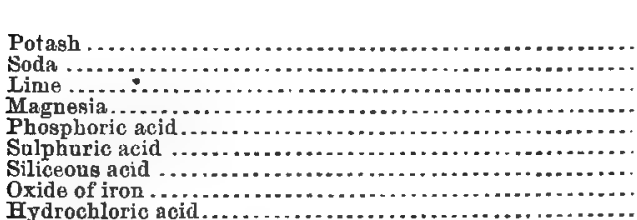 & $\begin{array}{r}\text { Tilograms. } \\
115.06 \\
\mathbf{5 8 . 3 6} \\
171.99 \\
\mathbf{5 1 . 5 0} \\
114.43 \\
\mathbf{6} .17 \\
\mathbf{2 5 . 6 0} \\
\mathbf{2 7 . 8 0} \\
\ldots . . . .\end{array}$ & $\begin{array}{r}\text { Bilograms. } \\
121 \\
8 \\
144 \\
60 \\
51 \\
30 \\
150 \\
102 \\
9\end{array}$ & $\begin{array}{l}\text { Kilograms. } \\
\text { Excess. } \\
\quad 50.36 \\
27.99 \\
\text { Excess. } \\
\quad 63.43 \\
\text { Excess. } \\
\text { Excees. } \\
\text { Fxcess. } \\
\text { Excess. }\end{array}$ \\
\hline
\end{tabular}

The deficiency of lime may be left out of consideration here, as there is generally a very large amount of this constituent stored up in the soil ; there remains, therefore, to be dealt with the deficiency of soda and of phosphoric acid. The first may be met by the addition of common seasalt to the extent of 300 kilograms. The 63 to 64 kilograms of phosphoric acid may be supplied by adding either 1,000 kilograms of fowl manure, 400 kilograms of guano, or 300 kilograms of ground bones.

The nitrogen withdrawn by a crop of 16,000 kilograms weighs 136 kilograms; supplied in 30,000 kilograms of manure, 120 kilogramsshowing a deficiency of 16 kilograms, for the supply of which may be added either ordinary stable manure, 4,000 kilograms; fenta desecada 
(dry cow-duug), 1,000 kilograms ; or pigeon-dung, guano, or bones, 300 kilograms.

From the above data it appears that the following mixture may advantageously be applied to each hectare thus cropped:

Kilograms.

Manure...................................................... 30,000

Ground bones ................................................ $\quad 600$

Seasalt .................................................... $\quad 300$

Field and cost. - The yield of the orange tree, admitting all other conditions to be equal, must necessarily vary according to age and species. In Castellon the product is stated at from 400 to 500 oranges per tree at ten years old, but full productivity is not reached before from six. teen to twenty years. In Valencia the product per hectare is given at 15,000 kilograms, eqniralent to about 107,000 oranges, allowing about 140 kilograms per 1,000. Very large single trees, of course, give occasionally extraordinary yields. There are in Mairena rlel Aleon (provinee of Seville) two colossal trees known as "Los Migueletes," of which each has been known to yield up to 38,000 oranges in one year. Largo and robust trees having attained their full grow th frequently yield from 2,000 to 5,000 each, but in planting on a large scale, from 800 to 1,000 per tree is all that can be assumed as a fair average yield. In the district of Seville the product of an orchard of full-grown trees is reckoned at 180 cases, worth on the ground about 10 pesos (\$1.93) per case. The cost of exploitation is summed up approximately as follows:

$\begin{aligned} \text { Pesos per } & \text { hectare. } \\ & \end{aligned}$

Rent of ground; also interest and amortization of working capital investerl.. 500

Irrigation (raising water, usually by animal-power) ................... .

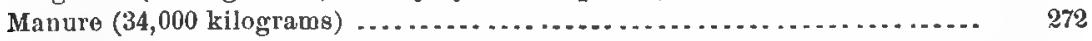

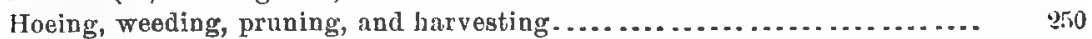

Plowing (with oxen usually) . . . . . . . . . . . . . . . . . . . . . . . . . . . . 90

Proportion of cost of keeping one horse or mule for hanling ............ 70

Sundries and unforeseen expenses..................................

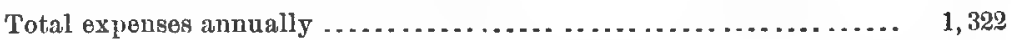

Taking gross product as above at................................... 1, 800

Leaving net profit ..................................... 478

From which, however, an impost of 20 per cent. must be deducted, leaving the grower, therefore, 382.40 pesos pere bectare (equal to $\$ 29.87$ per acre) as final net income. Calculating the total annual cost of cultivation at 1,500 pesos per hectare, this represents a return of something over 25 per cent. on the rolling capital thus employed. The total yield of the orange and lemon orchards in Spain was (in 1879) estimatel at $119,437,439$ kilograms, which, at the rate of 12 pesos per 100 kilograms, gives a total value of $14,332,49^{\circ}$ pesos, and the area cultivated was given as 8,362 hectares. The rate of 12 pesos per 100 kilograms is a low one, and is, moreover, only applicable to the fruit in the orchards, before packing and transportation expenses have been incurred. There seems 
good reason also to believe that the quantity of the crop was underestimated, as by deducting the quantity exported in that year the remainder for home consumption would be demoustrably below even a very moderate estimate.

Exports.-The following are the latest official figures showing the total exports of oranges and lemons from Spain :

ORANGES.

\begin{tabular}{|c|c|c|}
\hline Yoars. & Quantity. & Value. \\
\hline 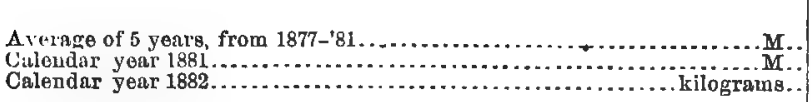 & $\begin{array}{r}673,199 \\
599,562 \\
116,667,600\end{array}$ & $\begin{array}{r}\text { Pesos. } \\
10,360,003 \\
8,993,430 \\
29,166,900\end{array}$ \\
\hline
\end{tabular}

LEMONS.

\begin{tabular}{|c|c|}
\hline 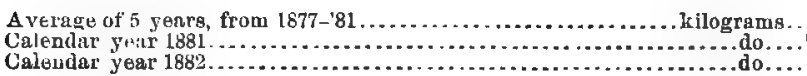 & $\begin{array}{l}4,971,089 \\
5,392,916 \\
5,415,503\end{array}$ \\
\hline
\end{tabular}

The destiuation of these exports for the year 1882 is given as follows:

\begin{tabular}{|c|c|c|}
\hline Countries. & Oranges. & Lemons. \\
\hline 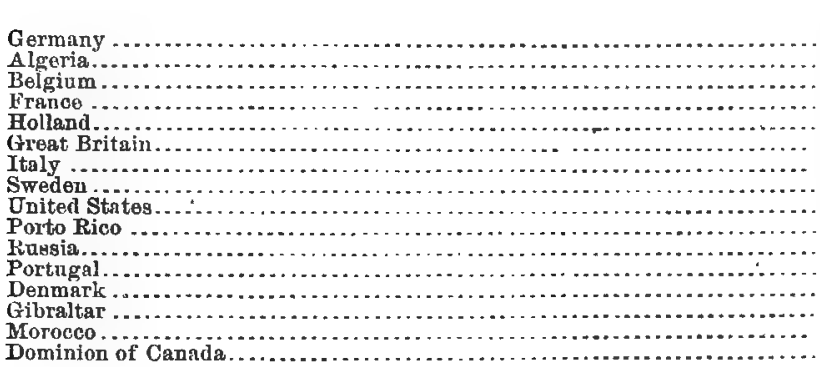 & 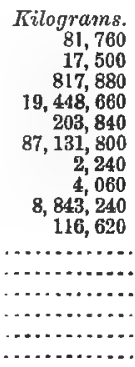 & \begin{tabular}{|r} 
Kilograms. \\
929,952 \\
8,550 \\
69,175 \\
$1,094,568$ \\
248,019 \\
$1,229,033$ \\
16,358 \\
29,644 \\
$1,695,302$ \\
$2,77,525$ \\
2,000 \\
53,125 \\
4,180 \\
7,392 \\
7,080
\end{tabular} \\
\hline Total & $116,667,600$ & $5,415,503$ \\
\hline
\end{tabular}

NoTk. - Up to 1881, inclusive, the orange expolta were eutered in thonsands.

ERNEST I. OPPENHEIM,

United Stateis Consulate, Consul. Cadiz, February 29, 1884.

\section{BARCELONA.}

REPORT BT OONSUL SOHEUOH.

\section{ORANGES.}

Tarieties.-Not all the varieties of orange trees are known to us, for being indigenous to the tropical regions of Asia, not all were brought over to Europe where about one hundred and seventy species have been 
lescribed by botanists; but serenty-seven kinds are particularly known and diviled into thirty-two of sour aul forty-five of sweet oranges. Of the latter only the ten species mentioned in my report of 1874 are cultivated for their commercial importance, in this province; of these the most valuable is the common, middle-sized orange, heavy in hand, of very fine peel, aromatic smell, aud containing a great amount of juice of great sweetness, spiced by an agreeable dash of sourness. Although there is also another very sweet orange called Imperial and Orange of the Queen, this early orange makes its appearance in the market at the end of October, when the same is exported to France and Algiers, and consumed in Spain. None of these oranges are exported to the United States nor to England, where they are not liked, for they are of too great a sweetness, without tartness, and found unpalatable, therefore of a limited cultivation.

The best results in this country are yielded by the open orchards in the districts of Alcira, Carcajente, and of Gandia, in the valley between the city of Valencia and the mountain chain which limits the province, facing the south and being sheltered from the north winds by said mountains; these orchards produce the finest and sweetest oranges, enjoying higher prices in the market than those of the district of Castellon, less shielded from the north winds, and producing oranges of a more inferior quality and prices; they also ripen later than the first.

Situation.-Some years ago a Frenchman founded in this port an important agricultural establishment called "La Malvarosa," situated about balf a mile from the very sea-shore where he cultivates with excellent results oranges on a large scale. Notwithstancling, on the road from this port (Grao) to Valencia, distant about 3 miles, and in the public gardens in and round this eity, they grow very poorly, yielding only a fer smail and sour fruits, while in the botanical garden on the west end of the city they grow with satisfactory results.

The soil of this locality is very sandy, and the subsoil may want certain elements and proper consistency in order to form a soil able to produce oranges in perfection. Before risking his capital the owner of the land should examine its topographic situation, aualyze the surface and subsoil to the depth of $1 \frac{1}{2}$ to 2 meters, and consider the possibility of irrigation.

The best soil of Alcira, Carcajente, and Gandia analyzed, wave: Sand (silicate), 70 per cent.; clay, 10 per cent., and salt of lime (carbonate), 20 per cent.

Cultiration.-Excepting some rare castes, such ground is not cultivated, and when so, then the distiuce between the rows of the trees, which generally is from 3 to 5 meters, intst be from 6 to 7 meters, and consequently at the expense of a certain number of trees planted less in a given space.

An intelligent orange-grower never cnltivates the ground between the trees, as such would make difficult the free access of airing the same, and tilling of the ground round each tree in a space of 3 meters in dame 
ter, the irrigation of trees from the top by pumps, and examines the roots in case of certain diseases. Moreorer, the plants cnltivated between the trees would act as parasites, exercisiug a pernicious influence apon the trees and fruits, which become less in quility, quantity, and size, and are more exposed to dise:ases. This is also the reason why the oranges grown in closel gardeus, where the ground between the trees is often cultivated, are less valuable than those grown in orchards with free ground.

Field.-The creation of an orchard should always be executed by the ow uer of the land and not by a farmer, because then all will be done in due order; he will select a good plantation and prepare the ground conreniently; he will not cultivate the ground between the trees; all the labor can take place in due time and the unfolding of the trees will progress more uniformly and better. At the end of ten years he will bave recouped himself; moreover the benefit and tho orangery will be in a better shape of production, duplicated or triplicated the value of the land and consequently also the rent and assured the progressive augwentation of prodiction alter the end of the first ten vears.

It is very difficult to give with exactuess a valuation of the yield and cost of an orchard, which may vary according to circumstances, but all circumstances being equal, the production must be by far greater in the rigorous and rirgin soil of Anerien than in that exhausted of Europe.

The following is the arerage yield and cost of the creation aud culti. vation of an orange orehard in a field of 8 hanegadas, distant 2 miles from a town, with high road and vatural irrigation by a canal.

One hanegada valenciaua, equal to 831.10 square meters, or the $\frac{4}{85}$ of 1 acre.

One arroba vileuciana, equal to 12.csi kilograms.

Ove real, equal to 5 cents Anericau money.

Cost during the first ten years.

FIRST YEAR.

Two hundred and eight young orange trees from the nursery at 26 per bane-

gada, at 5 reals............................................ 1,040

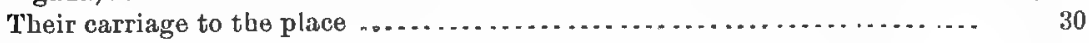

Four men to plant, at $s$ reals..................................... 39

Ten arrobas (128.880 kilograms) guano, at 18 reals per arroba............ 180

Collocation of same .......................................... 10

Made the plantation, digging and cost .......................................

Improvement of the conditions of the soil and hornigueros in May:

Journey work..................................... 120

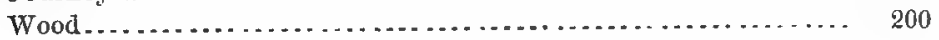

Six irrigations paying 1 real per hanegada ....................... 48

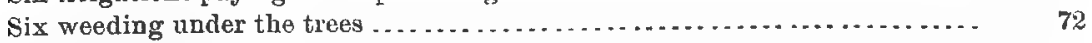

Contribution of the field.......................................... 182

Perceiving rent .............................................. 1, 080 


\section{SLCOND YEAR.}

Manuring with two baskets of manuro for each tree, being 42 loads, at 5 reals.

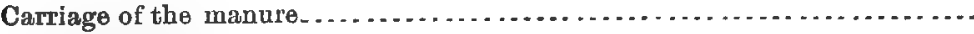

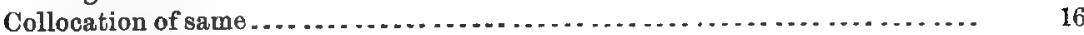

Four arations, at 15 reals each . . . . . . . . . . . . . . . . . . . . . . . . . . . . . . .

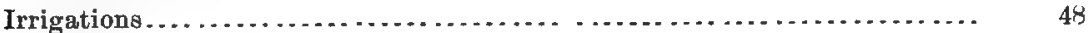

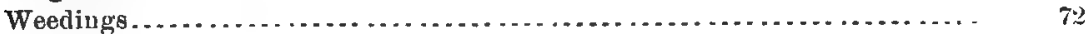

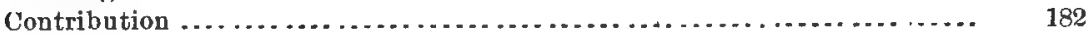

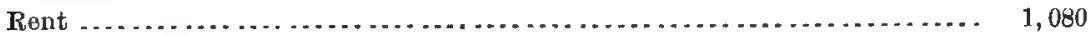

THIHD YEAR,

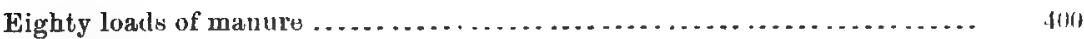

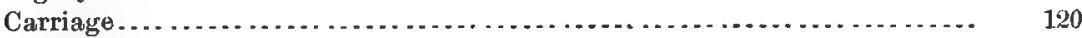

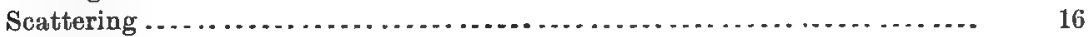

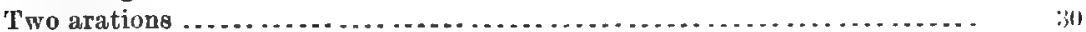

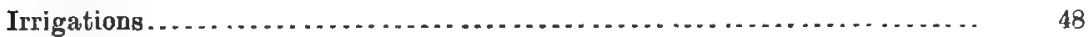

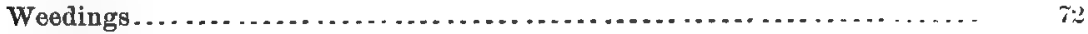

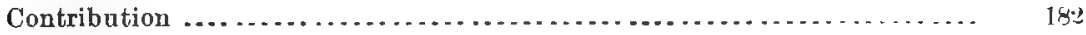

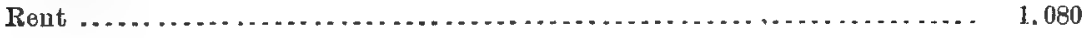

HOUR'IH YEAR.

I'wo arations and made borwigueron, al] cost. . . . . . . . . . . . . . . . . 350

To impulse the plant tion, addiug grutun firl . . . . . . . . . . . . . . . . . . . $1 \times 1$

('ollocation ...................................................... 10

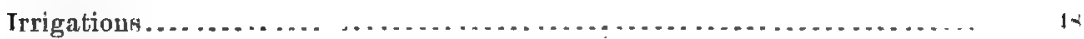

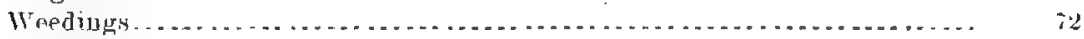

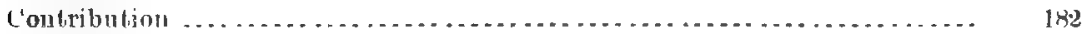

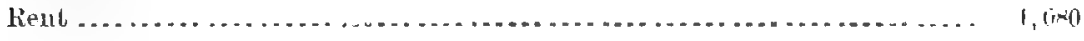

\section{FIFTII YEAR.}

Manuriug this year with 160 loads of mauure, at 5 reals . . . . . . . . . . . . 800

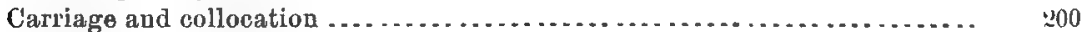

To conserve the maturity, for want of water, did order during the sumuer aration after each irrigation, and exponded . . . . . . . . . . . . . . . . 100

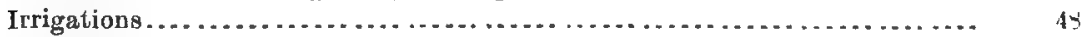

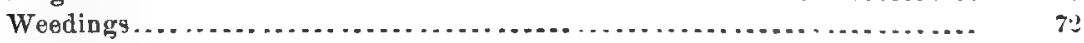

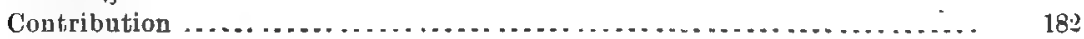

Ront ................................................... 1. 080

Calculatiug now at the rate of 200 reals per hanegadiu during the followiug five years, the oxihard boiug near tho town, would result............. 8,000

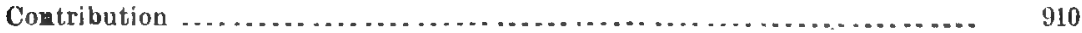

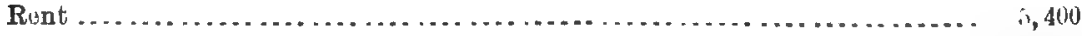


Yield during the first ten years.-First year, nothing; secoud year, took off the fruit; third year, collecting 8,000 , sold at 60 reals per 1,000 ; fourth year, collecting 31,000 , sold at 60 reals per 1,000 ; fifth year, collecting 42,000 , sold at 60 reals per 1,000 .

The practical farmer calculates that, considering the good state of the orchard, after the tirst ten years the oranges collected will result at the rate of 6,000 per hanegada. If so, 8 hanegadas at $6,000,48$ by $10=480$ thousands, which sold at 60 reals would give 28,800 reals.

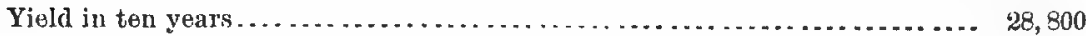

Cost of cultivation, etc . . . . . . . . . . . . . . . . . . . . . . . . . . . . . . . . 25, 904

Benefit ..................................... 2,896

Maturity.-The orange trees come into full bearing after ten years, and, according to their health and strength, augment aud remain bearing for unany years. In this province (Valencia) exists a sweet orange tree called the arriero, of forty-four sears, whose yield arrived to be of 8,000 and 10,000 orauges. There exists another of the age of fifty years having produced 11,000 oranges. They attain a vory high age. Some authors assure that some did arrive to the age of orer five hundred years. In the neighboring province of Murcia exist several trees of the age of two hundred years, each yielding nearly 8,000 oranges.

In Nice existed an orange tree of an unknown high age, whose trunk wanted two men to emblare; about 50 feet high; its branches covered a table of forty covers. One half of the tree yinded every yar from 5,000 to 6,000 orangen, whilst the other lialf reposed, giving only a few hundreds; in the m.xt. ratr this half yielded the 5,11100 or 6,000 oranges, and the other reposer, and thus succesisively.

\section{LWMONS.}

Letuon trees are cultivated in the same manmer as the orange trees, helonging to the same family of the Cit? the seed are generally the healthiest and yielding more and better fruits than the ingrafted. The export aud cultivation of lemons is very limited in this province ( $\nabla$ alencia). Some trials to export them to the United States were without success, becanse of their short durability and interior quality; those of Malaga are better, but che best in quality and durability are those of Italy; it is therefore from Italy whence those who intend to create a lemon orchard should procure a selected seed.

FREDK. B. SCHEUCH,

Consul.

United StTates Consulatie,

Barcelona, February 15, 1890. 


\section{MALAGA.}

REPORT BY CONSUL JLARSTON.

Varieties.-The names of best varieties for profit are "Chiua" oranges and the "Castillian" lemons. There is another kind of lemon called the "Reales," which is large and long, but the Castillians are more productive.

Location.-The trees that produce the varieties named above are grown in all parts of the province of Malaga where there is water, and generally by the side of amall rivers and streams.

The distance from the sea is about 2 lkilometers, and the elevation above sea-level 100 feet. Auy elevation with water and sun will answer. The more sun the better. Level land; sandy subsoil is the best.

Climatic.-Temperature $45^{\circ}$ to $90^{\circ}$ Fahrenheit; average, about $78^{\circ}$. Nights immaterial; for both oranges and lemons moist days, or ordinary atmosphere, are most beneficial.

No record of rain-fall is kept in Malaga. Rain-fall is always good for both trees and fruit.

Irrigation.-In summer only, three times a week, at any stage of growth and as much as possible; never water for ten or fifteen days before picking fruit.

Cultivation.-Twice a sear by plowing or digging around the roots.

Fertilizers.-Stable manure, placed around the trees to the depth of 18 inches or 2 feet, in the month of January.

Pruning.-After four years old begin to prune; height immaterial; if plowed with horses or oxen, then prune off lower branches; if ron dig around the roots by hand with spade it is immaterial.

Picking.-Picked when nearly ripe, for exportation; while thes are green and before they turn yellow; nothing done to cure them Lere.

Packing and shipping.-Packed in tissue-paper first and placed in cases one-eighth, one-fourth, and one-third, and sometimes one-half chests for shipment.

Planting and Propagating.-The distance the trees are planted apart is 12 yards; they are propagated from seed of bitter oranges, aud grafted. The best varieties are seedling:

The orchards are large and small.

Maturity.-Begin fruiting at four years of age; largest crop at about fifteen years; twenty-five years full maturity.

Insect pests. - Both lemon and orange trees, in certain locations, bave been attacked by some kind of insect, but growers here are ignorant as to its name or nature.

There are parasites, but their names are not known; they injure the fruit by eating the buds.

Packin! and chring.-Never pick either oranges or kemons while wet 
or immediately after rain; let them be perfectly dry. They are both hard and green when picked for exportation and taken to the place of packing, and there assorted as to sizes. The United States prefer the small, England and France the large, and North of Europe the medium sizes. The are then wrapped in tiue tissue-paper of different colors and placed in rows in the case or box by women and girls, who are remarkably adept at the work. The package is then taken by men, the lids nailed on and strapped with the ordinary wooden hoop-pole split in two pieces, branded, and then they are realy for shipment. The seasou for picking lemons is September and October, and for oranges November and December each year.

II. O. Marston,

\section{UnITED STA'TES Consulate, Malaga, December 6, 1889. \\ Consul.}

\section{TURKEY.}

REPORT BY OONSULGENERAL BEAP, OF OONSTANTINOPLE.

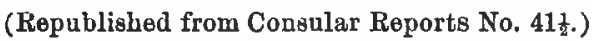

Varieties.-Although there are other kinds in the Levant, only three varieties of oranges and four of lemons are commonly grown, of which the oranges known as "Cundian," "Syrian," and "Mandarinian," and the lemons as "Candian," "Chio," "Paros," and "Messina," are considered the best. There is, however, a variety of lemon (the Citrus lumia) called the "sweet lemon," of which the juice is sweet. This is much used by calico printers in patterns with dyes containing iron, to produce greater clearness in the white parts.

Propagating.-The trees are grown both from seedlings and from grafts. Lemons are generally propagated first from the steds of the wild orange, as it has been found that the wild fruit tree bears the cold better. When three years old the plants from these seeds are taken up and replanted in other places, and the year following the lemon plants proper are grafted upon them. Five years afterwards they begin to bear fruit, and at ifteen years they reach maturity. When great care is bestowed, inarchiug is practiced, but growers generally prefer to propagate by grafting, while always rearing a portion of the trees from seedlings and from cuttings, especially the latter.

Insect pests.-Unless carefully tended, both orange and lemon trees are frequently injured by small canker-worms and moths, which eat the leaves, etc. Powdered charcoal ash is placed ou and around the trees, which destroys the eggs of the worms, etc. Sometimes a mixture of charcoal, soot, and strong vinegar is spriukled on the tree once or trice, as may be deemed necessary. 
Disease.-Unlike the orange, which presents a fine, close head of deep-green foliage, the lemon forms a straggling bush or small tree 10 or 12 feet high, with paler, more scattered leaves, and short, angular branches, with sharp spines in the axils.

In dawp valleys the lemon is liable to be attacked by a fungus (the Dematium monophylium), which corers the stem, leaves, and fruit with a black dust. Trees grown in the shade and not properly exposed to the sunlight suffer most severely from this cause. Syringing with milk of lime when the joung insects are hatched, and before they have fixed themselves on the plants, is found to be the most effectual remedy known for these pests.

Planting._In some places 7 to 8 paces, say 18 feet, is considered a sufficient distance between both kind of trees, but generally there is no strict rule for either.

Situation.-Orchards and orange gardens are to be found thriving in almost every situation suitable for the cultivation of the grape, but they give the best results when situated on hill-sides or gentle slopes, where, together with a good supply of moisture under ground, they are exposed to a gentie heat by day, and fresh, cool breezes by night. As before mentioned, they suffer and fade when deprived of light as well as warmth, and they never prove successful when the groand is damp for long in summer or is not properly drained. Both oranges and lemons thrive in a rich soil, and succeed well in good, strong clay with moder ate care and attention.

Althongh it is not the best situation for them, both lemons and oranges can be grown close to the sea-coast, especially lemons, which are more hardy than orauges.

They are strongest in the Archipelago, and on some of the islands they flourish almost anywhere as long as their roots do not come in coutact with salt water.

Irrigation.-When the trees are young they are generally well watereu by hand during the summer, but there is no system of artificial irrigation in general use, and the ground receives a similar treatment to that bestowed on the vineyards cultivated by the natives, as before men. tioned.

Yield.-Oranges, when gathered for export, should be quite ripe. Those fully formed and will the color just turning from green to yellow are chosen. They are wrapped in fine paper or in the husk of Illdian corn. A troe 20 feet in height and occupying a space of about 20 feet in diameter will frequently yield from 3,000 to 4,000 oranges in the course of the year. Many trees live from one bundred to one huudred and fifty years. As lemous are more profitable to grow than orauges on account of their keeping qualities and their bein $x$ less liable to injury during voyages, their cultivation is preforred in many parts of the Le. vant. The lemons are gathered green; the finest are picked out and packed in cases containing about 420 fruits; also in boxes, three of 
which are equal to two cases, each lemon being separately wrapped in paper.

Babitat.-The little island of Andros produces $10,000,000$ lemons annually; they are exported to Constantinople, the ports of the Black Sea, and those of the Dauube, realizing an average price of $\$ 4.80$ to $\$ 5.75$ per 1,000 . A similar quantity of excellent quality is exported from the larger island of Chio, where they are gathered in May, and a second crop in November and December.

Great numbers of "sweet lemons" are grown in the islands of the Archipelago and the districts around Smyrna.

The greater part of the oranges are grown in Candia and in Syria, especially in the neighborhood of Jaffa. In Paros, Mitylene, Tenedos, and Samos both oranges and lemons are largely cultivated for expurtation. The dried and candied rind of the bitter orange, known as "orange peel," is largely used in flavoring confectionery.

C. H. HEaP, Oonsul-General.

United States Oonsulate General, Constantinople, April 10, 1884. 



\section{PART 2.}

O L I V E S. 



\title{
CONTINENT OF AFRICA.
}

\author{
MOROCCO. \\ REPORT BY OONSUL MATHEWS, OF TANGIER.
}

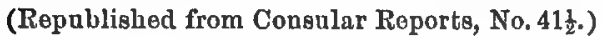

THE OLIVE.

Varieties.-Sereral varieti $s$ are grown, wild and domestic. It is impossible to proclaim in an absolute manuer which variety prodnces the best results, as in every conntry one is preferred which suits best the localit 5 and climate; and it happens that a variety which prospers in a certain climate in others fails to produce the sume results ; therefore it must be ascertained by trials of the best and hardiest varieties.

The varieties which will stand the severest cold weather are those nearest to the wild, such as the Odessa and the Beaked olice (Olea $E u$ ropea rostrata, Clem.); the olives of these trees are not large, but of a medium size.

There are nineteen defined varieties of olives; the principal ones are, the Royal Seville, of large fruit, which is gathered in a green state for pickling ; the Queen of Commerce, of very large fruits, with small, white spots, also gathered while green, for pickling; the Eicholiue, of long, oval shape. The Empeltre olive tree produces a small olive, ovalshaped, bearing abundantly on the sixth sear of its plautation, and in. creasing every successive sear; the fruits ripen very early and yield abuudant oil and of a superior quality; is a variety greatly cultivated in Aragon, Spain; a similar variety, but neglected, yrows near Meque. nez, in this country.

The province of Soos, south of Morocco, produces great abundance of oil. The plantations of olive trees in this province are very numerous; many of the trees are of great size and beanty, and are planted in a rery whimsical and peculiar manner in the neighborhood of Messa, the cause of which I learued from Governor Gilali Benhamos: that one of the emperors being on his journey tu Soudan encamped here with his army, that the pegs with which the cavalry picketed their horses were cut from the olive trees in the neighborhood, and that th'se pegs being left in the ground on account of the sudden departure of the army, the olire trees in question sprung up from them. I bave seen the Moors in the province of Angera, between Tangier and Ceuta, planting olive, pomegranate, and quince trees by cuttiug bits of wood of these trees, 
from 18 to 20 inches in length and 3 in circumference, which they knocked into the ground with a large stone while the ground was soft after a rain; two years after I saw these pegs, most of which had taken root and were in a fair way of becoming good trees.

The province of Soos produces abundant oil, which is brought to Mogador and shipped to England and France. The people of Ras-elWad make two sorts, Tabaluht and Zit-el-aud. The former is made from the olives when green and nearly ripe, with which they frequently grind limes or wild thyme. This oil is very rich and white, and not inferior to the best Florence or Lucea oil. , The Zit-el-aud is made from the olives when they are quite ripe and black, and after they had laid on the ground some time. In this state they jield the greatest quantity of oil, but it bas a strong taste, which is not disliked by the natives. It is used in Europe in the woolen and soap manufactories.

Cultivation.-In the countries where the olive tree is cultivated they generally plant it on the worst soils on the hillsides; they are raised from seed, stakes, slips, cuttings, from young shoots, layers, and by grafting or budding.

Vegetables, such as beans, peas, etc., can be cultivated between the rows of olive trees, provided the stubble, stalks, leaves, etc., while still green, are returned to the soil and worked in around the trees.

Propagation.-Propagation from seed, owing to the oily nature of the pulp attached to the olive seed, is tardy, unless these are placed in lyewater made of potash or ashes for three days, which will remove the greasy substance and allow the water when sown to penetrate into the small kernel inside. The soil should be light, well manured, and worked deep; the beds laid ont in an open, warm sitnation. The seeds should be sown a foot apart in drills. The best time for sowing is early in the autumn and watered. The plants will come up the following Jear, and the earth may be stirred between them while the weeds are being removed. The second season, when the plants are a year old, they should be budded with known varieties-with those producing the largest fruit, if intended for preserving and speculating with the olives, or with varieties rich in oleous properties, if chiefly desired for the extraction of oil. A year after budding they may be planted in rows 3 feet apart, and the plante 2 feet from one another, in case their final spot is not rearly to receive them, or else they may at once be transplanted in the place where they are to remain. In all this lifting and transplanting much care is necessary lest the roots should suffer any mutilation or injury. Thus followen the joung tree will commence to bear olives on the third year, and be in full bearing in its tenth jear.

The propagation by slips or stakes does not require budding nor grafting, and they make the best olive orchards; all the orchards and groves in Moroceo, and in Andalusia, Spain, where we see some of the finest trees in the world, are from slips or stakes. These should be chosen from the knottiest parts of the branches of the olive; they must be four 
or six rerdures old, at least, in rows where the soil has been worked and mixed with well-rotted animal manure, and so placed as to admit irrigation. The slips or stakes should be planted half a yard apart, and one yard at least from each row. In catting the slips or stakes the top part exposed to the air and sun should be at once covered with the varnish used by grafters to prevent cracking or decay by the rains. There should be no less than two-thirds of the length buried in the ground when they are 2 or 3 feet in length. There are several other modes of propagation from the protuberances of the roots cut in pieces, and planted in rows 18 inches apart, and watered until the shoots are 3 feet high, when they are again separated and transplanted; also by layers, and from suckers, etc. The time for these operations is from the middle of autumn to the first of March. In plowing the ground care should be taken not to go near the tree and injure the roots; the ground around the tree must be worked lightly with a dented hoe; the vegetable and animal manure must be buried in a ditch dug around each tree, but distant from it from 3 to 8 feet, according to its age and size, in order not to disturb the roots.

Queen olives.--There are two varieties of trees which produce the large olives of commerce :

(1) The Royal or Queen, Sevillian, known as Olea regia Boz., and Olea regalis Clem. The wood of this tree is less hard and lighter in color than that of the wild olive. The branches are tall and straight, the leaves long, and the fruit plum-shaped, its pulp adhering tenaciously to the stone, tardy in maturing, and is gathered green for pickling. When ripe the fruit is of dark violet color. It ripens with difficulty, producing a clear oil of sweet flavor.

(2) The Sardal Sevillian olive (Olea Hispalensis Clem.), (Olea Hispanica). The branches are less vertical than the former variety, the leaves are larger, the fruit is walnut-shaped and aromatic. It is very com. mon in Seville, Vera, and other parts of Andalusia. I have seen a few trees of these two varieties prospering in private gardens near Tangier, reared from slips brought from Seville, the fruit retaining its original quality. The queen olives of commerce are not the selected fruit of the common olive, but a particular species of itself, as above described.

Maturity.-In warm climates, and on its favorite soil, the olive tree comes into full bearing on the tenth year from its grafting, or from the plants of slips, cuttings, or stakes. In colder climates they come into full bearing some years later. The olive tree remains fruitful for centuries. There is an olive between Villefranche and Nice which was famous for its old age in the year 1515. It measures at its base 42 feet in circumference; its average yield of oil per year amounts to 150 kilograms. (A kilogram has 34 ounces.) In Spain and in the island of Mallorca there are olive trees which were old at the time of the Moorish occupation, and which at present continue to produce enormous crops of fine olives. 
Field.-The acre is not known in the olive countries; lands are measured by the hectare. A secular olive tree of great size, occupying 100 square yards of land, will yield on an average 40 gallons of olives, which is not at all exaggerated, as there are many which yield 100 and even 120 gallons of olives.

The adult field olives of moderate size pield from 20 to 40 gallons of olives. Short olive trees, occupying only 25 square yards of ground, yield on an average about 20 gallons of olives.

In the orange region a matnre olive tree, well cultivated, will produce 15 gallons of oil. If the trees stand at a distance of 30 feet from each other, or at about the rate of 75 trees to the acre, there will be a yield of 1,125 gallons of oil per acre.

In Spain they calculate on an average yield of 1.40 hectoliters (1 hectoliter measures 20 gallons) of olives per hectare of ground every two years, yielding 1,750 liters oil in this form:

1,000 liters of refined oil at a medium price of 1 peseta and 25 centimes...... 1,250

750 liters of inferior oil, at 75 centimes ............................. 526

Total ................................................... 1,775

(A peseta is equal to 20 cents; 5 pesetas to a dollar; 100 centimes to a peseta. Deducting 700 pesetas as cost of cultivation leaves a net product of 1,561 pesetas every two years.)

When the trees are at a distance of $\mathbf{1 0}$ meters from each other they yield, on an average, 6,000 kilograms of oil per hectare, of the value of 12,000 pesetas.

Planting.-The trees are planted from 30 to 40 feet apart.

Picking.-They are picked one month before the olives are quite ripe, when they are of a yellow-green color, for oil, and in the month of November, when the olive changes its color from violet to black, when intended for pickles.

Pickling.-The olives are kept in water until their bitter taste is en tirely removed. The water must be changed occasionally. Then they are ready for pickling either in salt and water or with sweet herbs, such as thyme, slices of lemon, etc. The Moors bruise first the olives, and alterwards pack them with salt.

Oil.-The process for extracting oil consists, first of all, in gathering the olives when they turn black, about the month of November, on a fair day, separating those found under the tree on the ground, and all discolored ones, with which the spcond quality of oil is made; they must be cleaued of all foreigu matters, such as leares, etc.; in gathering the olives must not be beaten, but picked by hand or with a book made on purpose. The olives are spread in a hall, the floor of which is of glazed tiles and having a slope in order to allow the water which oozes out of the olives to run out. The olives are turned orer several times, taking care not to allow them to ferment, as it wonld produce a rancid, inferior oil, and in this care lies the secret of success in obtain. ing a superior sweet oil. It is recommended when pressing the olives 
not to break the stone, as it contains a small almond which neutralizes the flavor of the first-class oil. In the second process in press. ing the stones should be crushed in order to obtain the oil still left adherent to the stone and on the kernal or almond, which will be a second. ary class of oil. Every utensil in the mill must be perfectly clean. It is essential that the entablature where the olives are pressed and gronnd, the baskets where the paste is placed for pressing, the receivers of the oil, etc., should not have been used in preparing rancid oils or of bad flavor. The virgin oil of first pressure must be extracted without the addition of the boiling water, which always alters its quality. With these cares a very superior first-class oil will be obtained from the first pressing.

On the second operation, the paste still contains a good deal of oil which the press by itself is not sufficient to extract, but with the assistance of boiling water, and a more efficacious pressure, an oil is obtained very good for kitchen purposes, and which unscrupulous merchants mix with cotton or other tasteless oils and sell in bottles as "huile surperfine d'olive." After the second pressure, the mass of skin, stone, etc., is boiled and repressed with more force and through a peculiar process, obtaining an oil that is very much in demand for the manufacture of castile and other soaps. Thus three qualities of oil is obtained: the fine virgin oil for table use; the ordinary oil obtained with the boiling water and employed in the kitchen; and last, the gross oil of inferior quality used for industrial purposes.

The American inventive genius will produce not only superior mills and presses more active and economical than those now used in Europe, but also pulping machines to separate the pulp of the olive from the stone, so soon as we have in the country forests of the truly surface gold mines, olive orchards.

Situation.-Best results are obtained on gentle slopes and hillsides; good results may be obtained in table-lands, provided the soil is not adobe or compact, and having good drainage. The orchards are in some places only a distance of 200 or 300 yards from the sea.

Soil.-The olive tree will thrive in all soils excepting low, damp grounds. It will prosper and yield abundantly on the top and side of mountains, amongst rocks-matters not the shallowness of the soilin gravelly and stony ground where neither wheat, barley, nor oats w ill grow.

On calcareous and volcanic grounds the olive produces the finest quality of oil ; all those precipitous side-hills and cañons, so numerous in some of the counties of California. all along the Coast Range eastward of San Diego, following up San Bernardino, Sauta Barbara, Los Angeles, San Luis Obispo, San Juan, Contra Costa; all the sides of Mount Diablo, up north to the mountains siding the Klamath River, 42 degrees north latitude. North of this the olive will grow aud flower, but will not mature the fruit, even if raised from seed. 
The great value and importance of the olive tree is that it will thrive and prosper in soils where nothing else of value would grow. Those dry soils of arid aspect in many parts of California are the genuine lands for raising the most productive forests of olives, worth, in due time and at not distant period, millions of money. In Africa, in Greece, and in some parts of Spain lands ouce abandoned for their sterility are now the source of wealth and revenue to communities and to the Government.

Irrigation.-None. The olive trees require no irrigation. They are only watered when transplanted until secured.

Rainfalls.-Thirty inches is the average. The rain-fall in the year 1881-'82 was 52 inches.

Pruning.-Of all the questions raised and argued with regard to the culture of the olive tree, none has been more debated than the praning; not only every country has its ways of pruning, but every district has its manners and notions. On the other hand there are parts where the olive is never pruned.

The olive tree must undergo a certain amount of pruning, not to the extent of the orange; the old and bare wood must be removed; the branches must be lept in such a trim so as not to exclude altogether the sun and air from the head; suckers must be avoided and those only left required to fill a clear place of the head; the foliage of the head must be kept equally balanced. The olive produces flowers on the branches and wood of the preceding year. It is rarely necessary. to cut large branches; some branches which have produced fruit for several years in succession and at last present an appearance of dryness about them, must be removed. By so doing, towards the end of winter it will soon produce new shoots, which on the following year will bring forth flowers. Olives must be thus pruned only every other two years. Following this practice from the beginning on young trees, the pruning will be but slight and easy to perform.

On pruning it is well to cover up at once the wounds on the tree with a mixture of earth and fresh cow's dung well mixed, which is just as good for the purpose and more economical than the varnish used by grafters.

The branches, leaves, etc., from pruning, which in some countries are given to the cows and goats, are the proper mannre for olive trees, and it should be buried while green around the trees, as well as all the oily waters and residue of the mills where the oil is made; these wastes are great fertilizers.

Besides the frosts and excessive cold, the olive has other enemies in the shape of insects, to combat which washes of rinegar or lime-water and whitewashing the trees are necessary. It is highly beneficial to keep the trees clear of moss aud parasite vegetation.

\section{FeLix A. Mathews,}




\title{
CONTINENT OF AMERICA.
}

\author{
MEXICO. \\ LOWER CALIFORNIA. \\ REPORT OF OONSUL YIOSOA, OF LA PAZ.
}

Varieties.-The Andalusia or Sevilla variety of culture of olives com. poses the best quality for pickling in the District of Mulege, a country and town bordering the gulf side of Lower California, and in latitude $26^{\circ}, 45^{\prime}$ north, which place supplies pickled olives in barrels to the state of Sonora, Sinaloa, and this portion of the territory.

From time immemorial a kind of an olive tree of the native genus has been in cultivation in the towns and valleys of Mulege, San Ignasio, Purising, and Comondu, bearing very small but oily olives in abundance. It is considered the best oil and the tree of more productiveness; nevertheless, for some reason or other, the oil made in this country is very insignificant in quantity.

Situation.-The towns in the valleys above described contain the principal olive-grove trees in the peninsula, the first bordering the sea gulf, and the others located on an average of 50 miles from sea. Hilly or level land is immaterial for its growth, but the exposure to the sun is necessary.

Climate.--Rain-fall is an assistance, although their dependence has to be entirely on irrigation. In watering the olive trees, the water is made to run and form a pool around within 3 feet from the tree and never to touch the stem.

Pruning.-Pruning takes place in October, and picking in the beginning of September, that is for pickling, and for oil in the latter part of October, when the fruit is ripe.

Maturity.-The trees commence fruiting after seven years old.

Planting.-Distance apart planted, 25 feet or more. Olive trees are generally propagated by cuttings over a year old.

Insect pests.-A very injarious worm sometimes causes great detriment to the tree, but it is destroyed by the use of a solution of ashes mixed with l:me. When the skin of the tree becomes very tight to the principal stem, a few slashes or perpendicular cuts of the skin with a sharp knife will enhance the tree's growth and make it prolific in fruit bearing. 
Soil.-The soil selected for olives is light, loamy, and limish, requiring water every second day when first set on the ground, and no manure until after tho tree is three years old.

I am sorry to say that there is no printed matter or statistical reports ou horticulture iu existence here, and the above is the best information obtainable on the treated subject.

JAS. VIOSCA, Consul.

United States Consulat'e,

La Paz, December 21, 1889.

\section{ECUADOR.}

There appears to be no reasou for doubting that in portions of Ecuador olives might be grown in perfection, for similar conditions of climate and soil exist to that of France along the shores of the Mediterranean Sea, where the best olives in the world are produced. So far as can be ascertained, growing olives in Ecuador has never been tried. Horatio N. BEACH,

GUAYAQUIL, 1884.

Consul.

\section{VENEZUELA.}

The cultivation of the olive is unknown here, owing doubtless to the fact that the climate is too hot and the season too dry.

Whatever of care or attention for fruits that the people are inclined to bestow is devoted to the orange and banana, though neither these nor any other orchard fruits are exported, and only enough are raised to satisfy the domestic demand; yet, in view of the favorable character of the soil and climate, it is doubtless true that, with a good foreign demand and speedy transportation, the growth of tropical fruits here might assume important proportions and prove amply remunerative.

WINFIELD S. BIRD,

United States Consulate,

Consul.

La Guayra, November 15, 1889.

\section{WEST INDIES.}

BERMUDA.

Mr. Heyl, fruit-grower, of Hamilton, to Consul Beckwith.

At one time olive plants were imported here by the country, but as no care was given them, they have since dwindled away, only a few trees here and there remaining, but the fruit is put to no use, A litte 
more energy and enterprise are needed in the island to advance various branches of agriculture and fruit culture, which at present, being carried on in a shiftless manner, bring no profit.

\section{TRINIDAD.}

Mr. J. H. Hart, government botanist, to Consul Sawyer.

Trees grow rapidly and exist for years, but have never been knowu to produce fruit.

\section{CUBA.}

-REPORT BY OONSULGENERAL WILLIAMS, OF HAVANA.

With respect to olives, I have to say that a few experiments have been made by the florists in the suburbs of Havana to cultivate this tree, but so far as I can learn, it has not borne fruit.

RAMON O. WILLIAMS, Consul-General.

Uniten States Consulate-General,

$$
\text { Havana, November 24, } 1889 .
$$

\section{GUADALOUPE.}

Director of Botanical Garden at Basse-terre, to Consul Bartlett.

Olive trees are very searce, perhaps not a dozen of them in the island. Olives are not grown for exportation.

St. Felix Olardeau. 


\title{
CONTINENT OF ASIA.
}

\author{
ASIA MINOR.* \\ RUPORT BY OONSUL EMMETT, OF SMYRNA.
}

Varieties.-The best variety for pickling is the round olive; the best variety for olive oil is the "coloves" (stemless). The other choice varieties for pickles (eating) and oil, worthy of culture and for profit, are the "Adramitti" olives.

Situation.-The trees that produce the varieties above given are grown in valley, hillside, table land, and plain, and near the sea and many days from it; elevation above sea-level is 3 to 6,500 feet; exposure to sun is immaterial, as the climate here is mild and agreeable.

The trees are grown in every soil, and good results are obtained on valley, hill-side, or table-land, except where the soil is marshy. The character of the soil and subsoil is calcareous.

Climatic influence.-The olive tree does not thrive in the open air except in latitude $43^{\circ}$, and where the temperature is not lower than $15^{\circ}$ to $20^{\circ}$ Fahrenheit.

Temperature.-Minimum, 32०; maximum, 95०; average, $68^{\circ}$ Fahren heit.

Rain-fall.-The annual rain-fall at Mitylene is about $\$ 5$ inches. Rain is always very good, but after September. If it rains during the flow. ering of olive trees-April and May-and when the fruit is very smallJune, July, and August-the crop is not likely to be good, as it falls off prematurely.

Irrigation.- When a plantation of olive trees is made it should be immediately irwigated and the irrigation is to be repeated every two weeks for three years, during the months of April, May, June, July, and August, according as the weather may be more or less dry; but after three years no irrigation of any kind is needed here.

Cultivation.-Olive groves are ploughed in the spring to the depth of 1 inch in the clear spots, and 2 to 3 inches deep in the vicinity of the trees; but after the ploughing is over they always dig the soil round the trees with a spade.

Pruning.-At. Mitylene we prune the olive trees every year after the crop with great attention, removing the dried and high branches, because it is not necessary that the olive tree should be higher than 20 feet.

"From informitiou supplied by tho United States consular agent at Mitylene, au extensive olive cultivator. 
Picking.-Abont the end of November the harvest begins.

Pioliling.-The best time for pickling green olives is the end of September, always after the first rain; and the best time for pickling ripe black olives is the end of November, during the barvest.

Oil manufacture.-Next step, after picking, the olives are sent to the mills for grinding as soon as possible.

The Mitylenists put the green olives in fresh water for five or six days and change it every day; after that they cork the olives in jars with pickle. They prepare black olives for table use in the common manner, in pickle.

The process for extractiug oil is as follows: After the olives become pulverized by grinding under millstones they are put in goat's-hair bags and pressed in either iron or wooden presses, and the oil is put into large earthen jars, barrels, or skins, for sale.

Maturity.-The trees commence fruiting the fifth year after plating.

Yield.-The average yield per acre per annum of mature trees is $\$ 25$ to $\$ 30$.

Planting and propagating.-The trees are planted at a distance of 25 feet from each other, and are propagated by the planting of branches or striking from branches; by the planting of pieces of root; by the cultivation of wild olive trees and transplanting to the field, and from seed.

Insect pests.-Insect pests do not exist.

W. O. EMaMetT, Consul.

\section{United States Consulate,} Smyrna, January 15, 1890.

\section{ASIA MINOR.}

REPORT BY OONSUL STEVENS, OF SMYRNA.

[Republished from Consular Reports No. 41ł.]

Situation.-The olive is not as extensively cultivated here as in the islands of the Archipelago and Mediterranean-the Sporades, Cyclades, and Ionian Islands. The reason for this is easily understood. The olive tree will not thrive inland; it must be planted near the sea-coast. Plantatious are prepared in this manner: Vigorous young trees, which grow wild upon the sides of the neighboring mountains, are taken up and transplanted in the plain or bill-side. After remaining two sears in the field they are grafted. Seven or eight years after the grafting process they begin to bear, reaching the maximum of productiveness from the eighteenth to the twenty-fifth year. They yield every other year. When $156 \mathrm{~A}-14$ 
transplanted the young trees must be watered once a fortnight during summer until they reach their fourth year. If well protected they will continue fruitful for two hundred years or longer. Trees planted on stony hill-sides yield more abundautly and of a better quality than trees planted on plain land. They should be planted about 36 feet apart.

Cultivation-The manner of caltivating olive trees is to plow or dig over the ground every year about a foot in depth, adding manure every third year at the foot of each tree and covering it up with earth. The mature tree will yield about 580 pounds of olives yearly.

Varieties. -The varieties which give the best results are known as "Thrillies" and "Adramitis," after the localities where they are grown. The "queen olives of commerce" are produced from an improved tree grown at Adramitis.

There are two species of olives, and these are, when ripe, green aud black, respectively. Those intended for pickling for table use are gath. ered green-ripe; they are put in salted water and allowed to remain until ready for use. These are of the black variety. Green olives also yield good oil for table use, but in much smaller quantity.

The most productive olive orchards in this proviuce are at a distance of 1 to 3 miles from the sea-coast.

Picking and expressing oil.-A description of the manuer of gathering this fruit and expressing and preparing the oil may prove interesting.

During the season of the erop the fruit is collected and salted, then stored away from one to three months. At Mytilene and Aïvali the olives are kept even during tive or six months before the oil is abstracted. It is claimed that the larger the quantity of salt used in this process the finer the quality of oil obtained. The fruit, packed in baskets containing 50 pounds each, is put into boilers and boiled for half an honr; then it is withdrawn and spread on a circular surface, where it is ground under a large millstone driven by horse-power. The horse is alway's followed by a workman whose care is to throw the olives under the stone with a shovel. The olives, first coarsely grouud and then carefully pounded, are placed in bags made with goats' hair, which are put, from 20 to 24 at a time, under a powerful press, operated by two workmen, and then squeezed until no oil flows ont; 63 poun s of good olives give 21 pounds of oil. The oil gathers in a trough placed under the press, and is then withdrawn and poured into casks. The olives intended to be used at table are put into stone jugs or barrels, after hav. ing been carefully washed, and are covered over with strong brine. In this condition they will keep good for a whole year.

W. L. S'TEVENs,

Consul.

Uníled Strates Consulate, Smyrna, February 28, 1884. 


\section{PALESTINE.}

REPORT BT CONSUL GILLMAN, OF JERUSALEM.

Varieties.-The finest olives of this country grow on Mount Lebanon and in the hill country of Judxa. Those near the sea coast are inferior. Five kinds or varieties of olives are generally distinguished here: the white; the large black, known as Bakkar (fat), gool for pickling, as is the preceding, but not good for oil ; the small black, Zmehri, which is grood for oil; the large green, called Sourri (navel), from its resemblance to that part of the human body, and which is used for pickling, and the small green, named also Sourri, and which is of like use to the large variety. There is also the wild or ungrafted olive called Barri (wild), the fruit of which is not used either for oil or pickles. The best variety for pickled olves is the large black (Bakkar). That best for olive-oil is the small black (Zmeliri). All the varieties mentioned grow throughout Palestine, and are found from the sea-coast, and the plains, only a few feet ahove the level of the sea, to the elevation of 3,000 feet or more. The trees have usually a full exposure to the sun, and hilly or even mountainuus country seems best adapted to them. The poorest olives, for instance, are found at Jaffa, where their cultivation is being gradually superseded by that of the orange, lemon, and grape. The soil which prevails over the greater part of this country is a stiff red clay, with a small proportion of sand occasionally, and in this the olive flourishes. The subsoil is also clay, with rock frequently underlying.

Climate.-As to the temperature and rain-fall the remarks made in connection with the orange, lemon, and fig apply equally here. It is, however, said that in dry seasons the olive produces more abundantly and better fruit. The trees bear a full crop only every second year. This is attributed to the fact that in securing the fruit the trees are beaten and ronghly handled, breaking off the small fruit-bearing shoots, and so preventing an abundant production in the succeeding year, which is known as the "off year," when but a small crop is secured. The fellaheen (peasants) also say that in those years the grape produces abundautly, the olive-tree yields but a poor crop, and vice versa.

Irrigation.-Irrigation is never used in connection with the culture of the tree except when young and first planted.

Cultivation.-A plowing once a year, in the autumn, is considered sufficient culture; but as frequently other crops are planted between the trees they thus receive more care and attention than they would otherwise get. In exposed places, where the rains have washed away the soil from the roots of the trees, small fences of stone are built to protect them. These, surrounding the trunks, are filled with earth, and are of good service in shielding them from the summer sun. Also, where a tree is partially hollow with decay, it is the habit to build up the aperture with stones, the object being to arrest the rot. 
Pruning.-Pruning is only practiced to the extent of removing the dead or dying timber.

Picking.-Olives designed for pickling are gathered a short time before ripening, lest they should be too soft for the purpose.

Pickling.-On being placed in baskets (the flexible basket in general use being employed) the olives are salted and then receive a gentle pressure. Afrer three or four days they are removed from the baskets, and, without any other preparation or process, are simply placed iu jars or barrels. This is all that is required, and for common use no other care is given the olive, which will keep in this way for two or three years, or perhaps even longer where greater care is observed. In towns the fruit is often pickled in vinegar; bnt in the country this is unknown to be followed.

Oil making.-Where the olives are required for making oil they are allowed to remain on the trees till quite ripe, when they are picked or beaten with long poles from the branches. Allowed to lie in heaps for a period extending from twenty to twenty.five days, at the end of which time they are usually quite soft, they next are crushed in the rude stone mills common in the country-the oil-mills of Palestine, which probably date back to biblical times. They are, however, first placed in the large flexible baskets already described. Heavy pressure being applied, the oil strains through the baskets into the trough placed to receive it. The oil obtained from this first pressure is the best, or of first quality, and will bring in the market as high as $\$ 4$ per gallon. Two subsequent pressures complete the extraction of the oil. It is all one of the most simple of processes. The oil of the second pressing is cousidered good, and may be sold for $\$ 3$ per gallon, but that of the third and last pressing is invariably poor or bad, and is only used for burning in lamps or making soap. The oil of the first and second grades is often mixed, and the result disposed of to the dealer. In fact this is a common practice, of course deteriorating the oil of the first quality, which it is often sold for. The expressed oil, without further manipulation or other process, is emptied from the trough into skins, and so conveyed to the oil merchant, that intended for export finally being transported to Jaffa. Here it is stored in great cemented cisterns, which are specially prepared for the purpose, from which it is emptied into barrels or casks when required for shipment. The greater portion of the oil is exported to France, where, having undergone the mysterious mixings aud adulterations known only to the dealer, it is placed upon the market, and reaches the public at large labeled pure French olive-oil. The oil produced from olives grown on the inountaius is far superior in flaror and quality to that made from fruit grown on the low-lying plains. The oilcake or refuse remaining after the extraction of the oil is not thrown away, but carefully preserved, it bringing a high price for fuel, being specially adapted for certain uses. For example, the baker's of Jerusalem prefer it, and consume large quantities of it in heating their ovens. 
Maturity.-Trees commence fruiting from the tenth to the fourteenth year. This includes the time from the first starting of the young wild olive trees. Where a very young wild tree is grafted, fruit may be produced in six years; but this is exceptional.

Yield.-It is difficult to arrive at the average yield per tree or acre. A very small tree may produce about two measures of olives, or nearly 48 pounds, while a large tree in full bearing yields a crop of as many as twelve measures. An average yield for a medium-sized tree, under fair conditions, ought to reach from five to eight measures, or from about 120 to 190 pounds. It is computed that it takes a measure of olives, or nearly 24 pounds of the fruit to produce three quarts of oil. The yield per acre, depending on so many variable conditions, such as the age of the trees, their distance planted apart, the nature of the soil, the culture bestowed, etc., can not be given with any certainty, especially as no statistics are kept herg.

Planting.-The usual distauce apart at which trees are planted is 30 feet; but this varies. Often very old trees are seen within 4 or 5 feet of each other, and even closer, in groups of from three to five individuals. These would seem to be the descendants of one original tree, the trunk of which, having reached extraordinary dimensions, has decayed at the center, leaving those outstanding parts of the circumference separated, and finally forming several trees out of one. In fact, unless utterly rooted out an olive tree appears to be indestructible and may live to an indefinite age, and when cared for will continue bearing to the last. Tradition says that some of the older trees of Palestine date back to the time of the Romans. The very old trees in the Garden of Gethsemane are supposed to be of the time of Christ. They are unquestionably of extreme age, and the oldest olive trees I have ever seen, yet those venerable trees bear aunually a crop of fruit.

Propagating.-The olive tree is propagated by being grafted on young trees of the wild olive, which are grown for the purpose. The young wild trees, being planted at a distance apart of about 30 feet and at sufficient depth to prevent the disturbance of their roots by the plow, for other crops are always grown between the trees, are generally watered to insure their taking and more rapid growth. But irrigation is not absolutely necessary even at this stage, and where there is difficulty in procuring water, or expense attending it, it is omitted. Irrigation, however, unquestionably produces a more luxuriant and satisfactory growth. At the age of from eight to ten years the young trees are grafted with whatever varieties it is desired to propagate, and they com. mence bearing in from three to four years.

Where trees are totally neglected they frequently cease bearing, but it is astonishing how quickly they recover from the most shameful usage, immeaiately responding with a crop to kindly treatment.

There are no printed reports, information, or statistics issued by the Government or otherwise. 
Insect pests.-Insects injurious to the olive are unknown in Palestine nor have any special observations been made of insects beneficial to the tree; in fact we are remarkably free from all trouble on the score of insect pests, consequently little or no attention has been called to the subject.

HenRT Gillman,

\section{United States Consulate, Jerusalem, February 10, 1890.}

Consul.

\section{SYRIA.}

\section{ALEPPO.}

REPORT BY OONSULAR AGENT ROOHE.

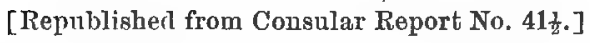

In reply to the circular which you did me the honor to address me under date of February 12, I make it my duty to bring to your notice that oranges and lemons are not cultivated in Aleppo owing to the severely cold weather here in winter, which is so injurions to these trees.

\section{OLIVES.}

Varieties.-Four varieties are cultivated in this district:

(1) Khul.khali, which is only used for pickles or preserved in vinegar. This variety, which is the best for eating, is included in the category of ordinary olives. It is sweetened by being immersed in spring water, in which 11 to 12 American pounds of natural soda have been saturated, with 3 pounds of lime for about 150 pounds of olives. This immersion is made when the water, mixed with these matters, has become cold. The olive berries, after being deposited in that water, should be removed without disturbance, and they lose their bitterness in from sixteen to twenty-four hours. This result being obtained, the olives are immediately placed into another tub of well or spring water, which must be occasionally renewed till the taste of the lime is removed. After this operation the olives are placed in pure, fresh water, sufficient to corer them, and the tub is then covered with a lid. They are then left twentyfour hours, after which they are pickled, and thus the operation is completed. Ulives can also be sweetened by being bruised and placed in pure water, which is repeatedly changed till the fruit loses all its bitterness. When thus prepared, the olives are generally eaten in salad or in stew.

(2) Shami.-This variety is only gatherel when the fruit has become of a dark color and thoroughly ripe. When pressed till quite dry the olives are salted and preserved to be eaten with salad.

(3) Zeiti.

(4) Huzromi Nizibli. 
'l'hese two varieties; although smaller than the two others, are used for oil, which is obtaived by means of a lever or screw press, and they are gathered when the fruit has become reddish and ripe. The sweet oil is obtained by a cold extraction. The olives after being crushed in a mill are placed in bags and put under press. The lamp-oil and that used for the manufacturing of soap is obtained by the hot system; that is to say, after the first pressure the bags containing the olives are submerged in boiling water and pressed out again. The best oil is obtained trom olives before they are fully ripe. A shumbul, equal to about 147 to 150 pounds, gives 12 to 14 pounds of oil in the vicinity of Aleppo, while here this quautity is reduced to one-half.

Cultivation.-The olive tree is reproduced by burying a piece of root, having many slips, in a rut one yard deep. When these slips shoot forth one of them is cared for without irrigation, while the others are destroyed. At the end of ten years this tree begins to give fruit in small quautities, but when it reaches its fourteenth year it gives every other year from 35 to 38 American pounds. The soil best suited for the growing of these trees is the reddish or light yellow one; the latter is, how. ever, preferable. The plantation is made without irrigation or manure ; a space of about 20 feet is left between each tree; the soll is plowed two or three times a year. The ground around the tree should also be dug and turned over, and the root, as well as a part of the trunk, covered with earth in the form of a mound. The tree, however, should be regularly pruned of the dry twigs every year.

F. Poche, Consular Agent.

United States Consular Agency, Aleppo, April 16, 1884.

\section{BEIRUT, *}

REPORT BY OONSUL BISSINGER.

Varieties.-The varieties of olives in this country are the Balady, the Somukmoky and the Soory; but the best of these for pickling and oil is the Balady. The trees grow in the littoral and middling high lands.

Climate.-A cold climate does not suit olive trees.

Irrigation.-Olive trees planted in soil suitable for irrigation are watered twice, when necessary.

Cultivation.-The land should be plowed four times in the sear. Once in the beginning of winter in order that the rains may be absorbed by the soil, and three times in the spring.

* The several reports, herewith from Syrla, with the exception of the report from Damascus, were forwarded by Consnl Bissinger, lueing prepared for him by parties in the distrists represented. 
Pruning.-Dry branches are cut away only.

Picking and curing.-Olives begin to fall from the trees in October, and those that do not fall are gathered up to the 1st of January. Olives for pickling should be picked when green.

Maturity.-Olive trees commence fruiting, in some localities, ten years after having been planted, in others later.

Yield. - Each olive tree yields from 28 pounds to 112 pounds, in proportion to its growth and size.

Planting and propagating.-The distance planted apart is about 18 feet. Olive trees are propagated by planting small trees in March and April, which must be grafted as soon as they can sustain the operation.

ERHARD BISSINGER,

Consul.

\section{United States Consulate,} Beirut, February 12, 1890.

\section{- beIRUT.}

\section{REPORT BX OONSUL ROBESON.}

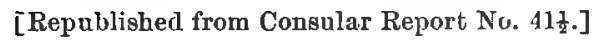

There are two varieties of olives cultivated in this district called, 1st, the smuc-mucky; 2d, the soury (Tyrian). The fruits of the first variety are poor and small, while the soury are of a larger size, thicker flesh, and richer sap. The best results are obtained during the twentieth or thirtieth year after the wild olive tree has been grafted. There are two methods adopted in the cultivation of olives in this district. The first is to transplant the wild olive shoots from their native soil into the olive groves and to graft them on the fourth year with grafts taken from a cultivated tree. Although this method of cultivation does not procure early crops, yet it is preferable to the secoud method in use, which is to graft the wild tree as soon as it is transplanter, because the former proves more productive.

The land where olive trees are planted must be plowed four or five times a year. Generally in this district where the soil is sandy a stone bench about 15 inches high is erected around the trunk of each olive tree aud filled with clay to keep the soil near the tree somewhat cool and damp. The queen olives of commerce are nnknown in this country. However, the olives exported from this port to Egypt and other places are selected from the Soury variety. Olire trees come into full bearing five or six year's after they are graftel, and remain fruitful for a great number of years. 'The average yiold per acre of mature trees is about 200 Turkish bushels $(8,250$ pounds). Five gallons of olives produce one gallon of oil. Olive trees are commonly planted 30 feet apart. Olives intended for pickling are gathered about the end of November, then lightly bruised, and after being spread on mats to dry in 
the air for a fow days, they are placed in earthen or glass vases with a sufficient quantity of salt in them to pickle.

Olives for oil are picked as they ripen until the end of December. The best results are obtained on table-land protected from high winds. The soil best adapted to the cultivation of olive trees is a reddish porous land or dark-brown rich soil. There is not any system of artificial irrigation in use for olive culture. Olive trees are never watered. In regard to the yield and proceeds they are as stated above. The cost of cultivation per acre per annum may be set down at $\$ 10.50$, not including the Government taxes. The nearest olive orchards to the coast are situated at about 1 mile from the sea-side, and extend from that distance to places 2,000 feet above the level of the sea. However, those planted in the high mountains, where cold is intense and snow falls annually do not succeed as elsewhere.

The arerage anunal rain-fall in this district is 38 inches, but the necessary rain for the growing of olives is 30 inches, which is quite enough. Olive trees in this country bear good crops only every other year.

JOHN T. ROBESON, Consul.

\section{United States Consula'le,} Beirut, May 3, 1884.

\section{DAMASCUS.}

REPORT BT CONSULAR AGENT DIESHAKA.

Varieties.-The names of the best varieties for picliled olives are the "Masaabee" and the "Julut" olives, and the name of the best variet $y$ for olive oil is the "Dan" olives. The other choice varieties for pickles (eating), and oil, worthy of culture and for profit, are the "Sas. saff" and "Maulee" olives.

The trees that produce the varieties here given are grown in the neighboring villages of Damasens.

Situation.-They are located at a distance of 70 to 80 miles from the sea, and about 2,300 feet above sea-levei.

Olive trees are well exposed to the sun, and grow upon hilly, rolling, and lerel land, bat the latter soil is the best.

Climatic influence.-Olive trees are not affected by the heat or cold.

It is impracticable to tell about the temperature in villages, agriculturists not having a thermometer. Damascus temperature in winter in Fahrenheit is not lower than $22^{\circ}$ and in summer is not beyond $95^{\circ}$ in the shade.

Rain-fall.-There is no rain-gauge.

The rain-fall, in December and Jauuary, agrees with the growth of trees and fruits. The quantity of rain can notbe stated for the reason above mentioned. 
Irrifation.-Ulive trees when planted are irrigated once a fortnight for the first year, excepting February. In subsequent years they are irrigated twice per annum, once during the first forty days of the winter season, and the second time during the same period of the summer season.

Cultivation.-Lands of olive trees are cultivated twice a year, once in December and another time in March.

Pruning.-Olive trees are only pruned after the third year of their plantiug by taking away what may be growing around their truuk.

Picking.-Olive fruits are picked green in October and ripe in December and January. The fruits are picked green for pickling and ripe for pickling and making oil.

Curing.-The next step, after picking the green olives, is to prepare them for pickling, and the ripe olives to extract their oil and to prepare tbem for pickling also. The process of pickling the ripe olives is to press them in a basket several days until the bitterness disappears, then they are washed with water, dried a little, salted, and put in oil for use.

The green olive (the Masaabee) is commonly used and prepared in the following manner: One-half pound of alkali and one-quarter pound of lime, both dissolved in water and put with 53 pounds of green olives in a vessel for a period of about a week, with a little shaking erery day until the bitterness disappears, when they are washed and put in salt water for use; or green olives are put in salt water several months until the bitterness disappears, then bruised gently and placed in oil for ise.

The process of extracting oil is as follows: Ripe olives are placed in a. warm place for about four days, then crushed by a heavy roller and put in baskets under pressure by side of a vat unitil the juice flows in to it. There the oil is gathered from the surface of the water, ready for market.

Maturity.-Olive trees commence fruiting at three years of age after planting and are in full bearing at about twenty.

Yield.-The average yield of a mature olive tree is abont 430 pounds of olives, according to the fertility of the soil; but olive trees bear only every other year.

Planting and propagating.-Olive trees are planted at 17 to 20 feet apart, and propagated from young olive plants springing up around a mature olive tree; they are disjointed with a piece from the oid tree to serve as a root. If the soil where they are to be transplanted is not stony a few stones are placed under them; most of their trunks are wrapped in straw and some clay is put upon the top of these plants for their protection from the sun and birds during the first year's growth.

Insect pests. - When hail falls upon the olive fruits a small worm infests them, but there is no treatment therefor.

Nasif Meshaka,

United States Consular Agency, Consulav Ayent.

Damasons, "Jumury 10, 1890. 
HAIFA.

REPORT IIT CONGULAR AGENT SCHWMICIRR.

Varieties.-The best variety for pickling is the "Irrsezy" (Arabic naine), a palo green olive, with a thin skin. The best variety for oil is the "Melisey," and "Syrian," a dark brown olive.

There are two distinct varieties grow $\mathrm{n}$ in this district; the one is called the summer, the other the winter olive; the first produces a better oil than the latter. Both kinds are pickled, but the white olives are preferred. The summer olives are the most profitable, and can be recommended for culture, as they are the best for producing the finest oil and equally good for eating.

Situation.-The natives claim that trees planted on hill sides produce a finer oil than those in the plain. The distances from sea are quite different, as the olive trees are spread over the whole country, say from 2 to 100 miles. The trees are planted from 10 to 500 meters apart, and are exposed to the sun without injury even in the hottest weather. The olive trees in my district are mostly planted on hilly land iu sandy black soil. But they grow also well in rolling and level land, only not so luxuriant as in the above-named soil.

Climatic influence.-The climate of Syria is good for the culture of olive trees, as frosts hardly ever occur. Temperature, minimum $2^{\circ}+\mathrm{R}$.; maxımum $33^{\circ}$ to $35^{\circ}+R$; average $20^{\circ}$ to $25^{\circ}+R$.

Rain-fall from 1 foot $7 \frac{1}{2}$ inches to 3 feet 3 inches all year. If rain falls atter the summer olives are ripe it is disastrous for the fruit. The olives become bloated and filled with water, and the oil in them goes back and is lost.

Irrigation.-The olive tree is irrigated ouly for the first two or three years, but not more; say once a week; after that no irrigation takes place.

Cultivation.-The best time for cultivation is early in the rainy season; say after the first rain has fallen in November or December.

Pruning.-The trees are pruned in the fall; the foliage must not be abundant. The natives say the tree must be pruned so that one can see through the foliage.

Picking.-The fruit is picked or gathered wheu nearly ripe, both for pickling and oil. Olives are not pickled here for the market; for home use they are put in fresh water for a day or two, and then put into stone jars containing salt brine and well covered.

Oil.-The natives make no good oil here; they take large heaps of the olives and then grind them under large upright circular stones, which revolve on a circular base. The pulp is then put in round press baskets, made of cane fibers, and pressed. The bulk of the oil produced by the natives is not fit for table use; it is mostly exported to France for illuminating and lubricating purposes. 
Maturity.-The trees begin to bear after seven or eight years.

Field.-..The average yield of a tree is 100 to 150 kilograms.

Planting and propagating.- They are planted about 25 to 30 feet apart, in regular rows. They are planted as wild siplings, which grow abundantly on the mountains; after a year or two they are grafted.

The Government makes no statistics, neither are there any issued by dealers or producers.

Insect pests.-There are no insect pests here that injure the trees. The greatest danger to olives is the hot wind (sirocco), which occurs sometimes during and after blossoming, which eanses the blossom on the young fruit to fall off, so that some years the entire crop is lost thereby.

$J_{A C O B}$ SCHUMACHER, Consular Agent.

United States Consular Agenoy, Acca and Haifa, December 5, 1889.

\section{SHWAYFAT * *}

Varieties.-The best olives for pickling are the black olive, called Shatawy, and the green, called Sourri; the best for oil are the black, of the Shatawy kind, which have small pits and thick flesh if sufficient rain-fall takes place, while the Sonrri green olives are good for oil, with or without suffieient rain. Other choice rarieties are the Damascus and Egypt olives, both of large and small size.

Situation.-They grow in the littoral in general and in high places up to an altitude of 3,000 feet and even higher. The particular region in the vicinity of Beirut, where olive trees grow, is the rillage of Shwayfat, in the "Shoof" district, as well as in the neighborhood of Tripoli, the southern part of the Lebanon, and in the interior. The exposure to the sun is of vital importance. Hilly, rolling, and level, but the latter is the best.

Soil.-Olive trees grow in all kinds of soil, but the red is preferable.

Olimate.-Such as the degrees of heat which prevail in Beirnt $40^{\circ}$ to $90^{\circ}$ Fahr., and in the mountains $30^{\circ}$ to $88^{\circ} \mathrm{Fabr}$.

Rain-fall from 30 to 40 inches is needed; less than 30 would injuriously affect olive trees, especially in the littoral. Rain-fall influences the growth of the tree and its production; as to quantity of the same it is stated above. The Uetober rains benefit the fruit, and the rains in December and Jaunary benefit 1 he trees.

Irrigation.-Olive trees prosper best with rain-water; irrigation diminishes the quantity of oil in the fruit, while it increases the growth of the tree.

* This report was prepared by the proprietor of an olive grove at Shwayfat, near Beirut, for Consul Bissinger. 
Cultivation.-Plowing must be done early in the spring, not less than four times; five times is still better. Hlowing is still done by means of the old primitive implewent.

Pruning.-Olive trees are not pruned; the dead branches only should be removed before the tree is in blossom in the spring.

Picking.-When fully ripe and turning black; the green in September and October and the black after this date. Olives can be preserved when green, $i$. $e$, before they get black.

Curing.-After picking the olives, heaping together shonld be avoided in order to keep them cool and prevent fermentation.

Oil.-Olives are first crushed under a cylindric millstone, then placed in bags made of goats' skin and pressed with a hydraulic press. In this way oil is extracted from olives. Sweet oil is obtained from olives that are fully ripe. Bitter oil is produced either from dried olires or from olives that have been left for some time heaped up together, or by the residue of olives that had been pressed. This residue, after being placed in large boilers over the fire until it is heated, is sprinkled with water and pressed again with hydraulic presses.

Pickling.-The process of pickling olives is as follows: Olives are gathered before they turn black; $i$. e., when they are yet green, and after removing all the dry and decayed or spoiled olives they are placed in water salted to a degree which would cause an egg to float thereon. The spoiled olives, and eren the good ones, are sometimes bruised and pickled in salted water ; in this way olives get sweet quicker than when not bruised. The process of pickling black olives is to place them in a shallow receptacle for seven days, during which they are every day sprinkled with salt in proportion of 10 ounces to 6 pounds and stirred up so as to be well soaked with salt, after which they can be either pickled by being placed in vases containing the salt-water that remains in the receptacle or in one containing some sweet oil. After olives are pickled, as above stated, it is always well to sprinkle some salt and spread olive leaves on the surface. Pickling the Damascus green olives is effected by placing them in water in which alkali (in the proportion of 2 ounces to the 6 pounds) and lime (in the proportion of 1 ounce to the 6 pounds) have been dissolved for twenty-four hours. After which a bath of sweet water is to be applied and renewed for three or four days until the taste of the alkali and lime has disappeared; they are then pickled and placed in vases filled with salt water. Black Damascus olives are pickled as follows: Stir them for a week in salt, then spread them in the sun for one day to dry, then put them in oil.

Maturity.-Olive trees begin fruiting when they are fifteen years old; in a good soil, from the eighth year.

Yield.-The average annual production of an olive tree is valued at from 25 to 30 piasters ( 89 cents to $\$ 1.07$ ). In the sear of fertility (olive trees produce every other year only), it is estimated to be double that amount. 
Planting and propagating.-Distance planted apart, from 21 to 30 feet. Olive trees are propagated by planting, in January or February, to the depth of 2 feet, the suckers that grow at the foot of the mother tree or by plauting, like the last, wild shrubs and grafting them.

Insect pests.-No insects infest olive trees. A small kind of worm is sometimes found in the fruit, but no special process of treatment is adopted or known.

SIDON.

Varieties._"Belady" fol pickling, also "Smukmuky" for oil. Other kinds cultivated are the "Kolb-el-Tayar" and "Korka-wa-Sisan."

Situation.-Both in the plains and in the mountains near the coast, and up to about 3,000 feet; sloping and hilly land, red and white clajey soil are best.

Climate.-Bountiful rains benefit olives.

Irrigation.-Not needed.

Cultivation.-Plowing necessary three times in the spring.

Pruning.-Pruning not necessary.

Picking and curing.-For pickling the fruit is picked while yet unripe; for oil when fully ripe. For pickling put in salt and water. Ulives are crusbed by large rolling stones, then put either under heary pressure or into hot water and the oil skimmed off the surfice.

Maturity.-From the sixth year upward.

Yield-Exact yield unknown.

Planting.-A A bout 20 feet, and propagated by budding or grafting.

Insects.-No insect pests.

Erhard Bissinger,

Consul.

United States Consulate,

Beirut, Eebruary 12, 1890.

SIDON.

IREPORT BY OONSULAR AGENT ABELA.

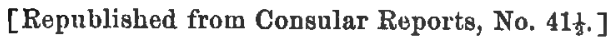

Varieties._Smuc-muky, small berry, little meat, but full of oil. Belady, larger and more meat, and is the best variety.

Oultivation.-Wild olive shoots are planted and then grafted, after which the only care they receive is an occasional plowing, except that the earth is often banked about the trunk to the depth of 10 inches. The young trees are set out at a distance of 20 feet apart. No irrigation whatever allowed.

Bearing.-After being planted and grafted the trees soon begin to bear berries, but the growth is very slow and the increase in the amount of fruit very gradual. 
Oil.-As nearly as can be estimated the average yield per acre is about 40 bushels of berries for mature trees. As the liquid measure of this land is based on the weight of the articles measured, it is castomary to estimate that a bushel of berries will produce about 1' pounds of oil; but the relation of the yield of berries to the amount of oil is a very varying one, differing according to the season and the rude methods used for extracting oil. After the olive has been crushed or bruised the pulp is treated either by being put into water and the oil is skimmed from the top, or else the pulp is pressed under a lever with weights at the end or by a screw-press. All these appliances are of the most clumsy pattern. Two methods are used in preparing olives for table food, according as green or black olives are required. For green olives the fruit is picked before ripening, and only those berries are selected which are wholly free from auy bruises. The fruit is placed in salt and water, and takes some time in curing. The black, ripe berry is very soon prepared for the table by being artificially orushed and then cured with salt.

Location.-The olive tree is very hardy, and thrives both near the coast and in the mountains, where it is found at an elevation of 3,000 feet, but the weight of snow does great damage by breaking down the little branches. The best soil is the red porous soil of the hills and stony, rocky ground. The annual rain-fall of this land is about 32 inches. As most of this falls in half the year, the olive thrives best when planted on slopes where the rain soon drains off:

\section{SHIBI,Y ABELA,} Consular Agent.

UNiTed، STATES CONSUlah AGency, Sidon, February 21, 1884.

TRIPOLI.

REPORT BI CONSUL BISSINGER, OF BEIRUT.

Varieties.-The best variety for pickling for olive oil and protit is the "Sourri" olive.

Soil.-Red richly manured soil is best.

Manure.-Manure is to be used in winter, and every tree needs about 112 pounds.

Situation.-Distance from the sea is immaterial. The position should be low, protected from the wind, but exposed to the sun.

Rains.-Plentiful rains benefit the fruit. Early rains, $i$. e., from September and on, are preferable.

Irrigation.-Olive trees need not be irrigated.

Cultivation.-Plowing is necessary three times in the spring, $i . e$. once every fortnight.

Pruning.-Dry branches only are pruned. 
Pickling-For pickling, olives must be picked while yet unripe and before they get black. For oil, whenever olives drop from the tree. The fruit that remains ou the tree is picked early in December.

Oil._For the extraction of oil, olives must be spread ten or twelve days after being gatbered, then pressed.

Maturity.-At the age of lirom seven to eight years.

Yield.- 1 he yield is proportional to the growth of the trees.

Planting and propagating.-The trees are planted about 5 yards apart, and propagated by budding or grafting.

ERHARD BISSINGER,

Consul.

United Staties Consulatie,

Beirut, February 12, 1890.

TRIPOLI.

REPORT BI ACTINE CONSULAR AGENT YANNI.

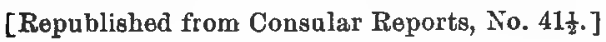

Varieties.-All the olives of this district are of one kind, known as the Olea vulgaris.

Orchards.-Olive trees are planted in two ways. The first is transplanting, the ground is prepared by digging large trenches 3 or more feet deep in which old domesticated or wild olive trees are planted. The land is plowed four or five times a year. The wild olive is grafted in the fourth year after transplanting. This method delays the crop, but is more successful than that employed in Lattakia, where the wild olire is grafted at the time of its transplanting, in order to hasten the crop. The loss in death of the trees is very heavy in consequence. The second method, which is good and less expensive, is to plant the shoots or suckers grown on the trunks of old trees. In most of the new plantations the mulberry is planted at the same time and place with the olive shoot. The mulberry grows rapidly, supports the olive plant, and gives good crops of leaves for the culture of silk, till the olive tree, which is of slow growth, begins to bear fruit, by which time the mulberry dies. These young olive trees require constant care to hasten their growth. Neglect in cultivating does not seem to greatly affect the product of old trees. To keep olive trees in good condition they require either fertilizers or a change of earth about the roots of the trees. The latter method is usually employed.

I am unable to give any information concerning the queen olives of commerce, since this sort is not found in the districts around Tripoli.

Maturity.-Transplanted trees come into full bearing after their tenth year, while plantations of shoots do not attain their maturity before their twentieth year. As to the age these trees can live, it is not kuown, but it is estimated that the groves around Tripoli are of great antiquity. 
Yield.-If we suppose an acre of land to contain fifty mature trees, well cared for, they will yield about 1,800 pounds of olives, worth about $\$ 25$; the cost of cultivation should not exceed $\$ 2$.

If the olives are of good quality, 1,800 pounds will yield from 500 to 550 pounds of oil.

Planting.-In the old plautations no rule is observed, but in the new ones a space of 30 or 40 feet is left between the trees.

Picking.-Olives are gathered green for pickling. Olives are gathered for their oil when ripe, and the longer they remain on the tree the greater the amount of oil.

Olives are prepared for the table in two ways: The first is to break the fruit by a slight blow of a hammer, after which it is abundantly sprinkled with salt, in which it remains two or three days, when it is put in pickle. This method gives a speedy result. The second method is to take chosen green olives and put them in pickle. This pickle is testel by the people as follows: an egg is put into it and the brine is strengthened till the egg floats. Olives prepared in this way remain sound and good for a long time. They even preserve their green color for three or four years.

Oil-As to the manner of extracting the oil the people employ one of three nethods:

The presses or maassirs. In the middle of a large room is a circular stone about 5 feet in diameter, with a large hollow in the top. Within this hollow a millstoue is made to revolve on its edge by means of a shaft and an npright post. The millstone is driven round and round either by men or horse-power, crushing the olives into a pulpy mass. The press consists of the trunk of a tree, which has been hollowed out by a mortise some 5 or 6 feet long. This log stands upright over a large jar or cistern. The olive pulp is put into small hay baskets, which are piled in the hollow log, and over the top of them passes a long, heavy bar, which presses down upon these baskets, the pressure being increased by heavy weights suspended at the end of the bar. The oil descends into the vessel below, which is partially filled with water, and the workmen use their hauds for dipping the oil from the surface of the water.

These mills are the same as those for grinding wheat. The only respect in which they differ from the preceding process is the using of revolving kuives, which ent the pulp from the olive seed instead of crushing the entire berry.

In the yorthern districts of Lafita and Akkar the people employ a ruder method for pressing the crushed olives. They put the pulp into ressels of water and press it with their hands, and finally skim the oil from the surface with their hands.

Soil.-The best soil for the olive tree is the alluvial. In limestone and chalky soils the trees grow more rapidly, and become strong, but are less fruitful. The quantity of oil yielded by their berries is much less than the average product of others.

$1.56 \mathrm{~A}-15$ 
Irrigation.-Olive trees are not irrigated.

Situation.-At Kalmun the orchards are very near the sea, with a northwestern exposure.

Rain-fall.-Though we have no meteorological observatory in Tripoli, still we consicler the rain-fall in the city a little more than that of Beirut, say about 40 to 42 inches per annum.

G. YaNNI,
Acting Consular Agent.

United States Consular Agenct, Tripoli, March 18, 1884.

\section{AUSTRALASIA.}

REPORT RY CONSEL GRIFFIN, OF SFDNEY.

Mr. J. H. Maiden, F. R. G. S., curator of the technological museum, Sydney, and author of an interesting and raluable paper on olives and olive-oil, mentions two species of oleas, Oleapaniculata and Olea apetala as indigenous in New South Wales. This fact he thinks shows that the climate here will be found suitable for olives generally. It is certain that many rarieties of the olive tree producing fruit that have been planted here and in other parts of Australasia have done exceedingly well, but the fact nevertheless remains that olive culture has not ret proved to be of any commercial or economic ralue, except, perhaps, in the neighborbood of Adelaide, in Sonth Australia, and"even there it is not regarded as of sufficient importance to be included in the statistical returns of the government relating to area undercrop, but the returns of exports show that, in 1887, 517 gallons of olive-oil, the produce of the colony, were exported, and in 1888419 gallons.

Sir Samuel Davenport, who is an authority on olive growing in Australia, informs me that his plantation, which is the largest in Australasia, contains about 1,500 trees,

placed as boundary lines inside vineyards and in oceasional odd corner lands. Although you may meet with a few olive trees in public and private grounds, where the climate is adapted for their growth, there are only a few individuals who pay the cultivation any attention. Beyond my own fruit, I usually buy olives off trees in my neighborhood, so that annually I make from 1,200 to 1,500 wallous of oil. A few other persous make a little but the whole production is relaticely insignificant, nor can be worthy of notice until onr peoplo wake up to the fact that the olive tree is one that they should, in their own intereats, largely grow.

Among the varieties cultivated by Sir Samnel for oil are the French Blauquette, Blanquettier, Verdale, Pendulier, Italian-that of Lneca; Spanish, a few kinds, whose names he has not given me. He has nearly all the best known varieties used for oil and sereral that are used for pickling, such as the big Spanish, which. howerer, gives but jittle oil. 
Sir Samuel Davenport occasionally supplies truncheons for starting plantations. Sereral thousand of these were sent to other parts of Australia last year for this purpose, the truncheon being the quickest and surest way of propagating the olive. The trees begin to bear at seven years of age and give about one gallon of oil from each tree. The fruit ripens in June and picking is continued through July and August. There is a plantation of 100 acres at a place called Stony Field, not far from Sir Samnel Davenport's property. The land is, how. ever, very poor, and it is said will not grow anything but olives. A calcareous soil appears to be the best suited for olive culture. Sir Sanuel Davenport says:

The calcareons nature of the soil aronud Adelaide and the warı and dry climate assist in briuging the olive as well as the vine to perfection.

\section{He adds :}

It is fortunate for the laborers as well as for the farmers that the olive harvest follows on the vintage, as the viutage follows on the harrest times of wheat and other grain.

Sir Samuel, when examined by the Victorian Royal Commission on Vegetable Products, stated :

In Adelaide, and from 100 to 200 miles from that city, there is a very sunny eutrance to summer, and the summer itself is also warm enough. The charncteristics of a cultivation to snit a dry soil consist very much of plauts which have a wondy character and consequently are better able to resist the effects of long beats, and for that purpose all the Sonth Anstralian soil, he thought, shonld be worked to a great dopth. The olive tree is delicate when flowering and will not fructify if much moistare is used.

: There is attached to the Aadelaide gaol an olive plantation of about 50 acres. Some of the trees are very valuable. The soil consists of chocolate loam. It is well manured and irrigated. The yield of fruit is something enormous. The branches are often so heavily laden that they have to be propped up in order to sustain the fruit. Two hundred and fifty of the best trees were imported from the grove of Count Spada by $\mathrm{Mr}$. W. R. Boothby, formerly mayor of Adelaide, and the trees in the plantation are usually worked from the same stock.

The olive groves of South Austrnlia are located from about 10 to 50 miles from the sea-const and at an elevation of from 150 feet to 200 feet above sea-level. The average ruin-fall for a term of years is about 22 inches, althongh in some sears it falls as low as 13 iuches. The arerage reading of the barometer is 30.652 inches, and the average temperature $62^{\circ}$ above zero. The maximum $110^{\circ}$, and the minimum $36^{\circ}$.

\section{MANUFACTURE OF OIL.}

The method pursued by Sir Samuel Davenport is to take the ripe fruit and crush it into pulp in mill on the Chilian mill principle. This mill consists of two granite wheels, each weighing 7 tons, revolving in a 
sircular granite receptacle, worked by horse-power like a pudding-mill. About 100 pounds of fruit are pulped at one crushing. The time occupied is usually about twenty minutes. The pulp is then placed in an oval rice sack and the oil pressed out in a press of rather peculiar construction.

The sacks are placed one on top of another inclosed in a strong iron-bound frame, resting on a cemented bottom with a false bottom grooved, so as to allow the oil to run away. Pressure is applied with a piece of wood, called a tongue, which is attached to a heavy beam or lever.

It appears that this kind of pressure, which is perpendicular, has been found by experience to extract the oil better than a screw press, which it is said confines the oil in the pulp, while the slow, steady pressure of the lever causes it to trickle through the bags. The oil of the first pressure is called "virgin oil," and the report on some sent by Sir Samuel Davenport to Italy was, "that it resembles the 'sublime' oil more than the oil of commerce." The oil of the second pressure is of inferior quality and is run into slate cisterns kept specially for its reception. This quality of oil is used by manufacturers and sold at a lower price than virgin oil. The utmost cleanliness is practiced in the process throughout, the mills and presses being washed every day with hot water and soda. The South Austrdian oil commands a higher price than the imported oil and carried off the first prize at the Vieuna International Exhibition. The oil made at the Adelaide gaol is also of very superior quality, and the process is said to be more economical than that employed by Sir Samuel Davenport. A press with hydraulic power is used at the gaol.

Samples of the Australian oil were sent to the Colonial and Indian Exhibition in London, in 1886. It was so highly refined and the cost of production so heavy that it was necessary to exclude it from the manufacturer's schedule, namely; 'ss. (49 cents) per pound quoted. That exhibited loy Sir Samuel Daveuport was described as being equal to the finest Lucea brands.

G. W. GRIFFIN,
UNIJED STATES ConsulaTE,
Sydney, January 21, 1890.

FIJI.

Whether olives have been experimented with or not, I am unable to say, but I think not. That they are not grown here I know.

The ouly fruit grown here for export is banaus and piues, both of which are quite extensively grown.

Andrews A. St. John, Commercial s gent.

United Strates Commeralal igenci, Levuka, January 11, 1890. 


\section{CONTINENT OF EUROPE.}

\section{FRANCE}

REPORT RT CONSUL TRAIL, OF MIRSETLTES.

THE OLIVE 'IREE IN TMY SÖTTH OF FRANCE.

The olice tree (Olea europea) is common to the whole of the south of France, and when nearing the south by rail the traveler can at once detect its familiar green color and its regular shape. For miles it can be seen on either side, sometimes in an uncared for, almost wild state, and sometimes in well-cared for, well cultivated, regular plantations. It grows in almost any soil, in rocky or stony ground, and even without attention produces fruit that is a small, though uncertain, source of income to the poor peasant, but when well cnltivated and attended to becomes a certain revenue to any farmer who takes the vecessary care and trouble.

The olive tree is essentially the tree of warm climates (it is said to originate from Egypt), lut not of tropical heat, therefore the Mediterranean district suits it admirably. It succeeds well in places where the mean temperature of the year is from 590 to $61^{\circ}$ Fahrenheit. It does not support heat above $104^{\circ}$ nor cold below about $15^{\circ}$. Frost below the latter freezes and kills all the branches, and one is obliged to cut the whole tree down to the ground and wait till it has grown again. It is the greatest calamity that can befall an olive tree, for it takes about ten years to regain its former position, and even then it is often far from being as good. In 1820 almost all the olive trees in this consular district were killed by frost, which was ruin to thousands, oil being then twice the value of to-das.

The olive tree is also essentially the tree of arry, ston $y$, hill, and undulating ground. Some of the hills and mountaius along the coast are covered with olive trees, and inland plains are also planted with them; but the fuct must be mentioned too that in some districts, notably around 'Toulon and Hyeres, olives are being rooted out of the plains and vines planted in their place. Calcareous ground is favorable to olives for fine oil ; sandstone, schist, and granite soils are less favorable. When the soil is rich the tree itself prospers and grows to a great size, but the fruit is less abundant and inferior.

The best is a mixed, fairly dry, red or calcareous soil, with exposure to the south. The ground must not be too dry nor too moist. Of the 
two evils a too dry soil is to be avoided most. Drought is unfavorable to olive trees, as the olives dry and fall off before they have attained maturity; but a good rainy winter or spring suffices to give enough moisture for the following summer. After a very rainy winter season an olive tree will stand excessive heat much better than after a dry one.

Now olive trees uncared for and left to themselves produce, under farorable circumstances, a light crop about every two years, sometimes oftener even, aud sometimes ụnder unfavorable circumstances, less frequent; but culticated and well cared for it becomes an interesting, inportant, and bighly profitable branch of agriculture; one can count upou fairly regular annual crops, and the result is generally satisfactory. The importance of olive-growing in countries that suit it can not be overestimated.

In the south of France, and all around the Mediterranean, the olive plays a part in domestic economy of which littlo is known in other countries. It can be seen on th' rich man's table as a relish, or its prodnct, in the form of salad oil or frying oil, is used daily in his kitchen, and a handful of plain olives form at certain times the daily meal of many a poor peasant and farm laborer. In countries and districts where butter is scarce and dear, olive-oil, in some form or other, is used in almost every dish that comes upon the table, and a fact that is not generally known is that, in the scuth of France, olive oil is even preferred to butter for frying purposes.

\section{VARIETIES.}

There are mauy varieties of olive trees and mauy that have simply changed through change of climate, soil, or care, but the chief ones cultivated in this district are these:

(1) The Brown olive tree, a slow growing, hardy tree (especially against cold), that gives few crops but usually abuudant ones. The olives are of a clarkish hue, fairly good for pickling, but not so good for oil. This variety used to be grown very much but is less cultirated now.

(2) The "Cayon" or white olive tree, a quick growing, small tree, with low branches; is sensitive to cold but grows again quickly after a frost. It produces olives in its third or fourth year, and gives a crop pretty regularly every two years. Its olives are reddish, produce good oil that retains the taste of the olive, a fact that is appreciated in these districts. It is largely cultivated around Marseilles and Toulon.

(3) The "Pendonlier" or high-growing olive tree, a good sized tree with large branches that frequently hang down. It produces a good crop, rather late in the seisism, pretty regularly every two years. It olives are of a dark hue, and produce very fine, tasteless oil that is much appreciated for export, and which is almost exclusively used in the perfumery trade. This variety is largely cultivated in the Grasse and Nice district. 
The two latter kinds are excellent varieties for profit, and are recommended for general purposes. In many respects the Cayon is prefera. ble, ehiefly because, being a lower and smaller tree, it requires less room and is easier to attend to. Its height is usually from 12 to 16 feet. They can be planted at a distance of', say, 15 or 16 feet apart each way; thus, from 150 to 160 would go on an acre. The Pendoulier, being a wuch larger tree, requires about 30 feet square to itself in order to develop fully; thus, about 40 would go on an acre.

\section{CULTIVATION.}

The cultivation of the olive tree is very simple, and it is this that makes it pay. The chief points are digging, fertilizing, prun. iug. Tho ground ought to be well dug up around the tree to at least 6 feet from the stem, and if possible kept loose throughout the rainy season. A good plan is to dig a trench around the tree and on sloping ground to connect these trencies one to the other by ditches, all to be closed up when the wet season is over. No irrigation is then necessary Artificial watering would only be called for in spring if the whole winter had passed withont any rain at all, a circumstance that rarely, if ever, happens.

\section{FERTILIZING.}

Fertilizing ought to be done at the same time as digging, that is, during winter and spring. In places and farms where stable manure is obtainable at a reasonable price it can be used to considerable adrantage; in towns and in the proximity of oil-mills the refuse of these mills is a good fertilizer, and the dirty water that comes from the mills can be used, mixed or diluted with pure water. Powdered oil-cake is an excellent stimulant, and ought to be well mixed with the earth. Finally, the dead leaves that fall from the olive tree itself and the small branches cut off when pruning, well dug into the ground, are largely used as fertilizers, and are by no means to be despised. Strong fertilizers must not be used too frequently.

Pruning.-The question of pruning is one that requires study, as it depends a great deal upon circumstances. An olive tree usually gives a crop every second year, therefore it ought to be pruned every second year, and then, of course, shortls after the gathering of the crop, say during January and February. But as enltivation in many cases makes the tree produce a crop every year, it is right in this case to prune the tree slightly every year. When the trees are pruned every year it must be done carefully and lightly ; in fact it must only consist of a slight thinning out. The chief thing to be borne in mind when pruning is, that those twigs that have blossomed and produced fruit once never do again, therefore that pruning must consist in cutting away useless twigs and branches to give light and air and make room for fresh and fruitful twigs and shoots. 
Pruning depends in a great measure, too, on the position and exposure of the trees. Olive trees exposed to high wiuds ought to be rept low and rather compact, but those in favorable positions, on sheltered hill-sides, for instance, can be allowed to grow larger. Thus it will be found that olive trees along the shores of the Rhone, and indeed in all the Rhone valley exposed to the pernicious mistral, are little more than bushes and are kept as such, whereas towards Toulon and further on, also in Tunis and other parts, the olive tree grows to a great height and size, and is pruned accordingly.

\section{PICKING AND CURING.}

The blossoming of the olive tree takes place in April and May, and if the rains have been favorable and no frost occurs the crop may be considered sure.

The gathering of green olives for pickling is done from about the 20th of September to about the 10th of October and must be done by hand. The date of gathering depends, of course, upon the stage of the fruit, as it ought to be done just when the olive has reached its full size and before it begins to turn black. Green olives can not be raten as they come off the tree, because they are too bitter, but are pickled by the very simple process of soaking them in brine or very salt water. Sometimes ashes are used as well as salt. As soon as they have almost lost their bitter taste they must be taken out of the brine and put into clear water, if possible running water, and washed.* They are then ready to be packed in kegs, barrels, bottles, or jars, but with a little salt water or water highly seasoned or aromatized, and are fit for export, for storing, or for immediate use.

Black olives for pickling are gathered, as their name indicates, when they are black, say during November. The pickling process of these is left to nature, $i$. $e_{\text {. }}$, they can be simply spread out on wicker-work hurdles or basket-boards exposed to sun and wind till their natural water has evaporated and with it their bitter taste. They can then be eaten in their natural state, but are more palatable well seasoned with salt, pepper, and oil.

The gathering of olives for the manufacture of oil must take place when they are black and quite ripe, generally from the end of Noremher till the end of January. They can even be left to fall to the ground and then gathered up, but as they do not all fall off together, it often takes a long time to gather in the complete crop. Care unust be taken not to let them rot on the ground, as such olives would spoil the oil for table purposes. A good plan is to wait till the first good fall hins taken

\footnotetext{
"The nawal way in which green olives are pickled in 1 his district is as follows: 'They are soaked in asolation of potash and water (1 pound to ld pounds of potash to a gal. lon of watre) for about two honre, then put into clean watr, which is changed once or twice a rlay until the water remains clenr. After this the olives are ready to paok in salt water for keeping.
} 
place and then to set about gathering in the whole crop eitber by shaking or picking off all the rest. Care and attention must be exercised when gathering in the crop for oil-pressing in not picking them before they are perfectly ripe, and also in not breaking off the joung branches that will produce truit the next year. Iu positions fuvorable to the ripening of the olives, that is, where the olives on any one tree ripen almost simultaneousl, , the trouble of gathering in the crop is rendered easier by stretching out coarse sheets or cloths under the trees and simply shaking or pulling the fruit off the branches into them.

Now in order to obtain olive oil of superior quality there are several primary conditions to be observed. Care should be taken in selecting only sound olives and picking out all bad ones and foreign substances, such as stoves, dirt, leaves, or anything that may have been gathered along with the olives. For superfine oils it is therefore advisable to press olives that have been gathered by hand only, or at least shaken into cloths.

Once gathered, the olives should be looked over, selected and separ. ated, and taken to the mills with as little delay as possible. They should not be left in heaps or in baskets for any length of time, as they are liable to ferment, which is detrimental to the obtaining of really fine oil. In some old-fashioned places peasants pretend that this fermentation facilitates the pressing out of the oil and even increases the quantity; but this idea is not to be recommended, as the slight gain, if gain there be, in quantity is more than counterbalanced hy the difference in quality.*

Cleanliness in the mills is a great point. It is essential that all presses, millstones, casings, recipients be perfectly clean, so that no bad taste nor color can possibly be given to the oil during the process of manufacture.

The simplest and the primitive way of manufacturing oil consists solely in placing the olives in a mill in which one or two millstones are revolved either by hand, by oxen, or by horses, until all the oil is crushed ont. But this altogether primitive and imperfect mode can only be seen now in country places at great distances from cities and villages in Algeria, Tunis, and in some parts of France. It has long since been supplemented and superseded by other more perfect and coinplete processes.

It is, however, seldom that a farmer or olive grower presses his own olives. In centers and districts of olive cultivation there are generally one or more oil-mills to be found. Proprietors of oil-mills can be divided into two classes, viz, those that are simply oil-crushers, who crush the olives and make the oil for the cultivator who brings his crop to them; and these are paid in kind, i. e., they are not paid in

\footnotetext{
" This onstom of allowing the olives to fernent before putting them into the oil presses is still observed in many parts of Spain, and for this reason Spanish olive-oil is generally of an unpleasantly strong taste.
} 
money, but by agreement retain a certain percentage of the olives brought to them. This system often gives rise to certain abuses that are difficult to suppress, aud the poor peasant frequently fiuds that he has been very far out in his calculation of the quantity of oil that his crop ought to have produced. The other class of oil-mill proprietors is composed of those that may be called merchant-crushers. These buy olives in large qiuntities from the. growers and dealers, manufacture the oil, and sell it themselves. There are several large man. ufacturers in the city of Marseilles who possess mills in several different centers of olive cultivation in this district and in Algeria and Tunis. These firms have very naturally acquired a certain reputation for their several marks, and many can command higher prices in the market on the strength of their reputation. Each manufacturer professes to have a special method of his own, but the basis is the same for everybody. The only difference that can exist is in the way of filtering and refining or clarifying the oil before it is finally casked or bottled.

\section{OLIVE-OIL MANUFACTURE.}

The process of manufacture is as follows: The olives ready to be pressed are first put into a mill, similar to those formerly. used for the whole operation, but the olives are only half crushed, and no oil is crushed out, so that they form a shapeless mass. This mass is then distributed into round flexible kinds of baskets (French name "scourtius") made of sparto grass and horse-hair, something in the shape of shortsacks with months only half closed, con'aining about 15 pounds of the crushet olive mass. From ten to twelve of these bags are then placed, one above the other, in a pile under the regular oil-press and in such a way that the base of one bag rests on the open mouth of the one below. The mouth of the bag being smaller than the circumference of the bag, the mere fact of placing one above the other closes them. At the base of the press there is a ledge with an opening on one side, below which the receptacle for the oil is placed. When all is in its place the press is set in motion, in small mills by hand, in large ones by stean, and the oil gradually oozes out from all sides of the baskets and flows in to the vessel below.

The oil that flows from this first pressing is the best, and is called virgiu oil (Huile vierge).

When no more oil Hows through the baskets the press is reversed and the crushed and hard mass of olives is taken out. This hard and apparently dry mass still contiius a good quilutity of oil of good ordinary qual. ity for kitchen purposen, and in order to obtain it the mass must be broken up and mixed with boiling water. The warm mass or pulp is then placed a second time into the baskets and the whole is pressed in the same way as the first lot, only, during the ophlation of phessing, boiling water is frequently throwu over it. The on and water that How from this 
pressing are received and left to stand in large stone vessels or metal tanks, and the oil that gradually mounts to the surface is the second quality oil.

Now, the mass that is found in the baskets after the second press is either stored to dry and sold as oil-cake, or is sold to special mills that extract a third quality of oil by means of acids and other agents. But this quality can not be used for table purposes; it is, however, very good for the manufacture of soap, and is largely used in this and other industries.

The oil that comes from the first and second presses is not generally sold in its primitive state, but is refined and filtered, and it is in this process that some manufacturers excel others. The principle of refiuing and filtering consists in letting the oil remain for a few weeks in tanks or immense jars, during which period a sediment gradually deposits itself at the bottom, and then passing the oil minus the deposit through filtering papers specially prepared and sold for the purpose. Some manufacturers even pass their superfiue oil through specially prepared cotton-wool, which is certainly an expensive process.

After being filtered the oil is ready to be casked or bottled for consumption.

\section{PRICES OF OLL.}

Concerning the prices of oil it is difficult to give any good idea, as so much depends on freight and charges on the oil from the time it leaves the mill till it reaches the cousumer. Really good oil in the mills in this district brings from 100 to 120 franes per 100 kilograms ( $\$ 8.75$ to $\$ 10.50$ per 100 pounds), but prices of olive oil in the Marselles market vary from 95 franes for common kitchen oil up to 200 franes for the finest possible salad oil ( $\$ 3.30$ to $\$ 2 \mathrm{~L}$ per 100 pounds), all according to quality and mark. Oil for manufacturing purposes is worth from 80 to 90 francs ( $\$ 7$ to $\$ 7.90$ per 100 pouuds).

\section{ADULTERATIOY.}

In many places adulteration is carried on to a great extent and refined cotton oil is largely used to mix with olive oil. Cotton oil being from 20 to 30 per cent. cheaper, and being tasteless, leuds itself very advartageously to the adulteration of olive oil. It is an open secret, too, that vast quantities of pure cotton oil are shipped and sold as olive oil to those markets that prefer tasteless oil. Cotton oil is, however, used under its own name by many people who prefer a tasteless oil for frying purposes.

\section{RÉsumé.}

From the foregoing, it will be readily understood that olive-growing and oil-pressing are two distinct professions aut that they are better if 
kept separate. This explains the existence of professional oil-crushers who do nothing but press oil for the growers; otherwise, unless a grower had a large ancount of capital at his disposal wherewith to work a mill and pay the necessary staff, he would never be able to attend to the digging, fertilizing, and pruning of his olive trees with due care, as this ought to be clone just at the same time of the year as the all-important first-oil pressing.

The olive-grower, if he attends to his task properly, has plenty of work to do and the more he does the better he is repaid. As already mentioned, an olive tree left to itself will produce fruit, but one well cultivated will repay its owner tenfold. Though it does not pay to be too lavish in expenditure, yet an ontlay of about $\$ 50$ per acre per year is considered a sound investment in these regions. Consjderably less is spent by many a grower, but if one has the courage to lay out about, the sum mentioned one can generally depend upon being well repaid.

A full-grown Pendoulier well fertilized and eared for will prodnce about 30 gallons of olives in a crop; very large and fruitful trees have been known to produce up to 100 gallons even. A full-grown Cayon under the same circumstances will produce from 7 to 8 gallons in a crop, and there are many that can produce 20 gallons.

The value of olives varies according to crop and quality, but roughly speaking about $\$ 1$ per gallon is the average price.

The out-turn of oil varies according to the quality and condition of the olives, but the average yield is 14 per cent. by the two pressings plus 10 per cent. by acids, say a total rough average of 24 per cent.

The olive-tree, well cared for, is almost always free from disease and parasites, but it is well to be on the look-out for any possible enemies. The branches are sometimes covered with a kind of yellow moss, produced in some instances by too much dampoess or moisture and in others by weakness of the tree. In the first case the ground must be immediately drained, and in the second it must be manured. In both cases it is well to cut off the branches so covered. Sometimes there is no remedy, and the trees must be rooted out, and the ground used for other purposes.

Sometimes a sort of a cochineal, the Cocous, attacks olive trees, and in this case a hard brush, dipped in vinegar, is the best remedy.

The Tinea oleolla occasionally attacks the leaves and the Hylerinus olece occasionally kills the buds, but these are not serious foes. Of all insects, that most to be feared is a tly that deposits its eggs in the wood of the olive; it is the Dacus olece. The larræo of this tly eat awas and destroy whole branches, and it is extremely difficult to exterminate them. The best way to destroy them is to scrape the branches and apply boiling water or a solntion of lime, but even these are not always effectual. Nature, how'ver, sometimes helps herself, and not unfrequently anotber in:sort, the "Cynips," deposits an egg in the bole bored by the Dacus and the larva of the Oyuips kills and feeds on that of the Dacus, thus saving the tree. 
The olive is a tree that attains a great age, aud that, with care, is said never to die. It can, however, be reproduced by cuttiugs and by seedlings that must be grafted the second year.

Chas. B. Trail,

United States Consulate,

Consul.

Murseilles, April 30, 1890.

THE OLIVE TREE IN SOUTHERN FRANCE.

REPORT BY VIOE.OONSUL MARTIN, JR., OF MARSEILLES.

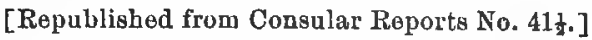

Varieties.-The olive tree is only cultivated in France in the departments bordering upon the Mediterranean. From the remotest antiquity it has been it source of great riches to this part of the country, as it thrives on land where no other culture could be attemped, and is productive for centuries.

The varieties are almost numberless, as the tree takes a different name in almost every district where it is cultivated, and are distinguishable by the fruit only, as the appearance of the tree is nearly the same for all the varieties. The best-known varieties cultivated in view of the fruit are the "Espanenque," "Prunaou," "Triparde," "Picholine," "Bouteillan," "Verdale," etc. Those that produce the best oil are the "Aglandaon" of Aix, the "Soloumen" of Salon, the "Amelon" in the departments of Hérault and Bouches du Rhône, the "Brun" and "Cayon" in that of Var, and "Aubanenque," "Saurin," "Rougette," etc.

Soil.-The nature of the ground appears to have but little influence with the jield of the olive tree; still a stony soil, with a rocky substratum, a mixture of clay and sand, or calcareous and gravelly earth with a little humus, appears to be more favorable than marly, granite, or schistic soil.

Situation.-As to the situation, hill-sides or table-lands sheltered from high winds, with an easterly or southerly exposure, give the best results. The proximity to the sea must he rather beneficial than otherwise, as many orchards are planted on the very shore, and those that are at the greatest distance from it are as a rule the most sensitive to cold weather. In fact, there are none to be found far off from the coast-

Cultivation.-The process of cultivation is of the most simple description. As a matter of fact, many orchards that are not cultivated produce the most esteemed oil, althongh in smaller quantities. In many others one hoeing in the year is deemed sufficient. In a few, where the trees are planted in quincunx at a distance (which is generally adopted) of 10 meters or 33 feet from each other, the alleys former between them are tilled with the plow, great care being taken not to hurt eithor the 
roots below or the branches above. There is in this way left around each tree a square space, which is theu hoed by hand. The same operation is repeated in the course of spring, and again in summer.

Pruning-I'runing is geverally considered as unuecessary, and must be conducted with great care, as the tree is liable to suffer by injudicious or excessire lopping. It is only applied once in three or four years, aud confined to the suckers and the withered or entangled branches.

Fertilizers.-Fertilizes should also be applied with a great deal of precaution. The best manure is that consisting of a mixture of animal and vegetable matter. It is placed once in four years a little beneath the surface of the ground. Close contact with the roots should be avoided. Many cultivators prefer to dig out the earth from around the foot of the tree and fill up the hole with fresh mold. An excess of manure has the same effect on the tree as an excess of water. It rots the roots, and in all cases produces an abundance of aqueous sap. As the olive tree vegetates all the year round, this abundance of sap makes it more liable to the effects of frost and cold. It also rends frequently the bark of the boughs, and flows out through these fissures with considerable detriment to the tree.

Irrigation.-On the other hand, irrigation, while impairing the quality of the oil, produces much larger quantities of fruit that is also larger in size, and in many districts where fruit forms the object of culture the orchards are frequently watered by hand, with watering pots, or, when the water supply is at hand, irrigated after the manner that meadows are.

Planting.-The olive tree can stand any degree of drought, but a temperature of trom $10^{\circ}$ to $14^{\circ}$ above 0 , Fahr., accompanied with snow, kills the boughs and trunk. There is then no remedy left but to cut the tree on a level with the ground, and allow the roots to grow new shoots, or to root it entirely and replace it by new plants. The olive tree is remarkably reproductive, and any part of a twig would, in course of time, take root and give birth to a tree. A shoot from the old roots about 2 inches in diameter is generally selected for reproduction; it is taken off from the roots with care, so as not to hurt either the scion or the roots, and planted in a square hole 6 feet on each side of the surface, and 3 feet deep. The hole is msially filled with other earth than that which has becu taken ont of it. The young tree, when planted, should not be more than 4 feet above the lerel of the ground, and frequently bears fruit after five or six years. Trees grown from the kernel of the fruit do not begin to be fruitful until the age of fifteen or eighteen. For this reason, this mollo of reprodution is only practiced in nurseries, where young trees are also raised from wild scions and slips, and sold at the rate of 1 frane or 1.25 fruncs. These are in many cases preferred to the trees grown from old roots, and when properly packed can be transported to long distances.

The yield, proceeds, anl cost of cultivation must necessarily rary widely aceording to the manner in which orchards are cultivated. The cost way amount to any sum between $\$ 5$ and $\$ 20$ per acre. 
As to the yield, it is eren more variable; ench tree may pay from 50) centimes to 3 francs. As a rule, an olive tree is only proluctice every other year; some rarieties, when placed under the most favorable conditions of soil and weather, produce two years in three, but in no case is the yield constant. It varies from 60 to 535 gallons of fruit per acre. The average price of the fruit ranges from 12 to 22 francs per hectoliter (9 to 17 cents per. gallou). The quantity of fruit turned into oil is not the same in all districts, some of which prepare a much larger quantity for table use than others. On an average little over two-thirds of the whole crop is sent to the mill.

Preparation.-Olives intended for table use must be perfectly sound, and of course are picked among the largest on the tree. There are two modes of preserving olives, in pickle and in oil. Those that are to be preserved in oil are picked when perfectly ripe, that is, black. They" are, withont any further preparation, steeped and kept in olive oil with some fennel, coriander, salt, and pepper. The pickled olives are picked before they arrive at maturity, and as soon as they have' acquired a bright green color. They are pricked and rolled iuto wood ashes to set free all the oil they way already contaiu. Atter being washed they are placed in the pickle, where they remain until consumed. The "Picholine" and "Verdale" are the varieties mostly prepared in pickle here. The "queen olives" are the produce of a variety of tree that is not grown in this country. They are imported at this port from Spain.

Nearly all the production of preserved olives is consumed in France. The exportation is exceedingly small, and does not amount to more than a few thousand kilograms, that are mostly sent to Algeria. The extraction of oil is made in special mills where the farmers bring their (rops by quantities of 400 liters (about 106 gallons). For this quantity, called "molte" in the country, the mill-owner geverally returns 40 liters or 10 per cent. of oil. The olires are thrown into a recipient, where they are crushed under the action of two wheels measuring two and a half feet in diameter and worked by water or steam power. After two bours the olives are reduced to a sort of a paste, which is placed in a number of grass bags and pressed. The oil thus expressed is called "virgin oil," the quantity being about one-half of the whole produce. The paste is then taken out of the bags, spread out on a cloth, broken up, and replaced in the bags. Each bag is drenched with about fivo gallons of boiled water and placed again in the press. The mixture of oil and water thus obtained is left for a day in the receivers. The oil comes to the surface, is skimmed off", and in most cases mixed with the virgin oil first extracterl. The mill-owner charges 3 franes for each " molte" and lieeps the residnes, from which he again extracts, on his own account, by a supplementary and more abundant addition of boiling water, an inferior grade of oil called "ressence." There is still left in the residue after this operation a small quantity of oil that is extracted, in special factories, by meaus of sulphide of carbon, 
Diseases.-The diseases of the olive tree are fow in number and seldom fatal to the tree. The most common are: The "mofée" or "uoir," which covers the bark and leaves with a sort of black matter that is sometimes friable, sometimes compact. The origin and causes of the disease are not well known. It is counteratted by a sprinkling of lime and water and by a pruning, more extensive than usual, so as to let the black deposit be freely swept off by the wind. The "mouffe" is produced by an excess of wetness, that decays the sap. When the vegetation is staid and the leaves turn yellow, the roots and branches attacked must be cut off, as also those parts of the stem where the rotteu sap, known by its stench and black color, has found its way, and draining trenches should be established without delay.

Insect pests.--Olive trees planted near the sea-shore are sometimes covered with a coat of green moss, that is not in itself injurious to the tree. Large numbers of microscopic insects live in that moss, but do not seem to hurt the tree; so that nothing is dune to remove them.

Cochineals are, among the parasitic insects that live on the sap of the olive tree, the most common and most dangerons; they are driven away by rubbing the boughs and branches with a piece of cloth soaked in vinegar or whiting.

No remedy has yet been found to protect the olive orchards against their worst enemy, an insect called the Dacus olea." It is a species of fy that deposits its eggs in the fruit. The larvæ feed on the pulp of the olive before it comes to maturity; when they make their exit they frequently cut the peduncle of the fruit, which falls to the ground. When the olive remains on the tree the produce in oil is considerably impaired both in quality and quantity. The damage made by the "ver" (worm), as the Dacus olea is commonly called, has been particularly great in the last two or three years.

United States Consulate, J. S. MARTiN, JR., Vice-Consul. Marseilles, March 11, 1884.

NICE.

(REPORT BY CONSTL HATHATAY, OF YOCE.)

Introductory.-I have the honor to submit the following report on the olive, as it has come under my observation within the district of this consulate, accompanied by some statistical data relating to its products, and accurate directions, obtained by diligent inquiry from reliable sources, for its successful cultivation.

This tree, of the family Olincea, which is a finture of the remotest historic landscapes, funts its matural home in the portions of southern Europe bordering immediately upon the Mediterramean basin. Here, restrained ouly by the choice of man and the hnitations of soil aud 
altitude, it covers the slopes, hill-sides, and valleys by millions. The general configuration of the coasts, the mountain barriers, sheltering against northern winds, and the proximity of the sea itself, which serves, as a vast reflector of the sunbeams, are explanatory of this result.

It attains to a height ustally of 20 feet, and even to 50 feet in some localities, and commouly to an age that appears almost fabulous. One of this species-a wonder of its neighborhood-lately carelessly destroyed at Beaulien, in this vicinity, had a positive record of five cen. turies, and mensured 36 feet in circumference when it fell. It has entire erergreen, lanceolate leaves, gray underneath, and its flowers, which appear in June, are white, anl disposed in axillary branches, and resemble the blossoms of the elder. Its fruit, named olive, is exceedingly prolific uuder culture, ind is oval in shape, with a ligneous kernal inclosing a seed in form like the almond. The flesh of the fruit yields about 70 per cent. of its weight in oil, and is tirm and covered with a soft skin, green colored before maturity, becoming an intense violet black when ripe.

Varieties.-Among the varieties of olives here I note the following:

(1) The black point, called in the dialect of Nice "Prince Neri." This is the bestquality of the fruit known in this district, and is grown at Beaulieu and at the promontory of St. Jean. These olives are gathered when entirely ripe, are then dried in the sun, and are excellent for the table.

(2) The "Pitcholine" and the "Caillette" (so called), both of which are esteemed best for preserving when gathered green.

(3) The "Blanquette" (light of color), the "Sauvagette" (wild olive), and the "Nostrala" (proper olive of Nice), all especially useful in production of oil.

Yield of oil.-It is computed that the amonnt of oil produced in Italy is 33,000,000 and in France 7,000,000 gallons annually. The amount of production in this department, although no statistics thereof are published, may be safely estimated at from $50,000,000$ to $60,000,000$ pounds biennially. This estimate does not include the very considerable quantity arriving here from Tuscany and Naples, nor the increasing importations to this port from Corsica, all adding to the immense stock of the reliners here, and from hence, in the distributions of commerce, solid in Europe and America under the name of "Olive Oil of Nice."

Situation.-The tree does not regetate readily beyond 2,000 feet abore sea-lerel or $45^{\circ}$ in latitude. The department of Alpes Maritimes, situated $43^{\circ} 42^{\prime}$ worth latitude and $4^{\circ} 56^{\prime}$ longitude east from the meridian of Paris, is most favorably adapted to its growth. The said department has an extent of 46,850 hectares of land (115,770 acres), more or less wooded with the olive, of which 12,000 hectares $(29,650$ acres) are exclusively planted with olive trees. From the Rirer Var up to the River Roya the hill-sides and valleys surrounding this regiou are sheltered against northern winds by the " contreforts" of the Alps.

The coasts facing the sun, the immense mirror of the Mediterranean reflecting back the sunbeams and the triple girdle of mountains, gradually 
sloping into hills toward the sea and protecting the country from frost, are the unsurpassed conditions, with the temperature, for the nurture of the olive and the maturity of its fruit. Nowhere is the earth blessed with a continuance of more polarized light. The temperature during the winter months, in which the olive ripens, is like that of spring in middle France. The winter is deemed exceedingly rigorous when the thermometer falls below $32^{\circ} \mathrm{Fahr}$. Thirty years of accurate observation have proved that of the fifty-six days of rain during the year forty-two were in autumn. October and November are the months in which the psychrometer gives the highest average. In May the temperature averages $64^{\circ}$, in Jun $670^{\circ}$, and the stroug heats of July and August $78^{\circ}$ Fahr.

During six months, viz: from the close of May to the end of November, more than one hundred days are enjoyed without clouds. The winter temperature on the whole, in the shade, averages 52०. The years when it falls below $32^{\circ}$ are rare but ruinous. Such an exceptional climate generally allows the fruit in winter to reach its full maturity. The tree grows everywhere here, except in marl or clay or other moist conditions, but best in a dry soil, on slopes toward the sun, sufficiently sheltered. On steep declivities, where quantity and quality of oil are only aimed at, no crop of any kind allowed beneath its foliage, but elsewhere and in plains a mixed cultivation is profitably employed. In prosperous seasons the olive is more remunerative than corn or the vine.

Picking.-The gathering of the crop begins in November and continues until May. The harvest is divided into three periods of two months each. From the first is produced an oil high.colored and called "fine," the second produces a straw.colored oil called "superfine," the last a pale-colored oil called "extra superfine." The product of the first period is most dense and has a strong flavor of the fruit, and can be congest preserved. But the best quality of the oil is that from the last gatherings of April and May, when the fruit has become fully ripened. This, although less flavored than the others mentioned, has more sweetaess and limpidity, and is in great demand in the home markets and not 2] ways easily procured for export in its finest grades.

Oil manufacture.-To express the oil from ripe fruit freshly gathered and unmixed with that which is immature or otherwise of bad condition is an essential rule, and to this method the reputation of the oil of Nice is mainly due. The olive is gathered from small trees by hand, and from large ones it is knocked off with poles. The first munner is preferable, as the fruit thus escipes being bruised and as any lengthy coutact with the soil affects its flavor. But this cau not so readily be practiced either on large trees or slopes or fields of large extent. Women and boys are employed for the purpose, for which as wages they receive 77 cents for every 20 liters.

The mills for griuding the olives are located on the little water. courses of the region, and a stone wheeling aronnd on its axle triturates the fruit and reduces it to a paste. The latter is then placed in bags of esparto and squeezed under a press in the mill. The olive oil then 
escapes through the texture of the bags and runs into a receptacle underneath. It is this first pressure which produces that which is styled "virgin oil." Afterwards the bags of said paste are removed and soaked in boiling water and placed a second time under the press. 'The same operation is a third time renewed, when all the oil is extracted. The secoud pressing yields the ordinary oil of commerce, and the third that used for illuminating purposes, and generally consumed here in preferenee to all other oils. It is styled "huile de colza."

The farmers bring their oil to market in barrels of about 200 pounds weight, or retain it in their cellars in earthen jars, glazed within, and guarded from dust by wooden covers. Merchants keep it in large, deep, cemented tauks, over which their warehouses are built, thus providiug an even temperature.

From these tanks the oil is drawn by pumps for the process of filtration and bottling for sale. The filter consists of a series of boxes, one above the other, with perforated bottoms, aud lined with layers, about an inch in thickness, of 'white cotton-wool.

Adulteration of oil.-That the alulteration of the olive oil, notwithstanding the severe penalties of the law therefor, is to some extent practiced is undoubted. The frand is accomplished by mixing with the genuine the oil of the oleaginous seeds of cotton, sesamun, and others. Immediate discovery of the imposition appears impossible, although much study has beeu given to the matter. Densities, degreo of congelation, refraction, specific weight, and all other chemical properties must be taken into consideration, which is a labor of hours. The following process of detection is generally used: In the trial tube is placed 0.3086 grains of dried albumen, to which is added 30.864 grains of nitric acirl, and au equal weight of oil. The tube is then heated over an alcohol lamp aud its contents mixed by ebullition. The operatiou affords the following tests: (1) If the oil be genuine olive the color will be of a yellow feebly greenish tint; (2) if the olice has been mixed with 5 per cent. of seed-oil the color will be of an amber yellow tiut; (3) the tint of the mixture will deepen down to a deep or. ange in proportion to the amount of the foreign oil.

Insect pests.-The special dangers to which the olive trees are exposed are frost, wind, bail, and the "dacus." When a tree has been canght by too low a temperature it seldom resists the frost. The loss in Provence from this cause, in the year 1830, was ruinous to mauy proprietors, aud amounted to 4,000,000 francs. When the tree is but partially frozen it can be saved by pruniug, but when leaves and branches are entirely frozen there is no remedy. A violent wind brings down the fruit pell-mell, ripe or green, according to the season. The hail cuts and bruises it as well as beats it from the brauches. Such fruit becomes mingled with the soil and more or less decayed, and produces an oil moldy in savor, disagreeable to the taste, aud improper to trade. The dacus, the chief enemy of the olive, appears in the month of August, as soon as the fruit begius to ripen. The little iusect destroys 
annually more than $3,000,000$ francs' worth of olives. Its larva, introduced into the flower of the fruit in the form of an almost imperceptible egg, hatches in the fruit, and is nourished by its substance. In Beptember the larva, becoming a perfect insect, issues from the olive, cutting and weakening the little stem which joins the fruit to the branch. The fruit, when this happens, soon falls in a spoiled and unripe condition, and the oil it produces is rancid to the taste, and only valuable for the lamp.

Diseases.-The olive tree does not escape fron vegetable parasites. A tree infected with morplua or fumago becomes all black-trunk, branches, and leaves. If it produces fruit, which rarely occurs, such contain no oil. This disease once fastened, lasts about ten years, and it is without a known remedy. Severe pruning in such cases is sometimes practiced, but it is usual to leave recovery to the operation of time. Twenty years ago, this disease wasted many groves in the environs of Grasse and at Beaulieu, but fiually disappeared. Recently the environs of Cette have been afflicted with that sickness. Some proprietors said it resulted from the fog, others ascribed it to emanations of the soil, and others to the wiud from the sea. M. Ang. Riviere, an expert in such matters, is of opinion that the disease develops from the honey matter deposited under the leaves by the insects $A$ phis coccus or Kermes. Among the numerous remedies for the scourge have been hyposulphite of lime, petroleum, and fumigations of tar, all of which, however, have been found useless. The same disease occurs among the trees in Spain, under the name of negruro.

Secondly, the decay of the olive. Among trees not too thickly planted and on lean, dry soils this seldom occurs, but elsewhere is quite noticeable. The decay arises, for the most part, from the cuttings, the breakings, and the bruises to which the tree is subjected. The wounds thus made, unless protected from the air, cause the linneous substance to become rotten. This disease proceeds, undoubtedly, to a large extent from the method in which many of the young plants are obtained. These, when extracted with a few horizontal roots from the foot of the parent tree, leave injuries inviting decay. The treatment for the trouble consists in removing the decayed portious as much as possible, and closing the cavities with mortar of sand and lime.

Cost and profits.-On slopes or undulating fields 1 hectare of land ( 2.47 acres) usually contains about 200 olive trees; on plains about 150 . To calculate as exactly as possible both the expense and yield in this district, I will make an average of both situations, observing, at the outset, that the crop is biennial, and that in the cstimates of expenses, therefore, only one-half is to be taken.

To cultivate a hecture on plains it is necessary to dig and loosen the soil, a labor of fifty days at 48 cents per dar, one-half of which sum is $\$ 12.06$; to manure the same (150 trees at 14.4 cents each), $\$ 21.71$; to prune the same, at 19.3 cents per tree (the halt), \$14.48. Each tree gives, on an average, three donble decaliters of fruit, equal to $13 \frac{1}{6}$ gal- 
lons; for the gathering of each double decaliter 77 cents is paid; onehall of this expense for the 150 trees equals $\$ 17.37$. The entire expense per hectare thus equals $\$ 65.62$.

One hectare of olive trees under good conditions produces every two years 450 double decaliters of olives, which, at the normal price of 3 francs each (58 cents), are of the value of $\$ 260.35$. One-half of said sum being regarded as the product of one year, the proprietor thus ob. tains 675 francs, equal to $\$ 130.17 \frac{1}{2}$ from each hectare. Deducting the above expenses therefrom leaves him a net profit of $\$ 64.65$ per hectare. On slopes, with 200 trees per hectare, $\$ 90.44$ of value would be the annual product. An average of $\$ 77.55$ is the net profit annually per hectare for both locations. Thus, the 46,850 hectares of olive lands in this department, of which about 31,000 , it is calculated, are planted in slopes, may produce the important sum of $\$ 3,830,000$ yearly.

Among the principal oil merchants at Nice are "Société des huiles d'olive," Stable \& Cie., and Joseph Mayrarque. Prices for table oil range from 2.50 francs to 1.90 francs, and illuminating oil from 1.10 francs to .80 francs per liter (2.113 pints.)

Cultivation.-The "Oleaster" (wild olive) and "Olea Europæa" (common olive) grow without cultivation, but the quantity and quality of their fruits are to a great extent the result of care and labor. When totally neglected the tree does not entirely fail, but, like the vine under the same conditions, brings some small profit to the owner, but the product always increases in proportion to the amount expended in its judicious care.

One of the primary essentials, as considered by the best cultivators here, is that the ground under its shadow be plowed, dug, or otherwise loosened thrice every year, great care being taken lest the roots are wounded. A breaking of the soil to a depth of ten inches is thought sufficient. On the plaius they use the plow, but upon the declivities the spade only is practicable.

soil.-It is generally allowed that a soil in which more or less lime, alumina, magnesia, silica, and some alkaline salts exist is especially farorable to this tree. Volcanic soils are also considered excellent, but neither of the above, though preferable here, excludes all other soils, except those which are mortal to the olive, viz, fat and rers moist lands and sandy and rery dry ones. Excessive moisture and excessive dryness are its enemies. Soils entirely of clay or sand are excluded from its culture, but the sandy clayey ones, the calcareous, the rocky or pelbule-covered, aud eren the calcareons rocks themselves, where the roots can penetrate between them and find water to snccessfully nonrish the tree are adapted to its culture. A soil not too dry, the bottom of which is gravel, provided clay is found over it mixed with sand, is preferable. A clayey soil is bad on account of the moisture with which it is filled in winter, and which canses the roots to decay.

situation.-The proper situation of the tree is a question simply of temperature. Much attention must be directed in various ways to sit- 
uation, as it involves a careful consideration of climates, altitudes, declivity, and the direction of predominant winds. Many different conditions thus present themselves, which may be summed up as follows: Gire the tree the maximum of temperature which its nature requires, aroiding places of excessive cold as well as those of burning heat. For this end, in cold localities the trees should be placed on meridianal hills and on septentrional ones in very hot localities. Further, light slopes are always preferable to high hills or the valleys.

Propagating.-The methods for the reproduction of the olives are numerous, but may be treated as uuder two distinct classes, viz, the natural and the artificial. The best natural way of reproducing the tree is from the seedling. The seed requires two years for germination when sowed in its hard kernel. The latter should always be crushed, therefore, but without injury to the seed, which will then follow the ordinary rule of development. Some cultivators, after remoring the kernel, soak the seed in a mixture of manure and clay. When planted the best dry soil should be selected and the seed corered to a depth of 2 inches. If sowed in April, the young plant will emerge the same year, and in six or seven sears bear fruit. In its first stages it should be protected by straw or leares against the cold, and its lateral branches pruned away and its stems guarded by an inclosing support.

Among the artificial means of reproduction are the following: The planting of shoots, multiplication by protuberances bearing buds, and multiplication by cuttings and grafting of the stumps. The artificial methods, however, do not afford the special advantages of the seedling process, which are: A more vigorous tree, produeing longer and more regularly; one of more hardibood, more readily existing on moist, arid, or rocky soils; a tree with more abundant roots, by which it can offer greater resistance to wind and cold, as well as obtain more nourishment; a better form of tree than simply portions of others, the wounds of which heal with difficulty and are frequently the source of decay. The seedling process is, therefore, most advised and most adopted.

The nursery.-The formation of the nursery for the young olive is of great importance, and is a special and very profitable industry. The soil for this purpose should not be either too clayey or too silicious, too dry or moist, sloould be well mellowed and on a slope of sonthern inclination. The land selected is here plowed or dug to a depth of " feet in November or December, and thus left until spring to the operation of rain and frost. A second breaking of the soil ly spading, less deep than the preceding, in April, completes the dispositions required for the reception of the seedlings, the young wild olives, the rooted cuttings, and the shoots.

Inasmuch as these plants when placed are intended to remain at least seven years, they are geuernlly planter a distance of 3 feret aprart. The first care taken, after the roots are developed, is to form the trunk of the future tree by careful lopping of the plant's lateral branches. This process is continued for about five jears. At the end of the fifth 
rear is the period to determine the height clesirable for the tree to attain. The height preferred depeuds upon the species, but more upon the locality and nature of the soil to which it is to be transplanted. If destined to deep and rich soils, a trunk of 4 to 5 feet in height is best; but if for a lean soil, or a place exposed to winds, then 3 to 4 feet is sufficient. Soon after its tifth year comes the time for forming the head of the tree, to which is given sometimes the form of a truncated cone, of a vase, of a fan, a sphere, or pyramid, the object being always to allow it to present as much surface to the sun as possible. The result is reached onls bo the labor of years.

Transplanting.- - In the transplantation the plants are placed about 4 inches deeper than in the nursery, and in lines from north to south, with a space between each tree of from 25 to 30 feet, as the tree will not be fruitful unless well exposed to the sun. The rule in that regard here is as follows: Plant the trees on right lines from north to south, with such a distance in the alleys between them that the tree to the sonth shall not cast its shadow on its neighbor to the north on the day of the equinox, the 22d day of March, at noon.

When the soil is dry the plants are transplanted in the autumn, and in moist soils in the spring, care then being taken that they be placed in the same position toward the sun as the, bad in the nursery. A bed of straw is provided at the foot and a circular gutter to retain the rain in summer. The soil covering the roots contains some fertilizer, such as pulverized bones or ordinary dung.

Pruning.-It is an ancient saying here that by planting the olice sou pray it to give you fruit; if you manure it, you not only pray it but yon entreat it; but by pruning you compel it to do so. To this end all dead wood is cut out, and those branches which prevent air and light reaching the center of the tree. The height is also thus reduced when detracting from the vigor of the lower branches, and rendering at the same time more difficult the gathering of the fruit. A regular pruning of young plants, howerer, should not commence until the fifth or sixth year after transplantatiou.

At Nice the trees are pruned every two jears, in the spring. In autumn the wounds have no time to heal before cold weather, but in the first case there is also danger-loss of sap. On examining more closely the rules for olive pruning it should be remarked that these should cor. respond to the mode of growth of the tree itself. Young branches present themselves opposite each other on the most vigorous branches, and are only prodnctive of wood; other produce knobs for tlowers all along their length, which expand in branches in the spring of the second year. Each of these small branches develop two lateral shoots; these new shoots fructify in the following spring, and so on. It will be remem. bered that the olive fruit grows only on the branches which are two years old.

If the new shoots were developed yearls without accident, the tree would annually produce its fruit, but in the years of abundance the sap 
is drawn to the nourishment of the fruit, and hence the number of young sprouts is restricted and the ability of fructification for the following year. Hence, also, it will be understood that one object of pruning must be to favor the birth of the young lateral shoots, either by arresting the terminal development or suppressing the smaller branches. The srnall and more perpendicular branches are more abundant, but the horizontal or hanging ones are the most productive. The skilled cultivator directs the pruning of his plantation in such a manner that one-half of it fructifies one year and the other half the next year.

The height of the tree here averages about 21 feet, yet there are trees in the neighborhood 56 feet in height and at the base 22 feet in circum. ference. Neither Greece nor Palestine could boast such trees.

Fertilizers.-The fertilizers devoted to this tree are numerous. These may consist of its leaves, unutilized otherwise, residues of its oil, oilcakes, and the refuse of animals, the refuse of skius, horns, feathers, woolen rags, and guano. Those decomposing slowly, as horns, rags, etc., are applied in autumn, in the spring those dissolving less slowly. At the period of fruitage strong manures are used which act immediately. The manure is placed away from the trunk and over the absorbent mouths of the extremities of the roots. It is usually disposed here in a ditch about 2 feet deep, encompassing the tree, and then buried. Slight but frequent applications are best, but it is usually practiced only once a year.

Grafting.-The usual methods of grafting can be applied to the olice. The following, however, are used in this district: (1) The "eye-bud" or "ring" graft, the latter being a variety of the former; (2) the cleft graft, preferred in Nice.

In nurseries the eye-bud is practiced, but the cleft only on older trees in the field. Cultivated and wild olives both are grafted.

To make an eye-bud graft, a furrow in the form of a $\mathbb{T}$ is cut through the bark of the trunk to be grafted, and in this a bud from a cultivated olive is inserted by raising the corners of the middle of said $\mathrm{T}$; the graft is then plastered with mud and covered with a rag, fastened with twine.

The cleft graft is formed from shoots or cuttings instead of bnds. The branch to be grafted is cut squarely off and the stump split by the knife. Into the cleft one or more shoots, previously sharpened in wedge shape, are then inserted, care being taken that the bark of each shootallheres to the incision; the interstices are then filled with paper or fine straw, and the place grafted is covered with moist clay and bound with a bit of cloth.

The grafts will not produce the olive until three years, and do not attain their full yield until nine years after grafting. From said period a tree 1 foot in diameter will produce, on an average, 34 pounds; i tree of '2 feet, 112 pounds; and one of 3 feet, 200 pounds of olives per annum.

Albert N. Hatilaway,

Uníled States Oonsulate, Consul. Nice, March 25, 1889. 


\section{ITALY.}

INFORMAIION FOR AMERICAN OLIVE-GROWERS.

REPORT BT OONSUL LAIIANTIA, OF OATANIA.

Variety.-The common olive tree in Europe has oblong leaves, and is the kind which was first imported, and from the wild state reproduced in varieties, aud grafted, offers so many varieties too difficult to mention. In fact, the Iudians knew but one kind; the Iegyptians only 3, and the Hebrews and Greeks 5. The Romans, as to Virgilius's statement, knew but 3 varieties; Cato says 10 ; Columella stated 12; Macrobio reported 14, and Pliny declared 15 varieties. In other times the Botanic Tournefort classified them to 17 varieties.

By an interesting report, however, published in 1871, by the Ministro d'Agricultura, Industria, e Commercio, it seems that there were registered 300 varieties actually cultivated in the several regions of Italy, viz: Lombardy, 23 varieties; Venetia, 21; Liguria, 24; Emilia, 10; Marches, 63; Tuscany, 30; Lazio, 27 ; Adriatic coast, 67, and Sicily, 21 varieties. The olive tree in Sicily blossoms from the month of April to June, and experience has proved that when it bappens in April yields a full crop, while blossoming in May or June gives a scanty one.

The flowers on the bunches develop very slowly, but as soon as they fade the fruit sets on and is formed in a few days. Ten or tifteen flowers compose the bunch, but only a few of them set on, and many of them fall down.

Buuches with three or four fruits stand well, and the fruits so formed come to perfect maturity from the month of October up to the end of March (see Fig. 3, with bud, blossom, fruit, and stone open in two). The olive tree, when it is located iu favorable conditions and cultivated properly, grows to an extraordinary size, very high, and lives very long. In fact, Pliny says, that in his time at Luiterno, a city near Rome, were seen trees which had been planted two hundred and fifty years before by Scipio Africauus. Gasparin writes to have seen at Rogliano, in the Island of Corsica, olive trees from 17 to 18 meters high.

Extraordinarily large are also several Saracene olive trees in Sicily, some of which Professor Alvi says yield as much as $\mathbf{1 0}$ hectoliters of fruit. One of them, near Girgenti, which he himself measured, has a circumference of 8.20 meters ( 25 feet) at 6 feet from the ground. Their age, he further states, is from one hundred to one hundred and fifty years, while other authors agree it to be from fire hundred to six hundred years.

In some counties in the province of Cosenza (Calabria) there are 
some olive trees, visited by Professor Alvi, which he judges to be of a very ancient date, and some people of that country even pretend the said trees to have been from the time of Luigi D'Angio, who was sent there in a manner of banishment and to govern in the same time that country.

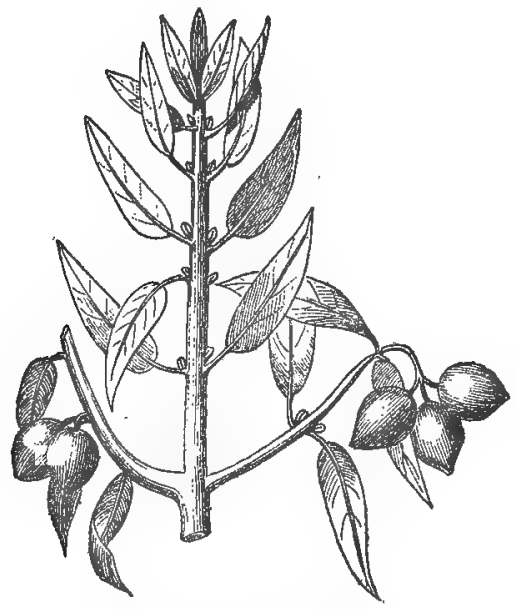

FIG. 3,-Albero con frutt.
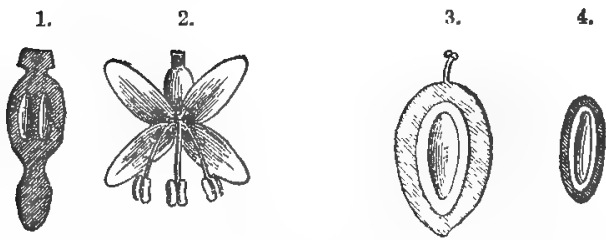

Vegetation.-In many parts of Italy this plant grows spontaneonsly, and principally derived from seeds deposited by some large bird's ex. crements, which are in a condition of sprouting. But the plant left to itself grows and rises slowly from the ground, the brancles furvish a few and sunall leaves, bearing very late, and the fruit yields but a little oil.

The olice tree propagated by seeds and subjected to grafting, when located on open air and on well adapted land, throws towards the ground a good main root, from which many others grow down deep, and the tree from its base acquires a majestic appearance. On points where the trunk joins the roots on the largest of them develop certain swellings called moli (springs), which are used for propagating the culture. If the plant be destroyed by storm or killed by frost from its base, yet many shoots will come out, although less than when it is in the regular course of vegetation; these springs repeat their growing from the orig. inal roots. 
The olive leaves last from two to three years, and grow matched on the branches one agaiust the other, as Fig. 1.

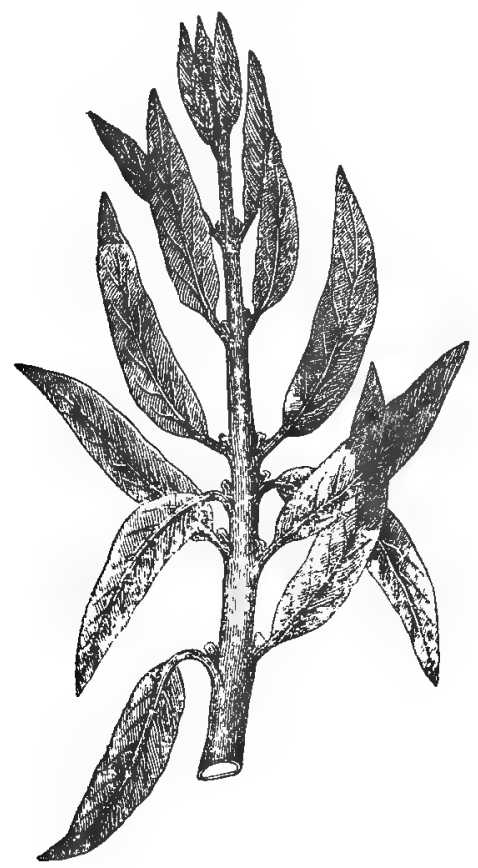

FIG. 1.

Climate.-The olive plant is one of those generally liking warm climates, and in a changeable temperature it grows well, and fructifies even exposed to any direction. The extreme limit of its regetation is marked about the 45 north latitude. Excessive heat and intensely cold weather are injurious to its culture. In fact, beyour the African Atlantic the olive plant is seen no more. As Humboldt remarker, 10 his voyages in the several parts of South America, and as Poiteaux obserred at Cajenna and St. Domiugo, that if the plant coulu regetate in those regions, it would nerer bear fruit. Some writers hare asserted that the olive plant wants to grow near sea, and they hare eren estab. lished the extreme limit, beyond which, under this respect, the plant does not find the necessary conditions for its regetation. This opinion has, howerer, been contradicted and proved by the fact that many olive trees are seen growing and producing well in the interior of continents and very far from sea-shores. If the olive plant shows its preference near sea it is because there the temperature is more suitable to its vegetation. The olve tree commences to vegetate when the temper. ature is at 12 centigrades above zero, and blossoms at 18 or 19 centigrades. A temperature of 5 below zero, followed by a sudden thaw, 
operated by the sun's rays, is sufficient to kill it totally at the base. With a lower temperature, not followed by sunny days, the plant does not suffer as much, as it can stand to a cold of 10 centigrades below zero. It is not so much the cold weather that injures the olive growth as it is the frequent change of cold weather to warm, and the often melting of ice.

One of the greatest enemies of the plaut is frosty weather, especially when the snow fallen on the branches dissolves by the sun's rays and congeals again during the coming night; at 12 below zero it not only kills all the leaves, but even the trunk and its roots to the ground.

A cold of equal intensity is more fatal during the spring season than it is in winter, for the reason that the plants are then in a state of vegetatiou, and consequently the new sprouts are ruined and destroyed.

A cold in a vaporous atmosphere hurts more than in a dry one, and it is for that reason that with the same degree of cold the olive plants on plain lands, because in a vaporous atmosphere, become more damaged than those located on hills. The altitude which the olive tree can attain varies according to the several regions in which it is cultirated. In central north Italy, for instance, it ordinarily trespasses 500 meters above sea-level, while in Sicily it goes orer 700 meters. But Professor Alvi assures me that he has seen elive trees in this island at 800 meters. It is proper, however, to note that if at the extreme limit of altitude the olive tree can vegetate, it is impossible there to bear fruit. Hence, planting in such localities does not pay. I may here give the agrarian climatic temperature in Sicily, which is dirided in three different zones, viz, the marine or warm climate, the medium or billy temperate, and the mountainous cold one. The height of the first is considered to be from 0 to 600 meters above sea-level; the second from 600 to 1,100 , and the third 1,100 to 1,800 .

The following table shows the sereral principal products cultivated and grown in same:

[Agrarian clinatic zoue in Sicily.]

\begin{tabular}{|c|c|c|c|}
\hline \multirow[b]{2}{*}{$\begin{array}{c}\text { First ynna (low land, warni climate } \\
\text { from } 0 \text { to } 600 \text { metors). }\end{array}$} & & & \\
\hline & $\begin{array}{l}\text { Second zone (hilly land, temper } \\
\text { ate clmate, fiom } 600 \text { to } 1,100 \\
\text { meters). }\end{array}$ & $\begin{array}{l}\text { Third rone roue } \\
\text { climato finm } \\
\text { ters) }\end{array}$ & $\begin{array}{l}\text { tainous cold } \\
30 \text { to } 1800 \mathrm{me} \text {. }\end{array}$ \\
\hline
\end{tabular}


Situation.-The success of olive cultur' greatly depends on situation and soil. Calculating the method of vegetation of this plaut, it may be determined that in wam climates situations facing from east to north are to be preferred, so that the plant will not suffer from the summer heat. In climates less warm, howerer, an eastern exposure is best, and in climates of the last zone a sonthern exposure is best. As above stated, in climates less warm the expositions to east are to be preferred, but if the locality is subject to frequent white frosts, then it is better to cultirate it iu expositions facing west and north, for the reason that exposed to east the plants covered with white frost, and quickly touched by the moruing sun, the sudden change from one temperature to an. other, they run the risk of getting dried.

As far as inclinations are concerned, those of hilly and rolling ones are to be preferred, for the reason that olive plants cultivated on flat land, although they present a flourishing vegetation, yield truit too rich in oil, while those situated on hilly and rolling land give best results. The same may be said of the trees planted in a mild temperature.

In flat land the fruit sets badly, becomes watery, yields less oil, and more dregs, is subject to fall before maturity, and is easily assailed by insects and disease. The trees on the highest zone of temperature suffer from the cold, and have of course less duration. It is, therefore, wise that in planting an olive grove preference must be given to middle altitude of hilly and rolling lands withont calculating the majestic aspect the trees may show on flat soils, for their fruit yields but a little oil.

Soil.-The olive tree is a plant which adapts itself to any soil, eveu to the most sterile one; but it does not give ererywhere the same quantity of fruit. In the soil it likes a certain coolness, but not exceedingl $F$, for the reason that too inuch dampness, stagnated in the ground, renders it too hard, thus causing damage both to roots and trees.

The best soil for olive culture is the calcareous siliceous-argellaceous, rather deep and permeable. A stony soil, covered with a little ground sufficient to let the young trees vegetate, may be adapted for the olive culture. The proofs thereof are the trees grown on the hills around Messina and on Mount Etna, which are covered with but a fow centimeters of ground. In compact soil and those on impermeable subsoil, the olive plant dies.

Fertilizing.-The manure adapted for fertilizing the olive tree must be subordinate to its composition. 
From the analysis made by Duracher and Malagati, the following has been obtained, riz:

\begin{tabular}{|c|c|c|c|c|c|c|c|c|c|c|}
\hline Description. & $\begin{array}{l}\text { 总 } \\
\text { 总 } \\
\text { م. }\end{array}$ & 莒 & 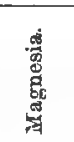 & 悬 & 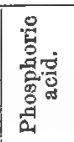 & 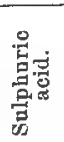 & 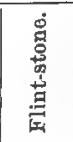 & 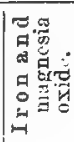 & 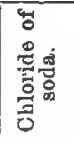 & 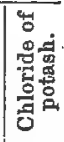 \\
\hline $\begin{array}{l}\text { In tho wood. } \\
\text { In the leaves } \\
\text { In the fruit... }\end{array}$ & $\begin{array}{l}25.54 \\
26.67 \\
7.13\end{array}$ & 20.51 & $\begin{array}{r}7.23 \\
7.31 \\
10.25\end{array}$ & $\begin{array}{l}20.12 \\
21.93 \\
22.91\end{array}$ & $\begin{array}{r}10.15 \\
7.98 \\
10.53\end{array}$ & $\begin{array}{l}3.43 \\
1.64 \\
4.60\end{array}$ & $\begin{array}{l}13.75 \\
20.88 \\
12.41\end{array}$ & $\begin{array}{l}4.43 \\
6.11 \\
2.59\end{array}$ & $\begin{array}{r}12.16 \\
5.39 \\
7.92\end{array}$ & $\begin{array}{l}1.2 \\
2.37\end{array}$ \\
\hline Total & 59.34 & 20.51 & 24.79 & 64.90 & 28.60 & 9.67 & 47.04 & 13.13 & 25.47 & 3.63 \\
\hline
\end{tabular}

From the above table it seems that the olive tree contains mostly all the materials generally needed by other plants, and that lime, flint, and phosphoric acid are the most in proportion of other materials. Consequently in manuriug said plant, the compost is to be made accordingly, in respect to others shown on the table. But many of said materials are contained in the soil, and in such cases it would be superfluous to add others. Therefore, it is necessary to learn the composition of the soil in order to know and to be sure how to properly manure the plants. Besides the above materials, well-decomposed excrements of any animals, as well as wood-ashes, etc., make also a good compost for manuring, and the proper time to do it is after the winter season, when through the watering vehicle the materials are absorbed in the ground. At last, in manuring the plants the material shown on the table must not be neglected, and of which potash, soda, maguesia, lime, silices and phosphoric acid must be more in proportion, as such composts greatly benefit the olive culture. The quantity of manure to be given to each tree varies according to its size, quality, and composition of ground; and it is therefore impossible to establish a certain quantity, and the best thing to do is to manure annually with a little compost, except in cases where a plant shows dullness, when a good dose of manure could be given iu order to make it revive again.

Propagation.-The olive culture cau be propagated by (1) semi (seeds); (2) ovoli (springs); (3) taleo (stocks); (4) polloni (sprouts); (5) tronco vecchio (oll trunk); (6) olivastrelli (olivasters).

All the plants derived fiom any of those propagated must be grafted, as they generally grow from a wild state. Exception, however, is to be malle in the case of coung trees derived from stalks taken from the upper grafted trees, or from plants which needed no sralting, and those which are obtained from springs, spronts, aud old trunks.

Propugating by seed.-This system, althongh requiring more time for growing and fruiting, as a method of propagation deserves to be appre. ciater, for the reason that plants originating from seeds are of longer duration, become larger, and better withstand cold weather, iusects, and diseases. 
To carry out propagation by seeds it is necessary first to prepare a good sized seed-plot, enough to contain all the young plants developing therefrom, and there to remain for three years, after which time they are to be planted in a reservoir for replanting. The seed plot inust not be exposed to tho uorth, aud the ground must be clear of roots and flint-stones. In winter it must be richly manured with animal exurements, not quite decomposed, the ground deeply dug up, and always kept free of grass. During the spring and summer seasons it is necessary to keep it fresh and water it whenever necessary to help the seed. ling to sprout. In July the young plants are out of the ground, and in November they are 4 or 5 inches high. During the second year the seedplot is to be worked the same as the first year, and in October, or in the coming spring season of the third year, the young plants are large enough to be trunsferred to the reservoir by taking off all the little branches therefrom.

Propagating by ovoli.-The ovoli (spring) is a bud found on rooty stumps and on the larger roots. It has the shape and the size of a goose's egg and shows out from the bark of trees. From each adult plant no more than three or four ovoli are to be taken off', otherwise you burt the tree. To obtain ovoli or talee instead of ruining many plants it is better to cut down one or two trees, from which a few hundred of them can be obtained for propagation. The said trees, however, must be of a good quality, apt to produce fruit of a white and juicy wood, and not reddish or veined. The springs on the roots are to be preferred to those located on the stumps of the trees, for the reason that the former are always more tender and juicy; hence better adapted for budding.

Propagating by talee (stocks).-This is simply done by cut. ting off from the best fruiting plants a bit of branch about $1 \frac{1}{2}$ teet long (Fig. 4), which is laid in the ground by the largest end deeper down. The trees of the said stocks must be regetating and of a large size, with thick bark, and well furnished with gems, wherefrom it is easy for rooting and budding. In order to succeed, however, it is necessary to lay it horizontally in a reservoir facing the same direction of its plant. Besides single talee propagation can also be done by talee composta (composed stock, Fig. 5), which be.

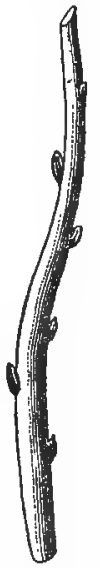

FIG. 4. forehand needs to be placed in a temporary reservoir; and only when supplied with roots and buds is plianted in another one. This method of propagating requires the identical work like the single talee, by placiug it horizontally in the ground, the largest end deeper down, as Fig. 6.

After one jear the young branches will provide themselres with 
leaves and roots, when the stock will be cut in pieces and each piece plauted in the reservoir. (Fig. 7.)

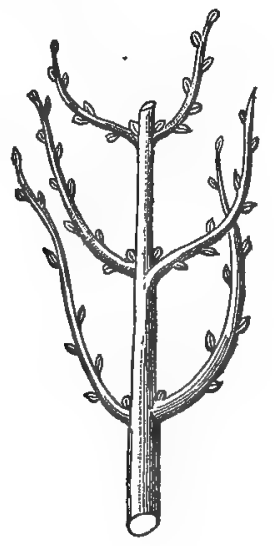

FIG. 5 .

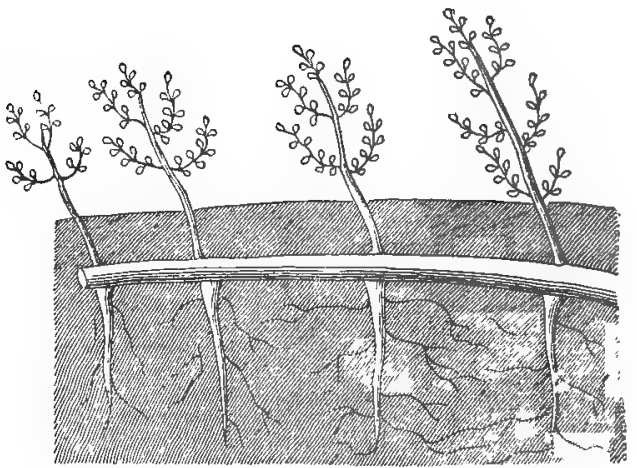

FIG. 6.

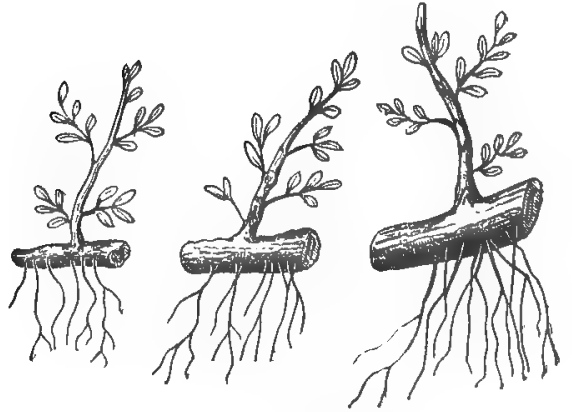

Fiti. 7.

Propagation by polloni (sprouts).-Between the intersection of roots with the trunk of the largest roots on the base of trees sprouts generally grow up, the same as in other plauts, from which good advan. 
tage can be obtained in propagating the olive growth, as this is the quickest mode of all. Very often it seems sprouts are provided with roots, and if they spring up in great number from the plant some are dug up, leaving the largest and most vigorous ones and covering their bases with earth.

Propagating by tronchi vecchi (old trunks),-Advantage can .also be derived from old trunks in the propagation of olive trees.

When a plant dies and contains living roots you see a great number of sprouts growing therefrom, which are also useful for propagation, and for which use those most vigorous and largest are left on the mother plant well cavered with earth, and the smallest ones are taken out to let the former have more space. In this state of growing they are left until their young trunks grow as thick as $1 \frac{1}{2}$ inches in diameter, after which they are hoed up and detached from the mother plant, transported to the reservoir, and planted at the distance of 2 feet from each other. Where the sprouts of the dead plant are not many, then it is better to leave them attached to the same.

Propagation by olivastrelli (olivasters). - Where the olive tree grows spontaneously in a wild state, and is not touched by animals' teeth, care can be taken of it until it grows to a proper size, when it is transported to final position, or planted in the reservoir, at a distance of 2 feet each side.

It is, however, worthy of note, that of all these methods of propagation, the one operated by seeds is the best, for the reason, as above stated, that plants so propagated live longer, aud better resist the cold weather. In propagating by stocks the character of the tree wherefrom stocks were derived is perpetuated.*

Grafting.-Following the propagation, I ought to proceed with the reservoirs, but as the small plants propagater by the methods above stated, must be, in most cases, grafted, which can be done in the reservoir as well as in final stay, I proceed about the grafting in reservoir. Plants propagated by seeds, springs and sprouts derived from grafting, as well as those from roots of trees already grafted, and those spontaneously grown by seeds iu a wild state, need, of course to be grafted.

The olive tree can be grafted by several methods, and they are as follows, to wit: (1) A scudetto (shield), Figs. 9, 10, 11; (2) An anello (ring); (3) A corona (crown).

The first method is mostly used in Sicily, on account of its simplicity and certainty ; the second one is seldom used, because it is difficult and it is operated late in the spring. The third one, Figs. 14, 16, 17, is practiced for adult plants, and likewise in the late spring season, when the plants are in a state of anger. Here I do not proceed minutely in de- 
scribing the several methods, as grafting is well known by every agriculturist in the United States.

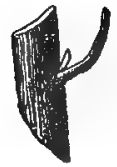

Fig. 10.

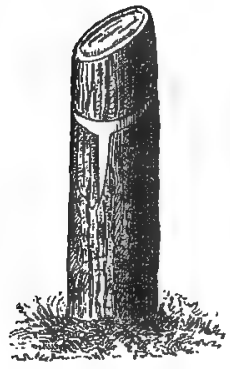

Fig. 9.

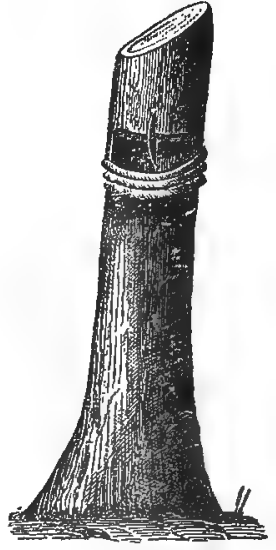

FIg. 11.

Treating plants in the reservoir.-While the plants develop in the reservoir, it is necessary to predicate all the possible intelligent care, for the

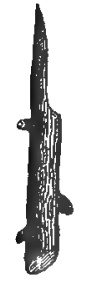

FIG. 16.

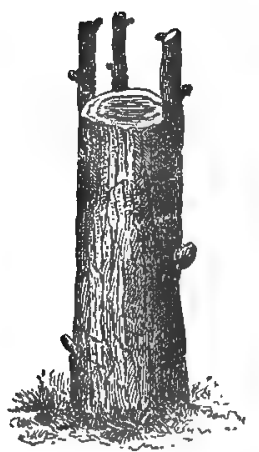

Fia. 17.

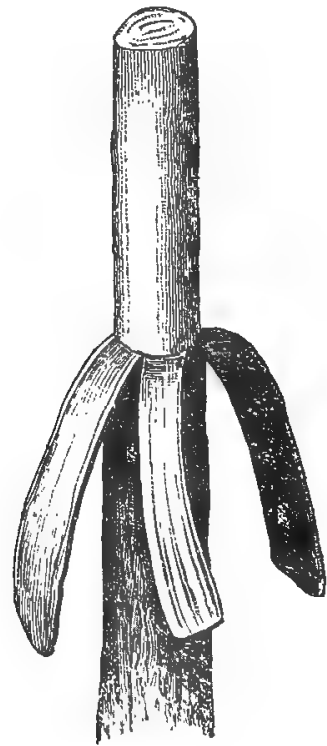

EIG. I4.

reason that if they are negiected, they will be of poor fruiting production. 
As to the length of time to keep them in the reservoir, several eminent agriculturists differ in their opinion, to wit: some propose five years, while others advocate fourteen. Practical observations, however, have proved that allowing plauts five years in the reservoir, they can never acquire sufficieut roots to be transplanted for fiual stay. On the other hand, if left for fourteen years, on the seventh or eighth year one half of them, the odd oues, are to be transferred in another reservoir, as the one would not be large enough to contain all the young plants located therein at a distance of 2 feet apart as above stated. It is therefore advisable, in Professor Alvi's practical experience, that the proper time of allowing young plants in the reservoir is from seven to eight years, counting the time of the seed plot.

For the first two jears, keep the young plants clear of little lateral branches, but leave the leaves remaining on the arm pits. Fasteu the little stocks on sticks placed alongside of them in order to protect them from strong wind or stormy weather. Water the reservoir in case of long drought and fence it to prevent animals from destroying it, and always keep the ground clear of grass.

From the second to the fifth year treat the plants as above stated; only on the fourth year change the sticks for larger ones in order to better sustain the growing plants. On the sixth year they are in a state of designating the shape you want them to grow.

The height of the trunks principally varies according to the situation of the ground wherein the plants are to be located for final stay. If the soil is fertile and fresh, they (trunks) can be left at about 6 feet high from the base, and if it is arid at about 4 feet. The reason for this is, that the shorter the plant the more vigorons they grow. And as Columella said on this subject: "Lactius enim frondat. Exiguus admodum supra scrobum emineat."

Having thus fixed the height of the trunks all the young branches grown under them are to be takeu off', and to the main sprout growing high must be done the same, and by leaving on its upper end about from five to eight branches well distributed around the same, in order to form the head of the trees.

Another method in fixing the height of them is by cutting all the branches of the plant to the ixed point of height, in order to permitits roots to develop and to iucorporate themselves in the soil before the plant requires nourishment, and at the same time sprouts will grow to the desired height.

Transplanting for final stay.-We have learned up to this the sort of litnd and the exposition better adapted for the olive culture, as well as the several methods of propagation and the treatment to be given young . trees in the reservoir. I now deem it proper to treat about the system of removing them therefrom, and the distance apart to be left between them. Further, I will proceed with pruning, and of the several insect pests and diseases afflicting the precious Minerva's plant. 
When a grower is to transplant young trees from the reservoir to final stay it is necessary for him to establish a plan, and decide whether he wants to exclusively form an olive grove or together with plants of other fruits.

The disposing of planting in different manners is subordinated more to the inclination of the land than to the grower's faculty. The land may be too hilly or too flat. In the first case, it is better to plant all the land exclusively in olive groves, and in rows for the reason that disposing them with plants of other fruits between they would yield less frnit, besides rain-fall on hilly soil washes out the necessary elements of their growth, and the roots of the other plants would always be exposed.

The several dispositions to be given to olive trees, and the inclination of the land, determine the distance apart between the trees. If a certain area of land is desired to be exclusively cultivated in an olive grove, the distance apart between the plants is to be such that, in the spring equinox, a plant must not shade the one standing by in the direction from south to north. For that purpose a distance of $\mathbf{1 6}$ feet apart is sufficient. In a very rich soil, however, where the plant can grow very large, this distance must be doubled, 32 feet.

The inclination of the land for the grove properly adapted to the cultivation must be running from north to south, for the reason that if ex. posed to north entirely the culture would be retarded by cold weather.

Disposing the plants in rows, however, with the object of locating plants of other fruits between, the distance amongst rows must be 32 feet and 22 feet between plants of the same row.

The best disposition to be giren trees is the hexagonal one, as shown in Fig. 25, for the reason that if it runs from sonth to east the plants will be in a position quite open to the sun and will vegetate and grow well.

The proper time of transplanting from the reservoir to final location is the month of July or August, when ditches, either round or square, of 4 feet wide by 3 deep, will be dug for planting the young trees taken from the reservoir on hilly or rolling land. If the ground is flat, the ditches must be no deeper than 8 inches, and if on inclining soil 16 inches deep. This done, throw therein some filling of old plaster or old mortar with some stratum of good earth, wherein place the tree with the roots well scattered around the base; cover the same with some earth again, manure over it, and some wheat husk or hashed straw to keep the soil fresh during the summer and to nourish at the same time the tender roots. Shake the trunk a little, so as to allow the ground to be well settled between the roots so that they will be easily rooting. After this operation has been done, cover carefully the ditches with the same ground removed therefrom. On the upper side near the plant form a sort of a little basiu, so as to hold the rain-water to water the same. 
In the summer, if a long dronght should prevail, they must be irrigated.

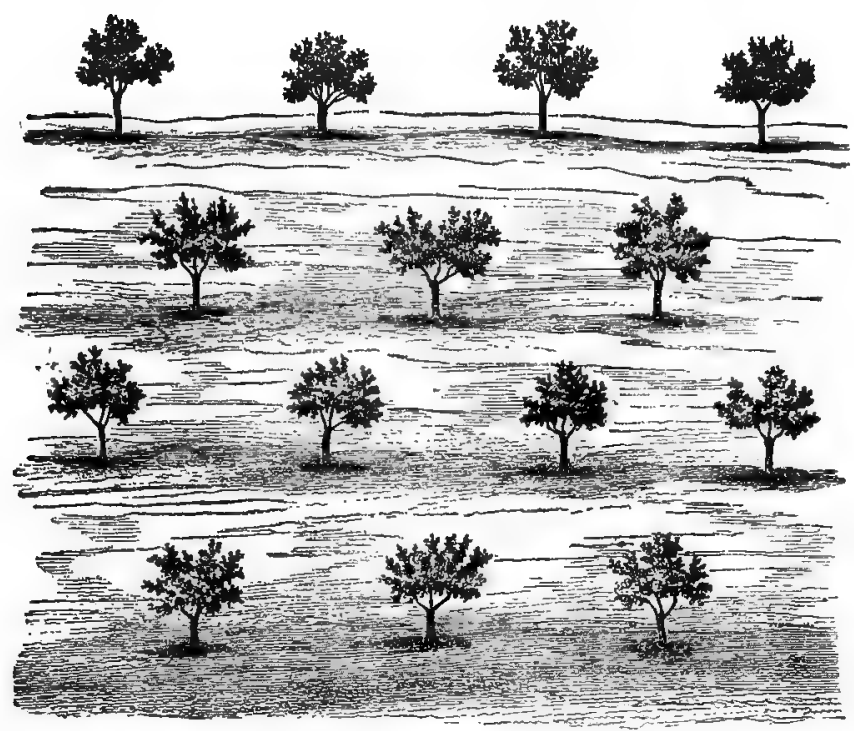

FIG. 25.

Pruning.-An old motto in Sicily says: "He, who works a growth demands the fruit; who manures it obtains the fruit; and who prunes the tree forces the grow th."

The principal forms to which olive trees can be reduced are four, to wit: $A l$ albero (shape of a tree), al pino, (sbape of a pine), al paniere (shape of a basket), al umbrella (shape of an umbrella).

The first form is mostly used in Sicily, in Calabria, and in some parts of the Roman and Tuscan provinces. It consists in learing the tree taking its natural habit, the pruning being limited by cntting now and then all the dried and broken branches and all those deriating the humor from the central trunk. The form al pino called also "cone," is more correct than the former, aud consists in allowing the branches to be disposed in a shape without hurting one another, thus forming a good exterior without exceeding leaves.

Pruning al Paniere, called also vaso (vase) consists in taking off the main trunk all the disfiguring branches to make a tree look in the shape of a vase. The olive plant so pruned appears with all the branches well ventilated, and, therefore, besides producing the great quantity of fruit, it furnishes them completely matured. For this reason pruning al paniere is considered as the most advantageous on $\theta$, and the same is generally used in this island. Finally, a good pruning must be based upon tile following principles, viz:

(1) An olive plant produces no fruit on new spronts before two 
years' time, for the reason that said sprouts in the first year bear no fruit but simply develop and bud fruiting gems, in the second year, when they will grow larger for blossoming, setting, and fruiting.

(2) The blossoms do not set neither produce fruit if not exposed to the sun rays during the longest part of the day. This fact must not be neglected by the pruner when he applies his pruning-knife, if he wants to gather the fruit. He must always prune so as to let the fruiting branches be exposed to the sun so that its rays will penetrate through the plants, as those thickly loaded with branches and leaves not pruned as above stated, bear less fruit than the former.

It is necessary for growers to keep those facts in mind, if they would succeed in this culture.

(3) The horizontal and bending down branches produce a great many fruit, while the vertical ones bear none. The pruner must consequently turn his attention to raise the plants as above stated, and not in a vertical shape.

(4) When a plant has a great number of bearing branches, the fruit will naturally be small, yield less oil, and the crops will be biennial. To aroid this the smart pruner should simply leave a certain number of the most rigorous branches sufficient enough so as not to force the plants, for by so doing they will render larger olives and more oil every year.

(5) The olive trees being of so many varieties they consequentls re. quire different treatment. 'To keep in mind the several varieties of olive plants while the pruning is going on, it mast be indispensable for the pruner to know that there are some branches tending to grow up straight, while others incline downward.

In the first case the former are not to be forced to grow low in a close shape, but simply prine them yearly, and try to prerent them from growing too high, and allow them to retain all the lateral branches except the dried and faded ones.

(6) The olive plant, according to the ground, its exposure, and the hoiglit where it is locatel, vegetates and bears fruit differentls. The quality of the soil has a certain noted influence on the regetation of the olive tree. If the soil is argillaceous and too rich of regetal and fer. tilizing matter, then little pruning is to be done, for the reason that the quantity of strength the plant draws therefrom permits it to maintain a large number of branches. If, on the other hand, the soil is poor, that is loose siliceous-aleareous, then it is necessary to cut many branches off, for the reason that the litile sap the plant draws from the soil is not sufficient to nourish many of them.

(7) The plants must be divided into three categories, according to where they are located: $(a)$ All the plants on argillaceous rich soil of the warm zone; $(b)$ all the plauts on calcareous soil of the midille temperate zone; (c) all the plants on the poor siliceous soil of the high cold zone. 
In conclnsion a good pruning consists of $(a)$ suppressing all branches tending to row up straight, as they are vely exhaustive; (b) cutting down all the parts from the plant, all the dead branches as well as those broken by the wind, and those growing longer than others; (c) suppressing all the sprouts developed in the plant during the year, leaving only some terminal ones, and some others grown near those having the force to bear. If many new spronts were left on the branches, the majority of them would fail to bear, because the sap the branches draw could not nourish them all. Praning in such a manner that the plants would grow in proper form, the branches should be well disposed without confusion, and the lower ones bending down would cover a part of the trunk. Another operation essential for the pruner to know is that if the trunk contains dried bark, knotty and partly detached from the wood, he should cut it off with a well sharpened tool, for the reason that in so doing he cleans the trunk from insects wherein they lay their eggs. Another advice to the pruner is that, following the years in which the plants bear much fruit, it is always better to shorten them a little, as it is proper to leave others longer, which during the years produced less.

In conclusion, following the rules above stated, the pruner can be sure of his success, provided, however, he will, with sharp eye, carry them on in accordance with the above instructions, always taking into account the local climate and coudition of the soil. These rules and modifications are the results of long experience.

Insect pests.-The olive has the most fearful enemies which attack it in erery way most terribly; in fact, insects, diseases, and inimical causes, more or less, make a slaughter of it.

Arrared in first line are the insect pests attacking the fruit, while others attack the wood and the leaves, thus hurting it in every way. The most terrible is the mosca dell' olivo (olire fl 5 ), or Daco delle ulive, known as Musca olea, Dacus olec, Cynips olece, Stornomus keironi.

The dacus is a small fly, about half the size of our common fly, and precisely as seen, greatly enlarged, in Fig. 27. It is an insect with orauge yellowish colored head, green eyes, jellow breast, with two black points. The female Dacus has on the extremity of its abdomen a sheath of black color, wherefrom it throws an arrow, piercing the fruit, wherein it deposits its eggs. This insect is so pernicions to the olive culture as to shorten two crops out of three. It works as follows:

As soon as the olires are formed the female Dacus throws its arrow, pierces the olive skin, shakes its wings, and into the pulp lays one egg, (Fig. 28). This done, the insect takes rest by cleaning its body as a sign of satisfaction, and then flies awily to other olires to perform the same operation until it deposits from 300 to 400 eggs in to as many olives. From the egg, in a short time, sou see a certaiu soft whitish larva with. 
out feet (Fig. 29), which, staying fifteen days in the palp, digs a vertical gallery through till it reaches the stone and diverging thereby.

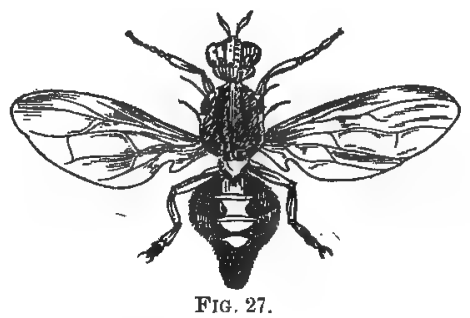

As soon as the larva is fully grown it gets near to the out fruit by enlarging the canal made by its mother on depositing the egg, so as to let the grown insect come out.

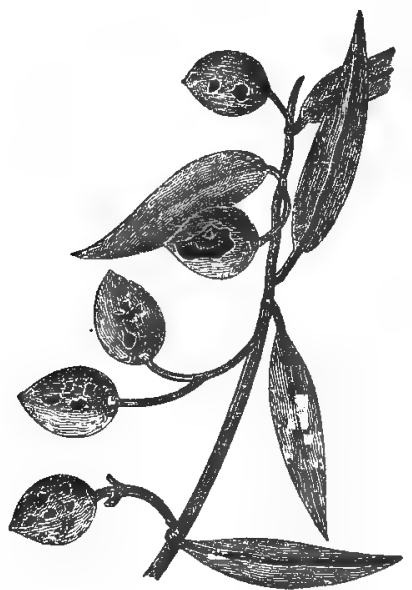

Fus. 28. - Olire intaccate dal Daco per deporvi le nova.

Twelve days from the time the larra is transformed in nymph grows the $\mathrm{fly}$, and the insect is formed in twenty-eight days, counting the time from depositing its egg.

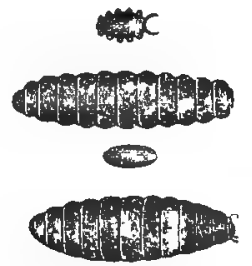

Tra. 29. -Larva o minfa del Daco.

The Cocciniglia (female Coccus) is another insect damaging the olive tree, which stays for several months immovably attached on the branches 
and on the leaves. When in a state of reproduction it lajs thousands of eggs, seeming as excrescences of the trees. The male Coccus looks different from the female, as shown in (Fig. 31), enlarged.

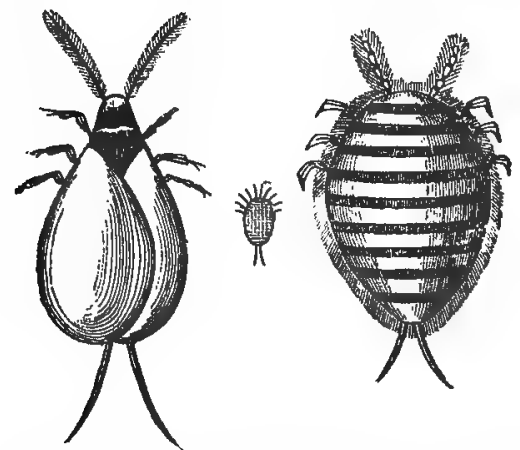

FIo, 31.-Coceiniglie maschio e femina ingrandite.

In the month of May the female lays about $1,000 \mathrm{eggs}$, which it covers and then dies, thus protecting the future progeny with its corpse.

The eggs under such protection open one month later and precisely in June, giving life to larvæ which develop in the bed formed by the mother skeleton.

The Coccus, attached to the branches and leaves of the tree not only sucks its juice, but prepares the tree for conditions favorable to the development of a fungus called "antennaria olæophila," "cladosporium fumago," or "torula oleæ," which darkens all the plants with black, and makes it look lurid-like.

In Sicily the olive plants are often invaded by the Coccus, and more especially on coasts fronting the African Sea.

According to the Gasparin and Roches method of destroying the insects, it seems that sulphur sprinkled on the attached plants, as it is done on the vines for the crittogama, is a good remedy.

La Tignuola (Tinea oleæ) is also an enemy to the olive plant. This belongs to the Lepidotteri family. Its butterflies are very small, with grayish wings and mostly marked with whitish spots-(Fig. 32, enlarged.)

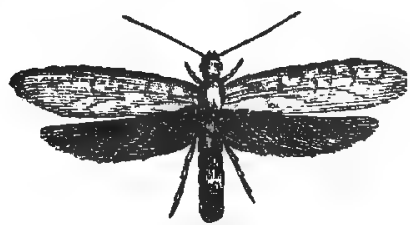

FIG. 32.

The evening moths, which ordinarily come to our house to die, burned at the candle flame, are "Tignole." The grubs are very small, voracious, and cause immensedamage. Their generation is as follows: In the spring 
seasons these insects, derived from the first generation, produce eggs; wherefrom grow larvæ, which voraciously ilevour the branches and sprouts of the olive tree. When it commences fruiting, the tignuole reproduce for the third time, after which they deposit their eggs at the base of the fruit, wherefrom new larva come out, and stay there until they ure in metamorphosis, and as long as the fruit remains on the tree.

To destroy said insects, Prof. Achille Costa published the bibiologia della tignuola, a copy of which I conld not find in this city. The Punteruolo is a "coleottero" belonging to the section of Xilofagi, and its botanic name is Plilojotribus oleoe. It also causes much damage to the olive tree. For its treatment the same Professor Costa published a report on the Agricoltura Meridionale (anno III, No. 13, 1880) and of which I could not procure a cony in this place.

Another small colleottero, Rosicante dell olivo (olive-eater), is the socalled Hylesinus oleiperda, a dark-colored insect corered with hair. The larva is white and nests under the bark of the tree, and sucks the life of the sap branches in the cell which it digs, accomplishes its transformation, and flies away when perfected, about the month of May. It then joins the female, which, having been impregnated, goes u pon the branches, which it wounds to deposit an egg, which forms a larva, as above stated. To destroy the said insect some people propose to cut off the perforated branches from the tree, while others recommend, as soon as the insect attacks the plant and weakens it, to manure it, plow and water the same so as to make it revire again.

La Cantaride (Cantharide vescicantoria) is anotler insect belonging to the coleottero order, tribic of the coleotteri vescicanti. From the deposition of the egg and its transformation into a perfect insect it undergoes fire stages, but only when it is perfected does it damage the olire tree.

La cantarides appear in the month of June in extraordinary number, when they dart in flight on the olice trees, feeding on the tender spronts and blossoms, and thus not only destroy the present crop, but eren the one of the succeding sear. The cantharides are very common in continental Italy but not so numerous, while here in Sicily they cause beavy damages. These agriculturists, however, perform an efficacious method, as the only one to destrop the terrible coleottero. It consists in shaking the branches early in the morniug, and precisels when ther they are asleep, to make them fall on sheets expressly placed under the trees. Thus gathered they are then sold to apothecaries for making blistering plasters.

La Psilla dell'Olivo (Psylla olivina) as well as l'Atide (Aphis adonis) form a sort of a white down under the arm-pits of the branches and leaves. The Aphis abide under the same; fueding on the humor of the trees, which become sickly and sometimes die if the infected brauches are not cut off at once. The saicl aphis, well known in the Tuited States-for I remember my boys used to catch them on trees on Canal 
street at New Orleans-is also another dangerous insect to the precions plant. The same shown enlarged in Fig. 33 is destroyed with lye of lime.

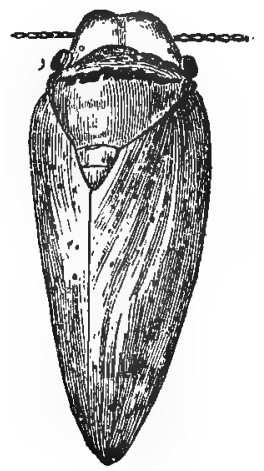

FIG. 33.

The Psylla, when in the state of larva, encircles itself in a sticky whitish matter, and causes the plant to droop.

This disease is generally called here malattia del cottone (cotton dis. case), and the most energetic remedy is to treat the plant by cutting off all the infected branches.

Finally, the Cosso perdilegno (Cossus legniperda) is the most terrible in. sect, damaging the rood. The cossus when in a grub state is bloodish-red on top and white-yellowish under. The butterfly deposits an egg in the bark, wherefrom grows a grub, which bores into the tree-into the heart of the tree-killing it at once; if the tree is young, the cossus is assistcd in its work of destruction by a special liquor of a strong odor secreted by the insect itself, which softeus the wood fiber. This terrible insect is difficult to be destroyel. It lives three jears in a state of larva, and the butterfly is found in the spring and summer; consequently at such a time it is necessary to use a certain activity to destroy it. The nat. uralist Professor Boisduval advised the municipal authorities of the infected places to "offer one lira of reward for every cossus canght as a good remedy to destroy the same."

Diseases.-Besides the said insects there are also diseases to which the olive plant is subject, such as (1) Il Chiodo o Rogna (the nail or scab) the cause of which is by some growers attributed to insect punctures, and by others to the imperfect assimiliation of the juices, which instead of alimenting the plant, accumulate at cortain points, producing deformed excrescences, as in Fig. $34, a, a, a, a$.

Il Chiodo (nail) generally dilates in olive groves propagated by onoli (springs), and greatly prevails where the forced method of propagation has been practiced. The extrarasation may be caused by wounls pro. duced by hail, or by the bark cracking while the plants are in active vegetation, or by the ill-treatment to the bark while gathering the crop. The canse most common, however, is excessive pruning. 
(2) There is La Fungosita vascolare (vascular fungus).

(3) La Lupa (she wolf), is a very cancer to the plant, which, although its exterior is sound it is rotten within, permitting the rain to enter and lodge in the interior.

The lupa may be apparent or not. It is necessary to extract it and thoroughly cleanse the infected part with a sponge saturated with a wash of ointment San Fiacre.

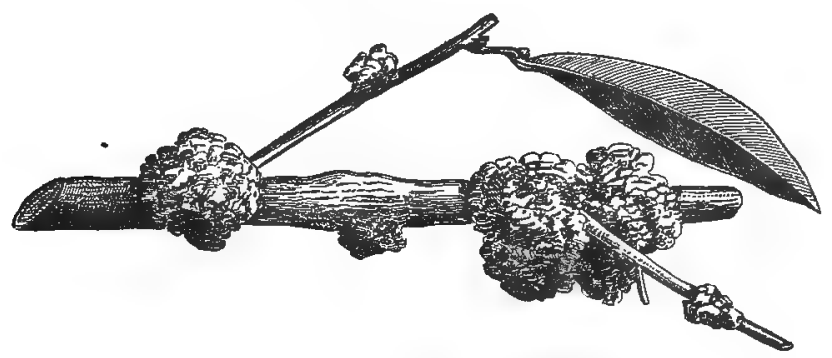

FIG. 34.

(4) Lo Screpolo (gap) is caused by excessive heat or cold. The gaps caused by the former are superficials, and are also cured with the same salve-San Fiacre.

Among the parasite plants hurtful to the olives are noted the Muschi (musks), the Licheni (lichen), and the Borracina, which establish them. selres in the bark of trees, on which they live in part.

The production of musks and lichens is due to the dampness abounding in some olive groves, or on account of the quality of the soil or dittle ventilation. To free the plants therefore from it it is necessary to scrape them with a well-sharpened spatula, and brush the infected part with whitewash on a winter das, but not cold or raing.

Besides those there is also Il Male nero (black disease), which is produced by a fungus, botanically known as Antenaria olacophila, Chados. porium funago, which sometimes causes the plant to sicken and die. Its multiplication is due to presence of the Cocciniglia; bence by destroy. ing the coccus you free the plant from the black disease.

Frost and strong winds are also enemies to the plant, and the damage which the former causes may be known only in the month of April or May, just at the time when it cau be partly remedied. Sometimes it happens that through intense cold the plant dies at the base. In that case, if it is orer thirty years old, the plant unust be cut off near the ground so that new s/rings will grow therefrom, some of which will take the place of the dead plant. A long drouglit is also hurtful to the olive culture, for the reason that the plant loses its leaves, its regetation is checked, and it yields no fruit.

Strong winds may also ruin the plants by breaking the branches or dislocating them. Finally, were $J$ to mention other insects, diseases, atc., it miglit have a depressing effect on the California growers. Con- 
sequently, I deem it proper to remind them that notwithstanding all the said insects, contrarieties, etc., in this island of Sicily, in an area of 104,585 hectares of olive cultivated land, it yields an annual produc. tion of 730,238 hectoliters of oil, at the rate of 7 hectoliters per hectare, a good paying industry, besides many quintals of pickled and dried olives for home consumption and for foreign markets.

Therefore I exhort the California agriculturists to go to work and dedicate themselves earnestly to the culture of that most precious plant, the olive tree, by repeating to them the celebrated Columella's motto, Olea prima omnium arborum est.

Vingent Lamantia,

UNITED STATES CONSUlate, Consul. Catania, January 22, 1890.

\section{ITALY.}

REPORT BY CONSULGENERAL RIOHMOND, OF ROME.

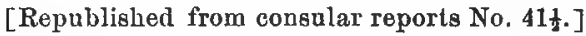

Only one species of olive is cultivated in Italy, Olea Europea L.

Varieties.-The widest spread varieties are the following: In Liguria, the Laggiasca and the pignole.

In Puglia, the pasole, the ogliarola, the leccese, and the siracusana.

In Tuscany, the morinelle, the morajole, the correggiole, the razze, the grosse, and the infrantoie.

In Sicil 5 , the ogliaja, the biancolilla, the calmignana, the caltabellotese, the cerasola, the calabrese, the patornese, and the giarraffa.

Maturity.-After the tenth year the olive commences to bear some fruit, and reaches its full maturity of fruitfulness at the age of forty years.

Green olives.-For green olives the fruit is used of the Cucca or Pesaro in Tuscany, of the Orfana in Romagna, of the Morellara and the Giar. raffa in Sicily, and of the white olive in Ascoli. Of all these varieties the fruit is large and less saturated with oil than any others.

Dried olives.-For dried olives the fruit of the common trees is best adapted.

Yield. -In Oalci a hectare of olive trees yields in abundant years 6.50 hectoliters, or an average of 3.25 hectoliters. The expense of the first planting of a hectare of olive trees amounts to 3,292 lire; annual expenses 250 lire until the tenth year. In the eleventh year the trees begin to bear and reach the climax of their fruitfulness, as has already been stated, at the age of forty jears. In the forty-first year the expenses of the hectare of olive trees have been 9,689 lire, and the average yield of oil per annum 3.25 hectoliters. The olives yield in weight from 
14 to 20 per cent. of oil, and in volume from 20 to 24 per cent., accord. ing to the variet5, the point of maturity reached, and the manner of extracting the oil.

Planting.-The trees are planted from 12 to 18 meters apart, if they are of a very large and ligneous variety, or if vines or other plants are grown together with them. For short-stemmed trees the distance is shortened to from 5 to 8 meters. On hillsides the distance between the trees is reduced somewhat.

Preserving.-Olives that are put in salted water, or in any other way preserved fresh and sweet, are gathered green; those that are to be dried are gathered ripe. Olives from which oil is to be extracted should be gathered when just ripe; unripe olives give but little oil, and that of a grassy flavor, while those over-ripe yield abundantly, but the oil is coarse and rank. The time for reaching the proper point of maturity depends on the locality, the variety of olive, and upon the season; but when the first fruit drops spontaneously to the ground it may be takei as a sign that the crop is ready for gathering. Generally this takes place through December and January.

The olives that are to be preserved fresh are first soaked in a stroug lye, then, after having been put through several washings in clear water, they are placed in salted water, together with wild fennel. Finally they are put into water slightly salted, which must be renewed at least once a month.

Olives that are preserved dried are spread out in the open air, in some place exposed to the tramontana (wind), or else they may be dried in ovens.

Extracting the oil.-To extract the oil the olives are placed in a crush. ing machine, where they are reduced to a paste, which is then subjected to a pressure sufficient to express the oil.

Soil and climate.-The olive grows best on slopes, well sunned, but not too dry, and trees grown in such localities produce a very superior oil. In fertile plains and valleys a large quantity of oil is obtained, but the quality is inferior to that obtained from the hillsides.

The soils best adapted to the growth of the olive are porous and rather moist; such are many chalky and argillaceous soils, also a yellow, sandy soil over argillaceous strata.

Irrigation is not necessary in olive culture.

Locality.-Olive groves are planted sometimes very near the sea, in places least exposed to the wind.

LEWIS RICHMOND, Consul-General.

United States Consulate-General, Rome, April 1, 1884. 


\section{ITALY.}

REPOIT BI CONSUL ORAIN, OF MILAN.

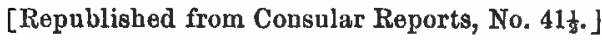

The superticies devoted to olive culture in Italy is approximately 900,311 hectares (equal to $2,224,668$ acres), and the total production of olive oil about $3,385,591$ hectoliters (or $89,437,157$ gallons), distributed as follows :

\begin{tabular}{|c|c|c|}
\hline Districts. & $\begin{array}{c}\text { Area of cal- } \\
\text { tivation. }\end{array}$ & $\begin{array}{l}\text { Total produc- } \\
\text { tion of olive } \\
\text { oll. }\end{array}$ \\
\hline 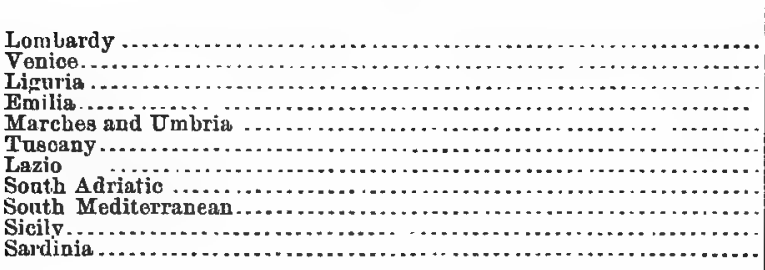 & $\begin{array}{r}\text { Hectares. } \\
4,591 \\
3,536 \\
84,931 \\
4,694 \\
76,271 \\
119,278 \\
41,667 \\
270,090 \\
139,928 \\
104,373 \\
51,582\end{array}$ & $\begin{array}{r}\text { Hectoliters. } \\
6,381 \\
9,321 \\
343,204 \\
14,757 \\
195,659 \\
285,006 \\
95,834 \\
557,649 \\
636,540 \\
730,238 \\
211,005\end{array}$ \\
\hline
\end{tabular}

The reports of the Italian minister of agriculture contain much that is interesting in regard to this industry.

The olive is indigenous to Asia. It is mentioned in Genesis, Hesiod, and Homer, but was not introduced into Europe, according to Pliny, until the two hundredth year of Rome. It is hardy, and grows wild in southern Europe-Linnæus calls it Olea Europcea, as if indigenous to Europe. It is cultivated in Spain, Greece, Italy, Languedoc, and Provence. The forty. fifth degree of latitude is considered the northern limit of culture. Great heat or coll is unfavorable to the plant. It is not fonnd in Africa far from the Atlantic; and Humboldt noticed in various parts of St. Domingo and South America that it grew there without bearing fruit. It has been erroneously claimed that the olive would only grow near the sea. It is found at great distances inland, but abounds most near the coast, where the temperature is more congenial. The variation of altitude at which the plant can thrive depends upon the region. In central Italy the greater part of the olive zone is below an elevation of 500 meters, and in Sicily below one of 600, while in the basins of the lakes of Garda and Iseo 4j0 meters is the extreme limit. At this extreme limit the cultivation is unprofitable, as the fruit often fails to mature. The plant requires a soft and temperate climate. In districts where the temperature is higher than required bs the plant it is cultivated by preference on elevated lands; in those where the tem. perature is low it is given a warm position. The north wind is the enemy of the olive. In the same region it flourishes on high lands pro- 
tected from that wind, and languishes in low lands exposed to it. Upon the plains of Mugello and the Borgo San Lorenzo, swept by northerly winds, it will not grow, but flourishes 3 or 4 miles away on the hills-protected by the Apenuines.

Cold affects the olive according as the atmosphere is dry or humid. The same degree of cold is more fatal iu spring than in winter, because in the former season, the plant having entered the period of vegetation, the young and tender germs are injured; so by reason of the greater moisture the cold of the plains is more injurious than that of the uplands. Nothing is more destructive than the formation of ice upon the branches after snow-storms. The greatest cold which the plant can resist is about $10^{\circ}$ Reaumur; at $12^{\circ}$ not only the leaves perish but the trunk and roots above ground. It sometimes suffers at even 70 when the cold is accompanied with humidity, or when the plant is in a state of vegetation. Sometimes the leaves are destroyed by a frost apparently light. The greater part of the olives of Liguria and Tuscany perished in the years $1709,1782,1820$, and 1845 .

As to the soil there is not much difficulty. Only exceedingly light or wet land is bad for the plant. It does better ordinarily in argillaceous or calcareous earth, mixed with stones, to which its roots cling, holding steadily against strong winds.

The olive is propagated in four ways-by seeding, by cuttings, by grafting, and by the system called ovolo.

Italian cultivators generally adopt the last method, but as the others are not unfrequently used it may be useful to give some facts in regard to them.

The mauner of seeding is much the same as with other plants. The olive used for this purpose is selecterl from trees well grown, of a robnst variety, possessing the qualities desired, and is stripped of its oily pulp. Seeding involves the labor of transplanting and improving by grafting, as the new plants raised from a given variety will not reproduce it, but return usually to the wild type. Another objection to this system is the slow growth of the olive. Hesiod said of it, "Those who sow the seerl never gather the fruit." However, some use this method, as plants thus obtained have greater dimensions and a more perfect root system.

When cuttings are used they should be young and vigorons, from 50 to 55 centimeters in length, and about the size of a man's wrist. The bark must be bright, smooth, and sappy, and contain towards the lower part some knots, upon which roots form more easily. The cuttings are set in the ground in November in warm localities, and in February and March in temperate. A bout one third of the cutting should be above ground, and the upper extremity, where cut, covered with grafting- $\mathbf{\text { anx. }}$. Although the olive is an exceedingly hard wood, it puts forth roots from cuttings as readily as the willow or poplar. Full grown trees, even when much denuded of roots, can be transplanted from the forest, alid often when those in the olive-yards are destroyed they are replaced in this way. 
In the process of grafting sprouts are taken from the base of the tree and the operation performed as with other species of trees.

The propagation of the olive by means of ovolo (eggs), called by the ancients occhi (eyes), is the usual mode, because surer, quicker, and cheaper than any other. Ovolo are woody excrescences on the lowest part of the trunk and on the roots of the olive, and so called because of a supposed resemblance to eggs. These are detached with a sharp knife and put in the ground to the depth of 4 inches. This is done in November in warm districts, and in March where colder. When the ovolo germinates, one shoot is preserved and the others cut off. The preserved shoot is steadied against wind by a stake to which it is tied. The plant thus started is removed after three or four years to the permanent olive.yard.

In most cases the olive has to be grafted, as the young plants usually take the wild type, and consequently yield only small fruit.

By cultivation a number of varieties of the olive have heen obtaiued, differing according to localities; some distinguished by a greater or less vigor of plant, some by drooping, and others by erect leaves, and more especially by the form, size, and color of the fruit. The color varies from green to red, and in some cases to a purple, nearly black. Professor Urphanides discovered in a grove of Attica an olive perfectly white, and which was exhibited at the Vienna Exposition under the name of olea cucocarpa, or chionocarpa. 'Tavanti's work mentions twenty-one varieties in Tuscany. Piconni observed sixteen in Liguria, and Caruso fifteen in Sicily.

The extent and kind of pruning depends upon the variety of the olive, and must be performed with care.

Composts of slow assimilation, such as horns, bones, woolen rags, etc., are most used.

OLIVE OIL.

The quality of the oil depends greatly upon harvesting the olives at the proper time. If this is done either too early or too late the product has a fatty flavor and odor.

Italian oil.-The oils of Lucca, Calci, and Buti are the best in the world, and those of Umbria and Liguria are but little iuferior. The best article is produced in moderately warm regions.

Thus the oils ot Italy are more esteemed than those of the Orient, and of the former the oils of Pisa, Lueca, Arrezzo, Perugia, and San Remo are better than those of Sicily aud the Neapolitan provinces.

While soil, climate, and the variety of the plant affect more or less the quality of the oil, much more depends upon harvesting and pressing the olives properly. This is done much better in central Italy than farther south.

Spanish oil.-Next to Italy comes Spain in extent of olive cultivation. According to Mueller the production of oil in that conntry is about $1,135,750$ hectoliters per year. It is chiefly cultivated in the basins 
Guadalquivir, Ebro, and Guadiana, and the produet constitutes an important branch of commerce for Andalusia, Aragon, Catalonia, Murcia, Navarra, aud the Balearic Islands.

Spanish oils are very little esteemed, and their exportation is rather diminishing.

French and Algerian oils.-In France the cultivation is confined to the southern districts, and covers 94,000 hectares. The production is about 250,000 hectoliters. In Algeria about 150,000 hectoliters are produced, of a quality inferior to that of Italy, but better than that of Levant, Spain, or Portugal.

Austrian oil.-In Austria the olive is a little cultivated in the sonthern Tyrol, in the territory of Gorixia, Gradisa, and Trieste; more extensively in Istria and Dalmatia. The yearly production is about 264,000 quintals. Of the preduction in Greece accurate statistics are wantiug, though it is known that the cultivatiou is extensive.

Ottoman oil.-In the Ottuman Empire it is cultivated in Syria, Brussa, Roumelia, and in the islands of Candia, Cyprus, Metilino, Samos, and Rhodes.

Greek oil.-Grecian and Turkish oils are, however, only used in Europe for the manufacture of soap.

\section{PRICES OF OLIVE OIL.}

The price of olive oil fell from 170 franes per quintal in 1879 to 120 francs in 1882, and the several grades of this article are quoted in the Bulletin of Agriculture, of the 8th instant, as follows: Oil of Lucca, 168 to 195 francs; olive oil for burning, first quality, 85 to 88 francs; second quality, 78 to 80 . The cause of this depreciation is the fow uses to which olive oil can be pat and the increasing competition of seed oils. The larger olive harvests in Italy and the whole Merliterrauean basin is another and lesser cause. The competition is principally with the kinds of olive oil used for industrial purposes, and which represent about two. thirds of the entire production. Alimentary oils scarcely feel this com. petition. In the retail market the price of the oils of Lucca and Barri has been almost unchanged, and the demand for them abroad fully sustained.

\section{GOTTON-SEED OIL.}

The seed-oil industry is assuming considerable proportions. Several kinds of this oil were exhibited at the Milan exposition in 1881, and classed among alimentary oils. There were some beantiful specimens of sesame oil exhibited by Messrs. Scerno \& Gismundi, who were then producing 30,000 quintals per year.

The importation of cotton seed oil was arrested in 1853, sinee which the demand for olenginous seeds has increased. In $185^{\circ}$ the importation of these seeds amounted to 252,835 quintals, being 52,335 quintals more than the previons year. It is therefore urged that a duty should 
be imposed on all imports of seeds and seed oils if it is to be contiuued on cotton-seed oil.

It is claimed that the duty on cotton-seed oil has served no good pur. pose; that the mixing of cotton oil with olive was not prejadicial to lealth, and that the mixture is now made with oils from flax and nuts, and other deleterious substances; and that the competition formerly coming from cotton oil has been replaced by oils of other seeds and by nut oils.

It is stated on good authority that no practical method exists by which these mixtures and their properties can be detected, and it is felt that frauds will diminish, and the publie good be promoted, when prejudices against good seed oils disappear and they are sold under their true names.

\section{Dunham J. Crain, Consul. \\ United States Consulate, Milan, November 10, 1883.}

\section{GENOA.}

REPORT BY OONSUL FLETOHER.

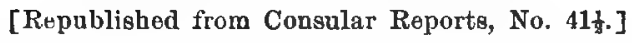

Varieties.-The best olive oil is extracted from the following-named trees:

I. The Giuggiolina, knowu as the Lavagnina or Taggiasca.

II. Radiola or Razznolo and Pendolina.

III. Grappolosa or Merlina-Pignola doppia.

IV. Tondolina or Pignola.

V. Martellina or Martena-Papollina.

Seeding and planting.-The length of time between seeding or planting and fruit bearing depends altogether on the manner in which the work of cultivation is performed. If trees are raised from seed, sixteen years is allotted before fruit bearing; if by spront, plant, or shoot, it depeuds on the age thereof; if by snags, it will take from twelve to thirteen years before a crop can be realized. A full crop can not be expected till the tree reaches twenty-five or thirty years.

Plants brought np from seed and shoots must be ingrafted; otherwise. the trees and fruit remain wild; snags also; in fact, all must be grafted if taken from the root or below the graft of the parent tree.

The mode of cultivating olires in this province is as follows:

Olives are multiplied by shoots or sprouts; they are, when sufficient vitality is assured, replanted in the soil where it is designed they should grow; they are mulched every three years with manure of slow decomposition as, for example, the scrapings off horns, grounded hoofs, woolen rags, and stable maunre. Manure of quick decomposition is good for 
only one year, and has this disadvantage, it develops more leaves on the tree and rank vegetation than it does fruit. The trees must be kept clean, that is, free from sprouts and weeds; standing water must not be allowed aronnd them, for in such case the wood will soon rot and be a subject for a malady called "lupa," which very much shortens the life of the tree.

Olive Regina, or queen olive, known in this province under the name of Olive of Spain, is a special quality grown from the imported tree cultivated for special purposes. The fruit, however, contains but little oil, and that little has to be extracted before using the olive for culinary purposes.

Production.-If olive trees are well cared for they generally give abundant fruit when they attain the age of thirty years, and even long after this age they increase if properly handled. An olive tree is liable to live for centuries if not destroyed by the "lupa."

The production of the olive depends on the care taken in its cultivation, and much on the weather, for, be it understood, the fruit is ex. posed nearly the entire year, before maturity, to all atmospheric changes. The yield therefore depends largely on the meteorological vicissitudes of the seasons, and for this reason the exact figures can not be given. This much, however, can be said, an olive tree between twenty-five and thirty years old will produce about 3 gallous of oil.

1 liectare of land ( $=2.471$ acres), in fine, if properly cultivated, ought to produce about 300 gallons of oil. The same measurement of land will produce better results providing the conformation of the soil permits the trees to be set closer than 12 meters, or about 40 feet, apart. The olive crop can be considered only from a biennial stand-point, and the above is the average for two years.

The relation between the weight of olives and the quantity of oil is not constant in all crops, nor equal on all lands, for this reason: On flat lands and in places where rains are frequent less oil and more water exists in the fruit; on the other hand, if the grove is on the hill-side the proportion is as one to four, or one gallon of oil from four gallons of fruit.

The distance between trees on lands exclusively devoted to olives should be about 50 feet-if on flat land and in orchards-on hill-sidès 39 feet, or even less-always less on pedente or abrupt inclinations. Flats are especially prepared on hilly lauds, and so arranged that the roots of one tree can not run down and interfere with those of another. In other words, the roots of trees are limited to certain space by the erection of stone walls, and when thus arranged the olive plant will flourish at at distance of only 30 feet apart from its neighbor.

Pickling.-For pickling purposes olives are gathered before they change from green to a reddish color. The faintish tinge from the original green indicates incipient ripeness. For pickling, olives are usually gathered toward the close of August. The olive must be fully 
ripe when picked for oil. When matured it drops from the tree. This occurs late in the fall or early winter, as in all its stages, from bud to full-grown fruit, the atmosphere also has its influence in bringing the olive to maturity.

For table use you have the olive in three ways :

(1) Pickled green.

(2) Dried when ripe.

(3) Pickled when dead ripe.

They are prepared as follows: The green olive is placed in a strong solution of lime long enough to take the oily substance out; the wellmatured olive is dried in the sun; the ripe pickled olive undergoes the same process as the green, only salt is used instead of lime. Further, the green olive, when purged of oil, is conserved in salted water. The dried olives are placed in jars, with sufficient oil on top to prevent the air drying and oxidizing the bulb, but no oil is allowed to sink to the bottom of the jar, for fear of getting rancid and therebs communicate a bad odor to the fruit. Aromatic herbs in certain quantity are generally used to aromatize the fruit preserved in this way. The ripe olive is pickled in brine of salt, as stated, but the brine is frequently changed in order to extract the oil and sour flavor. The olive must not be too salt. When prepared as given above olives will keep a long time.

Oil extraction.-Oil is extracted from the olive by crushing the fruit in a stone press. When a certain quantity are reduced to a pulp the crushed mass is placed in a sieve-like receptacle, and this mass when pressed produces the oil. Pressing by hydraulic engines has been tried in the past, in order to obtain a larger quantity of oil, but this power proved too great in that it actually spoiled the oil. Such a pressure is used now only for extracting oil from husks.

Results. - The best results in olive cultare are derived from hill-sides and protected by sea winds; in such locality even the most gentle and tender kinds are comparatively safe. Olives raised on flat lands, as elsewhere mentioned, contain more water, for the reason that they are not sufficiently exposed to the sun (on account of mountain shade), and are always liable to be frost-bitten. Even on table-lands the olive is often damaged by winds, which forces the fruit to fall before maturity. Cold winds always hinder the growth of olives, and they are especially damaging to young branches.

Soil and climate.-In Liguria, including all the province of Genoa, the highest elevation of land on which the olive is cultivated ranges about 1,600 feet above sea-level; the orchards, however, are all in the south side of the hills and protected by lofty mountains from north winds.

The olive tree will prosper in almost any kind of soil, rocky land included, except that of a sandy nature; the latter absorbs too much heat, and therefore cause rapid evaporation, which deprives the soil of the necessary moisture in summer. Very damp soil is prejudicial for the reason that the tree is liable to the ravages of the "lupa." Olive 
groves are not irrigated in the province of Genoa; the soil is generally considered strong enough to retain moisture a long time, even in the dryest seasons. Young plants are watered, however, in the summer, but great caution is practiced in this work, for too much moisture injures the roots and then comes the "lupa" plague. Throughout this entire province the olive orchards are all on the sea-coast; they extend inland but a short distance. You can find inland places, however, where olives would bear well; that is to say, in situations where the temperature undergoes no serious change.

The price of olire oil varies according to the quality and quantity of the crop. For same reason the average annual yield can not be given. On these points I particularly inquired, but failed to obtain satisfactory answer.

Cost of cultivation.-Answer 5 and 6 give possible yield under ordinary conditions, so I pass to the cost of cultivating olive groves. The work is divided into two parts each year, first, plowing so-called flat lands and hoeing hill-side orchards; second, clearing the ground of weeds.

The following statistics were given me by a gentleman experienced in olive culture, and while his statements may not be as clear as desired I can not do better than give them as narrated:

One day's plowing costs 11 francs $(\$ 1.90)$, and two days with the plow is sufficient for a hectare of land (2.471 acres). Where the plow can not tonch on account of the trees, a hoe is used. As there are abont 120 trees in a hectare of land 10 men at least are needed for such work, at 2 francs (38 cents) per day. Now as to manuring groves. The trees should be mulched once in every three years. Experience has taught that the best way was to manure one-third of the orchard this year, onethird next year, and so on. The compost for a tree which yields, say, 10 liters of oil (about 22 gallons) costs about 67 cents; at this rate the manure for an orchard of 120 trees will cost a fraction over $\$ 80$. Consider then a workman's labor at mulching, 20 days, at 38 cents per day ; clearing weeds 8 days at same wages, then pruning, plowing, etc., and you have incurred an average expense on each tree of 80 cents. In fine, you realize about $\$ 190$ from a Lectare of olive trees, and it costs you onehalf that sum to care for the land. From the other half you must pay Government, provincial, and communal taxes, which are no small items.

Rain-fall.-The result of meteorological observations for the last ten years in the province of Genoa shows that about 48 inches of water had fiallen each year (almost incredible, but substantiailly vonched for). It was nuch less on the oriental coast, and fully one-third less on the western coast.

\section{EXPORTS AND IMPORTS OF OLIVE OIL.}

Strange as the item may appear, it will be seen in the table that 28,358 kilograms of pure olive oil was imported into Genoa from the United States and Canada during the year 1883: 
IXPORTS OF OLIVE OIL.

[All measurement in kilograns, acuording to the rulo of Italy. One huudred kilograms tqual to 220 pouvds.]

United States and Canada .................................... 104, 045

La Plata States ........................................... 757,026

Chili and Peru ............................................ 15,022

Other American ports ......................................... $2.049,781$

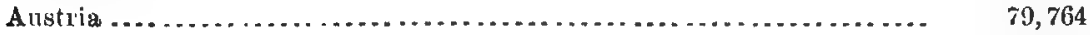

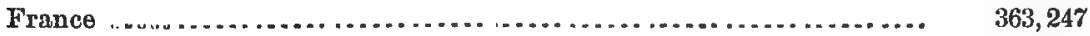

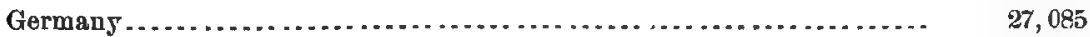

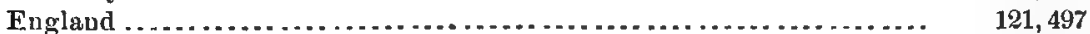

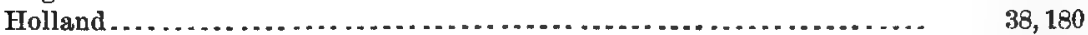

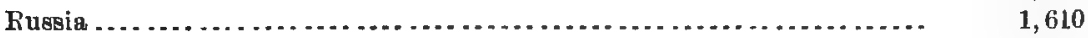

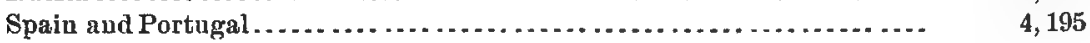

Turkey ... .................................................. 8,169

Tripoli and other African ports........................... 275

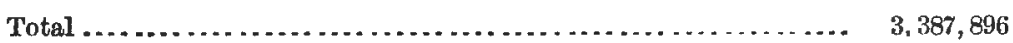

IMPORTS OF OLIVF OIL.

United States and Canada..... 28,358

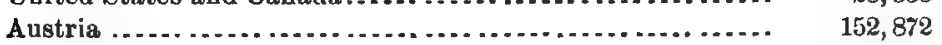

Tripoli and other African ports .................. 1,832,201

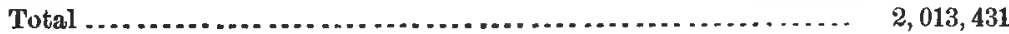

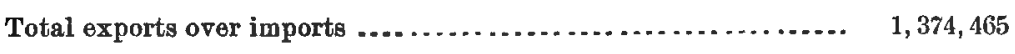

JaMes FLeTCHIR,

Consul.

United States Consulate,

Genoa, May 1, 1884.

\section{LUCCA.}

REPORT BY OONSUL RIOE, OF FLORENOE.

The variety best adapted for pickling is the Trantojo olive, also called "National" or "Gentile," and is also good for extracting oil. The "Morajolo," "Gremiguolo," and "Leccino" produce the purest oil.

The trees which produce the above varieties are grown on hilly ground, where the tree is planted, about 3 miles from the sea, and at an elevation above sea level of 650 to 2,300 feet, and in certain localities at even a higher elevation. The most favorable situation is facing south, and the soil best adapted is rocky and sandy. Serere cold spoils the tree and the olive.

When the tree is from three to four years old it is transplanted, always in the summer, and if found necessary watered. The cultivation takes place in antumn, for the manure, and in the spring for the working of the soil. The pruning takes place in autumn. 
The olive is generally picked from October to May, but this must depeud on the climate.

The olives are picked in two ways, viz: (1) In October, when the olive is green and not too oily, it is put under lime and ashes mixed with water, and washed afterwards in pure water; it is then put in other pure water, adding 17.10 pounds of salt for every 220.11 pounds of olives; (2) in February, when the olive is oily, it is picked by hand and placed for forty days in pure water and kept in it, until the nut leaves the fruit by squeezing it-then continued as above.

As to the process of making oil it is as follows:

The fruit as soon as gathered is brought to the store-rooms attached to the olive-mill, and there spread out until it can be crushed in a thin layer to avoid overheating. The ripe olives have a lustrous purpleblack color. In making the finest oil any damaged fruit is put aside.

The mill consists of a large mill-stone revolving in a trough built of stone. It is driven by water-power if available, or else by animal power, generally oxen. The olives are placed in the mill and quickly crushed to a pasty mass, including the stones. The pulp is next transferred to fiber-bags, and these placed in a screw or hydraulic press; on pressure being applied, the oil flows forth, and is collected in a suitable receptacle. In order to disengage all the olsaginous particles, water is poured over the bags. In making the finest oil it is essential to use only cold water, which must also be pure and uncontaminated. Hot water, though more efficacious, would deprive the oil of all its delicacy. The first pressing of sound fruit yields the finest quality of olive oil.

Newly made oil is allowed to rest a while in tanks, so that some of the solid matter from the fruit, which is held in suspension, may have time to deposit. It is afterward clarified by passing it through pure carded cotton. It is then fit for the market.

The pulp from which the first oil has been expressed is again placed in the mill and the same process repeated a second time, bot water being used instead of cold. A second-rate quality of oil is thus obtained, which is kept separate at those olive-mills where the finest oils are produced. Even then the pulp is not done with. It is crushed again in another mill with the addition of water, then passed iuto a circular tank, where agitators separate the residuum of pulp from the remaining small parts of the olive kernels.

The latter is renoved and used for fuel.

The pulpy residual is again subjected to pressare and some oil obtained of very inferior quality.

The water which has been used in the agitator flows down and passes through settling tanks where some little oil comes to the surface and is collected.

'The trees commenced bearing fruit when about ten years old. According to plants, soil, cultivation, and climate, the yield may give from 220 to 330 pounds of olives. 
The trees are planted at a distance of 10 to 11 yards from one to another.

Trees are propagated either by seedlings or cuttings. The latter are taken from trees which have been cut or blown down, and from the roots where suckers would develop. The seedlings revert to the wild species of olive tree, and hence must be grafted; this is generally done when the tree is from six to eight years old.

A fly termed "Musca oleae" is one of the greatest enemies of the olive-tree farmer. This insect is about half the size of the common fly; its head is of orange color, green eyes, body aud wings variegated. The female deposits its eggs in the olive berries; they develop into small white maggots, which destroy most of the pulp of the fruit. In the cavity so formed water penetrates, causing rottenness. Oil made from such fruit is thick and nauseous to the taste. This fly makes its appearance in Tuscany in September. The ravages it causes are almost incredible. There is no possible treatment.

William T. RIOE,

\section{United Stateas Consulate,} Consul. Florence, MLay $23,1890$.

\section{MESSINA.}

\section{REPORT BY OONSUL JONES.}

Varieties. -The best variety for pickled olives is the Ogliaio; best rarieties for olive-oil: The Ogliaio, Caloria, and Calabrese.

Nine-tenths of the olive-trees in this province are of the Ogliaio variety; the Biancolilla and Nasitana varieties are prolific bearers.

Tree planting. - The Calabrese must be planted considerably abore the level of the sea; it thrives 4 miles inland. The other rarieties above named do well on the coast and as far as 23 niles from the sea.

The elevation above the sea-level depends upon the exposure, variety, soil. With a southern exposure the Ogliaio thrives at an elevation of 1,200 feet; the Caloria at 1,500 feet; the Nasitana at from 1,500 to 1,800 feet, and the Calabrese at a still greater elevation.

When the olive is grown by the sea-shore a western exposure is the best. A southern exposure is required when the olive is grown at an elevation exceeding 1,000 feet.

Olives growu on hilly land yield the most oil and the best quality of oil. The crops on level land are much lighter and are of inferior quality. Level land produces the best olives for drying purposes.

Soil, etc.-The olive prefers a friable, porous soil. Water should not be allowed to stagnate around the trees. The olive rarely attains its full growth on level clay land owing to the humidity retained by such land. In winter clay soils run together; in summer, in cracking open, 
they break the roots and seriously injure the trees. A very dry soil is also to be avoided. In the soil best adapted to the olive alkalies, chalk, and phosphates predominate. The calcareo argillaceous, product of the tertiary calcareous rocks, is the soil of soils for the olive.

Climatic influences.-A moderately moist subsoil suits the olive best.

The olive prefers a temperate, drr, and equable climate. It does badly in hot climates, in which a southern exposure should be avoided by all means. The temperature from $34^{\circ}$ to $95^{\circ} \mathrm{Fahr}$. suits the olive; mean temperature, $68^{\circ}$ Falur.

Rain-fall.-In this olive zone the annual rain-fall never exceeds 23 inches. The rains are at irregular intervals; a drought of several months being followed by torrents of rain, greatly to the detriment of the crops.

Rain is beneficial to both trees and fruit, except when the trees are in bloom. It is invaluable in Angust, as it swells the fruit and thus increases the yield of oil.

Irrigation.-The olive does not require irrigation. When grown with the orange and lemon (which are irrigated) the olive produces heavy crops, but this fruit is good neither for pickling nor for oil ; moreover, trees subject to irrigation grow old prematurely.

In the neighborhood of Milazzo it is customary to water the trees at the time of trausplanting, 4 gallons to the tree. This is the only irrigation of the olive in practice in this province.

Cultivation.-The olive is worked three times a year. In October, after the first autumnal rains, when the earth from around the tree is thrown to a distance equal to the length of its branches and made into a low circular mound, thus forming a clean bed for the olives to fall on when the branches are shaken. This embankment also retains the rainwater around the trees.

In March and April this mound is broken up and the earth is piled in two swaller circles, thus offering as great a surface of the earth as possible to the action of the air.

About the end of May this earth is leveled.

As a rule the olive is not manured. There are growers, however, who enrich their trees every two years. They run a trench balf way round the tree 5 or 6 feet from the trunk, fill it with manure one year, aud complete the circle, manuring the other half of the tree the next year. Others open a trench near the tree on the side of the prevailing wind and fill it with manure to strengthen its roots on that side.

Near Milazzo the trees are manured every other year by turniug under lupins and beans.

Pruning.-Olive trees are pruued and suckers removed every two years, from December to February. The head of the tree should be cat back so as to admit of air aud light.

Pickling and Curing.-Olives lor pickling are gathered green in October and November. When destined for the oil press olives are left to 
ripen on the trees and are gathered as they fall. Olives are gathered by hand or knocked down with long poles. The young twigs are bruised and broken by the poles, which shortens the naxt year's crop; but, as gathering by hand is much slower, poles are generally preferred.

Olives for pickling are dried in the shade for a day or two, then soaked in water from two to four days and pickled.

Olives for the press are left for a few days in the baskets in which they are carried home; they are then thrown into vats and allowed to ferment; this fermentation diminishes the yield of oil and is detrimental to its quality.

The process for pickling olives is as follows: Dissolve in water a sufficient amount of rock-salt to float an egg or a potato. Put the olives in this brine and cover them with fresh olive twigs with their leaves on, wild fennel, bell peppers, and garlic. To make oil : The olives having become soft, macerated, during their fermentation in the vats, are run through ( $i . e$. , crushed) a mill with horizontal rollers. The pulp is then put into large, round wicker bags, made of bulrushes, and pressed. "Sansino," or oil from the husks, is obtained by pouring boiling water on the olive husks and pressing them a second time. Tin dippers are used to transfer the oil from the press to wooden tubs, in which it is carried to the warehouse. The oil is then poured into large earthen. ware jars and left to settle before being put on the market.

Maturity.-At ten years of age the olive comes into bearing and continues bearing for centuries.

Field.-Olive trees in full bearing yield from 1 to 2 gallons of oil per tree -78 to 156 gallons per acre.

Planting and propagating.-The large olives, Ogliaio and Calabrese, are planted from 36 to 39 feet apart; the dwarf olives, Biancolilla, from 15 to 24 feet apart. Trees are propagated by seed; eyes (excrescences that grow on the foot of the trunk and roots of the olive-best method); suckers; cuttings; and budding.

Insect pests.-The olire tree and the olive have a number of insect pests. The lepidoptera, in a chrysalis state, cut into the large branches ; the Tlesino oleiperda, and the Phlocotribus olea eat into the twigs; small buttertlies feed upon the leaves. A little hemipter, called ouphyllura olece, attacks the bloom of the olive tree and covers it over with a cottonous substance that smothers it. The fly, Dacus olece, lays its egg in the pulp of the olive, which egg produces a worm that feeds upon the pulp. This prolific fly is a terrible scourge. Olives attacked by the tly yield but little oil of inferior quality.

The beneficial insects are the parasites of the olive fly.

There are little hymenoptera that feed on the larva of the dacus.

WALLAOE S. JONES,

United States Consulate,

Consul.

Messina, January 27, 1890. 


\section{NAPLES.}

\section{REPORT BY OONSTL OAMPHAUSEN.}

Varieties.-The name of best variety for pickled olives is the Andria or Gaeta olives, and for oil the Ritordella. The other choice varieties for pickles (eating) and oil, worthy of culture and for profit, are the Corregiole and Punzione (for oil), also Morrajole and Razze; but the Emopaca olive is cultivated in preference in the province of Naples.

The trees are grown in the provinces of Bari, Salerno, and Naples, and are distant from the sea 1,500 feet, and from 90 feet above sea-level to the tops of the hills, with southern exposure.

The trees grow on hilly, rolling, or level land, but hilly is the best, with fresh, rich soil without clay.

Climatic influences.--The same as stated in answer to question No. 5, under the head of lemons, oranges, and figs.

Irrigation is not practiced.

Cultivation.-Every. year by working the soil and using barn-yard manures and refuse collected in the streets of the cities.

Pruning.-During the usual time, as in other countries, and by removing the suckers whenever necessary.

Picking and curing.-From November to February. They are picked by hand or beaten down. The middle of October is the time to gather those for pickling or eating. The fruit for oil is collected at any time after November. After picking, the fruit is mashed into a paste and pressed under a hydranlic press and the oil extracted. The pickling is done in the simplest and usual way, similar to pickling cucumbers, etc., in the United States. Before they are put in brine the olives are soaked for a day or two in a weak solution of potash and then for a couple of hours in fresh water.

Maturity.-The trees mature at the age of five years.

Yield.-Trees average 20 quarts of oil or 45 pounds of fruit per year. Planting and propagating.-Trees are planted from 35 to 40 feet apart, and propagated by seed, sprout, or graft.

Publications.-I have no knowledge of any statistics issued by the Italian Government on this subject. The best information on this subject is to be obtained from or through the United States legation, or the United States consulate-general at Rome. Publications, scientific re. ports, etc., on this matter are published in the different eities of Itals, and articles are quite frequently found in the daily papers.

Insect pests.-The kermes injures the tree, and is destrosed by cutting of the bark where it nestles, saturating the place with a solution of lime. When the oil-fly unakes its appearance the olives are gathered with the utmost diligence and made into oil to prevent the propagation of the insect.

United States Consulate,

Edward Camphausen,

Consul. 
PALERMO.

REPORT BY OONSUL OARROLL.

Varieties.-Among the six principal varieties cultivated in Sicily "Ogliaja" yields the most oil, as will be seen from the following table, viz:

\begin{tabular}{|c|c|c|}
\hline No. & Name. & $\begin{array}{c}\text { Oil found in } \\
100 \text { parts } \\
\text { of olive weight. }\end{array}$ \\
\hline $\begin{array}{l}1 \\
2 \\
3 \\
4 \\
5 \\
5\end{array}$ & 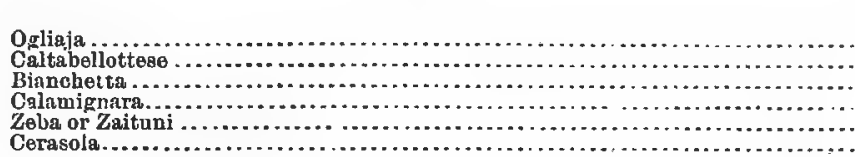 & $\begin{array}{r}\text { Kilogram. } \\
20.312 \\
17.187 \\
15.625 \\
15.625 \\
15.625 \\
14.345\end{array}$ \\
\hline
\end{tabular}

The names of other choice varieties for pickles (eating) and oil, worthy of culture and for profit, are Caltabellottese, Bianchetta, Zeba or Zaituui, and Cerasola.

The trees which produce the above oils are grown in Sicily and most parts of Itals.

There is no stipulated distance from the sea. The olive-tree grows either on the coast or inland, but groves adjacent to the sea or large bodies of water are more productive than those situated inland, the olives yielding more oil. The reason assigned for this is the influence of large bodies of water in modifying the extremes of temperature.

The limit of cultivation in the province of Palermo is stated at 827 meters (about 2,690 feet) above sea-level. As the trees suffer from extremes of temperature and from lack of moisture in either soil or air, the success of cultivation at various altitudes, depends largely on nature of soil, exposure to the sun, and distauce from the sea.

Sunlight.-The posit on of an olive grove in relation to the sun appears to be of great importance. In an eastern exposure the diurnal changes from cold to warm, and vice versa, are very rapid, while with a soutbern, and still more with a western and northern exposure, the direct solar rays are preceded, in the morning, by the gradual diffusion of the sun's warmth, and in the evening the change to the cold of the night is similarly graduated. From this it appears that in the northern limits of the growth of the olive the most unfavorable position is an eastern exposure, experiments proving that in seasons of extreme cold, the first trees to perish are those most fully exposed to the east.

In the southern limit of growth, however, the eastern, westeru, or northern exposures are more favorable than the southern, since, in the latter case, the trees suffer from the extreme heat. In the intermediate and more temperate zones exposures to the southeast or south west seem to be preferable. Aside from solar exposure it is important to choose a position sheltered from violent winds. In some parts of this island the 
strong sea winds, charged with salt, are found to be very injurious, while in other parts with different exposure the wind most dreaded is the hot dry sirocco, blowing from the southeast.

Soil, etc.-Latitude appears to govern the character of the ground. For instance, in latitude $30^{\circ}$ an inclination of $30^{\circ}$ would be indicated in the land. Open, rolling ground seems preferable as allowing a free subterranean circulation and the escape of excessive moisture.

It is not true, as sometimes asserted, that the olive prefers the poorest soil. Where the earth is too sandy, and, in some conditions, where too hard, the trees suffer from lack of moisture, they grow slowly and with difficulty, and in elevated positions, in the absence of profuse rains and pereunial moisture, the foliage is scanty, fruit ripens too rapidly, without full development, much of it withering half formed.

The most favorable is a loose mellow soil of moderate humidity. An open subsoil is preferable to clay, as the latter in winter seasons is apt to retain too mnch moisture and unduly chill the trees at the time when regetable life is most feeble.

Temperature.-It is difficult to state the exact limits of temperature within which the olive will grow and flourish, as so many other conditions enter into the question, but a uniform temperate climate seems to be absolutely essential to its well being. In favorable localities the tree commences to vegetate in March, when the mean temperature of the air has reached $10.50^{\circ}$ to $11^{\circ}$ centigrade (50.9 ${ }^{\circ}$ to $51.8^{\circ}$ Fahrenheit). The fruit buds commence to form, generally, in April, at a ternperature of $15^{\circ}$ centigrade (59० Fahrenbeit). The tree blooms in May, when the mean temperature has attained $18^{\circ}$ or $19^{\circ}$ centigrade $\left(61.4^{\circ}\right.$ to $66.2^{\circ}$ Fabrenbeit). In the beginning of June the fruit commences to form, under the influence of a mean temperature of $21^{\circ}$ to $22^{\circ}$ centigrade (69.80 to $71.6^{\circ}$ Fahrenheit). The fruit attains its growth early in July and reaches maturity in October.

The mean temperature in Palermo (a locality larorable to the olive), as recorded for the nine years from 1866 to $187+$ inclusive, was $18^{\circ}$ centigrade (64.40 Fahrenheit). The maximum temperature during that time being $40.4^{\circ}$ centigrade (104.72 Fahrenheit) aud the minimum $2^{\circ}$ centigrade (28.4 Fahrenheit).

The lowest winter temperature which the olive tree can support is $7^{\circ}$ to $8^{\circ}$ centigrade $17.6^{\circ}$ to $\left(19.4^{\circ}\right.$ Fahrenheit), and this not prolonged beyond eight or ten days.

In various parts of Italy where, during occasional hard winters, the mercury has fallen below this point, for two or three days only, the mor. tality anong olive trees has been very great.

There suems to be no regular method of irrigation in existence here, no governmental supervision, and no co-operation of different proprietors obtaining, Each grower seeks, apparentls, to utilize to the best advantage the rain-fall on his own property. Where this is scanty it is sometimes supplemented by the sinking of wells from which the water is 
pumped by hand or animal power. This is, however, an insignificant item. The general methol of irrigation seems to be to dig ditches close to and parallel with the lines of trees and connect these with cross canals in such a manner that the drainage of the land can be held in the ditches to be used when needed, or convesed away in case of superabundance.

In the case of terraced hills or undulatory land the intervening basins are often necessary to an intelligent control of the rain-fall. These basins, as well as the main aqueducts are, in this country, built of stone or cement, and in this equable climate endure for centuries. As the olive suffers from too mnch moisture to as great an extent as from too little, careful cultivators protect tho roots of their trees in the autumn from an excess of the cold rains of winter with as much care as they take to provile them with water during the dry months of summer.

Cultivation.-After an olive grove is fuirly started the annual labor incolved in its cultivation is as follows:

In autumn, in those localities where severe cold is apprehended, the earth is built up and solidly packed around the trees to prevent a too ready access of the chilling waters of winter to the roots. When no frosts are feared and the season is dry, the soil on the contrary is loosened about the roots to facilitate the entry of moisture.

In winter or early spring the earth is turned up as deeply as possible, in this country, with the spade.

In summer a superficial digging takes place to destroy the weeds.

In September the ditches and reservoirs are cleaned and opened to allow the winter rains to pass out.

The deep digging at the end of winter is to facilitate the absorption of the spring rains to as great a depth as possible. The superficial summer digging, besides destroying the weeds, breaks the continuity of the soil, the loose upper stratum acting as a blanket preventing the dispersion and evaporation of moisture from the lower depths.

In addition to this is the fertilization of trees in old and exhausted ground.

Pruning.-The olire, like the peach, bears fruit on the second year's growth; that is to say, the growth of one year bears the fruit of the next. The branches extend themselves from year to year, but the part thereof which has once borne fruit, nerer blooms again. In the absence of pruning these branches grow in length from year to year until they finally cease; the shooting out of collateral branches is very slow and the fruitage of the tree insignificant. By improper or irregular pruning: the fruituge of a tree may be seriously diminished or even temporarily destrosed. By pruning the form and extent of the tree are controlled.

To constitute a healthy tree, the amount of upper growth should be proportioned to the development of the roots and will constantly vary with the age and vigor of each individual tree. Olive trees should be pruned annually, in the spring. The most desirable form is the reversed. cone, the branches spreading more and more as the top is approached. 
This is thought to produce the most uniform exposnre to air and sun. The trees should not be allowed to grow too high, the trunk from the ground to the lower branches not to exceed $1 \frac{1}{2}$ to 2 meters (about $4 \frac{3}{4}$ to $6 \frac{1}{2}$ feet).

When the young tree is sufficiently branched and has reached a height of about $1 \frac{1}{2}$ meters (or $4_{4}^{3}$ feet) the top is cut off immediately above a vigorous embranchment. In the following spring the principal branches are pruned, being left shortest at the bottom and longer as the top is approached, and so on from year to year, preserving to the tree a symmetry of form and uviformity of density as far as possible. When the fruiting age is reached the skillful pruner will form such a relation between the general growth of wood and the fruit-bearing branches, from year to year, as will best subserve the health and vigor of the tree. In addition to this pruning there should be an annual cutting away of all decayed and unhealthy branches.

Picking.-All the olives on a tree do not mature at the same time and two pickings are generally made. In the first are taken the sontbern side of the trees and those trees situated on high ground, as these ripen first. The method is to pick by hand those within reach, then gently shake the branches until the balance drop to the ground. In large groves the wind is largely relied on to assist in the labor. It is estimated that to pick an ettolitro (or about $2 \frac{5}{6}$ Winchester bushels) of olives from the tree by haud requires a man's labor for eight hours, while the same amount can be picked from the ground in one and one-half hours.

Pickling.-Olives for pickling or preserving in any manner for table use are picked green; for oil, when fully ripe. It seems to be the opinion here that olives increase in amount of oil produced if left on the tree some weeks after fully ripe, but the quality of the oil deteriorates.

Manufacture of oil.-To make good oil the olires should first be thoroughly cleansed of all earth and leares. If washing is necessary to effect this, ther must then be carefully dried, after which they should be convesed at once to the mill; but, if this is inpracticable, they may be spread out 4 or 5 inches deep in a dry, airy place, care being taken to turn them over thoroughly every three or four days to prevent fermentation. If the olives are allowed to ferment the quality of the oil is effected injuriously both in color and taste. There are several varieties of machines for crushing the olives. Extensive producers have at least one grooved mill which crushes the olives but leaves the pips or stones intact. The oil from the latter, although amounting to 7 or 8 per cent. of the whole, is of an inferior quality, and its admixture letracts from the brightness and excellence of the first pressing. The olives, reduced to paste, are put in sacks made of a species of rush or reed (Juncus acutus), of strips of bark, or of hemp and placed under the press (worked by screw or lever), when the first extraction of oil is made. This is the "vircin oil," absolutely pure and highest in value. 
T'o the paste or mash from which the virgin oil has been extracted, the pips, previously removed, are added, boiling water is poured on pressure again applied, and another and inferior grade of oil expressed. The operation repeated a third time produces a still more inferior grade of oil, ased mostly in the arts.

In all these operations absolute cleanliness is indispensable; mills, fresses, and utensils should be frequently washed in a solution of lye, as the slightest contact with rancid matter will impart a disagreeable odor to the oil.

In sume districts the crushing-mill is dispensed with, the only ma. chinery used being a small screw-press. In such case the sack of olives is placed on the.bed of the press, trampled down by men, and then the pressure applied, and the so called "virgin oil" produced. The tramp. ling is repeated, water added, and pressure renewed, and so on, repeating all the operations until nothing remains but the shells of the pips and the dry pulp of the olives. The oil obtained by this method is more dense and mucilaginous than the other. Leaving the press the oil is poured into glazed earthenware jars, well washed with cold water (to which is addled a little vinegar) and wiped dry with clean cloths. The best form for these jars is that of a frustrum of a cone reversed. In some cases vessels hollowed out of calcareous stone are used, after being thoroughly cleansed with lime water. These jars or vessels are placed in dry cellars, cool in summer and sufficieutly warn in winter to prevent congelation of the oil, as this impedes the deposition of the lees (morchia).

The winter temperature of these cellar's should be from $15 \circ$ to $18^{\circ}$ centigrade (59० to $64.4^{\circ}$ Fahrenheit). In Juve the oil should be clear, aud can be poured off into other vessels.

This first pouring off is the "superfine oil" (olio sopraffino). From what remains in the jars a secourl pouring off or decanting takes place a month later, and this produces the "fine oil" (olio fino), and in August still :mother decauting from the bottom brings forth the third grade, called "fat oil" (olio grasso), used in manufactures.

The purification of the oil and deposition of the lees, or morchia, may be accelerated by washing or riusing with pure water or a solution of alum. - The color of the ofl may bè bleached, or clarined, by a solution of sulphuric acid and water, in the proportion of 20 to 24 parts of water to 1 of acid. There should be a quarter of au ounce of acid to each pound of oil. The mixture nust be placed in a vessel and agitated until it becomes milky, the agitation repeated several times during the first twenty-four hours, and theu left quiet for eight days to settle. The oil may theu be decanted, and will bo fourd extremely clear and limpid. This process also destroys any bad odors that may linger about the oil, though for this purpose vinegar or alcohol seems better.

Preparing for market.-For pickling the largest and most fleshy olives are selected. They should be immersed in pure water for five or six. $156 \Lambda-19$ 
days, the water being changed four or five times per day, and when they have lost all bitterness placed in a vessel (earthen jars aje used here) filled with brine, care being taken that they are immersed, after which they are ready for use in sixty days, and will keep tor a year or more.

Another method consists in steeping the olives in lye until the pulp is penetrated; then, having ascertained by taste that they have lost their bitterness, they are immersed in water, as before, renewed two or three times per day for four or five days, or until all disagreeable flavor has disappeared. This done, they are immersed in brine, to which may be added, according to taste, some odoriferous herb, as fennel. Cloves and cinnamon are also used.

Maturity.-The trees commence fruiting at from six to eight years of age.

Yield.-From experiments made in Sicily it has been ascertained that a mature tree yields 8.50 kilograms, and a hectare (abont $2 \frac{1}{2}$ acres) of land, in perfect condition, 850 kilograms of oil per annum, from which it has been concladed that an olive grove in Sicily of the extent of 1 hectare will, as a rule produce an average quantity of oil of from 6.t. to 734 kilograms per annum.

Planting and propagating.- - This depends on the soil and its formation. In Sicily they are planted from 20 to 40 feet apart, the closest being on side hills and poor land, and the farthest apart in rich valleys. From seed and by grafting. Trees dying, renew themselves from the root.

Successful cultivation.-The importance of avoiding all exposed localities in planting olive groves is enjoined upon them. As, for iustance, when the trees would be exposed to the cold winds from snow-covered mountains, the hot dry blasts from the deserts of Arizona or New Mexico and strong sea winds laden with salt. It would also be wise to plant different varieties of trees until those best suited to special locali. ties can be ascertained.

No doubt is entertained that in the sheltered vallers of California, as well as on the favorably exposed foot-hills and aloug the southern coast thereof, the olive wonld do well and prove a protitable source of revenue.

Insect pests.-These are rery numerous, and commit great haroc. Is there is a whole library of books on the subject, it is impossible in a report of this kind to give any summary that would be of value.

Philtp Carroli, Consul.

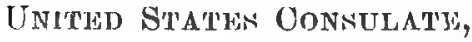
Palermo, Mareh 7, 1890. 


\section{SICILY.}

REFORT HE C'NASUL, LA MATTIA, OF OATANIA.

IHE OLIVE IN ANCIEN'T ANI) MODERN TIMES.

It is sail that Asia is the olive's uative place, and that Cecrope brought it to Alhens and the Phocesis to Marseilles (600 years B. C.). The olive plant is known from past centuries, and a proof thereof is that we find it mentioned in the Genesis, Homer, and in Hesiod. The legend of the pigeon having returued on the Noah's ark with a small olive branch as a sign of peace is well known. It would, therefore, seem that the olive tree regetated on the land, even before the universal deluge. The ancients paid to the olive great honors, and, as a mark of admiration, they beliered that the plant had risen through Minerva's action. Consequently, they consecrated it to that deity, and Columella declared it "The first tree of all trees"-olea prima omnium arborum est. In Asia nature disseminated the first olive shoot, which afterwards is seen cultivated all over Asia Minor, Phonicia, Palestine, and Syria. The ancient Hebrews, Etrurians, Greeks, and Romans paid the olive tree divine honors.

The olive tree likes the sea, the calcareous soil, the mounts and roll. ing hills, as well as the lake borders and river shores. That is because it was diffusely grown all along the coast of Asia Minor, Phœenicia, and Palestine, as it is now seen in Greece, not in the interior, but all along the Ionic Islands and Archipelago, Cyclades and Sporandes, still in a wild growing state.

In what epoch the Greeks alid really extract the oil fiom the fruit and use it for illuminating and condiment, as it is done now, it is im. possible to learn, for want of historical records. But one thing is certain, howerer, that the primitive extraction of oil aud its use is lost in the obscurity of night. When, between the seventh and eighth centuries, or eight hundred years (B. C.), the Greek colonies extended themselves towards the northern coast, they probably, with their industry and commerce, imported also the olive culture.

In the sixth century (B. C.) the olive tree was cultivated in sontheru Italy, in Sardinia, and in Sicily. The Romans knew the olive later thau the Greeks. A century previous to that, we learn from Pliny, no olives existed then in Romo, but that they did exist all along the Adriatic coast, cultivated by Greeks. Gradually, later on, the olives were introduced into central and sonthern Italy, hence into this island of Sicily.

The olive tree is now cultivated in southern Europe, ats in Spain, Portugal, and France, Austria-Hungary, Provence, Italy, Greece, and 'Turkey in Europe.

Italy is, however, a region of the lew most privileged mes by natmm, 
wherein the plaut cau easily vegetate and produce profitably. In fact, out of the 69 Italian provinces only in 19 of them the olive plant is not cultivated. The production, as considered in regard to land occupied by the olive culture, is nore profitable in Sicily, and precisely in the proviuces of Palermo, Trapani, and Caltanissetta. As reported by the ministro di agricoltura in 1874, it seems that the present olive cultivated land in Italy (together with other plants) occupies an extension of 900,311 hectares, yielding an average of $3,385,591$ hectoliters of oil, or 3.76 hectoliters per hectare.

The annual exportation from Italy is 635,000 quintals, equal to 63,500 tous, and the best and finest oil is made at Pisa and Lucca, and mostly in the whole region of liuscany, on accout of good picking and curing the olives and extracting and refining the oil.

The following table shows the olive cultivated land and the total production of oil in Itally:

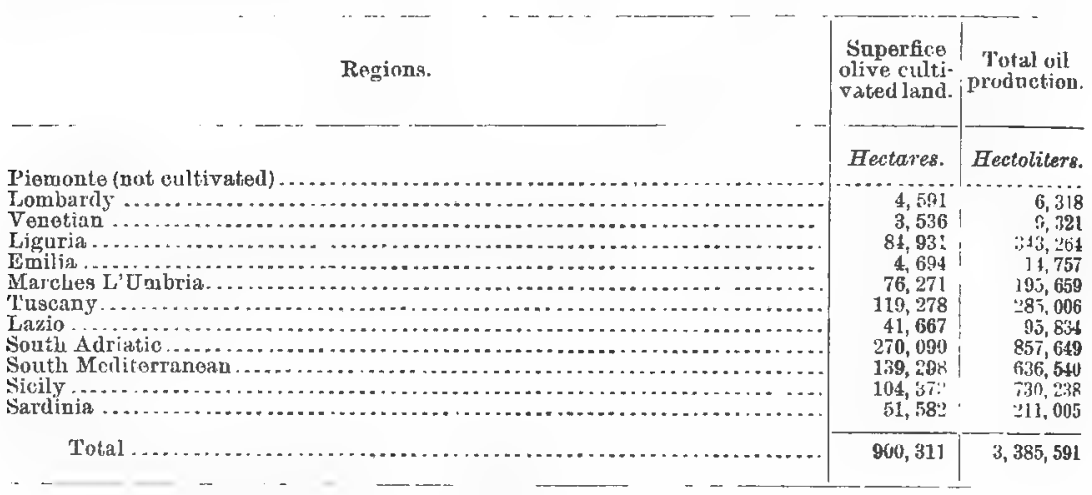

General average, 3.76 hectoliters per hectare.

After Italy the most oil-producing country is Spaiu; next comes France, Algeria included, aud Anstria-Hungary.

In Greece and Turkey the olive tree is also extensively cultivated, but the oil is mostly fit and used for soap-making.

In no other country of Europe does the oil equal the Italian made in quality.

As shown in the table, the extension of olive cultivated land in sicily is 104,373 hectares, with an average production of 730,233 heetoliters oil a year, and at rate of nearly 7 hectoliters per hectare. The oil, however, it is proper to say, is generally too rich and strong, on account of the poor system of picking the fruit and not refining the oil. The finest oil in this island is made in Termini-lmerese, 24 miles from the city of Palerino, by using the same system of Tusciny. I now proceed with the practical one, hy atuswering categorically the circular.

\section{BUHATIONA ABOTIJ OLIVLAS.}

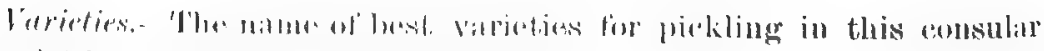

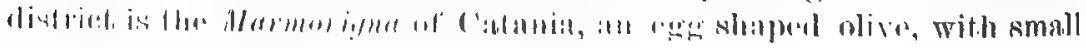

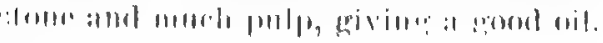




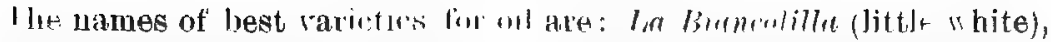
an oblong white, yellowish olive, even when it is ripe, yielding a very tiue oil; Lu Calabrese, a small olive, but very productive, yielding excellent oil ; La Ogliara, of medium size, wiving an ordinary quality of oil ; La Cerasola or Prunara, a precocions and pulpy olive, yielding plenty oil, but ver. rich ; it is nsed for eating. La Raitana, a very late fruit, of ordinary quality of oil; and La Caltabellottese, an oblong black olive when ripe, giving rather a rich oil.

The names of other varieties worthy of culture and for profit are the following: La Mortillara, Giarraffa, Patornesc, Messinese, Nasitana, Pizzutella, Piricuddara, Saracena, Siragusana, and San Francescana.

Situation.-The said varieties are grown in Sicily in the provinces of Palermo, Trapani, Caltanissetta, Catania, and Messina, at the distance of from 100 to 300 meters from the sea, and at au altitude of 300 to 800 meters above the sea-level, exposed to sun and planted on hilly, rolling land, for it is the best, and on flinty, calcareous, argillaceous soil.

Climate.-The climatic temperature is : minimum $5^{\circ}$ centigrade in .lanuary, maximum $35^{\circ}$ in August, and $17^{\circ}$ average in May.

The average rain-fall in Sicily is considered to be from 25 to 30 inches in the year. More than that rain would belp the cnlture greatly.

Irrigation.-There is no regular method of irrigating olive trees, and a good crop of fruit depends entirely upon favorable weather and rain. fall in the proper season.

Oultivation.-The earth about must be regularly dug at least twice a year; that is, in the month of June and August, and manured at the end of the winter.

Pruning.-Pruning is to be done regularly after the fruit has been gathered.

Picking.-The olives for making oil are to be picked when turning to the dark violet color, for then the pnlp is easily detached from the stone. When so picked they give the following favorable result, viz:

Pnlp ......................................................

Water .......................................................... 148

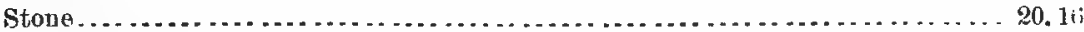

Residue ....................................................... 8.

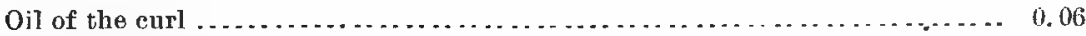

The following system may he established as the proper time for picking the fruit:

(1) Olives gathered before full maturity give very fine, but very little, oil.

(2) Olives gathered at full maturity yield the most quantity of oil and of a good quality.

(3) Ulives gathered late produce oil of a poor quality.

l'ickling.-The olives for pickling must be picked when full grown, but in green color. After so picked they are preparted for making oil and for piekling. 
The process of pickling green colored olive: in sicily is very simply done, viz, by putting them in salt water, made ont of one pound of seasalt to every gallou of fresh water, stored in barrels, casks, or any other receptacle, and let them remain there until eaten. In that manner they are shipped and kept for home trade. As to the process of makiug oil, it is impossible for me to rescribe it minutely.

Maturity.-Trees commence fruiting at the age of eight years.

Yield.-The average yield from $\frac{1}{2}$ to 4 hectoliters of fruit.

Ilanting and propagating. - The distance apart is from 16, $2:$, and :i2 feet, aud propagated by several methods.

\title{
VINCENT LAMANTIA,
}

Consul.

\section{United States Consulate,}

Catania, January 21, 1890.

\author{
SICILY. \\ RETORT BT GONSUL WOODOOOK, OF CATINIA. \\ [ Republisbed from Consular Reports No. 411.]
}

At least ten varieties of the olives of the present age were known and cultivated by the ancient Romans. There are the Pausio, Algiano, Licinio, Sergio, Culminio, Orchide, Regio, Cercite, Nevio, and Mirteo. of these the best for yielding oil are the Licinio and the Sergio. The fruit of the Pansio, Regio, and Orchide is of tine flavor, and excellent for eating as condiment, and yields a good quality of oil.

In this part of Italy, especially in the neighborhood of Syracuse, there are probably greater varieties of the olive than were known to the old Romans. Among these may be mentioned the Prsano (natire), bs some called the African; the Oglialoro, which produces a smaller fruit than the Presano, but it is rich in oil; the Biancolino (white), of which the pulp of the fruit is white; the Pizzuto (pointed), the fruit being some what pointed in shape; the Prunaro (plum), the fruit being roundish in form ; the I)attio (date), of which the fruit is elongated and oral in form : and the Ferlese, the fruit of which yields a finely. Havored oil, and is excellent for comfits.

The varieties that are preferred for the utility of their proluct and durability of the trees are the African and () wlialoro. These trees are possessed of great longevity, living to be three and tour huudred pears old, and continuing to be green, healthy, and produetive. The other varieties do not attain so great an age, expectially the Ferlese and Bian. colino.

A stony or calcareous soil is best for the olive. It must not be planted

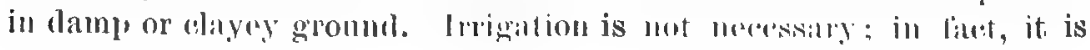


myjurious to the tree. 'The trees recuire a loose, dry soil. $A$ hill-side is stitable, provided there is no dauger of denudation by water and the soil is supported abont the trees by terraces.

Thi usual method of propagation is to sow the seed, plant suckers, or off-shoots that spring up from the roots of the parent trees, or by grafting the best varieties upon the wild-olive stock.

An olive orchard may be commenced from cuttings in the following manner: Prepare the ground by spading to the depth of 3 feet and surround the same by a deep trench. Let the soil thus prepared remain for a time exposed to the suu. Take young vigorous branches two or three inches in diameter from the kind of tree preferred; cut the same into lengths of about one and a half feet, being careful not to in. jure the bark. Smear each end of the cutting with stable manure, coating the same with ashes. Then plant the cuttings upright in the soil so that the upper end will be a conple of inches beneath the surface. Care must be taken to plant the cutting the right end up, as upon the tree; otherwise it will not take root.

Many prefer to grow the wild olive from the seed, and when grown to the proper size, graft upon its stock the best varieties. Whichever methor is resorted to, the time for planting must be in the latter part of the spring equinox.

The first year after planting; the ground should be frequently hoed; and in the second and subsequent years the rake must be used, that the young roots may acquire strength and vigor in a mellow soil. For the first two years the young plant must not be pruned. The third year it should be pruned, leaving but two branches thereon. During all this time the ground should be hoed and raked frequently. In the fourth rear the weaker of the two branches must be removed. After cultivating thus for five years the plants are ready for transplanting to the orchard.

In transplanting to the orchard, a distance of sixty or more feet, must be maintained between the trees, where the soil is rich. In poor soil the distance should be thirty or more feet apart.

A year before transplanting to the orchard, the holes for the trees should be dug to the depth of 4 feet. This should be done that the soil of the holes may become fertilized by the rays of the sun. If the trees are to be transplanted in autumn the ground must be dry ; if in spring the soil should be fresh and the trees moved before they commence to bud. Prior to plantiug it is well to mark the position of the plants as to the points of compass, and give them the same position in the orchard.

The young orchard (thus commenced) must be plowed and hoed at least twice a year. After the solstice, when the earth erodes by the heat, care must be taken that the roots of the young trees do not become exposerl to the sun. After the autumnal equinox equal care must be harl (especially if the orchard be upon a hill-side) that the rains do not denivde the roots. Each year the shoots that put forth from the stem 
must be remored. Every third year the ground about the trees should be manured, the amount to be determined by the condition of the soil.

It is often the case that even in dry situations a moss gathers upon the trees. When this occurs the moss must be remored by scraping. Dregs of the oil should bo smeared upon the trunks of the less vigorous trees. This will destroy the insects that infest the bark aud thus injure the trees.

After the lapse of eight years the trees must be thoroughly pruned; entting away all sprouts, and such branches as obstruct the air and sunlight; but no large branch should be cut near the body of the tree; and the lower branches should be spared, because being more exposed to the warmth they are the most productive.

At eight years old the olive is but a mere infant tree. At fifteen years of age it bears but little fruit. When thirty-five or forty years old it begins to bear abundantly, but then only every other year. Every alternate year there is generally a poor crop. At this age a hectare ( $2 \frac{471}{1000}$ acres) of trees in the fruitful year generally yields from 3 to 4 quintals metrique ( 660 to 668 pounds) of olives, or about 240 or 320 kilograms (530 to 705 pounds) of oil.

When the trees are fully grown the ground should be plowed at intervals during the year, and should be once hoed during the autumn. The cost of this per annum, including the pruning and cleaning of the trees, is about 100 to 130 lire $(\$ 19.80$ to $\$ 25.09)$ per hectare $\left(2 \frac{471}{1000}\right.$ acres).

For oil the fruit should be gathered when it commences to change color from gray to dark red. The fruit must be picker by hand, not knocked off with poles, and care taken not to bruise it. If bruised or injured in any way it soon becomes rotten, and the oil from it is of poor quality. As soon as gathered the oil should at once be compressed from the fruit. In Sicily there are mills for this purpose. The fruit is placed between two stones and the stones forced together by screw power. It spoils the fruit to let it lie in heaps in a store-house before extracting the oil. The oil as scon as extracted is placed in large jars. The jars should be thoroughly cleaned with rinegar and water betore receiving the oil. When the jars have been filled with the oil, they are placed in rooms where the temperature is kept abont $15^{\circ}$ above zero (Réaumar), (or Fahrenheil about $50^{\circ}$ above zero). In the month of dune, following, as soon as the oil becomes clear (impurities settling to the bottom) the upper strata of oil (the clearest) in the jars must be proured off into other jurs, the cloudy or poorer-quality remaining. This oil is the first grade or best quality. In a nonth after this process is repeated, libe turned-off oil being second grade or quality. Alter the lapse of whother month the process is again repented, giving an oil of third quality. The dregs are now left in the first jars, and are here nsed for' making soap, rubbing on the bark of sickly young trees, wte.

For export the olives must be guthered by hand in the month of De- 
cember, when they are of a green "1) whitsh green color, aceording to the kind of fruit. The fruit is then placed in barrels or large jars and rovered with a strong brine. In this condition the fruit is exported. The brine is thus prepared: Into a barrel or tub is poured fresh, clean water until it is three-fourths full; over this is hung a basket filled with coarse salt, the bottom of the basket being 3 or 4 inches beneath the surface of the water. When the water becomescompletely impregnated, and will hold no more salt in solution, it is ready for use.

Black olives for condiments are thus prepared: They must be gathered by hand when they begin to ripen and commence to turn black. They must not be fully ripe. When gathered they are cleaned and salted in baskets. The proportion of fruit and salt is about a large hardful of coarse salt to a gallon of the fruit. Coarse salt is first spread in the bottom of the basket, then a layer of fruit, then of salt, and so alternately until the basket is full. In this condition the fruit must remain a mouth, then with fresh water cleanse the fruit from the salt: and place it in clean jars, covering the surface with laurel leaves.

Another method of preparing the black olive for table use is thus: As above the olives must be picked when they commence to lose their green color, becoming somewhat dark. Place the fruit in shallow baskets in the shade, letting it remain thus for a day. Then close the frnit in jars for twenty-four hours. Then salt the fruit in jars, scattering upon each layer of the fruit two handfuls of tine salt to a gallon of the olives. Some hours afterwards when the fruit is impregnated with the salt, remove it to other jars, pouring upon it a copious supply of olive oil of the first quality that is pleasant to the taste. Cover the surface with laurel leaves.

\section{ALBER'T WOODCOCK,}

Consul.

UNITHD STATES CONSUlate,

r'atanir, .Ju?! 21, 1884.

\section{TUSCANY.}

REPORT RY CONSUL WELSH, OF FLORENOE.

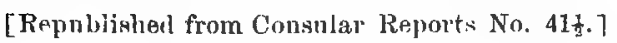

I have th' honor to hand you my reply to the circular issued by the Department of State, under date of the 4 th of December, 1883, and re. ceived at this consulate on the 23d of January, 1884.

I regret the delay, which has been nnavoidable, and in this connection I may mention that the answer from the consular agency at. Citgliari, Sardinia, reached me on the 15 th instant, aud that, il though vine: and olives are grown to a large extent in this district, there are semrcely any exports of the same made throngh this consulate. I have, there fore, had much difficulty in arriving at the information I am abla to yive. 


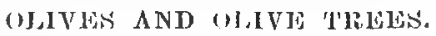

Olive trexs are alapted to few conntries, being so delicate that they cau thrive under the iufluence of a mild temperature only. Cold winds and a soil too fresh or too dry are equally unfarorable to their productiveness. Therefore, on the Mediterranean coasts, and nominally in Italy, it seems that olive trees meet with most of the conditions favorable to their development. Olive trees in a farorable climate and soil grow quickly, and are both strong and leafy.

In Tuscany the diameter of the trumk measures from 0.25 meters to 0.30 and 0.42 meters $\left(9 \frac{1}{2}\right.$ inches, $11_{2}^{1}$ inches, 1 foot $4 \frac{1}{2}$ inches). The ordinary height of the tree whell fully developed is from 5 to 7 weters (16 feet to 22 feet 7 inches), and the maximum and exceptional beight is from 8 to 12 meters ( $25 \frac{1}{2}$ feet to 38 feet).

It is difficult to state the length of life and prodnctiveness of olive trees. In the most favorable countries, howerer, they remain fruitful during two hundred or three hundred years, and if after this term of life they do not bear, young shoots are produced by them which become fruitful, so that actually, when properly tended, they may be said never to die.

Amoug the olive trees the following are the hietter kuown in 'Tuscany:

Infrantoio (fit for the press), one of the most delicate and very sus. ceptible to cold.

Olivastro (dark brown olive), found on the hills ; hardy, but not rery productive.

Moraiolo (resembling the mulberry), hardy, ripening early, and fitirls productive.

Razzo or Grossaio (large and lucent), much appreciated for the abundance and size of its olives and the good quality of its oil.

Coreggiolo (resembling the crucible from its lowering branches), susceptible to cold weather, and consequently not adipted to high localities, but still growing with northern expossure.

Gremignolo (a coarse description of olive), ripening in March or April, and found in the Pisan Mountains.

Iarcino (holm.oak), coarser, but very hardy, and not susceptible to cold.

Quercetano (resembling the oak), deriving its name from (Querceta, a small place in the Lucchese, where it is largly cultivated, owing to its strong constitution and resistance to sea wiuds.

Indolcitoio (tender and swort), whose fruit, larger than other varie. ties, but with little oil, is aten fresh after laving been for some time well soakerl.

The varietice mostly used in Thusemy are the -

Infrantoio, with favorable exposure, and the Mroraiolo alsewhere. The Infrantoio grows well in sheltered plices and on hillocks. This plant is very suscentible to exposure to or changes of weather. The Moraiolo,

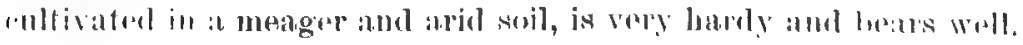




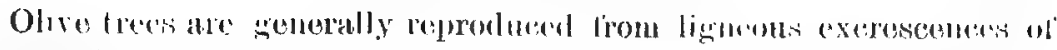

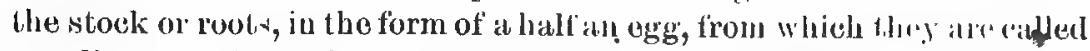
uovoli, cut in the spring, jlaced in holes made in al plowed soil, covered with fine earth and watered according to the exigencies of the season. 'The wovolo sends fort h shoots, the most robust of which are bronght up, and in the third year of their existence may' be planted. 'T'be reproduction by seed is not exclusive, however. Small plants are cared for in a nursery and grafted on in the third your, and in the fourth are transplanted. Olive trees are planted in square ditches of over 2 meters (6 foot $5 \frac{1}{2}$ inches) and at a depth of abont 1 meter ( 3 feet 3 inches), with proper arrangement for drainage.

Olive trees commence to bear one year after being planted, and farmers anticipate the amonnt and iucrease' of the crop from the date thereof, relying upon the Tuscan snyings, viz:

Se mignola d' Aprile, "ace' col barile (bearing in April, look for a bar. reltul ; abondant crop).

Se mignola di Maggio, vaci col saggio (bearing in May, hope for the best; scarce crop).

Se mignoli di Giugno, vacci col pugno (bearing in June, expect a handful; poor crop); which are confirmed by the following:

La prima oliva é oro (the first olive is gold).

La seconda argento (the second is silver).

La terza val niente (the third is of no value).

That is to say that the tree precocious in its bearing produces best; less sure are those flourishing later, and the produce of those bearing last is of little or no value.

In well-disposed orchards olive trees are planted at in distance of from 4 to 6 meters ( 13 to 19 feet 4 inches) one from the other. The number of trees is generally from 400 to 600 per hectare (

Pruning in the best-conducted orchards consists in well clearing out the center of the tree in order that all the branches bearing may luave plenty of light, sun, and air. The trees are pruned every two or three years. Any dying or dead branches are taken off' as soon as noticed. Every year the soil is turned with the spade aud every other year manured. It is thought by scientists that pruning is carried to too great an extent. Columella, the aucient agriculturist, who greatly ad vanced oil culture, says of this plant that "the plowing of ground is a request, the manuring is a prayer, and the pruning is an order to produce fruit."

The best orchards in the Lucchese may produce each two years 180 hectoliters (510 bushels) of olives per hectare ( $2 \frac{1}{2}$ acres), from which quantity there can be had 2,160 kilograms of oil $(4,761.33$ pounds), or about $24 \frac{1}{2}$ hectoliters ( 646 gallons).

It is calculated that one hectoliter ( 2.83 bushels) of olives gives 12 kilograms of oil (26x pounds), and Domenico Capponi, in his treatise on olive oils, consilers fairly remunerative the production of from 10 to 15 kilograms (2:2 to 33 pounds) per hectoliter of olives (‥83 bushels). 


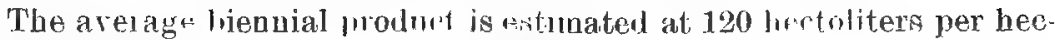
tare $\left(340+\frac{1}{2}\right.$ bushels, $2 \frac{1}{2}$ acres), equal to 1,440 kilograms of oil $(3,174.62$ pounds), or about $166_{3}$ hectoliters ( 430 gallons). The olive tree in Tuscany produces an average of 1.188 kilograms oil ( 2 pounds) per year. Such results, Lowever, are given, butin good years and considering the fluctuation of the product, the biennial average is redncen to 11 bectoliters (290 gallons) of oil per hectare (21 acres), at the price of 136 lire $(\$ 27.20)$ per hectoliter (26.417 gallons), as being the average price for the last six years, giving the gross amount of 748 lire per anuum. To that is added the value of olive husks, from 1 lire to 2.50 lire per quintal, and of fagots derived from the pruning, which amount to 64 lire every two years, making a gross amount of 780 lire per hectare and per year $\left(\$ 156\right.$ from $2 \frac{1}{2}$ acres.)

The following statement will show about the expenses of working a hectare of olive trees and the approximate net receipts, calculating for one instead of two years:

Lirs.

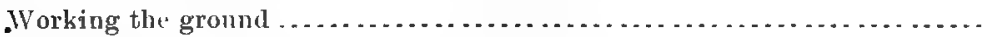

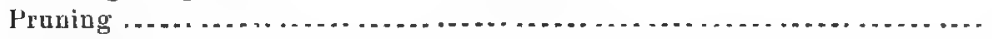

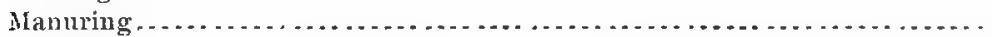

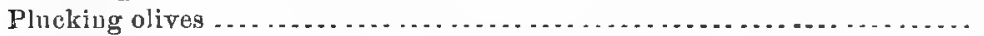

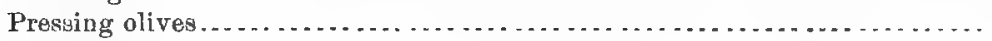

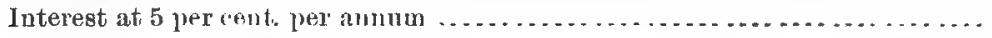

20. (i)

36. (4)

:300. 001

40. 00

7. 20

2i). 31

423. 40

Which, deducterl from the gross amount of 780 lire, leaves 356.10 lire net.

It is generally calculated that the expenses of an orchard represent one-third of the actual value of the produce, and that estimate is made as an average. The expenses, however, exceed ly far said figure, as the above estimate shows. The olive culture is sometimes managed by what is called meaverin, or a system when half the net prodits are paid to lahorers, all the axpense but that of pressing the olives being lorne ly: the owner.

Tuscan oils from Lueca, Calci, and Buti are esteemed as the tirst oils of the world. Not all Tuscan oils, however, reach that degree of perfection, but even jud ging in mass, they are considered the best. For twenty ypars past Tuscally has not prodnced oil for burning or lor lubrication, all attention being given to the production of walad and cooking oils.

In some places hot water is used to facilitate the pressius. The best rules adopted for extracting oil are the following, viz:

(1.) To axpedite the careful wathering of olives alrearly fallen from the tree.

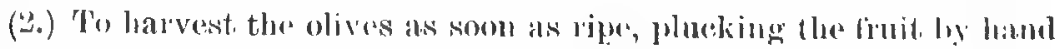
or whipping the trees wently:

(3.) 'To press olices before fermentation and to clispose them in sumall stratio in the basket.s. 
- (4.) To presis slowly and at a cold temperature.

(5.)'To have all machiuery and recipients very cleau, as well as to insist on the cleauliness of the laborer. Orushing presses of old system are used, aud the quintity of olives submitted to each pressure varies from

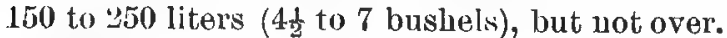

Olives must be well pressed and ground for about one hour, atter which they are reduced to a paste and placed in frails, submitted to presses, and then mixed with cold water for a second pressure, and even a third pressure, but with hot water in that case. The oil produced by a first gentie pressure is the virgin oil; the other is mixed, and constitutes a second quality, usually called olio mangiable (table oil); a third quality is derived from the deposit of oil, and used by colonists for buruing.

Olive oil is preserved in jars varuished inside, containing from 50 to 300 liters and orer (13.200 to 79.251 gallous). Olive husks crushed aud pressed again give an inferior oil for lubricating purposes. The clarification ef oil must not be too cold nor too hot. The temperature is not to vary from $10^{\circ}$ to $12^{\circ}$ centigrade ( $54^{\circ}$ Falhr.), in order that the oil fluid be such as to facilitate the deposit of heterogeneous substances.

The process of preparing olives for table use consists in their sweetening or drying; those green are sweetened, and the ripe olives are dried. To sweeten they are placed in clean water during five or six days, changing the water four or five times a day. When they have lost their bitterness they are trausferred into a pitcher of brine with a few brauches of fennel, taking care to keep then well plinged in. After sixty days they are good for table use and are so preserveci until the following year. They ean be sooner prepared for table use by erushing, extracting the nut and keeping the fruit moist for four or five days and changing the water four or five times a day. They are then placed in brine, and after six or eight days may be eaten alone, or with vinegar and oil, according to taste. Olives can also be sweetened by keeping them in brine until they lose their bitterness, after which they are placed in water renewed twice or three times a day for four or five days until they lose their disagreeable taste. Then they are kept in brine, adding thereto fennel, cloves, cinuamon, or nutmeg, but the fenuel if used must be used alone. Dark olives are dried by exposure to the sun for from fifteen to twenty days, and are subjected to a slight sprinkling of salt.

Another process is to place the fruit in baskets, with alteruate layers of salt. In the course of twenty-four hours the juice will commence to leave the fruit, and after five or six days the fruit is suffieiently dry fis table use. Day by day the baskets should be gently shaken aud a little. salt sprinkled on.

Olives for oil are to be picked when thoroughly ripe, which is clearly shown by the bright black color, and also by the fact that at such time 
their pulp is easily severed from the nut and has a violet color. Its compounds are:

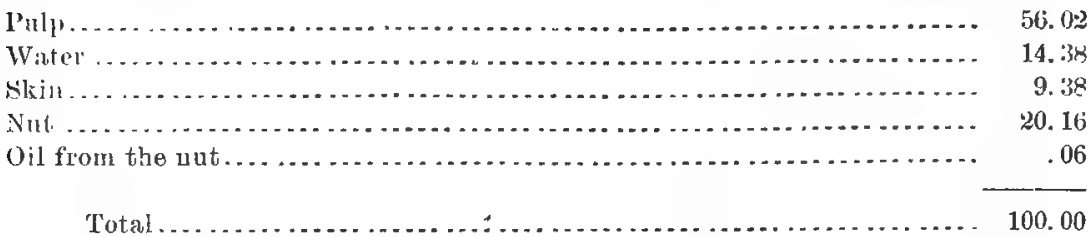

From experiments made it results that one hectoliter ( 2.83 bushels) coutains from 48,000 to 50,000 olives, the difference being ascribed to the variety, according to soil, climate, and season. Olives accumulated for some weeks might number 54,000 or 56,000 per hectoliter (2.83 bushels).

The "queen olives of commerce" are considered in Tuscany as the selected fruit of the common olive.

There is no system of artificial irrıgation in use for olive eulture in Tuscany.

The annual rain-fall in this district is about $1.067^{\mathrm{mm}}$, equal to about 42 inches.

Official statistics show that the following countries import olire oil from Italy, ranking in importance as to quantity of oil as nawed : France, England, Austria, Russia, South America, United States, Netherlands, Turkey, Sweden and Norway, Denmark, Portugal, Belgium, Greece, Switzerland, Fgypt, Brazil, Algiers, etc. Barrels, bottles, or tin caus are nsed to hold the oil.

In Tuscany there are three prevailing diseases which seriously affect the olive tree, riz:

Lupa, meaning literally wolf, but actually being a description of dead rot, produced very often by excessive pruning. To cure this the affected parts are gouged out and a hardening liquid preparation applied, that the circulation of sap may continue.

Mosca dell olivo (thr olive tiy).-This insect lays its eggs into the olive itself, and when the deposit is discovered the olives are sathered im. mediately. Should the eggs be allowerl to remin the fruit is much deteriorated, if not ruinerl. The eggs are red, and thereforo easily discovered.

Bruco dell olivo (the olive grub). - This insect is the most dangerous evemy to thr olive tree here, consuming the sap and thereby drying up branches and bukls. When discovered the tree must be thoroughly pruned, all the foliage removerl, and every portion containing the insect burned or huried away from the plantation.

ZONF FOR TIIS GULTURS OF OLIVL: TREE.

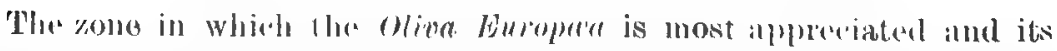

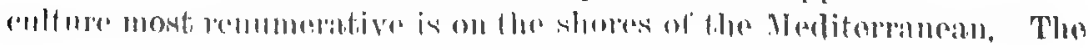


olive tree does not thrive with extremes of temperature; a climate too hot and dry or too cold and moist is not favorable to its eulture. It thrives well on the sea coast or on the hill-side, producing buds in March at a temperature of $10.50^{\circ}$ or $11^{\circ}$ centigrade $\left(52^{\circ} \mathrm{Fahr}.\right)$, blossoming in A pril at $15^{\circ}$ centigrade, flourishing in May at $18^{\circ}$ centigrade, and forming the fiuit in June at $21^{\circ}$ centigrade.

The lowest winter temperature supported without danage is $7 \circ$ or $8^{\circ}$ centigrade; but this temperature can not be withstood any length of time, indeed not over a week.

\section{OLIVE CLIMATE.}

(a.) The minimum of the temperature should be $7^{\circ}$ or $8^{\circ}$ cmitigrade, and that not to exceed eight days.

(b.) Snow five or six times per year, and the snow to not last more than two or three days at a time. Over that would undoubtedly injure the tree.

(c.) Olives should commence to ripen before the eud of October, and the average temperature should not be lower than $16^{\circ}$ centigrade.

(d.) The months of Jume, July, and August should be dry to render the olive healthy.

From $25^{\text {mm }}$ to $30^{\mathrm{mm}}$ ( 1 inch) of rain is necessary before June, supposing the previous winter to have been a fairly wet oue.

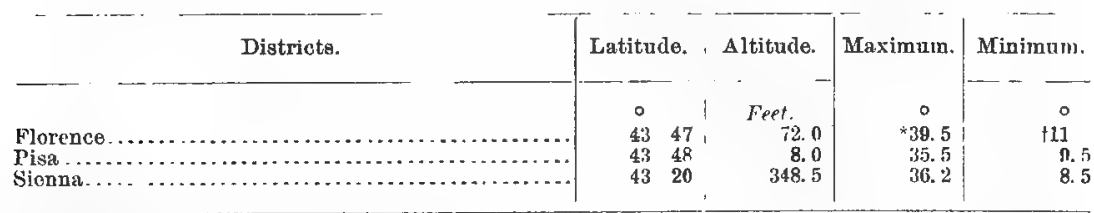

* Extreme heat known in summer at Florence; netually the thermometer seldon rige $80 v^{\circ} 30^{\circ}$ cent. or $86^{\circ}$ lialus.

$t$ 'This degree of cold is very rarely felt. T'le thermometer at Floreuce dnring the winter risy seldom falls lower than 50 cent. or $25^{\circ}$ Frahr.

\section{EXPORT OF OLIVF OLL.}

I have now given the method of making pure olive oil, but it is to be regretted that no pure oil is exported from Italy. The cotton-seed oil is made and imported in large quantities for mixing with the olive, thus giving to the dealer a larger profit than he would receive from the pure oil. Trentr.five per cent. of the liqnid exported is composed of cottonseed oil, and the mixture sometimes contains as much as 50 per cout.

My dispatch No. 23, dated May 2., 1883, gives an easy method of discovering the presence of the adulterating liquid.* The cotton-seed oil

- The test of Prof. Commendatore Beclui, directir of the Technicul Institnte and of the Agrarian School, is as follows:

In in wlass bulb place 5 enbic centimeters of the olive oil to be testerl; ardil to this 25 culbic centimeters of alcohol uf 980 areommere. Then ald 5 cubic centimeters of the test, which is composed thus: Ono gram of erystallizad nitrate of silver dissolved in

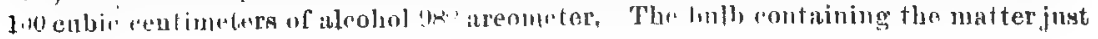


is not unhealthy, but simply detracts from the flavor of the pure article.

\section{WILliam L. WELSH,}

Consul.

UNITLE S'TA'TLS UONSULATL, Florence, March 17, 1884.

\section{VENETIA.}

IEPORT BY OONSUL NOYES, OF TENIOE.

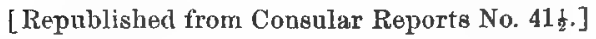

If, as has been seen, the production of oranges and lemons at a special point of the Venetiau territory is in reality a forced and artificial industry, that of the olive, so characteristic in many other parts of Italy, is hardly better suited to the natural conditions of the country here, and only reaches the importance of an industry in the same limited region. In all the eastern and central portions of Venetia the plant itself is rarély seen, and its cultivation for product insignificant or null. At the extreme west, on the.hilly slopes with southern exposure around Verona, are found occasional plantations, though their extent and production have coustantly decreased since the sixteenth century in consequence of the change of elimate, caused by the excessive denudation of the mountains, and the exaggerated risk and difficulty thus produced to the cultivation, besides the ontlay of time and capital before a return can be gathered. In an industry thus discouraged and declining, little effort is made for improvement, and in general, as it is one of the most ancient of all forms of culture, so is it perhaps that which has least benefited by the application of art or intelligence.

The olive cultivated here and throughout Italy, whatever modifications it may have undergone by climate and situation, belougs to but one species-Olea Europea-which, however, with long neglect and hardship is subject to a trausformatiou so marked as to appear a change of nature. When the tree becomes scrubby and uncouth, changes the

described is then placed in water, the temperatur. of which must be brought to $84^{\circ}$ centigrade (151 Fahrenleit). After half an hour's immersion the oil, if impure, becomes of a dark, muddy color, and with practice aud caltion the actual proportion of the adulterating liquid can be determincel.

Auctbre method is to place 5 centimeters of the oil into a bulb and add there to 30 centimeters of alcohol $98^{\circ}$. Shake the mixture thorougbly, and then let it rest unth

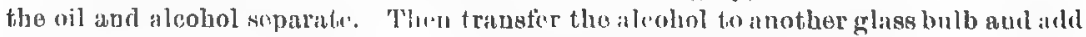

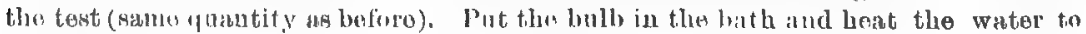

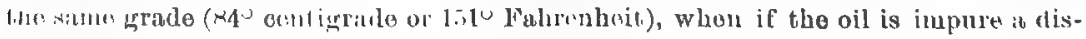
tiuct dark color will be prorlucoul. This test is bnsed on the essential quality possesurd hy the grlycerine of the cotton-oil to reduco the nitrute of silver. It is always woll to also uso tho tast with pure olive oil, when, if this oil be thoroughly pure, no

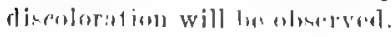


form of both its leaves and branches, bears only abortive fruit or none at all, and assumes almost the character of a different species, in this form it is known as the Olea silvatica. Ungrafted or abandoned trees always tend to return to this primitive type.

In the Veronese olive plantations a number of varieties are distinguished, resulting from local conditions, by which the plant is still easily influenced. Among these are specially prizen the Cosaliva or Prisint, a low spreading tree, with pendent boughs, long lance-shaped leaves, and small oval fruit, which has the merit of bearing each year regularly, not at all certain with other trees; the Drupo forte, taller than the above, with narrower and sharper leaves and fruit, rich in oil, but very delicate and capricious in its product; the Gagnan, likewise a considerable tree, with branches less inclined and rouudish fruit very full of oil ; the tree is hardy, but only bears every other year; the Rosa, Razza, or Razer, the tallest of its kind, with large pulpy fruit extremely rich in oil, but it bears only in two or even three years, and its oil is only middling in quality.

For table use, the varieties which give the best fruit are called usually compostar (from compost, French compôte, a conserve). These are the compostar simple, a delicate tree with large oval fruit, but very variable in size and quality, according to locality ; the compostar grasso, fruit large and round, more hardy, but, like the above, bearing well only in favorable years; the compostar di Spagna, fruit oblong, bears only in good years and favorable situations; the compostar piconlo, thrives every where, but inferior in quality; and others less deserving of mention.

Methods of cultivation.-The methods of cultivation and of propagation are simple in the extreme. The plant may be propagated by the talea, a quadrangular slip of the bark, some 3 inches long, with a portion of wood or woody protuberance adhering to it; or else by a fragment of the trunk, branch, or root, planted in earth well and deeply broken up, with the point only uncovered; but the tree thus produced would be weakly and short-lived. On the other hand, plants produced from the seed, although the most robust and diurable, give no fruit till twelve or fifteen years old, and are not in full bearing till twenty-five or thirty, while the slow return of the tree is already one of the greatest obstacles to its cultivation. Between these objectionable methods, the usual practice here is to reproduce from polloni, or sprouts, which rise spowtaneously from the more superficial roots of the old tree at their first ramification, or from wounds caused by instruments of labor. These sprouts are allowed to grow on the spot to about 3 inches diameter; the root is then uncovered and the bearing portion, with the sprout at- .. tached, removed to its future locality, the breach being neatly smoothed and covered with a plaster of dung diluted in water before replacing the earth. The sprout, at the moment of planting, is docked at about a foot from the ground, and the cut extremity covered with a similin $156 \mathrm{~A}-20$ 
plaster of dung and clay. The trees produced in this manuer commence bearing at the age of five or six years. Should these young plants be established in a locality differing much in soil or exposure from their original home they are grafted from trees already adapted to the situation.

When a new plantation is to be made the ditches for each row are opened some time before, with a width of 4 or 5 feet, and, if possible, 3 feet deep, or, if in separate boles, they should be 6 feet square and as deep as the soil will permit, and the first 9 inches of earth kept apart to allow that from below to profit more fully by the action of the air. When replaced it should be liberally mixed with inanure, or, if none at hand, with bits of leather, of hoof or horu, woolen rags, shrubs, grass, or dead leaves, tnking care to mix such materials well with the earth, but not in contact with the roots.

The distance between plants varies much with situation, but the medium in ordinary cases is to allow $\mathbf{1 0}$ or 15 yards between rows and from 6 to 10 in the row. A circular ridge of earth, a yard or so across, should be raised around the plant that the rain water mar be kept and forced to filter among the roots. Some cultivators envelop the stems for fear of exposure, but this is not necessary at the season of planting, and has the effect of preventing the absorption of light, air, and solar heat, most necessary to the plant at this period.

\section{INTERCROP CUL'TURE IN OLIVE PLANTATIONS.}

In most cases the intervening spaces are cultivated with the ordinary crops of the country, maize, wheat, luzern, or a rotation of those crops; but, while the constant movement of the soil between the trees is advantageous, the exhaustion of its nutritive elements by such plantations is certainly a prejudice, especially after the trees have attained a certain size and vigor. The best authorities urge their discontinuance after ten or twelve years, without, howerer, neglecting to sparle the ground in April or Mas, and, if possible, in Ingust of each year. Those who attach primary importance to their olice crop oftener sor vetches, lupines, beans, and such vegetables only around their trees, and turn them in with the spade or plow, it practice which, br common consent, gives precisely the mannre hest suited to the requirements of the plant.

\section{MANURE, AND PROTECTION FROM COLD.}

Alout once in three years the supply of more stimnlating manure should be renewed, and for this purpose, as butore mentioned, besides the orlinary stable product, the refuse of the tannery, remains of hoofs, and other substances containing imotates, phosphates, and carbonates of potassa ale cxeellent, material.

It. is nsual, on the approach of winter, after the crop, to raise a consirlerable heap of earth around the foot of aneh tree fo protect the roots 
from a possible excess of cold. The olive perishes if exposed to a temperature of $11^{\circ}$ or $12^{\circ}$ centigrade below zero $\left(=+10^{\circ}\right.$ or $\left.+12^{\circ} \mathrm{Fahr}.\right)$, and if attacked at the season of renewed vegetation, even at $-7^{\circ}$ or $-8^{\circ}$ centigrade $\left(=+19^{\circ}\right.$ or $+20^{\circ}$ Fahr. $)$.

\section{PRUNING AND CULTIVATING.}

A general pruning takes place in spring as soon as all danger of returning frost has disappeared, when decayed or suffering branches, as well as those which have borne fruit for several years, are removed, leav. ing the say to be engrossed by the young sprouts of the year, it beiug the nature of the olive to put forth and nourish, during one season, the branches which are to bear fruit the next, as the multiplication of these branches tends constantly to disseminate the productive force in a thicket of unprofitable shoots, in which case the tree will give a satisfactory crop only once in two or three years. Constant pruning is nec'ssilly to coucentrate its vitality. No less attention is required to com. bat the effort of the upper limbs, the so-called ghiottoni-gluttons-to draw the sap of their own vigorous growth at the expense of the fruitful branches lower down. The best bearing olives are generally kept low, often with pendent bonghs, and this practice becomes a necessary precaution in exposed and windy sitnations.

\section{YIELD OF OLIVES.}

It is extremely difficult to fix the normal vield of olives in a region where their cultivation is so precarious, and where the success of the crop is more subject, perhaps, than that of any other to the influence of the season. Without careful and intensive cultivation the plant becomes savage and bears nothing. With the best treatment it will give 6 to 8 liters ( 7 to $8 \frac{1}{2}$ quarts) at 10 years, 16 quarts at 17 years, and 32 at 25 years; but this only in exceptionally favorable years, with refreshing: rains in August and September.

It has already been stated that the olive in no case commences bearing fruit hefore the age of 6 years. It reaches a great age, 600 to 800 years on the arerage, frequently 1,000 , or more. Researches, more or less relitble, have been published, affirming that each cultivated plant gives during its existence an arerage product of 10,356 kilograms of oil, varying infivitely, of course, with the age and nature of the tree and mode of culture.

\section{GATHERING AND PREPARING THE OLIVES.}

Olives intented for the press are gathered at full maturity in October, November, and even as late as January, with much difference of practice in this respect, as the fruit of the same tree ripens with very unequal promptness and grows richer in oil to the last moment. On the other hand, if over ripe, the oil is much more subject to become 
rancid, besides the risk of injury from premature frost or snow and insects, so that the surer practice is to gather while some part of the fruit is still green.

For table nse, on the contrary, it should be plucked not quite ripe, and, the finest and largest being selected, to neutralize the contained acid which reuders them acrid to the taste, they are placed as soon as gathered in a vessel of glass or earthenware, filled with lime-water in which the olives float, aud the orifice closed with osier. After standing thus for twenty-four hours the lime-water is drawn off from below and replaced by water, fresh and pure; thenceforward it should be renewed every twelce hours, alternating pure and lime water till the liquid comes from the jar" "flat and tasteless. In this conrlition the olives may be long kept gond if immersed in a solution of seasalt flavored with any aromatic.

For drying, the olives are gathered later and riper, and dried in the suu or oven like any other fruit.

\section{PROCESS OF EXTRACTING THE OIL.}

The processes for extracting the oil all date from time immemorial, and are of the most primitive description. After fermentation the fruit yields its oil much more readily but of inferior quality aud already with a commencement of rancidity. Nevertheless the difficulty of extracting it completely with their imperfect appliances, leads many to provoke fermentation by keeping the olives closely covered with matting or woolen cloths. They are then placed in a hopper, from which they drop gradually into the hollow, inverted, and truncated coue of a great stone mortar, in the bottom of which turus a sort of millstone, grinding fruit and stones to a coarse paste. The pulpy mass is now mixed abuudantly with warm water, placen in sacks of hempen cord, aud realy for the press. This last is of the simplest mechanism; a heary wooden beam from 8 to 12 yards in length, fixed at one end and acted on by a screw at the other, forms a lever of the second class. The sarks are placed on the platform in piles of two and three or three and four on each other, in a double heap, to adjust them to the inclination of the press-beam, and as the pressure increases are crowded back and still bathed with worn water until tho pulp hegius to leavo the sack with the oil. This is the tarst dranght and the lirst quality of oil. The refuse mass is then emptied again into the mortar, with a liberal addition of warm water, ground over, and aguin put to press, yielong still a fair quality of indifferent oil. The whole opreration is repertenl a thind time, and after passing through a coarine sieve, oven a fourth time, but these last dregs are only fit for burning or mechanieal purposes. This is all that can beob. tained by the press power at jresent in use hore, and yet so rich is the fruit that after this insistent a tration, tha oil still hold in the relinise

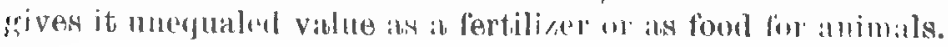

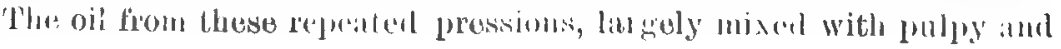


fihrons matter, passes into a larws vat, whinsts freer aud purer portion rises to the surface while the "morchia" or puly mixture is drawn off from below into large shallow basins, in which, when subjected to a warmer temperature, the albumen coagulates, and the remaining oil, with that already collected, is placed in stone jars ready for sale. From the refuse flux, if subjected to fermentation, which causes the still refractory oil vescicles to burst, a certain qnantity of very bad oil mar be extracted, but this operation is generally left to the press bands for their perquisites.

Another process is still more primitive. Here the olives are placed in a long woolen sack, and trampled under foot until the pulp is well separated from the stones. The sack is then doubled on itself and placed under the press, with constant additious of warm water as the operation proceeds, and the oil obtained purified in the manner above described. The refuse aud unbroken stones are then sold to the owners of grinding mills for a fresh extraction. The product olstained by this simpler process, though less in quautity, is much preferred in commerce, being the pure extract of tl.e pulp alone, the unavoinable mixtnre with that of the kernels after grinding greatly impairing the flavor of the whole.

\section{CIRCUMSTANCES FAVORABLE TO THE GROWTH OF OLIVES.}

All the circumstances which favor the growth of the olive are such as generally place it either on billsides or the shelves at their feet, where, well protected from the cold winds of the north, it may bask in a long season of summer sun, and where, also, it finds oftener the light soil of granitic or schistous detritus tbat suits it best, while the large mixture of clay common to valleys and bottoms produces the damp and compact formation of all others the most inimical to its vature.

It is traditionally the plant of warm regions and of long dry seasons; an over supply of water would be more injurious to it than otherwise, and no irrigation is attempted or thought of here. Howerer, moderate watering at the opportune moment is always of benefit, and, as before mentioned, those years when some rain occurs in August and September, improve the crop. Where the tree is intermittent, these are the bearing years.

Far from dreading the neighborhood of the coast, it has been said that the olive is never found more than 150 kilometers from the sea; and although instances are recorded of ancient plantatious in Piedmont somewhat farther inland, it is certainly true that the olive orchards of Europe skirt the shores of the Mediterraneau, and the most flourishing are those that clothe the narrow margin of rocky soil between mountaiu and sea. Those described above in the region of Verona, at abont 125 kilometers from the lagoon of $\nabla$ enice, are amoug the farthest removed, and not among the most prosperous.

Some notice has been given above of the productiveness of the olive, 
its ratber precarions in the uncongenial cirrumstaues of the region; I have not been able fo procure any detailed statement of the economical elements of the culture, but as the plant is grown either in the midst of other crops or on ground which would be otherwise unavailable, it is not generally regarded here as a factor of importance in the account of a farm. The latest statements give the present production of oil in the province at about 10,000 hectoliter's (264,000 gallons) consumed entirely there and in the neighboring region. The preparation of the fruit for table use is exelusively domestic, or, at most, for the retail trade and consumption of the town population adjoining, and no mention is made of it in the statistics of the country.

The rainfall registered for the eity of Vorona for a period of 20 years, from 1861 to 1878 , is as follows:

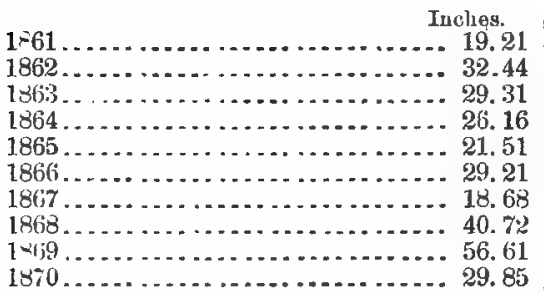

Inches.

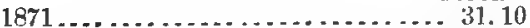

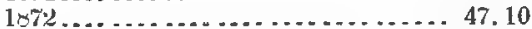

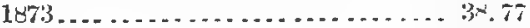

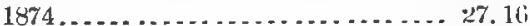

$1875 \ldots \ldots \ldots \ldots \ldots .62 .12$

1876........................ 42. 07

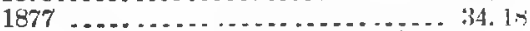

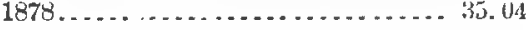

Arerage .........................

FIGS.

The fig is regarded here rather as a vile and common plant, insuff. cient either in quantity or quality for preservation as an article of export, and requiring neither care nor attention in its growth; it thrives everywhere unheeded, in sheltered spots, near country honses or along garden walls, and only serves to supplement the outfit of the market gardener for the nearest town. The frnit at Venice is neither succulent nor very well flavored, though large and showy, and often ripens badly, or rather decays in ripening. At Veroua it is cultivated with care in a few localities, aud one variety, with a fruit very small and intensely sweet, the Segalini, much resembling and probably an acclimation of the Piccoli Verdini of Tuscany, but inferior, has a local reputation. Bevides this, the Napoletani and Santi, introdnced trom the south, are drierl for home use.

As the tree is ouly found casually in odd cormers, ant usually single, there can be no estimate of yich per acre.

For planting, any portion of a branch, slightly besten and bruised, if placed in the earth will readily take root; the pariety prefiemed maty be grafted on it at a properer ace.

Along the shores of tho Lialie of Garda the prorluct less in demand lior the market as fresh fruit, is dried in sinall quantities ly the simple process of exposing to the sun on osior gratings and parclied in suall kegs with a little angar aud a liberal sprinkling of tlomr ; or else strung ou twigs and hung in the sunshine till completely evaporates, bat all 
this only for fumly consumption; there is no exportation of the article, the consumption of which, on the contrary, is entirely supplied by im. portation from the south.

MoWalter B. Noyes,

Consul.

United STates Consulate,

Venice, March 3, 1884.

\section{SPAIN.}

REPORT BY OONSUL OPPENHELM, OF OADTZ.

[Republished from Consular Reports No. 417.]

OLIVE CULTURE IN SPAIN.

Origin.-The olive tree has been cultivated from the most remote historical times. The ancients believed the tree to have been spontaneonsly created by a beneficent divinity, and the Greeks attributed the gift sometimes to Minerva, then again to Mercury. Diodorus states that Aristrus introduced the tree into Sicily, and was the first to use stone mills and rustic presses for the extraction of oil. Both the fruit and oil-pressing were, however, known to the Egyptians at a period even more remote than that of Greek myths, as is evidenced by wall pictures representing the process of filling the olives into sacks, which, when full, were placed in presses, from which the oil is seen to flow. Strangely enough, that very Egyptian process of pressing in sacks was until a few years ago in use in remote districts of Spain (in La Mancha), and mas still be practiced at this day. There exists some doubt as to whether the olive tree is indigenous to Spain. The wild species is undoubtedly found in many districts, from Catalonia to Cadiz, but by many it is held that these wild trees are merely the survivors of abandoned plantations, which have reverted to the aboriginal form. Be this as it may, and whether the tree be an immigrant or " to the manor boru," Spain is certainly to-day its chosen home, and it, is generally admitted that three-fourths of the olive zone in Europe lies within the borders of the Peniusula.

Varieties.-The varieties of the olive tree cultivated in Spain are numerous. The list following shors the kinds that are most largely raised, and describes the size and appearanco of the fruit.

(1) The Manzanillo: This tree under good conditions of soil and temperature, grows to a large size. It is found in Seville and in Granadi in great abundance, also in the maritime zone and some of the protected and fertile spots of the central region. It needs a rich soil, or, wanting that, high manuring and cultivation ; makes good oil, but in the provinew of Seville is mostly used for pickling. It is a great bearer, and the 
fruit, which is large, matures early. The dimensions and weight are as follows: length, 25 millimeters; diameter through the thickest part, 23 millimeters; weight of pulp, 7 grams ; weight of stone, 1 gram.

(2) The Sevillano Gordal: A small tree; is found chiefly in Seville and the lowlands of western Andalusia; wants rich soil, manuring, and usually irrigating also ; is not resistant to cold, and must not be pruned freelr, as it is very sensitive to mutilation; does not yield much oil, and that little is of poor quality ; is used almost exclusively for pickling; it bears the largest fruit known, which is identical with the "queen olives" of commerce. It is a small bearer and matures late. Dimensions and weight of fruit are: length, 40 millimeters, by 30 millimeters in diameter; pulp weighs from 12 to 14 grams, and stone about 2 grams.

(3) 'The Bellotudo: A large and luxuriant tree; not confined to any special district; requires phosphates in abundance and careful pruning, as the limbs have a tendency to intertwine; gives good oil and matures early, but is a small bearer. Dimensions and weight of fruit : length, 23 millimeters; diameter, 19 millimeters ; weight about 3.2 grams for pulp, and 0.9 for stone.

(4) The Redondillo: A medium-sized tree; a hardy and resistant variety, found chiefly in Central and Northern Spain; needs good soil, manuring, and thorough cultivation, also careful and extensive pruning for the same reason as above variety; is excellent for pickling, and gires good oil also; is a large bearer, and the fruit matures very early, requiring only 3,400 heat units (vide infra). Dimensions and weight are: length, 18 millimeters ; diameter, 16 millimeters ; weight of pulp, 2.5 grams, and of stone, 0.5 gram.

(5) The Lechin: Under good conditions this tree reaches a large size; is found in the provinces of Jaen and Cordoba, though not in abundance, being really a northeru variety, as it is very hardy and resistant. In Spain it is only used to make oil ; in France, however, it is a favorite for pickling; is a large bearer, and fruit matures early. This olive is one of the smallest known, total weight being approximately 1.3 grams.

(6) The Nevadillo blanco: A tree of fair size, found chiefly in Jaen, Cordoba, and Cadiz; must be planted only in well-sheltered spots, being sensitive to winds and to frosts; is only used for oil-pressing; matures the fruit early and is a prolific bearer. Dimensions and weight of fruit are: length, 28 millimeters; diameter, 15 millimeters; weight of pulp, 3.6 grams; and of stone, 0.7 gram.

(7) The Taral blanco: A large-sized tree, with straight and vigorous branches; chiefly foumd in the province of Jaen; needs manuring and careful cultivation; the fruit, which is always scanty in quantity, makes good oil, and is only used for that purpose; matures irregularly, making collection troublesome. Dimensions and weight of fruit: length, 23 nillimeters; diameter, 17 millimeters ; weight of pulp, 2.8 grams ; and of stone 0.6 gram. 
(8) The Bmpeltre: A small tree, throwing ont but few lindues; vers hardy, and therefore alapted to a cold climate; is chiefly raised in Navarre and in Aragon; requires light and fertile soil, plenty of bumid. ity and manuring, uuder which conditions it is a most prolific bearer; it matures early, and is by many considered as one of the most desirable varieties; the fruit yields good oil, and is also excellent for pickling. Dimensions and weight are : length, 28 millimeters; diameter, 16 millimeters ; weight of pulp, 3.2 grams; of stone, 0.3 gram.

(9) The Racimal: A medium-sized tree; resists a cold climate well, and thrives fairly even on poor soil; makes oil of a fair quality, though leaving much refuse in pressing; is given to "off years;" the fruit matures very early, probably earlier than that of any other viriety. Dimensions and weights are: length, 23 millimeters; diameter, 15 millimeters; weight of pulp, 3 grams; of stone, $0.7 \mathrm{gram}$.

(10) The Taral negro: A fair-sized tree, with straight and large bran'bes; only thrives in well-sheltered spots, as it hardly resists a temperature lower than $-5^{\circ}$ Cent., especially when followed by a quick thaw; found sparingly in Jaeu and Cordoba ; requires rery careful pruning and 'nltivation, and bearing limbs should be ringed; yields good oil; is objected to on account of its being given to "off" years;" in good years, bowever, it is a large bearer, and the fruit matures earls. Dimensions and weight are: length, 25 millimeters; diameter, 17 millimeters; weight of pulp, 2.2 grams; of stone, 0.9 gram.

(11) The Gordal.-A tree of large size, and fine, vigorons branches, also a very qnick-growing variety; is one of the kinds most generally distributed throughout Spain; is largely cultivated in Andalusia and in the central provinces; requires good soil, manuring, and much cultivation in order to bear well; resists the cold very well, matures early, and is a prolifie, regular bearer; the fruit is good both for oil and for pi kling, and its dimensions and weight are : length, 23 millimeters; diameter, 18 millimeters; weight of pulp, 3.7 grams; and of stone, 0.5 gram.

(12) The Verdejo.-A tree of medium size, with a tendency to dwarf considerably if not well cared for ; is found chiefly in Catalonia, Logroño, and Madrid; very hardy and resistant to cold; the vield will be in proportion to fertility of soil and the care given to cultivation; is generally used for pickling only; is not an early maturing variety. Dimensions and weight of fruit are: length, 22 millimeters; diameter, 12 millimeters ; weight of palp, 3.1 grams ; of stone, 0.6 wram.

(13) The Madrileño.-A medium-sized tree, of symmetrical appearance, limbs arching over; found chiefly in the south and in the mari. time zone; its name appears to be amisnomer, as it is not cultivated in Madrid or in the central provinces generally; requires good cultivation and cautions pruning; the fruit is excellent for pickling, next to the "queen" in size, and of delirious flavor; gives fair oil, but nnly yi+lds a small quantity in proportion to the wright of its pulp; matur.s late 
and is not prolitir. Dimensions aurl weight of fruil are: length, 35 mil. limeters; dicuneter, 28 millimeter's; woight of pulp, 11 grams; of stone, 1 gram.

(14) The Cornicabra, also called the Cornezuelo, the largest olive tree known, having strong, straight branches, is found all over Spain, but is most numerous in the central provinces; gives better oil than any of the other late-matnring rarieties, which, however, as a class, are in that respect much inferior to the early-maturing species; is very resistaut to cold and matures very late (it requires 30.978 of heat, vide infra); production is variable. Dimensions and weight of fruit are: length, 39 millimeter's; diameter, 19 millimeters; weight of pulp, 4 grams.; of stone, 1,2 grams.

(15) The Ficudo.-A medium sized tree, with luxuriant limbs, placed obliquely on the trunk. Like the above, it is most frequent in the central districts; bears a fruit which is very much prized for pickling, and has besides the peculiarity of being a "clear-stone" olive; a fair bearer, but matures late, though earlier than the variety immediately precel. ing. Dimensions and weight of fruit are: length, 30 millimeters; diam. eter, 18 millimeters ; weight of pulp, 3.2 grams ; of stone, 1 gram.

(16) The Nevadillo negro.-A medium-sized tree, very luxuriaut, and with short and distorted limbs; is largely cultivated in the province of Jaen, where it is prized ahove all other varieties; produces most plentiful and excellent oil; with careful cultivation and good soil it is a large and regular bedrer; matures late; the fruit is pointed and much bent at the distal end, causing this end to point at a right angle from the axial line. Its dimensious and weight are: length, 23 millimeters; diameter, 15 millimeters; weight of pulp, 3.6 grams; of stone, 0.7 gram.

Fvery one of the above-mentioned rarieties can be reproduced in several ways, which will be further descanted on when describing the mode of planting. The most generally adopted modes of propagation are either by planting estacas, which are round, large limbs specially raised for the purpose on the parent tree, as thick as a man's arm aud from 2 to 3 meters loug, or garrotes, which are shoots of from 70 to 90 centimeters in length, two of such shoots being usually planted in one pit. By the first system the trees bear after three years, but with garrotes it takes usually from six to eight rean's. Full bearing is in the larger varieties not reached before twenty to thirty yars after planting. With the small aul dwarf' varieties twelve to tifteen years may be nearer the truth. The maximum of growth is, at least with all large varieties, not reached before eighty years, and individual trees, either on account of especial vigor or favorable surroundiugs, keep on growing for centuries, reaching gigantic size. A French writer mentions three enormous olive trees standing metr Thisiseon. In the bollow trunk of one of them twenty persons conld stand next wath other, and another had branches 16 meters long. The trees were reputed to be nine huudred year's old. The trees standing on the Mount of Oliven, near Jermsilem, 
we by many believerd to be the nleutieal ones that stood there at the time of desils Christ. 'The dumtion of the productive period is also most difficult to determine; all that is kmown is that it liasts extremely long, when not eut short by injuries to the tree or exhanstion of soil surrounding it.

Planting and propagating.-Olive treos raised from the stone of the fruit always revert to the original form, called here acebuche or wild olive; hence in order to reproduce desirable varieties it is necessary to plant parts taken from the living tres, whether shoots, branches, of roots. The most general modes of reproduction is either by estacas or by garrotes. Both modes are followeil pretty nearly all over the country, though in the central provinees the second process is the more general, whilst the contrary holds good for the sonth and the extreme north. The best time for planting (by either mode) is from January to March in the maritime zone, from Jannary till April in the central provinces, and from January till May in the north; and it maty be takeu atis a safe rule to plaut only when the frosts are over and before the trees have begun to bud. The estaca, which, as before stated, is a stout linb about 3 meters long, should, it possible, be planted immediately after being cut from the parent tree. The hole is dug to a depth varying from 1 to 's meter's, the depth increasing with the severity of the climate; spluire pits 90 centimeters each way are the best, bnt quadrangular ones are less expensive and generally used ; this pit should be about 85 to 90 centimeters long by from 20 to 30 wide, and if planting on inclined ground, the length should cross the line of descent. At the bottom of the pit a layer of well-rotted mauure is first deposited, upon which a layer of active outer soil is laid to a depth of 3 or 4 centimeters; the limb is then placed in the center of the pit and earth (from the upper layer, not that dug from the pit) is then put iu, thoroughly broken up, and pressed down with the feet; when about even with the surrounding earth, a small concavity is left in order to retain rain or irrigation water. This operation is best performed by two men; one keeps the limb in position and compresses the earth, whilst the other is filling: in. In Andalusia it is usual to pile up moist clay against the protruding part of the estaca until no more than about 30 centimeters of its length is visible; this is held to be very efficient in all hot, dry regions, as otherwise it often happens that the limb produces shoots from the lower part only, whilst the upper part dries up. The moist clay is piled in the form of a slender cone, and at half its height an opening is left for supplying the limb with water, which in dry weather must be done plentifully. The garrotes are cuttings of from 70 to 90 centimeters in length, which with most varieties may be supplied in goodly numbers by such pruning as will benetit the tree. The pits are dug somewhat less deep than for the estacas, and two of the garrotes are planted together, leaning towards each other in such a position that the two entrings and the hottom of the pit form a triangle, 
of which the apex in aren with the grouud. In regard to manuring and filling the pit, the process is similan in both modes of planting, only the upper part of the smaller cuttings must be covered with about 10 centimeters of loose soil. The sprouts from these swaller cuttings are more exposed to damage by frost and by animals than is the cuse with the plan first described, and the bearing age is also reached some four or five years later, but it is held that the trees raised in that way are more vigorous and productive.

Other modes of propagation, such as by shoots from the living roots of a dead tree, or by raising stocks from seed upon which to graft later ou, are known to give excellent results, and are occasiovally practiced; but the vast majority of Spanish growers confine themselves to the two processes here described.

Cultivation.-During the first eight or ten years after planting, the orchard should be plowed three times each year (with a plow making a fuirow 10 inches deep), and the soil immediately surrounding the plants hoed three times the first and second year, aud later on twice a year. It will frequently happen that plants do not sprout the first year, in which case an extra supply of water and labor should be devoted to such plants; should they, however, not produce shoots for two complete years, they should be dug up and replaced by others. The distance at which trees should be placed depencls prinarily upon the variety plauted, the rule being to allow an interval equal to twice the height of the full-grown tree. This is the general rule, which must, however, be departed from accord. ing to local circumstances of topography, soil, and climate. Considerations in favor of closer planting are that trees closely planted resist both frost and drought better and also cause the soil to retain humidity longer. Against it may be urged that trees lacking rentilation are more liable to the attacks of fungous parasites and noxious insects; nor unst it be forgotten that the roots of the olive tree extend horizontally half as far again as the brauches do, and, as the diameter of the crown is usually equal to the height of the tree, close planting may stunt root development. The trees may be placed either in squares or on the dianond plan, as described when treating of orange culture. The most approved way of manuring olive orchards is todig a small circular ditch around each tree; the manure (which must always be well rotted and rich in phosphates) is placed therein and coverel with soil. The diameter of the circle within the ditch must vary according to the size of the tree, the object aimed at being to place the manure within the range of absorption of the outer rootlets. Manuring is usually effected once erery three years, and the best time is the fall of the year. Plaster from old walls is a beneticial ardition to the stable manure, and may also be spread within the circle surrounding the tree; and calcined bones in moderate quantitios are known to incite growth and to wreatly increase the vield. Gas. parin states that 100 kilograns of mannre prodnce abont 3 kilograms of oil. Hidalgo Tabladin, a prastical agronomist and recognized an- 
thority on fruit culture, gives the result of his experiments as more favorable still. According to him, 100 kilograms of well-rotted manure applied as above directerl increased the product of each tree the first year by 2.50 kilograns, the secoud year by 3 kilograms, and the third year by 2 kilograms, giving for the three years a total increase of 7.50 kilograms. Irrigation is advisable only in dry districts or in times of drought; in ordiuary years and in places where there is a moderate rainfall the grown trees thrive very well withont it. Latitude does not furnish any secure guidance as to the benefit conferred by irrigation, and, is a watter of fact, the practice is more common in the north and center than iu Andalusia. It must be borne in mind that irrigation has a tend('ncy to inaporerish the soil (by washing away the mineral constituents); hence, whenever it is practiced, manuring must go along with it pari passu. In Saragossa irrigation is much practiced, and so is manuring, whilst in Seville there is very little of either one or the other. If the orchards are properly and deeply plowed, two or three irrigations each year will be found sufficient. When, from the direction of the wind or other signs, there is appreheusion of a very severe frost, copious irrigation will often preserve the trees from iujury, as the evaporation from the soil has a tendency to mitigate the effects of a sudden lowering of temperalure.

Pruning and ringing.-Pruning olive trees is by many growers considered as the most delicate operation connected with olive culture, as well as the one upon which the prosperity of the orchard most depends. Independently of removing withered or injured branches, the purposes of pruning are the following:

(1) The removal of the secondary and tertiary branches that only bear weak and sterile twigs, thus making room for the development of more healthy and vigorous ones.

(2) The elimination of supertluous prinary limbs when they obstruct ventilation and light.

(3) The general thiuning out of the branches of certain varieties that have a tendence to extreme luxuriancy and to the intertwining of limbs.

(4) The correction of the babit of producing very long vertical shoots (which are usually sterile), thereby favoring the forming ot lateral beariug twis.s.

For the cutting of laryer limbs the following directions are given: Let the limb be sawn off even with the trunk, taking great care not to damage the edges of the bark, as it is those edges which are eventually to grow over and cover up the wound. In order to facilitate this liealing process, the exposed part of the wood is made slightly concave, using a scoop-shaped chisel for the purpose; the wound is then plastered with asalve made of wet clay and cow-dnng, which should be applied with a brush. It is very important that this work be well and ne:itly done, leaving no protruding splinters or irregalar surfaces. The

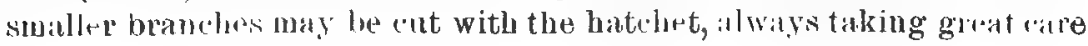


not to remove any more bark than is absolutely necessary; and for the removal of shoots and twigs pruning-shears are to be used. In regard to the best time for pruning, the custom varies in different districts. Some writers on the subject contend that if pruning is effected when the sap asceuds in the spring the healing process is more rapid; others are of opinion that it is best to prune at the end of winter and before the sap has begun to more upwards. It is, however, unirersally admitted that pruning is only to take place after the fruit has been collected and before budding has beguu. Thorough pruning is generally only done once every two or three years, and as the pruned trees give a smaller yield the first year after the operation, it is well to divide the trees into two or three classes, one of which is pruned and trimmed every year, thus dividing the work and equalizing the annual yield.

As a direct means of stimulating the production and ripening of fruit the practice of "ringing" is recommended. The process consists in removing an annular strip of bark, varying from one-half to $1 \frac{1}{2}$ ceutimeters in width, from the base of secondary or tertiary flower-bearing branches, thereby preventing the descent of the sap, which is thus utilized for the formation of fruit. This operation, which must be performed when the tree has begun to blossoin, but before the flowers are fully expanded and fecundation has begun, is of great usefulness with varieties that are given to " off years," or to exuberant flowering uot followed by bearing. Individual trees, as well as varieties bearing scantily and irregularly, have been made to yield both plentifully and regularly by this process, which, however, like all pains-taking practices, is limited to a few careful growers.

Climate and situation.-The olive tree in Western Europe thrives in the open air as far north as $46^{\circ}$, though bejond $44^{\circ}$ it ouls bears irregularly and scantily; from that point the size of the tree and the regularity of yield increase as one procetels further south until $18^{\circ}$ is reached; beyond that latitnde the tree grows luxuriantly, but does not yield fruit. Spain being situated between $3 \tilde{5}^{\circ} 59^{\prime} 49^{\prime \prime}$ and $43^{\circ} 4 \bar{\imath}^{\prime} 29^{\prime \prime}$ of north latiture, the whole of its territory is withur the limits of the olive region.

Observation has established the fact that the olive in order to mature requires a certain number of units of heat luring the period of most active vegetative life, said preriod beginning with the first appealance of the blossoms and euding with the first severe frost. This number of heat units (each of 10 centigrade), which varies with different varieties, and ranges from 3,4000 up to: $:, 97,5 \circ$, is to be computed by adding the mean hoat of each day during the priorl between blossoming (which requirs: a temperature of +190 ) and the tirst frost. Any district in which the temperature will sun up to:3,9780 during that period is there. fore adilpted to olive culture, provided the winter is not severe enough

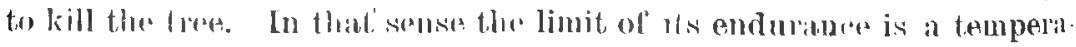

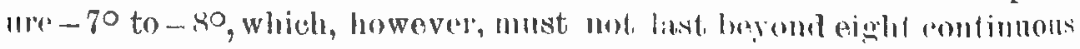


dayis. Given the meau temperature of the summer mouths aud the time of blossoming in any stated place, the time of maturity may be deduced; thus in Seville the olive tree bloom s about the 1st of May, and the mean temperatures are:

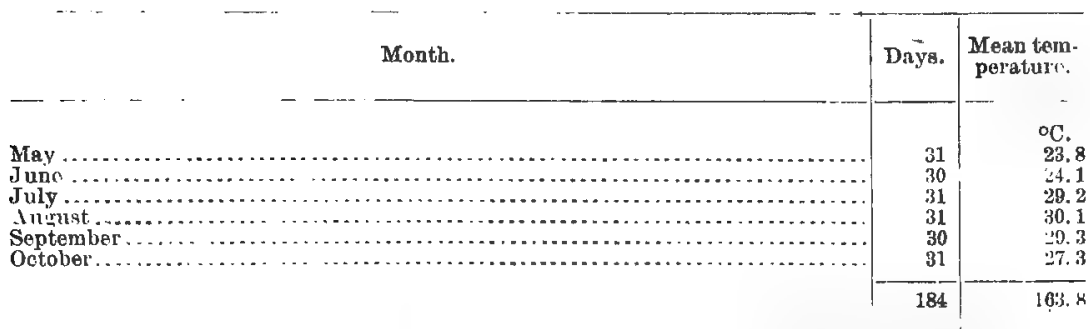

If we divide the number of degrees by six, we obtain the mean monthly temperature, $27^{\circ} .3$, which, multiplied by 181 (the number of days), gives a total of 5,0230; hence the fruit in Seville usually matures abont the 1 st of October.

For Morata de Tajuña, 6 miles to the east of Madrid, where blossoming trkes place at the end of Mar, the figures are:

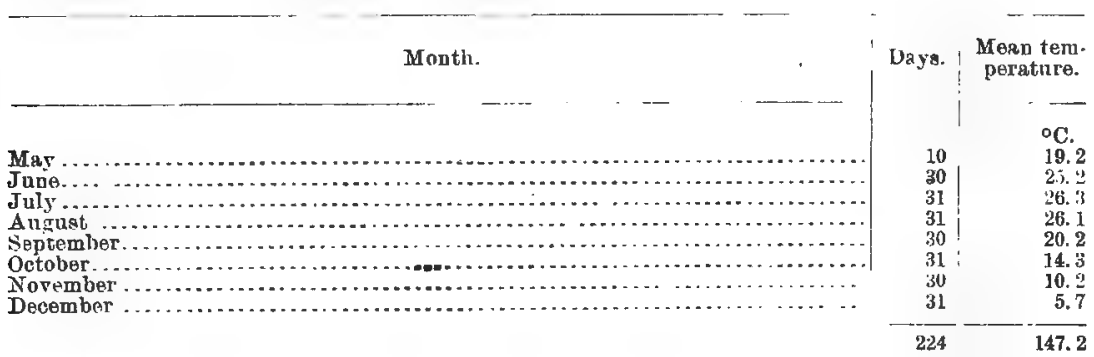

Giving mean temperature for eight months 180.4, which, inultiplied br 224 , gives $4,121^{\circ}$; bence the olive matures towarls the middle of December.

Valladolid may be cited as a place where, owing to late blossoming and early frosts, the maturing of the fruit is impossible. Assuming blossoming to take place on the 15th of June, there will be:

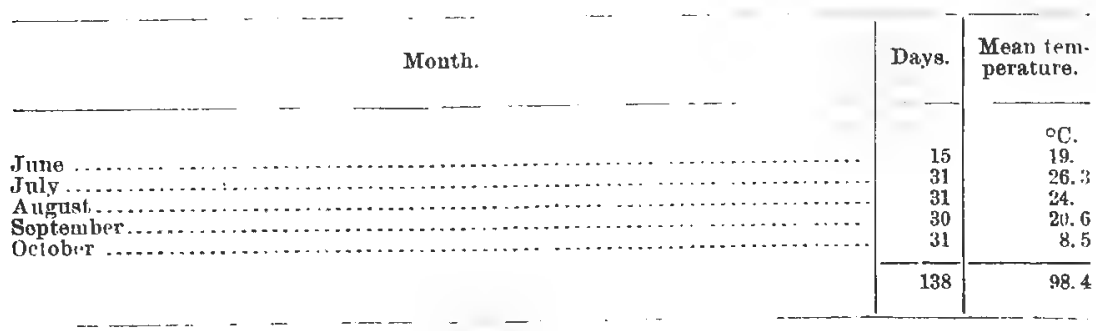

XกTR. - In Novomber the temperature falls to $4^{\circ}$. 
Giving a mean temperature of $19.7^{\circ}$, which, multiplied by 138 sums up to $2,718^{\circ}$, less by about $700^{\circ}$ than is required for maturing even the earliest variety of the fruit.

Altitude, in as far as it brings about a decrease of the temperature, is equivalent to Iatitude, and it is admitted that each 181 meters of height represent a change of climate equivalent to 10 of latitude, from which the conclusion may be drawn that olive culture can be carried ou at high altitudes only in the southern parts of its habitat, and vice versa. In the vicinity of Madrid there are productive groves standing on ground that has 655 meters of elevition above sea-level. The altitude being $40^{\circ} 24^{\prime} 30^{\prime \prime}$, and 615 meters being equivalent to $3 \circ 24^{\prime}$, the climatis conditions are those of latitude $53^{\circ} 48^{\prime} 30^{\prime \prime}$. In the province of Granada trees are found at an altitude of 1,000 meters above sea-level, representing $5^{\circ} 31^{\prime} 30^{\prime \prime}$, which added to the latitude of the district, which is $37^{\circ} 11^{\prime} 10^{\prime \prime}$, brings up the effective latitude to $42^{\circ}$ $42^{\prime} 40^{\prime \prime}$.

Exposure and incline are most important factors in olive culture. Exposure varies in its effects, both according to latitude and to local circumstances, hence no in rariable rule can be given, though generally southern exposure is best, as being less liable to frost. In a warm; dry climate, however, trees thus placed will need irrigation in order to do well. Near the northern limits of the olive region, and on high ground, where frosty nights are common in the fall, eastern exposure is deprecated, because in such situatious the first rays of the sun bring about very sudden and abrupt changes of temperature. A quick thaw after a moderate frost will generally cause more injury than a period of more severe cold followed by gradual thawing; this accounts for the fact that after a spell of very hard cold the trees most injured are those most accessible to the rays of the sun.

As regards incline, it is held by most growers that slightly rising ground is preferable to a perfect level. The benefit from an inclined situation, with sonthern exposure, increases as one goes further vorth, as the obliquity of the sun's rays is thereby counteracted. The rise should, however, not exceed the ratio of 6 meters to 100, as on steeper ground cultivation by plowing becomes difficult and the soil covering the roots on the upper side of the tree is apt to wash away. At inclines much exceeding the above it is nsually necessar? to bank up the ground, thus creating a succession of small level terraces, involring much labor aud expense, and also losing the advantage dericed from the greater perpendicularity of the sun's rays npon inclined surfaces.

Natural or artificial obstacles to injurions winds, snch as mountains, forests, or walls, shelfer a certain extent of gronnd on their lee side. Spots sheltered on the north :ue usually consilered as being benetited thereby to the sextent of fully one degree of tatitude. The ground sheltered extends horizontally in the ratio of 11 to 1 , as compared to the height, of the obstate: thus, a mountain dhain 1,000 meters high will 
shelter the land on its lee to a distance of 11,000 meters from its apex. Beyond that point, however, the injurious effects of winds thus imperded is more potent than it would be if the obstacle did not exist. The Sierra of Guadarrama, which rears its crest up to 2,385 meters, shelters its southeast exposure to a distance of 26,235 meters, but beyond that limit the action of the cold winds crossing its summits from north to south is felt most keenly.

The neighborhood of the sea is by no means prejudicial to olive orchards, and in the maritime zone, wherever the proper conditions of soil and climate prevail, olive culture is carried on in close proximity to the shore. The ancient dictum, laid down both by Latin and Arab authors, that olive culture could only be prosecuted within 30 leagues from the sed, has, however, been disproved by modern experience.

Soil.-It may be laid down as a general proposition that soil adapted to the vine is well suited also to olive culture. The characteristics of such a soil will be looseness and fair permeability, and for the olive it is necessary that the soil and active subsoil should have a depth of at least one meter. A calcareous soil, meaning thereby one which contains a large proportion of carbonate of lime, is considered valuable for olive culture, especially so in the south; in a northern district, where the summer is short, such soils are open to the objection of being cold, as their white coloring prevents absorption of heat. The presence of oxide of iron in such soil, by giving it a reddish tiut, corrects this objection, and it is on such soils nsually that great yields are obtained on the high central plateaus and in the north. Both magnesia and sulphate of lime are efficient substitutes for carbonate of lime-and some sulphate may always be advantageously applied with the manure. Oil produced on soils poor in these ingredients has usually a greenish tinge, and is not as limpid as oil from soils containing them. Potash is a necessary constituent tor olive culture, and when not present in sufficient quantity, must be artifieially supplied. A tendency to exuberant flowering and aborting of the fruit, shows a deficiency of phosphates in the soil, which must be remedied in order to obtain good yields.

The hygrometric properties of the soil are an important factor, which, however, must necessarily be appreciated according to the general climatic conditions of the locality. Here it is held that in order to be well adapted to the olive tree, soil should retain its looseness after a rain of forty-eight hours' duration, and that during the hot season it should contain 10 per cent. of its weight in water.

Pests. - The olive tree is subject to a disorder which some years ago guve rise to considerable controversy, some authors holding that it was caused by insect, while others ascribed it to the agency of a fungus. It goes by different names in the different districts; in Andalusia it is spoken of as melera, mangla, melazu, tiñuela, tizne (smut), accitillo, etc., and in otber parts it is frequently called negra, negrilla or negrura, all $156 \mathrm{~A}-21$ 
meaning blackness, and indicating the outward appearance of the affected trees. The disorder is now generally believed to be caused by a fungus either identical or closely allied to the Dematium monophyllum, already alluded to as one of the most damaging parasites of the orange tree. Trees standing on very moist grouud are especially subject to its attacks, though dry ground does not give immuuity when the foliage is luxuriant; removing excess of moisture from the soil and liberal pruning so as to admit light and air, are both preventive and cure for the disorder.

The olive tree has many enemies amongst the insect tribe, and the following is a list of those most frequently encountered:

The olive bug (Lecunium olece), which fastens itself to the green parts of the tree and sucks its juices. Pruning the infested limbs, and thereby giving free access to light and air, is the most efficient remedy, and the larger affected parts are to be smeared over with petroleum.

The olive moth (Acophora olivetta, also Oruga minadora) does damage chiefly in the caterpillar state. Bernard describes its appearance thus:

It is about 7 millimeters in length, and is composed of twelve segments, the body is of the same color as the under side of the olive leaves and sometimes yellowish; its mandibles are at first black, and later on they grow yellow. It frequently penetrates under the bark of the twige, and causes the formation of the s. c. agallas (gall-nuts) upon them. It also introduces itself into the fruit, eating the pulp and even the kernel itself. The perfect insect is greenish white in color, has four wings and two large antennæ. Careful cleaning and pruning, removing all visible nests, and the application of petroleum or of a solution of lime to the limbs are the means usually successfal in fighting this pest. It seems to be established that this insect is never found on a tree infested with the olive bug.

The olive fly (Dacus olex) is an insect about 5 millimeters in length, yellowish red in color, with three black stripes on the abdomen, wings larger than its body, and of a golden color with black striæ. This insect lays its minute eggs upon the nascent fruit, and the worm burrows galleries into it and feeds apon the pulp. When the caterpillar has reached its full size, it resembles that of the olive moth, but it has only 11 segments instead of 12 , and its mandibles are always black. When this insect bas obtained a foothold, it is best to gather the fruit at once (even though it be green and yield but very little oil), as this prevents the propagation of the pest and may thereby avert more serious dam. age the following season.

The olive flea (pulguilla del olivo) derives its name from its peculiar mode of rising, which looks more like jumping than flying. It is about 5 millimeters long, has transparent ovoid wings dotted with yellow, thread-like antenno, and greenish abdomen. The larva, or worm, is light green, with head of a dirk red. It places itself usually on the petioles of the leaves and buds; its time of feenndation coincides with the blossoming of the olive. The larrate are deposited on a laver of a whitish downy matter called by the country people algodon del olivo 
(Anglice, cotton of the olive tree). The insect's life does not last much beyond one month, but it causes many blossoms to fall off, and rain showers in blooming time, though in themselves prejudicial to the yield, are effectual in destroying the insect.

Two small beetles, respectively the Hylesinus olesperda and the Phloio. tribus, are especially destructive to the soft white layer underneath the bark; the ova are deposited between the bark and the wood of broken branches, or after pruning. The perfect insects are about 3 millimeters in length.

The Aspidiotus couchyformis is an insect about 5 millimeters in length, ashy in color, provided with a proboscis with which it fastens itselfs to the bark of the tree in great numbers, generally, however, avoiding the leaves or tender shoots. This facilitates their removal by rubbing with a coarse mop or brush. As with all other noxious insects, petroleum is an effective remedy.

A swall worm, commonly called talartrilla (Anglice, small borer), of which the perfect form is not identified, introduces itself into the stone of the olive, and after devouring the kernel, makes its exit by way of the petiole, causing the fruit to drop off, usually in an unripe state. In this case, as with the olive fly, it is advised to sacrifice the year's yield and gather the fruit at once, in order to prevent the recurrence of the pest the following season.

Picking.-The time of ripening varies considerably according to locality and the species cultivated. When intended for pickling the picking in Andalusia usually begins about the middle of September and lasts till about the 10th or 10th of October. The fruit at that time has reached its full development as far as size is concerned, but is yet green and hard. For oil pressing the harvest begins in November, and may last as late as early Jauuary. The usual mode of gathering is by knocking the fruit down with sticks, which is to be deprecated on account of the great damage done to the tender shoots on which the next season's fruit is to be borne. Careful growers pick by hand, which is less expeditious, but more profitable in the long run.

Pickling.-For pickling there are two processes in use.

The first one is the slow process, and the modus operandi is as follows : Place the freshly picked olives in fresh water, which must be changed every day, and let them lie thus about a fortnight. The water should be drawn off quickly and promptly replaced, not leaving the fruit exposed to the air more than is absolutely necessary. The water drawn off will at first be very bitter; this bitter taste will go on decreasing day by day, and the taste must be taken as a criterion as to when this process is to be considered completed, a fortnight or twenty days at most being nsually the time required. The olives are then placed in a pickle made of salt and water, of a strength indicated by the French salinometer as $9^{\circ}$, found in practice to be equivalent to a proportion of 
about 1 volume of salt to 14 volumes of water. It is best to use butts or barrels in which wine or brandy has been kept; those having been put to any other use are apt to give the olives the flavor of their previous contents; if new vessels are provided, they should be of oak, not pine, and they should be soaked about thirty days before being used. At the bottom a layer of olive twigs and leaves is first placed, which protects the olives from injury by pressure, and on the top of the fruit another similar layer is placed, taking care to have this layer well covered by the brine; the whole is kept down by some oak staves weighted with bricks or stone, all of which must of course be scrupulously clean, as any noxious taste or flavor imparted to the brine will affect the olives. The vessels should be covered with a cloth or tarpaulin, in order to exclude dust. Olives thus treated will be in good order for bottling or for consumption within about four months, and will keep sound certainly two years.

For pickling by the quick process a solution of caustic soda is prepared, this solution to be of a strength of about $4^{\circ}$ of the French sal. inometer, and the fruit placed therein. After remaining in soak an hour a few olives must be sampled by cutting, in order to ascertain how far the solution has penetrated into the pulp; the depth of such penetration can be readily noticed by the color, and should not exceed half the thickness of the pulp ; if after an hour this is not the case, other samplings must take place at intervals of not more than ten minutes, until the olives are found to be in the proper condition. Then the solution is to be immediately drawn off and replaced by fresh water, which must be changed quickly three or four times, the fruit being allowed to remain in the last water for twenty-four hours. During that time the brine is prepared, and next day the olives are placed in it, following the same directions as were given when describing the first process. By this mode the olives will be ready for use within about thirty days.

In both modes of preparation the olives should after being once wetted never be exposed to the air more than a few minutes at a time; and to handle the fruit ladles of wood or tin dippers should be used.

This gives a fair outline of the modes in gemeral use for pickling, although undoubtedly some of the picklers hive special recipes, upon which, however, no defiuite information could be obtained. It may be stated here that pickled olives in the Seville trade are at present roughly classed as Manzanillas and Gardales, meaning thereby, respectively, very sinall or very large (the latter being tho " queen olives"), which names Lave no connection with the variety of the truit put up.

Oil-pressing.-Oil-pressing is carried on in many ways, some of them yet very primitive. The first prossing is done by meaus of a mi!l somewhat akin to a cider-mill; the pulpy mass then has hot water poured on it, and is subjected to an second pressing, which in the Seville district is now usually accomplishen by hydraulic machinery. The refuse from this second prossing is used us fuel, and in somo cases as a cattlo 
food. Recently a new process has come into vogue whereby a further quantity of fatty matter is extracted, which is used for making soap. Where it is not thought advisable to utilize the refuse in any of the above ways, it will prove a very valuable fertilizer for the olive grove.

The yield of oil from a given weight of fresh fruit varies from 16 to 25 per cent.; the latter figare is not often reached even with the best oil-yielding varieties and the most improved processes. I have obtained data showing a higher perceutage, but I believe that the figures expressed the proportion of oil to a given weight of olives which, as is usual in Andalusia, had been lying heaped up on the mill floors for several weeks, thus losing moisture and weight.

Extent and yield.-The area covered by olive plantations in Spain is not accurately known. The official cadastral data are notoriously misleading, nor do they exist in any shape whatever in relation to some provinces; no professional economist would take them to be more than mere approximations, of which the factor of error would probably vary in every district, rendering any scheme of recticication extremely difficult. Hidalgo Tablada," who bears the reputation of heing a safe guide on such matters, makes the following estimates :

Area of olive groves....................................hectares.. 2, 099,651

Number of olive trees (80 per hectare) .......................... 167, 972,080

Arrobas of oil produced (1 arroba + to 6 trees) ...................... 27,992,347

Value of annual yield (at 10 pesos per arroba) ................pesos.. 279,953,470

Gross product per hectare.................................... 133. 33

From which product he deducts 80 per cent. for cultivation, harvesting, pressing, interest, and taxes, learing net income of 26.67 pesos per hectare (equivalent to $\$ 2.08$ per acre). This extremely low average yield can only appear credible to those who, like myself, have seen miies of olive groves in a state of utter neglect, unprotected from the inroads of cattle or game, and, in fact, left to thrive or perish without the interrention of human agency save at cropping time. The province of Cadiz has a perfect wilderness of just such groves, and of course the product must in these cases be miserably small.

The province of Seville possesses a number of carefully cultivated groves, ranking probably in that respect along with the best, and the value of olive orchards in that district some fourteen jears ago ranged from a minimum of rsvn. 500 (\$25) to a maximum of rsvn. 4,000 (\$200) per aranzada. $\neq$ The value of a good orchard does not frequently exceed the latter sum at the present day, although the working expenses and income of an aranzada of that class, as given me by a planter from the Utrera district (Seville), seem to indicate a higher value. These

" He wrote in 1870.

+ The arroba $=11 \frac{1}{2}$ kilograms=about 25 pounds aroirdupois.

$\$$ The aranzada $=3757$ ares, or 0.9244 of an acre. 
figures-which in my opinion only apply to a small grove of exceptional excellence-are as follows:

Peros.

Gross yield-90 arrobas of oil, worth

Plowing. Pesos. 10

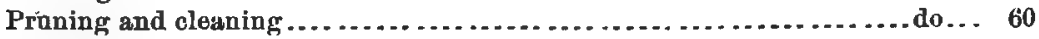

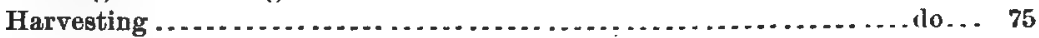

Pressing........................................................ 90

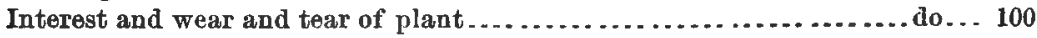

Net.

From which deduct taxes (about 20 per cent. of net yield)

Leaving net income

Equal to about $\$ 58$ per acre.

The following data, in reference to a grove of 180 aranzadas situated near Ecija (province of Seville), show.what, in my opinion, may be considered mean results of careful culture on a large scale:

Fruit collected (in fanegas).*

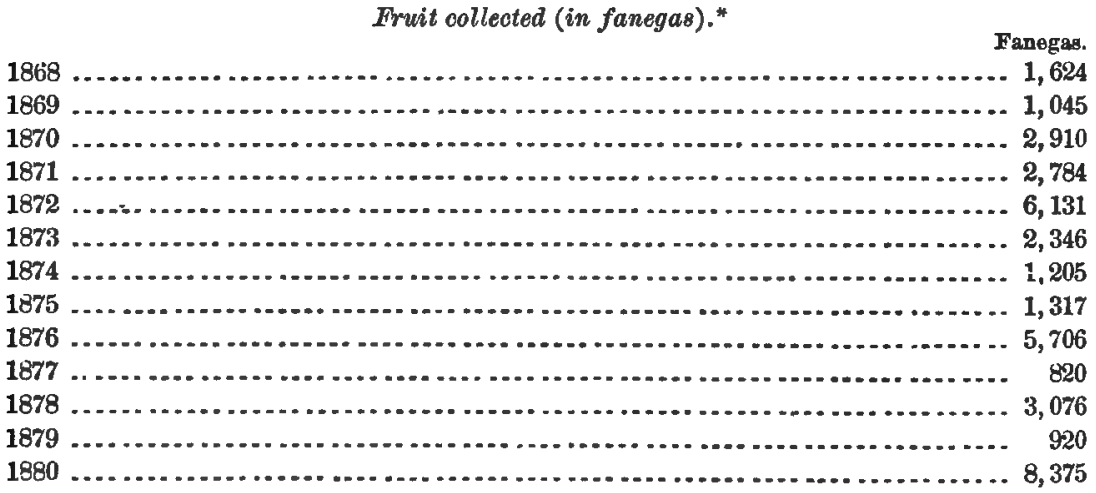

Mean annual product (equal to 16.35 per aranzada)................. 2,943

Taking the oil yield at 15 pounds per fanega of fruit, and estimating oil at 7.50 pesos per arroba (of 25 pounds), the average value of the harvest per aranzada will be 73.50 pesos (eqnivalent to $\$ 15.28$ per acre). This estate previous to 1868 had not been carefully tended, and it is, therefore, fairer to take the mean of the last five years (1876 to 1880) as a standard, the extraordinary crop of 1880 being offset by the very small yields of 1877 and 1879. For this quinquennium the account stands thus: Total of five years' yield, 18,897 fanegas of fruit; annual yield, 3,779 fanegas; annual yield per aranzada, 21 fanegas, yielding 315 pounds, equal to $12 \frac{3}{5}$ arrobas of oil, which, at 7.50 pesos per arroba, have a value of 94.50 pesos, equivalent to $\$ 19.66$ per acre. Great as is the range of estimates in relation to the results of olive culture

\footnotetext{
* The fanega of olives weighs from 65 to 75 pounds, and yields from 12 to 16 pounds of oil.
} 
for pressing oil, it would be as nothing when compared to the variations in the figures bearing upon the raising of fruit for pickling purposes. I do not believe that authoritative data can be obtained on the subject, and I therefore thiuk it best not to discuss the financial results of this branch of culture at all. It may be stated, however, that any farmer engaged in raising fruit for pickling would expect a larger cash income per acre than if raising for oil, both on account of the more perishable nature of the finished commodity and of the more contracted and more fluctuating market. Olive oil is a staple of the first importance in this country, of which any quantity almost can always be disposed of readily for cash. The pickled fruit is looked upon more in the light of a fancy article, the sale of which, it is true, is just now very brisk, but which some vagary of taste or fashion may any day render less readily salable.

Exports.-The following are the latest official figures showing the exports of olive oil and of pickled olives from Spain:

OLIVE OIL.

\begin{tabular}{|c|c|c|}
\hline Years. & Quantity. & Valne. \\
\hline $\begin{array}{l}\text { Average of five years, } 1877-1881 \ldots \\
\text { Calendar year } 1881 \\
\text { Calendar year } 1882, \ldots\end{array}$ & $\begin{array}{r}\text { Kulograms. } \\
17,585,865 \\
24,625,487 \\
13,730,474\end{array}$ & $\begin{array}{c}\text { Peso8. } \\
16,148,877 \\
22,901,702 \\
12,357,426\end{array}$ \\
\hline
\end{tabular}

PICKLED OLIVES.

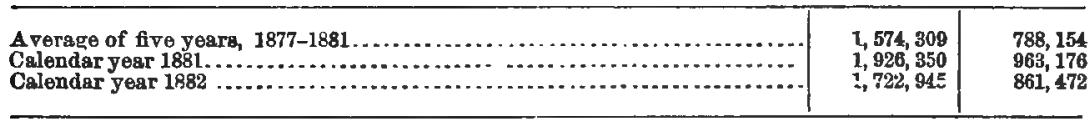

The destination of these exports for the year 1882 is given as follows :

oILs.

\begin{tabular}{|c|c|}
\hline Germany & $\begin{array}{r}\text { Kilograms. } \\
956,417\end{array}$ \\
\hline Algeria .................. & $1,531,326$ \\
\hline 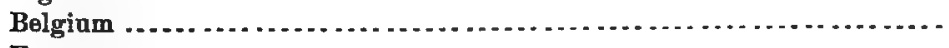 & 63,663 \\
\hline 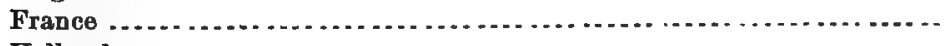 & $3,123,874$ \\
\hline 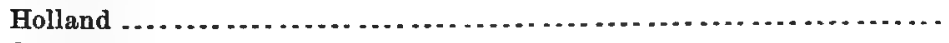 & 53,208 \\
\hline 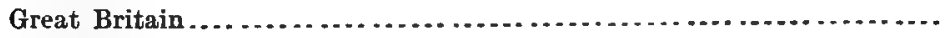 & $2.189,611$ \\
\hline 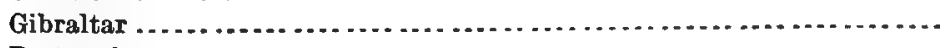 & 342,390 \\
\hline 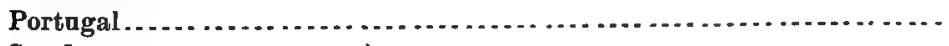 & 760,093 \\
\hline 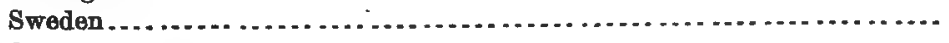 & 442,354 \\
\hline 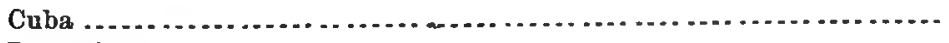 & $2,824,990$ \\
\hline 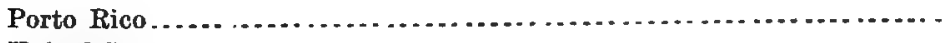 & 476,161 \\
\hline 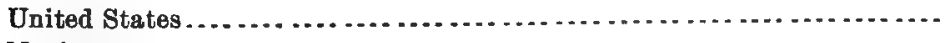 & 80,596 \\
\hline Mexico $\ldots \ldots \ldots \ldots$ & 183,771 \\
\hline 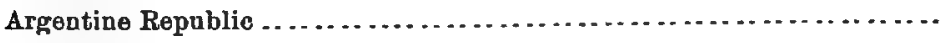 & 240,399 \\
\hline${ }^{\prime}$ & 192,119 \\
\hline 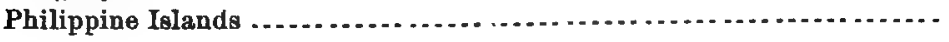 & 101,001 \\
\hline$\ldots \ldots \ldots$ & 168,501 \\
\hline & \\
\hline
\end{tabular}




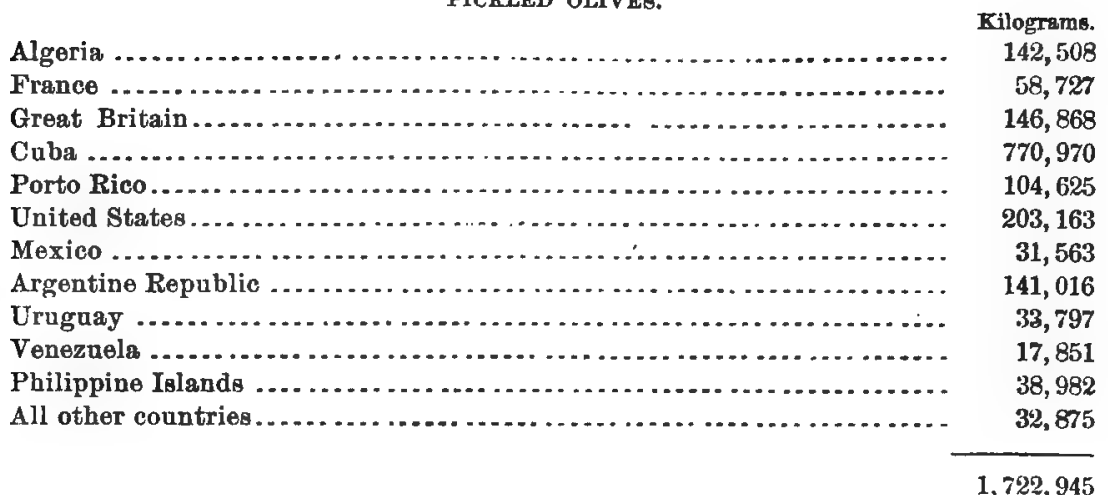

Erinest L. Oppenheim,

Consul.

United States Consulate,

Cadiz, March 11, 1884.

\section{MALAGA.}

REPORT BY CONSUL MARSTON.

Farieties.-The name of the best variety for pickled olives is the "Mansanilla;" the best varieties for olive oil are the "Picudo" and "Ojiblanco."

Other choice varieties worthy of culture and for profit are, for eating, "Mansanilla," the largest of which are called the "Queen olive." In Malaga for oil the best is the "Picudo;" in Cordova, the "Ojiblanco."

The trees which produce the above are grown in the provinces of Malaga, Granada, Cordova, Jaen, and Seville.

Situation.-Distances from the sea, 2 or 3 kilometers; almost any elevation above sea-level; the more sun the better. The olive tree will grow almost anywhere, but best on level land; white subsoil is best.

Climatic influences.-Temperature $45^{\circ}, 90^{\circ}$, and $78^{\circ} \mathrm{Fahr}$.

No rain-fall record to be had here.

Trees and fruit require as much rain as possible.

Irrigation.-No irrigation for olive trees.

Cultivation.-The land is cultivated three times each sear, during winter and spring.

Pruning.-Every three years-one-third of the orchard each Fear.

Picking.-For pickling, green; for oil, when ripe.

Piclling.-To pickle olives the following process is followed in this province. Put the olives, when green and just before they ripen, in fresh water for, say, fifteen or twenty days, changing the water every 
two or three dass during the interval; at the end of that time they then make a brine of salt and water, and in order to prove the sufficiency of salt they place a fresh egg in the brine; if the egg floats on the surface, the condition of the brine is good, and they then submerge the olives in such quantities that they will all be covered. They then make a kind of lattice-work of bamboo canes, the canes being split in two parts and fastened together, and these are, when arranged, placed on the surface of the water to keep the olives from floating to the top. The olives are then allowed to remain in this brine for at least twentyfire or thirty days before they are ready for use, or longer if they are not required for sale and shipment.

After being taken out of the brine, in order to please the taste of the Spanish people, they are frequently seasoned according to taste of those who are going eat them, by adding garlic, laurel leaves, thyme, or other herbs.

Oil. - The olires intended for making oil, after gathering are placed in small compartments under cover, from which place they are taken to the mill to be ground. These mills in the country are of the most primitive kind, their capacity being about 25,40 , to 100 fanegas per diem. From the mill where they are ground the paste that remains is put into esparto mats or bags and then placed in presses of different kinds, hydraulic and those more ancient with the old-fashioned wooden screw, which extract through pressure all the oil, and from these presses the oil runs through little gutters into a tub or receptacle of large proportions. They then pour in boiling water, which separates the oil from the water contained and extracted from the olives themselves. The oil is allowed to remain at least one month, in order to settle before being drawn off for market, but the longer it remains in the tub or vat the clearer it becomes.

Oil is always moved from country to city in goat-skins (prepared and made for the purpose) by mules and donkejs.

Maturity.-Trees commence fruiting at eight or ten years.

Yield.-There is great diversity of opinions upon this subject-depends upon size and age of tree; I can find no one who will venture an opinion.

Planting.-The trees are planted 12 yards apart, and propagated by planting branches.

Insect pests.-There are none.

H. C. MARston,

Consul.

United States Consulath, Malaga, December 6, 1889. 


\section{MALAGA.}

\section{REPORT BY OONSUL MARSTON.}

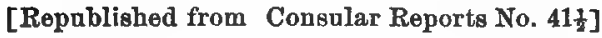

Varieties.-The province of Malaga produces but few olives, Cordoba and Seville being the localities most favorable to their growth. I have, however, obtained all the information possible at Malaga upon the subject of olives, viz :

There are two kinds of olive trees which grow near Malaga, but not to any great extent. The "verdialis" proudces the olives used for making oil, while the olives from a tree called the "manzanilla" are used for eating purposes. Olive trees begin to yield at ten years, and at the age of fifteen years they are in their prime, and live for hundreds of years.

The "queen olive of conmerce" is a splendid variety, and is produced in Cordoba and Seville, bat not in the province of Malaga.

Cultivation.-The process of cultivation is plowing the ground, except in the immediate neighborhood of the tree, where the ground is loosened and broken by a hoe.

Maturity.-The older the olive tree the more it produces.

Yield.-I can get no estimate in this province as to the arerage yield per acre. It is estimated here that trees of fifty years old may produce from 200 to 4.00 pounds of olives, according to the richness of the land and the care taken in the cultivation. Every 100 pounds of olives is said to produce 25 pounds of oil.

Planting.-The trees are usually planted about 12 yards apart.

Pickling. - Ulives for table use are put in very salt water, and, with the addition of certain herbs and pimento, etc., remain until they are fit for eating. The olives for making oil are ground into a kind of pulp, and with the use of a press the oil is extracted.

Situation.-Hill-sides. Olive trees do not grow to any extent near the sea-coast on account of the sea winds, which are injurious.

Soil.-Any soil will answer for the growth and production of olives. They require no water except that produced by rain.

Rain-fall.-The annual rain.fall in Malaga for the four jears ending 1883 was follows:

Inohes.

1880 23.80

1881 30.73

1882 16. 33 1883 17.05

Average rain for four years, 21.98 inches.

Olive oil.-It is very difficult, if not impossible, to determine the average production of olive oil in Spain, for there are no statistics; nevertheless $40,000,000$ to $45,000,000$ arrobas may be considered an average crop, of which only about $5,000,000$ arrobas are exported, the 
remainder being used in Spain. The principal cities from which oil is exported are: Malaga, Sevilla, Valencia, and Barcelona, the last two, however, ouly in a limited quantity.

The crop of 1882-'83 in Andalusia is considered a good one regarding quantity as well as quality.

According to private notes, about $1,426,000$ arrobas were brought into Malaga by railway from July 1,1882 , up to May 31, 1883, of which abont 1,012,000 arrobas were again exported. There was on the 31st of May, 1883, some 414,000 arrobas as stock on hand in Malaga.

The largest exports were made to the following countries, viz: Germany, 386,400 arrobas ; England, 276,000 arrobas ; France, 156,400 arrobas; United States and South America, 55,200 arrobas.

It is not possible to give an accurate estimate of the quantity of oil entering Malaga by beasts of burden, the largest part of which is consumed in the town (the daily consumption being about 500 arrobas); thus some 138,000 arrobas may have been brought into Malaga during the eleven months preceding May 31, 1883, forming a total (with the above-mentioned 1,426,000 arrobas) of 1,564,000 arrobas. Prices during the said period ruled from 30 to 35 reals vellon per arroba in store, the market having been depressed since the end of March, 1883.

H. C. Marston, Consul.

United States Consulate, Malaga, March 28, 1884.

\section{TURंKEY. \\ REPORT BY OONSULGENERAL HEAP, OF OONSTANTINOPLE.}

[Republished from Consular Reports, No. 41t.]

Darieties.-Through cultivation an olive slip becomes in twenty to twenty-five years a tree of from twenty to forty feet in height. The kind known in the Levant as the " thafnoyah" produces the fruit best suited for the table, and it is generally grafted. When grafted they give fruit in three or four years, but when planted in slips they seldom boar fruit in less than fifteen years, and the best results are not obtained until they have reached the age of from twenty to twenty-five years. Other descriptions are grown more especially with a view to the manufacture of oil for exportation and domestic consumption.

Cultivation.-As a rule the olives grown in this country receive little cultivation after the young trees reach maturity. At the end of autumn or early in winter a trench of 2 to 3 feet in diameter and from 18 to 27 inches in depth is dug round each young tree and filled with animal manure more or less rich according to the age and strength of the tree. The manure is well covered with soil so as to prevent its being disturbed 
and to keep it as long as possible in the position best fitted to feed the roots of the tree. The ground between the trees is generally neglected.

The "queen olive of commerce" is almost unknown here. It is the pick of the largest and finest fruits produced by the best olive tress of Spain.

Maturity.-The olive tree generally comes into fall bearing about its twenty-tifth year when it has been grown from slips; but when grafted it yields abuodantly between its eighth and twelfth year. In both cases it continues to produce largely every alternate vear for about fifty or sixty years, and if cultivated as mentioned above it will continue to yield fruit, though less largely, up to the age of one hundred years.

Yield.-Under ordinary circumstances a young healthy tree that has reached maturity will produce in a "poor" year about $82 \frac{1}{2}$ pounds, and with careful cultivation the same tree will yield in a "good" year double that quantity.

The trees vary in yield every alternate year. An acre will contain 120 trees, and each tree will yield an average of about 100 pounds of fruit; the produce of the acre will therefore be about 12,000 pounds. As it takes about 60 pounds of fruit to produce 1 gallon of oil, the yield of the acre will be 200 gallons.

In Smyrna, etc., a few new mills have been constructed to be worked by steam, but elsewhere the mills continue to be worked on the old system, notwithstanding the urgent necessity of substituting improved machinery.

Planting. - The trees are generally planted in rows at about 20 feet apart, but in some places they are grown much closer, especially on the steep slopes of hills. In the islands of the Archipelago, where the land is often broken and irregular, they are planted in places where the soil is so arid and barren that it will hardly grow anything else.

Picking.-When olives are intended for pickling a small portion is plucked while green to be pickled in that state; but the larger portion of the fruit intended for preserving is gathered when it has fully ripened and has turned black. It is preferred in this state by those who relish the oily flavor, and there is a large consumption of black pickled olives in Turkey.

Oil of a superior quality, but small in quantity, is extracted in some districts from green olives that have been plucked or have fallen from the trees; but as a rule olives specially intended for producing oil are picked only when they have become quite ripe and black. It is chiefly from the seed-vessel that olive oil is obtained, and not from the seed, contrary to the general rule of the vegetable kingdom.

Pickling.-To preserve black olives for the table, the fruit is packed in casks or boxes with a layar of common salt three-quarters of an inch thick at the bottom. On this is laid a layer of olives about two and a half to three inches in depth, upon which a light covering of salt is 
sprinkled, and so on until the cask or box is flled, the upper layer of stelt being deeper than the others except the lower oue. The staves of the cask are left loosely bound to allow the bitter water from the olives to drain off. When they are drained the hoops are tightened.

To preserve green olives for the table, the fruit, after having been washed, is packed in casks in its natural state. The casks have a small hole bored in the bottom to allow the water to run off slowly. They are filled with olives to about 3 inches of the top, and the cask is then filled to the brim with fresh water once in twenty-four hours, until the bitter taste of the fruit has all but passed off. The hole in the bottom is then plugged, an aromatized pickle is poured on the fruit, and after the pickle has taken effect a little oil is added to soften the olives and reduce any bitterness that may remain in excess of what is required to give them piquancy or an agreeable savoriness.

Extraction of olive oil.-In the interior the method practiced to extract oil from olives is probably the same as was employed in the earliest tunes. The fruit is collected in a large bin near the mill where the crushing is done. The mill is simply a large, circular, shallow tank with an upright beam in the center, which runs through a large stone, and serves as the pivot around which the stone revolves. A horse harnessed to a horizontal pole attached to the stone sets it slowly and laboriously in motion. An improved apparatus consists of two stones attached to the horizontal pole and are dragged around with it. These machines resemble the Mexicun arrastra for crushing quartz. The one ldst mentioned is the most effective of the two, as the stones describe a larger circle, but it requires greater power. The olives are crushed, but the oil is not expressed. When a sufficient quantity of the fruit has been throwu into the tank, the machine is set in motion, and a man precedes the horse with a pole armed with iron to push the olives under the stones. After a fow rounds a couple of gallons of water at boiling heat are poured in to assist the action of the stones, and moro is added as required, until the mass acquires the consistency of a thick paste. The mass is now put into a large jar and conveyed to the press, where it is kneaded with more hot water into a thinner paste, and as often as it is emptied into a shallow dish it is emptied into a square cloth of the same coarse material of which the cloaks of the country people are made, which will bear the greatest power of the press without bursting. A man forms the paste into a square flat mass, folds the eloth neatly over it, and ties it with a string attached to each corner, and places it in the press to the number of sixteen or seventeen cloths. The press is turned down by means of a hand-lever, and when more power is required a rope is carried from the lever to an upright rotary beam at some distance, which two men turn round with bars rapidly.

The oil and water expressed run into a trough before the press, which though rudely bewn from a $\log$ of wood is constructed on principles showing a howledge of the relative specific gravity of oil and water. 
The trough is divided into two parts longitudinally by a partition, which comes up to about 2 inches below the lerel of its sides, so that when the oil and water run in together on one side of the partition, the oil, coming to the surface, floats over to the other side, while the water is conveyed away by a pipe placed at the level at which it is desired to maintain the water within the trough. After the press has been screwed down as far as it will go, it is loosened and hot water is poured upon the pile to wash off any oil that may remain on the cloths, and they are kneaded without being unfolded. More boiling water is poured upon each package, and they are again placed in the press, to be again removed and undergo for a third time the same process, until no oil remains.

The oil comes out a light-green color, and is poured into a large jar near the press whence, after depositing any water or dirt it may have, it is poured into skins. It is uext emptied into large earthenware jars, 4 or 5 feet in height, where it remains for at least two months, till all impurities are deposited.

Olive oil is refined by agitating it with a saturated solution of caustic soda which reuders the whole soapy; but after a time the oil precipitates a saponaceous deposit, and the remainder becomes quite clear and pure and is then poured off. It is now of a yellowish color, with a slight odor and a milder taste. The bark of the olive tree has been used extensively by the French instead of einchona, and large quantities of excellent soap are made from the refuse of the olive oil.

Situation.-The best results are obtained on the sides of lower hills, when the land is of a suitable nature; but very good crops are obtained from trees growing on the high $\rightarrow r$ table-lands.

Soil.-Although the olive tree will grow on almost any kind of ground where it can obtain nourishment, it thrives best in a rich argillaceous soil, which is neither too damp nor too dry. It grows in the greatest perfection in the fine rich clays which, in many parts of the Levant, cover the hill-sides.

Although it is not the most suitable situation for them, olive orchards are sometimes planted near to the sea-coast, and in such places may be frequently seen extending to within a few yards of the sea-shore. In these situations they often suffer from exposure to cold winds, and are not so healthy.

Irrigation.-When the plants and trees are young they are sometimes watered in a rude fashion, but there is no system of artificial irrigation in olive culture.

Yield.-Around Smyrna, in Candia, Chio, and other islinds of the Archipelago, more timi and labor are bestored on the cultivation of the olive than it receives elsewhere in Turkey. IIowever, as even there, in certain districts, the natives attach unecunal or secondary importance to this culture, very consirleruble rlifferences are to be found in the cost of cultipation as well is tho yield of this crop. O.wing to these and 
other reasons, especially the absence of clear and regular accounts among the native farmers, it is impossible to give a correct statement of the yield, proceeds, and cost of cultivation per annum of an acre planted in olives.

Rain fall.-The annual rain-fall in this district during the last four years was:

In 1880

Inches.

In 1881

22.33

In 1882

25.76

In 1883

In the three years first mentioned the annual rain-fall was comparatively light, and it was only in 1883 that it reached the average of the ten years from 1870 to 1879 , inclusive.

\section{United States Consulate General, \\ Constantinople, April 10, 1884.}

\section{H. Heap, Consul-General.}

\section{CRETE.}

REPORT BT OONSUL-GENERAL HEAP, OF OONSTANTINOPLE.

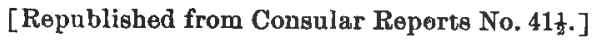

The island of Crete (Candia) is the most important olive oil-producing district in Turkey. The olive harvest for the season 1883-'84, just ended, is considered unusually snuall and of poor quality. It only augmented by 742,500 gallons the stock of oil remaining from 1882-'83 in the hands of merchants and with the cultivators. This result was foreseen in consequence of the exceptionally fine crop of 1882-'83, which exceeded the expectation of the most hopeful growers. Never, in fact, had Urete been known to produce so abundant a crop of olives or one of such good quality.

The following returns show the difference between the last and the preceding crop:

\begin{tabular}{|c|c|c|c|}
\hline & District. & 1882-'83. & $1883-' 84$. \\
\hline \multirow[t]{2}{*}{$\begin{array}{l}\text { Khandia ........ } \\
\text { Candia ......... } \\
\text { Rethy mo ...... }\end{array}$} & $\begin{array}{l} \\
\cdots \cdots \\
\cdots \cdots \cdots \cdots\end{array}$ & $\begin{array}{l}\text { Gallons. } \\
4,125,000 \\
6,875,000 \\
2,750,000\end{array}$ & $\begin{array}{l}\text { Gallons. } \\
220,000 \\
412,500 \\
110,000\end{array}$ \\
\hline & & $13,750,000$ & 742,500 \\
\hline
\end{tabular}


Of the crop of 1883-'83 there were exported to-

Gallons.

England

Russia. $1,100,000$

Austria.................................................. 750,000

Germary .............................................. 275,000

Turkey .................................................... 577,000

Egypt ...................................................... 412,500

Syria...................................................... 137,500

Anatolia ................................................... 357,500

Barbary .................................................. 192,500

Other places.............................................

$7,177,500$

Owing to the excellent quality and the low price of the oil produced in France that season, there was almost none exported to that country. The local consumption of Crete amounted to 3,272,500 gallous, and the soap works on the island absorbed about $2,200,000$ gallons. Considerable stock remains on the island. The sellers who know that a good crop . is always followed by a bad one prefer to hold their oils in the expectation of a rise in prices, which can not fail to come. At the commencement of the olive barvest, oil was selling at $\$ 1.39$ to $\$ 1.41$ the $2 \frac{33}{4}$ gallons, while on the 1 st of March last it was quoted at $\$ 1.67$. In London the oil is selling at this date at $\$ 174.66$ per ton weight, gross.

G. H. HEAP,

Coxwsul-General.

United Stateis Consulate,

Constantinople, April 10, 1884.

\section{DARDANELLES.}

\section{REPORT BY OONSULAW AGENT OALVERT.}

Varieties.-The best varieties are the Ropadhes. There are a few other varieties, but they are little cultivated.

Trees.-The trees are grown all over the district, but principally in the Gulf of Adranytium, and from sea edge to some miles inland, at an elevation from sea-level, say, to 1,000 feet.

Situation and soil.-Wild olive trees generally affect sunny exposure. All situations but rocky sheltered valleys give the best fruit and most oil ; clay and light soils, with rock or deep subsoil.

Temperature.-Rarely above $90^{\circ}$ or below $5 \circ$ Fihrenbeit.

Rain-fall.-Thirty inches per annum. 'The olive crop is uncertitin and does not appear to be much intluenced by greater or less fall of rain.

Fertilizers.-Not used except when new plantations are made. Water, if required, is applied by baud.

Oultivation.-When practicable the gronnd is plowed between the trees and grain crops raised; more fiequently in rocky situations. The 
trees are surrounded by loose stone walls which are filled in with soil. Goat or sheep manure is sometimes applied.

Pruning.-Is limited to clearing out branches when too close-in the spring.

Picking and curing.-Picking commences from September up to November for green olives for pickling; from November to February for black olives and for oil; pickled with salt for olives and for oil. The olives are crushed in a revolving stone mill, the pulp is put in goat'shair bags and saturated with boiling water; pressure, hand or power, is applied. The liquid runs off, the oil floats, and is collected fit for the market. The oil-cake is reset two or three times and repressed, but the oil is of an inferior quality. A still further quantity of oil can be extracted by chemical appliances, but it is fit only for making soap.

Maturity.-Four to five years. The life of the olive tree is very uncertain. There are trees with a girth from 12 to 15 feet and more, said to be over a thousand years old.

Planting and propagating.-Trees are planted from 20 feet in poor to 40 apart in rich soil, and propagated most frequently by planting wild trees, by separation of cultivated trees, or by off-shoots. In planting, from February to May, the stems of the trees, wild or cultivated, are cut down to 4 to 5 feet. They are taken with the massive root, the wild trees being grafted before or after removal; a hole is dug and water poured in, a portion of fine soil is added, and the whole worked to a semi-fluid state. The tree is then plunged in and set, the rest of the loose soil is drawn around the tree, but not trodden down till the following day.

Insect pests.-A worm attacks the fruit when ripening, in Thessaly, where the variety of olive is much larger in size. It does not exist here. The olive decays when the maggot grows and falls off the tree.

Frank Calvert, Consular Agent.

United States Consular Agency, Dardanelles, February 11, 1890. 22 

PART III.

\section{FIGS.}





\title{
CONTINENT OF AFRICA.
}

\author{
MOROCCO. \\ REPORT BY OONSUL MATHEWS, OF TANGIER.
}

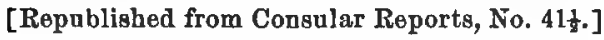

Varieties.-There are various kinds of figs-white, red, and blackwhich are dried for commercial purposes. Of the white variety there is the White Burgasot, of excellent flavor both fresh as well as dry. It loes not produce the early large fig, but only second season figs.

The Marsellaise or Athens fig.-Fruit very sweet and small, round in shape; it ripens in Angust, and is the variety most preferred for drying.

The Blanquette fig.-A middling variety, which resists cold weather better than any other rarieties, and can prosper north of the regions of the olive; is also of second season, and is preferred while ripe before drying.

Of the red varieties the best for drying are the following: The Date $f i g$, the most preferred for drying purposes; it ripens in August. The Jerusalem fig matures in Septémber, very fine and large. The Rose Blanche, very large, and is only used for drying. Sultana or Tunisian, a large, choice variety similar to the Smyrna.

There are numerous varieties of black figs, bearing a different name in the various countries where they are grown.

Morocco produces a large variety of most delicious figs. They are called by the Arabs "Kermuse" in general, although each variety has its name. There are figs of various colors, some of which are white, yellow, black, purple, and others green. The Jews extract " aguadiente," an ardent spirit, from figs. In Spain they prepare a savory wine from which they extract spirits which they flavor and term "anisette."

Suffren has given a description and figure of three hundred and sixty varieties of figs cultivated in Spain, France, and Italy. Most of the fig trees yield two crops during the year : the first, producing the large fig, matures in June, and the second in Angust, September, and October. The fig tree grows on any soil, provided it is free of stagnant water retained on the surface over the roots. It prefers a light loam of a calcareus nature; should this retain its moisture the trees would grow taller; in dry soils the fruit is smaller. 
Planting and-propagating.-The fig is propagated from seed, shoots, suckers, slips, stakes, layers, and by grafting. From seed is only practiced by some to discover new varieties. In raising from slips or stakes, these should be chosen from vigorous branches of the shoots of the previous year, and about 26 inches in length. The proper time is either in February or November. A hole is opened about $2 \frac{1}{2}$ feet deep; good manure and a little lime should be well mixed with the soil which is dug out of the hole. The slip or branch is then laid horizontally, leaving out the last eye perpendicnlarly, which on shooting out will form the tree. Budding or grafting is seldom practiced in fig trees. The distance between trees should be 16 feet. During the heat of summer of the first two years the young plants should be watered.

Fertilizing.-Manuring the trees will greatly increase their crops. They require no pruning, only removing dry branches and new shoots from the trunk. When the tree obtains age it requires no cultivation. It is well to cover with straw the branches of the trees while from one to three years old, in the winter in cold climates, to protect the eyes from frost, after which the trees become hardier as advancing in age. There are male and female trees; the male is the wild or goat fig.

Male and female fig.-There should be amongst the fig orchards some of the masculine species, as those trees producing the small variety of fig and which yield so abundantly require the proximity of the male sort to come to full maturity and size, otherwise the fruit drops before coming to maturity. In the absence of male trees in an orchard where these varieties are growing the male figs, which are very small and unfit to eat, are brought and hung to the branches of the feminines. The wild fig produces a multitude of small insects of the genus Cynips, which settling on the fruits of the culticated trees convey the pollen with which they are infected. This is a practice from time immemorial.

Maturity.-The fig trees commence to yield fruit when they are three years old, and come into full bearing when they are twenty years of nge. From one hectare of land the yield generally is about 4,000 kilograms of dry figs, at value of $\$ 5$ per 100 kilograms; total, $\$ 200$.

Yield.-As an example of the great yield of the fig-tree, I may cite some trees at San Pedro del Pinatar, Spain, which produced each as much as $\$ 12$ of early figs, besides 150 pounds of dried sold for $\$ 3$, and 7 quintals of second-size figs sold for $\$ 9.50$, which make the yield of each of these trees in full bearing annually to the amount of $\$ 20.50$.

Curing the fig.-The fruit must be gathered when quite ripe, when they commence to dry on the tree, on a clear sunny day, after the dew has dissipated. They are exposed to the sun in lattice work made of canes or slips of boards, or in rough straw mats placed from the ground, allowing, if possible, the air to circulate under. The tigs after a few days are pressed one by one into shape, to facilitate their curing. After sunset the fruit is removed to a dry and well-ventilated place for the 
night. This operation is followed until the figs are perfectly cured. When they are selected, the various sizes are spread on sheets for a few days in a ventilated place, the windows of which must be closed when the atmosphere is damp; and lastly the figs are pressed downwards on a table to give them a round shape; then they are packed in boxes lined with paper. The boxes must be kept in a dry and ventilated room. The common figs are packed and pressed in mats.

\section{Felix A. Mathews,}

Consul.

United States Consulate,

Tangier, April 2, 1884. 


\section{CONTINENT OF AMERICA.}

\section{MEXICO.}

\section{LA PAZ.}

\section{REPORT BY OONSUL TIOSOA.}

The Spanish or Moorish black fig is the best for preservation and for palate taste, and are very juicy once dry. The best varieties for eating when ripe are the Bordeaux and Smyrna white fig, but the early black Moorish (breva) is superior. Dry figs are an important export industry in this country, and their growth is found in every watering place or valley in this country. Trees are generally planted in limish and sandy soil, and whenever the soil is too rich ashes of any kind mixed in the soil is its best fertilizer. Never use manure or guano; it is the worst enemy of the fig-tree; the fruit becomes tasteless and besides attracts the insect pest called conchita, (turtle shell).

As to watering fig-trees: While young or the first and second year after planting are watered erery third day; during the rainy season don't require any irrigation.

In pruning time, which is in October, the tree is simply cleaned out of dry branches or young ground-root shoots.

Picking and drying takes place in May and June, before the first rain falls. Early figs in April and part of May.

In this country the fruit is simply spread on the top of the house's roof or on mats, with full sun exposure all day, and at midnight it is taken in the houses.

JaMES VIOSCA,

Consul.

United States Consulate,

La Paz, December 26, 1889.

\section{ECUADOR.}

REPORT BY CONSUL BEAOH, OF GUA YAQUIL.

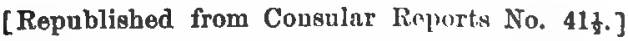

The only kind of fig grown in Ecuador is the purple.

Though the fruit does well it is grown only in a small way. The trees should be subjected to treatment similar to that of the orange and lemon, in which respect the requirement is lived up to in Ecuador, 
all being neglected. A tree in full bearing will yield about 100 pounds of fruit.

None of the fruit is dried in Ecuador. All that is grown is consumed fresh or made into. sweetmeats.

Horatro N. BEACH,

United States Consulate, Consul. Guayaquil, February 26, 1884.

\section{VENEZUELA.}

\section{LAGUAYRA.}

REPORT BY CONSUL BIRD, OF LAGUATRA.

The fig is rarely met with here, although the soil and elimate seern well adapted to its culture. One may occasionally see a fig tree, planted, it would seem, more for ornament or shade than for its fruit, notwithstanding the fact that the tree yields two or three crops per year.

United States Consulate,

WINFIELD S. BiRd, Consul.

Laguayra, November 29, 1889.

\section{WEST INDIES.}

\section{BERMUDA.}

\section{REPORT BY OONSUL BEOKWITH, OF HAMILTON.}

Figs are grown on the island, but the same insect which has destroyed all the peaches has attacked the figs, also the guavas, so in a short time these fruits, like the peach, will be a dead letter, for scarcely anything is done to destroy the insect, and as we have no winter they increase the whole year, the fruit falling on the ground and being allowed to rot there. At one time olive plants were imported here by the country, but no care was given them. They have since dwindled away, only a few trees here and there remaining, but the fruit is put to no use. A little more energy and enterprise are needed in the island to advance various branches of agriculture and fruit-culture which at present bring no profit.

HENRy W. BECKWITH,

United States Consulate,

Conswer.

Hamilton, November 29, 1889. 


\section{TRINIDAD.}

J. H. Hart, Government botanist, to Consul Savyer.

Only here and there a plant exists which ripens fruit fairly, but the produce is carried off when nearly mature by the frugiverous bats.

\section{CUBA.}

REPORT BY OONSUL-GENERAL WILLIAMS, OF HATANA.

Figs grow here, but their cultivation is limited to private gardens, The trees do not obtain the size observed in the gardens of Norfolk, Va., Charleston, S. C., Sarannah, Ga., or New Orleans, La. Neither does the fruit seem to be equal in flavor to that grown in those places. It is rarely ever seen for sale in the market houses, fresh from the trees. Dried figs in considerable quantities are imported from Malaga, Spain, where great attention is given to their cultivation.

\section{RAMON O. WILliams,} Consul-General

Untied States Constlate-General, Havana, November 24, 1889.

\section{GUADELUPE.}

The few fig-trees found in the island are always sickly and covered with aphis or lice and ants.

St. Felix Elardean, Director of Botanical Garden at Basse terre, to Consul Bartlett. 


\title{
CONTINENT OF ASIA.
}

\author{
ASIA MINOR. \\ REPORT BY OONSUL EMMETT, OF SMYRNA.
}

\section{INTRODUCTORY REMARKS.}

There are several elimatic influences which can not be foreseén or guarded against and yet have great effect upou the success of the crop, as, for instance, a greater rain-fall than the average tends to darken the fruit when ripe. A high wind blowing for several days from the north while the fruit is maturing has the tendency to make the stems wither and fruit fall prematurely, etc.

There are as many uncertainties and surmises about the fig crop of Smyrna before gathering as there are in reference to the peach crop in the United States.

As regards the cuttings which the honorable Secretary suggests my obtaining, I beg to say that $\mathrm{I}$ am informed that it is too late this season to take the same with any chance of their growing when they arrive in the United States.

Some provision for defraying the expenses and further directions as to quantity and to whom to be sent would be requisite before making a shipment of enttings.

In 1886 a party from California, apparently well posted, came here in the summer, went to the fig district, and inspected the different varieties; he made his selection and marked the trees from which he desired cuttings. When the crop was gathered he obtained 30,000 female and 3,000 cuttings from male trees, packed and shipped the same about the end of October. I have been informed that great success rewarded his enterprise.

A box of figs grown and packed in California reached here this antumn and was inspected and universally praised by many dealers. In some instances it was impossible to persuade the parties that said figs were grown outside of the Aidin district; in fact some went so far as to desig. nate the orchard. Those who grasped the fall importance of this American enterprise predicted that Turkey's supremacy in the fig trade was waning. Some console themselves with the opinion that the American fig will not continue to be good; as the trees (grown from Smyrna cuttings) grow older the fruit will have thick skins and become tough; in fact become native American figs. 
This deterioration of the fruit is very common here and has been well known for a long time. The transplanting of trees from their own orchard, even for a short distance, makes them give fruit of entirely a different flavor and nature.

It has been suggested to me that if some grower will grow seedlings from the fruit of young trees grown from Smyrna cuttings, the chances of American fig-growers will be greatly enhanced, and, perhaps, in time eclipse one of the staple articles of this country.

Varieties.-The best variety for drying and packing is known under the name of Lop. There are two kinds of figs for table use when ripe, but which will not bear drying and packing, viz, Zardajik and Cheker Inzir.

Situation.-The trees that produce the varieties above named are grown in the Aidin district.

Distance from sea, 30 to 100 miles; elevation above sea-lerel, 250 to 500 feet. Much exposure to sun is required.

The trees thrive in all descriptions of land, provided thes should be protected against the north wind.

Soil.-Rich black vegetable mold is best.

Climatic influences.-A temperate climate is the main thing; the thermometer should never fall below the freezing point during winter; frost during spring kills the trees.

Temperature.-Minimum, $40^{\circ}$; maximum, $110^{\circ}$; average, $80^{\circ}$ Fahrenheit.

Rain-fall.-Yearly average, 24 inches. Rain during winter strengthens the trees; during summer it injures the crop.

Irrigation.-Good fig orchards are never irrigated; newly-planted young trees need watering during the first two years of their growth.

Cultivation.-Fig orchards are plonghed four or five times a year, beginning from November.

Fertilizers.-Manure is made use of when the soil is poor.

Pruning.-When the trees grow old they need pruning during winter.

Picking and curing.-When perfectly ripe the fruit falls by itself. If not quite dry it is spread in the sun. There is no fixed time for pick ing, as the fruit when ripe falls.

The fruit is gathered from the ground and put in black hair bags; it is then loaled on camels and carried to the nearest railroad station, put in the freight-cars, and conveyed to Smyrna; loaded again on camels, it finds its way to the fig market, whence it is sent to the packing houses to undergo the final process of sorting, shaping (flattening out or squaring), and putting in boxes or bags, and is then fit for shipment abroad.

No chemical solution is employed; the packers wet their hands with plain sea-water, which hasters considerably the sugaring of the figs.

Planting and propagating.-Distance planted apart, 25 feet. The trees propagated by cuttings. There are small and large orchards. 
Maturity.-The trees remain fruitful from eighty to one hundred years and even longer.

Insect pests.-A kind of bug, known under the name "Basra," is very injurious to the fruit, which it covers with dark yellow and black spots. No one knows how to free the trees and fruit of this pest.

The only beneficial insect is the one which comes out of the male fruit and impregnates the female figs, and the ants which feed on the bug called "Basra."

Securing cuttings.-Unovassi cuttings are the best and should be gathered by some one having a good knowledge of the trees.

\section{W. C. EMMETT,}

United States Consulate,

Consul.

Smyrna, January 15, 1890.

\section{PALESTINE.}

REPORT BY OONSUL GILLATAN, OF JERUSALEM.

Varieties.-There is no exportation of the figs grown in Palestine, and scarcely any care is given to the cultivation of the trees. There are said to be as mauy as twelve varieties of the fig in this country, and, with few exceptions, they are all good for eating. The best known and more easily distinguished varieties are as follows : (1) The large green fig, early in fruiting, known as dafouri. (2) Sinall green, later fig, called ghoudri (greenish). (3) Large purple fig named gharroubi (carob, from its resemblance to the color of the pod of the carob). (4) Small purple fig, named also gharroubi. (5) Yellow fig, white inside, known as biadi (white). (6) Yellow fig, crimson inside, called karawi (crimson), resembling the Smyrna fig of commerce. (7) Black fig, named swadi (black).

While, as already mentioned, all these are good for eating in the fresh state, Nos. 1, 2, 3, 5, and 6 are the best for this purpose. Equally, though, all the varieties are used for drying. Nos. 5, 6, and 7 are the most suitable for the purpose.

Situation.-The trees flourish all over Palestine, from the sea-coast, up into the hill country, at an elevation of 3,000 feet or more. They generally have a full exposure to the sun, but seem to do well in all situations. They frequently attain an enormous size, even on the most rocky hill-sides; and whether the land is hilly, rolling, or level, appears to make no great difference to them. The soil is generally clay, or sand and clay mixed, with clay subsoil.

Climate.-At Jaffa and on the plains the minimum temperature is $32^{\circ}$ Fahr., the maximum reaching $107^{\circ} \mathrm{Fahr}$; the average temperature in the day-time being about $70 \frac{10}{2}$, and at night, $55 \frac{10}{2}$ Fahr. In the mount- 
ains it is considerably colder; though, in general, there are only a few days in January in which it freezes. The rain-fall at Jaffa has already been given. At Jerusalem the average annual fall amounts to 25 inches. The growth of the trees and fruit is favorably affected by abundant rains.

Irrigation.-The trees do not require irrigation, and, except when growing in orange groves, are never watered. With systematic irrigation and cultivation, such as received in the orange groves at'Jaffa, the fruit is improved.

Cultivation.-As already mentioned, but little cultivation is bestowed on the trees. At most they receive a spring and autumn plowing.

Fertilizers.-Fertilizers are seldom used except when in connection with the orange or lemon trees; and the kind preferred is generally horse manure, or the dung of the mule or camel.

Pruning.-Pruning is not practiced with any system, or to any appreciable extent. It is considered best to spare the lower branches, and when cuttings for propagation are made they are taken from above.

Picking and curing.-The fruit is picked when fully ripe. For eating, the morning is deemed the best time of day for picking; but there is little choice observed in the matter. In general, the fig of this country is of inferior size, doubtless in consequence of being given such little attention, and being only used for home consumption. The fruit is dried by being spread in the sun, usually on the roofs of houses, or sometimes on the ground. When partially dry the fig is pressed flat in the hands. Subsequently the nearly dried fruit is strung on strings; and it is often sold in this shape or when placed in sacks.

Planting and propagating.-The distance at which the trees are planted apart varies from 6 to 10, or even 20 feet.

Though the fig can be grown from seed, the usual method of propagation is by cuttings, or rather branches slipped off the parent tree.

The size of the orchards is in general not large, though sometimes consisting of several acres. There are only a few hundred fig-trees dispersed over the vineyards and gardens at Jaffa; but at Bethlehem, Hebron, and around Jerusalem orchards of fair size devoted to the fig may be found.

Maturity.-The tree here attains to the age of one hundred sears, and with proper care and culture continues fruitful to the last. If neglected too much, it ceases to be productive; though on attention being renewed, it again responds with crops. The trees begin to bear at the third year, and are in full bearing when five years of age.

Insect pests. - But little has been observed as to insect pests, beneficial insects, or the parasites of the injurious ones. The fig seems to be unusually free from such. A fig is occasionally found containing a worm, which appears to be the larva of one of the smaller moths; but the species has not been determined.

Outtings.-The rooted cutting, or the young tree would be, in all 
probability, the best method of procuring desirable varieties. I understand that mang thousands of young trees have been successfully transported from Smyrna to California, giving full satisfaction.

HENR Y Gillman,

United States Consulate, Consul. Jerusalem, February 11, 1890.

\section{SYRIA.}

\section{BEIRUT AND VICINITY.*}

FLRST REPORT BY OONSUL BISSINGER.

Varieties. The best fig for drying is the green variety. The best va. riety for eating when ripe is the red variety with elongated stem, called "Buckaraty." Also a rounder red variety called "Seedany." Other varieties worthy of culture and for profit are the black variety and one which ripens in the fall.

Situation.-The trees that produce the varieties above named are grown in plains and on the hills, and from the shore to a distance of 25 miles inland to an elevation of 2,500 feet. Constant exposure to the sun is needed. Hilly and rolling land with white clayey soil are the best.

Irrigation.-No irrigation needed.

Cultivation.-Plow the land in the spring.

Fertilizing.-None put about trees, as it is injurions.

Pruning.-Pruning is not practiced.

Picking and curing.-The figs are picked when fully ripe in the early morning. Little curing is done-in this country; simply dried in the sun. Either whule or split; no solution used.

Planting and propagating.-Distance planted apart, about 20 to 25 feet; propagated by slips. The orchards are small.

Trees attain an age of from fifty to sixty years, and are fruitful from four years till they decay.

Insects and worms are treated simply by covering the trunk of the tree with a coating of bitumen.

Slips can be put into earth and conveyed from place to place.

\section{BEIRUT.}

Rain.-Moderate rain-fall; about 30 to 40 inches on an average yearly, The abundance of rain is beneficial to old trees as well as to the fruit. October and November rains benefit the trees, and March and April rains benefit the fruit.

\footnotetext{
" The several reports for Syria were forwarded by Consul Bissinger, being prepared from statistics supplied to him by parties in the several districts reported.
} 
Irrigation.-Irrigation is only necessary the first and second years after planting. In light soil watering is necessary twenty days after the rains are over and in heavy soil one month thereafter.

Cultivation.-Plowing is necessary once or twice after the first rains in November and is then to be discontinued until the 1st of February, after which it is to be repeated four times or every fortnight, after the rains. As soon as the fruits appear no more plowing is necessary.

Fertilizers.-The fertilizing substances are: A donkey load of sand around each tree once a year, about the early part of December, if the soil is red, and a small quantity of cow's, or other manure if the soil is white, $i . e$. clayey. This treatment increases the growth of the trees and the quantity of the fruit.

Pruning.-Pruning is effected at the end of January by removing the weak and dead branches. To prune the low branches of fig-trees in. creases their growth and production.

Picking.-Gathering or picking takes place when the fruit is fully ripe; when for sale, it is effected either in the evening or before sunrise, and if for drying, it must be after sunrise, so as to be dry from dew, which would spoil the color of dried figs.

Curing.-After the figs are gathered they are split open in the morning and placed in an exposed position to the sun for three days, until they contract and assume a red or yellowish tint. They are then gathered from the drying-floor, and after being full 5 flattened out are spread in equal layers in a basket until completely filled up. A heavy weight is then placed on the top of the basket. As to figs dried in a heap, they should be gathered when perfectly dry (in other words when withered on the tree), and spread as they are on the drying-floor for four or five days, at the expiration of which they are picked up and pressed flat between the fingers. This species of dry figs may also be placed in hot water for 10 minutes, then left to dry well in the air before packing up in boxes. This bathing process imparts a good color to the figs and preserves them from worms. Dry figs are never placed in any solution.

Planting.-The distance between each tree should be at least 9 feet. The larger the distance the better the trees grow.

Fig-trees are propagated either by suckers or shoots (which grow at the foot of the mother tree) or by slips from the trees.

(1) The way of transplanting by suckers is to dig a hole in the ground about 15 to 20 inches in diameter and depth in which to place the same, after which the soil is to be so arranged as to be on a level with the surrounding ground, or even a little lower, to retain the water. Watering is necessary just after planting. Some people resort to the practice of putting in the hole of the nowly planted sucker a handful of barley, to serve as nourishment for the roots. A sucker planted with barley never fails to take root and to thrive.

(2) To propangato by slips it is necessary that a hole be dug in the ground having an average length of 27 inches by 13 in depth. In this 
hole the slip, which should be about 27 inches long, is placed obliquely, so as to leave about 2 inches of it above the ground. The planting of suckers must take place between the 1st of Decomber and the end of January, and the planting of slips should begin with February and end with March. Watering is needed, as stated in answer $\mathbf{6}$, for the lands that had not been previonsly tilled and sown. As to the rich lands which bad been plowed, they should be irrigated once a month or once every forty-five days.

There are some large and some small fig orchards, but generally their size is limited.

Iig-trees live from five to thirty years, some eveu longer, and produce fruit until they die off.

The insects are worms produced by excess of water and manure and want of proper pruning. The way to treat them is to put only a little manure or none at all, to prune the trees well, and to make a passage for the water, so as not to allow it to gather around the trees. Birds also attack fig-trees, such as the sparrow and the becafico. A scare. crow is most always successful in frightening away these birds.

No insect other than those mentioned above are known to exist.

Cutting.-Eitber by taking suckers which grow at the foot of the tree or cuttings from the tree itself.

No statistics or reports are published by the Government or otherwise.

Erhard Bisstnger,

Consul.

United States Consulate,

Beirut, February 12, 1890.

\section{SEOOND REPORT.}

Varieties.-The best variety for drying is the "Abyad," white inside green outside, and for eating when ripe, the "Bokraty:" "red inside, green outside. The "Asfoory" and "Bokraty" are also cultivated. The Smyrna district is the principal one, Syria coming next, in which fig-trees are grown.

Situation.-No matter where fig-trees are planted, moderate altitude is best. Fig-trees are benefited by being exposed to the sun.

Soil.-The white clayey soil is preferable. It should be manured once every three years.

Climate.-Minimum, $40^{\circ}$ Fahr.; maximum, $90^{\circ}$ Fabr.; average, $65^{\circ}$ Fahr. The more abundant the rains the better the trees and 1ruits prosper.

Irrigation.-Fig trees need no irrigation.

Cultivation.-After the soil gets dry it should be plowed three times during spring-time,

$156 A-23$ 
Fertilizers.-The soil should bo manured once every three years and plowed as stated above.

Pruning.-After the fruits have been gathered the dead branches only are cut awar.

Picking and curing.--When the fruit is ripe the morning is the best time for picking. If they are to be transported from place to place figs must be gathered before they are fully ripe and placed in boxes, but can not be sent to any distant place. When figs are to be dried they must be gathered when fully ripe, then spread on a lofty spot for 1rom ten to tifteen days and nights. In this way they can be preserved in boxes during the whole year.

Planting and propagating.-The trees are planted about 13 feet apart and propagated by slips. The orchards are generally small.

Maturity.-Fig-trees attain thirty to forty years of age and produce fruit from the fourth or fifth year.

Insect pests.-There are some insects which infest the soil and invade the trunk of the tree and sometimes cause them to decay, but they do not injure the fruit. Trees so attacked are treated by introducing an iron wire into the affected holes until the insect is reached and destroyer.

Slips.—Slips are to be secured in March.

No printed matter, reports, or statistics exist or are issued by the Government.

ERHARD BISSINGER,

Consul.

UNited S'Ta'l ES Consula'te,

Beirut, February 12, 1890.

SIDON.

Verieties.-The "green" varieties for drying atre the "Bookraty" and "Abrad" for eating when ripe. Other varicties cultivated are the black and oue which ripens in the fall.

Nituction.-Both iu plaius and hills; best kiuds within 30 miles of coast; best growth from 500 to 2,000 feet above sea-level; constant uxposure to the sun; hilly linds the best; chyey and rhalky soil the best.

C'limate,-Thirty degrees Falur. to $90^{\circ}$ Fahr.; rain-fall about 30 inches, on an average, aumually; an abuudance of rain is beneficial.

Irrigation.-Nover irrigited at all.

C'ultivation.-Spring plonghing.

Fertilizers. - None inplied. Figs become wormy in rich earth.

Pruniny.-Dearl linaldeses only are removed.

Iticking. - When ripe, and in the moruing.

Curing-Drierl in sun only. No solution of any kind used. 
Planting and propayating.-The trees are 32 to 35 feet apart; propagated by slips; the orchards are generally small.

Maturity.-The trees attain to abont fifty years aud bear from four years till they die.

Insect pests.-Priucipally worms. The remedy is to cover the trunk of the tree with a coating of bitumen.

Cuttings.-Cuttiugs are secured either by suckers which grow at the foot of tree or cuttings from the tree itself.

\section{TRIPOLI.}

Varieties.-The best variety for drying is the "Bayadi" (white inside); the best variety for eating is the "Bookraty ;" the other varieties known in this country are the "Bookraty," the "Bayadi," the "Asfoory," the "Aswad," the "Hammary," and the "Shataway."

Situation.-Fig trees grow in the plains as well as in the mountains; the more they are exposed to the suu the better they prosper; they are fonnd iu rolling and level land, which is alike adapted for their growth. It is customary in this country to plant fig-trees in either white clayey soil or in a blackish soil (the latter not being good for other kinds of trees). In red soil the fig-trees grow still better, but the taste of the fruit is less delicious than if grown in a white or blackish soil.

Olimate-CTemperature varies from $30^{\circ} \mathrm{Fahr}$. to $90^{\circ} \mathrm{Fahr}$; average, $60^{\circ}$ Fahr.; rain-fall averages 26 to 40 inches per annum, according to locality.

Irrigation.-Most of the fig-trees in this country are found in non-irrigated lands. The fruit of irrigated fig-trees are affected by worms and liable to rot.

Cultivation.-Lands upou which fig-trees are planted should be plowed three times in the spring.

Fertilizers.-Manure is the fertilizer known, but it is not used for figtrees, although it increases their production, for the reason that it causes the fruit to be invaded by worms and to rot.

Prining.-Dead branches only need to be removed.

Picking.-Figs for thying are picked when fully ripe any time in the course of a sunny day, so as to be well driod by the rays of the sun and thus prevent their contracting a sour taste.

Curing.-Figs, after being gathered, are spread in the sun for from ten to fifteen dars. When they become dry they are placed in a basket and plunged for two minutes in il large copper kettle full of boiling water, in which a small quantity of the fennel plant has been deposited to impart a nice aroma to the figs. After this process of "bathing," the figs are dried agaiu aud then stored away. Figs are gathered and dried as they ripen, during August, September, and October. 
Planting and propagating.-Distance planted apart, 12 to 15 feet, according to the quality of the soil. Fig-trees are propagated by cuttings from the branch of a large tree having three or four sprays, which is to be placed in a hole dug for the purpose, then covered with earth, allowing one of the sprays only to project, at a height of about 2 inches above ground. This should take place in the spring, $i . e$. from the beginning of March to the end of April. Orchards are generally small.

Maturity.-The age of fig-trees depends on the quality of the soil and the care bestowed upon them. If good care is taken of a fig-tree it lives up to one hundred years.

Disease. -The branches of fig-trees are sometimes liable to a disease that manifests itself in the shape of slight swellings called snails. The remedy adopted is to make small cuts in the tree, which causes the disease to subside.

Cuttings.-No plantations of young fig-trees exist in this country. The way to plant fig-trees is to secure cuttings from large trees and plant them as stated above.

\section{ERHARD BISSINGER,}

Consul.

\section{United States Consulate,}

Beirut, February 12, 1890.

\section{INDIA.}

REPORT PREPARED FOR VICE-CONSUL BODE, OF BOMBAY, BY MR. G. MARSHALL WORDROW; LECTURER ON BOTANY AND AGRIOULTURE AT THE OOLLEGE OF SOIENOE, POONAH.

Varieties.-Figs wre not dried in India to any considerable extent, as the local consumption absorbs the supply. The retail price of ripe figs is about 2 annas per pound (say 6 cents) at Poonah, within 14 miles of extensive gardens. Varieties of figs are not named in India except with the name of the village they are grown at, and such a name is not distinctive. The variety grown in the Deccan is inverted conical, green at the stalk and gradually deepening to brown at the broad end. Good examples weigh one-serenth of a pound.

Situation.-The village of Khed Shivapoor is an important center of fig culture. It stands 14 miles south of Poonah, which cits lies in north latitude $18^{\circ} 28^{\prime}$ east longitude $74^{\circ} 10^{\prime}$. The altitude of Khed Shivapoor is about 2,200 feet abore mean sea-level, but the fig thrives at Baroda as low as 100 feet above the sea-level. The orchards ire fully exposed to the sun.

The land of the orchards is nearly level, but they are situated on the slope of a range of hills 3,500 feet in altitude, at al height of 2,200 feet, and about 50 miles from the sea. 
Soil and subsoit.-The soil is calcareous loam, the subsoil, at a depth of about 2 feet marl (a mixture of lime and clay), overlying disintegrated trap.

Temperature.-A verage, abont $75^{\circ}$; minimum, $48^{\circ}$; maximum, $95^{\circ}$. The village is shut in on the northeast and west by hills, which keep out hot winds.

Rain-fall is about 50 inches annually, falling chiefly from June till October. The setting in of rain makes the trees ripen the young growth that was made during April and May in the hottest and driest season, and determines the ripening of fruit.

Irrigation.-Irrigation is effected from wells, abont 25 feet in depth, by a leathern bucket drawn up by oxen at a cost of 10 pies (say 2.5 cents) per 1,000 gallons. Two inches of water on the surface of the orchard, per month, from the end of October till the fruit is ripe; the low quantity of water given keeps the fruit sweet. One inch of water is given twice monthly.

Cultivation.-Cultivation consists of plowing or hoeing once yearly after the fruit is gathered.

Fertilizers.-Fifty pounds per tree of well decayed village sweepings is applied at the end of the dry season, in May, after the crop is gathered.

Pruning.-After the young tree has been made to send up five to seven shoots from near the base by stopping the first strong shoots sent out by the cutting, little, if any, real pruning is given. Weakly decayed or broken branches are cut out to the base, and such as have gone too high for a man's hand to reach are stopped, and if branches are plentiful, cut out when all the fruit is gathered from them; but the less pruning that is necessary the better. In a few instances the trees are grown as standards; a straight stem is led up about 6 feet, and from the iop of this branches are encouraged to spread horizontally.

Picking.-The picking is done when the fruit is full grown and shows a slight yellowing at the stalk. Early in the morning is preferred because fruit picked at that time and lsept in shade retains a delicious coolness. For local use each fig is wrapped in a leaf when it has attained this stage to protect it from birds and left on the tree a week longer. This improves the quality greatly bat prohibits carriage to a distance. No boxing or curing is done in India. The skin of the variety grown is much too delicate and I have not been successful with Enropean varieties.

Planting and propagation.-Propagation is effected by cuttings of one year old wood planted in a moist, shady place during February. The trees are set out 10 to 12 feet apart.

Size of orchards.-Tine orchards are 2 to 3 acres in extent only, becanse the position on the slope of a hill does not afford larger spaces sufficiently lerel, and a well rarely waters more.

Maturity.-The trees attain fifteen sears and are fruitful about twelve years. 
Insect pests.-Rerl spider, Tetratichus telarius, or some nearly allierl insect, is a serious enemy. No fatile attemptis are made against it by the cultivators. They think sacrifices to idols effectual. Much yet remains to be done in the entomology of the fig.

Cuttings._I have nerer sent cuttings as far as America, but I think that if cut in February, packed in moist sand in a tin box aud sent by post, a few would survive the journey. Whether it would be profitable is doubtful, as I am of opinion the fig of the Deccan is synonymous with brown Turkey, which you probably have in cultivation. I will be glad, to send you cuttings if wanted.

Publications.-The Government of India does not issue statistics regarding figs. The latest edition of my book on gardening in India, published at the end of 1889 , has the fullest acconnt I know of, but it is not as full as this report.

Olives are not grown in India; the tree lives but does not fruit.

PoONaH, March 14, 1890. G. Marshall Woodrow.

\section{AUSTRALASIA.}

REPORT BY OONSUL GRIFFIN, OF SIDNEY.

The fig is not cultivated to any great extent in the Australian colonies. The tree will grow and bear excellent fruit all over the country, but its cultivation can not be called an industry in any part of Austral. asia. Figs are not dried or prepared in any wap for export. There are growers who have experimented with drying figs, but I have never heard of locally dried figs being offered for sale. The figs that find their way to the Sydney market are in a green state. Baron Fred. von Mineller, goverument botanist for Victoria, in his work entitled "Select Extra. Tropical Plants," strongly urges the extensive planting of the fig throngh favorable portions of desert waste for shade and fruit and in warm districts where the fruit could be dried with particular ease. He clirects attention to the ease with which small cuttings of the fig tree were sent by horse post in the early history of these colonies from Port Phillip (Melbourne) to the Central Australian Mission stations, a distance as far as from St. Petersburg to the Black Sea, or from San Francisco to the Upper Missouri. Baron von Mneller uentious two main varieties which Lave been successfully introduced into Australlia. One includes the purple, white, and golilen fig-trees, produciug two crops a year, but are not suitable for drying. The other min in vitety embraces the Marseillaise, Bellonne, Barnisote, and the Aubique. These produce but one crop a sear and supply the wreatest quantity of ligs for drying. The Marseillaise and Bellonne are usually regarded as the best varieties. The Barnisote and Aubique aredried with fire heat and are usually consuned fresh. The ordinary drying is uffectod usually by the sun. Mr. Angus 
McKay gives the black Province and black Italian as the best rarietif.: for drfing in Australia, but say's rery little drying i:; lone her'.

The wbite and yellow Ischia are farorite varieties. Then there are the Moroceo and the white and brown Turkey. Different names are given to the same variety of figs and, as no systematic attempt has been made to classify them, there is some confusion in the nomenclature and it is almost impossible to say which is the best. The fig grows on the sea-coast and also many miles inlaud. It has been fonnt to do fairly well at an elevation of 2,500 feet above the lerel of the sea. Excellent: figs are, I am informed, grown in the Forbes and Parlses districts of New South Wales, but the finest figs I have seen were grown at Tumut, also in this colony, where the soil is of a dark rich loam to a lepth of about $\mathbf{1 0}$ feet. Figs also grow at Port Stephen, where the average annual rain-fall is about 62 inches. Mr. Angus McKay says the fig thrives best in hilly country, and as to soil, it seems that they do very well in

-. poor sandy soil; where the temperature is $100^{\circ}$ figs are produced and where it is not less than $20^{\circ}$ above zero. When the rain-fall is not less than 12 inches or more than 30 inches they appear to succeed best. When the rain fall is heary the trees run to wood. When cultivated here both plowing and digging are practiced; the trees are usually 20 feet apart ench way and are propagated principally from cuttings. The only insects yet observed consist of a small beetle. The tree fruits in the third year. Caprification is said to be practicel in New Zealand, but it is not done, so far as I have been able to learn, in Australia, and Baron von Mueller says it is unnecessary and in some instances injuri. ous and objectionable.

$$
\begin{aligned}
& \text { G. W. GRIFEIN, } \\
& \text { Consul. }
\end{aligned}
$$

UNited States Consulate, Sydney, January 21, 1890.

\section{FIJI.}

Figs are not cultivated. The very few experimental trees that bave been planted have proved a decided failure. The fruit has not been grown in these islands. $\mathbf{A}$ blight, black in appearance, strikes the trec before it comes into bearing, which, if it does not kill the tree, so retards its growth that it never bears any fruit.

ANDREWS A. ST. John, Commercial Agent.

United States Commercial Agency, Levuka, January 11, 1890. 


\title{
CONTINENT OF EUROPE.
}

\author{
FRANCE.
}

REPORT BY CONSUL TRAIL, OF MLARSEILLES.

The tig-tree (Ficus carica) that is cultivated in France was brought from Greece many centuries ago and is now, like the Olive, common to the whole of the south of France and of the adjoining countries, more especially eastward.

It grows in a wild state in almost any place and position. On many an old wall small fig-trees are to be seen and on many a road-side bank they are the tree most frequently to be found. In country farm-yards, inn-keepers' gardens, stable-yards, the fig-tree is invariably present and very often as a solitary specimen. It would be diffeult to find a garden of any description in southern France without a fig-tree.

Varieties. - The varieties are innumerable, and it would be hard to give a list of all the different ones, as they vary according to soil exposure, treatment, and climate.

The chief varieties cultivated in this district are the following:

The "Marseillaise," or Atheus fig, a white fig of very nice, delicate taste, both when eaten fresh from the tree and when dried. This variety is considered the best in the south of France, and many people prefer it even to the Smyrna fig.

The "Mouissonne," "a dark fig with a line skin, very good when eaten ripe and fresh, and good for drying.

The "Barnissotte," one that is almost only eaten fresh.

There are several other varieties that could be mentioned, but thes are all more or less similar to the above three kiuds.

Soil.-The fig-tree grows in almost any soil common to its climate, but dry gronnd suits it best. Along certain dry and even arid strips of land bordering on the Mediterranean fig-trees flourish and produce fruit in abundance.

Olimate. -The same climate that suits the olive tree is favorable to the fig, i. e., a warm climate, where excess of heat and cold is scirce. With special reference to this district it is worthy of note that on the right side of the Rhone figs do not develop vory well; the fruit remaius small and is not good for drying. Whereas on the left side, and from the Rhone to the Italian frontier, figs attrin a far higher legree of quality; they are lnrger, sweeter, more delicate, and are excellent for drying. 
The explauation of this fact is that the plains and districts on the right side of the lihone are not sheltered by hills as on the other side.

Situation.-Sheltered hillsides are very liavorable to fig culture; exposure to cold winds is not conducive to good results.

Rain.fall.-The winter rains generally give sufficient moisture to the soil for tho whole jear; fig-trees that are intended to produce fruit for drying ought not to be watered artificially. Too much moisture lessens the quality and the richness of the fruit, and frequently renders drying difficult.

Tree planting.-When planting fig trees care should be taken to select a deep soil, or in any case to dig as deep as possible and mix some fertilizer (manure, old leaves, etc.) well into the earth, on which the roots will rest. During the first two years it is always advisable, in districts that are subject to frosts, to cover or bind the trees with straw for the winter. After the second year the young trees are generally stroug enough to stand the winter uncovered. The ground should be well dug up at least once in winter and once in spring.

Fertilizers.-Fertilizers should be dug into the ground ouce a year, during spring, for young trees, and once every two years for older trees. Fig-trees, ouce well rooted and well established. in a place, require very little fertilizing, and this can even bedispensed with if the soil be well dug occasionally.

Pruning.--Pruning should be done once a year, but only lightly, i.e., one should only thin out dead and useless branches in the body and crown of the tree, and cut away all young shoots that spring up at the foot of the stem. The latter point is important, as the fig tree being very voracious young ungrafted shoots would only uselessly exhaust the soil and weaken the original tree. For this reason, too, it is well to keep figtrees apart from other trees, for not only does the fig-tree weaken its neighbors, but its neighbors weaken it as well.

Maturity.-The fig-tree produces fruit pretty regularly every year. Some varieties give two crops, the first of which begins about the 20th of June and lasts till about the 20 th of July, the figs of which, called "Flower" figs, are not good for drying, and the second at the end of September. Several black and gray figs come under this variety.

The other kinds, of one crop only, begin to ripen about the middle of August and continue ripening successively throughout August and September; these are the best for drying, and to this class the "Marseillaise" belongs.

With reference to those that give two crops, it is interesting to note that the figs of the first are borne by the branches of the previous year only, and that those of the second crop are borne by the young branches of the same year. This accounts for the latter ripening successively, as each fresh leaf that opens out bears a fig in its axil.

Picking and curing.-Figs, eitber for immediate cousumption or for arying, ought not to be gathered before they are quite ripe. The signs 
of ripeness are complete softening of the fig, slight bursting of the skin, a tear or drop of gum oozing out of the center.

Figs must be gatherel by hand, and in plucking them off the branches care should be taken to pick them with the short stalk that attaches them to the branch.

The state of the weather and the time of day are points to be taken into consideration when gathering figs for drying. It is true that in this district it is seldom that the weather is not fine during August and September. However, fine days shonld always be selected, and picking should not commence until the morning dew has disappeared from off the fruit. As soon as the figs are picked they must be laid in rows on wicker or basket.work hurdles or boards aud well exposed, bat in a sheltered position and raiser from the ground, to the full force of the sun. The figs sbould not bs placed too close together, and they must be turned round every didy about midday, when the sun is hottest, so that every day a fresh surface is exposed to the direct rays of the sun. The hurdles or boards, without touching or disturbing the figs, must be taken indoors every evening and p'aced in dry, airy rooms till the morning, when they are brought out again in the same way. No dampness vor moisture must be allowed to get to the figs whilst drying, and if the weather be uncertain one should be near at hand and take them in at the first sign of rain.

In fine weather six days suffice to dry figs, and this is geuerally the case with the first batches in August and beginning of September. But as the days grow shorter and the sun becomes less powerful more time is required and the process of drying lasts from ten to fifteen days. Wet weather is exceedingly detrimental to drying, as it is a rery diffcult and uncertain operation to dry figs indoors by artificial heat. Artificially dried figs are never as good as sun-dried ones.

The quicker the drying takes place the better the figs are, and the exact stage of complete dryness can generally be ascertained by the firmness of a fig taken between two fingers and rolled. The interior seeds lose their red color when the fig is quite dry, and this is one of the signs that the process is completed.

They can then be classified aecording to size, appearance, and qualit5. and packed in baskets of flat wicker, or boxes, ready for storing or for shipment. They are usually packed in rows and layers, pressed down one by one with the thumb, in such a way that the stalk is in the center underneatli, and then each layer should be pressed down with the aid of a small board, slighily, until the basket or box is full.

Prices.-Fresh ripe figs sell very readily at the time of the crops, especially the early ones, for a few cents a pound. No exact price can be given, as the value varies from 3 to 7 or 8 cents a pound according to time, quantity, and quality of crop, also place where they are sold. In unfavorable seasons for drying and in late crops, quantities are made into jam and are sometimes even boiled into other fruit jams, such as 
las lowery and strawbers, to which the fig, when boiled, assimilates itself in appearance.

But the chief trade is done in dried figs and the prices of these vary according to quality, quantity, and time of year. The grower dries his own figs and usually sells them in bulk to the dealer, who then sorts them and sells them again separately as per their respectire qualities.

The "Marseillawse" fig fetches from 75 centimes to 1.50 francs per kilogram (from $s$ to 16 cents per pound) and frequently eveu more in retail. Uther varieties sell cheaper ; ordinars dark and blue figs generally fetch from 30 to 40 centimes per kilogram (from 3 to 4 cents per pound). Very common small tigs, dried, are sold in some districts in large quantities, packed in sacks, for distilling purposes, but this applies more generall to Italy and Spain. This kind of fig is also sometimes used, baked or roasted and ground into coarse powder, to adulterate coffee with.

Insect pests.-The fig-tree, well cared for, is very rarely attacked by either disease or injurions insects; in some regions these are unknown. In some cases a kind of a louse attaches itself to the branches and spreads over the whole tree, if not detected in time and rubbed off carefully by means of a coarse piece of cloth. If, however, it lsas not been detected in time and the parasite has already covered and killed certain branches, these branches must simply be sawn off.

Reproduction.-Like the olive, the fig-tree grows to a good old age. Reproduction tikes place, uaturally, by seedlings, but as this process is slow and uncertain, it is geuerally done by cuttings, which are selected from good healthy trees and planted in deep soil. Thoy must be grafted in about the second yon and bear fruit in their third year already after trausplautation to their definite ground. If the grafting takes well, fruit is even produced before the third year.

Chas. B. Trail,

Consul.

UNitei States Consulate, Marseilles, April 30, 1890.

\section{CORSICA.*}

REPORT BI CONSULAR AGENT DAMTANI, OF BASTIA.

Varieties.-(Common fig-tree, Fions carica.) The varieties cultirated in this locality are, for drying, the White (Bourgassotte Blanche); Napolitaine, very good quality, very good to dry, yields small number of flowers; for eating when ripe the Verdale; the Marseillaise; $\Delta$ theus fig, the kind best adapted; Dunmine, very good for drying; Franciscana, for drying and for eating. 
Black (Bourgassotte noir), very good fresh figs; Niello noir, the earliest eating figs.

Colored (Figue latte), excellent fresh and dry; Observantine, very numerous flowers; Bellone, excellent fresh or dry.

Situation.-The fig tree is abundant in Corsica, particularly on the littoral, especially on well-exposed hill-sides, on the rocks at the foot of the mountains close to the sea, on dry ground. The roots being very long, it is cultivated in deep, calcareous soil. It grows from the sea-level to 800 meters of altitude. The trees grown in the plains and shoals produce figs which dry and have not the requisite flavor and whiteness. Although the fig-tree grows on dry soil, often in the fissures of rocks and walls, it yields the most abundant and best flavored fruit when cultivated on good light soil. It is affected by dampness, but jet requires watering in very hot weather.

Cultivation.-The fig-tree does not require much attention; the ground has only to be dug once or twice a year and the fig-tree thrives. If planted in a warm locality it assumes a goodly shape.

Climate.-It prefers a warm climate, especially in the vicinity of olivetrees. Where the thermometer does not fall below $12^{\circ}$ Centigrade it produces leaves and fruit continuously. It does not prosper without manure from farm-houses. It is multiplied by cuttings. Small brauches of 2 centimeters broad by 20 centimeters long are the best.

Planting and propagating.-'The slips are put entirely under ground, except the terminal bud. The ground should be dug to a depth of at least 45 centimeters, and the trees should be about 6 meters distant from each other. Figs ripen at two seasons, at the end of spring and beginning of summer, and in the autumn for the second figs. The second is the most important.

Picking and curing.-The gathering is long, because they ripen successively. They wait till the figs are perfectly ripe, and even overripe. Those gathered unripe mature by keeping, but have not the flavor of those matured on the tree. Perfect ripeness is indicated by their being soft, the cracking and falling away of the rind, and by a liquid in the center. The day and hour are important if the figs are to be dried. The dew must have disappeared and the weather must be dry. After being gathered they are taken into the loouse and placed on planks or on hurdles, exposed to the greatest heat of the sun, and in a sheltered place, and at night in a well-aired place. The form and preservation of the fig depends on the promptitude of the operation of drying. The figs have to be turned over and flattened frequently.

Sometimes during the operation of arying rain comes on. The drying then becomes difficult and almost impossible except by means of the artificial heat of furnaces, which, howerer managed, injures the quality of the figs and lessens the market ralue by a third.

Field.-A fig ground of a lectare, containing 267 fig-trees, twontyfive years old, will yield (at the rate of 12.5 kilograms each, 3,214 
kilograms of dry figs, of the average value of 37 francs the 100 kilograms, and 30 francs, reckoning losses) about 963 francs. On account of the difficulties in drying nearly oue crop in three is lost, which reduces the averago protit to 640 francs.

Simon Damiani,

Consular Agent.

Bastia, CORSICA.

\section{SOUTHERN FRANCE.}

IEPORT BY YIOE.OONSUL MARTIN, OF MARSEILLES.

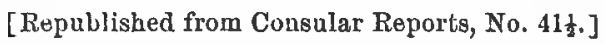

The fig tree is common in Southern France, and specimens of the several varieties known in the country are to be found in almost every ground lot, but it is not the object of special culture. The preparation of figs requires too much time and care, and the price could not repay hired labor. The figs must be culled one by one, when perfectly ripe; great care must be taken not to bruise the fruit or sever the peduncle. The figs are then laid on cane hurdles, exposed to the sun, and turned over every now and then until perfectly dry, that is, for a period of ten or fifteen days. As the least exposure to moisture would turn the figs black and reduce the value by one-half, these hurdles have to be taken in every evening, to be again taken out every morning. The difficulties of the operation deter most farmers from undertaking it, except those that own small farms where everything must be turned to account, and that cultivate them themselves with no other help than that of their fam. ily. The small quantities thus prepared are gathered at the end of the season by coumercial travelers, who pay from 1.50 to 2 franes per kilogram for "Marseillaises" figs (which are the most esteemed variety), and generally mix them with figs imported from Italy, Spain, Algeria, and the East. It is in consequence impossible to form any idea of the importance of the production, or of the proceeds. In 1882 the importation of figs from the above-named countries amounted to 9,964,743 kilograms, whereas the exportation was not eren given separately, for it was included in the official returns with that of other dried fruit not elsewhere specified, amounting in all to 397,269 kilograms.

The climate of this consular district does not agree with orauge and lemon trees, which are not seen in the open field except at a short distance from Nice.

United States Uonsulate, J. S. MarTin, JR., Vice and Deputy Consul.

Marseilles, March 11, 1881. 


\section{ITALY.}

REPORT BY OONSULGLNERAL RIOHJOND, OH ROME,

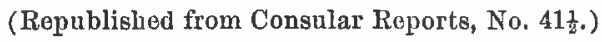

In Italy many varieties of the Ficus carica are cultivated. The widest spread of these varieties may be divided into two groups, as follows: The fico gentile and the fico portoghese, which are the earliest; the verdini and brogiotti neri, the brogiotti bianchi, the brianzosi, the datteri or dottati (which are thick skinned). All these varieties bear fruit only once a year. The fico albo and the fico San Pietro bear fruit twice a year. A fig tree of medium size will yield generally from 44 to 60 kilograms of fruit. Usually the fig is planted in company with other fruit trees (olive, almond, and others); but fig orchards, where figs alone are grown, may be found (at Lecce, for instance), and in such cases the trees must be planted at such a distance apart that when they reach their fullest development they may not come in contact one with the other; (1) because the fig needs a great deal of sun; and (2) because, otherwise, if the partial and easily located infection called rizoctonia should show itself it would spread rapidly through all the orchard. In many places it is the custom to alternate the fig, almond, and olive, so that each fig tree may be isolated.

In Tuscany the figs called dottati are preferred for drying. They are peeled and dried in the sun, and then, with a slight spriukling of aniseseed, are rolied into disks or small loaves. In other cases the rind is not removed, but the fig is split in two, flavored with anise or fennel seed, dried in the sun, and so sent to market.

The common pnrple or black figs are dried in the oven or in the sun, just as they come from the tree. At Lecce, Reggio, Calabria, Cosenza, and Cotanzaro this system is adopted. They also make a fig paste with walnuts, almonds, cinnamon, etc. It is customary to drop a little honey on them while drying.

There are coming into use stores with hot-air chambers, especially adapted for drying figs as well as other fruits.

United Sta'tes Consula't'W-General,

\section{LEWIS liLHALND, Consul-General.}

$$
\text { Rome, ipril 1, } 18 \mathrm{st.}
$$

\section{CATANIA.}

REPORT BY OONSUL WOODOOOE, OF CATLAYLA.

(Republished from Consular Reports, No, 41

Of the fig tree there are severalvarieties; some yield a large fruit, others small. The fruit also varies in its degree of sweetness; also in color from white to black. The fruit of some varities ripeu sooner 
than that of others. The trees grow well in poor or rich soil, and bear abundantly in our mild climate (mountain side, if not too high), or hot climate (of the vallevs). The soil for the fig must be dry. It will not flourish iu wet ground.

The favorite varieties here are the Sangiorannaro, the Sottuno, the Melinciano, and the Ottato. The Ottato has smooth leaves; the peduncle of the flower and fruit is longer, and the fruit is sweeter than of other varieties. The fruit of the Ottato is best for drying.

The fig' is here propagated from the suckers that spring up from the roots; cuttings from the tree also are used in propagation. Cuttings in this climate should be set in the months of February and March. In orchards the distance to be maintained between the trees is 8 meters (26 feet). The fig is long-lived, because it is constantly being renewed by shoots that put up from the roots taking the place of the main trunk when it becomes old and decayed. The soil must be worked in the spring, also in November following. The best rarieties are grafted, also budded upon the stock of the wild fig. Grafting and budding arealso done upon healthy trees of the best varieties. The time for pruning is in March, or when in blossom in June. All deal and diseased branches should be cut away. But little pruning is necessary. Too much is in jurious.

Figs here are dried in the following manner: The fruit must be gath ered wheu partially ripe. It must not be what is termed "dead ripe ;" in other words, it must be more green than ripe. When gathered give the fruit a plunge bath in boiling water, removing them from the water quickly. Then place the fruit in a shady place. The next moruing at sunrise spread the same upon a platform (not upon the ground, becanse of its dampness), that it may be flooded with sunlight. Here shallow willow-work baskets are used for holding the fruit while drying. These are never placed upon the ground, but in an elevated position. At going down of the sun the fruit must be covered to protect it from the night dews or unexpected showers of rain. Continue thus for several days until the fruit becomes dry.

When dry place the fruit in lavers in small boxes or baskets, artistically and neatly arranging the same. Press the fruit down firmly by hand, and continue the layers of fruit until the vessel is full. The boxes (or baskets) must be securely covered and kept in a dry place.

The culture of the fig is not a specialty in this part of Sieily; but little of the fruit is exported from this district and none from Catania to the United States.

The raisin grape is not cultivated here. The grapes grown in this part are mauufactured into wine.

For the information given on the culture of the olive and fig, I am indebted to our respected consular agent, Mr. N. Stella, of Srracuse. The foregoing statements about the olive and fig are almost a literal 
- rendering of his excellent Italian letter addressed to me on this subject. Mr. Stella has represented the United States at Syracuse for thirty-nine years past. He is certainly a veteran.

ALBEL' WUUDCOCK.

Consul.

\section{UNITEd STates Consulate,} Catania, May 21, 1884.

MESSINA.

REPORT BY OONSUL JONES.

Tarieties.-The best variety for drying are the fico albo, white fig (round), aud the fico petrociano, purple fig (oblong). The best variety for eating when ripe are the brogiotto, the adottato, the graziano, the catalano, the palermitano, the verunio (winter fig), and the lardaio.

Tree planting.-The above-named varieties are grown throughout this province. They are not planted by themselves but are scattered through the vineyards, groves, orchards, and pasture-lands.

Distance from sea.-The fig thrives 10 miles from the sea-shore. The brogiotto and the petrociano do better near the sea than any other varieties. The graziano is ill adapted to low levels and sea-breezes.

Elevation.-The fig does well at an elevation of 2,000 feet above the sea-level.

Exposure to sun.-All exposures suit the fig. A northern exposure is the least desirable.

Position.-Hill-sides suit the fig best. At but a slight elevation abore the sea the fruit is insipid and soon spoils. The finest trees are to be met with at an elevation of from 900 to 1,200 fuet above the sea. Upland fruit has the highest flavor and the best keeping qualities.

Soil, etc.-The fig delights in a friable, dry, and somewhat cold soil, composed in special of the detritus of calcareous rocks. It shuns wet and marshy soils. The best soils for figs for dryiug are bill-sides of disintegrated calcareous rocks of the Tertiary and Quiternary periods. Soils in which sulphur abound are excellent for the fig.

Climatic influences.-Spring frosts aud antumnal fogs are lisastrous to the fig; the former kill the young buds and the latter cause the leaves to fall off; which prevents the fruit from ripening.

Temperature.-The fig requires a temperature of from $28^{\circ}$ to $95^{\circ}$ Fahr, average temperature, $66^{\circ}$ Fahr.

Rain.fall.-The fig requires from 22 to 28 inches of rain annually. It suffers greatly during protracted dronghts. Spring and summer rains are always of benefit to the fig. September rains are most injurious; they are heavy and so charged with nitrogenous salts that they cause the nearly ripe fruit to split.

Irrigation.-Irrigation is not fequirel by the fig: When grown in 
oryoge and lemou groves which are subject to irrigation the flg pro. duces a large crop but its fruit is inferior in quality and is lacking in keeping qualities.

Cultivation.-The fig might well be called the pariah amongst plants. It is rarely worked-occasionally the soil is stirred around the base of the tree (in November). When grown with orange and lemon trees, vines, etc., being worked when they are worked, it comes into bearing early and dies early.

Fertilizers.-In this district the tig is not even fertilized with its own leaves, which are gathered and fed green to cattle. Stable manure does not suit the fig; ashes and rags are better adapted to it.

Pruning.-The tig is never pruned, as pruning causes the wood to rot; dead branches only are removed.

Picking and curing.-Figs for drying are left on the trees until they are overripe and soft. The season for gathering depends upon the time of flowering. The varieties that produce two crops a year, such as the fico albo and the fico petrociano, bear their first crop in June and July and their second crop in September and October. The fruit of the one crop varieties, the brogriotto, graziano, catalano, ripen in September and October.

Figs for market are gathered at sunrise or at sunset. Figs for drying are gathered at noon.

A small plot of land, near the farmer's house, is carefully swept and inclosed by a temporary brush fence. In this space large flat trays, made of reed cane, are laid on the ground, and the figs to be dried are spread out upou them. The figs are turned over daily at noon until they are thoroughly dried. They are left out at night unless it rains. Some figs are dried whole, others are cut in two. When dried the figs are strung on pieces of split cane 24 inches in length. If a tig does not split open when pressed between the first finger and thumb, it is thoroughly dried and readly for exportation.

Should it raiu on figs put out to dry, they are put in an oven and dried. Figs dried in an oven are inferior to those dried in the sun. These figs are never dipped in any kind of solution whatever. They are cured simply as above stated. The exporter, not the grower, boxes this fruit.

Planting and propagating.-Properly speaking there are no fig plantations. Figs should be planted from 24 to 36 feet apart-dwarf varieties from 15 to 24 feet.

The best varieties are propagated by budding. The fig is also propagated by cuttings-the euttings are set out in winter; no manure is used. Old fig-trees are cut down and the most vigorous shoot sent up by their roots takes their place.

Maturity.-Very few trees live forty years. The tig begins to bear the year it is set out and goes on bearing as long as it lives. At twenty it produces its maximum crop. 
Insect pest8.-The Cossus ligniperda, a large night motb, destroys nearly every tree that it attacks. The homopter, the Columnea testudinata, covers the trees with little pustules (fig-tree scale or mange) as it feeds on the tender twigs, leaves, and fruit. Remedies: Bleed the tree or sprinkle it with a mixture of kerosene and water-nine-tenths water to one-tenth kerosene.

The Halterophora hispanica eats into the pulp. Remedy: Smoke the tree during July and August with sulphur fumes.

There are no parasites of the injurious insects of sufficient importance to mertion.

United States Consulate, Messina, January 27, 1890.

WALLACE S. JONES,

Con̈sul.

\section{NAPLES.}

REPORT BY OONSUL OAMPHA USEN.

Varieties.-The name of the best variety for drying is the Dottato, and for eating when ripe, the Troiano. The other varieties worthy of culture and for profit are, the Samese, the Nerolello and the Paradiso.

Situation. - The trees that produce the varieties above mentioned are grown in the province of Naples. The Troiano is largely cultivated on the plains of Sorrento, where it attains a height of from 30 to 40 feet and 18 inches in diameter. Some trees reach a height of 50 feet and yield about 900 pounds of green fruit per year, which matures between August and the first half of October. Some of these trees grow about 2,200 feet above the level of the sea in Mojano near Sorrento; but figtrees grow generally on land, varying from 300 to 600 feet above the level of the sea. Figs are also largely cultivated in Basilicata and Calabria.

Climatic influences.-Rain is very beneficial to the trees and also to the fruit. What was said regarding the climatic influences regarding lemons and oranges, applies also to figs. During the months of June, July, August, and part of September, there is generally no rain at all, but the atmosphere is moist and vegetation hardly ever suffers from drought.

Irrigation - Fig trees do not require any irrigation; neither are the orchards cultivated nor fertilized.

Pruning.-Every two years in the month of January, in the usual manner.

Picking and "uring.-They are picked from July to September, when they begin to soften and the skins burst. After they are picked they are cut in two and aried in the suu and finilly put in boxes. They are not dipped in any solution. The treatment is very simple, about like the drying of apples in the United States. 
Planting and propagation.-The trees are planted about 30 feet apart, and propagated from sprouts, slips, or graftings. (All trees in this dis. trict are propagated by sprouts.)

The orchards are of all sizes. They (fig trees) are usually planted among other trees.

Maturity.-Sometimes one hundred years, bearing all the time.

Insect pests. - The cocciniglia, which must be looked for and destroyed by hand. There are no beneficial insects.

Cuttings. Cuttings may be secured by writing to Dammann \& Co., at San Giovanni a Teduccio, near Naples.

Edward CampHausen, Consul.

\section{United States Consulate,}

Naples, January 31, 1890.

\section{PALERMO.}

\section{REPORT BY CONSUL OARROLL.}

The introduction of the fig-tree into Italy is so remote that it is difficult to even approximate the periud thereof. Pliny refers to a tree which existed loug anterior to the founding of Rome, under which the citizens of that city were wont to assemble to discuss the topics of the day, years thereafter. Tradition ascribes this tree to have been that under which Remus and Romulus were found, and in commemoration thereof it was preserved.

The fig-tree grows spontaueously in the arid wastes of Greece, Asia, and Northern Africa. In conntries where the thermometer does not fall below $59^{\circ}$ Falurenheit, the growth and maturing of the fig proceed without any appreciable interruption, but in colder countries upon the advent of the first frost the fig-tree loses its leares and those seed receptacles which, under favorable circumstances, would havecontinued to develop, harden, and remain inert until the following spring, when, with the return of warm weatluer, they resume their growth, being the first to mature in the summer. The figs thus resulting are denominated "fig flowers" in orler to distinguish them from those which first appear in spring and mature later.

In hot countries the fig-tree grows to large proportions, and in isolated and favorable localities it assumes a beautiful form, without need of modification or pruning. Its branches project themselves regularly toward the earth from year to year, and finally reaching and entering it they throw out new roots, thus forming additional sources of propagation.

The tree prospers best in a deep, rich, moist, calcareous soil, but in a warm climate it will grow in almost any soil.

The fig tree is propagated from the seed, slips, and roots, as well as 
by grafting, but the former method is rarely resorted to on account of the slowness thereof and only under peculiar circumstances.

A good method to propagate the fig on a large scale is to amputate a young tree at a point of about two inches from the ground and as a result, and soon thereafter, a myriad of sprouts or branches present themselves which in due time may be bent and the ends thereof buried in the ground to the depth of a few inches.

After the branches in question take root they should be amputated close to a joint, thus detatching them from the parent tree, each of which then being a separate tree, may be planted at pleasure.

There are many varieties of figs, differing in size and color, the white growing larger, and, in a fresh state, not standing transportation.

The fig in most favor here is that known as the "Indian fig." It is a native of South America and is the dried fig of Italian commerce. It only prospers, however in sonthern countries, and in calcareous ground without too much moisture, etc.

Philip Carroll, Consul.

United States Consulate,

Palermo, March 7, 1890.

\section{SICILY.}

REPORT BY OONSUL LAMANTIA, OF CATA NIA.

Varieties.-The nane of the best variety for drying is the Dottato, an excellent quality of fig largely cultivated. Figs with fine peel and small seeds are also worthy of culture and best for drying.

The names of best varieties for eating, when ripe, are the Sangiovannaro; the Datternolo (an early fruit), and the Natalino (a late fruit).

The other varieties, worthy of culture and for profit, are the Melanzana; the Olivuzza (a)small fruit), and the Ficazzana (a very large fig).

In reference to the latter, I desire to mention it, for the reason that it is an extraordinary large black fruit, bearing twice a year, viz, abont the end of June; and the second crop, larger than the first one, commences in August and lasts till the end of October. This fig, howerer, is not for drying purposes, but simply for eating when fresh. The fig is so large that six generally weigh about 2 pounds.

Situation.-The trees producing said varieties grow around Mount Etna, as well as in the low lands of this province, from 300 to 6,000 meters from the sea-shore, and from 500 to 600 meters above sea-lerel. When exposed to sun, on level ground, they yield more fruit, but those on billy, rolling land produce them sweeter. Tho same grow also by the sea-coast, and either in poor or rich soils. The soil must be rather dry, for in wet ground the fig.tren does not flon rish well. 
Olimate.-The minimum temperature is 5 centigrades in January; the maxinum 35 in August, and 17 average in May.

The sweetest drying tigs are grown in mild climate land, while those in warm regions are fit for eating when fresh. Rain-fall in this province is known to be at an average of 25 to 30 inclees per year. Rain favors these fruits greatly when they are small, before maturity; but when full ripe it hurts them badly, making them lose their natural, sweet flavor.

Irrigation.-Irrigation is never resorted to, the rain.fall being sufficient.

Cultivation.-Cultivation is very simple, and it does not require much labor to be done. A good digging in summer aud winter time is more than sufficient. The planting is seldom done by rows and the trees are generally spread out throngh vineyards and olive groves, where they grow and bear well.

Fertilizers.-Tuis plant, as a rule, is never manured in Sicily; but in arid lands it is always better to remove from time to time the gronnd, in order to give its base some fresh air.

Pruning.-Pruning is done by cutting off all the dead branches, and the best time to do so is in the months of March and June, or when the pitch is dry. In hot climates, however, pruning is not necessary, for the reason that the plant is one of those which, left to itself, yields always many fruits.

Picking.-Picking is done when the fruit is fully ripe, and generally not before the sun is up, so that the fruit is dried from the night dew. The process of drying is very simple, and is as follows:

Curing.-When the figs are thus gathered they are cut in two, and so set on planks and exposed to the hot sun's rays for drying. Every once in awhile they are turned to be dried on both sides. In the evening, however, they are taken into houses, or are well covered, to protect them from the night dew, dampness, or rain. After four or five days, when they are sticky dry, they are pressed by hand, facing one another together on the pulp sides, and then they are strung together with a big needle and twine and formed in reste (traces) of about 2 feet long. Others, dried in the same way, are passed through small sticks and formed in chiappe (square tables) of about $1_{\frac{1}{2}}$ feet each way. After this has been done the figs so dried and prepared are dipped for a few minutes in hot water, to prevent them from fermentation, and exposed to sun àgain for drying.

The small figs, however, are picked, dried, and cured in the same way, but not cut open, and pressed and packed with somelaurel leaves in boxes, containing 25 pounds, and in round or square baskets for shipping, many of which are exported to the United States.

Planting and propagating.-The distance planted apart is from 20 to 30 feet. They are not planted in rows, but are generally scattered in vineyards and olive groves, where they grow and produce well. Prop- 
agation is generally done by succhioni (suckers) springing from the roots, or by talee (cuttings). Seeding propagation is seldom used, as it is difficult, and trees so obtained take a long time to bear. The orchards are small ones in some localities, while in others are pretty large and give favorable production.

Maturity.-The fig-tree lives very long and almost perennial, for the reason that shoots springing from the roots take place of the old trunks on decaying.

Insect pests.-The insects injuring the fruit and tree are: The Bostrico (Bostricus fici); the Cocciniglia (Ceroplastes caricae), and the Psilla (Psylla fici).

The Bostrico is a very small insect, which digs a gallery in the trunk under the bark, causing the tree to rot, and dies. Said insects during the fall and winter abide in lethargy under the bark of the tree, and in summer, after they have joined together with the females, go on the branches to deposit their eggs.

The "cochineal" is known from the remotest times. At first blush it appears like a small piece of whitish wax, and, in fact, this insect, from its chemical composition, is of a wax nature, and, like the other cochineals, the females protect under them their eggs, and when dead their corpses act as a covering.

The fig tree, badly attacked by the said insect, follows the same phenomenon as the olive tree and acid fruit trees, in similar conditions. The leaves become covered with a sort of black smoke, owing to a very small microbus (fumago) generating from the sticky substance which forms the so-called melata (sugar and gum) exuded from the leaves, on account of the cochineal's presence, although they stay on the branches and not on the leaves. The damages brought the fig tree b5 the cochineals it is useless to speak of, as they are identical to those caused by other cochineal and aphis. The former insect is a rery singular parasite, belonging to the calcididei's family. To destroy the same, it is necessary to cut all the branches off, when badly attacked, and burn them.

The psylla is quite different from the olive psylla. It generalls lives on the leapes, sucking their humors aud causing the tree to become quite a skeleton. Besides destroying them, the branches thrive ill, the fruits fail, and the tree remains damagerl. The insect is a little larger than the olive's psylla, with greenish body and large transparent wings. The larva seems to have no waxen secretion, for the fact that no such substance is seen on the leaves like soft cotton.

Vingent Lamantia,

Consul.

Untted States Consulate, January 22, 1890. 


\section{PORTUGAL.}

THE AZORES.

A considerable quantity of figs is produced, but they are consumed in a fresh state, with the exception of a small proportion converted into an ordinary brandy for home consumption. Scarcely any are dried, the climate being unfavorable to the operation.

S. W. DABNEY,

Consul.

Fayal, 1884.

\section{SPAIN.}

MALAGA.

REPORT BT CONSUL MIARSTON.

Varieties.-The names of the best varieties for drying and eating when greeu are the Hijo Verdijo, thin skin, white, and very sweet when green and ripe; the Hijos Blanco, a white fig with harder skin, and the Hijo Panetijo, brown in color, inclined to purple. All the above are good to eat either fresh or as they say here "green," or can be dried as figs. The quality is in accordance with the order in which they are given.

The trees that produce the varieties of above-named figs are grown throughont all the province of Pralaja, Granada, Almeria, Sevilla, and all other provinces of Southern Spain.

situation.-Distance from sea, 2 kilometers; elevation above sea-level, 100 feet. The more sun the better. Hilly land is the best. Sandy subsoil is best.

Climatic influences.-Temperature, $45^{\circ}, 90^{\circ}$, and $78^{\circ}$ Fahrenheit.

No record of rain-fall to be had here.

The trees require no more water than falls naturally in rain.

Irrigation.-No irrigation for figs.

Cultivation.-Dig around the roots in the latter part of November or December, to the depth of 18 inches, and use stable manure.

Fertilizers.-None used here.

Pruning.-In the month of December, by cutting the ends of all projecting branches.

Picking.-In month of August, when full ripe and when the sun is shining brightest.

Curing and packing.-When the figs are quite ripe they are picked only on fue days, during sunshine, and are cured in the same way that raisins are dried. The sun furnishes all the heat required. It is enough to construct simple divisious made of either brick or stone, exposed to its rays, in an inclined position, say 10 yards long and 2 yards wide. The 
divisions or apartments are built up at one end with a sort of trian. gular masoniry, which, from afar, gives them the appearance of a range of uniform tombs. The triangle is so constructed that the sun, during clear days, never fails to shine upon the contents, the interior of these divisions or compartments being filled with fine gravel which attracts the heat.

Immediately after picking, the fig's are placed in these divisions, and are exposed to the heat of the burning Andalusian sun of August. Never, it appears, have they dreamed of ascertaining the degree of heat thus obtained, but the experienced cultivator affirms that they do, during the heat of August, attain a temperature of $145^{\circ}$ Fahrenheit.

At night.fall a very simple method of covering is applied to guard the figs from the heavy dews or rain, either of sail.cloth or heavy canvas, so arranged that it covers entirely the figs that are drying within, and being supplied with rings on the two sides, slide up and down as a curtain at a moment's notice, in many places planks or boards are used for covering, giving the appearance of a sort of roof. The tigs during the process of drving, which occupies from ten to fifteen days, are turned over and over, in order that they may dry and color uniformly. When completely dried they are then packed in boxes, or frails, the latter made of the palm leaf dried, nailed or sewed up, and are then ready for shipment. They are not dipped in any solution.

Planting and propagating.-Planted apart about 5 yards, and propagated by planting a branch when the tree is beginning to bud.

The orchards are mostly large.

Maturity.-The tree begins to field in six years and lives seventyfive to one hundred years.

Insect pests.-There are no insect pests or parasites.

Cuttings.-Cuttings can be secured by arranging with some grower of figs to give or sell the cuttings about the time of sprouting.

H. C. Marston,

Consul.

United States Consulate, Malaga, December 6, 1889.

\section{TURKEY.}

REPORT BY OONSUL-GENERAL HEAP, OF OONSTANTIYOPLE.

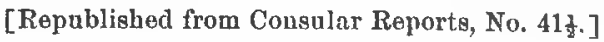

Production.-The fruit of the fig tree may be reckoned among the staple foods of man for ages before cereals were cultivated by any suttled agricultural population. In the temperate regions, where it thrives best, it fills the place of the banana of tropical climates, and yields fruit during several months of the year. In Asia Minor, where 
the tree is found wild and where the best figs of commerce are grown, it is extremely liruitful.

The best figs for drying come from the valleys of the Meander and the Kaistros, to the south of Smyrna, where tho trees are planted with great regulurity and care, and the ground is dug and boed from four to six times during the summer. When the tigs reach smyrna they are sorted by women and packed in boxes by men. They are best when newly packed, and as months go by get drier and harder in the warehouse. No one who has not eaten them in the Levant, packed in the ornamental drums in which they are sold for local consumption, knows what the best figs are like. The cardboards of the tig boxes are supplied chiefly by Belgium and Austria.

Two seasons ago 5 5,000 camel-loads of 4 hundredweight each had reached Smyrna by the 2:d of Uctober of that year; and the production increases annually. Fifteen years before that time not more than half that amount was recorded for the whole season.

England, Germany, and the United States take the greatest part of the figs exported. France, where the smaller and much inferior figs of the Mediterranean are consumed, takes little of the finer kind of the figs of Smyrna.

The improved facilities of transport which have so much increased the stock brought to market have also brought down prices. Taking averages, prices ranged about tou years ago from $\$ 4.08$ the kintal (112 pounds) for Aidin figs, to $\$ 8.75$ for Elemés, while the very best, the Bkinis, sometimes brought $\$ 19.22$ the kintal, or nearly $16 \frac{1}{2}$ cents per pound. Now small parcels of excellent quality bring about $\$ 6.60$ the kintal.

Although throughout the world there are to be found about one hun. dred different species of figs, only some five or six kinds are cultivated in this country. Of these, the best description are called Elémé, and are grown most largely and in the greatest perfection in the districts around Smyrna; but considerable quantities are also grown in other parts of Asia Minor. The fruit is of various colors, from deep purple to yellow or nearly white. The tree usually bears two crops, one in the early summer from the buds of the previous year and the other in the autumn from those of the spring growth. The last forms the chief harvest.

Yield.-The trees are propagated by seeds and suckers, and frequently by layers and cuttings. When young they require care in pruning, and the immature fruit formed late in the summer should be removed to strengthen the shoots.

The Ficus carica, which yields the well-known figs of commerce, is a bush or small tree, rarely more than 18 or 20 feet in height, with broad, rough, deciduous leaves, very deeply lobed in the cultivated variety, but in the wild plant nearly entire. After the young tree attains maturity it receives but little care beyond being occasionally lopped in places and being well manured in the fall of the year. The fruit begins to ripen at 
the end of June, aud the summer yield, which gives employment to a large population, comes to market in immeuse quantities in September and October. The trees sometimes give a third crop, which ripens after the leares have fallen.

Curing. - When ripe the figs are picked and spread out to dry in the sun, the sugar which they contain in abundance being thus rendered available for their preservation, those of better quality being much pulled and extended by hand during the process. Thus prepared, the fruit is packed closely in barrels, rush baskets, or wooden boxes for commerce. Recently the practice of preserving fresh undried figs has been adopted, but the amount used in that form is as yet insignificant compared with the quantities that are preserved by drying.

\section{OBSERVATIONS.}

Figs, especially when fresh, are largely used by the local population as an article of food. The trade in this fruit is of long standing and of very considerable importance in this country. During the Jear 1880-'81 Smyrna district exported 6,9911 tons, worth at the port of shipment $\$ 1,646,995.89$. The exportations were principally to England, Germany, the United States, and France. In one fortnight no fewer than 195,000 barrels, cases, bags, boxes, drums, and baskets of figs and rasins were shipped from Smyrua alone. The export trade of figs at the other Turkish ports is unimportant in comparison with Smyrna. Figs are grown largely in the other provinces of Turkey, but the quantity exported is small compared with Smyrna. They produce but little more than is sufficient to meet the local demand, but if railroads existed in the interior the production would be immensely increased.

It is probably not generally known that a considerable quantity of the iuferior kinds of figs find their way to the Austrian "chicory coffee makers" and the French brandy distillers. Much liquor labeled "fine champagne," "cognac," elc., owes its origin to the refuse of the Smyrna fig market.

United States Consulate-General,

$$
\begin{aligned}
& \text { G. H. ШEAP, } \\
& \text { Consul-General. }
\end{aligned}
$$

Constantinople, April 10, 1884.

\section{DARDANELLES.}

REPORT BY CONSULAR AGENT OALTERT

Varieties.-Figs are not dried here. The best variety for eating when ripe is the Syah Ingir (Black fig).

Trees.-Very ferw trees of other kinds are cultivated. The trees producing these figs are grown in Thracian Ohersonese, Dardanelles coast, and elsewhere. They are planted from the sea inland, but not above 1,500 feet, and open to all exposures. 
Soils, etc.-All soils and position, rocky ground with sunny exposure, produce the best flavored fruit.

Alluvial, light, and stony soil in general; hard subsoil is best suited to the fig.

Climatic influences.-Rarely above $90^{\circ}$ or below $5^{\circ}$ Fahr.

Rain.fall.-Thirty inches per annum. Much rain is apt to cause the fruit when ripening to split and decay.

Irrigation.-Irrigation is not practiced.

Oultivation.-No method of cultiration practicerl.

Fertilizers.-No fertilizers are applied.

Pruming.-No pruning. Suckers are removed.

Picking.-When the fruit matures the early morning is the best time for picking.

Planting and propagating.-Trees are planted from 15 to 30 feet. The ordinary method of propagation is to take a cutting (or branch torn off preferred) 3 to 4 feet in leugth, with terminal bud. A trench about 20 inches deep is made, the branch is layered with the end projecting 4 to 8 inches above ground. If the summer be dry, a little water is given the first year. Suckers and spray-wood are not generally planted (unless to be grafted like the wild fig) as they produce fruit inferior to that of the parent tree.

Orchards.-All sizes.

Maturity.-Fifty to a hundred jears. Frnitful till decay. The stem, when it decays, is almost always replaced by its offshoots.

Caprification.-A contested question is that of caprification. The prevailing idea is, the parasite of the Ficus carica, or wild fig (called ly the natires the male fig), fertilizes the cultivated tree. The Blastophaga grossorum and Cynips sycomori are now recognized to be the apterous male and winged female of the same insect. So rooted is the idea that in a year of scarcity the puff figs are sold at $\$ 2$ and $\$ 3$ per pound to suspend on the cultivated fig-tree. A series of observations have been made to test the theory in different countries. I was requested by Sir S. Saunders, of the Entomological Society of London, to contribute by the examination of the fig-trees in these parts. Like all the other observers, $I$ found the parasites and their ichneumonidæ in abundance in the wild fruit, but failed to discover any trace of these insects in the cultivated fruit at any stage of its development.

Insect pests.--A kind of blow-fly attacks the fruit sometimes when mature, especially when damaged by rain.

Cuttings of best varieties can easily be secured.

The matter relating to the parasites was published in the Entomo. logical Monthly Journal (London). No Government statistics exist.

Frank CaLVERT, Consular Agent.

Unteded States Consular Agency, Dardanelles, February 11, 1890. 



\section{PART IV.}

$$
\text { THE VINE. }
$$





\title{
CONTINENT OF AFRICA.
}

\author{
MOROCCO. \\ REPORT BI OONSUL WATHEWS, OF TANGIER. \\ (Republished from Consular Reports, No. 411.)
}

The grape-vine is truly a cosmopolitan plant; is a gross feeder; it will flourish in the richest soil as well as in the poorest, on hills and in valleys and amongst rocks; in fuct it will grow and its roots will find their way in the smallest crevices of rocks, where no other plant will grow ; the vine will stand repeated droughts as well as the most severe winters. The preferable soil is that which contains alkali and lime. Manure will increase the yield of fruit and assist in resisting diseases and insects.

The vine will live in, but is impatient of, continued or stagnant wet soil.

The vine raised from cuttings is capable of producing a given quantity of wood and fruit to perfection, and if allowed to exceed that proportionate quantity, a small, unripe fruit, and rusting, shriveling, or other evils will be certain consequences.

When a little less proportion of wood and fruit than the vine can mature is left on it no evil can be derived, but certain advantages.

The vine bears on shoots of the present year out of the wood of last year; hence the practice of learing a sufficient quantity of last year's wood.

There are numelous ways of pruning vines; every country, in fact every province, has its favorite way; but always bearing in mind that so long as a proper quantity of last year's wood be preserved, and not too much be left to push fruit and wood, a vine will bear, the actual style of pruning and training may be suited to the place in which it has to grow. In Jerez and other places they cut the first roots near the surface of the soil, to allow the lower roots all the force to penetrate deeper in the soil ; in other places they condemu this practice. Still, the Jerez vineyards, treated as stated, leave nothing to be desired.

The length of barren stem before the branches are allowed to start is immaterial ; therefore a vine with its bearing wood 30 feet high on the roof of a house and a bare stem all up the front will give as much and as fine frnit as a fellow-vine with its bearing wood within a foot of the ground. 
The vine is propagated from cuttings, by grafting, by layering, from eyes, and by seed.

The vines propagated from cuttings, graftings, layering, and from eyes, being the direct issue of wood centuries old without intermixture, are sooner or later liable to run out by impoverishment and produce numerous diseases and evils, and lastly the phylloxera, although it is said that a well-manured and well-kept vine will not be troubled by the latter pest.

Propagation from seed is the most natural, and more important and certain of success than all others. It is from seeds that the innumerable varieties are obtained. A vineyard reared from seed will not be troubled by the phylloxera, even if the surrounding vineyards are all infested with the pest. The strong phosphor and youth in the vine raised from seeds will not permit the phylloxera to live; whereas the exhausted vine raised from cuttings, the origin of which is perhaps centuries old, and which have lost those peculiar defensive fluids of phosphor and potash, will breed the phylloxera, in the same manner as parasites and other miseries are created on old, wasted, careless men or poor animals.

Propagation from seed is a very simple operation. Obtain seeds from all the finest varieties of grapes and raisins; sow the seeds in compost of loam, sandy soil, and dung manure, equal quantities, in the month of Jannary or February if in Upper California, or in November or December in Lower California. They will grow rapidly, and as soon as they can be handled well plant out the desired distance 5 or 6 feet each way, and water well with manure water, and they will make a good growth the first season. They should be fastened as they advance to prevent the wind from breaking them, and they may be then treated and trained like plants from cuttings or eyes as soon as they are large enough. On the sixth year they will bear fruit, which will improve in size and quality as they advance in age. On the seventh year the selection is made, learing the finest varioties, and grafting those varieties which may not be found acceptable; they can be grafted from the others or from any other old plants, as the young roots will stand the attacks of all pests. When no selection of new varieties is desired, seedlings can be grafted when two years old of cuttings imported from foreign countries of the finest, choicest varieties. When planted the results are uncertaiu, according to the nature of the new soil when they are set, while choice seeds on new soil are certain of producing some of the most excellent rarieties, particularly if the young plants are encouraged by attentive cultivation.

Manures.-Returu to the vine all that which it bas given with the exception. of the wine. Here is the great reform, of easy execution and fecund results. The lees and drosses of the wine-press and of the casks where the wines bave fermented, the skins of the grapes, the ashes of the cuttings, and the residue of the distillery after "vaporation has taken place until dry in the open ail-these sre the most precions mannres for the vine, owing to their richues: in allkaline salts. 
Phylloxeric Congress. -The members of the Interuational Phylloxeric Congress, which had its session at Bordeanx, affirmed that they obtained satisfactory results in their vineyards by submersion.

The submersion, according to their opinion, gives luxuriance to the wines, because water supplies phosphor and potash, both of which elements are indispensable to those plants, and of which elements much is used up in the shoots, leaves, and fruits yielded annually, and submersion restitutes tlem in the proportion which is mixed with water.

The submersion should be made by leaving the water standing in the vineyard, as in this manner the phylloxera dies quicker by drowning for want of air, because if the submersion is made through running water, the current of which carries air with it, the insect is not destroyed.

Phylloxera takes a longer time to die by submersion in winter, on account of the slower evaporation of the water.

Finally, submersion will always give good results if it brings to the vine the necessary quantity of potash and phosphoric acid.

These are the conclusions arrived at in the discussion sustained by the vine-growers, who agreed on this point with scientific men, each side of which brought forward their arguments.

Felix A. Mathews,

Consul.

UNITED STates Consulate,

Tangier April 2, 1884.

$156 \mathrm{~A}-25$ 


\title{
CONTINENT OF AMERICA.
}

\section{SOUTH AMERICA.}

\author{
ECUADOR. \\ REPORT BY OONSUL BEAOH, OF GUAYAQUIL, \\ [Republished from Consular Reports No. 41․․]
}

Until very recently no attempt has been made to grow grapes in Ecnador, except here and there vines about dwelling.houses. These have been grown on frames or poles, and with little or no attention to pruning or cultivation. Nearly all classes of grapes can be grown to perfection. Of late some attention has been given to the subject in the interior; and on mountain sides, between ranges of the Andes, at an altitude of from 6,000 to 8,000 feet (the soil decomposed lava), small vineyards have been started with very favorable results, indifferent cultivation cousidered. The vines are set by digging a hole with a hoe, and are cultivated only by the use of a machete-a long, broad-bladed knife-with which all other regetation is cut down. The land costs little or nothing, and the laborer is paid 20 cents a day and kept. The vines are grown to stakes. As considerable wine is consumed in the country, the National Congress, now in session, to promote grape culture, has passed a law that all persons engaged in their cultivation shall be exempt from military service-a great inducement to engage in the pursuit, as the numerous revolutions have made frequent calls for soldiers, retarding all industries. The value of the grape crop per acre can be approximated by the value of wine, the most common bringing $\$ 1.25$ per gallon. The yield of grapes would doubtless be as large as elsewhere under similar caltivation. It is not known that grapes may not be grown in any section of the country. The general conditions appear to be favorable for the growth of raisin-grapes, but I can not ascertain that the experiment of growing them has ever been tested here.

United States Consolate,

HORATIO M. BEAOH,

Consul. 


\title{
CONTINENT OF ASIA.
}

\author{
ASIA MINOR. \\ REPORT BY OONSUL STEVENS, OF SMYRNA.
}

[Republished from Consular Reports No. 41t.]

Aidin.-The vilayet of Aidin contaius about 35,500 square miles, and has a population of nearly $1,000,000$. It is the most productive and in all respects the most important section of Asia Minor. It lies in latitude north $38^{\circ} 28^{\prime} 7^{\prime \prime}$, west $1050^{\prime} 44^{\prime \prime}$ longitude of Constantinople, compared with the meridan of St. Sophia. Two considerable rivers flow through it. The arable surface is made up of valley, table-land, and hillside. The soil, except in the more mountainous districts, is extremely fertile and easily tilled. The climate is mild and admits of field labor at all seasons of the year.

Climatic effects.-The cultivation of fruits, tigs, and raisin-grapes, especialls, is extensively carried ou. Smyrua figs have a world-wide reputation for excellence. The raisins produced are also of superior qualtiy. The natural conditions are favorable, and to this fact more than to the methods pursued in cultivation must be ascribed the success attaiued. To reach the fullest development of which these fruits are capa. ple a semi-tropical sun, unobscured by clouds during the summer months and early autumn, is needful. A wet winter and early spring with a dry summer and autumn are conditions most desired by the cultivators of these fruits, and indeed for nearly all the other crops of this regiou. The accompanying table, marked $\Delta$, showing the amount of the rain-fall in Smyrna for each month, beginning with the year 1864 and ending with 1882 , will be found useful in this connection. 'To enable American fruit growers to estimate the influence of climate apon the raisin product lere it should be stated that, even in mid-winter, frosts are very infrequent, and the freezing point is rarely reached. The spring is very short, the transition from the cold rains of winter to the balmy breezes of summer often being almost immediate, but the hot season does not set in until the middle of May. From that time until the middle of September the thermometer ranges from $78^{\circ}$ to $90^{\circ}$ in the shade. For weeks successively there is very little variance in the temperature. Both in winter and summer the wind for long intervals blows from one quarter. On the sea-board the heat of summer is tempered by a breeze from the sea, called "imbat," which blows fresh and strong nearly every afternoon. 
Coming now to the specific interrogatories, I submit the fullest information obtainable upon the subject.

Situation.-The vineyards are located on table-landsand hill-sides, the latter always facing the south. The soil of the former is sandy and of a light red color, the alluvion of torrents; that of the latter, calcareous and clayej. Vines planted on the plains are more productive than those planted on the hillsides, but do not last so long, the latter continuing in good bearing condition for well nigh a century, while the former became barren at the age of thirty years, sometimes sooner. The quality of the hillside product is far superior.

In the vicinity of Smyrna vines are planted near the sea-shore, but there are flourishing vineyards in localities from 7 to 20 miles inland. Vineyards planted near the sea-shore are often injured by mists and fogs.

Varieties.-Four kinds of raisins are cultivated, viz, Sultanas, Red, Plack, and Muscadine. The Sultanas are not palatable while fresh, and are marketable only when cured. The black and red are excellent while fresh, and are put in that condition on the local markets in large quantities. There is also another variety of black grape which is cured and shipped to France, where it is used in the manufacture of wines. The wines made in Smyrna are the product of the same variety of grape.

The vines on the coast run the greatest danger during the months of March, April, and May, from the cool, damp mists blown in from the sea. The losses sustained from this cause are frequently from 20 to 30 per cent. of the total yield.

Pruning.-Pruning is done in December and January with small, sharp saws, curved at the end. The branches are cut about 1 foot 6 inches from the ground. Care is taken to do this work during the first and second quarters of the moon.

Planting.-Vines are planted from the beginning of March to the middle of April, according to nature of soil and atmospherical condition, the ground having been dug the previous summer to a depth of $3 \frac{1}{2}$ feet. This manner of plauting was introduced here some twenty years ago by emigrants from the Grecian Archipelago, and gives the best results. Another and older method is to plant fields which have been plowed over three or four times by the plow of the country, which dates lack to the infancy of ancient Greece.

Cultivation.-The cultivation of vines in vogue here is as follows: In November trenches are dug round the vines and filled with manure. Six weeks later, as above stated, the process of pruning begins. During January, February, Mareh, aud April the vineyards are dug twice only, the first time at a depth of 1 foot 6 inches, taking care, of course, not to injure the roots, and the second time very lightly, in order to destroy the weeds which absorb the moisture necessary to the plants. The process of watring vineyards is not in favor with thu growers of this province. 
Maturity.-The Black, Red, and Muscadine vines begin to yield in their third, bat do not reach their full strength until their fifth or sixth year. The Sultana vines begin to bear in their fifth and attain the maximum of production in their seventh or eighth year. A good, healthy plant will produce about $25 \mathrm{cwt}$. per acre, but the average yield is from 10 to $15 \mathrm{cwt}$. per acre.

Vintage.-The grapes begin to ripen about the 1st of July, the Sultanas being the earliest. Their vintage begins towards the end of July and lasts till the middle of August. The vintage of the Red grape begins by the end of August and lasts till the 20th of September; that of the Black in the early days of September, ending with October. The Muscadine is gathered during the second half of August. An excellent wine is made with this variety, but in small quantity. Less than $5,000,000$ gallons of wine are manufactured annually in this province, although the best materials are at hand and in great abundance.

Rain-fall.-It happens occasionally that rain falls during the vintage time, causing heavy losses to growers through the inevitable deterioration of quality. This was the case last season, and large quantities were in consequence shipped to France to be made into spirits.

Cultivation.-The work required in the cultivation, gathering, and curing of the grapes is performed by hand, and, notwithstanding labor is cheap, is rather costly. The average yield per acre per annum is valued at about $\$ 88$. The value of vineyards per acre is about $\$ 440$, and the cost of a crop per acre, tithes to Government included, is nearly or quite $\$ 50$.

Exports. - The exports of black raisins amount yearly to from 800,000 to $900,000 \mathrm{cwt}$; 70 per cent. of this quantity is shipped to France; the remainder finds its way to Austria, Germany, Russia, and Roumania. The best quality of black raisins is exported to Roumania, to the extent of $45,000 \mathrm{cwt}$. per year. In general, the crop of raisins of all qualities and kinds, in the province of Smyrna, amounts to about 1,900,000 cwt. It is yearly increasing. Out of this quantity $650,000 \mathrm{ewt}$. consist of Sultanas, 80 per cent. of which is exported to England, 10 per cent. to Russia, and 10 per cent. to Germany, Austria, and the United States.

W. E. Stevens,

United States Consulate, Consul. Smyrna, February 28, 1884.

\section{MITYLENE.}

REPORT BY CONSULAR AGENT FOTTION.

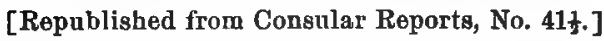

Vineyards are cultivated at Mitylene in valley, table-land, and hillside, inland and on the sea-coast. They are cultivated very near the sea-coast because here there are no sea-fog's. The custom of pruning 
in the best conducted rineyards is at the eud of January or daring the first half of February. All the large vines are pruned on two stems, but middle-sized and small ones on a single stem, preserving one eye more. In March the first work is done on the vine, when the first digging is done. In April they sulphate the vine, and in May give the first nipping to all branches which grow very rapidly. In June they repeat the sulphur. In July and August the heat does not permit any work on the vines. The harvest begins abont the first half of September, and usually about the end of October the second digging is finished. At the close of autumn and in the winter, manure is used for old vines, but in very moderate quantities, about 4 pounds per vine in best soils and 7 pounds per vine in medium, and 10 to 12 pounds per vine in poor soils. They are manured every three years. The character of soil where best results are obtained is on a shallow dry soil, receiving the sun's rays, on hill-side, valley, or table-land. The vines here come into full bearing the fourth year and they remain fruitful until the fifteenth year.

No system of artificial irrigation for raisin culture exists here.

The yield value per acre per aunnm is abont $\$ 68$, and the cost of crop per acre is about $\$ 1$. The different kinds of vines grown are: In dis. tricts of Kallonie red grapes and white grapes, from which are made the celebrated Kallonie wines, anciently Anthosmias. In the districts of Ploumari black grapes, from which are made the celebrated Kountoura wines, very much better than the Bordeaux. All the wines made at Mitylene are for home cosumption; the export is iusignificant.

M. M. FotTion, Consular Agent.

United States Consular-Agency, Mitylene, March 12, 1884.

\section{SYRIA.}

BEIRUT.

REPORT BY CONSUI, ROBESON.

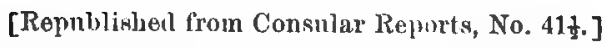

In the district of Beirut, vineyards are mostly planted on high tablelands or hill-sides (where the best results are obtained), at an elevation of from 1,000 to 4,000 feet above the level of the sea. Some years ago a disease something like mildew spread iu Syria, and destrojed most of the vineyards. Asphalt was used to counteract the same; but little, if any, benefit was gained by its use. The only remedy was to destroy the affected vines, and plant in their place plants taken from healthy vines. In January and February vines are pruned; two or three strong shoots are left on each rine.

The soil luest arlapterl to the cultivation of the vine is reddish-black in color; however, grapes are raised in all kinds of soil, but when the 
vines have not the adrantage of rich soil, they require to be carefully cultivated. Hill-side and table-lands are preferred for the planting of vines for raisins. Vineyards are plowed three times a year: 1st, in December; 2d, after the pruning of the vine stocks; and $3 d$, a short time after the appearance of the leaves.

The vines come into full bearing in six or seven years; they remain fruitful fifty or sixty years if properly cared for. In regard to the irrigation there is no system of artificial irrigation in practice for raisin culture throughout this country. It is considered that the watering of vines, by increasing the juice, diminishes the sweetness of grapes, and they become, in consequence, unfit for raisins. The yield per acre per annum is estimated at from 2,000 to 3,000 pounds, the average value of which is from $\$ 15$ to $\$ 25$; the cost of cultivation amounts to about $\$ 5.50$.

JOHN T. ROBESON,

Unteed States Consulate,

Consul.

Beirut, May 3, 1884.

ALEPPO.

REPORT BY CONSULAR AGENT POOHE.

[Repnblished from Consular Reports, No. 41․․ㄹ

In the vicinity of Aleppo very few vines recently planted are found. As a large majority of the inhabitants of this country are Mohammedans, they are probibited by their religion from using any alcoholic drinks, and the manufactaring of wines being constantly forbidden to them, the vine is only planted for its fruit, and the cultivation of the same is very poor. The care taken of the rine consists of pruning and the frequent plowing of the soil. Vines are indifferently planted on the declivity of the hills or table-lands, in reddish soil, both near to and far from the sea. The slopes exposed to the wind are preferable. No consideration has been given to the disease of the vine, for want of competent persons to examine the same, althongh the rine disease has raged in some parts of this country. The vine begins to produce in the third year; in the sixth it comes into full bearing, at which time it yields about 20 to 30 pounds of grapes. It lasts for a great number of years. When the stem is opened up it is cut and the root shoots anew, and the vine produces again after threo years. No system of artificial irrigation is adopted. The fruit is either used fresh or dried. The planting is made at the same distance as the olives; i. e., about 20 feet between each plant. Raisins are cured, just like figs, by being dried in the shade and then steamed.

F. POCHE,

Consular Agent.

UntTed States Consular Agency, Aleppo, April 16, 1884. 
HAIFA.

REPORT BY OONSOLAR AGENT SOHOMAOHER.

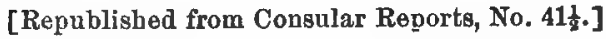

Raisins are not produced in my consular district; but as we have been enguged in the culture of grapes for the past ten years, and this question being closely related to the question upon raisins, I want to answer it at the same time.

Experience has shown that southern hill-slopes and table-land are equally well adapted for grape culture, whilst in valleys and on plains no very good results have been obtained. Directly on the sea-coast grape vines do not prosper near as well as in the interior.

The vineyards of the American-German colony here are situated abont a half mile from the sea-shore; the close proximity of the sea (we never have fogs), however, appears to act injuriously to the vines, as we have but very little dew, which further inland falls abundantly, and which causes the vines to remain fresher during the rather hot and rainless summer months. In the mountainous district of "Belâd Bishâra" (Galilee), at an altitude of 1,500 , to 3,000, feet above sea, the saccharine contents of grapes is greater both in quality and quantity, so that wine made from them has a finer flavor; the acidity contained in the grapes cultivated in the rineyards near the sea-shore, and which makes wine made from them unfit for exportation, is almost entirely absent in the grapes from Galilee. Besides this, our vines suffer from mildew. This is a flour-like substance which surrounds the berries of the grape when they are about half grown, preventing them from developing and ripening. Every locality of our vinejards, whether in a valley or on a hill-side, has suffered with this mildew, but the higher elevated the vineyards are the less they suffer.

As a remedy we were advised to strew the grapes, shortly after blossoming, with powdered sulphur, but it did not prove to be very efficient with any of the foreigu or native rarieties. The Isabella (a blne grape originally imported from the United States) was the least affected of all, and in some spots did not suffer at all. Experiments will have to be made yet whether we can not find a variety which is not subjected to this malady.

According to information from natives, thei $r$ vineyards in the interior have at times also been affected with mildew, b ut it disappeared after it had lasted seven years, whilst we on the sea-coast hare had to contend with it for nearly ten years. But we find on the slope of Mount Oar. mel, where our vineyards are located, ancient wine-presses and cisterns cut in the solid rock, which shows that grape culture must have flourished here formerly. From experience thus lar, I can make the assertion that for this region grape culture does better in the interior than on the sea.coast. 
Pruning.-The vines are pruned in the months of December, January, and February. The first-grown shoots are cut off, so that ouly four or five buds remain on them. A reddish humus soil with limestone beneath appears to be especially well adapted for vines. The ground is worked twice with the hoe, the first time after pruning, and then again wheu the first leaves come out. The vines come into full bearing after four or five years, and remain fruitful until they are at least fifty years old. No vineyards are irrigated here, and if practiced would tend to diminish the saccharine qualities of the grapes. The yield is from 400 to 800 gallons per acre per annum.

\section{JAOOB SCHUMAOHER, Consular Agent.}

United States Oonsular Agenoy, Haifa, February 20, 1884.

\section{SIDON.}

REPORT BY CONSULAR AGENT ABELA.

[Republished from Consular Reports No. 41t.]

Position.-Vineyards are placed in this section of the country mostly on the high mountains or on high lands from 2,000 feet in elevation to 5,000 feet above the sea-level. A southern exposure is preferable to any other. Vineyards on the mountains away from the sea give somewhat better crops than those near. The vines are not injured by clouds or mists; fogs are very rare in this climate, and seem to do no harm. Vines grow within two miles of the shore, but do not give the best results. About thirty years ago all the vineyards of this land were blasted by mildew, and the only effectual remedy was to dig up tho old vines and plant new ones from stock untouched by the mildew.

Pruning.-Before the vines put forth leaves they are very closely pruned, all shoots being cut off, with the exception of two or three left quite short.

Soil.-The nature of the soil makes little difference. Red, loose soil is preferred. Stony, rocky soil produces the best grapes.

Cultivation.-In the best vineyards nothing else is planted in the soil, nor is manure usnally applied. The ground is plowed three times a year, which in this land is merely scratching the surface, the object being to pulverize the soil.

Bearing.-Vines begin to bear fruit about the fourth year. Grood crops are raised by the seventh, but the fruitfulness increases to the fifteenth year.

Irrigation.-No system of irrigation is practiced anywhere, but is con. sidered very injurious to the crop. 
Yield.-This, of course, varies from year to year, and according to the soil, etc.; but on the average may be estimated at about 1,500 ponnds to 2,000 pounds the acre.

SHIBLT ABELA, Consular Agent.

United States Consular Agency, Sidon, February 21, 1884.

\section{TARSUS.}

\section{REPORT BI AOTING CONSULAR AGENT A VANIA.}

[Republished from Consular Reports No. 41ł.]

The best sites for the culture of vineyards are the hill-side lands, the table-lands, and in general all light soils. The interior of the country is better suited than the coast. In this province there are but very few vineyards in the vicinity of the sea. The largest part is at a distance of from 9 to 12 miles and upward. At Mersine there are some vineyards at a distance of from one-half to 3 miles, the produce of which is middling. Mildew and fogs not being very frequent all along the province, vineyards never suffer from the same; consequently no specific is used. Sulphur, however, is the only remedy used, as in Anatolia. In this country, and I think in all the Levant, vineyards are never irrigated; the winter and spring rains are sufficient. The best results are obtained where the soil is a light reddish and more or less sandy. Vineyards are cultivated twice a year, because if they are kept free from parasites, and in condition to absorb the necessary water, they yield better and last longer. In Adana, a vineyard country, people sow even cotton and sesame in the vines without prejudice to the same. After the third year of their plantation the vines come into fall bearing and begin to give fruit, which increases gradually. They remain fruitful till their fortieth year. However, vines last fifty or sixty years, and give relative fruit if they are regularly cultivated and pruned annually. The pruning of vineyards commences about the end of January. The pruned branches, when sound, are used for the plantation of new vineyards.

There is not any system of artificial irrigation in this province. The rains that fall are sufficient to revive the plants.

The yield, value, and cost of vineyards per acre (of 49 square acres) are in this country as follows: In every acre from 150 to 160 vinestocks are planted, which yield on an average from 13 to 17 pounds of grapes each; value from $\$ 50$ or $\$ 60$ per acre. In this country, where the wages of workmen are rather low, the keeping of vineyards costs but little.

The greatest part of the grapes produced are absorbed by the local 
consumption either in their fresh condition or for distillation. Nevertheless since France began to ask for foreign grapes a quantity of about $3,300,000$ pounds of raisins at a value of $\$ 66,000$ is annually exported from this province. The raisins destined for exportation are dried up in the sun, placed in bags, and sent to the sea-ports to be shipped in steamers.

United States Conśular Agenot,

Elie Afaria, Acting Consular Agent.

Tarsus, March 3, 1884.

\section{TRIPOLI.}

REPORT BY AOTING OONSULAR AGENT YANNT.

[Republished from Consular Reports No. 41ł.]

RAISINS.

Vineyards are found in all parts of this district, but especially in the hedges surrounding the orchards of the large village Elminyeh, about 6 miles northeast of Tripoli, on the hill-sides of the Dunniyeh district, in the elevated valleys of the Lebanon, and on the table-lands of Elkoura and El-Zawiyeh districts.

The above-mentioned village, Elminyeh, is very close to the sea.

Nothing is known concerning injury caused by sea fogs or mist. The only injury to the vines occurred in the District of Dunniyeh, about thirty years ago. This district is some 9 miles from the sea, and before the time mentioned was famous for its excellent grapes. Some disease of an unknown character reduced these grapes to a very poor condition, so that the vines were almost destroyed. It is only within the last ten years that the vines of Dunniyeh have begun to revive.

In February and March, after the heavy rains are over and the sun's rays begin to animate regetation, people begin pruning the vines by cutting off all the branches of the last year, so as to give place for others. All kinds of vines are not pruned, for there are some sorts which need no such treatment except in case of dead branches only, which are cut off.

Vineyards are planted in all soils, but the best results are obtained from those of siliceous character.

The lands planted to vines are cultivated four or five times a year, and if neglected the product is correspondingly small.

Vines begin to bear in their third year, but do not come to maturity before the fifth year. They remain fruitful as long as they are properly attended, except when they are planted among olive trees, which, when grown, kill not only rines but other trees. Vines in such situation rarely live more than fifteen sears. 
There is no need of irrigation for the vineyards of this region; and in consequence vines are planted where no irrigation takes place.

The estimated average yield from each vine is 5 to 10 pounds of grapes, worth from 4 to 8 cents for the whole product. The expenses are about 7 per cent. of the income.

G. YANNI,

Acting Consular Agent.

UntTed States Cosular AGenct,

Tripoli, March 18, 1884. 


\title{
CONTINENT OF EUROPE.
}

\section{AUSTRIA-HUNGARY.}

\author{
REPORT BT OONSUL-GENERAL WEATER.
}

[Republished from Consular Reports No. 41t.]

\section{IN'TRODUCTION.}

Although the raisin industry, strictly speaking, does not exist in this empire, and the production of figs, olives, oranges, and lemons is very unimportant, yet it is thought that the grape and wine industry and the commerce in tropical fruits may be of sufficient interest to the fruitgrowers of the United States to warrant the transmission of the following items in regard thereto.

The Austro-Hungarian Empire is situated between $42^{\circ} 10^{\prime}$ and $51^{\circ} 5^{\prime}$ north latitude, and $9^{\circ} 10^{\prime}$ and $26^{\circ} 15^{\prime}$ longitude east from Greenwich. Omitting, however, its irregnlarities, the empire lies mainly between the forty-fifth and fiftieth degrees of north latitude and the twelfth and twenty-sixth degrees of east longitude, having, therefore, a rectangular form of about 350 miles in breadth by 750 miles in length, comprising an area of 261,272 square miles, with Bosnia and Herzegovina inclucled. The mean latitude, therefore, of Austria-Hungary corresponds very closely to the morthern boundary of the United States.

The climate of this country, however, is much less rigorous, as is well known, than that of the United States. The extremes of heat and cold at Vienna, which is located at about the center of the Austro-Hungarian Empire, were during the past thirty years $98^{\circ}$ and $4^{\circ}$ Fahrenheit, while the average yearly temperature during the same period was $10^{\circ}$ centigrade or $50^{\circ}$ Fahrenheit.

It may, consequently, be very confidently affirmed that in AustriaHungary the winters are not as cold nor are the summers as warm as in the United States by probably from $8^{\circ}$ to $10^{\circ}$, notwithstanding its higher latitude. The rain-fall during the last thirty years varied at the $\mathbf{1 8 6}$ stations for meteorological observations in Austria-Hungary from 43 to 242 centimeters per year, equivalent to 17 and 95 inches.

These stations are grouped as follows: 41 in Hungary, 80 in the Alpine region and on the Adriatic coast, and 65 in Bohemia, Galicia, Moraria, and other interior provinces removed from the sea. The rain-fall 
in these regions was respectively 28,49 , and 28 inches, making for the entire empire an average of 36 inches per year.

The average cloudiness of Vienna, estimating complete obscuration at 10, during the years 1853-72 was 5.7, the months of July, August, and September giving a minimum of 4 and November a maximum of 7.4. Consequently the degree of moisture in the air is very large, averag. ing for Vienna during the last thirty years a humidity of 72 , when reckoniug complete saturation at 100.

The foregoing data will aid those interested to estimate the general influences of climate upon the production of fruit in this empire whose territory in general is usually far removed from the sea and other large bodies of water which might injuriously affect the grape crops by excessive moisture.

The same influences, however, arise from the large river system of this country, particularly in Hungary, to the end that the best vineyards are found upon the highlands aud slopes of hills and mountains, of which Austria possesses a great number and variety.

\section{GRAPE AND WINE INDUS'IRY.}

The methods of grape culture, as practiced in the neighborhood of Vienna, will be seen from the following reply of Robert Schlumberger, proprietor of valuable vineyards in the Vöslan region, given in response to certain inquiries as to soil, vines, crops, and the methods of cultiva. tion practiced in his district. He says :

The methods of pruning the vine in the various wine-growing districts of Austria differ somewhat, and vary also in regard to the kind of grapes in the same part of the country.

In most districts, especially those to the south of Vienna, in the neighborhood of Vöslan, where the best red wines of Austria are produced, the branches are cut down to one or two ejes, and on each vigorous vine five to six branches are left. At a longer cut, the vines usually growu in the country, the Portuguese and Blue French, bear grapes superabundantly, producing an ivferior quality and resclting in the exhaustion of the vives in a fow jears. A longer cut is only customary in regard to the Blue Burgundy aud the St. Laurent vines, whiuh, however, are not very extensively eultivated, at which operation either four eyes are left on each of twelve branches, or on a louger grape-bearing branch five to seven ejes, whilst the remaining branches are cut down to one or two eyes. During the subsequent year, the old grape-bearing branch is cut off and the strongest of the branohes produced from the eyes of those cut down the preceding year will be employed as the grape-bearing one.

The soil in the vicinity of Vöslan and Gumpoldskirchen, where the most excellent white wines are produced, consists of a light, flat, and loamy ground, the subsoil of which near the mountains cousists of culcareous rock and on the plain of alluvial gravel.

The tine wines grow on the slopes ouly. The valleys are left to the cultivation of other products.

In the plains wines of inferior quality are produced, but in larger quantities than on the hills. The produce, however, is very uncertain on account of the uight frosts in epring, which do great damage on the plains, while the slopes are spared.

'I'he soil in noarly almust all the vineyards of Austria is worked three times a I cilf' with the hoo: First in spring after the $A_{\text {pril }}$ cuttiun; secousl allor the binding up and weediug at the ench of June; and thirel, al the chel of July or carly part of Argast. 
In Vöslan and vicinity tor the last fifteen years the soil has also been worked a fourth time, at the and of the vintage in October or November, by digging the soil as deep as possible, in order to keep it loose during the winter, which has an extraordinarily favorable influence on the grow th of the vine and renders the working in spring much more easy.

This example has often been followed, and in course of time no doubt this fourth working will be generally adopted.

In some districts, especially in Vöslan, in the plains and on some hills lately, the vines were trained on wire frames after the French style, in order to be able to work the soil with the plow. The number of workings is the same as with hand work. The plows employed were mostly imported from France.

The full fruit-bearing period of a vineyard occurs at different periods, according to the situation, nature of the soil, etc. Most vines will fully produce the tifth year after the planting, but with some kinds, like Bnrgundy, this will happen the seventh or eighth year. The time daring which the capacity of producing will last depends upon the situation, nature of the soil, and especially upon a careful working.

Some well-cultivated vineyards will give a good return even after thirty years, whilst neglected ones will lose their fertility much sooner. Vineyards on the plains . which have often suffered from spring frosts also soon lose their fertility, whereas there are vinejards on the slopes which are more than fifty years old and still give a sufficient return.

Artificial irrigation is nowhere employed in Lower Austria in the oultivation of the vine.

The yield of one hectare, ${ }^{*}$ without regard to the various ages, varies according to the situation, the nature of the growth, and the kind of grape.

On an average a return of 40 hectoliters t per hectare may be obtained in Lower Austria.

The value of a hectare of vineyard property in Lower Austria depends upon the district, and there again npon its particular situation, and varies from 400 florins $\ddagger$ to 5,000 florins.

The working expenses naturally are nnequal in the various districts. In Vöslan the same amount to 550 florins to 600 florins per hectare per year, includiug fertilizers, whereas they are much less in most of the other districts.

The vineyards of Austria-Hungary, in 1881, covered 1,192,446 acres; of which 440,722 acres belonged to Austria and 742,724 acres to Hungary. The area cultivated varies very slightly from year to year.

The fruit gathered is almost entirely consumed for the manufacture of wine, as only 4,338 tons of grapes are reported as being sold for table consumption in Austria-Hangary in 1881.

Furthermore, the quality of grapes cultivated for wine are, as a rule, not saited for table use, being much less palatable than the well-known varieties in the United States, nor are they suitable for the raisin industry, as they possess neither size nor pulp sufficient for the drying pro. cess.

The average wine production of Austria.Hungary during the last five years, 1879-'83, amounted to $6,954,934$ hectoliters, of which $2,603,956$ hectoliters were produced in Austria and 4,350,978 hectoliters were produced in Hungary.

- 1 hectare $=2.471$ acres.

+1 heotoliter $=26.43$ wine gallons.

$\$ 1$ florin $=40.1$ cents ${ }^{\circ}$ United States curreucy. 
The average value was estimated by the departments of agriculture at Vienna and Budapesth at about 10 florins per hectoliter, being only 40 kreuzers, or 16 cents, per gallon, which is manifestly quite below the commercial value of even the most ordinary wines.

In Austria the chief producing districts are Dalmatia, Lower Austria, the Northern Tyrol, Styria, and Istria. The character of the Austrian red wines is lighter and cruder than those of France, while the white wines, in respect to quality, are inferior to those of the Rhine, but possess a larger quantity of alcohol than either those of the Rhine or the Moselle.

Among the finest and most celebrated Austrian wines stands the Vöslaner, while of the Hungarian the Tokay and Paluggay are the most noted.

The phylloxera appeared in Austria in 1872 in the gardens of Klosterneuberg, near Vienna, from some vines imported from Germany for experimentation. Chemicals were first employed; sulphuret of carbon placed about the roots of the infected vines, but without avail. Flooding was then tried with like results, and finally the total destruction of the vines growing in the infected district was enforced by law, but without satisfactory results, as the phylloxera was found several years after the destruction in a living condition upon the roots of the vines. So that the plague is extending from year to year, until in Austria in $\mathbf{1 8 8 3}$ there were 4,000 vineyards, aggregating 612 hectares, infected.

In Hungary during the past several years experiments have been made with imported American vines, with great success it is affirmed, but the Austrian Government until now has refused all applications for permission to import Americau vines, on the ground that insects equally dangerous to agricalture might be imported with them; consequently only the seeds of the proper varieties of grapes have as yet been imported and planted iu Austria proper, but the growth is so slow that the result can not yet be declared.

Uufortunately there seems to be a difference of opinion, and probably of interest, among the experts of this country in regard to the importa. tion of Americau vines, for while one party cry out loudly against the arbitrary action of the Governmeut in refusing the introduction of the American vines, which they claim to be the unly salvation for the decaying wine iudustry of this country, the other party as violently attack the projected move, and deny that success has attended the same either in Hungary or in France.

\section{COMMERCE OF WINE AND ARGOLS.}

The importation of wine into Austria-Hungary in 1883 was 4,167 tons, valued at $1,192,552$ tlorins, against an export of 40,818 tons, valued at $7,555,938$ florins.

The prices of the importis were taken at 26 tlorins per bectoliter in barrels, 50 tlorin per bectolitur in lontiles, and 100 florins per bectoliter 
for champagne, while the prices for the exports of these classes were, respectively, 18,50 , and 70 florins.

The imports and exports of wines during the last five yodrs, 1878-'82, were as follows :

\begin{tabular}{|c|c|c|c|c|}
\hline \multirow{2}{*}{ Years. } & \multicolumn{2}{|c|}{ Imports. } & \multicolumn{2}{|c|}{ Exports. } \\
\hline & $\begin{array}{l}\text { Quantities } \\
\text { in metrical } \\
\text { oentners.* }\end{array}$ & $\begin{array}{l}\text { Value in sil- } \\
\text { ver florins. }\end{array}$ & $\begin{array}{l}\text { Qnantities } \\
\text { in metrical } \\
\text { centners. }\end{array}$ & $\begin{array}{l}\text { Value in eil- } \\
\text { rer florins. }\end{array}$ \\
\hline 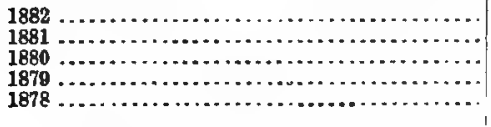 & $\begin{array}{r}39,409 \\
30,271 \\
33,912 \\
106,580 \\
91,268\end{array}$ & $\begin{array}{l}1,500,883 \\
1,311,270 \\
1,236,816 \\
1,888,980 \\
1,898,735\end{array}$ & $\begin{array}{l}410,427 \\
438,213 \\
905,841 \\
434,674 \\
222,140\end{array}$ & $\begin{array}{r}9,150,777 \\
8,852,684 \\
15,539,957 \\
7,105,1168 \\
5,125,267\end{array}$ \\
\hline
\end{tabular}

*One metrioal centner $=100$ kilograms $=220.46$ pounds a roirdupois.

The origin of the wines imported to this country can not be definitely given, except for the chanpagne which came from France, via Germany, to the amount of 5,346 hectoliters in 1882 and 4,284 in 1883 .

Of the total importations of wine in 1882, 21,388 metrical centners crossed the German frontier, 8,867 the Roumanian, 4,933 the Servian, 2,103 the Italian, 1,846 via Trieste, and 185 via Fiume and other ports.

Of the exports 182,477 metrical centners crossed the German frontier, 85,938 passed out by Fiume and other ports, 62,708 by Trieste, 37,625 passed over the Italian frontier, 13,690 the Swiss, 13,297 the Roumanian, 9,477 the Russian, and 4,994 the Servian.

Wines to the value of about $\$ 50,000$ are shipped annually from this country to the United States. It is affirmed also that large quantities of red wines are sent from Bungary to France to be manufactured into claret, etc., and the large quantities shipped from Fiume and Trieste would seem to give credit to the charge.

The quantity of raisins and dried currants imported into this empire is very considerable, amounting in 1882 to 6,991 tons, valued at $2,473,682$ florins, on which a duty of 711,744 florins gold was paid, being at the rate of almost 30 per cent. They entered almost entirely by the port of Trieste.

The duties on wines imported into Austria-Hungary at present, according to the general tariff law May 25, 1882, are as follows: In casks or bottles, 20 florins per 100 kilograms. Italy and Roumania, however, enjoy special privileges by virtue of conventional tariff's for the frontier traffic, by which they pay respectively 3.20 florins and 5.26 florins per 100 kilograms in place of the 20 florins of the general tariff.

Champagne pays by the general tariff 50 florins per 100 kilograms, but the recent commercial convention with France reduced the duty on French champagnes to 40 florius per 100 kilograms.

The total amount of duties collected on wines in Austria-Hungary 
during 1882 was 552,144 , against 362,316 florins in 1881, and 365,881 florins iu 1880.

The commerce in crude tartar or argols has become very important of late years; the exports amount annually to over $1,000,000$ florins. The following table gives the quantities and values of the imports and exports during the last five yeảrs, 1878-'82:

\begin{tabular}{|c|c|c|c|c|}
\hline \multirow{2}{*}{ Years. } & \multicolumn{2}{|c|}{ Imports. } & \multicolumn{2}{|c|}{ Exports. } \\
\hline & Quantity. & Value. & Quantity. & Value. \\
\hline $\begin{array}{l}1882 \ldots \ldots . \\
1881 \ldots \ldots . \\
1880 \ldots \ldots \\
1879 \ldots \ldots \\
1878 \ldots \ldots\end{array}$ & $\begin{array}{r}\text { Met. cent. } \\
3,651 \\
4,745 \\
4,352 \\
3,157 \\
4,069\end{array}$ & $\begin{array}{l}\text { Floring. } \\
310,335 \\
403,325 \\
348,160 \\
210,990 \\
264,485\end{array}$ & $\begin{array}{r}\text { Met. cent. } \\
11,505 \\
12,362 \\
15,572 \\
8,826 \\
4,849\end{array}$ & $\begin{array}{r}\text { Florins. } \\
1, \mathbf{0 3 5}, 450 \\
1, \mathbf{1 1 2 , 5 8 0} \\
\mathbf{1}, 32.1,620 \\
\mathbf{6 6 1}, 950 \\
\mathbf{3 3 9}, 430\end{array}$ \\
\hline
\end{tabular}

The shipments of argols were made almost entirely to or through Germany, amounting in 1882 to not less than 11,188 metrical centners. Considerable quantities of these, however, were in trunsit to the United States, as the value of the invoices of argols authenticated by the consular officers in Austria.Hungary during the last three years shows large increase, being as follows: In 1881, $\$ 174,537$; in $1882, \$ 254,041$; and in $1883, \$ 342,445$.

\section{PRIOES AND CONSUMPTION.}

The average import and export prices of wines, as estimated by the Central Commission, are respectively about 40 florins and 20 florins per hectoliter, being equal to $\$ 1.60$ and 80 cents per gallon.

The prices at the vineyard cellars generally run from 12 to 15 florins per hectoliter for the ordinary red and white wines, and from 25 to 40 florins for the finer qualities.

The prices at which the various wines are retailed for consumption are so varied as almost to defy any approximate average price; but it must range somewhere between 75 kreutzers and 1 florin per bottle, coutaining about four-fifths of a quart, to the end that the averdge price of a gallon of wiue in Austria-Hungary may be set down at \$1.50.

The average annual production of wiue during the last five years is given at $6,954,934$ hectoliters, the iwportation at 60,085 hectoliters, and the exportation at 482,259 hectoliters, leaving for consumption an annual average of $6,532,763$ hectoliters, equal to $172,59,5,598$ American wiue gallons.

If, therefore, the average price stated hove he not excessive, which can hardly be the case, the total anuual average value of the consump. tion of wine in Austid- - ungary amounts to $\$ 2599,000,000$, equivalent to a pro rata of $\$ 7$ per year lor each inbabitunt. If to this amount we

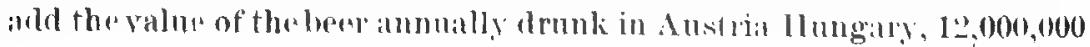


hectoliters, equal to $317,000,000$ wine gallons, valued at $\$ 79,000,000$, we have a grand total of $\$ 338,000,000$ as the value of the wine and beer annually consumed in the Austro-Hungarian Empire.

\section{JAMES RILEY WEAVER,}

Consul-General.

\section{United States Consulate.General,}

Vienna, April 8, 1884.

\section{FRANCE.}

\section{SOUTHERN FRANCE.}

\section{REPORT BY VIOE.CONSUL MARTIN, OF MARSEILLES.}

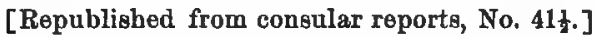

Climate, soil, etc.-The climate of that part of France which is washed by the Mediteraneau can be placed among the most pleasant in the world. Extreme heat and cold are alike unknown, and while under the influence of regular sea-breezes the thermometer rarely shows a temperature of more than $80^{\circ}$ or $86^{\circ}$ Fahrenheit in sumıner, the winters are remarkably mild, and snow and ice are in fact a rarity in the country. On the other hand, drought is exceptionally severe, and in the warm season months are sometimes passed without a drop of rain to moisten the parched ground. The water streams are mere torrents, which can not supply any water for irrigating purposes in the dry season, and, when swollen in the fall by frequent floods of rain, rush impetuously to the sea, carrying away large quantities of the light vegetable earth, in the place of which they leave rocks and pebbles brought dowu from the steep barren hills with which the country is covered.

The soil is generally light and stony, calcareous or argillaceous, some times granitic or schistic. Frequent and strong winds from the northwest sweep across the country, and, being cold and dry, are extremely injurious to agriculture.

For all these reasons the modes of cultivation and the produce of the soil are widely different from what they are in the other parts of France. 'The culture of graiu, so largely predominant elsewhere, is here confined to a few plains and valleys that are favored with means of natural or artificial irrigation, and is entirely inadequate to the demands of local consumption. Arbustive culture, on the other hand, is extensive, and furnishes the country with most of its revenue. The olive tree, which is not cultivated beyond a compartively short distance from the Mediterranean shores, and the vine, which is more extensively grown in these than in any other parts of France, stand foremost in that branch of agriculture.

Varietien.-In a general way, vines in this country can be planted in 
any sort of ground, without regard to altitude, declivity, or distance from the sea. Still it is a well-established fact that better results are obtained in valleys and plains as to quantity and on hill-sides as to quality. In other words, wine being the chief object of vine-culture in this country, the produce of hill-side vineyards will be less abundant, but obtains higher prices for its superior flavor, richness, and strength.

As for the nature of the soil, every different ground appears to be better adapted to the different varieties, numbering three hundred or more. A complete enumeration of these varieties wonld be tedious and of little interest, and I shall confine myself to a brief description of the varieties mostly to be found in southern France.

The "Mourvedre" or "Mourvedn" thrives best on calcareous soil, with a thin layer of vegetable earth and a substratum consisting of crackled rocks. Each plant can then give as much as five pints of a wine that is substantial, of a rich color, with a slight tannic flaror, containing about 11 per cent. of alcohol. The grapes are sweet, black blue, round, rather small, and more or less thick on the bunch. In this country they come to maturity in the first days of September, and do not rot as easily as other varieties. The "Mourvedre" bears fruit on its third year, comes into full bearing on the sixth, and is fruitful after that as long as it lives, viz, from forty to one hundred years.

The "Grenache" has a preference for hillsicles aud dry and gravelly soil; it thrives on all kinds of ground, provided they be free from dampness; it is more sensitive to cold than the Mourvedre, and can be killed by a temperature of $17^{\circ}$ Fahr. There are two varieties of Grenacbe, the black and the white. The white produces good fruit for the table, and a kind of white wine that is much esteemed.

The "Peconi tonar" is remarkable for its durability and abundance of produce. It gives the best returns on rocky hillsides and meager soil, but does not bear fruit until the fifth or sixth year. As the wine produced is light in strength and color, the grape, of a black purple hue, is generally mixed with the fruit of other varieties in the preparation of wine.

The "Aramon" or "Ugui noir" only thrives in loamy soil, and must be extensively cultivated. It produces large quantities of a wine that is light, poor in alcohol, does not keep long, and suffers much from traus. portation:

The "Brun fourca" is mostls cultivated on hill-sides or in dry, graw. elly, or stony land. The grape, which is large, elongated, of a bluishblack color, is not fit for the table, and must be mixed, for the making of wine, with other grapes richer in sugar and tanuin. The production, which begins in the third year, increases as the plant advances iu age. On favorable soil it. reaches the quantity of three quarts of wine for each plant.

The "Carlgraat" or "Monistol" must be planted on high, substantial gromel, fres firom dampmess. It begius to bear froit on the second yeate, 
and produces a spirituous wine that keeps well; improves with time, and stands transportation remarkably well, but is somewhat rongh to the taste. The vine is apt to suffer from oidium.

The "Picardan" is one of the most productive varieties cultivated in this country. The best results are obtained in rich, pebbly, consistent, high land. Dampness is rather beneficial to the plant. The grapes are lare, elongated, fleshy, sweet, and very palatable. The wine produced is of a fine rel color, mellow. It possesses a pleasant flavor, with a smack of the fruit, and keeps well.

Owing to the general preference given by the consumer of this conntry to red wine, the white varieties are but little cultivated, and the grapes are generally consumed fresh. Still the number of these varieties is large, and I shall only mention those that are most common in the country. The "Ugni blane" is one of the few white varieties that are grown in riew of wine-making, owing to the small size of the grapes. In low and rich land the quantity produced is larger and amounts to an average of two quarts for every vine. On high, stony, or gravelly grouml, on hill sides, the quality is much superior, and the wine pro. duced commands much higher prices than that of the plains. The plant thrives better near the sea-coast, where it is less affected by cold. The other varieties, "Clairette," "Colomband," "Mavorguin" or "Marseilles plant," and "Muscat," are generally cultivated on bill-sides, and their produce is sent to the market for table nse. The Muscat grape is onls turved into wine in one district of the department of Herault, that of Lunel and Frontignan.

Pla fation and cultu e.--In this warm and dry climate it is necessary to break np the earth to the depth of 2 or 3 feet; the time when this preparatory work is performed varies according to the nature of the soil. It can be clone on high and dry gronnd before the rainy season sets in, and even in summer; for low and damp soil it is preferable to wait until the heavy fall raius are over and delay the operation until March or April.

When the ground has been previously planted with vines, it is a gen. eral custom to allow it to rest for a number of years, varying from one to two for strong, consistent, fertile, or clayey soil, and for a longer time in sandy, ligbt, permeable land. Lucern or other leguminous plants are raised in the interval, but the culture of wheat sbould be aroided, as it deprives the earth of much of the gluten which is necessary to the grape from which wine is to be made. When the ground has been properly prepared the vines are planted in the form of cuttings or young plants raised in nurseries. The latter grow faster, but vines that have grown from cnttings appear to do better in the long run, especially when they hare been taken from vines twenty or twenty-five years old. Slips can be kept for some time before being planted, but must then be allowed to soak in water for some days.

The time and depth at which to make the plantations are also regi- 
lated by the nature of the ground. In dry and high land winter is the most favorable season; in low and moist ground the middle of spring is preferable. The depth generally adapted is that of $2 \frac{1}{2}$ feet in dry and light soil, 20 inches in medium land, and 13 inches in rich, damp earth. In this conntrs, where vines are grown in bushes and without the support of poles, no other care is taken of the vineyard for the first year beyond that of keeping it clear of weeds by tilling and hoeing. After the first year the first pruning takes place. Only one branch is left on the stem, generally that which is nearer to the gronnd. It is well established that a short stem helps maturity to a great extent, but as on the other hand the plant is made by it more liable to rot and frost, the above rule is only followed on hillsides or dry land; in valleys and low, damp land the branch which is left on the plant is selected at a distance of 12 to 14 inches from the ground. In all cases that branch is itself pruned short and left with two or three eyes only. Every year after the first a new branch is left on the stem, but the total number is rarely over four or five. The guiding rule for pruning is that branches shooting from the stem are unprodnctive and should be cut close to the stem. The fruitful sprigs issue from one-year-old branches. Each eye of these sprigs generally produces two bunches of grape and one shoot. The quantity of eyes that should be allowed to remain on the vine depends largely upon the nature of the soil and the strength of the plant; the number on a fullgrown vine varies from 12 to 24 . There is no generally adopted time for pruning, every vine-grower using in this respect his own judgment. It ordinarily takes place between the months of Jannary and March, and is followed immediàtely afterwards by a first plowing, which after a few days is completed by a second hoeing; the same operation is repeated in April and May; and, in the best-conducted vineyards, a third time in June. The culture should alwass be applied with great care, and never exceed the depth of from 10 to 12 inches, for fear of hurting the roots.

There are but very fow districis in this region where an abundant supply of water can be obtained, and the vineyards are in consequence rarely irrigated. When practicable, water is brought into trenches that run along the rows of vines, but nerer in excess, as it is well ascertained that moisture, while improviug the yield as to quantits, is detrimental in a large measure to quality, and makes the vine much more sensitive to frosts and cold weather.

Fertilizers. - In new soils the vine can easily dispense with fertilizers of any kind for thirty years or more; it is eren claimed by some good cultivators that an addition of virgin earth or calcareous marl prove to be the best fertilizers. Still the custom is prevalent to use stable dung at the rate of 12 tons per acre, applied once in from four to six years. A ton per acre of horns, woolen rags, or oil-cakes, which are abundantly imported or produced at Marseilles, is frequently nsed as a substitute. 
Horns and rags remain effective for five years, oil cake for two only. Whatever may be the manure employed, it is customarily buried in furrows cut between the rows of rines. These rows are generally from $3 \frac{1}{2}$ to 5 feet apart, and the same distance is kept between each plant in the row, but in some parts of the country a larger space frequently exists between the rows. The intervals thus intervening are then devoted to some other culture, wheat in most cases. But it has been found ont that the system prores injurious to both cultures, and it has been aban. doned to a a great extent.

Field.-Grapes are never dried in this country, except by such farmers as do not have a suffiriont number of vinos to enable them to undertake the making of wine, or are too far away from a consuming center where they could send to the market the small quantity of fresh grapes produced on their farm. The method followed by such farmers is very simple: The grapes are dipped in boiling water and exposed to the rass of the sun for eight or ten days. The raisin thus prepared can not compete with that imported here in large quantities from Spain, and the amount produced is consequently insignificant.

Railroad facilities have made it possible to dispose of a certain quantity of fresh grapes at paying prices, but still the great object is the production of wine. In consequence, all the calculations made regarding the yield, value, and cost of crop depend upon this production, which is regulated by so many circumstances that it can not easily be established on a fixed basis.

While the cost is submitted to little rariation, between the sums of 300 and 400 franes per hectare (\$2 to $\$ 40$ per acre), including the purchase of manure, sulplutur (as a preventive against oidium), and the making of wine, the rield is entirely subject to the weather throughout the year, as is the ralue to the quotations of the wine market. It is generally conceded that one acre of vines can produce from 200 to 400 gallons of wine, and that the cost of cultivation takes up one-third of the proceeds.

Diseases.-Many causes can affect the yield and value of the crop. Amongst those of frequent occurreuce are atmospheric influences, early spring frosts, that blight the plant and leave no other remedy than the cutting of the stem on a level with the ground to let the new sprouts grow from the roots, or the uprooting of the whole plant, which is either replaced by a new one or, more rarely, by means of "provining;" that is, forcing in to the ground one of the long branches of the next vine.

Extreme drought prevents the growth of the grapes in size and quantity, but improves the quality of the wine wonderfully, according to the common saying, "A year of drought is a year of good wine." A wet season, on the contrary, brings abundance of wine, but impairs the quality, so that in many instances the wine is unsalable and must be turned into alcohol.

The vine also suffers from ming parasitic insects or diseases. Fow 
of these ever produce disastrous effects except oidium, phylloxera, and, more lately, mildew.

Oidium, which at a time endangered the future of the French vineyards, has been and is still successfully counteracted by the use of flowers of sulphur. They are mixed with an equal quantity of plaster, or a smaller proportion of lime, and carefully sprinkled on the young leaves once or twice before the ripening of the grapes. The wine-growers of this country, who could procure flowers of sulphur at low rates from the important refineries of Marseilles, were in the end benefited by the appearance of the disease, as it opened for the abundant but inferior wines produced in this region a more extensive market, and brought about a decided advance in the prices, which had been as low as 6 francs per hectoliter ( 8 cents per gallon). When the rates of 20 and 30 francs per hectoliter could be obtained the production of wine increased in a remarkable measure. In 1874 the seven departments of Bouchesdu-Rhône, Gard, Aude, Hérault (the production of which alone amounted to $13,000,000$ hectoliters), Pyrénées-Orientales, Var, and Vaucluse, forming this consular district, contributed more than twothirds of the total production in France.

It was just then that phylloxera made its appearance and raged in this district, where it worked its more pernicious effects. Many vineyards were entirely destroyed, all were attacked, and an idea of the extent of the damage can be formed from the following table, giving the area planted in vines in thousands of acres and the production of wine in thousands of gallons, in each of the seven departments, for the three periods 1856 -'60, 1866-'70, 1876-'80:

\begin{tabular}{|c|c|c|c|c|c|c|}
\hline \multirow[b]{2}{*}{ Department. } & \multicolumn{2}{|c|}{$1850-60}$. & \multicolumn{2}{|c|}{$1866-' 70}$. & \multicolumn{2}{|c|}{$1876-' 80}$. \\
\hline & $\begin{array}{c}\text { Surface } \\
\text { cultivated, } \\
\text { 1,000 acres. }\end{array}$ & $\begin{array}{l}\text { Production, } \\
1,000 \text { gal- } \\
\text { lons. }\end{array}$ & $\begin{array}{c}\text { Surface } \\
\text { cultivated, } \\
1,000 \text { acres, }\end{array}$ & $\begin{array}{l}\text { Produotion, } \\
1,000 \text { gal- } \\
\text { lons. }\end{array}$ & $\begin{array}{c}\text { Surface } \\
\text { cultirated, } \\
1,000 \text { acres. }\end{array}$ & $\begin{array}{l}\text { Produetion, } \\
1,000 \text { gal: } \\
\text { lons }\end{array}$ \\
\hline 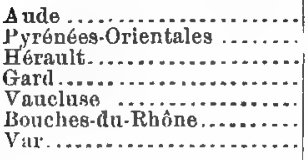 & $\begin{array}{r}175 \\
111 \\
390 \\
198 \\
71 \\
108 \\
200\end{array}$ & $\begin{array}{r}17,013 \\
7,555 \\
108,228 \\
30,379 \\
6,393 \\
11,040 \\
20,341\end{array}$ & $\begin{array}{r}200 \\
131 \\
524 \\
2222 \\
74 \\
114 \\
185\end{array}$ & $\begin{array}{r}44,480 \\
16,062 \\
362,636 \\
50,192 \\
10,435 \\
10,540 \\
23,564\end{array}$ & $\begin{array}{r}279 \\
161 \\
303 \\
54 \\
30 \\
67 \\
161\end{array}$ & $\begin{array}{r}85,565 \\
34,844 \\
143,576 \\
5,468 \\
1,479 \\
2,747 \\
12,733\end{array}$ \\
\hline
\end{tabular}

In this connection the following table of importation and exportatiou at the port of Marseilles may be a more striking evidence of the ricissitudes undergone by the production of ordinany wine in southern France:

\begin{tabular}{|c|c|c|c|c|c|}
\hline & 1862. & 1867. & 1872. & 1877. & 1882. \\
\hline 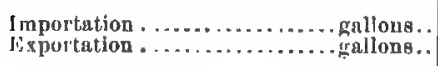 & $\begin{array}{l}185,206 \\
207,544\end{array}$ & $\begin{array}{r}263,563 \\
0,045,848\end{array}$ & $\begin{array}{l}1,605,202 \\
7,806,198\end{array}$ & $\begin{array}{l}1,308,355 \\
5,719,651\end{array}$ & $\begin{array}{r}13,175,188 \\
4,602,899\end{array}$ \\
\hline
\end{tabular}


The emotion created by the ravages of pluylloxera was iminense, and the French Government instituted a prize of 300,000 francs to be awarded by a special committee sitting at Paris every year to examine into the progress of the disease and that made in counteracting its effect. In its last sitting, which took place this year, the committee decided that submersion, sulphide of carbon, and sulpho carbonate of potas. sium should again be recommended for the year 1884, and admitted that it wonld be well to use American vines as "graft bearers," particularly the Riparia, Solon, York, Madeira, and Jacquez. It finally de. cided that the prize of 300,000 francs should once more be reserved, as none of the remedies so far invented were of a sufficiently effective character to justify its being granted.

As I have already remarked, there are but very few places in this region which can dispose of a sufficient supply of water to make the submersion system available.

The appliance of sulphide of carbon is costly, and although it has proved an efficient preventive, it does not appear to possess marked curative efficiency. In consequence, the planting. of American vines has met in this part of the country with general favor, and it is ex. pected that in a few years hence all the vineyards that have been lestroyed will be renovated by means of American plants.

Most satisfactory results have been obtained wherever the experiment was made. M. Rejnaud, our consular agent at Toulon, informs me that he planted several acres of his property with Riparia and Jacquez vines on which he grafted the French varieties previously grown on the same soil. After three years, he reaped 3,360 liters per hectare (a result somewhat superior to the average) of a wine that was in all respects the same as was formerly produced by the original French plants. His plantation does not suffer in the least from phylloxera, but requires more cultirating and fertilizing than the French vines.

Mildew.-It was not until last year that mildew caused noticeable damage in the vineyards of France. No means have yet been found out to counteract the disease. In fact very little is known so far about it and the conditions under which it propagates. It has been noticed that vines planted near the sea-shore were more liable to it, and the prevalent opinion is that mildew is cansed by a persistence of moderate moisture in the atmosphere, which is of very rare occurrence in this climate, except in the month of September. As the crops have already come to maturity by that time, and the disease seems to attack the leaves only, no great anxiety is felt here concerning it.

Wine-making.-The making of wine is, in the southern region of France, carried on in the most simple method. A dry, sunny day is selected, when practicable, for the picking of the grapes, which must be ended before sunset. All the grapes are placed, just as picked from the vine, in immense wooden or masonry vats of from four to six thou. sand liters' capacity, and trampled under the feet of a number of men 
sufficient to permit of the operation buing completed in one day. The " must" is left to ferment in the rats some eight days, and then decanted into barrels, which are not bunged until fermentation has stopped, that is, forty or fifty days.

As the producer generally sells his wine at once to the merchant, he does not submit it to any of the many manipulations that take place in the traders' cellars.

The only practice in force is to sprinkle the top layer of the grapes in the vats with a small quantity of plaster, which, it is claimed, gires to the wine a better color and a slight degree of astringency necessary to its preservation.

J. S. MaRtin,
Vice-consul.

United States Consulate,

Marseilles, March 1, 1884.

- CHAMPAGNE.

REPORT BT OONSUL FRISBIE, OF'RAEIMT.

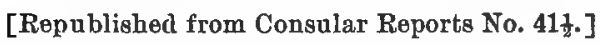

I have the honor to acknowledge the receipt of Department's circular dated December 4, 1883, with interrogatories regarding grape culture, methods of cultivation, etc., in the best condncted vineyards, and the method in practice for raisin culture; which interrogatories have been prepared and submitted at the request of some of the leading fruitgrowers of California. I realize that the subject is one of considerable importance, and shall be glad if I can furnish anything of interest and profit to the great industry centered in the cultivation of the vine in the United States. In the first place, however, I am estopped from giving any information regarding raisin culture from the fact that no grapes are grown in this consular district for that purpose, the climate and soil not being suitable.

The vineyards here are cultivated and the grapes grown for the ex. clusive purpose of manufacturing champagne sparkling wine, the best growths always being used for that purpose, the manufacture of table and dessert wines for commercial purposes havingentirely ceased in the champague district.

Recognizing the importance of the cultivation of the vine and the manufacture of its product to a large class of cultivators in the United States, soon after my arrival at this consulate I began an earnest study of the subject, and in the spring of 1882 I communicated to the Department, in three separate reports, the results of my investigutions, which were soon after published in the monthly consular reports. In those reports I wrote all there was to be written on the subject, in so far as I 
could inform myself at the time, and I have really learned but little new or interesting touching the matter since. However, as a greatly increased interest seems to have sprung up among all classes of our people within a short time past in regard to the importance and value of consular reports, and as very many are now interested readers who never read them before, and as the reports now callerl for are for the special benefit of a class of interested cultivators, I have thought it well for me to go back to the minutes of my study of the subject two sears ago and give our California friends and other rine-growers a recast of what I then learned about the cultiration of the vine in the champagne district and the manufacture of its product, together with such new facts as I shall be able to give, believing that it will now come under the notice of mans new and appreciative reallers.

As far as the champagne country is concernel there can be no doubt that the vine has been cultivated since the most remote times, the dry and chalky soil of the surrounding hills and valleys being specially adapted to the cultivation of the vine. The cultivation of the vine in the province of Champagne, in the department of the Marne, and particularly in the districts of Rheims and Epernay, is, according to the most reliable authorities, of very ancient date. One writer says: "Strong men, we know, lived before Agamemnon, and strong wine was made in the fair province of Champagne long before the days of the sagacious old monk, Don Perignon, to whom the world is iudelited for the sparkling vintage known under the now familiar name of champagne." Cato the elder informs us that in his day vine plants were brought into Italy from Gaul; and Cicero, in his speech on behalf of Fonteius, refers to the great trade in wine carried on by the Gauls, of which at that time Rheims was the capital.

Domitian ordered all the rines in Champagne to be uprooted and destroyed. He had an idea that the culture of the vine cansed people to neglect that of cereals and general agriculture, and he also feared that the desire of drinking wine would attract the barbarians to the country. It was not until about two centuries later $(280 \mathrm{~A}$. D.) that they were replaced by the Emperor Probus.

There are several groups of low hills situated on the banks of the Marne and the Vesle, possessing a light, shallow soil, and with a pervious understratum principall 5 composed of Tertiary layers and of chalk, with a mixture of silica and light clay, combined with a varying proportion of oxide of iron. These groups of hills are inely situated for sunshine, and of very little good for the cultiration of other vegetable produce. Such advantages as these seem to point to a special provision of nature for the cultivation of the vine. Poor, sometimes eren barren soils, so long as they are easily accessible to air and water, are, as erery one here will tell you, quite sufficient for its grow th.

If the first attempts at cultivation were crowned with success, still it was not till a comparatively recent date, which we may fix at the last 
quarter of the preceding centurv, that this industry sprang iuto in. portance. It was, indeed, from this time, that champagne wines, already renowned for their fineness and lightness, legan to be the object of new experiments. These resulted in a gradual increase and improvement in vine-growing and to the perfecting of the produce.

Sixteen thousand five hundred hectares (about 40,700 acres) are at the present time devoted, in the department of the Marne, to the cultivation of the vine. In each district the nature and situation of the soil, and more especially the experience of vine-growers, partly founded on tradition, have led to the adoption of different kinds of vines and various modes of culture.

Unquestionably the finest grapes are produced in the hilly regions in the neighborhood of 0 Rheims and Vertus. The wines coming from the slopes of these hills have long been celebrated; the first under the name of river wines, and the second under the name of hill wines; but this distinction has nearly ceased since the appropriation of wines of a certain quality for the manufacture of sparkling champagne.

The most renowned vineyards extend-

1. Along the right bank of the Marne from Mareuil to Damery. Along the line of railway from Paris to Rheims, the traveler sees on his left in succession the fertile hills of Damery, Cumières, Hautvillers, Dizy-la-Rivière, and Ay. Further on, as the line curves, those of Mareul, Bouzy, Ambonnay, and Trépail come into view.

2. On the slope which faces the Vesle and the city of Rheims are the not less prosperous ones of Villy, Mailly, Tillerv, Verzenay, and Verzy.

3. On the left bank of the Marne, 4 or 5 miles from the railroad aud the river, lie the celebrated vineyards of Epernay, Pierry, Cuis, Oranant, Le Mesnil, and Avize.

Not far from these vineyards, from which are made the celebrated champagne sparkling wines, are others of less pretensions, which produce red table wines of some value. In the districts of Châlons, Vitry, and Ste.-Menehould, only wines of less value are produced, which are seldom used in the manufacture of champagne.

In these different localities the principal kinds of wines grown are: White grapes, épinette, or the white morillon, and the large vert-dore of Ay; red grapes, the pineaux, and among them the small vert-doré, distinguished by its compressed, irregular bunches of middling.sized grapes, by its large leaves, somewhat rough on the npper and smooth on the under side, lobed, and but little indented. The épinette is a prolific bearer, and its round, transparent berries, which hang in no very compact clusters, are both juicy and sweet. It ripens much earlier than either the other varieties. The vert-doré is robust and productive, but yielaing a less generous wine than the pineau, the plant doré of $\mathbf{A y}$, and the berries of which are dark and oval, and very thin-skinned, and re. markably sweet and juicy.

One variety is the plant gris, or burot, a somewhat delicate vine, whose fruit has a brownish tinge, and yielsts a light and perfumed wine. 
There are several other species of viue of second rank, cultivated in the champagne vineyards, notably the common meunier, or miller, bearing black grapes, and which derives its name from the circumstance of the joung leaves appearing to have been sprinkled with flour. There are also the black and white gonais, the meslier, a prolific white variety, yielding a wine of fair quality; the black and white gamais; the tour. lon; the marmot, aud several others.

These second-rate vines produce in abundance the wines which were formerly reserved by the vine-growers for their own consumption, but which are now used by not over-nice speculators to mix with their superior wines. It is but fair to say, however, that these second-rate vines are rapidly disappearing, and vines of the first class taking their place.

On the hills around Rheims and Vertus the method of low cultivation prevails, whilst tall vines are almost exclusively grown on the hills of Chateau Thierry. These widely different methods are said to be required by reason of the different nature of the soils. Along the course of the Marne the vine grows on a shallow, dry soil, receiving and reflecting nearly the whole of the suu's rays. The mode of culture employed allows of the assimilation of the vines to a sort of trellis-work, the trunks of which are in the ground, while the bearing branches grow. ing up from them extend along the face of the soil just the same as if they were trained on a wall, only in this case the face of the soil representing the wall. On the hills of St. Thierry, on the contrary, the situation is less favorable, the soil being richer, deeper, and more humid; hence the need of a higher growth and a special mode of cultivation. The vines are almost invariably planted on rising ground, the lower slopes, which usually escape the spring frosts, producing the best wines.

In the champagne country the vine, whether cultivated on the high or low method, becomes productive as the result of the most minute, incessant care and attention. In the localities where it is almost the only industry, it involves during the whole year a series of operations which employ the greater part of the population. According to the statistics the hands employed are about equal in number to the hectares of land in cultivation, and an average of one vine-dresser for every $2 \frac{3}{4}$ acres of cultivated land.

The various operations required in cultivating the vine are performed by the owners or vine-growers, properly so-called, or by laborers em. ployed by them, who are to be hired at wages which vary according to the urgency of the work.

The heads of the great champagne houses are as a rule proprietors, in one or more localities, of extensire vineyards. They possess also a large wine-making establishment, and retain a regular troop of vine. dressers, whom they lodge and employ by the year.

Pruning, tilling, propagating by layers; bedding, hoeing, propping, prunisg and nipping the buds, and making storehouses are the principal 
operations of these workmen from January to September, when the harvest is made. At this season they conduct the vintage; then, when the wive is made, and the vine props pulled up, they profit by the fine weather at the end of autumn, and in the winter, by manuring, digging ditches, charring or sulphating the poles, etc.

For the champagne vine-dresser the year begins directly after St. Vincent's day; that is, at the end of January or the first half of February. At this date, if the weather be fine, operations are begun by pruning. At Ay and Dizy all the large vines are pruned on two stems; but mid. dle-sized and small ones on a single stem, preserving one " eye" more. At Avize, Cramant, and Verzenay they are trained on a single stem, but a much longer one. It is also towards the end of February that the twigs that have been cut off are gathered into bundles, either to be burnt or to be sorted out and kept for slips. In March the first work is done on the vine, when the first digging is done. If it were done earlier, there would be the inconvenience of the soil being too hard; and if later, the danger of losing the young shoots, so tender and so slenderly attached, ly want of attention mainly on the part of hired work people. In this month, too, the vine is usually rebedded, which is done by surrounding the plant with earth as high as the new shoots of the year; but in some places this is done by leaving a cutting of the year before out of the ground. This work is done with a hoe, the workman digging a small hole under the stem, which be then lowers by pressing on it with his foot, and then fills up again with fresh soil.

In April these operations are continued. It is also in this month, if the weather be favorable, that the making of layers is begun. In order to do this a ditch is dug, or perhaps was dug the season before, 20 centimeters (about 10 inches) dueper than the roots of the parent stem, aud a layer of well mellowed earth taken from the surface soil is placerl there; then a horizontal layer of cuttings, prepared for the purpose, is inserted on the parent stem and is covered with tresh soil taken from the bottom of the trench. This method of propagating the vine (the bedded plant being destined to separation from the parent stem) Las the advantage of rapidly producing new sources of production, and is in general use in the champagne district. It is also during April that the prolping of the vines is commenced, the rines being supported by stakes, usually of oak, and as a close system of plantation is followed, no less than 24,000 stakes are required on every acre of land. These stakes are set up by men and women, and au expert laborer, it is said, will set as many as 5,000 of them in the course of a dar.

In May, if the season is early, it is convenieut to give the first nip. ping to those branches which grow too rapidly. About the 25th, when there is no longer any fear of frost, the ground is plowed (or delved) again. This light work, which is needed to get rid of pernicious weeds and vegetation, is performed with a hoe or weeding-hook. This is bestdone in dry weather, and shonld not be done alter lain or heary morning dew. 
Toward the end of May, and especially about the beginning of June, commences the training of the vines. All the branches of the same - stock are tied by the same band to the supports (stakes). It is the custom to cut off the shoots which do not reach the ligature at a leaf above the last grape, and to cut off short those which do not show any sign of fruit. After the vines have been sceured to the stakes and bave been carefully hoed around their roots the tops are broken off at a sboot to prevent them from growing above the regulation height, which is usually from 30 to 33 inches.

The cultivators regard the numerous stakes which support the vines as affording some protection against the dreaded white frosts of spring, but I think there can be placed but little, if any, reliance in such a source of protection. These frosts invariably occur between early dawn and sunrise, and, to guard against them, some cultivators place heaps of hay, refuse, dead leaves and branches, etc., about 6 or 7 rods apart, taking care to keep them moderately damp to prevent too rapid combustion. When a frost is feared the heaps on the side of the vineyard from whence the wind blows are set on fire, and the dense smoke spreads over the vines, aud is said to produce the same results as an actual cloud, warming the atmosphere aud converting the frost into dew. In case there is no wiud blowing, all the surrounding heaps are set on fire and the desired effects obtained. There are other methods of protection against frosts employed, such as roofing the vines over with a straw matting about $1 \frac{1}{2}$ feet in width and in rolls of considerable length, etc., but the system of creating a dense, warm smoke, as stated, appears to be most in favor.

Besides the plowing, which a good cultivator is never afraid of repeating too often at this season, it is useful toward the end of June to give the ground a second delving. This second digging over (it is generally finished by the first week of July), it is well to prune the lower "eyes" which have sprouted since the first operation of the kind, it always being considered desirable and important to prevent, so far as possible, the growth of superfluous woody matter, which tends to draw nourishment from the growing fruit and injure its development. This is a matter which I believe should more earnestly engage the attention of vine-growers in the United States with profit to themselves and satisfaction of their customers, iu being able to procure well-developed and consequently luscious fruit.

From the 20th of July to the 15th of August the heat is too great to permit of work in the vines, which in fact are now in no need of particular attention, except it be a little digging if the weather be rainy. The vine-grower makes use of this time to make use of his magazines; this is the name given in the champagne country to the heaps of fertilizing matters which be collects at the side turnings from the roads or other places as near as possible to the vines, and which fertilizing matters are composed chiefly of at kind of compost formed of the loose 
friable soil dug out from the sides of the high hills, and of supposed volcanic origin, mixed with animal and vegetable refuse. This is also the time to look after the young plants of the year.

Toward the end of August it is the rule to submit the vines to a severe pruning, so as better to expose the grape to the air and the light, always taking care not to bruise it.

At the vintage season, which is generally the middle of September, hundreds of families of the surrounding districts and departments, the Aisue, Ardennes, and Somme, throng into the vineyards, and receive as compensation for their labor from 40 to 60 cents a day.

The harvest is made with the utmost precantion. The grape-gatherers are advised to support the fruit with the left hand, so as to prevent the riper grapes from falling; not to bruise it by throwing it into the basket. These small baskets are afterwards emptied into larger ones, or hampers, in which the fruit is taken to the owners of the vineyard, where their contents are minutely examined by men and women, who pluck of all the bruised, rotten, and unripe berries and throw them into a separate basket, as such fruit is a decided if not fatal injury to a first-class wine. If the grapes are very ripe, wisps of straw are placed in the bottoms of the hampers to prevent joltiug and bruising.

The picking ordinarily commences with daylight, and the viutagers assert that the grapes gathered at sunrise always produce the lightest and most limpid wine, and that by plucking the grapes when the early morning sun is upon them they are believed to yield much more juice. Later on in the day, too, spite of all precantion, it is impossible to prevent some of the detached grapes from partially fermenting, which frequently suffices to give a slight excess of color to the must, a thing to be especially avoided, no matter how rich and ripe the fruit may be, in a high-class sparkling wine. I desire, in passing, to call the special attention of those attempting to make sparkling wines in the United States to the important fact that the nse of unsound or unripe fruit, even in a small quantity, is fatal to success.

When the harvest is over, usually about the end of October, the stakes are taken up and arranged in vertical piles or horizontal heaps. Then, until the bad weather, the roads or paths of the vineyard are repaired; old vines are pulled up; the earth is leveled, the materials from the magazines (manure, etc.) are turned out; the trenches for propagating the vines are constructed; and when on approach of the frost the vines can not be approached, the time is spent in making stakes (props), the earth ends of which are first charred and then soaked in a solution of sulphate of copper.

Such are the principal operations which custom and experience hare sanctioned in the true champagne rineyards; that is, in the hilly regions of Rheims and Vertus.

In the vines callod St. Thierty, or high vines, the suceessiou of operatims is much the same, and the work differs but little from that al. 
ready described. This method of cultivation, however, necessitates three or four plowings; further, at the early spring pruning all the fruit-bearing branches of the preceding year are lopped off'; then suppose one had to choose between four branches left by the preceding time of growth, it would in general be best to cut off' two and preserre those which were nearest tho parent stem, one being pruned with two "eyes" and provides the woody matter, and as for the other, destined to become the fruit-bearing branch, it should be of medium thickness, with well projectiug knots, aud with a tendency to grow horizontally. At a later season the first is fixed vertically to tall stocks 6 feet high, and the second is bent round, fixed, and becomes the bend.

Both low and high vines undergo at proper times, differing according to locality, manuring, and improving operations of various kinds. Whether the vine sbould be manured, and if so under what conditions and at what times, is a disputed question amongst the greater number of writers. 'Thus, Dr. Guyot recommends manuring every three years, and enongh manure to be put in each time to last those three years, viz, 3 pounds per vine in the best soils, 6 pounds per vine in medium soils, and 12 pounds per vine in poor soils. On the other hand, M. Violart, of Ay, another emiuent authority, recommends the moderate use of manure for oldish vines, and protests against the mischievous use of manures for young vines.

The fruit which is grown from it is only nourished by the manure that has been put into the soil; it hardly takes any of the nature of the soil. An abnormal vigor is given to the vine, and it is in a way plethorized for several yeare, and when the juices of the manure are exhansted it begins to grow weak; it is ill, as the vine-dressers say. It is therefore necessary to manure young viues with much moderation, but the older ones will bear more.

One of the most important questions, important both by reason of its presence and its dangerous character, is without doubt that of the diseases of the rine.

Although the phylloxera has not yet made its appearance in the champague country, still there is no lack of other scourges to the cultivation of the vine. Every year has its records of substantial disasters, more or less local in character. Here, as everywhere else, despite the attention and shrewdness of vine-growers, and notwithstanding the invention of many meaus of protection, there are some vines, generally those with the lowest situation, which pay a heavy duty to the frosts and mists of spring. Often, also, some districts are robbed of their produce by hail.

Apart from these cosmic disturbances, in some districts where the earth, more likely rich than poor, rests on an impervious understratum, generally of a strong character, there appears, after a luxurious vegetation of several years, the disease which the vine-dressers call chabotthe withering and death of the plant;, which is due simply to the rotting of their roots, caused by an excess of humidity collected in an retentive substratum.

$156 \Delta-27$ 
But it is especially vegetable and animal parasites that have for a longer or shorter time back threatened the harvests. Of late years an infinitesimal mushroom, the Oidium tuckeri (vine mildew), has appeared very frequently, not only on trellised vines, but even in the vineyards. Flowers of sulphur is an undoubted antidote; but notwithstanding its efficacy it has not yet been generally adopted by vinegrowers. Frequently, too, the leaves of the vine suffer from the incursion of another fungous or asexual plant, Erineum necator, but the damage done by it is of small importance.

Animal destroyers belong chiefly to the insect order. Every year the different districts suffer from the devastations of several kinds of Coleoptera. In the early spring the shoots suffer from the incisions of the Culs-crottés or Coupe-bourgeons (Oliorhynchus ligustici, O. raucus). Later on the Gribouri (a vine-grub) or Eurivain, scribe (Bromiris vitis), comes out and bites the leaves and buds, and lays its eggs on the stem of the vine. Lastly, in June and July, appears the Bêche, grafter, and Lisette, vine-fretter (Rhynchites betuleti), which rob the plants of their leaves.

Among the Lepidoptera there are two which are especially obnoxious: The vintage-worm (Cochylis omphaciella) breeds twice a year, and destroys the fruit both in spring and in autumn. The summer worm (Olnophthira pilleriana) bas taken up its abode (as is testified by many old records) for a long time past in two localities especially. It commits its depredations at various intervals of time, but always for several years at a time. Its scene of operations is the locality of the best vines half-way up the hill between Ay and Dizy. Its second rendezvous is at Verzenay, in the best vineyards, also situated about half-way up the slope.

Every year the champagne vines, more or less the victims of these accidents, yield, as a rule, a rather poor crop; in fact, in spite of the careful attention and care of the vine-grower, an acre rarely yields more than 3 or 4 measures ( 6 or 8 hogsheads), of 2 hectoliters, $i . e_{\text {. }}$, about 6 or 8 measures to the hectare of prepared wine. To this calculation of yield we must add abont two-thirds as much again for secondars wines, known under the names of first "taille" (pruning), second "taille," and "rebêche" (second tilling). With the exception of the first " taille," which is sometimes used in the preparation of sparkling wines, these wines are consumed by the proprietor and his vine-dressers.

At Ap, which may properly be chosen as the center and type of the true production of champagne, unbottled wine is worth in an arerage year from 600 to 800 francs a measure of 2 hectoliters, and the price is about the same for the not less famous rintages of Crumant and Verzenay. Une jear with another, then, the vine-growers receive a sum of about 1,800 francs $(\$ 360)$ per acre, that is, by reckoning the minimum price of 600 francs and the production at three "pieces" per acre; but they have veen abliged to spend from 1,000 to 1, (1)! francs during the 
year on the vines and in the production of the wine. This result would be certainly most satisfactory if this average figure of production was reached every year, which unfortunately can not be said to be the fact.

The comparatively limited extent of the champagne vines (for although there are in the department of the Marne 16,500 hectares-40,700 acresof vineyards, the real centers of champagne making only occupy from 600 to 800 hectares) is the principal cause of the high prices which the first crop, good or bad, fetches every year.

JOHN L. F'RISBIE,

Consul.

United S'Ta'les Consulate, Rheims, January 31, 1884.

\section{COGNAC.}

REPORT BY OONSUL PRESTON.

The culture of the grape-vine is the first and most important industry of the people of this district. It is the principal source of employment and of wealth, and therefore great attention is paid to it. They spend much time and money in experimenting and studying the best means of planting, grafting, and overcoming the chlorosis and phylloxera.

The committee of riticulture of the arrondissement of Cognac which directs these matters is, then, a very important body; its transactions are made the subject of an annual report, the last one being made in February of this year.

They spent 30,000 francs for the purchase and gratnitous distribution of American plants for grafting on the native vines of the country of the Charente, for the creation of a nursery garden, and for the estab. lishment of a school of grafting.

The number of plants received the past year for grafting was 256,000 . To aid in the success of the plantations, they published and addressed gratuitously to every one who asked for the plants, detailed instructions to guide them in the grafting. There was some trouble in finding land having all the qualifications necessary for a nursery garden, but at last they hired land at Crouin, on the route to Saintes, containing 13,300 square meters.

The soil was good, entirely cleared up, and sufficient for two hundred and fifty to three hundred thousand grafts. A house was built of wood, in which to preserve the plants which they receive for distribution, and there they will start a school of graftage.

Numerous grafts will be made under the direction of a professor and in the presence of the proprietors who will be convoked to witness the works.

Mr. Rivas, the able professor, constantly occupied in the study of the 
subject for many years, has hired a young man from the agricultural school who directs it.

Five experimental fields have been established, in which about two bundred and fifty new varieties of hybrides have been cultivated. At the annual meeting I speak of, in February last, Professor Rivas made an elaborate report to the committee of which I transmit a free translation.

William S. Preston, Consul.

\section{United States Consulate,} Cognac, A ugust 26, 1890.

\section{CULTURE OF THE VINE IN COGNAC.}

\section{Report of Professor Rivas to the committee of riticulture of the arrondissement of Cognac.}

\section{[Tranglated by Consul Preston.]}

The old French vines, planterl in the low-lands where the soil is clayey aud moist, continue to become more and more vigorous. This is due solely to the persistent rains of the last two or three years. Retained in the low-lands at the surface of the soil by a clay very compact they have almost drowned the phyloxera, as if making a complete submersion, or at least placed them in such a condition that they ean not nultiply themselves actively. A proof that it is really so is that the vines placel on the hillsides where the water runs off continue to perish. This state of thiugs is maintained if the years are rainy, but not if they are dry. When the dryuess becomes more intense all the vives to-day more vigorous disappear anew.

It would then be impruclent to make new plantations of Freuch vines; inasmuch as the young vines succumb rapidly to the attacls of the phyloxera. In the dry lands, it goes without saying, the young viues last bardly three, four, or five years, which is proved by numerous examples. It is not the same if these new plantatious are treated for the destruction of the inseots. The sulphur of carbon and the sulphurated carbonate of potash have been tried and proved. The sulphur of carbon in the warrens, in the lands which drain well aud even in elagey land when the soil is well dried again: the sulpho-carbonate of potash in the lands of the open country.

The high price of the vines indemnify largely for the expenses of the application of these insect-destroyers.

\section{FIELDS OF DEMONSTRATION.}

The fields of demonstration which the committee of viticulture have created in this arrondissement of Coguac are six. They aro situated on the priucipal routes which end at Cognac, Jarnac and Chateaunenf.

The fiold of Chateauneul' is established in a thinty land, or in some places clayey, redish aud sometimes poor. The plantation has been made in grafts on the saintEmilion and of Balzac or Jacquez, York, Vialla. Sone ranks have been planted in roots, which will be graftel in the rpring.

The vegetation of these vines is vory fine, save in one point, where the water bas remained during a long time, and their vigor has vory farorably impressed the numerous visitors.

The two tields of demonstratio:s of Jarumo are less line. This coures from the bad quality of the plants (the last year the plants grafterl with liaves were rare, and those which should have been employed were dofoctive), and abovo all from abundant 
rains, which came so soon after plauting. The groutd was very compact, the water had been retained in the holes and drowned the roots. Besides, in the low country, many of the French vines have been completely stranded for the same reason. This year the failures will be replaced with very fine plants, grafted and soldered; and there is reason to hope that very soou these fields will leave nothing to desire.

The vegetation of the vines of demonstration established near Cognae is really very remarkable. One of these is situated on the ronte to St. Sulpice, on ground belonging to Mr. J. Brisson. The plantation has been made in grafts and sondes de Folle, or Jacquez, Solonis or York. Five ranks have been planted in roots, not grafted, of Rupestris, Solonis, York, Riparia, Jacquez, etc. A part will be grafted it some months in places; the other parts will serve as witnesses, and will furuish the slips. As I have already said, all these vines are very fine; many of the grafted plants bear grapes this year, that is to say of the second leaf; and it is hoped, if there is no accident, that the harvest will largely cover expenses of culture.

Another vine is found on the high road to Saintes near Yourezac, and if I am well informed it is the admiration of all who have seen it. The ground is reddish, flinty clay, above an under soil of chaple of 60 centimeters and over of depth.

The graftings employed are the Solonis, the York, the Jacquez. They have not been able to cultivate there the Rupestris and Riparia; these two were wanting, bat they will be vigoronsly developed. The plantation has been made in soldered grafts; some feet only of roots not grafted are cultivated as specimens.

For manure, 5 cubic meters of manure have been employed from the farm. This is not excessive, and the vine-growers are advised to use more on the new plantations (for the grafts and soudes it is important above all that the first year the vegetation should be very vigorous in order that the closing of the cuts may be more perfect in the folds); but I insisted that in order to render our vines demonstrative as rapidly as possible they must be planted under rather bad couditions.

The field of demonstration of Cronin has been planted in a great part with roots of Jacquez, Solonis, Rupestris, and York, which will be grafted in the coming spring. The grafts soudes occupy but five ranks; here they will be able to judge in the same ground of the comparative value of the plantations of grafts soudes and of plantations made with the roots planted and grafted on the spot.

Up to the present these vines are all very vigorous; all the fields of demonstration have been broken up to a depth of from 40 to 45 centimeters by the hand or by the plow, afterwards the plantatiou has been made in holes, the roots of the young plants being cut 15 or 20 centimeters in length.

Some persons planted the roots with a bar, grafted or not, after cutting the roots smooth. This is a bad system of planting; above all for the plants grafted and soldered. It bas already been said that these plants ought to vegetate vigorously the first year, in order that the solder may be completed. It is important, then, to leave them all their roots. The planting with a bar, which requires their suppression, or at least their reduction to almost nothing, is not suitable to grafts soudes.

To sum up, the rines of demonstration of the committee leave nothing to desire (those of Jarnac excepted), and these certainly connt for something in the great enthusiasm manifested in favor of American vines in the borderies near Chatean Neuf, etc.

RECONSTRUCTING THE VINEYARDS WITH AMERICAN PLANTS.

What prevents many from planting American vines is that they believe these plantations are very expensive. We will try to show that it is not so.

Without doubt the plantations made with plants grafted and soldered, taken from the nursery gardens, come very dear, and this is not a very practical way of reconstructing to a great extent; but these same plants can be raised here, and then the cost is insignificant.

With a thousand slips of Jacquez one meter in length they can make three thousand grafted slips. Put in nursery gardens and well cultivated, they can give a 
harvest of 50 per cent. ; somo in the neighborhood of Cognac obtained even 60 and 70 per cent; say 1,500 plants grafted, which will have cost the enormous sum of $\$ 2$. This is the price of 1,000 slips of Jacquez; with the Solonis, Riparia, Vialla, the price woull be a little higher.

We clo not mention here the expense of hand work of grafting, of the culture of the nursury slips, etc., for this kind of work can be done in the evening by the fireside, or on rainy days, etc. But these plants will yield some grapes the second year, and a passable harvest the third year. I can mention here a vine at St Merne which has yielded four barrels of wine to the journal at its second leaf. Besides, in the Beaujolais they often harvest the second year of planting, always the third; while the French vines generally produce but at the fifth, sixth, or even the seventh year. Dare we add that the American vines grafted produce a third more than the French vines; this, bowever, is the exact truth.

'The grafted slips are, then, a rapid and economical means of reconstructing vineyards; but they can operate differently and just as economically. Instead of grafting the slips on the stalk they can graft on the roots, and so put them in the nursery. The success of the grafting is better and the plants finer.

Another econonical means is good; to put the slips of 45 or 50 centimeters long in a nursery and graft them there the following year, and plant the vines afterwarls the second year where the grafting has succeeded. The slips themselves cost from 4 to 15 fraucs per thousand, according to the graft bearers; that is less than the Folle-Blanche, and St. Emilion cost.

They can also plant the roots, which are grafted where they are at the end of a year from planting. If the grafting succeeds, the vines are thus very vigorous, but in one locality the grafting in place often gives but very insignificant results.

The cause appears to be the cold and moist climate. The reasons are not very well known, but they can very easily obviate that inconvenience, or at least attenuate its effects. It suffices to make at the same time the grafting takes place a nursery of grafts and soudes with which they can replace all the failures.

Some graft the roots on table and at once plant in nursery. This is a bad proceeding, for it has all the inconveniences of grafting in place and of grafting on table without the advantages. They suceeed well sometimes, but very rarely. The breaking up of the ground is what costs the dearest. The American vines require a ground well broken up, but when they understand it a hectare of land can be broken up with a plow for 150 francs $(\$ 30)$ or less.

Besides, the expense of breaking up of plantation of grafting might be still greater, the two or three harvests that the grafted American vines produce sooner than French vines would more than cover the expense. If we add that they produce moreduring their duration; and that, thanks to them, the blight is no more to be feared, or at least it will not be very serious. We shall have shown what every one already knows, that if the American vines have some inconveniences, they offer also serious advantages.

Grafting still frightens many: but the school of graftage which will be open three months at Cognac will offer them an opportunity to couvince themselves that there is nothing in the world so simple or so ensy to do. As for the difficnlties of the choice in best graft-bearers for a given soil, they are not very great. It is well understood to-day what lands are suitable for the usual graft-bearers; such as Riparia, Solonis, Jacquez, Vialla, York Madeira, etc. Besides, in many of the lands of the arrondissement all these old vines cau give good results. Where the difliculty commences is where the proportion of calcaire becomes onsilerable; but this is a question we will examine later. Hereaftor they can plaut without hesitation the American vines in a large part of the arrundissement. We can not give exact figures; but after what I have ubserved in my voyages for the gratuitous distribution, I believe I am not far from the truth in estiwating it as about one-half of the total surface of the arrondissement. 
That is, then, 30,000 hectares where American vines can now be planted in all security; that is to say, the area of the old vineyards before the phylloxera. Here is a list of communes where success is certain: Cognac, Crouin, Saint-Laurent, Louzac, Saint-Andr6, Saint-Sulpice, Cherves, Bouthiers, Breville, Saint-Sovére, Houlette, Nercillac, Reparsac, Julienne, Chassors, Jarnac, Bourg-Charente, Saint-Brice, Gondeville, Saint-Amant de Graves, les Graves, Châteauneuf, Mosnac, Saint-Surin, Saint-Simon, Triac, some parts of Fleurac, Foussignac, Sigonne, Ars, Maiuxe, Saint Prenil, Touzac. Malaville, Bouteville in Champagne.

Besides the nature of the lands, which can not deceive us, plantations dating already from several sears show that in these communes American vines work well and give good results.

\section{AMTRICAN VINES IN CALCAREOUS SOILS.}

For the lands of Champagne and of Groie we are less favored. For the most part American vines which have there been cultivated bare not prospered well.

But it will be seen that we need not despair of finding one, and perhaps several, graft-bearers which will develop very well.

Let us first see what is the organization of our fields of experiments. These fields, four in Champagne, with Henry Perrin, of Bonssac; Henry Pelletant, of Genté; Ainé Richard, of Louzac; Filloux, of Angeac. The fifth, in Groie, with Mr. Arsandean at Sigonne. Two other experimental fields will be created this year. One in the Groie will be planted exclusively with varieties which have already given good results in Champagne. The other, in Champagne, will receive from two hundred to two hundred and fifty new varieties. We will have, aleo, in the spring of this year, from four hundred and fifty to five hundred varieties on trial, all very rare, and all recommended for diverse reasons for calcareous soils. It is the unique collection of the world.

Each variety is represented, as far as possible, by ten, twenty, thirty, or forty slips in each field. The Berlandieri, Cinerea, and Cordifolia vines are the most numerous. Half of these will be grafted, the rest not; so that we can judge of the value of each old vine as a graft-bearer and direct producer (for many can do both) and the influence of grafting on each one of them. All these varieties resist the phylloxera ; most are unharmed, others carry it on their roots but do not suffer from it. The phylloxera in our judgment is the most inoffensive insect, and in what follows it will not be in question. The soil is the great enemy of the vines. It is not then a study to find a vine that will resist the phylloxera (there are thousands), but to find a vine that will not only resist phylloxera, but also prosper in lands of Champagne and Groie. This, we shall see, is not far from achievement.

\section{CHLOROBIS IN AMERICAN VINES.}

Before examining in detail how American vines prosper in calcareons soils, we should endeavor perhaps to find out what are the causes of non-success of most of them in these lande.

Notwithstanding the number of works already published on this subject, which do not throw much light on it, I have not at present any plausible explanation to give for want of success. I do not, therefore, give any detailed examination of opinions which have been expressed on the subject. I merely observe that many are in contradiction with certain facte, which all hare had occasion to observe.

The chlorosis of the vines, grafted or not, and the stunting which follows, have turn by turn been attributed to moistnre, to drought, or to these two elements combined; to want of coloring in the soil, want of iron; to want of light or too much light; to climate, to the calcareous soil itself, etc. The influence of too much moisture on the vegetation of the vines can not be denied. I even believe that it may become a serious cause of failure; but to attribute all cases of chlorosis to moisture is clearly 
an exaggeration, as I have seen vines planted in very moist lands (the water remained on the surface from October to ofune, and the culture was impossible, save at rare and sbort intervals) that never grew yellow; and I have more than mere doubts about the part that moisture plays in turning the leaves sellow.

Indeed, the stains of chlorosis which at times are noticed in the vinevards in question are always on the hillsides, where water never remains and where the soil and subsoil are neither too moist nor too dry. Besides, the chlorosis is never very dangerons which can be attributed to excess of moisture. It appears chiefly in the spring, and in the course of vegetation it disappears.

The influence of drought is equally great. I have often noticed vines that were planted in very dry land. After a few days of sun and a slight breeze to dry the land entirely, the leaves fade ind the grapes wither and fall, but no chlorosis.

As for the alternatives of drought and noisture, these seem to be the natural conditions of vegetation. Under this hypothesis, calcareous lands absorb much water, then rapidly dry; at first drowning the roots, then leaving them completely dry. The chalky lands in the vicinity of Cognac do not swell with water, and a few hours after rain they can be easily worked. They do not dry up either. We have never observed vines suffer from chlorosis, although it is in such lands as these that chlorosis is most intense.

Iron seems to play a certain role in the formation of the green matter of the leaves; some have even supposed that the yellow color might be owing to this element in the soil; but this is not so. For a loug time past it has been remarked that the white soil (where this cause is chiefly placed) is as rich in iron as highly colored lands.

This metal, it is true, is not found there in the same state of oxidation and of liability to assimilation; but it matters little, since the roots which grow in the white soil contain as much iron as those growing in soil very rich in color. Besides, most of the land of Groie in the Charentes where American vines do not thrive is the most highly colored, the soil being very red, and consequently ought to contain more oxide of iron in the best state to assimilate.

It must, however, be said that an addition to the soil of a solution of sulphate of iron ponred at the foot of the roots has a bappy action on the formatiou of the green matter of the leaves. This is the result obtained from numerons trials made in land of Groie* by Mr. Jord in the Charente-Inférieure. The same result I have myself obtained from experiments made in laud of Champagne. But this action of sulphate of iron is very limited; the vines thus treated are a little less yellow, that is all the difference.

The slight overheating of the soil, which results from want of coloring on the surface, does not account for the greater part of cases of chlorosis. The lands of groie, it has already been stated, are colored red or ocher; the heating of the soil is almost too intense. The greater part of the land of Champagne has a deep gray, or even blask color, like marsh-land.

The same may be said of the pretended influence of light, which, according to some, is one cause of culorosis when it is not intense, and according to others when it is excessive.

As for the climate, it surely plays a certain role in the adaptation; but generally spenking, the more it is soft, temperate, and, above all, less burning, the nure it favors the development of American vines. And this is so true that in the sonth of France the Riparia rupestris and Jachnez solonis are alnost the sole vines cultivated as graft, bearers, while less-heated regions cultivate many more.

The Vialla, which does not grow badly in the south, vegetates here very well, and equally well in the Beaujolais. It is quite the best for light lands that are silicious.

The Herbemont, that turns yellow so rapidjy and is stunted in the Heranlt, thrives in analogous soils of the Charentes, and even in bad soils it grows vigrorously. 'The same is true of the Oporto, York Madeira, etc. It is clear that the phyloxera makes

" Groie: Light, yallow soil, mixed with ohalk-stones. 
less ravage in moist and temperate climates, and that is owing to the fact that the moist lands are more favorable to the vegetation of the vine than very hot and burning lants. 'The Mediterranean region is not, therefore, considered any more as a favored land for the recoustruction of vines.

The soils being equally good the Charentes have the advantage over the south west, center, etc., the facility of arlaptation of the same grafts to different soils being here much greater.

The intluence of carbonate of lime appears more certain. It is of daily observation that the richer in calcaire tho lands, the less they favor the culture of American vines. This his been proved by Mr. Chauzit by moans of two hundred comparative analyses of soil from regions quite diverse. The most interesting is to know just what these "special properties" are. Others suppose that the carbonate of lime acts directly on the plant. This supposition pleases me if it were confirmed. Unfortunately up to the present time nothing has justified it. The researches I commenced last year and have continued this year will perhaps give the key to some of these phenomena.

To resume, neither moisture nor dryness, or the two combined, count for anything in most of the cases of chlorosis and stunting which occur in very calcareous soils. If their action is not completely nnll, it is at least very limited.

Most of the phenomena of chlorosis are owing to the carbonate of lime, with which they appear united, as cause to effect. Carbonate of lime is much more injurious to the vine in proportion as it is mixed with the regetable soil, whatever may be its depth.

In a trial field of the committee of viticulture the vegetal land has a depth of 40 centimoters. It is a soil of good quality, where formerly vines grew with vigor, and I hoped that in consequence of the depth of earth most of the American vines would grow there, at least for a certain time. But it is there that they are more yellow; the soil contained 39 per cent. of calcaire.

While in another field of the same geological formation, and of which the regetal bod was not more than 15 centimeters deep, overlying immediately a bank of chalk, tender, and easily pulverized, the vines are much less yellow, the soil containing not more than 34 per cent. of calcaire. I believe, then, that the composition of the subsoil has not all the importance which was at first attributed to it. Without doubt, when the arable land is calcareous it will injure the vines if it contains much lime; but, if the arable bed is not calcareous, whatever may be its depth, the American vines have grood chances of prosperiug, even when placed over a subsoil of marl or chalk. Besides the examples oited, there are a good number of lands in Champagne whose regetal bed does not exceed 20 or 25 centimeters immediately over chalk, tender and easily pulverized, and yet American vines grow well there. It is because the thin lajer of earth is not at all calcareons. There is a third deposit, sometimes clajey, sometimes formed of quartz gravel. Such is also the case of several plantations which have been cited as examples of reconstruction in chalky lands. They are in reality in entirely dufferent conditions.

It is erualls certain that all American vines are not alike sensitive to the action of carbonate of lime. Most are not adapted to calcareous soils ; some appear to resist it completely, and this is the case with sereral vines which Mr. Vjalla observed in America. Furthir on it will appear that it may be necessary to add several new bybrick, both natural and artificial.

In the same species the numerous forms inclosed present differences tangible enough that it is prossible by selection to isolate those which offer a real interest.

The squecies and raricties the most meritorious will now be reviewed and some details griren on most of the vines which have been tried in very calcareous land. These condensed indications have be en gathered by myself in the experimental fields of the committee of viticulture of the arroudissement of Cognac established in chalky lands, where until now American viues have failed. We have verified them during a long voyage made last year in all the regions where the soil offers some analogy with 
those of the Charentes (in the center, southeast, south, southwest) by observations made in the experimental fields and in the vineyards.

The wild species (Riparia).-After having been much used for the reconstruction of vineyards then almost abandoned after numerous cases of chlorosis, the Riparia is once more in favor, and properly so, for it is one of the best known graft-bearers.

In the first place, it strongly resists phyloxera, a quality deficient in mans Americau vines cultivated for the same purpose. It bears quite well grafte of most French vines (except Balzac and Mourvðde, and a few others which it nonrishes badly), both in Provence and Languedoc, as well as in the Charentes. Its stalk does not swell qnnch where the land in which it is planted does not suit it, but this is perhaps of minor importance.

Grafts have beeu seen on the Riparia double the size of the subject, and the same were not in appearance less vigorous. Can these dimensions have any bearing on the duration of the root It can not yet be asserted, but it certainly is much to be feared. The exaggerated swelling of the graft, or, rather, of the graft bearer, have been attribnted to the effects of annular incision.

In fact, it is known that in plants which have undergone this operation the part above the cut swells much, while the lower part remains thin. The consequence is a general feebleness which if not excessive favors the fructification, but which may also hasten the decay of the plant. This is often the case with grafte on the Riparia. French varieties grafted thereon are more fertile than when alone; they fear less the blight and their fruit ripens more rapidly. But in reality, notwithstanding these analogies, there is nothing in common between the circular incision and the graft, except during the first and second years that follow the grafting.

Until the solder is complete, the graft can be assimilated to a partial incision or cut of any kind; lout as soon as the solder is perfect, and the tissues of the graft are n communication with those of the subject, there is nothing that resembles the incision.

In a branch or stem in which an incision is made, ars soon as the ends are rennited and soldered, the circulation of the sap is re-established as before the cut, and the lower part swells like the upper part; the tree or branch ceases to be more fertile. In grafts on the Riparia, well soldered, nothing like this occurs.

Althongh there is no apparent cbstruction to the circulation of the sap, yet the grafted part continues to grow immeasurably, while the subject rests feeble. The explauation of this phenomenon, I believe, is of the physiological order. There is perfect harmony between all the organs of the same vegetable; each one contributes to the gruwth of the others in the best conditions. Grafting seems to me to break this harmony. The matter elaborated by the new stem is no longer that which suits the subject; placed benceforth in less favorable conditions of growth it is less developed; it sulfers and remains feeble; the matter, not absorbed by the subject, accumulates in the grafied part and produces an abnormal swelling.

The disorders, then, which follow the grafting are not in consequence of the graft itself. They arise, in my opinion, from the internal and external differences, or the vital differences which exist between the graft and the subject.

A vine grafted on itself (whether Riparia or any other species) ought not to produce any anomaly like this. As soon as the solder is complete it should grow as if never grafted. It is easy to give proofs. Besides those found in arborioulture, and which are en well known that it is unnecessary here to cite them, I will observe that our old French vines, grafted with neighboring varieties, have never slown any thing like that offered by the Riparia. 'They grow as before; their vegetation is the same.

There is the most purfect analogy betweon the functions and node of living of the grafterl part and the subject. The latter preserves the same conditious of vegratation that it bad before the grafting. The more, therefore, two grafted vines offer analogy in their functious, the less the subject will suffer from the grafted part. It is this analogy which establishes the identity (in the case of a vine grafted upon itself), 
which is now called aftinity. On the other hauch, the more two grafted vines differ from each other, the more the subject will suffer from the grafting.

Riparia being quite different from the French vines, which it must bear, it is not surprising that, for the reasons given, the grafts are always feebler than other kinds. This weakness will, in certain cases, kill the vine, or, at least, engender chlorosis and stunting of grafted roots. Riparia has frequently developed quite vigorously, as well as other vines, as long as it is not grafted, even in very bad soils; but once grafted regetation suddenly stops. And theu the disorders caused by grafting increase those of the nou-adaptation of the soil. This weakness is prodnced in all kinds of soil, but it is, perhaps, mitigated by a good adaptation. For these rensons the Riparia requires a deep aud rich soil, or it must be manured very highly, and the manure must be azote to maintain it in good vegetation. And thus Riparia will prosper many years. For some time it has been an experiment to plant Riparia in all soils, but soon it appeared that it could not be an universal graft-bearer. Wherever the white marl, chalk, tender and easily pnlverized, forms a part of the arable bed, Riparia, when grafted, turns yellow. It is cne of the most calciferous of American vines. All these varieties are not equally subject to chlorosis, and some were selected which turned yellow less thau others, although none have a suffi ient vegetation to besafely used. In general these varieties die earlier than the common varieties. Considerable noise has, however, been made of late about a certain species of Riparia called Riparia-Ramond. This species has its own value, as the propagator of it has succeeded in reconstructing vineyards in parts where the ordinary Riparia and other graftbearers have rapidly turned yellow.

As it has become notorions, let us examine nnder what conditions of soil and culture it thrives with Mr. Ramond.

The subsuil of his vineyards is very calcareous. Sometimes quite hard, of white rock, but now and then quite tender, and softening nnder the influence of frost, it changes in some parts to a pulverizable marl. The composition of the vegetal land varies. It is almost deficient in calcaire in narrow places where it has not been broken ap or mixed with the subsoil. In some places it is siliceons, flinty in others, whatever may be the depth. Wherever the subsoil is near the surface, ferns, pines, chestnuts grow, although I did not know that such plants and trees were adapted to calcareous soils. The composition of the parts cultivated is unlike. In plowing the subsoil has mixed with the siliceous or flinty surface and numerous small fragments of calcareons marl, and the soil is consequently quite diversified; but it offers often strong resemblance to land of Groie. Now and then it is a sandy soil, with 20 per cent. of calcaire; sometimes the land is quite fertile and even very rich, with 12 per cent. of carbonate of lime. This proportion of carbonate of lime may be less than that.

The depth is from 10 to 40 centimeters, with subsoil more or less compact of calcareous rock. The Riparia-Ramond thrives in all these lands; the grafts last year were much admired and the harvest bountiful. But in every case the soil is broken up carefully and abundantly manured. It moreover profits by the flinty and sandy soil. The Riparia-Ramond certainly benefits from this cultivation. But unless it resists chlorosis better than Riparia it can not last. Still, in addition to increasing the nutritive properties of the soil, these considerable additions to the land from the third year of plantation profoundly modify the physical composition of the arable land. There are some places, it is true, where this is not the case, but then either the grafts have not been grafted or only recently. To be able to estimate the value of this vine it should be planted under the most ordinary conditions.

In an experimental field containing above 40 per cent. of calcaire, Rupestris, York, and Solonis fail, while Riparia-Ramond thrives, but only after two Jears of growth. Riparia-Ramond, in fine, in lands of Groie, of Charente, Bourgoine, ete., which are partially calcareous, will do well, but it will certainly be insufficient in chalky grounds containing a large proportion of carbonate of lime. These lands have been tried in four different places and invariably the vines turned yellow, although lese 
than ordinary Riparia, and, in some cases, very stunted. In land of Groie, wherever I have observed, it was deep green.

Riparia-Ranond is easily described. Its root or stem grows higher than ordinary Riparia, but does not equal it grafted. The brancbes shorter, knit bard, of hazel-unt color, as they ripes, red during vegetation, and this shade is occusionally found in the veins or fibers of the leaves. The latter quite ample, opening like $\nabla$, iutensely green on both faces, and bright. On the lower face the filaments are stiff as well as in the veins and on the edges. These filaments are united at joints of the principal veins. or fibers. The teeth are large, slightly projecting, wall-crowned, unarched, regnlar or almost so at the end of the limbs. The treth facing the lateral and terminal lobes are only a little bent. The grapes are small, short, and thick seeds, compact and peculiar to the taste.

All this proves that it is not a gennine Riparia. The form of the teeth, the shape of the veins, the diminutive size of the stalks, and the hardness of the wood, its color like weeds, as well as the form of the grapes, etc., are so many indications which seem to establish the relationship with Rupestris.

Each time I have occasion to compare it with Ruparia-Rupestris, cultivated side by side, it has always seemed to bear the closest an alogy to these luybrids.

Last year was remarkable for Riparias in calcareons lauds. The number was considerable. One of them is native of the Chareutes. According to the information at hand, it grows in lands which contain over 60 per cent. of calcaire. Bnt Riparias, not grafted, and slips from them planted in siruilar lands and subsequently grafted, quickly disappear.

Another species coming from the North will also be vigorons. According to the information acquired it does not sustain its reputation. It will grow, it is true, in very calcareous soil; but that proves nothing.

As for those grafted, and which compose the small vinefards, the land is yot the same as those of Groie and Champagne in the Charentes. In some the subsoil is clearly chalky, a tender turf, rich in chalk; but it has already been shown that the subsoil does not play a great rôle in the mauifestation of chlorosis.

The soil is quite flinty, red or gray, and the ordinary Riparia, as well as many others, should certainly have prospered in it.

Without limiting these olsservations to the vegetation of plants not grafted, a dozen forms of Riparia and as many of Rupestris might be named, which have lived for the past ten years in open ground of Cbampagne very calcareous and chalky.

The Taylor, Clinton, Solonis, and Yacquez were planted in these lands thirteen or fourteen ycars ago, and do not turn yellow; but none of these vines are grafted.

Some have, however, been grafted in these poor lands and bavedone well. It was done on roots of seven or eight years old, which had acquired sufficient strength to sustain without much suffering the greffage.

One of the ablest viticulturists in the Charentes bis already confirmed this observation. He only grafts on roots of three or four y'ars on the sprouts of a year's growth cut down close to the ground. This may be an interesting item; but of what practical value? And then it is not proved that these vines would liv' oven grafted upon vines of seven or eight yenrs, after a few ycars of graftage.

On the whole, after all that has been said, it will not do to try the Riparia (except with prudeuce) so much recommended for calcareous lands, for none bave as pet been proved in these lands. Riparia-Ramond alone is an exception. Yet it can not 20 cultivated in the chalky lands analogous to those of Champagne.

Rupestris.-'This vine has also been recommeacd-I scarcely know why-for very calcareons soil. Perbaps the reason is that it has boen scen growing vigorously on rocks which border the rivers in the United States. But thore are many species of rocks, and even calcareons rocks, when very hard, are quite favorable to American vines. Some of the wnste lands in the Horault are proofs; and some calcareous chalky lands in Charente which contain 95 per cent. of carbonate of lime. 
And then Mr. Vialla states that Rupestris grows specially in America in very poor ground, tormed, however, of flinty gravel, and not intermixed with vegetal soil. It is the same thing in France.

It does not answer to plant Rupestris in calcareous soil. It dies there even sooner: than liparia, and if it is superior to the latter in many parts of the South, it is only because these lands are not too calcareons. In all cases when the proportion of calcaire is too great, Kupestris dies. In the Iands of Champagne and Groie it dies where the liparia is sometimes strong. The silicious is by far the best enil for it, and in such a soil it is superior to all graft-bearers, which it surpasses as the lauds are less and less fertile. I have seen it very vigorous in tertiary doposits formed exclusively of gravel of the size of buckshot and hazel-nuts, while Riparia, Vialla, and York-Madeira were there very feeble.

$R$ upestris is then the best vine of all for poor, silicious soil, although it succeeds in rich soil, also ; yet cheaper graft-bearers are as good. It grows admirably, also, in certain calcareous, sterile lands, formed of calcareous fragments rolled very hard. In these lands Riparia does not turn jellow, but Rupestris is far superior to it. For the old alluvial earth of Charente, of which the subsoil is gravel mixed equally with calcareous and silicions fragnents, I believe Rupestris the best vine. Like Riparia various species of Rupestris were recommended for calcareous soil. Certain ones are in our experimental tields, and othors in soils of diverse nature, all growing in about the same way, and in very chalky land they all turn yellow.

$V$. Cordifolia. - This vine has been recommended by Mr. Vialla for several years for calcareous soil. Until receutly this vine had not been much cultivated on account of the numerous suckers that grow from it, and it does not appear to play any impertant part in the reconstruction of the vineyards. It is not adapted, either, to very calcareons soil. Several trials of the vine have failed. In chalky land it is affected. with chlorosis, and soon dies, often during the first year. This, at least, is the result of our experiments. The greiter number of varieties cultivated were, it is true, issues of the seeds plauted in France and gathered, not upon Cordifolia in calcareous lands of America, but on those growing in the rich alluvial earth of the rivers. It is possible that the vines which grow spoutaneously in rich silicious lands are not adapted to calcareous, poor soil, and therefore our experiments may not be considered important. But I have unfortunately cultivated Corl ifolia that came direct from calcareous lands in Awerica, and they did no better than the others. In conclusion, I do not consider Cordifolia of use in poor ground.

V. Cinerea.-The remarks made above of Cordifolia will apply word for word to Cinerea. Like Cordifolia, it turns yellow and is stunted during the first year, both the species coming directly from calcareous lands in America, as well as those obtained in France.

Notbing, then, can be expected from this vine.

It has been recommended for moist and flinty lands; it grows in fact very well in flinty beds in the sude; but until now no plantation of this vine has been made to any extent in France, and it is preferable to abstain from much use of it.

V. Yonticola (Foxeana Texana). - A species of vine but little known as yet in France. Mr. Vialla noticed it in America in very calcareous land, and which bears much analogy to land of Groie. It might therefore prosper in anglogous soil in France. We have several cultivated in chalky land; none have turned yellow; their strength is sufficient, notwithsanding the vine passes for very feeble. This is all that is known of this vine, and its futare can not be judged.

Candicans.-The Mustaug ( $V$. Candicans) is the vine that attains the greatest dimensions in America. It grows vigoronsly even in quite bad lands.

It has been little cultivated in France, on accuunt of the diffeulty of propagating it by cuttings or slips, and this is the reason why we have not been able to cultivate it in our experimental fields. Some of these slips are always found mixed accidentally with roots sent to us from the South. They turned yellow like those of Cinerea and Cordifolia. It follows that, if this ubservation is of ang value, it will uot do to 
plant this vine in bad land. Moreover, Mr. Vialla nezer observed it in Texas in lands rich in carbonate of lime. It has not yet been tried in other lands, and should it be an object to find a process of rapid multiplication, the trials of adaptation, which have been made with other varieties successfully, must be recommenced.

F. Arizonica.-This vine is very rustic and a strong risistant of phylloxera. It is employed in California as a graft-bearer, and not cultivated in France.

It grows spontaneously in California and Arizona on very dry hills, stony and calcareous.

If it was more vigorous, it would perhaps have some value for lands of Groie. We have planted a dozen roots in Champagne. They grew jollow a little, but without degenerating. It is not in any case a vine to multiply.

V. Californica.-This vine is of no value either in France or America. It dies of phyloxera, and samples we cultivated in Champagne turned rapidly yellow.

V. Berlandieri.-It has been in France for some tinie ; resists phylloxera very well, and uakes a good graft-bearer. Until now it has but little multiplied in France, on account of the difficulties to propagate it from slips that easily break. It has, however, been proved te grow well in bad lands even where there was much lime. On Dr. Davin's lands it grows in chalky soil. The same may be said of the experiments made by Mr. Planchon in loam, composed of four ingredients and very calcareons. Its grafts were really remarkable. The same is seen at some places in the Charente Sufirieure, where it remains deep green, while numerous varieties around it turned yellow. Nothing more was known about this vine, when Mr. Vialla discovered it in America in Texas, in soil analagous to the calcareous land of Charente and of Champague. The various experiments I have made show that it will resist a strong dose of calcaire.

In our experimental fields four hurdred roots planted show no trace of chlorosis. It is the same in other parts of the Charente Inférieure, while numerous varieties, recommended for calcareous soil, even the Folle Blanche, planted in equally good conditions, have not escaped phylloxera. It is not jet known whether these hopes will be realized or not. It is objected that in the beginuing this vine is feeble, but, later, it is strong, and compares favorably with the most vigorous graft-bearers. It is propagated by slips of a year's growth. This system is excellent, and it is advisable to multiply it by grafted slips. This way, I hoped, last year would overcome the difficulty. But it failed. The grafted slips succeeded no better than the slips. It is preferable to graft slips of Berlandieri from 30 to 35 centimeters long, or even shorter, on French or Ameriean stallss. They grow very well. The slip planted in good soil, leaving one or two eyes above ground, take root at once, but the Belandieri soon throws off a certain number of roots. Very fine roots are thus obtainel. Crafts with only one eje have not succeeded, and the issues from them have not had sufficient strength. A preceding report, all that was interesting to relate of the hybrids of Berlandieri and French vines, was given, so far as chalky land is concerned. Numerous experiments have verified these previsions.

We shall see, in the next place, that even if Berlandiera can not play any great part as graft bearer in chalky lands, it is not the same with these hybrids.

HYBRIDS-American hybrids.-Hybrids that result from orossing American vines are very numerous. The best known are Solonis, York-Madeira, Huntington, Champins, Nnvo-Mexioana, Cordifolia-Rupestris, Riparia-Rupestris, Rupestris Eistivalis, Cinerea $R$ upestris, etc.

Solonis.-This vine is, according to Mr. Millardet, a hybrid of Riparia-Rupestris and Candicans; of Riparia and Caudicans only, according to Mr. Vialla. In either case Solonis is a graft-bearer that is less exposed to chlorosis in chalky lands, as well as in finty and cold soils. The reason is not to be found in the aptitude of its generators. Riparia and Rupestris are not, as has been soen, adapted to calcareous soil. Mustang ( $\boldsymbol{V}$. Caudicans) is aven better, although donbted, It is a viue with acquired qualities by hybridation, and this is commou to all bybrids. Solonis, in very oalcaruous soil, develops well genorinly when uot grafted, and is uat exoessively ohlo. 
rotigue. But, grafted, it is rapidly stunted. In land of Groie the grafte exist, do not turn yellow much, but remain very feeble. When the ground is broken up and narnured, it is better. It gives good enough results under these conditions. Bat really it is only in flinty, moist lauds that Solonis sbould be planted. Thnre it is the best graft-bearer of all. When it has been planted side by side with Riparia, York, etc., in such conditions, its vigor was always superior to them; but for land of Groie it must be entirely abaudoned.

Novo Mexicana.-According to Mr. Vialls, hybride of Ruparia and Mustang, and consequently related to Solonis, to which besides it offers the greatest analogy. NovoMexicana, then, is a group of hyhrids only dissimilar by very little. Solonis is one of these hybrids. It resists chlorosio, like Solonis, better than many other vines; but it has been cultivated for so short a time in France that we can not pronounce upon its value. In one of our experimental fields of Champagne it turned yellow, but less than soloris. In ordinary lands it is vigorous and woll adapts slips, but it has not yet acquired resistance of phylloxera. It is, then, an interesting vine for study ; but too great hopes must not be placed upon it. Among its many varieties a choice should be made. Mr. Vialla sent me lately a remarkable species, called Nova Mexicana d'Hutchon.

York Madeira.-This vine is recommended for dry lands. It succeeds there very well, and few phylloxera are found on its roots, but these dry lands ought not to be calcareous. It does bettor in siliceons soil formed of big stones, with a little vegetal earth and poorer than the soil of Rupestris. York is quite feeble whenever the siliceous. grains are unmixed with good earth and compact. In these conditions its grafts are. never very fine. They bear much fruit, too wuch, even, but it ripens badly. In the calcareous land of Groie it does not turn yellow much, but its development there is always so restrained that it can not well be utilized for plantations. In Champagne. lands it dies rapidly, and it is equally bad in woist, flinty soils.

The Vialla aud Franklin should be planted in light, siliceous land, as it is only there they will grow vigorously. If the proportion of calcaire is a little raised they soon die, and they are aleo feeble in moist and stony soils. Wo pass by the Clinton and Tiaglor, which have been almost abandoned as graft-bearers.

The Oporto has been recommended for calcareous soil, but, I think, wrongly. It is only vigorons in soils that suit Vialla, where it is even more vigorous than the latter.

The Champins.-These vines, cultivated in France, are bybrids of Rupestris and Mustang. Their characteristics are quite varions. Some which are bushy with glittering leaves, almost smooth, resemble Rupestris; others which are portly, dull leaves, downy, as well as the branches, are more like Mustang. These vines do not equally resist phylloxera. Although for the most part quite difficult to multiply (the slips take badly, the layers ouly succeed), still, hopes are entertained for their adaptation to bad soils. Some of them have so far resisted chlorosis, where Riparia was torn up ; but the resistance of many of these hybrids to phylloxera is more than doubtful. Some even died nnder the attacks of this parasite. And in the experimental fields of Champagne all the species (Nos. 1, 2,5,10) which were cultivated turned yellow the first year. Elsuwhere they did well a little longer time, but only to the moment of graftage. It is uncertain how they would do in land of Groie, as they are not strong, and it is not likely that they will ever serve as graft-bearers in these lands. The hybrid Champins, result of crossing Berlandieri, Monticola, ete., with Mustang and what Mr. Vialla found in America, may prove to be better resistante of phylloxera and less liable to chlorosis on account of their origin. I have not yet made the trial.

Huntington.-This is a hybrid of Ruparia and Rupestris. According to Mr. Millardet, it is alled to $V$. Labrusca. The latter's influence must be foeble, for there is no well defined characteristic of Lebrusca in the Huntington. The fruit is not foxy; the leaves are entirely smooth as well as the branches and the tendrils are prolonged in some of the branches, Until now this vine has been little used as a graft-bearer, on 
account of its feebleness, and also as its resistance to phyloxera has not been yet determined. It is multiplied in the Charentes and the south of France as a direct producer. The grapes are very numerous, small, of medinn seeds, compact, of a peculiar taste, but not sour. The wine produced is bad. For want, however, of better, the inhabjtants of the Charentes mix it with other wines and drink it. It is most remarkable for ite fine vegetation in very bad lands. Whatever may be said against Huntington it remains green and vigorous in lands of Groie where Rupestris, Solonis, and Riparia are soon stunted. It is the same in lands where American vines grow well; much better than Riparia, York, Solonis, Rupestris, etc., and which nevertheless grew finely. It is not to recommend its culture or to advise its use as graftbearer or direct prodncer, for it does not resist phy loxera well; but in calcareous soil it is a vine least of all liable to chlorosis. The cause is nnkvown.

Riparia-Rupestris.-This vine is an example of what has already been said, that certain hybrids offer certain aptitudes which certainly were not transmitted from their originals. Almost all hybrids are more vigorous than their generators. They swoll more and their branches are longer and stronger. They are letter adapted to bad soils than Riparia or Rupestris. Few of these vines have been grafted, bnt they will not do it well and their trunk would rapidly develop, as we believe. The swellings, so frequent and voluminous at the point of solder on Riparia, are never seen, and it is thought that Riparia-Rupestris, or some among them, will make excellent graft-bearers. Other reasons, too, than these might be given. First, among vines that grow well in very calcareous soil, like the Groie, are found just two of these bybrids, Huntington and Riparia-Ramond.

In a plantation in very poor, calcareous land some roots were more vigorous than Rupestris planted under the same conditions by their side, and on examination the roots were identified as hybrides of Ruparia and Rupestris. In very calcareous land of Provence a Rupestris, result of crossing with Riparia, grew very well where many vines planted at the same time are alreaty dead.

Nearer Cognac, in land of Groie, where the best of Rupestris may die, some of the Riparia-Rupestris are very fine. In Ardèche, in soil of bad quality, of Mr. Couderc Ruparia-Rupestris is remarkable. And I may be excused in my preference for these vines by adducing proofs of their beanty in the worst lands of the Charente, as may be witnessed in lands of Messirs. Foex, Millardet, and Grasset. All that have been cultivated in our experimental fields have a fine vegetation in ('hampague, a few only" have turued a littlo jellow; it is not believo d, however, that they will be good graftbearers for these lands. But, on the other hand, in lands of Groie they may be used without apprehension. In fact, they have a marvelous vegetation and surpass the finest species of Franro-American hybrids. All are not equally fine, it is true, and a serious selection wust be madu. Thus a Riparia-Rupestris of Yeger comprised two kinds: one, more like Rupestris (its brazches erect, shurter, and red-colored like herbs), was the nore vigorous; the other, resembling Riparia, has louger brauches of yellowish green, prickly leaves; it turns yellow in land of Champagne, while the first remains green. In addition to several well-sclectel specimens, upon which experiments have already be'n made, wo shall continue to make others known.

Cordifolia-Rmpestris.-Fh»se vines grow vigorously in America, and also in some parts of the south of France. Mr. Millardet has commended their cse iu calcareons soil. But, in uy opinion, it is an error, for they will not prosper. Several I havo had planted, both natural aud artificial, all turned yellow rapidly and died in a few months. They take better in land of Groie, but the poorest vines imagiuable. It is not known for what reason they liave been recommonded so highly. Mr. Millardet maintains that they are adaptod to lliuty soil, cold and compact. But they have failed in good garden soil, and no reliance can he placed in them, whatever be the kind of soil. They are not of value either in chalky lands or in (iroie.

Linpstris AEstivalis. Of this vinu we ponsess very fow specimens. One did well in lands of the south of Frunce; but trausplanted in ohalky laukl near Convac, they were stunted before she expiration of the tirst year. Nothing can be oxpected of these 
vines. Some of them, however, have merit. That of Leziguan grows well with Mr. Bonisset, aud the Taylor, after four or five jears, continues to grow vigorously in land of Groie, according to Mr. Tord. But these vines are not adapted to chalky soil.

Cinerea-Rupestris.-This vine is no better than Cinerea and inferior to Rupestris in onr experimental fields. In some bad lands of the South there is a variety quite fine, but it is not of any interest to ourselves. Experiments are actually made with several of these hybrids, sent to me by Messrs. Foex, Coudere, Millardet, and Grasset. They have been too short a time in the fields to give an opinion, and we have but five or six samples. Those which resist phylloxera best are othello $\times$ Rupestris, Solonis $\times$ Othello, Canada $\times$ Rupestris, Cognac, otc. The American hybrids, by FrancoAmericans are greenest. Canada $\times$ Rupestris is also very fine with Mr. Coudere, in Ardeche, and will surely be a good graft-bearer.

Hybrids Franco-American.-This name is assigued to crossings of a variety of vine viuifera with any American viue. And during this report by vine of French origin, must always be understood vine vinifera.

Jacquez.-As a direct producer this vine has been much cultivated in the south of France, and it is now grafted almost exerywhere. In warmer latitudes the color of the wine changes very rapidly, and in the north the fruit ripens badly and is very susceptible to cryptoganic diseases. It is advantageons as graft-bearer. A few years ago when chlorosis generally prevailed among riparia vines, and they ceased for this reason to multipl 5 it, Jacquez grafts alone remained green. In very calcareous land of marl Jacquez die, but much later than Ripravia. They are fine graft-bearers for most of our viues; save, perhaps, Balzac or Mourvéle, which in most places are covered with excresences. It is so well adapted to grafts that after a short interval the joint can not be distinguished. It.is known already why these grafts are less fertile than on Riparia.

The affiuity between subject and graft places the root in as good conditions as if it were not grafted. The harmony is perfect and it is not therefore surprising that grafts on Jacquez produce less than on Riparia, aud they are fully as fertile as French vines of the same age.

Jacquez is especially remarkable for the facility with which it grows in very diverse lauds. In marl and chalky soilit is not a good graft-bearer, but it grows best there; but in Champague it is the only graft-bearer that succeeds well. It is not yet proved that it resists phylloxera, or its rcconstitution in calcareous soil would already be possible. In cold, flinty soil it also grows well. In a word, it grows like our French vines and is at the same time hybrid of American vines, to which it ores its resistance to phylloxera, and of a French vine, to which it owes its adaptation to all kinds of land and resistance to chlorosis. And from these analogies it arlopts easily most of the grafts.

But it is more sensitive to blight than Riparia, and this is a sign of great strength. This defect can be remedied, too, by a longer slip, or perbaps by proper manure. When grafts on Riparia grow feeble they should receive a compost of azotes; here, on the coutrary, it slould be mauure of potash and phosphates. It is important to note that Jacquez, hybrid Franco-American, resists better than its American geverators chlorosis, and consequently agree well with it as a graft-bearer, and develop as if they had not been grafted.

Othello, Canada, Triumph, etc.-They make little resistance to phylloxera; but, as direct producers, these hybrids are interesting species, found in our vinejards on account of their facility of adaptation to very bad soils; and they enable us to judge the value of species daily furnished to us by Messrs. Couders, Foex, Grasset, and Millaudet. But whatever may be their value as direct producers, and the quality of their fruit, they will never replace in renowned vineyards our ancient French varieties. It is in their culture in very calcarcous soils that I have to speak. They all sustain " very bigh dose of calcaire. According to Chauzit, Uthollo, a bybrid of clinton of Canada, bj Black Hamburg. will live in soils containing 50 per cent. of car- 
bonate of lime, and it is also successively cultivated in lands of marl, where the reconstruction of the viveyards with Riparia, Rupestris, Solonis, and Vialla was checked. It has been seen in several chalky lands around Cognac, aged from three to eight yeare, very fine and green; while by its side Noah, the famous American hybrid, the savior of Cbarentes, was stunted.

Canada also resists chlorosis. It has been seen in bad land of Groie, subsoil marl, to grow well, very green; by the side of herbemonts very feeble. The same with Triurph, etc. Thus we see that these vines by right of origin are well qualified for our land (except as to their resistance to phylloxera). Their American generators are AEstivalis, Cinerea, Labrusca, and Riparia, all sensible to chlorosis, and we can expect to do even better with crossings of Berlandieri or other species resisting phylloxera with our native vines. And by selecting those adapted to calcareous soils, such as Folle-Blanche, St. Emilion, Ugni-Blanc, St. Peter, Colombo, Pinet, etc., the success would seem to be assured for the most calcareous soils. These hybrids offer nuch interest. In my opinion, after several experiments, hybrids Franco-American and $V$. Berlandieri are sure to reconstruct chalky soils. Hybrids $\nabla$. Berlandieri by French are among the most remarkable. In several of onr fields of Champagne Berlandieri by Roussaune, Cabernet, Sultanieh, Aramon, Malbec, ete., have not turned yellow, but have all retained a very bright green color. They are not all, however, equally vigorons and a choice must be made. A few received from the school of Montpellier are feebler than Rupestris hybrids by French ones. But their vegetation is more vigorous than Jurangon Folle-Blanehe planted by their side. French bybrids by Rupestris vegetate better than the preceding and are of equal foliage. They are certainly the most vigorous hylurids yet known.

At the school at Montpellier they have had for some years Rupestris $\times$ AlicanteBouschet of unheard-of growth, and it succeeds in our trial fields very well.

Among other plants of the same group which grow fuely, Aramon-Rupestris-Gauzin may be here mentioned. They furn a little yellow in ehalky soil around Cognac, but very little. Gamay-Conderc is also very strong and green in our trial fields and elsewhere. One of the finest is Rupestris-Cabernet, of Mr. Millardet, then Gros ColemanRupestris, Aramon $\times$ Rupestris, Alicante-Bouschet $\times$ Rupestris, Petit Bouschet $\times$ Réparia, etc. There are also diverse hybrids of Rupestris by French vines in other trial fields which have been established in chalky lands of Champagne and Groie identical to these, which are still greener and more vigorous. These I have myself proved. Hybrids of value are not formed from Vitis-Cordifolia. They turn yellow a little less than Cordifolia, bat can not be relied on, and the same may be said of hybrids from Cinerea. Crossings between these and our French vines have not succeeded. The samples sent to me have almost all turned yellow. Hybrids Riparia are very vigorous and not very liable to chlorosis.

The complex hybrids of American vines, Yorle, Othello, Solonis, Clinton, Taylor, etc., and French are not strong and some turn yellow. The following is the order of preference to be given to vines, according to their strength and foliage, which I have carefully observed in our experimental fields and elsewhere in identical lands:

First. Those strongest and greenest: Cabernet $\times$ Rupestris, Gros Colman $\times$ Rupestris, Colombean $\times$ Rupestris Martin on Gamay-Condere, Canada $\times$ Rupestris, Aramon $\times$ Rupestris-Ganzin, Petit-Bouschet $\times$ Riparia, etc.

Second. Very green and not so strong. V. Berlandieri, Folle-Blanche, Aramen $\times$ Berlandieri, Malbeo $\times$ Berlandieri, Cabernet-Berlandieri, Sultanieh $\times$ Berlandieri, Roussonne Berlandieri, and a few other hybrids of French vines, with Berlandieri $V$. Monticola.

Third. Very strong, but a little jellow. Ruparia-Rupestis, No. 10875 RupariaRupestris of Jrger, and a few numbers of the Montpellier sohool. In Groie they do not turn yellow.

Fourth. Less strong and more snbject to chlorosis, Riparia-Ramond. Diverse hybrids of $V$. Cordifolia, Riparia, York, Othello, with sundry French vines, may be joined to this group. 
Fifth. Most subject to chlorosis: Mexicana, Solonis, York, Champin, V. Arizonica, Californica, etc.

Sixth. Those very yellow and more or less cottis: $V$. Cordifolia, Cinerea Candicaus, Cordifolia Rupestris, Rupestris-.Estirvalis, Cinera Rupestris, etc.

\section{CONCLUSIONS.}

Can definite conclusions be drawn from all that precedes?

These experimeuts are of recent date, but the results are in harmony with numerous facts of vine culture proved several years ago and alroady reported by me. First. V. Berlandieri aud hybridy resulting from crossing it; Rupestris and even Ruparia with Europenn varieties grow best in the cbalky lands of Champagne; most of them do not turn yellow there.

Second. In lands of Groie these vines grow finely; but it must be adred that RipariaRamoud and sundry species of Riparia-Rupestris, such as Nos. 108, 101, 75, and some natural hiparia-Rupestris of Jæger, develop well in the save soil.

Third. Other varieties of hybrids or species, although offering more or less resistance to phylloxera, will not in any way suit for cultivation in lands of marl or chalk.

Fonrth. How will these vines do when grafted On account of their relationship to the slips which are grafted upon them there is every reason to believe that they will unite much hetter with them than Riparia, Solonis, etc. Some of the fucts brought forward by Mr. Millardet seem to prove this. What has been said of Jacquez and Riparia show it as well. Consequently, the disorders which are followed by chlorosis aud appear so frequently after grafting will not here be apprehended, and the adaptation to the soil will be so much more easier on account of this.

It is to be feared that their grafts will be less fruitful than those of Riparia, Solonis, York, etc., but they will surely be more vigorous: besides they will always produce as much as the same French varieties, not grafted, of the same age and strength.

\section{PHYLLOXERA IN CHAMPAGNE.}

\section{REPORT BY OONSUL PRESTON, OF NIOE.}

So much has been said in the papers lately about the reappearauce of the phylloxera in the French vineyards that I thought anything on the subject would be useful to our viticulturist. The inclosed slip is taken from the Little Gironde of August 20, 1890, and shows the energy with which some proprietors are determined to act to destroy the pest and the prompt measures they have taken.

I seud inclosed the original article, with my translation, as an addenda.

Wm. S. Preston,

Consul.

United States Consulate,

Nice, August 20, 1890.

\section{PHYLLOXERA IN CHAMPAGNE.}

A prominent wine merchant of Champagne, Mr. Chandon, while waiting for sulphur of carbon to come from Villefranche, Rhone, had the vines attacked by phylloxera in the district of Treloup, Aisne, torn up and destroyed by fire. To one of our 
correspondents who criticised this way of doing Mr. Chatulon replied and gave the reasons that induced him to act.

"As soon as the news that the vines were touched with phylloxera reached me," he says, "I immediately proceeded to the land and satisfied myself that the disease dated at lerist from four years.

"Numerous delegates of phylloxera, commissioners, inspectors, etc., had been there, and nothing had been observed by them during four years. No sulphur of carbon prescribed; in fact, nothing dons. Without waiting for administrative formalities, so slow, or administrators who, without my initiative, would still be inquiring what was best to be done, I purchased the land and ordered the vines to be rooted up. At the same time I covered the land with straw satnrated with petroleum and fired it, in order to prevent the escape of a single insect. Then I had the land planted with clover. These preliminary steps closed as soon as the sulphur of carbon and poles arrived. The latter eight days after the phylloxera was discovered."

Mr. Chandon adds that in destroying the vines he pursued a twolold end :

First. He prevented the spread of the evil by the shoes and clothing of the crowds who came, out of enriosity, and walked all over the contaminated vineyard.

Second. $\mathrm{He}$ indicated, or used, the only practical remedy, namely, destruction when the disease is in its infancy. This system is practiced in Switzerland and Hungary with perfect success.

Mr. Chandon complains that the people of the locality refused to co-operate with Mr. Conanon, inspector delegate of the Secretary of Agriculture, and they were consequently obliged to wait a month after the discovery of the plyylloxera for credits, decrees, regulations, etc.

In comclusion, Mr. Chandon says :

"In order to prevent the swarming and subterranean propagation it is necessary to act promptly and at once, and I have contributed, I think, in the best way possible to destroy this formidable insect.

"I nention these facts to stop the malevolent insinuations which have been put in circulation.

"To conclude, growers can only preserve their vineyards by the formation among themselves of great syndicates, which will be able to indemnify fully proprietors of contaminated vines destined to be completely destroyed.

"This is the only sure way known to-day capable of hindering the progress of the invader and of protecting the rinegards."

\section{GIRONDE.}

\section{REPORT BY UONSUL ROOSETELT,* OF BORDEAUX.}

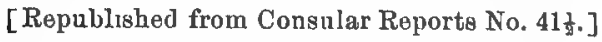

Soils.-The land more or less devoted to viticulture in the department of Gironde may be divided into six categories: (1) Alluvial or palus land, (2) rich, strong soil, (3) marly calcareous land, (4) gravelous land, (5) siliceous, and (6) sablo-argillaceous land.

The alluvial or palus lands lying in the bottom of the valleys are the result of the successive deposits of rivers. This category includes the drained marshes and substratum of the valleys.

* Consul Roosevolt acknowlerlyes bis indobtedness for the prenter part of the information contained in this report to M. Edoner I'eret, of Bordean, a recoguized authority and author on vine culture. 
The soil of drained marshes is mixed with mold, fine sand, and organical particles of regetable and animal matter; the subsoil is composed of clay, sand, turf, and sometimes marl. The nature of palus soil is simply that of the marsh where the alluvial ground has been drained and improved by culture. The best palus land is in the district of Lesplarre, in the cantons of Blanquefort, Barbon-blanc, Blaye, and Saint-CiersLalande, and borders the side of the Garome, the Dordogne, and the Isle. The wines of those vineyards possess color and vinosity, but lack delicacy of taste.

The highlands are those where the argils predominate; they exact, according to their nature, the assistance of manure, transports of light earth, and constant plowing. These lands are generally to be found on the hills and hill-sides; they have, in general, a calcareous or stony subsoil; this kind of soil is particularly appropriate to the vine.

The marly calcareous land covers a considerable part of the country; it agrees with the vine when sand, argil, or gravel forms an important proportion of the ground.

Gravelous land is the most favorable for vine culture as regards the quality of the production, and may be divided into two classes: (1) On gravelous land composed of stones or quartz, being about 3 foet in depth, and having a subsoil of clay and argil or alios, the best growths of Médoc and Graves are cultivated; (2) sandy, gravelous land, form. ing a composition of sand and stones, based on an inert sand or upon aliotic layers, is not propitious to the vine in consequence of the humidity of the subsoil.

The siliceous land covers nearly half of the department. It partakes of the siliceous nature, mixed with clayish, calcareous elements, which, when properly worked, is well suited to the culture of the vine.

The batardes, or terres batards, present an intermediate state between the rich land and the siliceous sandy lands; their fertility is more or less great according to their situation; the ordinary white plants grow in these soils with facility.

Subsoils.-The study of subsoils is also of importance to those desiring to cultivate vineyards. They have a considerable influence upon the snccess of the viue and upon the nature and quality of its production. I shall divide them in six classes: Argillous, sablo-argillous, calcareous, marly, gravelous or stony, sandy aliotic.

Argillous subsoil, when it is composed of close or compact argil, is hurtful to the vine, because it is moist, and in consequence the roots are easily attackerl by cold, and giving to the fruit a very definable earthy taste.

The sandy argillous subsoils are favorable to the vine, providing the sand enters for about one-half into its composition, permitting the water to pass through sufficiently to exercise a salutary influence on the roots-that is to say, refreshing them without leaving behind an unhealtby humidity; but then the vine on these soils is ordinarily mure 
cultirated with a regard to quantity rather than quality of its productions; meanwhile the soil is fertile, and admits of the finest vines being cultivated here.

The calcareous or marly subsoils are often compact and not suffciently porous, by reasou of which a free flowage of water is checked, and when near the surface of the soil they are extremely hurtful to the vine, they may, notwithstanding, be of great use by digging the ground and mixing it with the upper layers of earth. If these layers are sandy or sandy gravelous, a very favorable result may be obtained; but if composed of greasy sand, the mixture will not be so good. The nature of this soil is especially favorable to the white vine.

The gravelous or stony subsoils are very favorable to the vine. They present sometimes small siliceous stones or pebbles, white, gray, bluish, and transparent; these stones are termed "graves;" sometimes little blocks or stones of a dull opaque; sometimes also little pieces of stone or rock in the crevices of which the roots of the vine generally penetrate, thereby forming the base of a great hardiness and vigor for the plant, and of an agreeable, well-developed taste and flavor for the wines.

The sandy subsoils are suitable to the vine, because they permit its roots to penetrate to a great depth, to find the stability of temperature which is favorable to them. The most part of these soils produce a fine delicate wine, but lacking sometimes in body and color.

The aliotic subsoils, sometimes ferruginous, are impervious as those of the argil and marl; they furm a bed which arrests water, thereby rendering the earth too dry, especially if sloping; the water, following the bent of the incline, settles in the lower parts. When flat it is too damp, a defect, however, which can be easily remedied by digging up the earth to a certain depth. Under these circumstances, they are very much in request. The best vinejards in the Médoc are established on grounds of this nature.

Planting.- Before planting the vine the nature of the soil should be attentively studied, and the preparatory labor performed according to its species. It is most urgent that the rine should be sheltered from prolonged dampuess; to this effect the earth must be disposed in such a manner as to regulate the slopes and facilitate draiuage. If in a rery hard, argillous lind, called terre tape, or boulbaine, or tuf, the marl or alios should be found of shallow depth, the subsoils must be broken up to render them pervious and to mix them with the superficial layers of earth.

The earth, purified by the means above indicated, and by drainage whenever it is essential, deminds a most important operation-improvement aud manure.

To manure the earth about the rine is always a most essential preparatory feature, at least when not operating upon alluvial soil, but when this is the case a liquid manure is sometimes emplosed and poured in to the hole assigned to each plant. When planting superficial earth, 
which has not been before used for cereals, or which has not been manured for a long time, at least half a cart-load of manure is required for a row containing from 75 to 80 plants. In planting a feeble or used. up ground double that amount of manure must be employed. It is very important to have the plants well chosen; to this end it is only required that the foot or base should be healthy and vigorons, taking them only from branches having hitherto borne fruit. In certain communes each cutting has a little of the wood of the preceding year; but great importance is not attached to this latter precaution, as many succeed as well in planting the yonng eud. To replace the dead feet in a young plantation root-plants are sometimes preferred (called "chevelus" or "barbeanx") to the ordinary plants or layers.

This replacement is also made by "provins." The term "provins" is applied to a branch or tributary of the old vine-stalk, upon which new roots develop without separating it from the mother vine. In order to make a "provin" a long hranch is left upon the old vine-stalk nearest to the one to be replaced, and if possible in the same row; a pit is then dug, about 1 foot deep, between the two plants; it is then filled up with mold or mauure, if the earth be poor; the branch is then put into the pit without separating it from the mother vine, and the end raised in the place of the dead stalk; it is supported by means of a wooden stake, and requires to have its top cut off like the mouth-piece of a flute, care being taken that the bud should be on the side opposite the slope in order to avoid its being drowned or damaged by the flowing of the sap. The severing of the "provin" is indispensable to prevent the mother plant from declining or even dying. The scparation is begun after the second year by cutting on the branch a cross-section about one-third deep, and by completely cutting it the year after. These "provins," or layers, have the advantage of producing from the first year; it is admitted in the Médoc that every "provin" pays its expenses from the first year. The "provins" are made at the period when the sap begins to ascend into the branches, rendering them more supple; care is taken to make some slight incisions in the part of the branch lying under ground, so as to facilitate the growth of the roots. In the planting of the vine by layers I find that five different modes are $\mathrm{cm}$ played in the department. The three first are the most extensively used.

(1) Planting by reversion.-This mode is certainly the best, but also the most costly, inasmuch as the work for one acre costs about $\$ 117$. It consists in opening treuches in the direction of the rine-rows, a sufficient distance apart; the first trench being finished, the earth coming from it serves to fill up the last; manure is then thrown in and the plants, or " barbeaux," are placed in, being supported by stakes. The next trench then undergoes the same operation, and so on to the end. Planted in this manner the vine produces early, but is not of long duration. 
(2) Planting by staving and with a stake or bar.-Another mode generally used when the subsoil approaches the surface of the ground and when its nature renders it accessible to dampness, were it not broken up, consists in turning up with picks the subsoil of alios or clay to a depth of about 2 feet and mixing it with good earth or manure brought for that purpose. These operations being over, a crowbar is driven into the ground to make a hole, into which the scion is placed, and which is carefully filled up with earth all around the scion. Sometimes, in order to increase the adherence of the plant to the ground, it is watered with a kind of liquid mud or manure.

(3) Planting with the stake or bar.--This mode is certainly the simplest and most economical, but can be employed only in loose earth easily perforated and comparatively fertile. Pulverized and liquid manure is generally employed in this mode of planting. It consists in thoroughly plowing and harrowing the earth, after which a hole is made with an iron bar. This hole is sometimes enlarged by means of a wooden cone armed with an iron point in order to increase the quantity of manure given to the plant.

(4) Planting with "araire" or plow.-This mode, which is one of the less expensive, can only be used in deep soil. It is little employed. It consists in making a deep furrow by means of the plow and filling in with manure, placing the plants therein and covering the furrow.

(5) Planting in the little trench.-This mode has been for a long time almost entirely given up. It differed slightly with the preceding method inasmuch as a little trench one foot wide and one and one-half deep was dug instead of a furrow. All of these plantings are generally made in the months of February, March, and April, even before, weather permitting, and can be continued up to the middle of June, on condition that the plants be kept under ground in a northern direction, in order to prevent them from growing. Finally the plant is set up. right, earthed up, cut at the third knot above ground, and fastened to a little stake.

During the first two or three years after planting, certain vineyards of Médoc are tilled six times yearly, but for the greatest part tillage takes place but four times during the year. The young viues at this period require particular attention; they must be freed from snails as much as possible, and each year the plants which have not thrived must be replaced by layers. If amoug the plants that have succeeded there shonld be one or more of any kind not wanted, these must be grafted. Grafting, which was formerly occasionally employed by the vine-growers, is every day becoming more miversal; since the invasion of the phylloxera many fine plants have been ingrafted on American plants, which resist phylloxera.

Situation and care.-For the ridges there are no fixed directions; the slope of the ground is previously consulted, in order to facilitate drain. age withont risk of the subsoil being carried away. Some vine-growers 
(when the ground permits) set their ridges from east to west, asserting that the wind and hail come from the west; by this method the first feet of each row alone are injured; the others, affording mutual shelter to one another, have less to suffer. It is noticeable that this direction of east to west is practicable only in the Médoc, where the vines are very low, because the shade of any individual plant can not be preju. dicial to the others ; nevertheless, it sometimes happens that the land is not ereuly exposed to the action of the sun, which, of course, is not so favorable. Uther vine-growers plant in the direction of north to south, so that the rays of the sun may penetrate in to the vine rows as long as possible, in order to heat the surface of the ground and the different parts of the fruit in a more equal manner.

The soil, according to its condition, is tilled from two to four times a year, either by plow or by spade. The wages of laborers having doubled of late jears, the plow is consequently in greater use in most of the vineyard.

When the vine is stripped of its leaves and fruit laborers are employed to exannine each vine row, in order to weed out the quick or dog grass, which is very destructive. The old vine plants are often covered with a kind of moss which serves as a refuge for crowds of injurious insects to the vine. Some proprietors take the precaution to destroy them during winter; others do not attach the same importance to them. Since the appearance of the new disease of the vine, some proprietors have obtained favorable results from barking, by which means a great number of insects and their eggs can be destroyed, including those of the phylloxera.

Another part of the winter labor consists in removing the earth brought by the plow or by the waters into the "capvirades," a kind of alley made between the rows for facilitating the running of water and for allowing sufficient room for the teams to turn.

After the pruning, which should take place as late as possible, on account of the spring frosts, the laths and decayed stakes are replaced; the brauches or hastes are then fastened by means of a kind of rush to the nearest stave. The best season for this, as the hastes have frequently to be curred or bent, is when the sap begins to ascend into the branches, rendering the wood pliant. This work should be carefully avoided in dry weather. When once the vine is in good condition labor commences.

In the month of June the vine is nipped; that is to say the sap is stopped from going into the "suckers," thus named because, though possessing much rigor, they notwithstanding are unfruitful. The shoots or sprouts appearing on the old wood are cut off (at least, those not intended to become fruit-bearing branches). In July the vine is somewhat freed of its suckers, in order that the air may circulate round the plant and that the grapes may be better exposed to the solar influence. This also facilitates the passage of the plow. 
In August the leaves are thinned. This work does not take place every year throughout the department, particularly in those vineyards which only produce common wine. Great attention should be bestowed upon this work, in order to avoid too much exposure to the sun, and at the same time aid maturation.

Pruning is certainly the inostimportant operation that the vine claims from its care-takers. On this depends not only, in a great measure, the abundance of the crop, but especially the health of the plant. It takes place generally from the end of the fall of the leaf until the commencement of the hard frosts. Before this period the wood is not sufficiently ripe, and would cause the loss of a part of the sap. Later the cicatrice arising from the pruning would not have time to heal up before the sap ascends, and a serious flow would occur in spring. For some years past the vines have been considerably tried by spring frosts; it has therefore been judged wise, even at the risk of losing a small portion of the sap, to prune as late as possible, in order to retard the shoot. This is customary in the Burgundy vineyards.

It is recommended to vine-dressers, when operating, to have with them a little box of some fatty liquid, and to put a little of such on each wound made by the pruning, above all on the old wood, so as to protect it from the changes of temperature, which often cause the interior of the plant to decay. The pruning is couducted in two fashions: with a pruning-knife or with vine-scissors; this latter instrument is very expeditious. But in the Médoc, and many other places, they prefer the pruning-knife, with which the judicious vine-dresser carries on his work better, without iujuring the wood, cutting and paring here and there, where he thinks fit to do so, making incisions, lifting a very light piece of wood, etc. The vine-shears are preferable to the pruning-knife when cutting young vines which have no thick wood to take up. I shall not undertake here a treatise on the pruning of the vine, or an appreciation of the different modern systems. Such details would require a volume, and are consequently out of my compass. The value of these different systems is so intimately connecter with the vature of the soil and its situation, and with the nature and vigor of the plant, that I can not go further than commendiug practice, observation, and intelligence as the best guides to the vine-dresser. To the general information already given I may add the following fundamental principles:

Charge the vine only in accordance with its age and vigor; equalize the burden of the different arms of the rine, so that one side should not bear all the sap at the expense of the other; carefully sare on each plant the short cuts which are iutended to become fruit.bearing branches for the next jear, and which, being low shoots, keep down the vine, which has a tendency to spring up.

In the Médoc the vine is planted in rows which, according to the rineyards, vary between 180 to 300 feet in length; the latter is seldom nsed, on account of the difficulty of trausporting manure, gathering the grapes, 
etc. In certain districts the rows are 3 feet apart; in others, a little less. The plants are more or less distant, according to their nature and that of the soil ; this distance varies from 3 to 4 feet. The trunk of the plant is from 6 to 8 inches long, and fixed to a little stake about 15 inches high; laths are attached to the tops of the stakes, and to the laths are fastened the two arms of the vine. For some years past these wooden laths have, in several vineyards, been profitably replaced by iron wires. This system, which presents great advantages above all in an economical point of view, has been in use for the last twenty-five years by Monsieur Richier, the inventor, and by his heirs, in all of their vast vineyards.

The stakes are sometimes of pine, but more generally of chestnut wood; the latter cost from $\$ 2.30$ to $\$ 2.70$ the thousand, while the former, which do not last so loug, cost from $\$ 1.35$ to $\$ 1.55$. The laths come from the west of the Médoc, where for some years past pines have been grown on a large scale. When delivered at the vineyard they cost from $\$ 3.85$ to $\$ 4.80$ the thousand.

Pruning.-On the first year of planting the vine is pruned from the two eyes nearest to the ground. The second year the process is performed in the same manner. The third year, when pruning, three or four buds are left untouched. In strong earth the weaker plants are cropped short; but two arms are left to the most vigorous plants. The fou th year, in light soils, arrangements are commenced for establishing the two arms; in heary soil this operation is completed, the trunk of the vine is then made 6 inches high, so that when the plant is earthed up the arms start almost on a level with the top of the ridge. Special care should be taken that the arms follow the direction of the laths. The vine always having a tendency to rise, great attention is paid to -save, when pruning, the short cuts which are intended to become fruitbearing branches, in order to be able to cut off the old wood when it becomes too long. The fruit-branches are chosen from those of the preceding year, near the old wood; the under branch is chosen by preference, so as to avoid the plant rising too quickly.

The branches are allowed $13 \frac{1}{2}$ or $15 \frac{1}{2}$ inches in length ; they are fastened horizontally to the lath; this is intended to equalize the distribution of the sap, and to form at the base of the branches a proper wood for renewing the vine. Une, two, and sometimes more of the last buds of the branches are taken off to increase the strength of the shoots produced by the others, and to fasilitate fastening. As soon as the pruning is over, the branches gathered up, the different kinds of winter work concluded, such as the clearing of the dog-grass and of the moss covering the trunks of the old vines, the transports of earth conveyed from the alleys to the middle of the ridges, and the vines propped, plowing commences. Four plowings are made; the first one toward the end of February or the beginning of March. The object of this is to "open the vine," according to the expression of the country; that is to say, to 
uuearth it; but as, in plowing on both sides of a row, the earth can not be raised between each plant, women pass behind the plow with a hoe to take up the earth and spread it in the middle of the rows. The second plowing generally takes place in the middle of April, with a plow of a peculiar shape called "bent." Its purpose is to earth up the vine, so as to spread about the foot the earth taken off by the last plowing. When the viues are young or surrounded by the young plants, a woman with a shovel follows the plowman and lays her shovel between the plow and the young plants or layers, so as to aroid their being stifled or bent by the earth. The third plowing takes place in the month of May, before the flowering, and is exactly the same as the first one. The fourth takes place at the end of June, after the flowering; for this the special plow called the "bent" is again used. After the fourth plowing, women or children pass down the rows to raise the young bunches which are sometimes a little earthed up. It is also at this time of the year that the leaves begin to be thinned more or less, according to the strength of the vegetation and to the tempera. ture.

In all vineyards a constant war has to be mado against the destructive insects which swarm in them, especially suails. Many proprietors in the Méloc keep for this purpose hens and ducks, which go iuto the vineyards to feed on these parasites; but care is taken to remove them in due time, in order to avoid their iujuring the new bnds or attacking the grapes.

Expenses of culture.-The expenses of culture in the Médoc vary according to the communes, and, above all, according to the facilities of working. (1.) A small property caltivated by the hands living on the place has hardly any expenses beyond the keeping of the rive-dresser and his family. (2) A large property requires a manager, with foreman, laborors, vine-dressers, etc. (3) A middle-sized one is cultivated by the proprietor, who hires a team of oxen and oversees his laborers. Each of these properties not only has different expenses of culture, but obtains different prices for the products.

The "prixfait," or "agreed price," is the name giren to a certain space of ground, for the culture of which the price has beeu agreed in adrance.

Expenses for " " mix-fait" composed of 24,000 rines, llanted about 1 yard apart and occupying about 6 acres of land.

The following necessary expenses attendant on the vineyard are almost invariable:

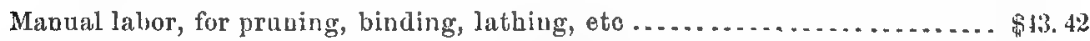

Manual labor, for clearing away the clog grass....................... 4.63

Purchase of 10,000 stakes, at $\$ 2.02$ tho thonsant...................... 20.20

Purchase of 5,000 laths, at $\$ 3 . r i$ the thousand ......................... 19. 30

Purchase of 10 shoaves of binding roeds, at 1.16 ach .................. 11.60

Four plowings and a winter supplementary plowing ................. 52.11

One hundred and fifly days' wages to the women for rnising the vines, destroying the insects, unearthing the young branchos, eto., at 19 conts..... 
Layers

Expenses of vintage of 5 tuns, at $\$ 6.75$

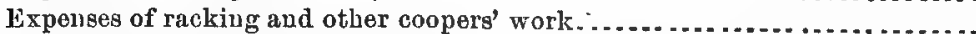

Purchase of twenty casks, at $\$ 3.47$.

69.40

Expenso of delivery at Bordoaux for $4 \frac{1}{2}$ tuns

4.82

303. 17

Expenses varying according to the nature of the soil and according to the proprietors.

Sulphuring : Lalor and purchase.

Manuring 5,000 feet a year: Manual labor, at $\$ 2.70$ the 1,000 feet ...........

13.51

Purchase of manure or mold : 92 cubic yards, at $\$ 1.18$

108.56

Cleauing of the trenches and vine-tracks, hanling earth, eto .:

17. 37

General expenses incumbent on the vine domain.

Taxes, duties, etc

Keeping the buildings in repair.

Overseeing and sundry details.

Keeping the stock in good order (wine-vessels, etc., wheelrights, black-

smiths, farriers, etc.) ..................................................

Wear and tear on teams, harness, etc ....................................

Renewal of the vineyard, 2 per cent. every year..........................

Interest on advances, six months, at 5 per cent. per annum.

Total general

Average yearly revenve, supposing the sale of 5 tuns (20 casks) of wine at vintage time at $\$ 168.87$ per tun

844. 35

To be deducted :

7 per cunt. discount aud brokerage ................................ \$59. 10

3 per cent. waste for 6 months................................ 33.77

If from this be deducted the expenses for culture (\$606. 21), there remains $\$ 145.27$, representing the net yield of each " prix-fait," corresponding to about $6 \frac{1}{2}$ acres $(6.42)$, which makes $\$ 22.63$ per acre.

If a vineyard of superior table claret be valued at $\$ 390.50$ per acre, it will be found that it yields a net revenue of 5.80 per cent. per annum. Such a revenue can be obtained only by those who can afford to approprate a certain amount of money to improve the estate. A yearly outlay of about $\$ 485$ per acre is indispensable, and has to be repeated for several consecutive years before giving any profit, because the harvest is generally sold only after two or three years, in order to gire the wine sufficient time to acquire its qualities and realize a fair price.

The sum of $\$ 485$ per acre is overreached in some of the famous vineyards of the Medoc, where the care and treatment of the vines and wines are almost luxurious. Extravagance may well be afforded when the wines are sold from $\$ 380$ to $\$ 580$ the tun of four casks. In this case the capital represented by the vineyard is much more considorable than the foregoing valuation, and the price of the land rises proportionately 
to the produce of the vines and the price of the wines. The vineyards at Château-Lafitte are valued at nearly $\$ 4,700$ per acre. On the other hand, there are many vineyards in the Médoc-in fact, the majority of them-whose wines at vintage time do not obtain quite an arerage of $\$ 16 \mathrm{~s}$ per tun. Yet most of those vineyards are worth $\$ 390$ per acre. In fact, good management, a thorough experience in the watter, and money adwajs in readiness, are indispensable conditions for success.

\section{GEO. W. ROOSEVELT,}

Consul.

\section{United States Consulate,} Bordeaux, January 23, 1884.

\section{ITALY.}

REPORT BY OONSUL.GENERAL RIOHMOND, OF ROME.

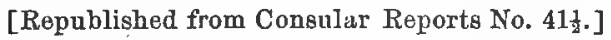

The vine in Italy is cultivated on the plains, in the valleys, and up the sides of the mountains to an altitude of 500 and even of 600 meters above the level of the sea. On Mount Etna the cultivation is successfully prosecuted at an elevation of 950 meters above the level of the sea. Along some portions of the coast the rineyards are brought close down to the edge of the sea, and the vines are planted right in the sand deposited by the action of the waves. In this latter case, however, it has been found that the sea-breezes are often hurtful to the vines, but no remedy has ever been thought of to combat the evil effects resulting therefrom.

The Italians cultivate the vine in vineyards, which are exclusively devoted to that end, or in orchards in conjunction with other fruits and vegetables. In many places the vines are only allowed to reach a low growth, and are not supported by props, while in others they attain a medium height, and are supported by poles or trained along wires. When trained to a greater height they are attached to trees, of which latter the most affected for the purpose are the black poplar (in the Campagna), the white poplar (in Tuscany), and the elm (in Emilia). There are also trellises especially adlapted for the training of grapes in. tended for table use. All these different methods of vine-culture are to be found in the same sections, only varying with the different conditions of the soil, the qualities of the vines, and the exigencies of the wine trado.

With regard to the soil, it may be stated that in Italy the vine is cultivated pretty much everywhere. But there are certain qualities of soil which are more favorable than others to secure a desirable result as to quality and quantity of crop. The most productive vines are those growing in localities suljject to inundations, and the best quality of wino is produced by the vineyards plinted in light gravel soil of the hills, 
containing a certain quantity of oxide of iron. In porous volcanic soil the grape is of excellent quality, and the wine obtained from the growth on chalky soil is very highly esteemed. The best Chianti wine comes from a slaty soil of reddish color, containing a certain percentage of carbonate of lime, and in the hilly districts there is considerable chalky soil not adaptable to any other use than that of viticulture. In the majority of the vineyards where the custom is to plant the vines in rows, and train them on trees, the intervening spaces are cultivated in the usual rotations of planting, but care is taken to avoid such growths as might be incompatible with the successful development of the vine. In low-growing viueyards, however, no other culture is ever prosecuted.

It is not generally customary to irrigate the vine, althongh it is sometimes done with marked success. Drainage is always carefully provided for in the vineyards.

The average yield of wine to the hectare may be set down as 14.29 hectoliters. The yield in Veneto is only 10 hectoliters, but in Piedmont it reaches 23.07 hectoliters to the hectare.

The cost and mode of planting vineyards vary considerably according to locality. In Viterho the vines are planted some 18,000 to the hectare, and are trained on poles at an outlay of $1,823.58$ lire to the hectare, for the first four years, and the cost of maintenance averages 383.03 lire, while the average yield to the hectare is 33 quiutals of grapes. At Bari, in Altamura, the vine is cultivated without props, and the cost of planting 6,200 vines to the hectare is $1,215.24$ lire, the annual cost of maintenance is 266.86 lire, and the average yield per hectare is 25 quintals of grapes. In Tuscany the vime is also cultivated without props; the planting per hectare costs 2,518 lire; annual cost of maintenance, 466.12 lire, average yield 49.50 quintals to the hectare.

\section{LEWIS RICHMOND, \\ United States Consulate-General, Consul-General. Rome, April 1, 1884.}

\section{TUSCANY.}

REPORT BY OONSUL WELSH, OF FLORENOE.

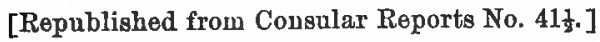

To the cultivation of oranges, lemons, and figs little or no attention is given in Tuscany. More attention is paid in Tuscany to vine culture than to that of olives, inasmuch as the grape-vine is less delicate, and withstands better the severity of elimate and variety of soil. Excepting in some mountainous regions, it may be said that the grape is cultivated all over Tuscany.

To enumerate the different vines of Tuscany would take up too much space. For the province of Florence alone there are about 150 different 
varieties grown, of which two-thirds (or 100) produce raisins and grapes for table use, and, with the others, the grapes are made into wine.

The systems of cultivation are not less numerous than the varieties of vines. There are vines disposed in the French system, trained low and in rows at a meter ( 3 feet 3 inches) distance one from the other, supported by iron wire or stakes; low vines placed in rows on the edges of fields; vines stretched between maple trees, elm trees, or poplar trees; low vines in rows over the trees, and in the neighborhood of Pistoia and Lucca many vine arbors.

Vines are reproduced sometimes with sprigs, but generally by shoots left free for two years in the ground, which should be well dug at the commencement and end of each summer. The third year the shoots are dressed and the most vigorous selected. Two or three sears later the vines are affixed to stakes and the year following the grapes appear. Ditches measuring 1.20 meters (4 feet) in width aud depth are dug for planting vines at a distance varying from 60 to 70 centimeters ( 2 feet) for rows with low vines, the distance being less on the hillside than in the plains.

At Val di Nievole, in the middle of a field surrounded by vines, a row of mulberry trees is always to be found, and on the sea-coasts of the Lucchese olive trees are to be seen along the edges and rows of vines in the interior of the fields. Olives and vines are often grown together.

The pruning of the vine is done before or after winter. For rines united to trees, two systems of pruning are in use, viz piegatoio, or tralciaia, and penzana, or catena. The former is the most common, and consists in twisting two vigorous shoots, to which twenty or rnore cuts have been made, and tied to a supporting branch with the extremity turned down. For the latter the shoots are preserved much longer, twisted with another vine and supported by another stake. Low vines are usually pruned on the system "cornetto," viz, with two, three, or four cuts, according to the variety, and while growing they require the taking off of the tops of the shoots, they being tied to a stake whenerer they are 50 or 60 centimeters ( 1 foot 8 inches or 2 feet) long, and tied again when they have reached the height of the stake; and finally twisting the extremities of one vine with another, so as to make an arch, which last operation is made when the grape is already completely formed. In the vinevards managed according to the French system the soil is spaded in the spring, and also in August, and each year well manured. The vine thrives throughout all Italy, needing a sunny expo. sure in northern Italy, while in the middle and the south it thrives equally well in valley, table, or hill-side lands, but jwelers a rongh soil, far from moist or foggy localities, and avoiding ground excessicely com. pact or clayey. Stouy soil, if sufficiently watered, is well adapted to vine culture.

United States Consithate, Writ. L. WeLsI, Florence, llerelh 17, 1884.

Consul. 


\section{VENETIA.}

REPORT BY CONSOL NOTES.

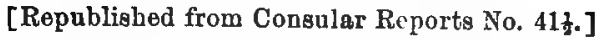

OLIMATE AND FRUIT-GROWING IN I'TALY.

While it is true that the soil and climate of Venice seem specially favorable to the fruit of southern regions, and while in fact almost every species of such fruit ming be produced in some specially favored spot of its territory, even the palm tree flourishing unsheltered at certain wellknowu points of tue Riviera, yet this is far from being a tropical country; and when it is remembered that Naples has almost exactly the latitude of New York, that Venice lies farther north than Halifax and uearly on a line with Mackinaw, regions where fruit-culture of any kind is rather precarious than otherwise, it will be evident that with all allowance for the isothermic variations of the two continents, the success of such semitropical fruits as oranges, lemons, and olives must always be partial, and dependent rather ou exceptional advantages of situation than on the normal conditions of the country and climate.

That vegetation so foreign to the latitude should find a congenial home in Italy is mainly due to the topographical. peculiarities of the region, as is proved by the abrupt transition in crossing the Adriatic to the inhospitable climate of the Balkans. The semicircle of the Alps, shutting out the vicissitudes of temperature caused by the action of frost and thaw on the plains of Northern Europe, leaves these narrow shores only open to the genial rays of the southern sun, and to winds charged with the heat of Africa and the nooisture of the intervening sea. The influence of these exceptionally favorable conditions is strikingly illustrated by the fact that while the orange and lemon are in their natural element only in Sicily, the point where, after Gibraltar, Europe approaches nearest the coast of Africa, yet, strangely enough, the only other locality where their production becomes a profitable industry is found at the northern extremity of the kingdom and almost in the heart of the Alps. All travelers are familiar with the olive plantations of Northern Tuscany and the Riviera of Genoa. The oil of Lucca is proverbial for its excellence, due evidently, with the prosperity of all this favored region, to the redoubled barrier of the Apennines, a protection not only from the rude climate of Northern Europe, but from the chilly influence of the Alpine snows as well, maintaining here perpetual spring even when winter reigus on their sheltering heights

\section{VINE-GROWING IN VENETIA.}

The vine, on the contrary, thrives anywhere with the luxuriance of a native product, finding all its requirements satisfied by the relative warmth which barely suffices for more sensitive plants, and finding, be$150 \mathrm{~A}-29$ 
sides, in the volcanic origin of much of the Italian soil the elements best suited to nourish its vigorous growth: This natural adaptation, and the extreme facility with which it lends itself to every situation and every mode of treatment, have, by allowing the persistence of antiquated methods of cultivation, almost as effectually as the difficulty of succeeding with the more exotic plant, maintained the present imperfect and unsatisfactory state of the industry. Until very recently no efforts have been made to improve the stock of vines or the appliances and processes for the manufacture of wine, and no standard types exist to fix any permanent character for the one or the other. The plants change their nature and name as they change their locality; the same product bearing different names, or the same name applying to different varieties in neigh. boring regions, while the quality of the wine depends on the accidents of the season and the chances of unintelligent manipulation. Including all the slight variations caused by climate and situation, and known only by their rustic names, some 125 varieties of red and 70 of white, grapes are counted in the territory, mostly belonging to the species Vitis Vinifera, a few to the Vitis silvestris.

ISLAND AND LAGOON VINEYARDS.

Of these, several of the sweeter and more delicate kinds, cultivated on the Lido and islands of the lagoon, are abundant in the market of Venice; but this very abundance and cheapness would make it seem here an idle superfluity to prepace them as conserves for commerce, and nothing of the kind is thought of. Besides that, being the lightest and least alcoholic of Italian grapes, it is doubtful whether theJ possess the strength and flavor desirable for the purpose.

The existence of these vineyards, surrounded by the sea, and often so low-lying that they must be defended from the invasion of unusually high tides, as well as the abundance and excellence of their product, is sufficient assurance that the situation causes them no prejudice. It seems, howerer, to deprive them of the vigorous flavor necessary to a good wine-grape; and for the sinall quantity of wine fabricated at Venice is generally used the fruit of the neighboring mainland. For this purpose the hill-side grow th has a traditional superiority well established here, as in all vine-growing countries.

The plants employed in these island vineyards are none other than the choicer varieties common to the surrouvding country. The Marzemena or Lugliatico (the Balsamina of the Romans) is a rine of medium growth and extension, the leaves indented to one third of their width, with branches of moderate size, aud grupes quite ronud, deep colored, and extremely sweet. Inland it thrives best in the ralleys and along the foot of the hills, and is used to color and sweeten the finest wines, but is too poor in tannin and salts to suffice alone. The Pignola (Pig. nola rossa of Tuscany), much resembling the above, but more robust in flavor, is prized in mixtures for its large proportion of salts. The Ver- 
diso and Bianchetto are the commonest of white grapes thronghout Northern Italy, and need no description. Besides these varieties, evidently of the ordinary stock, the red and white Muscadel are abundant, with larger and more oval fruit, of a decided musky Havor, called the Fragola (strawberry) grape by the Venetians, and a certain quantity of the small, deep-colored truit of the wild species, in long, close bunches, with the pungent sweetness every where familiar.

The absence of trees and want of space on the diminutive islands where these grapes are grown have made close cultivation a necessity. The vines are planted 4 and 5 feet from each other, in rows about 3 yards apart, and trained on gratings of lattice, slanted from about 5 feet 9 inches, the height of a man, to within $2 \frac{1}{2}$ feet of the ground, or else on upright espaliers or trellises around the inclosures or on the banks of the numerous canals and ditches which intersect these amphibious gardens in every direction. The plants are tended with the care and attention of the market gardener, and so far have been free from all the prevalent diseases of the vine.

The nature of the clinate is a sufficient guaranty against any risk of injury to the fruit from sea-fogs and mists, the long summer heats and frequent dronghts being the dangers most to be apprehended, and often compromising the success of crops of every kind. Fogs are rare at all times, and during the season of vegetation absolutely unknown, while the ordinary evening mist from the water does not prevail till late in autumn, when the sun, sinking early toward the horizon, loses somewhat of its dissipating power. The rare wet seasons cause an occasional falling off by preventing the full maturity of the grapes, but the permanent enemy is drought, which the vine certainly fears less than many other plants.

\section{VINEYARDS ON THE MAINLAND.}

On the mainland the plan is far from receiving the same careful and rational treatment. Every traveler has been charmed with the graceful luxuriance of the vine-mantled trees which border the routes of Northern Italy with their interminable festoons, and overrun the coun. try, making it an ideal picture of exuberant vegetation, but an example of the worst possible farming, say the specialists. From time immemorial the Venetian cultivator has imitated the simple arrangement of nature in marrying the vine to its primitive support, and the best proof of the inexhaustible fertility of the region is the fact that with such a system he succeeds in producing delicious grapes and passable wine. Efforts are made to introdnce vineyard culture, but the want of capital or impatience for hasty gain still prevails, and in the Valpolicella district of Verona, where the choicest of Venetian wine is made, the old system is universal, while in Conegliano some of the new plantations commenced under the auspices of the schnol there have been torn up, and the number of vineyards has rather diminished during the past tem 
years. The practice is the same for fruit or wine grapes, and the same varieties serve indifferently for both.

In this double cultivation the sustaining trees are planted some time previously, with the same regularity as the vines, from 3 to 10 yards from each other, and in rows from 10 to 30 yards apart, according to soil and situation, much deeper if possible, also, to avoid the interference of their root as well as to lessen the drain on the soil to the prejudice of the vines. The ash, maple, and cherry are generally preferred for the parpose, as less impervious to the sun, on the hill; the maple, elm, and poplar in the plain. After reaching the height of 6 feet, all the vigor of the young tree is confiued by pruning it to three or four of its most robust branches.

\section{PLANTING AND OULTIVATING THE VINES.}

The vine (and the methods of cultivation are given here with some detail, as they are the same substantially for all sorts of vines and in all parts of the territory) is reproduced from slips (magliwoti) carefully chosen from the best individuals, well furnished with buds, and cut near the middle of the bearing trunk with a small portion of the wood attached. Before planting, these slips are subjected to a sort of maceration, exposed to the sun with their lower ends immersed in running water. This softening process predisposes them to take root and bud more promptly. The are then planted by some cultivators in a nursery for two or three years, but most generally on their permanent locality, to allow the young vine to adapt itself at once to the soil in which it is to grow. The furrow is commonly 2 or 3 jards wide and half a yard deep, shallower in light and loose earth, but a compact or clayej soil should be broken as deeply as possible. At the bottom are often placed large stones or fascines of osier, a sort of rough sewerage to aid a freer circulation of air and moisture. On rocky hillsides it is also a means of economizing the scanty supply of vegetable earth. These furrows should be opened and well broken up some time beforehand, in autumn if possible, since the soil gains in quality by the action of air, sun, and frost.

The planting takes place with the opening of spring-from the middle of February to the 1st of April. The slips are placed fonr or five on each side and at 9 inches to 1 foot from the tree, disposing them in the best position to take root easily, and covering lightly at first with fresh soil and manure or vegetable refuse, to be filled up afterward with earth improved by exposure, according to the progress of the season, till the surface is leveled or the plant properly imbedded; rapidly in the plain, more gradually on the hillside, where the spring rains would soon wash away the unsolid mass, while on the contrary the cavity, aided by a little support of stones below, retains and profits by whatever they may bring from above.

The choicest and best cultivated vives of the region, those of the 
Valpolicella, often require to be terraced thus with a succession of sustaining walls, and are in such localities so closely planted that in a fow years the tendrils are festooned not only from plant to plant but from row to row-a thing never permitted in the plain, where this crossfestooning would obstruct plowing for other crops in the intervening spaces.

Gewerally both the vine and its support are pruned low and only allowed to spread horizontally, the vine, as it extends beyond its sustaining limbs, being led over their forks and left pendent till long enough to be attached by its extremities to those of a neighboring plant; more rarely bound to upper limbs it mounts to the height of the tree, siuce at a certain distance from the earth it loses its vigor and sterilizes. At Valpolicella, the sustaining plant, after reaching the neces. sary size and force, is often killed, that it may no longer rob the vine of its nutriment.

During the earlier period of its growth the vine is pruned rigorously to confine its rigor to the portion by which it attaches itself to the tree, lopping all but the clinging tendrils. Afterwards the practice is to retrench the higher shoots and force it to bear as low as possible, removing at the same time those which have borne for one or more years, the better to re-enforce those intended to bear the succeeding year. According to treatment and situation, the vine begins to give a profitable crop at from three to six years.

\section{VARIETIES OF GRAPE.}

Of the 200 or more indistinct varieties, confusedly attributed to the various districts of the territory, not more than 25 are cultivated to any extent or furnish a product of commercial value.

The principel of these for the district of Verona, the base and substance of its most generous wine, is the Corvina, a close-growing vine, whose branches, with little tendency to spread, are thickly budded and bear an unusual abnndance of rather small fruit in pyramid-shaped clusters. This grape is specially rich in all the elements for vinification, saccharine, saline, coloring, and tannic, and is at its best along the bases of the hills and in the upper valleys. On higher ground it changes its character somewhat, with lighter avd longer brauches; the fruit is less crowded and abundant, extremely sweet, and delicious for table use. As a rule, the red varieties succeed better on the hillside, the white in the valley, and the same plant removed to a bigher level changes more or less, the fruit becoming rarer and smaller, but more concentrated in quality, while both it and the stems take a deeper color. This alteration the cultivators call "ingentilire" The Corvina is the only grape capable of producing superior wine alone and without mixture, though to heighten its excellent qualities it generally figures only for $\mathbf{4 5}$ to $\mathbf{5 0}$ per cent. in the best fabrication.

Next in value is the Terodola, a plant more spreading than the above, 
with deeply serrated leaves, small but well-furnished bunches of round, thick-skinned, and very black grapes; affects the same localities with the Corvina, and makes strong, high-flavored wine, improved by mixture with the last named and others, where it serves best in the proportion of 20 per cent.

After these superlative products come the Rossignola, choice, also, but very delicate; thrives only in the best exposures, always the first attacked by epidemics, and requires constant sulphuration.

The Schiavo, a strong-limbed and vigorous plant, abounding with fruit; only tolerable for wine, but excellent for the table.

The Lambrusea grows wild in Tuscany; improved by culture and properly qualitied by mixture gives superior wine; and the Marzemina, indifferent for wine, delicious for eating.

Among white varieties, the Bigolona and Durassena, gathered extremely ripe and concentrated by drying, both make an exquisite dessert wine, the Vino Santo, so called because the grapes may be kept, and sometimes are not brought to press till Holy Week.

The Montenara and Torbiana are preserved more exclusively for the table during the winter.

Most of the white varieties may be kept and improre in flavor by dry. ing till the approach of spring. For this purpose the clusters are laid on a grating or hung from the ceiling in a well aired situation-a process as old and as well-known as the grape itself.

It is hardly necessary to make special mention of the grape cultivation in other parts of the territory, where the same varieties in less fa. vorable conditions are produced with less perfection. The whole range of country along the foot of the Alps is fertile in abundant and excel. lent fruit.

At Conegliano, to the north of Venice, as mentioned in my last an. nual report, the soil and situation are exceptionally well adapted for the culture, and a school has been established, aided by state and provincial subvention, for promoting more rational and efficient methods. The soil here is the most decidedly calcareous to be found in the territory, derived from the disaggregation of the masses of dolonite and oolithic limestone of the mountains above, and from extensire beds of marl lower down, largely mixed with fragments of the underlying porphyry, quartz, and granite. Where this soil rests on strata of loose conglomerate, as is generally the case here, the vine finds a congenial situation.

Here, to the contrary of Verona, the white wines succeed best. The Verdiso and Bianchetto have much local reputation, and, properly manipulated, make a good foaming wine of unusual body and flavor. The Prosecco, Pignola, and Basohero are also excellent, and are largely consumed in Venice and the surrounding country, though their want of alcoholic force prevents exportation to any great extent. 
The red wines of the Rabosn and Schéavo are also a permanent staple in the consumption of the eastern part of the territory, and all are ex. cellent for table use, being cultivated along with others for the exclusive purpose.

In proceeding westward the soil, with the constant predominance of the calcarcous element, but with a larger admixture of scoriæ and volcanic matter, lends itself to the production of stronger and richer qualities both of fruit and wine. This is particularly the case in the extreme westward districts of the territory, where the bills of Verona are almost exclusively.composed of the detritus of Cretaceous strata, mingled with quartz and the disaggregation of basalt and friable basaltic tufa. The vine prospers every where, varying with the differences of the region; sweet but light and watery on the limestone of the plain; deep colored, strong, and aromatic on the basaltic hills to the east; rough and tonic on the glacial accumulations beyond the Adige.

\section{INTEROROP OULTIVATION IN VINEYARDS.}

The practice of cultirating for other crops the spaces between the vines is universal; in fact, the vine can hardly be said to hare any distinct apportionmeut, but rather to be superadded as the necessary garniture of every field, which, regardless of its presence, is tilled in all respects according to the ordinary agricultural routine of the country, and this double culture only fails $"$ here the situation is so precipitous or so bare as to make any product but that of the vine out of the question.

\section{PROFITS OF VINE CULTURE.}

According to situation and treatment, the vine begins to become profitable at about three years, and is in full bearing at six.

Throughout the Venetian provinces in strong contrast with those of Lombardy, artificial irrigation is little developed; in several it is almost unknown, and where it exists is much more in request for meadow and other culture. The vine, intermingled with other crops, may receive an interloper's share of the common benefit, but the localities which it prefers, as well as the nature of the plant, mostly place it without the scope of ans special arrangement for the purpose. Occapying, besides, no special place in the apportionment of the farm, its balance of outlay and return is always liable to be confounded with the general mass of operations for the year, while the selling price of its product differing more widely with slight shades of real merit, and often depending on an artificial or fanciful value of appreciation, the ordinary calculations of commerce are not easily adjusted to it. Estimates vary greatly in official as well as professional publications. The following data, however, are the most detailed that $I$ hare been able to procure, and may represent one of the most successful and best-conducted vineyards of Verona: 
Expense per acre for harrowing, hoeing, ete............................ \$4.80

Expense per acre for manuring....................................... 3. 20

Expense per acre for pruning, osiers and stakes....................... 3.60

Expense per acre for leafing .......................................... 40

Expense per acre for sulphur ....................................... 2.40

Expense per acre for gathering ........................................ ${ }_{96}$

Expense per acre for bringing in................................... 40

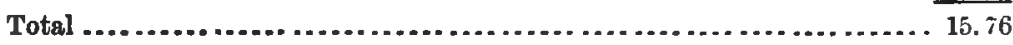

Product, 1, 200 kilograms of grapes, at $.04 \ldots \ldots \ldots \ldots \ldots \ldots \ldots \ldots \ldots \ldots . . \overline{48.00}$

'To illustrate the extraordinary differences of return to which the industry is subject, independently of outlay or treatment, an estimate purportiug to represent facts may be cited from a parliamentary return on the subject. The comparison is limited to a parcel of 60 vines married to 15 trees, and provided each with 5 additional sustaining stakes, and the expense incurred, in each case the same, is :

300 stakes, at 2 cents each............................................ $\$ 6.00$

Pruning (6 days' work) ......................................... 1.20

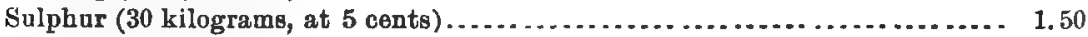

Sulphnration (2 days' work) ....................................... .40

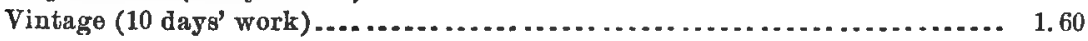

Total ....................................................

MAXIMUM PRODUCT.

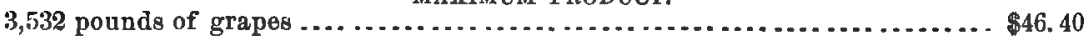

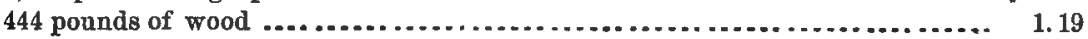

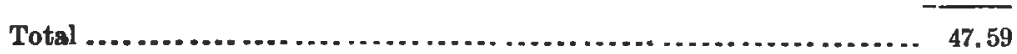

MINIMUM PRODUCT.

444 pounds of grapes........................................... $\$ q^{5} 80$

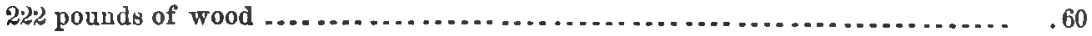

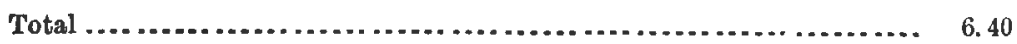

MoWALTER B. Noyes,

Consul.

United States Consulate,

Venice, March 3, 1884.

\section{RUSSIA.}

REPORT BY OONSUL-GENERAL STANTON, OF ST. PETERSBURA.

[Republished from Consular Reports No. 30.]

Along the shores of the Black Sea, Sea of Azof, and on both sides of the Caucasian Mountains, Russia possesses a vast territory devoted to the culture of the grape. Astrachan may be considered as the home of Russian grape culture, since the first vines were planted there at the 
beginning of the serenteenth century. During the latter half of the same century Russian vintners were sent to the river Terek, and laid the foundation of the present grape culture in that district.

In Transcaucasia the culture of the vine dates back to immemorial times, and the opinion prevails that the diffusion of the grape-vine over Lurope proceeded from this country.

In the Taurida peninsula and modern Bessarabia the grape culture owes its origin to the Grecian colonies founded there some six conturies before the Christian era. Old Grecian amphora, which have been found on the banks of the Don, justify the inference that the Greeks extended the culture of the grape to these districts also.

In the Orimea, grape culture attained its prime between the eleventh and fifteenth centuries, under the dominiou of the Genoese. Under the Tartars, however, it fell into decay, similar to that of the Caucasian districts under the rule of the Turks and Persians. With the accession of the Russians the grape culture began to flourish again, and was extended by them to the Kuban and Terek districts.

In the following short review of the grape culture in the various districts of Russia, the data given (with the exception of Bessarabia and the Don districts) refer to the period of 1870 and 1874.

\section{GRAPE CULTURE IN EUROPEAN RUSSIA.}

1. In Bessarabia the culture of the vine extends over the whole Government and into the bordering districts of the Governments of Kerson and Podolia. In 1870 the yield was 965,250 gallons of wine, and, according to official data, in 1879 Bessarabia alone produced 18,756,000 gallons. The wines are generally light, the red varieties resembling the French, the white the Rhine wines. The wines produced in Bessarabia from French and Rhenish vines are known in trade as Bordeaux, Burgundy, Rhinewine, Sauterne, etc., the label indicating also the district in which the wine was grown. The best known are the Ackermann, the Odessa, and those of the Bulgarian colony. The majority of the grape-growers sell young and unfermented wines to dealers, and in the whole district but six wine-growers made and sold a finished wine under their own names.

2. In the Orimea grapes are cultivated throughout the whole Taurida peninsula, but only four districts are of importance, viz, Yalta, Eupatoria, Simferopol, and Feodosia.

Compared with the rest of Russia, grape culture has attained its greatest perfection in the Crimea. The newest methods are adopted, and relatively a large number of vine-growers, particularly those on the southern shores, make and sell their own wine under their own names in St. Petersburg and Moscow.

The Government has paid the greatest attention to grape culture in the Crimea. In 1812 the Imperial Nikita garden was laid out on the southern shores in the vicinity of Yalta; and in 1828 the Margaratsch 
school of vine culture was established. In 1868 the above-mentioned garden was transformed into the Nikita vintage and gardening school, but Margaratseh school remained unaltered, in order that the students of the Nikita institute might learn grape culture practically.

In 1870, 3,037,500 gallons of grape juice was pressed in the Crimea. The yield of this district has steadily increased since the beginning of the present century, viz, in $1823,466,154$ gallons; $1819,2,119,000$ gallons; $1853,650,000$ gallons; $1870,3,037,500$ gallons. In the district of Yalta the yield has increased as follows, from 1861 to 1871, viz:

Gallons.

1861-1863, annual average ...................................... 29., 854

1 1 664-1866, annual average....................................... 382,846

1867-1869, annual average.................................... 566,557

1870-1872, annual average ...................................... 1, 130,676

The Crimean vintners pass the grapes through a kind of grater, in order to separate them from the stems, the juice flowing into donblebottomed vats, the upper one being perforated, and the berries are then put in the press. Ordinarily the wine-presses are of wood and of the simplest construction. The must is filled into casks, in which it rem'aius 24 hours, when it is poured into other casks, where it remains fermenting from 10 to 12 days, being kept at a temperature of from $16^{\circ}$ to $22^{\circ}$ Celsius. When fermentation ceases the partially empty casks are refilled. The first transfusion takes place in December, the second and third in March and September. For clarifying, gelatine and isinglass are used, and at times, for red wines, albumen also. The majority of the vine-growers sell their wine to wive dealers in unfermented and unripe condition, by whom it is perfected and put upon the market. In the main the Crimean wines are knowu by the name of the estate in whose cellars they have ripened, sometimes by the name of the grape they are pressed from. They are consnmed throughout Russia and also abroad. In 1872 and 1873 the Yalta district exported 364,443 gallons and 212,904 pounds of wine.

3. The Don wine district lies in the Government of the Cossacks, and owes its existence to Peter the Great. Up to 1820 the annual yield was not more than 65,000 gallons, while in 1870 it was not less than 4,875,000 gallons. The grape-growers seldom make any wine themselves, but sell their crops to wine-makers called "Vinniki." Fresh and dried grapes are used for wine-making, and that made from the latter is the best and strongest. The wine is seldom ripened and clarified by the "Vinniki," but transferred by them to wine dealers for this purpose. Geverally the Don wines are light, watery, and keep badly. A certain quantity is employed in the manufacture of "Don cham. pagne." Those vine-growers who make wine for their own consump. tion pay the greatest attention to its manufacture, and produce an article which will compare favorably with many a European wine. These wines are not in the market, however, but only the very inferior article produced by the "Vinniki."

4. The Astrachun wine district embraces the lower reaches of the 
Volga lying in this district. The wine production is unimportant, since the grapes, which enjoy a good reputation, are sold as fruit. In 1870 not more than 48,750 gallons were produced, and, according to official data in 1880 , one firm made $\$ 15,000$ worth of wine.

\section{OAUCASIAN DISTRIOTS.}

The culture of the grape is carried on north of the Caucasian Mount ain chain in four districts, viz, the Kuban, the Kumaschia, the Terek, and the Daghestanian. The Terek-Kunyksian district produces the greatest quantity, viz, in $1870,4,875,000$ gallons; in 1874, 9,750,000 gallons. These wines are quite celebrated among Caucasian wines, about 1,625,000 gallons being sold annually at the Nischni-Novgorod fair. Grape-pressing in this district is done in vats and troughs, with the hands and feet. The must ferments in casks, in which it remains until autumn, when it is clarified and put on the market. The Kuma district ranks second, and produces annually from 812,000 to 975,000 gallons. The wine of this region is sold after the first fermentation, is light and watery, and consumed chiefly in the Novgorod and Black Sea districts. In Daghestan about 487,500 gallons of a wive is produced which is chiefly consumed by Cancasian Mussulmans. In the Kuban district grape culture is of recent date, and the wine produced is consumed on the spot. In 1870 the production was about 18,200 gallons; in $1873,33,508$ gallons.

In Transcaucasia not less than $32,500,000$ gallons of wine are annually produced. The province may be divided into five districts, viz :

1. The Rion-Black Sea district, which yielded in $187010,725,000$ gallons ;

2. Kachetian, yielding $9,725,000$ gallons;

3. The Kura district, with an annual production of $4,872,500$ gallons;

4. The A rax district, yielding 3,250,000 gallons ; aud the

5. Shemahka district, producing 325,000 gallons.

The Oircassian wines are for the most part consumed in that province, but latterly the better varieties are finding a market in the leading cities of Russia. The best wines are found in the Kachetian and Black Sea districts, where red wines especially are of good quality. The Government of Erivan produces the strongest wines. Only about one-third of the annual production finds its way into the markets, the larger portion being reserved for private consumption.

In Kachetia the vintners erect a peculiar style of barn called " ma. ralyen," in which are placed wooden or stone presses, whose floors slope to an opening for the issue of the wine. A bove the press is a beam, to which the laborers eling whilst treading out the grape juice with their feet. Earthen jars serve as receptacles. The must first issuing is separated from that resulting from an increased pressure. The former yields a poor and weak, the latter a better and stronger, wine. The fer. mentation takes place in jars. White wines ferment from eight to ten, 
red wines from three to seven, days, when they are transferred to new jars. The lees are used for the distillation of brandy. The wiue remains in lightly closed jars, which are buried in the ground until December, when they are hermetically closed and covered with about 2 feet of earth. This method of wine-makiug prevails, with slight alterations, throughout the Caucasian wine districts. In Transcaucasia the wine is transported in goat-skin bags, and generally sold in them. The casks are smeared with fat or kerosene, which gives the wine a disagreeable taste. The rine is also cultivated in Turkestan, and to some extent brandy and wines are made.

\section{RUSSIAN VS. FOREIGN WLNES.}

The great drawback to Russian wines is the faulty manner of preparing them, which leaves much to be desired, especially as regards their keeping qualities. There is, moreorer, a great deal of mixing and adulteration practiced in the districts where the wine is grown. Wines of various vintages are constantly mixed, causing a great variation in the quality of the wiues. Dealers are also in the habit of adding various ingredients to the unripe wine for the purpose of connterfeiting the better known varieties of foreign wines. Laterally, in consequence of the depredations of the phylloxera in France, foreigners have appeared in certain districts who buy up the now wine and export it abroad, whence it returns labeled as French wine. The habit prevailing in so many lands of giving the foreign product the preference over the home. made article is a serious obstacle to the development of the Russian wine trade. The majority of Russian consumers prefer the imitations sold as Madeira, Sherry, Bordeaux, etc., to the natural Crimean wines.

The Crimean, the Kachetian, the Bessarabian, Don, and Astrachan wines are better than the others. All have not been carefully analyzed, but in 1864 and 1870 many of the better rarieties were analyzed in Moscow and Odessa. The dessert wines have the greatest specific weight, the table wines (vins ordinaires) the least. All carefully-prepared and well-fermented Russian wines are as a rule stronger than foreign wines made from the same varioty of grapes.

The Russian wines, classified according to their acidity, rank as follows, viz: The Bessarabian red wines are the sourest; then come the Caucasian and Crimean red wines, the Caucasian and Bessarabian white wines, and the Crimean dessert wines. Altogether the Russian red wines, as regards acidity, resemble most the French red wines; the white wines are less sour than the German wines. The Russian red wines contaiu more tannin than the French ones, while the white wines have little or none.

\section{TOTAL WINE PRODUOT.}

The grape-growing districts of Russia aud Oaucasia yield annually not less than $48,750,000$ gallons of grape juice, nearly $16,125,000$ gallons 
of which are consumed on the spot, the remainder coming into the general market. The following table shows the relation of that consumed by the vintners to that consumed by the public.

\section{Edgar stanton,}

Consul-General.

United Sta'tes Consulate-General,

- St. Petersburg, February 13, 1883.

\section{SPAIN.}

\section{DENIA.}

\section{REPORT BY OONSUL ARQUIMBAU.}

[Republished from Consular Reports No. 411.]

The production of raisins in Denia for 1883 amounted to $2,800,000$ boxes, of 28 pounds net each, valued at $\$ 4,200,000$; the crop is considered to be about the same as that of last year.

These raisins are principally consumed in the United States and England; the exports to the former amount to 979,000 boxes and to the latter $1,385,000$ boxes, leaving a stock in the country of 436,000 boxes.

The consumption in the United States has increased, although the price has been $\$ 1$ higher for each 112 pounds during the past two years. I also observe that the fine qualities, such as those called "selected," have been in much request of late. Previously this grade was mostly - consumed by the English markets.

All raisins are prepared here by scalding, and the system is as follows: They construct furuaces of feeble draft, in which wood is used as fuel. A round kettle, varying in capacity from 300 to 400 liters, receives a lye formed from the residue or refuse of the grape after pressing. The lye used is either that obtained from the present year or that which has been kept from the previous vintage. Placed in wire colanders, with long handles, containing 20 pounds each, the raisins are plunged in this lye, boiling at a temperature of about $212^{\circ} \mathrm{Fahr}$. After this immersion the workmen examine the skins to note if they are sufficiently shriveled, and if not they are immersed again. Thus scalded, they are carried to the drsing place, and, after a space of seven to ten days, from thence to the stores, where they are packed in boxes.

The process of immersion is a very delicate one, and requires skillful watching and great judgment on the part of the workmen who conduct it. In reality, according to the quality of the skin, its resistance, which varies with the fruit, the immersion should be more or less rapid, at the risk of having the grapes burst; besides, much skill is necessary to recognize the fissures which may appear. When the heat has been too great, the raisins too rich in sugar will mold shortly after having been packed. This process has the advantage of drying the fruit more rap- 
idly than when only exposed to the sun, and avoiding by this chances of being damaged by rain while drying.

American ships.-None have visited this port for many years, the entire freight business between this port and the United States being done by English steamers, which, from Augnst to December, average three a week, loading from 200 to 1,200 tons each.

Lumber for boxes.-Lumber being scarce and dear, it is largely imported into this district from Norway and Canada, for the manufacture of boxes for raisins and oranges. The last transaction I have information of was at $£ 8108.11$. for spruce, St. Petersburg, standard 3 by 9 with deal ends. It seems to me that a portion of this business could be done, if well looked after, by dealers in the United States. So far I understand the business is transacted through London dealers with the said mentioned countries.

John D. Arqumbau,

Consul.

United States Consulate,

Denia, December 31, 1883.

\section{MALAGA.}

BEPORT BY OONSUL MARSTON.

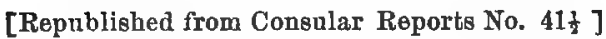

Climate.-The climate of Malaga bas the reputation of being the finest in the world for persons suffering from cousumption and all diseases of the throat and chest, and many invalids are ordered by their physicians to this part of Spain, their only hope of recovery, or, in some instances, to extend their lives for a few short months. In many cases they die, away from family and friends, from the lack of mauy comforts easily obtained at home, but which a stranger never finds while temporarily residing in Malaga.

People in Malaga during the winter seasou wear as heavy elothing as they do in the coldest season in America, but instead of wearing this heary clothing in the open air they wear it in the house. Outside the air is balmy and spring-like, but the massive stone-built houses are cold with their marble floors (eren to the fifth story), and in your walks along the promeuades you will find the residents walking dressed in almost spring-lize costume, while in your social visits, an hour afterwards, you will find thom wrupped in shawls and cloaks suffering from the damp cold which a small fire would instantly dispel. One day of such experience would affect a person suffering from consumption more than a whole winter in a colder climate where home comforts could be more easily obtained.

The hotels or boarding houses here offer no comforts to invalids; they 
have no fire-places; the floors, of marble or brick, are uncarpeted, and the portióres and table-covers, if the rooms possess any at all, are faded and covered with the dust of ages. The fare of the table is generally of Spanish cookery, which, though sometimes not bad to one in health, is not such as an invalid could eat, and not nourishment in any sense to one of feeble digestion. Unquestionably the climate would arrest disease if its hand was not too firmly posed; but without the aids of comforts, which are nowhere to be found in Malaga-in hostelries I meanit is a cruelty to the invalid to be oriered here.

There is, it seems to me, a fortune for some enterprising American who can "keep a hotel" with the American standard of comfort; but it would take time to draw the winter visitors of former years, who, for the reasons I have given above, have sought cities more hospitable, though less gifted in climate.

Situation.-The relative position of rineyards is about 80 per cent. of hill-side lands and inland, about 10 per cent. of valley and plains, and about 10 per cent. of sea-coast. Vines are said to grow equally well on sea.coast or island.

The nearest vineyards to the sea-coast are about one-fourth of a mile.

Sea fogs are seldom expexienced at Malaga, and are not considered as injurious to the production of grapes; on the contrary, they are beneficial.

The valleys and table-lands when especially cultivated produce the best grapes.

Pruning.-Pruning-soissors with a spring are chiefly used here for pruning vines, and are considered in the best conducted vineyards as superior to all others, although the old custorn of using something like a chisel, about 2 inches wide, very sharp, which cuts a "clean cut," is still used by many in this province. Vineyards are pruned once a year, viz, in the months of November and December.

Soil.-The nature of the soil on the mountains is clas slate; in the vegas or plains gravel, clay, and ferruginous earth.

Planting.-The vineyards are generally planted in new lands and when the soil becomes exhausted fertilizers are employed. Stable manure and streetsweepings for table-lands hare been found to be productive of fruitful vineyards. The usual distance between each vine is about 7 feet.

Best results are obtained in valleys, table-lands, and plains inland, much better than on the hill-side, where the rains wash away all the richness from the soil to the plains beneath.

Cultivation.-Lands are cultivated in the vineyards twice a year, viz: First, in December, cutting the branches (within $1 \frac{1}{2}$ or 2 inches) from the root, where it protrudes from the ground, leaving only one single sprout; then they clean perfectly the knob of the rine, removing all the soil to the depth of 10 or 12 inches. Second, in April, when they corer again the root with the earth, cutting away all grass and weeds, 
which draw the richness from the soil. Later in the season, if there are any more grass or weeds they are pulled by hand.

Maturity. - Vines come into full bearing at eight years old and last about thirty or forty years in fruitful condition if the land is good.

Irrigation.-There is no system of artificial irrigation in practice in this province for grape culture, but all vines receive the necessary rains naturally during the winter and spring.

Yield.-An estimated average yield per acre per annum is about 9,000 pounds of grapes, which will yield about one-third that amount when prepared as raisins, viz, 3,000 pounds, or 120 arrobas, at an average value of 30 reals vellon per arroba in the vineyard as they run, good and ordinary alike, which aggregates 3,600 reals vellon, or $\$ 180$. From this must be deducted 20 per cent. of the total yield for all kinds of Gorernment taxes, 10 per cent. on average production as interest on capital invested, and about 30 per cent. for cost of crop, leaving a profit to the producer of about 40 per cent. on the total yield.

The figures are given for vineyards that are fruitful and healthy, free from phylloxera and other plagues; but it would be impossible to attempt to average any particular crop, as years differ, from many unforeseen causes.

Picking.-The vintage season for raisins commences about 1st of September each year, and the record of all statistics is calculated by vintages.

I have prepared a table, annexed, marked A, containing a comparative statement, at parallel dittes, of the raisin crop of Malaga, for each vintage, for the five years ending Angust 31, 1883, including the amount exported, together with the names of the different countries to which these exportations were made.

General exports of box raisins up to end of orop compared with other vintages at parallel dates.

\begin{tabular}{|c|c|c|c|c|c|}
\hline \multirow{2}{*}{ Whither exported. } & \multicolumn{5}{|c|}{ Crop of- } \\
\hline & 1882. & 1881. & 1880. & 1879. & 1878. \\
\hline 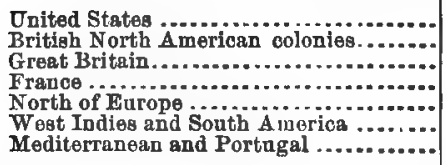 & $\begin{array}{r}067,571 \\
38,431 \\
176,379 \\
277,253 \\
130,646 \\
88,007 \\
76,842\end{array}$ & $\begin{array}{r}1,043,727 \\
31,730 \\
141,415 \\
251,382 \\
101,828 \\
81,196 \\
72,746\end{array}$ & $\begin{array}{r}1,115,101 \\
46,717 \\
174,126 \\
297,412 \\
108,222 \\
75,456 \\
83,785\end{array}$ & $\begin{array}{r}1,146,328 \\
30,598 \\
237,659 \\
368,420 \\
107,888 \\
68,688 \\
60,330\end{array}$ & $\begin{array}{r}1,182,088 \\
58,242 \\
194,471 \\
330,767 \\
99,661 \\
98,429 \\
65,107\end{array}$ \\
\hline Coastwise and fnterior . . .................. & $\begin{array}{r}1,765,099 \\
102,901\end{array}$ & $\begin{array}{r}1,724,024 \\
75,976\end{array}$ & $\begin{array}{r}1,909,769 \\
105,231\end{array}$ & $\begin{array}{r}3,023,811 \\
101,189\end{array}$ & $\begin{array}{r}2,028,765 \\
151,235\end{array}$ \\
\hline Total boxes ( 22 ponnds eaoh) ....... & $1,868,000$ & $1,800,000$ & $2,015,000$ & $2,125,000$ & $2,180,000$ \\
\hline
\end{tabular}

H. O. MaRs'TON,

UNited Statha Consulate, Consul. Malaga, March 28, 1884. 


\section{MALAGA.}

THE EXTENT TO WHIOH GRAPES ARE OULTIVATED, AND THE MANNER OF THEIR PREPARATION FOR EXPORT.

\section{REPORT BY OONSUL MARSTON.}

[Republished from Consular Reports No. 411.]

Notwithstanding the neglectful condition of agriculture in Andalusia, and the primitive processes still followed in many ways, the marvelous fertility of the soil impresses the most inattentive and indifferent observer. But among all the natural riches that abound in this luxuriant country, the most worthy of mention are the vines, so justly famous both through the celebrated wines and the delicious raisins, of which Malaga is the principal market for all Europe and the New World.

It will, perhaps, be instructive to make some remarks on the production, preparation, and commerce of the raisins, which seems to me, although of ancient origin, to offer an attraction of novelty.

There are two distinct vines, the muscatel and the Pero-Ximenez, the first indigenous, the second imported from the borders of the Rhine two hundred or two hundred and fifty jears ago by a German, whose name, corrapted in Andalusia, was given to the vine. Opinions seem divided as to the respective merits of these two vines; some insist that they are equally good, others that the muscatel are much the best. I give the decided preference to the muscatel. A box of raisins made from the.muscatel, recently sent to the exposition at Moscow by a firm of Malaga, contained samples presenting the appearance of large prunes.

The caltivation of the vine requires hard labor. The soil is dug out around the root, leaving a circular hole about 1 foot deep, and, owing to the firmness of the soil, the digging is very difficult. Manure of great strength is used by many proprietors.

Different from Meridional Italy, where the vine, always clinging to the elm, throws itself from the soil in forms of graceful arbor, as in the time of Horace and of Virgil, in this country it stretches itself over the ground and thus gathers all atmospheric heat. Thus, although white, the grape has a golden tint, the skin resisting and slightly tough. The branch appears like a root.

The vintage is conducted with great care; they do not gather all the fruit at one time, but mostly go over the same piece of ground thrice, in order that the grapes may have the necessary ripeness.

There are three different methods of preparing the raisins, viz, washing, drying by steam, and the simple drying in the sun. The drying by steam is more particularly followed in the province of Denia, because of the insufficiency of solar heat. It is also employed in the south in case the season is wet during the vintage.

The cut grapes are put in baskets aud carried either on the backs of mules or donkeys or in carts to the places, often distant, whele they $150 \Delta-30$ 
are prepared, and although they transport the fruit with great care, it suffers naturally; the skin often breaks, which renders the drying difficult, if not impossible.

To dry the grapes by the washing method they construct furnaces of feeble draught, in which wood is used as fuel. A round kettle, varying in capacity from 300 to 400 liters, receives a lye formed from the residue or refuse of the grape after pressing. The lye used is either that obtained from the present year or that which has been kept from the previous vintage.

Placed in wire colanders with long handles, containing 2 or 3 kilograms each, the raisins are plunged in this lye, boiling at a temperature of about $212^{\circ} \mathrm{Fahr}$. After this first immersion, the workmen examine if the skins are sufficiently shriveled; if not, they immerse the grapes a second time, usually the last. Thas scalded, the grapes are carried to the drying place, and from thence to the stores, where they are packed in boxes. It, is not difficult to imagine that the process of immersion is very delicate and requires skillful watching, and great judgment on the part of the workman who conducts it. In reality, according to the quality of the skin, its resistance, which varies with the fruit, the immersion should be more or less rapid, at the risk of having the grapes burst; besides, much skill is necessary to recognize the fissures which may appear. In cases where the heat has been too great, the raisins too rich in sugar will mold shortly after being packed. This process offers, among others, the inconvenience of exposing the raisins to fermentation during transportation, necessitates expense for the construction of furnaces, and the necessary last drying in the sun; besides, no matter what grapes emplojed, or what care bestowed in the preparation, the results will always be relatively inferior.

The method of preparing raisins by steam is as follows: After having been exposed nearly twenty-four hours to the sun's rays, the grapes are carried on boards under cover to a building arranged with shelves 6 or 7 feet high. A heat is produced by steam that circulates in an iron tube 7 or 8 inches in diameter through the entire building. It is unnecessary to submit the grapes to a jet of steam, which would injure them by making them damp, but to a veritable heat of $160^{\circ}$ Fahr. Valves, arranged on the floor, cause an even temperature. At the end of twenty-four hours, usually, the drying is finished, but as the immediate transfer from a temperature of $160^{\circ} \mathrm{Fahr}$. to the open air would injure the ultimate result, it is necessary to let raisins cool gradually in a room constructed for the purpose adjoining the heated room, and only when the raisins are entirely cool are they carried to the stores for packing.

This is the process most generally employed in the region of Malaga, a process they are trying to extend to other less favored climates. The sun furnishes all the heat required; it is enough to construct divisions, of either brick or stone, exposed to its rays, in an inclined position, say 10 yards long and 2 yards wide; the divisions or apartments are built 
up at one end with a sort of triangular masonry, which from afar gives them the aspect of a range of uniform tombs. The triangle is so constructed that the sun never fails to shine upon the contents, the interior being covered with fine gravel, which attracts the heat. Immediately after gathering, the grapes are placel in three divisions, and are exposed to the heat of the burning Andalusian sun of Angust. Never, it appears, have they dreamed of ascertaining the heat thus obtained, but the experienced cultivators affirm that, during the heat in August, they attain a temperature of $145^{\circ} \mathrm{Fahr}$. At nightfall a very simple method of covering is applied to gnard the fruit from the heavy dews or rain, either of sail-cloth or heavy canras so arranged that it covers entirely the grapes that are drying within, and, being supplied with rings on two sides, slides up and down as a curtain at a moment's notice. In many places boards or planks are used, giving the appearance of a roof. During the process of drying they carefully remove the grapes that remain green or spoiled, and they turn each grape in order that they may darken in color uniformly. Competent judges give the preference to this simple method of drying, as much for the results as for the simplicity of the process. The raisins that have been prepared by the scalding process dry in four days, while those dried by the sun take ten dass, but this loss of time is largely compensated by the economy of expenditure. The raisins are not ready for packing immediately after being dried, but have to be kept several days in the stores on the planks on which they are carried.

The raisins that are spoiled or defective are picked out, especially any that are broken or bruised, out of which one drop of moisture would be likely to damage a whole box. This has to be done with exceeding great care. Finally they are classified, which is a task exceedingly difficult, as cultivators and merchants differ greatly in their opinions. The merchants nearly always remodel the boxes packed by the producers. In the demands of foreign countries for Malaga raisins each has its particular and special requirements for what may be cousidered first-class fruit.

For France, raisins may be classified as follows:

Sur-couches, ordinaire, sur couches, choix, sur-choix, royaux, impériaux. The first, which is the most ordinary, is never shipped, except under a fictitious name: the other brands bear the true name of the merchant, but rarely the name of the producer.

For England the raisins may be classified as follows:

1st. Finest Dehesa, 3 crowns.

2d. Finest Dehesa, 2 crowns.

3d. Fine Dehesa, 1 crown.

4th. Dehesa.

5th. Choice layers.

London layers (from good to poor).

For the American market the following brands are shipped:

1st. Imperial finest Dehesa layers. 
2d. Royal finest Dehesa layers.

3d. Finest Dehesa layers.

4th. Fine Dehesa layers.

5th. Dehesa layers.

6th. London (ordinary) layers.

London, loose, 1, 2, and 3 crowns, the last being in three qualities.

The boxes are mostly made by contract at 75 centimes of a peseta (about 15 cents) each. I think the best boxes are made of fir imported from Portugal. The producer almost always provides the boxes and packs them, but they are always repacked in the town by the merchants, who usually employ women or girls for this labor. All raisins are packed in boxes, except those shipped in barrels and frails, and are divided into four layers in each whole box, which, if of full size, contains 22 pounds of fruit, the total weight with the box usually being 28 or 29 pounds. The first or top layer is always the finest and largest, being selected with great care. The merchant is obliged to be familiar with the tastes and demands of the country for which the raisins are intended.

Although the United States are the principal buyers, they do not purchase the finest quality, almost all the best going to England and France.

For England the layers are not presented in bunches, but are all separated from the stem and pressed very tightly down by the lid of the box, which has the effect of making them, in show, a very large raisin.

For France the bunches must be entire; this difference proves that in England the buyers observe the appearance of the fruit, whilst in France they examine very critically, more desirous to assure themselves of the quality rather than appearance. In this regard, and contrary to their usual habit, the English show themselves less practical than the French.

The average cost in Malaga of 100 boxes loose muscated raisins, the staple shipped to the United States for the jear 1880, was about-

Raisins (100 boxes) ................................................. \$126. 10

Boxes (100 boxes) ................................................. 14.55

From holder's warehouse to ship, including examining, marking, cartage,

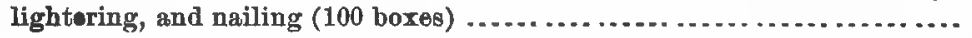

145. 65

In the choicest raisins sent from Malaga, there can be expended in decorations of inside papers from 5 cents to $\$ 1$ per box, at the option of the purchaser.

Before closing my report upon raisins, I would allude to a practice which has caused much dissatisfaction between American purchasers and Malaga merchants in the fruit trade, $i$. e., in the shipping of lightweight boxes of raisins. It has been customary to make the boxes of exceedingly thick wood, which weighed more than the amount allowed for tare. Thus the New York purchasers paid for one or two pounds more of raisins in each box than they received, and great trouble was experienced in consequence. Lately, however, there has been a con- 
certed agreement upon this point, in which the New York buyers have united, and they have issued a circular laying down the rule that all intend to follow hereafter, which is, that all boxes of raisins that do not contain 22 pounds net will not be received, but will be considered unmarketable, and will be sold at public auction for account of shipper.

Under this new rule, fear is expressed by some that, wood being scarce and dear in Spain, and not being able to continue to profit out of the thickness of the box, boxes will be made so thin that they will lack the strength to bear the necossary handling in transportation.

The crop of raisins produced in the Malaga district from the vintage of 1880 and 1881 is estimated at between $2,000,000$ and 2,050,000 boxes, not much varying from the previous vintage.

The stock of raisins in the province of Malaga to-day is estimated at about 150,000 boxes, while one year ago it was estimated at only about 50,000 boxes. At the commencement of the present vintage prices ruled about 40 per cent. higher than during the same time the year previous, and since the 1st of January last but few shipments have been made to the United States as compared with the same period in 1880.

H. C. Marston,

Consul.

United States Consulate, Malaga, April 27, 1881.

\section{TURKEY.}

REPORT BY OONSUL-GENERAL HEAP, OF CONSTANTINOPLE.

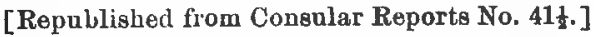

Situation.-In this district and throughout the Levant there are vine yards on the table-lands, on the hill-sides, and in the valleys-both inland and near the sea-coasts; but the positions preferred as the most suitable for growing the vine are on the slopes of elevated and sheltered undulating lands, or on the sunny sides of the lower hills that do not lie too near the sea-coast, or are naturally protected by higher lands from the cold winds and fogs that arise in the neighborhood of the seashore at certain seasons.

In the island of Cos, which is called the "Paradise of the Sultana grape," and in many other places in the Levant, nature has protected the vine by the best possible shelter.

The steep slopes of bills are often planted with vines, and nothing can be more suitable than situations where patches of good soil are mingled with bare rocks, nor anything more beautiful than the rocks covered with foliage and rich fruits.

In some places, especially in the islands of the Archipelago, on the 
shore of the Marmora, and on the coast of Caramania, vineyards extend down to within 50 yards of the sea-shore.

Near the sea-coast, sea fogs and mists, especially when frequent or of long duration, are very apt to injure the vines, particularly those grow. ing nearest the sea-shore; but to check and counteract their injurious action the plants and fruit are sprinkled lightly with powdered sulphur, the sprinkling being repeated two or three times if after the first application the rain should wash the sulphur off before the heat of the sun has had time to complete the sulphuration required.

Pruning.-In the opinion of foreigu planters, the system in vogne here of pruning and "backing" is rather the carrying out of a hand-to-mouth principle than the application of a scientific or economic idea, because the wholesale, ruthless pruning is often done, first, to get a second crop; second, to ripen the grape quickly, or rather prema turely; third, to allow the sun to color the grape a rich golden hue; and, fourth, to admit of greater facility in getting around the plants.

Vines "backed" and pruned in the native fashion in summer, unless they are planted in deep, strong, and heavily manured soil, become prematurely old, ant their yield diminishes yearly, until at last they become quite unprofitable.

But in the best-managed vineyards extensive proning in summer, especially of the foreign vines, is regarded by foreign vine-growers as robbing the plant of its lungs, and that, too, at the time when all its breathing powers (leaves and branches) are mostly wauted. Happily, both systems bare been triel and found to prosper here.

Soil.-A cultivator who wishes to plant a vineyard that will give profitable results should have considerable scientific as well as practical experience to guide him in the selection of the most suitable ground for the purpose, as any defect in the nature of the soil or in its position, both as regards exposure to the sun and protection from cold winds, might render the enterprise abortive.

The vine dislikes a damp soil, but will thrive in almost any open ground with good drainage. In rich, deol soils it grows luxariantly, but on shallow, dry soils the fruit, though less abundant, is of finer flavor, especially where the earth is ferruginous.

The best results are obtained from vineyards planted in good soils on the hillsides, the next best being those situated on undulating tablelands, and afterwards from those planted in the ralley, especially where the vines are most exposed to the influence of the sun, and best pro. tected by nature against dry, hot winds and sudden and unseasonable currents of cold air.

Cultivation.-Lands cultivated by native farmers are first turned up about the end of June, with rude plows or implements of husbandry of the most primitive description. In some places the foung vines receive little care beyond being occasionally hoed and partially cleaned of weeds and couch-grass (Triticum repens). In other places they require and re. 
ceive more care, and have to be manured once in two or three years. On lands in the vicinity of Coustantinople, cultivated by foreigners, many of the local methods of culture have been retained, to which the aid of the most economical implements has been added, together with the science, art, and practical skill that have brought the vines of France, Spain, and Italy to so high a degree of perfection.

When about to lay out a vineyard on virgin lands, foreigners some. times plow the earth first for wheat, and after the wheat has been har. vested they turn the soil again, so as to allow the sun to get at the roots of the couch-grass, which is the only sure method of destroying this enemy of the young vine. New varieties are raised from seed, but the ordinary modes of propagation are by layers and cuttings. Fine varieties are sometimes budded or grafted on less valuable ones.

Besides the native grapes grown for the purpose of making raisins, native wines, and for food, special kinds have been introduced inta.the conntry especially for the manufacture of wine for exportation. Within the last ten years upwards of a million of plants, costing from $\$ 5$ to $\$ 10$ per thousand, and embracing thirty-seven varieties of the best French vines, have been introduced, acclimatized, and successfully cultivated. A French company, with a capital of $\$ 500,000$, in five hundred shares, has purchased estates near Heraclea, on the Roumelian (European) side of the Marmora, with the view of producing wines for the Trench market. The vines are cultivated in rows, about a square meter being allowed to each vine, which enables the numerous processes of cultivation to be carried out promptly and efficiently, and permits the cultivator to inspect the plantation with scrupulous minuteness.

The planting of the vines in rows sufficiently wide apart to give free passage between them allows the sun free access to all the plants alike, and facilitates the carrying out of certain operations, such as hoeing, pruning, dressing, powdering, destruction of insects, ete., upon the proper performance of which the quality of the vintage and sometimes the very existence of the vineyard depends. This system, besides offering these palpable advantages, allows the whole of the cluster to ripen equally, and precludes the possibility of unripe grapes getting mixed up with the ripe ones. The fruit can, moreover, be more promptly gotten in than in the case of vines cultivated on the system known in France as "en foule," where they are allowed to grow closely together and at random. Although some vine-growers are in favor of this system, common practice in France and other vine-growing countries has shown that its disadrautages outweigh its advantages. The vine must have equal exposure to the sun on every side, and to facilitate the many operations which promote a good vintage it must be of easy access.

When the ground has been selected on which a new vineyard is to be planted, it should be carefully trenched by digging with fork and spade to a depth of $2 \frac{1}{2}$ to 3 feet, the earth being thrown up in a series of rows. This long and expensive operation has to be repeated several times. 
It is generally done late in the fall or in the winter, when the ground is damp and soft. Great care must be taken to remove all stones, roots, and other hard substances. The ground is then ready to receive the tender shoots, which are generally planted 3 feet apart. Then begins the long and unprofitable period, during which the vines must be tended with unremitting care in order to bring them to maturity and fruitfulness.

Many open and hidden enemies threaten the life of the young vine, and it is only by resorting to methods which are sometimes elaborate and expensive that it can be safely reared.

While the grower in Turkey has no such pest to contend against as the deadly phylloxera, he has several species of vine-fretters, including the aphis or pureron, the vine saw-fly, the grub, and numerons other small insects which infest both the young and the old vines, to tax bis patience and science.

The most dangerous enemy of the vine-grower is the vine mildew, a fungus of the genus Oidium, which forms a white, delicate, cottony layer upon the leaves, young shoots, and fruit of the vine, causing brown spots to appear on the green parts, and finally a hardening, and the destruction first of the surface, and, if not taken in time, of the whole vine, root and branch. A rusty or moldy vine if left to itself soon becomes worse than useless, because it not only cumbers the ground, but comnunicates its deadly taint to its healthy neighbors. The Oidium, however, can be easily kept down, and if taken at its first appearance is generally stamped out by one or two applications of sulphur.

Concurrently with these elaborate precautions against the numerons dangers which threaten the safety of the whole vineyard, other daties claim the constant attention of the grower. The growing plants must have the earth coutinually hoed around them, special care being taken not to disturb their feeble roots ; in seasons of drought each plant must be carefully watered, and when its leaves and tendrils begin to shoot, the vine must be continually trimmed, dressed, and pruned, so as to induce a strong growth without reducing its productiveness.

During the first year the grower does not, of course, expect to gather grapes, nor even in the second year, but he considers himself fortunate if at the end of that time all has gone well. He may hope for a few grapes the third year, but it is not until the fourth year that he has a real crop to reward him for all his pains and outlay.

When properly cultivated, the vine blossoms from about the 25th of May to the 5th of June. The flowers are small, of a greenish-white hue, and fragrant. Seventy to seventy-five degrees Fahrenheit generally suffices to ripen the grapes, and they mellow between the end of August and middle of September. The vine comes into full bearing in its fourth or fifth year, after which it continues very fruitful up to its thirtieth or thirty-fifth year. Its stem sometimes attains a diameter of eighteen inches, and it is said that in certain instances the vine has lived upwards of three hundred years. 
Irrigation.-When any system of irrigation exists at all in this country it is generally of the most primitive kind, such as trenches supplied with water by the aid of the manganos, or waler-wheels of the natives. But properly speaking there is no system of artificial irrigation usually employed, and as a rule the cultivators depend mainly on the showers and dews, which generally feed and refresh the vines during their growth. Of course advantage is taken of springs or small streams that may exist in the neighborhood of the vineyard to secure as long as possible a sufficient supply of water from such natural sources, and where they exist the vines are generally well watered, and as often as they require to be.

Field.-The crop varies according to the nature of the soil, the seasons, the position of the vineyard, and the degree of care and attention bestowed on the vines. An acre of good vine-growing land in Turkey will, as has been proved by repeated experiments, give from 616 to 880 gallons of wine. It is estimated that when the vineyards held by French companies at Omurtshed and Heraclea, which contain about 10,000 acres, have attained full maturity, their vintage will be about $6,160,000$ gallons.

The following is an estimate of the cost of laying out a one-acre vineyard, with the working expenses, for five consecutive years, and the probable profits during the first five years if cultivated according to the French system :

Trenohing, eto $\$ 116.16$

Planting 4,000 vines, hoeing, etc., tirst year....................... 38.72

Digging, pruning, hoeing, eto., second jear..................... 38.72

193. 60

Less 60 gallons wine, at 70 cents.

42.00

Lose

Digging, pruning, hoeing, otc., third year 38. 72

190. 32

Less 140 gallons wine, at 70 cents 98. 00

Loss

92. 32

Digging, pruning, hoeing, etc., fourth year 38.72

131.04

Less 300 gallons wine, at 70 cents 210.00

Profit.

To be placed against cost of plant, cellar, casks, ete................. 78.96

Digging, pruning, hoeing, etc., fifth year

Less 500 gallons wine at 70 cents 
Varieties.-The principal varieties of grapes grown in the Levant are the following : the "Sultaninas" (without kernels), the "Tchaouche," the "Amigdala" (on the island of Scio), the "Psilaroga," the "Robola," the "Caramisali," the "Resaki," the "Roditis," the "Koutoura," and the "Mavreli."

The "Sultaninas," "Tchaonche," "Amigdala," "Robola,"and "Resaki" are white; the "Psilaroga" both black and white; the "Roditis," red; and the "Saramisali," "Koutoura," and "Mavreli" are black.

The finest quality grown in the neighborhood of Constantinople is the "Tchaouche," which is remarkable for its size and tine flavor, and is the most esteemed for the table. The French growers admit that for the table (and unpreserved) its quality is unequaled, with the exception of the "Sultanina." The other varieties, especially the black, are nsed chiefly for the manufacture of wine. Besides affording a wholesome article of food to the local population, considerable quantities are exported to Russia and elsewhere.

Process of drying raisins.-The raisins of commerce are dried grapes, prepared by two different methods.

One method consists of partially cutting through the stalk of the ripened bunches and allowing them to shrink and dry npon the vine by the heat of the sun.

The raisins prepared by the other method are gathered and hung on lines or laid on prepared floors to dry in the sun. When dried, they are dipped in a hot lye made from wood ashes or barilla with water until the filtered fluid has a specific gravity of about 1.1; to this are added, for every four gallons of lye one pint of olive oil and four ounces of salt. After dipping, the fruit is laid on hurdles of wicker-work to drain, aud is exposed to the sun for abont a fortnight. The raisins are then pulled from the stalks and packed in boxes for export.

Distilled spirit from grape skins.-From the skins of the grape a spirit is distilled called "mastic" (the gin of the East), which is largely used by the natives, both Turk and Frank.

Raisin trade.-The raisin trade much exceeds in importance that of figs.

The three principal kinds known in commerce are the "Small Sultana," the "Large Red," and the "Large Black."

The "Sultanas" are chiefly taken by England and Germany; about three-fourths of the "Large Red" go to Trieste, Germany, and Holland, and the "Black" were until lately almost entirely for Constantinople, Salonica, and the Danubian provinces. But the growing manufacture of raisin wine in France draws an increasing quantity of raisins to French ports. Vast quantities are taken by distillers in all European countries.

Quantities of raisins produced.-A well-kept vineyard in Asia Minor ought, it is calcnlated, produce an average of 7 tons of grapes to the acre. In the Turkish custom-house returns for 1880-'81 the valuation of the 
raisins exported from all Turkey was $\$ 4,393,655$, but this sum is evidently incorrect, as trustworthy statistic s give the exports from Smyrna and the neighboring district for the same period as follows :

Valne In Smyrna.

Black, 528,278 kintals, of 112 pounds each . . . . ................. $\$ 2,522,397.18$

Red, 185,754 kintals, of 112 pounds each ....................... 1, 077, 084.06

Sultanas, 173,237 kintals, of 112 pounds each .................. 1, 002,907.13

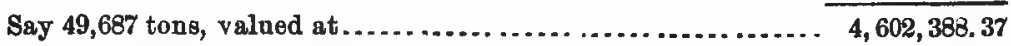

During the last two years the quantities produced have increased, but the quantities exported have not been published.

Raisins come principally from the neighborhood of Smyrna, the shores of its gulf, and the valleys of the nearer rivers. Quite three-fourths of the laboring population are said to be Greek Christians and the remainder Turks. The highest prices are obtained for the Karaburnu fruit, which was recently quoted as high as 18 cents per pound for red raisins and 24 cents for Sultanas. The black raisin ranges as low as 3 cents per pound on the spot. The total yield of raisins in the Smyrna district, which was 48,000 tons in 1871 and only 31,000 tons in 1872, had risen in 1879 , in consequence of the general planting of new vineyards and the greater facilities of transportation from the interior, to the large quantity of 75,000 tons.

While the quantity produced has beew increasing so largely, the prices, instead of falling, as in the case of figs, have considerably risen, principally, no do ubt, in consequence of the vine diseases in Western Europe. It mas be mentioned, howerer, that the removal of the stalks adds much to the value of an equal bulk of fruit and forms an important element in the rise of prices. About fifteen years ago the practice of stripping the red raisins from their stalks commenced at Tchesmi. This rendered them more salable, and they afterwards were clıssed with "Eleine" (choice). The practice also applies' to the Sultanas and the black fruit.

Most of the fruit grown in the immediate districts of Smyrna is known as "Yerlis," and in the island of Samos a red "Muscat" grape is produced, which goes in barrels to Holland and Austria, there being scarcely any demand for it in England. These exports for 1882 amounted to $\$ 35,000$. About Aïdin, where the population is almost entirely Turkish, a small black and not very sweet raisin is grown in large quantities. Half are kept in the country, and the rest, which bring a low price, go, withont their stalks, and packed in bags or barrels, to Russia, Greece, France, and Trieste.

Packing.-The manner of packing the fruit differs according to its destination, in order to meet the requirements of the markets. The best " red raisins," whether with or without stalks, are packed in boxes of thirty pounds, except for Russia, where they go in barrels of 250 pounds. The "Sultanas" for Trieste are sent in boxes of 12 pounds, and they go to England in larger boxes of 22 pounds. To Germany and 
Holland they go in cases of 30 and 60 pounds. The "Large Black" raisins are generally exported in barrels of about 370 pounds each, and the Eri Kara of Smyrna are shipped in sacks.

Freights.-The freight charged by steamers for raisins is at present $\$ 8$ to $\$ 8.50$ per ton, but it is sometimes as high as $\$ 10.32$ per ton to Liverpool for small lots. Freights are not quoted to the United States, as there is no direct trade.

Besides the foregoing, some five or six thousand tons of grapes are conrerted into wine exported aunually from Smyrna. Oonsiderable quantities of wine are also exported from Roumelia, principally through Constantinople to France, where it is converted into French clarets, but the quantities have not been ascertained.

A mong the other districts which produce considerable quantities of grapes may be mentioned that of Broussa, the islands of the Archipelago, and Roumelia. During the season 1881-'82 the wine produced in the Kirkillisia region alone was $3,581,907$ gallons. The vilayet of Trebizond produced in $1882,3,790,300$ pounds of grapes, but rery little in any shape was exported.

G. H. HEAP, Consul-General.

United States Consulate General, Constantinople, April 10, 1884.

\section{SALONICA.}

REPORT BY CONSULAR AGENT LAZARO.

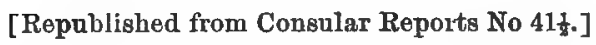

Situation.-The best position of vineyards is the hill-side lands of the interior, at least 2 miles from the sea-coast.

There are some places on the plain where mist and fogs occasion mildew, for which sulphur flour is used.

Pruning.-The vines are pruned in the month of February.

Soil. - The soil where the best results are obtained is a pebbly, sandy loam, and on warm, south-side positions.

Cultivation.-The ground is hoed in ridges once a year, and is afterwards weeded. Before the grapes are ripe the ends of the vine are pruned 1 yard from the root to give strength to the plant.

Maturity.-Vines bear fruit the third year and are in full bearing the fourtb. When well tended they remain fruitful for fifty years and over.

Irrigation.-Irrigation is not practiced in this district.

Yield.-The yield varies with the position. The best fruit is grown on dry soil, but it is less abundant. Generally the yield is from $3 \frac{1}{2}$ to 10 tons per acre per annum. Prices vary from $\$ 15$ to $\$ 20$ per tou of 2,000 pounds. The cultivation of vineyards costs abont $\$ 28$ per acre per annum. 
Climate.-As to the climate of this district, it is mild; the severest weather is limited to two months and a half; snow seldom falls, and ice never forms over half an inch thick. The greatest heat, which occurs in July, is about $96^{\circ}$ Fahrenheit.

The total yield of grapes in this district is unknown, for want of any kind of statistics. It is supposed, however, that two-thirds of the vintage are exported in the shape of native wine, manufactured simply by extracting the juice and keeping it a couple of months. The rest is consumed at home in grapes and wine.

Exportations are made in barrels to Constantinople, Alexandria, Roumania, and Servia. French buyers purchase much of the wine of this province to remanufacture it in France and convert it into French wines.

P. H. Lazaro.

Consular Agent.

United States Consular agenot, Salonica, February 19, 1884. 



\section{SUPPLEMENT.}





\title{
CRYSTALLIZATION OF FRUIT IN FRANCE.
}

\author{
[Republished from Consular Reports No. 60.]
}

\section{MARSEILLES.}

\section{REPORT OF CONSUL MASON.}

The business of preserving fruits by the crystallizing process is peculiar to Southeastern France, and is practiced on a large scale at Apt, in the department of Vaucluse, at Olermont, in Auvergne, as well as at Marseilles, Grasse, Avignon, and other places of less importance.

The product is exported largely to England, the Uvited States, and various other countries, including Algiers, the East and West Indies, and even South America, where the profusion of fresh fruits would seem, at first thought, to render such an expensive import almost superfluous.

The kinds of fruit preserved by this process are mainly pears, cherries, apricots, pine-apples, plums, figs, citrons, oranges, melons, and a kind of dwarf orange called "chinois," which grows to some exrent in the district of Nice, but is imported here mainly from Italy and Corsica. Peaches are used for this purpose only to a limited extent in the region of Marseilles, the "free-stone" varieties being too costly and the supply too small for protitable use on a large scale.

The erystallizing process is in priuciple simple and nearly uniform for all the above kivds of fruit, but it requires a certain skill aud del1cacy of manipulation which can only be obtained by experience, and which it is difficnlt to precisely define.

The essential thing to be done is to extract the juice of the fruit and replace it in the pulp with liquid sugar, which, upou hardening, not only preserves the fruit from fermentation and decay, but retains it in its original f.rm and consistency. For this purpose it is necessary that the fruit shonld be fresh, clear of all decay or other blemish, and of prerisely the correct degree of ripeuess. This last is an important and difficult requirement, as the proper degree of ripeuess for crystallizing raries with the different varisties, and is so precise as to exclude from use for this purpose much of the fruit sold during the season in open market, and which has not been gathered, assorted, and transported with sufficient care. 


\section{SUPPLY OF FRUTT.}

In the neighborhood of Apt and Avignon, where this method of preserving forms a leading industry, fruit-growers are carefully instructed in this respect, and deliver their crop to the confectioners in the best condition. Contrary to what is popularly believed, native fruits are rarely or never really cheap in Sonthern France, except sometimes for a brief period, when, by reason of some exigency of weather or sanitary trouble, the supply of apricots, figs, or melons, may temporarily exceed the demand.

Oranges, which come from Spain and Italy, and citrons, from Corsica and Algiers, are, in favorable seasons, plentiful and reasonably cheap, but apples, pears, cherries, peaches, plums, and berries are alwajs costly in the market of Marseilles. At this time, the end of October, ordinary apples command at retail from 4 to 8 cents per pound, and the average price paid by confectioners for the various fresh fruits used in crystallizing varies from 8 to 10 cents per pound.

At Apt and Clermont, which are small towns in the midst of fruitgrowing districts, prices are somewhat less than this. Refined sugar, the other principal material, costs $\$ 9.65$ per 100 pounds. If moist or inferior sugars are used, this item of expense may be slightly reduced, but the saving thus effected is more than lost by the inferior quality of the product. This is exemplified by the Corsican citron preserved at Leghorn.

It will be borne in mind that the preserved fruits under consideration are of two kinds, "fruits glacés," glazed, and "fruits crystallisess," but this difference relates simply to the exterior coating of sugar, which results from the final stage of the process. Until that finishing process is reached, the method of preparing glazed and erystallized fruits is identical and the value of the product is the same.

\section{THE PROCESS OF CRYSTALLIZING.}

The fruit is first carefully assorted in respect to size and uniform degrees of ripeness.

Pears, nine-apples, and quinces are pared, citrons are cut into quarters and soaked a month in sea-water, and the "pits" of apricots, cher" ries, and peaches are carefully removed.

Even this preparatory process requires a certan degree of skill, since the stone must be removed with as little injury as possible to the form and soliclity of the fruit. 'This work is done mainly by women, who earn thereby 50 cents per day.

Thum prepared, the fruit is immersed in boiling water, which quickly penetrates the pulp, dissolving and diluting the juice, which is thereby nearly eliminated, when the fruit is subsequently taken from the water and druined, leaving only the solud portion of the pulp intact.

This process of "plapching" must also be dono with exact nicety, the 
period of immersion in the hot water being determined by the size and ripeness of the fruit. If immersed too long, the pulp is either overcooked or is left too dry and woody. If taken out too soon, the juices left in the pulp prevent perfect absorption of the singar afterwards, and, by eventually causing fermentation, destroy the value of the product. In this, as in other stages of the process, the only guide is experience. A skillful workman can tell by the color and appearance of the pulp when it is properly "blanched," and this knowledge invariably commands employment and liberal compensation.

After being thus scalded some fruits, apricots, for example, are again assorted into two or three classes, according to the degree of softness that has been produced, for the reason that if kept together they would take up the sugar differently, some losing their form entirely, while others would remain sufficiently impregnated. From these different grades, sugar-sirups of different degrees of density are required, the sotter the fruit the stronger the sirup required for its preservation.

For the same reason each of the different varieties of fruit requires a sirup of corresponding strength.

Pears, citrons, and pine-apples, which remain bard and firm, take best a sirup having a density of from $18^{\circ}$ to $25^{\circ}$, while apricots, plums, and figs are treated with sirups which gauge from $30^{\circ}$ to $42{ }^{\circ}$ by the aerometer.

The requisite sirup having been prepared by dissolving the sugar in pure water, the fruit is immersed in it and left at rest for a certain period in large earthenware pans, glazed inside, and having a capacity of about 8 gallons.

The sirup penetrates the pulp, and gradually withdraws and replaces the remaining fruity juice, which, as it exudes and mingles with the transparent liquid, produces a certain filmy or clouded appearance, which marks the commencement of fermentation. When this has reached a certain stage, the vessel containing the sirup and fruit is placed over the fire and heated to $212^{\circ} \mathrm{F}$. This corrects the fermentation and raises all impurities to the surface, whence, if necessary they can be removed by skimming. If the sirup is of proper density, this process of impregnating the fruit with sugar will be complete in about six weeks, during which time it is usually necessary to perform this heating process as above described three times. The impregnation of the fruit with sugar being thus complete, it is taken out, washed in pure water to remove the flaky particles that adhere, and is then submitted to one of two finishing prócesses, as follows:

If the fruit is to be "glacéd," that is, covered with an ice or transparent coating, it is dipped in a thick, viscid sirup of sugar and left to dry and harden rapidly in the open air. If it is to be "crystallized" it is dipped into the same sirup, but is then cooled and dried slowly in a kiln or chamber warmed to a temperature of $90^{\circ}$ Fahreuheit.

This slow cooling causes the thick sirup with which the fruit is cov- 
ered to crystallize and assume the usual granulated appearance. The work is now finished. If properly done, the fruit thus preserved will bear transportation to any climate and will keep, firm and unchanged, for years. It is packed in light wooden or card-board boxes and may be shipped in cases containing several hundred pounds each.

\section{USES OF THE SPENT SIRUP.}

During the process of impregnating the fruit with sugar the sirup in which it is immersed is gradually deteriorated by losing its sugar and absorbing the juices of the fruit. It is finally utilized in the preparation of "confiture'd'Apt," which is made of the soft overcooked and irregular pieces of fruits of all kinds mixed in irregular proportion and preserved in the spent sirup, which is boiled down to the required consistency. This branch of manufacture, like many others, gives opportunities for sharp practice, particularly in the use of glucose in place of pure sugar, and of certain chemicals, notably salicylic acid, which there is reason to believe is employed to some extent by certain confectioners to shorten and thereby cheapen the process of preservation.

Salicine, the basis of this acid, is a flaky substance derived from the bark of certain species of willow. It is used in medicine as a febrifuge, two grains per day being regarded a safe allowance for adults. Salicylic acid is made by the action of sulphuric acid, bichromate of potash, and water upon salicine. In just what degree salicylic acid is deleterious to health $I$ am not informed, but it is the opinion of good judges that its use in the preservation of fruits and wines should be probibited by law. It is a powerful antiseptic, and is for this reason used in the mixing of wines and, as already indicated, in the fruit-crystallizing process, to arrest and prevent the acetous fermentation of the juice, which would otherwise spoil fruits which have been imperfectly prepared.

As has been shown above, the process of eliminating the natural juices of fruit and replacing them with sugar by immersion in sirup requires about six weeks. By the use of salicylic acid, which penetrates the pulp and exerts upon the juices an antiseptic influence which prevents fermentation, this process can be reluced to a few dars only. Time, labor, and sugar are thereby saved, but naturally at the expense of quality in the finished product.

\section{COS'T $\triangle$ ND MARIE'L VALUES.}

The net cost of preserving fruit by this process varies, of course, with the price of sugar, labor, interest on investment, etc., aud this is moreover a point upon which confectioners are not disposer to be communicative.

But with the facts at our disposal, the question of costs cau be closely approximatel. Sugar costs hero this season, as alrealy staterl, 9.65 ceuts per pound, and fruit in condition for crystallizing ou an average 
8 cents per pound. 'The labor of' women to pare, stone, and otherwise prepare the fruit costs 50 cents per day; that of men sufficiently skilled in the processes of scalding and preserving to work under the direction of a foreman, commanils from 80 cents to $\$ 1$ per day. In most estal. lishments the proprietor or a member of the firm is the superintendent, who personally directs the work.

Most leading confectioners aud caterers of Marseilles manufacture their own crystallized and "glace" fruits, which they sell at retail from 50 to 75 cents per pound.

The wholesale trade prices of quantities for export are much less, as will be shown by the following exhibit of the average values, as declared for export to the United States and other countries, of the several fruits during the season of 1884, which was a year of abuudant fruit harvest, and the present summer and autumn, when all fresh fruits, except cherries and figs, have been more expensive by reason of a short and interior supply:

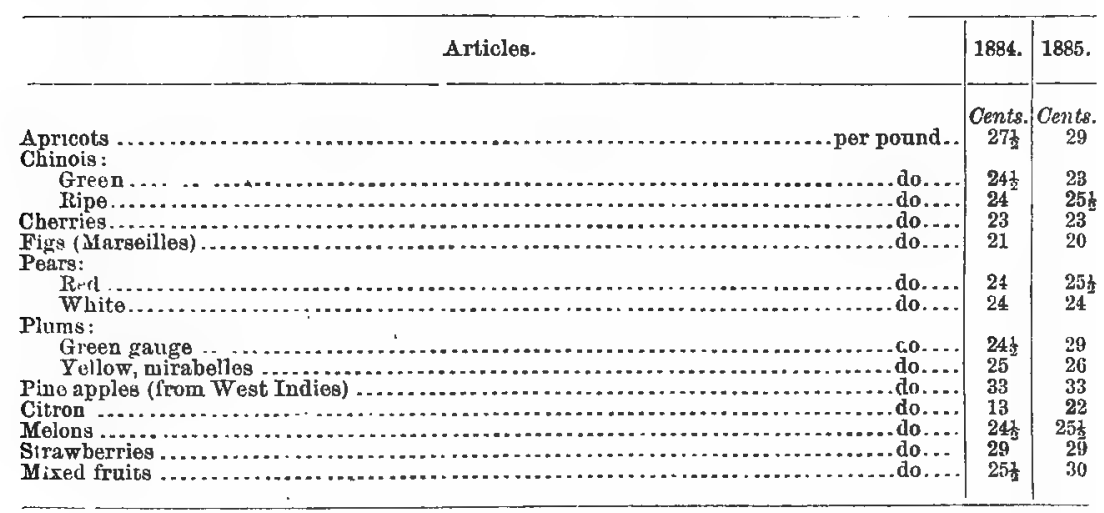

This would give an arerage of about 24 cents per pound for 1884 , aud 26 cents for 1885 .

Deduct from these values, say, 20 per cent. for manufacturer's profit, and we reach from 19 to 20 cents per pound as the average cost of production.

Add to these valnes the cost of importation and a duty of 35 per cent. ad valorem, and the crystallized fruits of Provence become a rather expensive sweetmeat to American consumers.

\section{THE INDUSTRY IN THE UNITED STATES.}

But there would seem to be no good reason why this dainty and profitable industry could not be established with immediate and complete success in the United States, where most ordinary fruits grow in profuse abundance and with finer flavor than is developed by the same varieties in any part of Europe. Sugar is equally cheap, and fuel far . less expensive in our country than it is here. From the foregoing ac 
court it will be seen that the process of crystallizing fruits, as well as the reqnisite apparatus, are exceedingly plain and simple. But the most profusgly furnished kitchen, abundant raw material, and a library of books on cookery will not enable a novice to prepare a well cooked dinner.

There is so mnch in the art of crystallizing fruit, which can only be learned by experience, that in order to begin the experiment with certainty of success, American pioneers in this manufacture should employ competent French workmen to superintend the construction of their plant, instruct the operatives, and superintend the whole process of preserring and packing during the infancy of the busiuess.

The extent to which the erystallized fruits of this conntry are imported by the United States would seem to indicate that here is an opportnnity for a new and profitable enterprise.

United States Consulate,

FRANK H. MASON,

Consul. Marseilles, October 31, 1885.

\section{COGNAC.}

REPORT BI OONSUL IRISH.

I have extended my inquiries as far as practicable for this portion of France, and am enabled to state that the actual processes of crystallizing fruits have been generally abandoned throughont the country, on account of the expense attending thereon and the general scarcity and usually high price of fruit.

However, there are, in all the towns of this region such as Cognac, Angoulême, Saintes, Rochefort, La Rochelle, and Limoges, persons who are familiar with the business, who deal in the crystallized fruit, and who have formerly engaged in its manufacture. The testimony on the sub. ject is to the effect that the process of crystallization is now largely and almost entirely confined to a few points, namely: Clermont-Ferrand, in the department of Puy-de-Dome, in the consular district of St. Etienne, and Carcassonue, department of Aude, in the extreme south of France, and in the bounds of the Cette agency of Marseilles.

A reasonable amount of manufacturing is done at Paris, and also at Bar-le-Duc, department of Meuse, where the production is chiefly confined to the preserving of currants, gooseberries, and such like fruit.

Clermont-Ferraud is the most important place for this industry in 'France, and as fruit is ustually abundant and cheap in that locality, they are enabled to furvish the dealers throughout all this region to much better advantage than the dealers themselves can manufacture it.

As a consequence of the confineweut of the work to localities beyond my bounds it will be seen that $I$ have not the data for its cost and extent of production. 
Neither are the manufacturers usually disposed to furnish detailed information concerning their business, and many obstacles lie in the way of an investigation.

I am enabled, however, to furnish a tolerably clear statement of the varions processes of the work, which, as a whole, is quite uniformly practical whenever the labor is performed.

\section{WHITENING FRUITS.}

Much precaution is necessary to be taken to well preserve the fruit, whether it be drs or watery, in order to obtain good results.

Success depends largels upon the first act of bleaching. The bleaching, or whitening, of the fruit must be regulated according to the quality and maturity of it; the water must not boil, must simmer only.

It is well to choose each kind of fruit a few days before being ripe; it should be hard or firm and gathered in dry weather in the worning, and whitened as much as possible the same day, for if too ripe it will fall in marmalade; if not enough it can not be prop'rly preserved, the pores will become closed, and the sugar can not penetrate. The fruit will becouse hard, acid, black, and moldy. It is necessary to place the fruit in a considerable quantity of water to whiten it, that the water cover it at least 8 inches, in order that there be no necessity to iucrease the quantity during the process. In such a casis added water sbould be of the same temperature. Cover the fruit with an osier screen or liuen cluth, and put about 4 inches from the bottom of the ressel a copper colander, to prevent injury from the fire. Stir the fruit from time to time lightly, with a skimmer, to aid the riper portion to rise. Usually the fruit is whitened with the naked fire, but it is much easier to do it with steam, because in that case it is not exposed to the danger of scorching, and the degree of heat for the various kinds of fruit is easier regulated.

M. Rangot, confectioner, 4 Rue de la Verrerie, Paris, bas invented an apparatus, called a confisuire, very convenient for preserving fruit. The use of this is to avoid the necessity of decanting, and 25 gallous or more can be preserved at a time in sixty hours, and watery fruit in 72 hours.

Each kind of fruit is whitened in a different manner. Stoue fruit is placed in cold water over a slow fire, and removed with a skimmer as soon as it rises to the top of the water. The condition of the cooking is ascertained by the use of a pin, which must easily penetrate, or by softly pressing with the fingers; when it is found to be sufficiently soft it is taken out and put in cold water. If there is a great quantity of fruit to be whitened, the same water may be used again, especially for plums aud green fruit.

Plums that are whitened in the first water, not being so nice and transparent as those whitened in the second, the poorest and ripest and ill turned may be whitened first to acilulate the water. Some con. fectioners employ lemou juice, virjuice, pyroligneons acid, alum, marine salt, epsom salt, etc., to preserve the whiteness of the fruit, and blue 
vitriol, vinegar, or salt, to turn it green. It is dangerous, however, to use the blue vitriol; too great a quantity causing the water to turu bluish, the fruit will then become black. If used, pat not more than 3 grains to a quart of water, and when the fruit is whitened, put it in water for twenty-four hours, changing four or five times.

'To be assured the water or fruit does not contain any part of the vitriol, plunge a well polished bar of iron into the water; if it is not covered with a copper tint there is no danger.

When plums or other fruit are to be whitened, if the water is to be used again, let it cool before using until it becomes lukewarm, and leave the fruit in it awhile before heating; this is why the use of steam is so helpful.

Fruit with a tongh skin requires longer to whiten, and time, according to its quality; hence the following notices of the time required to preserve each kind of fruit.

\section{SUGARING FRUIT.}

After the whitening process is completed, great care is still reqnired to properly preserve them in sugar. If the fruit is too firm or hard, or not ripe enough, on being removed from the whitening process it must be put in sugar reduced to a sirup of $23^{\circ}$; the water contained in the fruit will be eliminated and the sirup reduced to 200 ; it will be necessary the next day, for the first operation, to increase it to $25^{\circ}$. Cover the fruit and boil it, pour it out gently into an earthen dish, and place it in the cellar in a cool and dry spot to avoid fermenting. Continue cooking it from day to day, making it one or two degrees thicker. Covered when boiling.

Ordinarily this process is repeated from five to eight times, thickening to $36^{\circ}$, or more, according to the maturity of the fruit. If the fruit is soft or too ripe it will be necessary to cook the sugar more to harden it and preserve it from falling into marmalade. Rednce the sugar to $28^{\circ}$ for the first shape or condition, increasing $2 \circ$ each day for each shape. It is sometimes necessary to give two shapes each day, morning and evening. In that case increase the sugar only $1^{\circ}$ each time, and only simmer the fruit; afterwards put it in the cellar. If it is desired to preserve the fruit very clear and white, it is necessary to change the sirup in the middle of the shape. In such case it is necessary to thicken the sirup with apple jelly or glucose, to prerent its candying. When the fruit is sufficiently preserved, it is left in a cool and dry place from eight to fifteen days, in order that all the water may escape and it become impregnated with the sugar.

It is necessary that the fruit be well drained at each sbape or stage of the process, because if reduced sirup remains at the bottom of the vessel into which the fruit has been poured, and a corered boiling or simmering has been neglected, it will contribute to its termentation.

A spigot at the base of the vessel for the purpose of draining the 
sirup is very useful in the case of apricots, chestnuts, strawberries, raspberries, and all tender fruit. The quantity of sugar necessary to preserve each sort of fruit is not indicated, as the fruit will take only the amount of sirup necessary for it; it is only necessary that it bathes in the sirup.

\section{PREPARING PARTIOULAR FRUITS.}

\section{I present berewith instructions for preserving a number of the more important kinds of fruit:}

Apricots, whole.-Choose the white apricots, from high trees, or grown in a garden, along the wall. They will be recognized in opening by the meat forming species of rass around the stone.

It is necessary to take them some days before their maturity, when they begin to turn yellow, and the stone is easily detached, and they are firm.

Make a little incision at the head with the point of a knife. Hold the fruit in the left hand with the thumb and fore-finger, then pushing the kuife at the place of the stem, the stone goes out at the top or head. Propurtion the apricots in water slightly alumed, or acidulared with lemon juice. Prick them in the green parts which are not ripe enough, then whiten them on a slow fre, stir them from time to time to aid the ripest to rise to the surface; try them on the skinmer with the fingers or a pin, and put them in fresin water as soon as whitened. When they have becowe coolerl, after having changed the water several times, put them in sngar warmed to $20^{\circ}$, and mako then simmer or slightly boil, if they are not too ripe. Tbe next day put them in sulgar at $22^{\circ}$, boil them, covered, if the fruit is firm, or simmer them if it is tender; continue thus each day for five or six days or processes, increasing $2^{\circ}$ each time until $36^{\circ}$, then let them remain for fifteen days, as heretofore indicated.

When the fruits are a little large, turn them with a thin and suitable knife that the sides may correspond; with a toothed knife the sides are better and neater. Cherries, oranges, nuts, pears, etc., are turned in the same manner.

Stuffed apricots. - Take whole, preserved apricots, and introdnce in each plum or other small preserved fruit separated from the stone, which replace by lemon or lime.

They are equally stuffed with the marmalade of apricots, pine-apples, strawberries, apple-jelly, currants, cherries, raspberries, etc., and a peeled almond is put in the middle.

Apricots in quarters.-Choose apricots already yellow, withont being ripe, firm, and with the stone easily detached. Peel them, or turn them, and prick them lightly with a pin, and immediately throw them in fresh fountain water lightly alumed. Whiten them and put then in the sirup like the whole ones. When they are preserved, drain them, put them in a stewing dish with sirup at $20^{\circ}$, and add the juice of a fine orange. The apricots are iced and candied, drained, and placed with preserved fruits in boxes. Increase the sirup at each process, so that the fruit is bathed in it.

Pine-apples.-Choose the pine-apples before they are entirely ripe, remove with care the first pellicle, leaving half of the middle of the crown, prick them with a large needle to the heart in several places. Whiten and preserve them like the apricot.

Cherries.-Take fine cherries with considerable acidity, take off the stems, push out the stones with a quill, and place them reversed side by side on a strainer. Afterwards put them in an earthen dish in layers, with equal parts of powdered sugar, until the next day. It is necessary to decant them several times to dissolve the sugar. Heat them slowly and proceed as with sirup.

Quinces in quarters. - Choose quinces of a fine yellow, and well ripe and sound. Take off the down with a linen cloth, prick them to the heart with a large needle, put them in a proportional quantity of alumed water, place them afterwards over a quick 
fire, boll for time, and when tender throw them into fresh fountain or river water in preference to well water (as such contains less calcareous salt and is softer.)

Foursain water is preferable for preserving all fruit, especially white fruit. Peel them and take out the cores, cutting them in equal quarters; put them again in alumed water, and continue whitening them until the head of a pin passes easily throngh the quarters and the hole closes up again. Quinces are also whitened in the following mauner: The fruit is just peeled, and a lemon rubbed over each slice to prevent its becoming red; then put in alumed or acidulated water, then they are whitened.

The former process is preferable. They are preserved like apricots, having care to cover them with a white linen cloth at the surface of the water, and to cover each vessel into which they are pourea with linen or white paper, to hincler the fruit from reddening. It is necessary to take these precautions for all white fruit. When it happens that water reddens in whitening them, it is necessary to cbange the alumed or acidulated water.

Lemons.-Choose fine lemons well united, turn them, make a hole with a punch at the right of the stem, put them successively in fresh water. Whiten them, empty them like oranges, preserve them, and ice them the same.

Quarters of lemons.-Take fine lemons, well ripened, united, and without spots; separate the largest part of the white, after having cut them in equal quarters. Whiten these skins like citrons, and preserve them and ice them the same.

Citrons.-Cboose five citrons uniformly ripened. Test them with a piece of glass to raise only the surface of the rind. Make a hole with a punch a little larger than for lemons. Whiten them with much water. When they are half whitened, empty them with a coffee spoon, pat them in fresh water, and finish them and whiten them like lemone, and preserve them the same. Citrons in quarters are emptied only when they are whiteued. Leave them forty-eight hours in fresh water, changing it two or three times a day to remove the bitterness of the rind.

Raspberries.—Choose fine red raspberries, not too ripe, that you examine carefully. Put them in an eartben dish; about 9 pounds in each : cook with an equal part of sugar au souffe; empty, decantiug four or five times during an hour, into a similar dish; put them on a slow fire, bringing them to a boil again; put in the cellar until the next day, draining slowly so as not to crush them; and cook in sugar at $28^{\circ}$, covered while boiling. The next day cook them at $30^{\circ}$, the third day at $32^{\circ}$, afterwards drain them 80 as to dry and candy them. I need not speeify their numerous nses.

Strawberries.-Choose them firm, without being quite ripe, and preserve them the eame as rasplerries and cherries.

Oranges.-Choose very fine oranges, very firm, and with a thick skin. Turn them, makiug all sorts of designe, and put them in fresh water. Whiten them, and empty like lemons and citrons. They are preserved and iced the same.

Oranges in quarters. - Choose similar oranges. Mark four separations in the orange without detaching the quarters. Whiten as heretofore shown, and when they are well preserved divide the quarters for the various ases. The skins and peels are pre. served and iced the same, and are used to porfume sweetmeats, etc.

Plums, - Choose fine fresh plims, not too ripe, but commencing to turn jellow. The plums of Metz aresuperior to all others in Frauce for preserves. They are very transparent, and once preserved have a very delicions taste. Prick them to the stone with five or six pins fastened in a cork. Put them in a proportional quantity of fresh water lightly alumed. Let me Lere xefor to a former statement about usiug water more than once in whitening plums. Care must be taken to put the fruit only in lukewarm watnr to commence to whiten it, and to lenve it in some minutes before increasing the heat. The plume are whitened and preserved the same as apricots.

Pears.-Chnose fine peare, like the bnttor pears of Englaud or Rheims or Bergamots, and when not too ripe, when the pips are black, and when in paring them they are white uuder the skin. Put them, with a good deal of water, on a quick fire, or with 
steam, until they are softened, then remore them and put them in fresh, cold water. Pare them as lightly and promptly as possible, prick them from the head to the core, out and scrape the end of the stem, and throw them into a quantity of fresh water, alumed and acidulated. Put them again on the fire, cooking them until the head of a pin enters easily, and the hole closes on withdrawing it; then put them again into fresh water, lightly alumned or sharpened with lemon juice. Preserve them with the same precautions as quinces and apricots. As the pears are easily candied, the sugar must be thickened with apple jelly or glucose.

Peaches. - Choose fine peaches, before their maturity, and quite firm; whiten them and preserve them whole, or in quarters, like apricots, being careful not to boil them, for it is a very tender fruit and liable to fall into marmalade.

Green gages. - Take green gages of a good s1ze without being ripe or colored, of a fine green rind, firm, the stone being detached easily. Cat the end of the stems, and prick them in divers places, notably near the stem, with a little bodkin. Pat them in a basin full of water on the fire, or with steam, so that they may have ample room. As soon as they become yellow, remove them from the fire, and throw in a pinch of salt, vinegar, and spinach, or verjuice. Blue vitriol is also employed, but in small quantity; to make them green again let them remain quiet for some hours, then put them on a slow fire without boiling, stirring them from time to time until they again become green; then increase the heat, and as they rise to the top of the water, remove them and put them in fresh water, removing it several trmes until they become thoroughly cool. They are preserved with sugar like other plums.

Chestnuts.-Which grow very large in this conntry and are much sought for as an article of food. Take the fine chestnuts of Lyons or Lucques, rend off the outside with a point of a knife, being careful not to touch the meats, and pat them in a proportional quantity of fresh water. When they are all prepared, put them on a quick fire, or with steam, with a large quantity of water. Boil them until the skin can be removed and they become tender, of which assure yourself with a pin, then remove them from the fire, and change the warm water, diluting the second water with a little flour to preserve the whiteness of the chestnuts. Peel them as prompty as possible to prevent them becoming too tender, and also not to break them, for this fruit is one of the most difficult to preserve, and all possible precantions must be taken. Put them in a proportional quantity of hot sugar reduced to $20^{\circ}$; keep them warm over a slow fire, covering each dish with linen or white paper. The dishes must be provided with fancets to drain them more easily. Proceed to preserve them with the same care as with apricots; they may be iced with vanilla. Some confectioners do not give them the shape or fashion for fear of spoiling them, for they separate easily at the least contact with too strong heat. They keep them continually warm in a drying stove or slow oven. With steam or a hot water bath, they decant them from time to time; or stir them, the sirup can be reduced to $32^{\circ}$. This means is very difficult and only a small quantity can be made at a time.

\section{ICED FRUITS.}

The preserved fruits are iced to dry them. They are drained, then passed through lukewarm water to wash them, then put an hour or two in a drying stove in an earthen dish. Sugar cooked to the grade au petit souflé is put with them, and they are made to take a covered boiling, are skimmed, the basin taken from the fire, and placed on a table in an inclining position, where the sugar is massed on the border of the basin with a spatula. When the sugar commences to whiten, turn one or several of the fruits in the whitened portion, remove them with a fork, and spread tiem on a grate or strainer placed over a dish or mold to candy. 
When the fruit is small and the sngar commences to grain, mix the whole together, raise the fruit quickly with a skimmer and put it on a strainer. When the fruits are soft it is necessary to cook a little harder and mass the sugar more than for hard or dry fruits and rinds.

This ice is now kept for use, and when wanted a little sugar is added each time. When thick or gelatinous, it is cooked and massed more, or replaced.

\section{CANDIED FRUITS.}

Drain the preserved fruits, wash them in lokewarm water, and put them on a strainer on the stove to dry. When they are dry put them side by side, and put them between two strainers made for the purpose, and place them thus in a mold to candy

Take sugar cooked au petit souffé at $36^{\circ}$ to $37 \circ$, and pour it slowly over the fruits from above, and then-place the mold in a drying stove, heat to $40^{\circ}$, drain when sufficiently candied, ordinarily at the end of five or six hours.

Fruits that are dry and firm are also candied cold, the candy is finer and less subject to mass, in that case the sugar is cooked $1^{\circ}$ or $2^{\circ}$ less, is put to candy at night and drained the next morning.

\section{SUGARS.}

I now, perhaps, have sufficiently presented the processes required by my instructions, but it seems inportant, to make matters clear, that sometbing be said concerung the various forms of preparation of sugar that are used in the business.

Only clarified sugar is used, and this is reduced to sirups of various densities. The degree of density is ascertained by a pese sirup, an aerometer invented by Beaumé.

The first condition of cooking which I shall mention is called La nappé, and the sugar weighs $20^{\circ}$. When, in dipping the skimmer into boiling sugar, after a turn of the hand the sirup apreads alons the skimmer, it has reached this stage.

Petit lissé. - The sugar weighs $25^{\circ}$. Some boilings after la nappé, pass the forefinger on the skimmer charged with sirnp, and apply it against the thumb. If in spreading these two fingers you see a little thread which breaks immediately, leaving a drop on the finger, you have petit lisse.

Grand lisse.-The sugar weighs $30^{\circ}$. When the thread has more consistenoy, and epreade more, you bave grand lissé.

Petit perlé.-The sugar weighs $33^{\circ}$.

Grand perle.-The sugar weighs $34^{\circ}$ and $35^{\circ}$. If at last in speading the two fingers the thread sustains itself without breaking, jou Lave the grand perl6. The attentive workman will distinguish these two cookings by the aspect of the liquid. It prodaces large, high, round bubbles going out from the boiling in the form of pearls.

Petit soump -Thesugar weighs $37^{\circ}$. It will be recognized when, in blowing through the holes of the skimmer after it has been shaken, the liquid forms little bubbles on the side opposite, which lightly detrob. This is the petit sonfle employed in icing fruit.

Grand souffe.-The sugar weighs 3:30. After some boilings operate as in petit soufle. If the bubbles are largur, resombling sorp-bubbles aud maintaining themselves a mownt, it is the grand soumd. Or dip your tinger in fresh water, plunge it in the 
sugar and dip it again in the water, if there remains a little compact sugar at the end of your finger you have the same thing.

The same means are employed for the cooking of yros candi.

Petit boule.-The sugar weighs $39^{\circ}$. Dip your finger in fresh water, then in the boiling sugar, and then again in the water. If it forms a soft ball which one can turn in the fingers you have the cooking for bon bons with liquors.

Grand bould-The sugar weighs $40^{\circ}$. After some boilings more renew the preceding operation. If the ball is larger and harder you have the cooking for preserves which are not elear.

Petit cassé. - After some boilings operate as before. If in cooling the sugar it breaks ; if it attaches to the teeth, it is a petit eassé.

After the grand boule, the degree of the sugar is no more observed. It is then the cooking of the twisted sugars, or suorestors.

Grand casse.-When after being further cooked the sugar produces a little simmering in water and adheres no longer to the teeth, it is a grand casse. This is the cooking of barley sugar, caramels, burnt almonds, etc. An experienced workman will readily recognize it by the crackling which the sugar makes in the fingers.

$$
\begin{gathered}
\text { J. E. IRISH, } \\
\text { Oonsul. }
\end{gathered}
$$

\section{United States Consulate,} Cognac, November 25, 1885.

\section{RHEIMS.}

REPORT BI OONSUL FRISBIE.

While crystallized fruits (fruits glacés) are kept on sale by all firstclass grocers and confectioners, and quite extensively used by the peo. ple, they are not manufactured to any extent in this district, for the principal reason that the fruit growu here is not of sufficient, variety, quality, and quantity for the purpose, and by reason of its scarcity it usually commands too high a price to make the business profitable. I have found that the industry of manufacturing crystallized fruits, and other preserving methods, is carried on in Southern France, the great center of the industry being at Clermont-Ferrand, in the department of Puy-de-Dome, about 100 miles west of Lyons, which is the greatest fruitproducing section of France, and where fruit of many kinds is nearly always plentiful and of the best quality. The dealers in this section usu. ally purchase their crystallized and other preserved fruits from the wholesale houses of Paris, who receive it in large quantities from the section named, and in some considerable quantities from Nice, where it is also quite largely manufactured. It is said that this fruit is not so finely and nicely made at any other place in France as at Clermont-Ferrand and at Nice. There is at Rheims, however, an occasional confectioner of the first class, who finds himself in a position to advantageously manufacture his own fruits, but this is always done on a small scale and only for the needs of his local customers and never for wholesale nor for export, and which my information teaches me they manu- 
facture according to the following methorls, and which are sdid to be substantially the same as that employed in the large establishments in the south of France:

\section{ORYSTALLIZED FRUIT'S.}

Begin the operation by dipping the fruit into bot, melted sugar for a moment; let it drain and dry. Then wash it lightly in lukewarm water, after which put it in earthenware pans or dishes and place it in a warm (not hot) oven for a couple of hours. Cook some sugar over a slow fire in a copper dish at $105^{\circ}$ of heat; put the fruit in the boiling sugar for a few seconds; skim; remove the dish from the fire and place it on a table in an inclined position and collect the sugar on the side with a spatula. When the sugar begins to whiten roll the fruit in it, one or two at a time; remove it with a fork and place it on galvanized or tinned wire sieves or grates, over earthen ware dishes or candy molds. When the fruit is small, as soou as the sugar begins to granulate mix the whole, fruit and sugar, rapidly together and remove quickly with a coarse skimmer, placing the fruit on a wire sieve as above described. If the fruit is soft cook it a little more, and stir the sugar longer with the spatula than if it be hard, dry, or of the rinds.

Keep the glazing (sugar) for future use, and, if necessary, renew it br adding more sugar. Should the sugar become pasty, cook and stir it longer, or, better still, replace it with fresh glazing.

\section{CANDIED FRUITS.}

First dip the fruit in hot melted sugar for a moment, let it drain and dry, after which wash it lightly in lukewarm water ; then place it on a siere to dry in a warm (not hot) oven. When it is dry cook some sugar over a slow fire to $95^{\circ}$ or $100^{\circ}$ of heat. Place the fruit side by side between two galvanized-wire sieves or grates in a candy mold; pour the sugar carefully over the fruit and then place the molds in an oren heated to $105^{\circ}$. When the fruit is sufficiently caudied, which is usually accomplished in five or six hours, remove and let the fruit drain and dry.

Fruit that is hard or dry may bo candied by the cold method, the candy being finer and less liable to granulate. Cook the glazing to between $95^{\circ}$ and $100^{\circ}$ of heat. Place the fruit in the glazing in the evening and remove it the following morning, when it is allowed to drip) aud dry.

\section{CAIIAMELED FTUI'l'}

Begin by preparing each kind of fruit, according to its nature, to be dipped into the caramel, a substance obtained as follows: Cook about 2 pounds of clarified sugar, which is proferable to melted sugar, to which arld a spoonful of glucose to proveut its granulating, and cook it until it becomes hard and brittle when placed in cold water. Place 
an earthen or copper dish in an inclined position over a slow fire or over hot coals lightly covered with cinders or ashes so that the sugar does not get cool. Dip the fruit in the sugar and then place it on a sieve or haug it on strings over an oiled marble slab; for small fruit, on wire sieves or grates made for the purpose, and for large fruit, such as oranges, chestnuts, etc., simply place them on the marble.

If the fruit has been prepared on strings, cut the strings aud place the carameled fruit on sieves and put it away in a dry place. If the fruit has been done on skewers, especially oranges, remove the skewers before the caramel is completely cold, as otherwise the caramel gets broken and the juice of the fruit escapes. When remored in proper time the bole made in the fruit by the skewer is easily closed up by the warm caramel.

Fruit should only be carameled a few minutes before serving, so as to be nice, fine, and fresh. Carameled fruit can be either served up in fancy structures and forms or separately. When carameling fruit two or more persons should always be engaged in the operation, as the car. amel should be kept hot and never allowed to cool, as if it is reheated it will granulate and redden. To caramel fruit wooden skewers, string, or galvanized or tinned wire may be ased.

In carameling cherries there are three things to be considered, viz: If fresh they must be very fresh and sound, and have the stems cut short, that is, about half length; (2) if the cherries have been preserved they must be dried before the operation; (3) if brandy cherries are used they must be allowed to drip and be left a few minutes in a warm oren. They are either tied together or fastened on skewers, then dipped aud hung up to dry.

Chestnuts.-Roast the chestnuts slowly so as not to scorch them; remove the shell and inner husk. Put them on skewers and dip them in the caramel. In removing them give them a twirl, so as to spread the caramel evenly over them and lay them on a slightly oiled marble slab.

Oranges.-Choose the finest and firmest fruit, remove the peel, divide into quarters, remove all the white with a knife, taking care not to cut the skin, as the juice would come out and dissolve the caramel. Put them on skewers on a sieve and place them in a warm (not hot) oven, to be slightly dried before dipping. Finish as with chestnuts. Oranges should be skewered through the center so as to prevent the juice from runuing when the skewer is withdrawn.

Preserved fruits.-All kinds of preserved fruits, such as apricots, small oranges, plums, nuts, pears, dates, prunes, etc., can be carameled by following the foregoing instructions. Only care should be taken that the fruit be first washed in luke-warm water to removie the sirup and then dried in a warm oven.

Grapes.-Fresh or dry Malaga grapes are frequently used and grapes of the country in their season. Several grapes are fastened on galvanized wire, and the bunches thus formed are fastened to a wooden skewer; 
they are then dipped into the caramel and then placed on smail wire sieves, of which the meshes are made of proper size to hold the grapes, and placed as usual above a marble slab.

Small fruits, such as currants, raspberries, strawberries, almonds, filberts, hazelnuts, etc., can be carameled, but care should be taken that the fruit be separated when removed from the sugar.

JoHN L. Frisite,

Consul.

United States Consulate,

Rheims, November 11, 1885.

\section{BORDEAUX.}

\section{REPORT BY OONSUL ROOSEVELT.}

Having carefully examined the methods employed in crystallizing fruits, I am enabled to report as follows:

All fruits indigenous to France, and a few select fruits from other countries, as also several species of soft shell-nuts are employed.

The kettles used are generally of copper (much broader than deep, to prevent crushing the fruit), provided with a wire frame placed 1 or 2 inches from the bottom to protect the fruit from scorching. When ready for use they are three-fourths filled with water, which is heated to boiling point ( $95^{\circ}$ centigrade) and covered by a towel or straw cover.

The fruit shoull be gathered several days before maturity; and, if possible, early in the morning of a dry day. The first important step is the bleaching, or, more properly speaking, the parboiling of such fruits as are to be subjected to this preliminary process. The fruit should be picked and bleached the same day to obtain best results. The pits are carefully removed and the fruit plunged into very cold water before being transferred to the kettle. During the process of boiling, the fruit is occasionally gently stirred, so that each separate piece may be equally cooked. When the fruit begins to settle at the bottom of the kettle the fire is reduced for ten minutes, then gradually increased until the fruit again rises to the surface and becomes sufficiently tender to be punctured with a straw. They are then carefully remored from the kettle with a skimmer and dropped into very cold water, which is renewed several times, or until they are thoroughly cold; they are then placed upon wire frames to dry. The boiling should be accomplished quickly so as to submit the fruit to as rapid and sudden change of temperature as possible. The boiling is generally done orer an open fire, but the most satisfactory results are obtained when steam is employed, as it is an easier matter to regulate the heat from steam necessary to tho different kiud of fruits.

Great care mist be taken in the first boiling, since the fruit, if orer. done, falls to pieces, and if underlone the pores are compressed, prevent- 
ing a thorough permeation of the sugar, and in consequence the fruit becomes tough, dark in color, and soon grows moldy. When the same water is used a second time for the purpose of boiling, it is thoroughly cooled before receiving the fresh fruit; it is then slowily heated, the temperature being maintained at a low point for a considerable time.

When the fruits are not sufficiently soft after the first boiling, they are put into a lot sirup (invariably made of cane sugar) of $25^{\circ}$ of density, the water remaining in the fruit is absorbed by the sirup and is gradually reduced. After the preliminary bolling in water the fruit is submitted to the sirup daily for five or ten days, or until the sugar has thoroughly penetrated the pores. After each boiling the fruit is carefully removed trom the sirup and put in to a cool place to dry. The sirup for the first boiling is always $25^{\circ}$ of density, and is increased $2 \circ$ each day until it reaches $30^{\circ}$, excepting in cases where it is necessary to submit the fruit to the sirup twice in the same day, then it is only in. creased $1^{\circ}$ and is not allowed to boil, but only to scald the fruit.

Fruits are crystallized with and without rind, whole, in halves, and in quarters. Pears, apples, quinces, and oranges are generally crystallized peeled. To retain the delicate coloring in such fruit as the apricot, pear, peach, and chestuut, it is necessary to add to every hectoliter of cold water 40 or 50 grams of pulverized alum.

Some confectioners employ lemon juice, verjuice, salt, sugar of milk, and epsom salts, to preserve the whiteness of the fruit after boiling and sulphate of copper, vinegar or salt, to retain the green color natural to certain fruits.

When the crystallized fruit is destined for warm countries it,receives additional cooking. The fruit when crystallized is packed in boxes containing from a quarter of a pound to two pounds each.

There are several establishments in Bordeaux devoted to the crystallization of fruits. The most important of which is that of Alexander Droz \& Co., to whom I am under obligations for much valuable information. Their average annual sale of crystallized fruits is 160,000 pounds, the half of which is consumed in France. Their annual exportation of cherries alone to England and Russia is 24,000 pounds.

It is estimated that very nearly 700,000 pounds of fruit is crystallized at Bordeaux annually. The average cost per pound (not including the price of the fruit) to the producer is 15 cents, or $\$ 15$ per $\mathrm{cwt}$. The fruits in greatest demand on this market are apricots, cherries, and chestnuts. The separate preparation of each I give in full below.

\section{APRICOTS.}

The apricots should be picked several days before maturity. An incision is made by a knife at the head, and the pit gently forced out, the unipe parts are lightly pricked, and the fruit is then pluaged into very cold water containing a little alum or lemon juice. The water is chauged frequently before the fruit is transferred to hot sirup of $20^{\circ}$ of

$$
156 \mathrm{~A}=-32
$$


densitv, preparatory to bolling. After boiling, the fruit is taken from the sirup and removed to a cool place until the next day. This process is followed for five or six days, each day increasing the density of the sirup 20 until it reaches $36^{\circ}$. The fruit is only permitted to boil after the first cooking if it continues too firm; if soft, it only simmers. The kettle containing the fruit is removed from the fire, and as the sirup begins to whiteu the fruit is carefully turned in the whitish parts and then removed from the kettle and placed on a wire frame to dry.

\section{CHERRIES.}

Large cherries should be chosen. After the stema are removed the pits are taken out, the cherries are placed on a dish side by side, with the open side up, and covered with powdered sugar; layer after layer is thus formed uutil the dish is filled; it is then set aside until the next day. They are frequently stirred, and finally are slowly cooked and crystallized.

\section{CHESTNUTS.}

The large chestnuts of Lyons, France, or Lucques, Italy, are preferred. The outer shell is removed, care being taken not to bruise or break the nut. They are immediately put into cold water, from which they are trausferred to a large kettle of boiling water, where they remain until they become tender; they are then taken from the boiling water, freed from the skin surrounding them, which is a delicate operation and should be accomplished as quickly as possible, as the nut is liable to crumble, and in consequence is dificult to crystallize. Once peeled they are pat into sirup of $20^{\circ}$ of density, and are kept hot over a slow fire. The kettle is covered with a towel or piece of white paper until the sirup begius to whiten. The kettle is then removed and the same process followed as employed in erystallizing apricots.

$$
\begin{aligned}
& \text { Geo. W. RoosevelT, } \\
& \text { Consul. }
\end{aligned}
$$

Unteded States Consulate, Bordeaux, November 19, 1885.

\section{NICE,}

\section{IEPOIT BY OONSUL HATHEWAF, OF NIUE.}

The art of fruit crystallization, as employed in France, is, in theory, a process by which certain fruits are preserved br withdrawing their juices which lead to fermentation sud substituting a thorough saturation of sugar.

The stccessful practice of the art depends lingely ou the judgment and experienced skill of the confectioner, for many conditions, independent of any formula, may operate in favor of or adversely to the desired results. 
The nature of the soil from which the fruits have been produced must first be carefully considered. Confectioners here prefer, therefore, to select their fruits among those grown on a dry soil, as such are more palatable, damp land producing those too soft, or of an insufficient firmness of fiber to support the fabrication.

The process also is modified by the variety of fruit used, and its degree of hardness or ripeness; and the exact adaptation of the sirup thereto is also a requisite to complete success. For instance, pine-apple demands a density of sirup of only $18^{\circ}$, while other fruits of less coasistence require according to their kind a sirup up to a maximum of $42{ }^{\circ}$.

$\Delta$ gaiu, some fruit must receive a special preparation. Thus cedars, mandarin, and bitter oranges should be soaked first in a bath of seawater, often changed, which gives them consistency and removes a disagreeable flavor which renders them otherwise unfit for use.

All fruits produced here, apples excepted, can be crystallized, but the more "fat" the fruit the less easily the sirup penetrates into its pulp; thus oranges admit the process easily, but plums much less readily.

The oranges used for this purpose are gathered at times commencing when the fruit is hardly formed, and has simply the firmness and taste of fruit, and continuing until when nearly ripe and of full size it begins to be somewhat colored.

\section{PROCESS OF CRYSTALLIZING FRUITS.}

The fruit is plunged into very hot water for a short period, or until it is white or has become bleached.

It is then completely drained of water and placed in a sirup of white sugar which has been cooked until a small quantity separated between the thumb aud forefinger forms slight filaments, and it is adapted in strength to the hardness, softness, and degree of ripeness of the fruit employed.

In this sirup the fruit remains until the mixture of juice and sirup shows a white clouded appearance, indicating the beginning of fermentation. The whole is then again subjected to heat and raised to the boiling point and then removed.

Such alternate fermentation and boiling is usually three times undergone, the fruit and sirup remaining together from two to five weeks, according to the kind and quality of the same.

Red copper boilers, with iron handles at the sides, and containing about 25 pounds, are used in the process.

\section{BEAUMÉ AEROMETER.}

The aerometer employed to show the amount of sugar which the water contains is about 8 inches in length, formed in ordinary glass, and in weight the same as the volume of water which, when used, it dis. places. 
One end of this is heavy, that it may stand upright in the liquid, the center has a chamber of rarified air, and the other extremity is a slender tube, on which is marked a graduated scale from the top toward the center of its length, and numbering $50^{\circ}$. The rising of this tube above the liquid shows the density of the sirup.

One of the confections made from this preliminary process is styled "crystallize;" the other " glace."

To crystallize the fruit thus prepared (as in the foregoing description) it is taken from the sirup and dried in a room at a heat of $100^{\circ} \mathrm{F}$., when the sugar appears in small crystals on its surface. "Glace" is prepared by removing the fruit from the sirup and allowing it to dry gradually. The sugar thus forms a glaze on the fruit, which gives it its name.

\section{PRODUCTION AND COST.}

The quantity of fruits thus preserved in this consular district can not be accurately determined, as there are no statistics of these products. 'The following data per year may, howerer, be received as nearly correct :

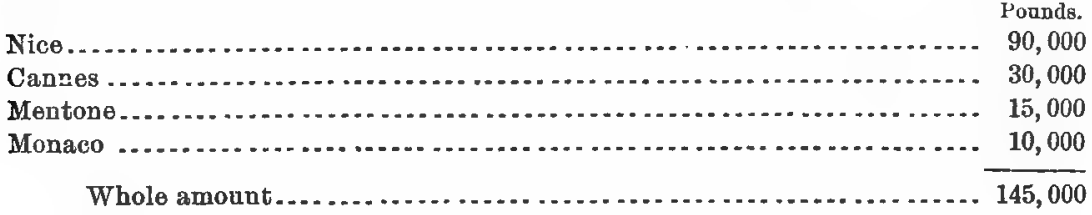

The expense of labor and sugar employed in the manufacture of them may be estimated as follows: (1) $1 \frac{1}{2}$ pounds of sugar to 1 pound of fruit, cost price of sugar, 14 cents; (2) labor, per pound, of production, 5 cents; entire cost of sugar and labor, 19 cents.

One pound of crystallized fruit is sold here at the manufacturers' wholesale sales, at from 28 cents to 50 cents, according to its kind and quality.

I am indebted to the most experienced confectioners of this district for the foregoing information, and especially to the courtesy of M. Voggade, of Nice, and J. Negree, of Cannes.

ALBer'T N. HatmWWAT,

Consul.

United Staths Consulatie, Nice, December 1, 1885.

Consul Dufais, under date November 9, 1885, sends the following translation of a letter of the mayor of Clermont-Ferrand on the subject of crystallized fruits:

Cremmont-Fenrand, Nurember 7, 1885.

In answer to your letter, 28tb last mon,th, I have the houor to transmit to you the following information which Mr. Dionis, confectioner, has been plaused to give mo:

"The candying (glaceage) of tiruit is au operation learned entirely by practice, and which is diffrealt to desoribe. 
"When the fruit is well drained boil the sugar briskly, put the clrained fruit in it cover up your pan (a large one) after one boiling, then withdraw it from the fire, work your sugar until entirely melted. Take the fruit out with a skimmer, put them on gridirons in a drying stove. The price of candied fruit varies according to quality and kind from 2 to 4 franes per kilogram (about $2 \frac{1}{6}$ ponnds)."

\section{THE DATE-PALM IN PERSIA.}

\section{REPORT BY MINISTER PRATT.}

[Republished from Consular Reports No. 86.]

As a first result of my endeavors to obtain practical information on the subject of the date-palm (Phoenix dactilifera), with a view to its introduction into the United States and cultivation along our South Atlantic and Gulf coast and in Lower California, I have succeeded in gathering from Persian sources the following:

The date-palm is found in countries situater within the zone of 16 and 30 degrees north and south latitude. Except, however, in rare instances it will bear no fruit in localities removed 120 or 135 miles from the sea.

There are two methods employed for propagating the date-tree; one by setting the date stone, the other by transplanting the seedling (self-sown).

When it is desired to raise a plant from the stone of the date one perfectly ripe and faultless is selected and both ends are either filed, or scraped off with a knife, until the inner kernel is laid bare. It is then planted in a mixture of gravel, sand, and camel manure. From twelve to forty days usually elapse before it makes its appearance above ground. It will then put forth long, narrow, thin, and tender leaves, somewhat the shape of a saddler's needle. From the fourth to the seventh year it produces nothing except long, rough, reed-like leaves. It is, however, possible that during this period the tree may, from its leaves, which resemble the shoots of the oleander, briug forth other leaves; but owners of palm gardens pluck off these in order to give the tree a graceful appearance. Under no circumstances, however, do they touch the leaves that shoot out from the crown of the tree. If its head is severed from its body the whole tree withers and dies. Each iudividual plant is either male or female.

When the tree has attained its full stature a flowering branch is cut from the male paln and applied to the half.open fluwer bowl of the female, thus giving it the fecundating principle without which it can not mature its fruit germs.

In no instance has it been recorded by botanists that one of these trees possessed in itself the different natures of male and female, and for this reason was it that the Arab savants classed the palm as the first of the vegetable kingdom and the last of the animal. 
The height of the date-palm varies from three to twelve meters. The tree itself will indicate the time of fruit bearing.

When it has arrived at its maturity it will cease its upward growth and throw out from its head a large mass of long, broad, green, leares, which protect the neck from the glare and heat of the sun. The young seedlings must be removed from the foot of the parent tree in the month of January, and planted and reared according to the foregoing instructions.

In Persia the palm is grown near the ports on the Persian Gulf; also, in the hot districts of Kerman, Khûrzistan, and in the oasis of Jandak.

Lega'ion of the United States,

F. Spencer Pratt.

Teheran, July 3, 1887.

\section{CULTIVATION OF THE ALMOND TREE.}

\section{REPORT BY OONSUL MATHETS, OF TANGIER.}

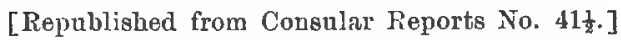

Soils, etc.-The almond is a tree of third magnitude, and is remarkable for the facilty in raising it, for its hardiness in standing continued droughts growing in the poorest soils, in the sands, gravels, and amongst rocks; and finally for the abundance of and high price which its fruit commands. In fact, the almond-tree being the easiest and cheapest to rear and cultivate is the most useful tree to industry, medicine, and the arts.

California abounds in soils which are considered, owing to their locality, lightness, or hilly nature, unprofitable or unfit for any use but pasturing cattle in certain seasons of the year, which, if planted with almonds, would become sources of great wealth and utility. The cultare of almonds is in fact the easiest, most economical, and productire. At the sixth year the almond trees commence to yield by far greater product than the expenses incurred in their raising and cultivation, owing to their rustic habit, requiring no care from the time of their planting to the long period which these trees live.

The many varieties of almonds are variously described; they are dirided in two groups, the sweet and the bitter almond. The most prominent are the Princess almond, tho largest and most superior of all; others, large, soft-shell, and large, sweet almond, vers much sought; the common almond, with a small fruit; sweet almond, with a teuder shell; Jordan almond, with a tender shell and a large, sweet kernel. These almonds are largely exporterl. The Sultana almond, or Ibiza of the Balearic Islands, with a small fruit and tender kernel; the Pista. chio almond, with smaller fruit than the last mentioned, and a variety of hard-shell and bitter almonds. 
Propagation.-The only and usual mode of propagating the amond is from seed. The soil preferred by almonds is a light sandy soil; ; xcessive or eren great richness is to be avoided, as in this the trees will produce large and luxuriant branches and foliage, but no fruit. The barliest almond is the bitter, and is preferable as stock for bulding or grafting on a given variety. The next hardiest for stocks is the sweet, hard-shell almond. The land selected should be plowed or worked with hoes immediateiv after the first rains. In the month of November or December swall holes are dug, as it for sowing water-melons, and distance 20 feet each way. Procure the nuts of the last season aud those which have not been much exposed to the air. In procuring almonds for seed the best quality of soft-shell almond must be used; then they will grow as standards, requiring no budding nor grafting, producing tine almonds oven if some issue the hard-shell variety. Plant an almond in each hole from $1 \frac{1}{2}$ to 2 inches deep, but not deeper; sow them with the sharp point upwaids, without breaking their shells. They will come up in aloont thirt. . five to forty days. The first year they should be protected against frost and snow with sticks and straw around them, for, hardy as they may be when once established, they would be in some dauger while young. They must be kept clear of weeds, and in the spring the surface of the soil should be stirred. On the second year trim off the lower. shoots and head down those in exposed positions or intended for dwarfs. The buds that are pusbing on the main stem should be rubbed off; branches, where they are wanted, should be encouraged, and the buds, where shoots are not wanted, rubbed off. It is far better to prevent the waste of strength in wood that has to be pruned off; then the almond will require no pruning, but an annual removal of dry branches.

In order to provide and replace with plants those holes where the seed has failed to come up, there should be a number of almonds sown in some selected place near at hand; sow them as you would walnuts, or rather plant them at regular distances 8 inches or a foot apart every way, and 2 inches deep; in the spring they may be transplanted to their definite places, and well watered.

Fertilizing.-The best fertilizers of the almond trees are grass, weeds, leaves, etc., buried around them. Almonds are grafted or bulded on plum stocks when it is desired to retard their bloom, but it is considered more certain, in order to avoid the only defect of the almond tree, precocity to plant the trees in sites exposed to the north winds, in cold places, in order to retard flowering as much as possible, and escape the spring frosts.

Maturity.-The almond tree comes into full bearing in the eightu or tenth year, according to soil and climate. The fruit is gathered when quite ripe and allowed to dry before it is cleaned and packed.

Field.-The annual product of the almond varies according to the age or situation of the plant; a twelve-year-old tree may produce from 8 to 16 pounds of unshelled almonds-the average yield is 12 pounds- 
which sell readily at 10 cents per pound in France, Italy, Spain, and even Moroceo, the above being the lowest wholesale price; and should the trees stand 20 feet apart, at the rate of a hundred trees to the acre, the yield per acre will be 1,200 pouuds, of the value of $\$ 120$ per acre. If we take into consideration that the culture of almonds in a favorable climate is carried on on lands which are often useless for other crops, and the expenses of cultivation very small, often absolutely nil, it will be seen that it is a most profitable culture.

Felix A. Mathews,

Consul.

\section{United States Consulate,}

Tangier, April 2, 1884.

\section{GRAPE-VINE FERTILIZER. \\ REPORT BY COMMEROIAL AGENT MALMROS OF ÕT. ETLENNE.}

[Republished from Consular Reports No. 117.]

M. George Ville, the eminent professor of vegetable chemistry at the Paris Museum of Natural History, writes as follows:

During the last five years I have been devoting myself to the study of new formulas of chemical fertilizers. The one employed for the grape-vine, in 1889 , at the experimental vineyard of Vincennes, has yielded 20,000 kilograms of raisins per hectare, equal, say, to 180 hectoliters of wine. The receipe is as follows:

Superphosphate of lime, at 15 per cent. Kilograms.

Carbonate of potash, refined, at 90 per cent... . . . . . . . . .

Sulphate of lime................................................ 400

Total ................................................ $\overline{1,000}$

The manner of employing this fertilizer is very simple. A little cup-shaped cavity is made with the spade around each vine and into this cavity one pours the quantity of fertilizer, which has been ascertained by dividing the 1,000 kilograms by the number of vines on the hectare. A common water-tumbler mas serve as a measure by surrounding the tumbler with a thread at the height of the dose required. After the fertilizer has been applied, the hole is filled up with the earth removed in order to make the hole. In case the vineyards are of very great extent, one may proceed in a still simpler manner-one spreads the fertilizer in front and behind the vines and covers it with earth by plowing. This manure ought, as far as practicable, to be applied in autumn, in November and December, or in case this can not be done, in Jannary and February.

The above recipe is applicable to every variety of soil on which vines are grown. I have only experimented on French vines, but an convinced that the above fertilizer will have the same effect on American vines. To the above recipe I may add that it is desirable to trim the vine stocks but little, and to let them remain tall, very tall. This will have a tendency to avoid the attacks of the plyylloxera, for it is a fact well demonstrated to-day that vines on trellis-work have been free from suoh attacke.

The Année Scientifique, inclorsing the recipe of Professor Ville, says that, in view of the fuet that in the entire south of France short-cut 
vine stocks are of immemorial trarlition, the recoumendation to keep them very tall (taille a long bois) constitutes a bold innoration, but feels no hesitation in advising viticulturists to reform their habits in this respect iv order to place themselves in the conditions prescribed by the distinguished chemist for the application of his recipe.

I am informed that the above-mentioned large production of the experimental vineyard at Vincennes can not exhaust the soil, as the said fertilizer fully restores to the soil all the ingredients consumed by the production of the crop of raisins. I am also informed that the favora. ble consequences of keeping the vines tall may be attributed to the circumstance that vines kept in that condition are provided with plenty of leaves, which constitute the respiratory as well as digestive organs of the plant, and that an abundance of leaves are required in order to give vigor and productiveness to the vine; that, on the contrary, a deficiency of leaves causes a decrease of sugar in the raisins and, in course of time, probably, a tenderness or sponginess in the roots.

\section{OscaR MaLMros,}

Commercial Agent.

\section{United States Commerdial Agency,} St. Etienne, June 4, 1890.

\section{THE CITRON OF COMMERCE.}

[Republished from Consular Reports No. 61.]

\section{ITALY.}

ROME.

\section{REPORT BY CONSUL-GENERAL ALDEN.}

As citron is not grown within the limits of this consular district, I have been able to obtain but a limited amount of information in regard to it.

The citron tree, or shrub, will grow wherever lemon or orauge trees grow. It flourishes, however, only in a sandy soil and in the im mediate neighborhood of the sea. It is most successful in sheltered situations on the shores of bays. As might therefore be expected it is largely grown on the Ligurian coast, which is sheltered br mouvtains from the north wind, and also in the Southern Mediterraneau proviuces of Italy, and in Sicily. The French islaud of Corsica is probably the most prolific citron-producing district of the Mediterranean Basin. The present Corsican crop is estimated to be nearly $5.510,000$ pounds. Great care is needed in the cultivation of citron. Tue fruit when full grown is large and weigbs from 1 to 3 pounds, aud will, unless the branches are carefully propped up, either break them or bend them to the ground. 
The average crop per acre of citron can hardly be ascertained, as the size of a crop depends upon so many conditions-such as the climate and soil. If we assume that each shrub or tree is plantell 3 jards from every other, which by many growers is regarded as the best arrangement, we should have 1,110 shrubs to the bectare. If the average prodvet of each shrub be assumed to be 14 citrons, we should have a total

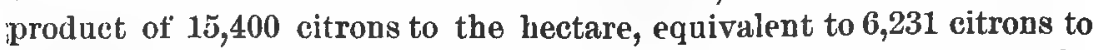
the acre; or, assuming the average weight of the fruit to be $1 \frac{1}{2}$ pounds, about 9,346 pounds to the acre.

The cost of production varies so greatly in different localities and at different times that no trustworthy and generally usefui answer to the question of cost can be given. In the neighborhood of Genoa, how. ever, it is roughly estimated at about $\$ 68$ per acre.

More citron is imported into than is exported from Italy. The following table shows the imports and exports of citron for three years:

\begin{tabular}{|c|c|c|}
\hline Year. & Imports. & Exports. \\
\hline 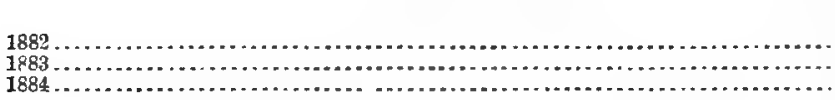 & $\begin{array}{l}\text { Porumds. } \\
3,696,701 \\
3,996,791 \\
2,733,454\end{array}$ & $\begin{array}{r}\text { Pounds. } \\
513,119 \\
341,719 \\
262,572\end{array}$ \\
\hline
\end{tabular}

The greater part of the imports of citron comes from France, and nearly all from the island of Corsica.

Citron is chiefly prepared for the market at Leghorn, which is the most important citron port in the Mediterranean. The fruit is first put into a salt pickle, in which it is allowed to lie for three months. This pickling in the case of the Corsican fruit is done to a limited extent by the Corsican citron grower, but as a rule it is done after the Corsican fruit reaches Leghorn. The next process consists in dividing the fruit into halves and quarters, and packing them into sugar sirup. The sirup when first used is weak, but its strength is gradually increased by additions. Four weoks is the ordinary period during which the fruit remains packed in sugar, after which it is ready for the market.

The market price everywhere fluctuates greatly. During the present year the price at Leghorn has varied from $\$ 14.47$ to $\$ 22.19$ per 50 kilograms, or 110.20 pounds. To some extent, so it is said, these fluctuations were due to the speculative condition of the market in New York, where the price has varied greatly.

United States Oonsulate-General,

$$
\begin{aligned}
& \text { William I. AldeN, } \\
& \text { Consul-General. }
\end{aligned}
$$

Rome, November 29, 1885. 


\section{LEGHORN.}

\section{REPORT BY OONSUL SARTORI.}

- CULTIVATION.

The citrons which are subsequently converted into the candied citron of commerce are grown ehiefly in Greece, Calabria, and the islauds of Sicily and Corsica. Most of those which come to this port, Leghoru, are from Corsica, where it is claimed the finest qualities are produced. The citron tree is of the same family as the orange and lemon, and is propagated by cuttings, which begin to bear fruit the third year after being planted. It bears one crop of fruit yearly, which matures and is gathered during September and October. The trees are pruned every year, the branches being made to grow as much as possible in the shape of a hollow circle. They are also manured yearlv, generally witu stable dung. In summer it is essential that they should be kept well watered; otherwise, if there should be a drought, the trees suffer, and the truit will drop off or will not attain its full size. The citron tree is more susceptible to damage from frost and cold winds than the orange or lemon, hence sheltered situations with a favorable exposure are sought for planting them, and hedges of brushwood disposed so as to protect them from the winds. The fruit resembles a huge lemon, and is often so large and heavy that it must be supported on the tree.

They are shipped to the factories for candying, sometimes in sacks, but nsuidly in large hogsheads filled with brine. On being taken out of these hogsheads or sacks they are placed in tubs containing fresh brine and left for about a month. The brine is then renewed, and the fruit may remain in it until required for use, even for a period of four or five months.

\section{CANDYING OITRON.}

When the citrons are to be candied they are taken out of these tubs and boiled in fresh water until sufficiently soft, which is ascertained by testing them with a fork. This usually takes about one and onequarter hours, and they are then cut into pieces, the seeds carefully remored, and they are immersed in cold water aud left for twenty-four hours, and become a green color. After this thes are placed in large eartheu jars with hot sirup, which should entirely cover them, and remain about three weeks. During this time the proportion of sugar in the sirup is gradually increased. They are then put into boilers, with crystallized sugar dissolved in a little water, and cooked ; then allowed to cool for twenty-four hours, and boiled angain until they can absorb no more sugar, and then taken out of the boilers and placed on a wire netting to dry. They are now ready for packing and aro placed in small wooden boxes containing about 25 pounds each, and these in their turn are packed in cases (half cases they are termed in the trade) swhich contain ten of them. The proportion of sugar used in the proc- 
ess of candying is 80 per cent.-that is, 80 pounds of sugar to 100 pounds of citron-and the kind used is generally Egyptian crystallized sugar, which costs at the factorios 11.85 cents per pound. The Government allows a drawback at the above rate-that is, 80 pounds of sugar to 100 ponnds of fruit-on such as is subsequently exported. As the duty is $\mathbf{5 . 7}$ cents per pound, it being returned makes the cost of the sugar used in candying the fruit afterwards exported 6.15 per pound.

There are nine factories for candying citrons in Leghorn, employing about 300 men and producing annually 4,400,000 pounds. In 1884 the United States took of these $1,921,341$ pounds, ralued at $\$ 214,652.23$, and up to the present date in 1885 they have taken $1,819,764$ pounds, valued at $\$ 261,566.61$, a decrease in the quantity and an increase in the valuation. The remainder is sent principally to Holland for distribution through northern Europe and England.

As there are no citrons grown in this consular district, it is difficult to give correct figures as to the cost of producing this fruit. The price paid by the merchauts here varies according to the supply, $5 \frac{3}{4}$ to $6 \frac{1}{4}$ cents per pound being about the average cost of the fruit in brine at the factories.

The article is handled almost entirely by speculators, and the prices of the candied fruit show great variations. While during the early autumn the prices ranged from $16 \frac{1}{2}$ to $18 \frac{1}{2}$ cents, it can now readily be purchased for 13 cents per pound.

\section{Dnited States Consulate,}

VIOTOR A. SARTORI,

Consul.

Leghorn, December 21, 1885.

\section{MESSINA.}

REPORT OF OONSUL JONES.

THE OLTRON 'TREE.

Formerly in the Province of Messina the citron (Citrus medica) was extensively grown in hedges, as dividing lines between neighbors, but within the last twenty years this tree has been nearly exterminated in this viciniby by the diseases known as gomma (bleeding) and cagna (footrot).

The citron was the first of the citrus family introduced into Europe. In its bearing and general appearance it is the most strongl c characterized of the genus. The tree is low, with a full head; it is strong-shooting; its shoots are temlen and straggling; its leaf is large, thick, oblong, wingless, and toothed. Changes occur at short intervals in the vitality of the tree. It frequently happens that healthy shoots live but one or two years; hence the necessity of cutting off the vertical shoots to prevent sudden disturbances in the head of the tree that would exhaust 
its strength. The diseases of the citron are constitutional, and prematurely destroy its life. The most promising subjects suddenly cease growing and became chlorotic; the branches gradually turn yellow, and are often covered with scabs, from which exudes coagulated sap resembling gum; the sores assume a cankerous appearance, and the tree dies. The citron's dying out to such a great extent in this province was due principally to its propagation by cuttiugs. It has been found that where the eitron was budding on an orange seedling, a d more especially on a sour orange, it acquired a stronger constitution and did not grow in such a straggling manner. The citron blooms at all seasons of the year. The flowers are white inside and purplish outside. Black ants destroy mauy of the blossoms. Once set, the fruit grows rapidly. Citrons often weigh from 6 to 8 pounds. The fruit presents a bumpy appearance; its base is full and flat; its perfume is delicious. It is necessary to prop up the branches of vigorous trees, as unassisted they could not support their heavy fruit. Good culture dinbtless would improve the nature of the citron and perfect its developm $\cdot n t$, but it cannot prolong its life, which is very short compared with that of the citrus family generally.*

Citron trees receive the same attention as the orange and lemon trees among which they grow. From March to October these trees are worked five times. Irrigation is found indispensable. During the summer, the dry season, the trees are watered twice a week. The average cost of cultivating an acre in orange or lemon trees is $\$ 50$ a year. The distance between these trees is from 14 to 20 feet, according to the soil aud the location.

\section{SHIPMENT OF CITRONS.}

The citrons now exported from Messina are brought from Reggio, in Calabria. They are shipped in brine, and are prepared as follows: The citrons are cut in halves, thrown into casks and salted-100 pounds of salt to the cask. The casks are then filled up with sea-water, and turned on their side. The citrons are left to soak from fifteen to twenty days. The casks are then opened and the citrons weighed-770 pounds of citron are allowed to the cask; sea-water and a little salt are added, and the cask is ready for exportation. A small auger-hole in the bung permits the gas produced by fermentation to escape. The casks are of chestnut. They cost $\$ 3$ apieco, and contain 105 gallons. It costs $\$ 1$ a cask to cut and salt the citrons, and $\$ 1$ a cask to pack them, cooperage included.

\section{PRICES AND EXPORTS.}

A citron tree bears from 35 to 50 citrons, which are worth to the grower from 5 to 10 cents apiece. First quality citrons weigh 1 pound and upwards. Last year citrons on the tree sold for $\$ 20$ the 220 pounds.

\footnotetext{
* For the above details I am indebted to the comprehensive work of Prof. F. Alfonso "Coltura degll Agrumi."
} 
November 1, 1885, they brought $\$ 17$ the 220 pounds; December 1 , 1885 , they fell to $\$ 12.50$. Salted citrons, November 1,1885 , were quoted at $\$ 64$ the cask; December 1,1885 , at $\$ 59$. November and December are the great shipping months; the fruit is then balf grown and half ripe.

The custom-house statistics show, for the year ending December 31, 1884 , that 455,400 pounds of citron in brine; valued at $\$ 16,560$, were exported from Mrssina. No preserved fruit is shipped from this port. England, France, Genoa, and Leghorn are the principal markets for the "citron of commerce."

\section{WALLACE S. JONES,}

Consul.

\section{UNited States Consulate,}

Messina, December 8, 1885.

\section{NAPLES.}

REPORT OF CONSUL OAMPHAUSEN.

\section{CULTIVATION.}

The cultivation of the citron begins with the sowing of the seed of the bitter orange, being the same seed from the fruit of which marmalade is made.

After four or five years, when the seed has produced plants or small trees, they are transplanted, at the time of blossoming, in regular rows, at a distance of 25 centimeters.

When they have a diameter of 8 centimeters they are grafted with swall citron branches. The grafting is indispensable to give long life to the trees and hasten the production of the fruit.

Three years after the grafting the tree is transplanted into a ditch 1.25 meters wide and 1.50 meters deep, at a distance of 4 meters from one another. In plancing the trees in the litch particular care should be taken not to injure any part of the roots.

The leaves are taken from the trees and the branches cut back to the length of 20 centimeters. The ditch is filled with earth to a depth not exceediug 25 centimeters, left sufficiently loose to allow the roots to sprear with ease, and prevent smothering the plants. If the plants do not sprout at once the earth on the roots is loosened and moistened.

For fertilızing old horse-manure or other old maunre is to be applied. No fresh manure ought to be used, because it would bo injurious and have a tendency to kill the plants. Manure should be used only in the winter, between October and March, and be placed at a distance of 10 or 15 centimeters from the roots. Around the tree a deepening in the shape of a basin should be formed, and unless the ground be moist or damp the plants require frequent applications of water during the summer. 
In Sorrento the planting is done from March to June, according to the state of the temperature; grafting during the same months. The rest of the cultivation is the same as for the orange and lemon. Hoeing and praning of useless limbs are done in May. The tree requires great protection against severe cold or very warm winds, as well as against hailstorms. In order to give it as much protection as possible hedges are planted and coverings of straw-matting or something similar provided, having regard to the situation of the tree and the means within reach of the cultivators. The plant is much more tender and delicate than the lemon.

The tree blossoms between March and May and up to the months of September and Uctober, at which time the fruit is ripe. In about two years' time the grafts will begin to bear fruit, and after six years, if the ground and climate suit, the tree will bear from 40 to 50 kilograms of fruit a year, and when in full age up to 2 quintals, and perhaps more.

The greatest part of the expense in the cultivation is caused by covering the tree to protect it against the winds. In milder climates this expense is not incurred, and the only outlay is for manuring and hoeing. These expenses vary according to the price of labor in the different localities. When the ground is of the right kiud-that is, loose and moist-the climate mild, there is a great profit made in the culture of the citron.

The exact amount of the profit can not be given, as it varies according to the price obtained for the fruit, which is subject to great fluctuations, ranging from 15 to 100 lire per quintal on the ground. This year, for instance, garden citrons have sold at from 30 to 70 francs or lire a quintal on the ground. Some years when Corsica, where the citron is cultivated to a very large exteut, gave large crops, the fruit sold for 15 lire a quintal, while at other times, when the crop was small, 100 lire a quintal was paid.

\section{PACKING AND PRESERVING.}

This fruit is packed the same as lemons, wrapped in paper and boxed or barreled.

The fruit is not candied for exportation in this neighborhood, but seni to Leghorn or Genoa, to large factories for this industry.

The information received on the subject of preserving the fruit is as folluws:

The citron is cut in two or four pieces; it is then placed on the fire and boiled until the inside ean be easily taken out with a spoon then soaked in cold water for 4 or 5 days, and the water changed twice a day, until the citron has lost its bitter taste. To every kilogram of fruit 1 kilogram of sugar and 1 liter of water is added, and placed over a slow fire and left standing for two days.

Then 100 grams of sugar to every kilogram of fruit is added, and the boiling process repeated, left again fọr two day s, and then again repeated 
at intervals until the sirup is thick. The fruit is then dried in an oven or before the fre, and can be exported in wooden boxes.

According to another authority, the fresh citron is divided, the pulp taken out, and the rinds are then steeped in brine for several weeks. They are then boiled in sirup until the rinds are quite cooked; they are next dried and boxed, as above described.

Others again, after taking the rind out of the brine, boil it in water for two days, changing the water two or three times per day and beginning each time with cold water; then 1 kilogram of sugar to one-half klogram of water is taken'; put into the quantity of sirup thus made 1 kilogram of the rind as above prepared. Each day for six or seven days briug the fruit now in the sirup to a heat in which you can just bear your hand, adding 50 grams of sugar each time. Let the fruit in this sirnp become cold, and, as above, add 50 grams. Make auother sirup of 1 kilogram of sugar to one-half kilogram of water; boil for one-half hour; then take the fruit out of the first sirup and put in the last prepared, which should be exceedingly hot, and boil the fruit ten minutes, stirring it at the same time. Thus the last sirup is absorbed by the fruit, and it becomes dry.

The citrons, both fresh and in brine, are exported in immense quantities from Messina, Palermo, and other places to foreign countries, but shiefly to the English markets.

\section{Eoward Camphausen,}

Consul.

United States Consulate, Naples, December 19, 1885.

\section{SICILY.}

REPORT OF OONSUL WOODOOOK OF OATANIA.

In this district, comprising the southeast third of Sicily, the land rises gradually from the sea-shore to the summit of 2 tna. The mountain is a little over two miles high, and Sicily is in a semi-tropical climate. The slopes of Atna, therefore, have everv rariety of climate from the semi tropical to the frigid, according to altitude. Citrus gloves make beautiful these slopes with their vivid green, from the sea-shore to an altitude of about 1,000 feet. At this higher altitude the cultivation of the orange and lemon is not so profitable, owing to the uncertainty of a crop. Heavy frosts at such an altitude are liable to injure the buds. The fruit, however (called montegna), is of the best quality.

The orchards that skirt the reil-shore bear abundantly, and seldom fail in producing a good crop. The fruit (ealled marina), is inferior to the mountain fruit, and bo:h trees and fruit are more subject to dis. easo and pests, 
The must desirable locality for a citrus orchard is that most distant from the sea and not of such an altitude as to lie within the frost line.

PROPAGATING THE PLANT.

There are four methods of propagating the citrus plant; by the seed, by cnttings, by grafting, and by budding.

The seeds for plantiug are taken from the choicest fruit when perfactly ripe, and are planted in the spring in some wat "n sbeltered spot from 4 to 5 inches apart. The soil should be composed of loose earth and well-rotterl manure. The young plants should be sparingly but frequently watered. The plants must be trausplanted to the orchard after the growth of a year or two.

To propagate by cuttings, young healthy shoots that are straight are selected. They should be about 1 foot in length, and must be planted in the ground to the depth of 4 or 5 inches in a soil similar to that used for the seed. Care should be taken to plant the cutting upright, as it grew upon the tree. When the cutting becomes well rooted, and has had a bealthy growth of a year or two, it may be removed for final planting to the orchard.

The grafting and budding methods, which are so commonly practiced, need not be described. Citrus plants in this part of Sicily are propagated almost entirely by the budding method.

For the stock upon which to bud, use is made of the bitter-orange tree. The bitter orange is indigenous to this climate. It is more bardy and less liable to disease than those that bear the choicest frutits. Its natural fruit has no value, but the Sicilians sometimes convert it into at kind of preserves.

For the purpose of propagating the choice fruits, the bitter-orange plant is grown in nurseries" from the seed. When the plant is a year old it is transplanted, and when it has attained a growth of about 1 inch in diameter (being three or four years old) it is again transplanted to the orchard.

\section{ORCHARD.}

The distance to be maintained between the trees in the orchard depends much upon the location and nature of the soil. When the locality is warm and the soil is naturally rich, mellow, and of easy culture, the distance between the trees must be greater than when the soil is hard and the climate colder, because the trees will grow more luxuriantly and form larger tops. In such a soil, for lemons the plants should be about 24 feet apart, and for oranges abont 17 feet. When the soil is naturally hard and poor and the climate colder, the distauce between the trees for lemons may be about 20 feet, and for oranges about 13 feet. The judgment of the horticulturist must determine this matter.

When the bitter-orange plauts are thus trausplanted to the orchard the tops are cut off about 4 feet above the ground. When thes become $156 \mathrm{~A} \longrightarrow 33$ 
well rooted and of healthy growth, tikcy are budded from the choicest varieties of orange and lemon. Two buds are generally inserced in the stock opposite each other.

The orchard is thoroughly eultivated, being worked over with the mattock and spade at least five times during the season, conmenciug in March and ending in October. The ground when the trees are joung does not require so thorough a cultivation.

The plants are irrigated whenever they require it. For this purpose the streams that tumble down from Aetna are utilized. Where this is impracticable, water is elevated from wells by steam or mule power.

Some grow regotables between the trees, but this practice is condemned by the best horticulturists.

As to the time when the trees begin to bear a full crop mucin depends upon the climate, cultivation, and fertility of the soil. Geuerally they commence to bear a full crop when fifteen years old.

As to the longevity of the citrus tree, there is here a diversity of opinion. I have been told by sowe horticulturists that the lemon and orange budded upon a bitter-orauge stock will live and continue fruitful from one to two ceuturies. Doubtless they will live and continue to beal from fifty to one hundred years.

Lemon trees are healtuy and vigorous, bear anunally on the average about a thousand of the fruit, and oranges about six huntred. There are instances in which trees have borne ten times the number specified.

\section{GATHERING AND BOXING THE FRUIT.}

The time for gathering the fuluit for export is here in the month of November. For export to so distunt a countrs as America, the best and soundest fruit is generally selected. It is plucked when not fully mature, and is yet of a greenish color.

In gathering the crop great care is taken not to bruise the fruit. It is plucked by hand, and gintly deposited in a basket that is lined with cloth. The stem is not removel from the fruit, but is cut off about a quarter of an inch from its base.

Great care is taken in preparing the fruit for market. Each individual fruit is carresully cleaued of all insects, or injurious matter, with a sponge and cold water, and is wiped perfectly dr; before boxing. The fruits are carefully assorted. Those that are lirese, plump, and healthy in appearance, without marks or spots upon the surface, are boxed by themselves, and denominated "first class." Ihose whose skins bear auy blemish or otherwise are not tine in appearance are hoxed by thomselves and donominated "second class."

The boxes for the firuit are so constrneted that they will bold from 250 to 360 of the fruit. Wuh box is inspected to see that no natil or sliver protrudes to injuro hae fruit. 1.t is then lined with common silk paper. Each individuil lemon is emreloped in the same kind of yaper 
prior to being deposited in the box. The boxes are frequently opuued, inspected, and all infected fruit removed. Especially is this done just prior to shipment.

Laborers in citrus orchards recive as wages from 30 to 40 ceuts a day, without food being furnished to them. In summer they are required to work ten hours a day, and in winter eight hours.

The cost per annum of cultivation in the best orchirds per hectare (2.471 acres), as estimated by a práctical grower, Mr. Augustus Peratoner, United States vice-consul, is on the average 650 lire $(\$ 125.45)$.

DISEASES AND PESTS.

The diseases and pests attackiug the citrus trees in this part of Sicily are as follows :

A disease called the "colla" (glue) sometimes (though not often in this district) affects the citrus. It is said to be caused by a sudden change from a high to a low temperature; this checks the exhalation of the tree, and the matter to be exhaled accumulates within until it bursts the passages and forces, its way out through the bark. On coming in contact with the air it condenses in drups of a light-yellow gum. The only remedy for this disease is to cut off the branches infected.

A parasitic growth of a fungus nature freqnently gatbers upon the bark of the trees. The lemon tree is more subject to this than the orange. It is removed after a heavy rain, or after thoronghly soaking the parts affected, by scraping.

An insect called the pidocchio nero (black louse) infests the bark, leaves, and fruit of both the orange and Jemon; also, an insect called the pidocchio bianco (white louse) infests in a similar manner the lemon tree. In appearance it is like a minute scale or scab, of oval form, and attaches itself with great tenacity to the bark, leares, and fruit. This insect prevails to a large extent in our orchards. As a remedy, a wash of lime-water is used; also, water slightly tinctured with kerosene.

The fruit of both orange and lemon is sometimes injured by an insect called the tly. It makes its appearance in the beginning of summer, and commences its devastation by stinging the fruit aud depositing therein its eggs. These eggs develop into grubs, which destroy the fruit. When the fly first appears the fruit on the tree should be frequently washed. The water should be applied with a sponge. Some slightly tincture the water with kerosene or soda. Fumigating the trees with the smoke of sulphur has also been tried. No remedy has yet been discovered that effectually (lestroys the noxious pests. Good ventilation, thorough culture, and plenty of sunlight are the best preventives.

\section{EXPORTS TO UNIPED STATES.}

In the export of citrus fruits from Catuila :o the United States during the past three Jears there hats been a gradual decline. This is prob- 
ably owing to the decline in prices. There were exported from Catania to the United States of lemons and citrons-

\begin{tabular}{|c|c|c|}
\hline Years. & Boxes. & Value. \\
\hline $\begin{array}{l}1882 \ldots \ldots \ldots \ldots \\
1883 \ldots \ldots \ldots \ldots \\
1884 \ldots \ldots \ldots \ldots\end{array}$ & $\begin{array}{l}241,107 \\
228,857 \\
168,575\end{array}$ & $\begin{array}{r}\$ 441,2297.72 \\
324,284.84 \\
391,068.20\end{array}$ \\
\hline
\end{tabular}

ALBERT WOODCOCK,

Consul.

UNITED S'TATES Consulate,

Oatania, November 25, 1885.

\section{CUBA.}

REPORT OF CONSUL PIERCE OF MATANZAS.

In the district of Matanzas the citron, though not indigenous to Cuba, is to some extent cultivated here, but not as an article of commerce. Scarcely any attention is paid to its cultivation, and, like a great many other useful products, it is almost entirely neglected, owing to the prior preference for the staple product, which up to this day is the sugarcaue.

It may be surprising that an article so universally growing in the island should not appear as an article of export, but to one well and thoroughly informed as to the tendency of the anricultural class here it is not surprising. Nearly every farm-house garden or plantation has a few citron trees growing. The soil is eminently adapted to its cultivation, and, in the production of it, it is flourishing and florescent, but as small cultivations have been entirely abandoned in preference to the sugar-cane, there has been neither foreign exportation nor an interior commerce in the article-at least in this clistrict.

The citron is used to a limited extent here as a touic and for preserves. In its use as a tonic or a mediciual article only the outside bark or peel is used. The interior is used as a refreshment and for preserves.

The citron is grown on a bush about three yards high. From the time of planting, in about two years, fruit may be expected.

It will grow in any ground, but rich earth is naturally preferable. As the fruit has wever been attentively cultivated here, it is almost im. possible to digest the many opinions riven by the isolated cyltivators who have given it auy attention; but I hare given what I deem a fair synopsis of the various duta obtaiued, and will add that it is leemed and classified as hardy as the orange. 
Propogation naxy be done he planting the seeds (hut production is later in this way), or by cutting, or, as in the cise of the banyan tree, by intertwining branches which readily take root.

Frank H. Piniree,

United States Uonsulate,

Consul.

Matansas, November i7, 1885

\section{MADEIRA.}

Acting Consul J. Hutchinson writes from Funchal under date Decem. ber 3,1883 -

The cultivation of the fruit on the island is on so small a scale that it is impossible to obtain any definite information. There are a few trees in two or three districts, on the lands of small holders who never think of making any calculation as to the cost of culture, vield, or profits.

The fruit is sent into town in small parcels for sale to the shippers. The present prices range from $\$ 1$ to $\$ 2$ per hundred, according to size. The buyer places the fruit in a cask with sea water for shipment. It all goes to London, the average anuual shipment being about 50 casks of 1,000 citrons each.

\section{MEXICO.}

Consul James Viosca, of La Paz, Mexico, reports, under date November 24,1885 , that, while the citron has never attained a commercial importance in Lower California, the tree thrices luxuriantly, bearing yearly an abundant crop of very deliciously-flavored fruit, weighing from 1 to 5 pounds each, thus proving the fitness of the soil did a market exist for the produce. A sinall quantity of the green or seasoned fruit is yearly exported to the ports of Mazatlan and San Blas, for domestic uses in making sweet preserves, or what is known as frutn enbuelta en azucar. Otherwise it has no commercial importance.

\section{FRUIT-TREE CULTURE IN COGNAC.*}

REPORT BT CONSUL EARLE.

[Republished frou Consular Reports No. 108.]

There seems to be several reasons for dwarfing fruit-trees, distortlng them ont of their usual shapes, and planting tnem in queer and unusual places and positions. These reasons may be stated, according to iny observations, as follows :

(1) For eronomy of space.

* As carried on in the Billardine, a garden near Cognac, belonging to Mr. Hennesy. 
(2) For protection against weather.

(3) For facility of making medical applications when the tree shows sigus of disease.

(4) The facility with which the ripening of the fruit may be accelerated or forced.

(5) For ornament.

Let us glance a moment at these various objects, and how they are accomplished.

(1) Economy of space.

The great bulk of the land holdings here are small-very many of them very small-and as grapes for brandy making was the great, the all-absorbing crop, every rood of available land was concentrated to that to the exclusion of everything else whatever. And after the prosperity of the country was gone, through the death of the vines by the phylloxera, the farmer required all his land for fool crops to support his famils. So in both cases, avarice and poverty, the fruit tree, a luxury, had to take the wall

Again, in close built quarters in town there was naturally no space for fruit or vines. There is almost always a court-yard, however, and along the walls of this the thrifty Frenchman has strung his fruit trees. On the outside he takes up a flag-stone from the pavement of the sidewalk, prepares a place, plants a rine, and replaces the stone so as to conform to the new conditions. The vine grows, its stem is supported against the wall to a height, say, of from 10 to 1: feet, when it is trained ont laterally between the upper and lower windows on a sort of a horserack shaped frame of iron rods. Thus it forms a beautiful ornament to the dead white house front and furnishes many a welcome cluster of juicy grapes to the breakfast table at no cost.

(2) Protection against the weather.

This is by no means a rigorous climate, measured by New York standards, although by reference to a map it may be seen that Cognac is about the latitude of Hout real, Canada. The Gulf-strean has so modified the climate, however, that the "winter isotherm," so to speak, would fall about Macon, Ga., Montgomery, Ala., or Columbus, Miss. It was not colder here last winter-an average season-than in any of the three sonthern cities. But, remembering tho latitude, it will be seen that, the shortest winter days are only about eight hours long, and after that the long, cold night. Then the wind blows chill and cold, piercing aven to the joints, and ou still nights the frost lies like snow on the ground. As to snow itself, other than as a feathery shower, melting almost as soon as it fulls, it is rare. So with sleet-that sleet which even in tho far sonth thickly glazes all out-doors, from leaf, twig, and stem of tree and plant to rool of house and bed of road-here it is almost unknown. Still, as this climate is ill adapted to such delicate fruits as peaches, apricots, ste., some sort of artificial protection against cold and frost is nevessing for them, and they obtain the best protection 
from the wall itself. The body of the wall protects against the wind and driving cold, and the screens and sheds, which can be readily adapted to the wall, against frost and snow. These screens are made thus : The walls are almost invariably capped with a coping or fluted tiles projecting several inches; under the little shed thus formed a slanting frame of iron rods and wires is adapted, supported below by braces of the same metal. Upon this framo and overhanging the trees is placed a blanket of straw made by the gardener himself at a nominal cost; if this is not enough, it is very cissy to haug similar mats of straw or old rugs, etc., against the wall and in frout of the trees.

(3) For the facility of making medical applications to the tree when it shows signs of disease.

The trees here are subject to mauy ailments, some affecting the present or prospective crop of fruit only, and others tonching the life of the tree itself French hor irultural therapeutics seems to limit itself to a solution of sulphate of copper and quicklime (tEe boullie bordelaise), or a solution of sulphate of copper aur aqua ammonia (the eau celeste). The solutious are applied by meaus of a spras apparatus, or an atomizer, and when the tree is fairly spreal out against the wall, as in the methods of cultivation now under consileration, these applications are a rery simple matter.

(4) The facility with which the ripening of the fruit may be accelerated or forced.

From what has been said under the second heading it needs no further argument to show how the earl, heat of the sun may be utilized for the ripening of the fruit and what measures should be taken to protect the tree and its fruit against sudden lowerings of the temperature in the late spring. Suffice it to say that the thrifty gardener, by making use of the means above indicated, can get his apricots early into market when they bring lim 5 to 6 cents apiece.

Lastly, for ornament. All the gardens here are surrounded by high stone walls, and, of course, no gardener of taste or feeling could permit his wall to remain white, bare, and naked. Henre many of the designs used are merely to hide the nakedness of the wall. They have but little practical utility so far as bearing fruit is concerned, and are maintained in the forms in which they are drawn with infinite difficulty. Sometimes, after several years of careful management, the tree is gotten into the desired elaborate form, when suddenly, to the great disgust of all concerned, half of it dies and its symmetrical beauty is gone.

With this style of tree culture, howerer, I have but little sympathy, since it is much easier to get rigorous, hardy trees, bearing fit uit, whose forms are more graceful to my eye than those intended merely for ornament.

So much, then, for the raison d'etre of this method of tree culture. Let us glance now at how the results are obtained.

(1) The first requisite is, of course, the wall. This should be from 9 
to 12 feet ligh, depending on the size of the garden or inclosed space. It should be covered with some sort of slightly projecting coping, as tiles or slate, and should be of sufficient thickness to insure its stability. Here, where the whole soil is nearly underlaid with soft chalk stone, the cost of the wall is a mere trifle-the trench for the foundation and that for the trees futwish nearly enough stone for the purpose.

(2) After the will is built some sort of trellis should be attached to it upon which to tie and train the trees. The poorer gardeners employ a plain wooden diamond-shaped trellis, made of slats nailed against the wall. The walls of the best gardens, however, are provided with trellises of iron wire, and each strand is furnished hero and there with thumb-screw swivels so that they may be drawn taut, when required. This is much the neater, more desirable, and, in the long run, more economical system.

(3) A trench should be dug at some sligbt distance from the wall for the reception of the new plautation. The distance from the wall and the dimensions of the trench will depend on the height of the wall as regulating the beight of the tree and the kind of fruit-tree to be planted, say, ordinarily, $1 \frac{1}{2}$ feet from the wall and 2 feet deep by 3 or even $2 \frac{1}{2}$ feet wide. This trench should now be filled with carefully prepared upper soil, or loam, mixed with a suitable quantity of stable manure. The tree, or vine, is now planted, in the month of November or February, with the stem slanted through the side of the trench and towards the wall, and, its first bent being given it, attached to the trellis.

Here let me stop a moment to say that the consensus of opinion among gardeners here seeined $t u$ be decidedly in favor of seedling trees in preference to budded or grafted stocks. Of course, if a bough can not be gotten where it is clesired to have it by natural means, that is, if a wood bud cau not be found at a point where a limb is required, this want may be supplied by a bud artificially introduced, or by a graft. Still, the French gardener prefers to deal with a seedling in the first instance, holding that it is easier to give it the desired shape, and that the buds for the production of lateral and other boughs may be more certainly counted on than is the case with grafted or budded stocks.

Having now arranged the prelimillaries it becomes a question of what shape shall be giren to the trees. For my own part, I much prefer the rather simpler forms, say the U forms and their modilicatious, or the candelabra forms. The best of all the forms, hoverer, both as to beauty and utility, I regard the palm.shape and its modifications. There are other very good shapes, the names of which I have been unable to get. My distiuct preference, also, is for the forms which have vertical or oblique branches, for these reasons: The sap of a tree has alwajs a tendency to mount, and under ordiuary condjtions the best frnit will be found on the ends of the branches or the periphery of the tree. Therefore, the oblique forms follow more nearly untrammeled nature, and thus yield better general results. As a proof of the for'going may be 
cited this fact: If a horizontal form is sought after, and one sido of thr tree (that is, the boughs forming one side) develops at the expense of the other, or if any one bough on the one side is weaker and smaller than the corresponding branch on the other, the condition is easily remedred by bending the overdeveloped brauch downwards or the atro. phied hranch temporarily upwards. In either case the sap quits the dependent for the elevated branch, and soon they are brought to in equal development, when the restraints may be removed. Whatever form is selected, however, the trunk of the tree should not be allowed to grow higher than 12 or 15 inches. At this height it should be made to branch or bifurcate, and the branches then arringed in such forms as maly be desired. I can not here go into the various methods of pruning and training. These will vary, naturally, with the sorts of trees with which we have to deal. Suffice us to say that all redundant growths are to be cut away, and even the bearing branches pinched back from time to time as the exigencies of the tree and its crop require.

Une word as to the results obtained here by this method of fruit-tree culture. In my judgment it is the only system practicable in this clinate, but with the protection which the trees thus obtain even peaches and apricots do fairly well. I have counted, for example, a humired well-formed, beautifully colored peaches on a single $U$-shaped tree whereof the stem was no larger than my wrist.

\section{Edward P. Earle,}

Consul.

\section{Uni'ted States Consulate,}

Cognac, A ugust 21, 1889.

\section{FRUIT CULTURE IN MENTONE.}

REPORT BY CONSULAR LGENT VIALE, OF MENTONE; TRANSLATED BY CONSUL WILSON, OF NICE.

[Republished from Consular Reports No. 54.]

Two promontories of the Maritime Alps, Cape Martin and Cape Martola, descending to the Lear, form in the Mediterranean, at the gates of Italy, the beautiful gulf which the ancient geographers called Sinus Pacis. From the midst of the semicircle, protected from the winds of the north, the east, and the west, another promontory advances, less important, which finishes in low bills at the edge of the sea. In this delicious corner of the rorld was formerly fonnd a little village, surrounded by olive and lemon trees, which were reflected in the azure sea - this was Mentoue.

One day some travelers, wandering on the Cornichè road, perceived its picturesque sitnation and learned of its mild elimate. It required but few years to bring to it renown, and the little village bas become 
a town, where the valetudinarian and the chilly people from all the countries of the world meet during the winter season. During the season of 1882-'83, 2,500 families from a distance came to warm $1 \mathrm{hem}$ selves under our sun. There were 87 American families, making about 350 individuals. The reports of subsequent years will doubtless shon an increase.

Mentone and its environs was the ancient station "Lumone" of the Roman road of Julia Augusta. In this small territory are cultivated the lemon, the vine, and some fruit trees.

THE LEMON.

The lemon tree is propagated by sowing the seed. Generally it is preferable to sow the seed of the bitter orange, and graft the lemon on the plant when it shall have acquired a certain strength. It requires about ten jears' growth to obtain a productive tree. The lemon is cultivated on the plain, and on the sides of the hills, or wherever it can be irri gated. For this culture, as well as that of the olive and the vine, the hills are terraced with stone walls. One are (4 square rods) of gronnd contains ten lemon trees.

According to the strength of the tree it yields during the year from 100 to 500 lemons, and even more. The tree requires much care. It must be manured. For this they use the common farm manure, the scraping and refuse of horn, and old woolen rags.

In summer the trees must be watered at least every two days; must be dug about in winter, and the soil loosened every year. The lemou tree Howers all the year, and the fruit is gathered every day.

The harvest is divided into three grand epochs. The first aud second blossoms, produced by the flowers of spring, are harrested fiom Norem. ber to February and March. Then follows the Granètte (second grade) harrested from March to September, at which time the Verdamie (third grade) begins to ripen.

In a good season the harvest amounts to $30,000,000$ lemons.

The culture of the lemon is diminishing for two reasous : First, because much of the land is now being occupied by hotels and rillas; and second, the workmen have become scarce and the price of labor high, so that the culture has become uuremunerative.

The lemons from Mentone, though not so fine as these of Messina, were formerly much preferred for expontation during the montlus of March and April because they could be seut fresh from the trees, while those from Messina, haring been harvested in the previous Norember (their harvest is but once a year) wero already tive months in boxes.

One can searcely form an idea of the care necessily in picking and liandling the lemons and in parking them for exportition. Formerly one-half the population of Mentone were thus employed.

The merchants bad their chosen liborers of much experience to gather the fruit, Inake the boxes, and ho the patekgy. 
Since this pretty rillage has become a winter resort, the habits of the villagers, in respect of their work and their wages, bave changed greatly. The picturesque capellina which shaded the face of the young Mentonaise has been replaced by fashionable hats, veils, and parasols from Paris. The young men have become valets, chefs de cuisine, waiters, etc., and thus the cultivation of the lemon is left to strange and ignorant laborers.

This has lost to Mentone its export to the United. States, for fruit badly gathered or poorly packed arrives at its destination in a pitiable state.

The first choice lemons are usually sent to the North and to America; the second quality are used in France and Italy. The first quality are those haring no blewish, are large and fine, and not too ripe to stand the long voyage.

The lemon and orange trees are subject to divers maladies:

La Morfea. $-\mathrm{A}$ sort of louse which eats the rind of the fruit, and also covers the tree in its worst stages with a disgusting white mildew. When this malady attacks a garden the trees are unproductire for years.

La Fumie is another malady, which turus the branches and leaves of the tree as black as though they came from a chimney.

For some time past they complain of a little worm which attacks the center of the flower, eating the pistils.

Hail will also destroy the fruit, but happily this rarely occurs in Mentone.

The changes of weather, such as a prolonged spell of damp weather, predispose the fruit to certain maladies which may develop in the packed fruit if not well guarded by an experienced packer, and eren with the best care in choice of fruit and packing the fruit of certain years is more likely to spoil and rot.

The exportation of lemons to the United States, as taken from the books of the agency, has been as follows:

\begin{tabular}{|c|c|c|}
\hline Year. & Introices. & Cases. \\
\hline
\end{tabular}

Cases packed for the United States contain 360 lemons.

THE ORANGE TREE.

The oranges of Mentone have but lit tle commercial value. The trees ornament and perfume the gardens and furuish a passable fruit for the table. Very few, if any, are sent away. 
The culture is mnch the same as that of the lemon trea. It flowers but once a sear, in the spring, and the fruit is perfected about every other year. It resists the cold better than the lemon tree. It flourishes at Nice and Caunes, where the lemon does not grow successfully.

THE I $\times$ R.APE VINE.

The grape lores the lills. It prospers at some distance from the sea and 200 or 300 meters from its level. All land seems to agree with it, but especially that which is stony.

The vine is propagated by branches or shoots, having 6 or 7 buds, and about 50 to 60 centimeters long, which are buried in the gronnd with the aid of a piece of iron, leaving only one bud, or eye, out.

Before planting the vines the land is dug up about 1 meter in depth, the vines are planted from 30 centimeters to 1 meter distance, and $1 \frac{1}{2}$ meters is better.

At the end of four years the vines commence to produce. A rine in good condition, well cared for, ought to produce at least 1 kilo of grapes for each stock. At the third year they commence to tie up the loose branches to stakes.or trellises. The vines are manured with woolen rags, bone shavings, and stable manure.

The soil must be worked two or three times per year, for the vine will permit no other to partake at her table. It must be white and light, into which the vine roots may push at will and receive all the nourishment possible.

The pruning is done in January and February, and two or three times a year the straggling and useless branches are trimmed off to prevent the sap being wasted on brauches not destined to bear fruit. The best means of pruning is to leave one large branch at the bottom of the vine with two buds, or eyes, only, which will prod ace two new branches for the next year, and to leave at the top of the rine a fine branch with several ejes. Every eye will produce a branch with at least one bunch of grapes; and the year following, this branch will be cut away to per. form the same operation with the two new branches which will have been left at the bottom of the vine.

The vines are never watered, as that would injure the quality of the wine.

The country of Mentone produces scarcely enongh wine for a month's use. Italy and the center of France furnish the rest.

The wine of Mentone is somewhat strong and heary. We class it between the wines of Burgundy and Spain. It is the type Ifarucerno. Tho grapes are sweet-black, with round seeds.

Other varieties are the Varlentin, the Rossese, the sillerno, and the Tobaceo; but all are in such small ql' antities that they are mixed in the cellars and are known only as a .Marmerno.

Latterly some proprietors have brought slips firm Alicante. The 
wine, in small quantities, is good, and is distinguished from the Maruverno.

The maladies which attack the vine are the oidium and phylloxera. The first shrivels the leaves, destroy's the grapes, and puts the vine in danger. Happily the flour of sulphur is a sufficient remedy. The second, much more terrible, are microscopic worms attacking and covering the roots of the vine. Its ravages have extended more or less over all France. Happily Mentone has thuir finr escaped, though the scourge has appeared within the department.

\section{THE OLIVE TREE.}

The olive trees of Mentone are several centuries old; they are said to have been planted in the twelfth century by the Crusaders.

They are propagated by means of young plants which are detached from the parent tree with some roots. This is the theory. Actually none are propagated in late years. The same reasons mentioned as affecting the lemon, to which must be added the slow growth of the olive, have conspired to turn trade into other chanuels, and the propagation of the olive tree has nearly ceased.

Ten or twelve years are necessary for the growth of a small tree commencing to yield fruit. The life-time of a man, fifty or sixty years, or even a hundred, is necessary for a full-grown tree. They grow in the plain and on the hills.

A full grown tree in a good season will yield 60 to 80 liters of oil. One can never have two good harrests in two consecutive years; fortunate if you have one. A fruit which remains a year on the tree is subject to many dangers. Sometimes the early heat burns the flower, or the wind blows it or the fruit off the tree; a prolonged rain prevents the gathering, or destroys the fallen fruit, or the dryness of the season may blight it, etc.

But the greatest enemy of the olive is the worm. Myriads of small flies (Musca oleavia) sting the olives and deposit their eggs, which in a short time attack the palp of the fruit. These worms go around the fruit and then go out in the form of a new fly. These in turn attack the remaining olives, so that the entire harvest can be destroyed in less than a month.

The ground must be worked once a year; useless or dead branches lopped off every two or three years.

The olive is never watered here, as watur is almost always scarce and sometimes insufficient for the lemon trees.

The olive oil of Mentone and its neighborlıod is good, and is used here and sent to other parts of Fran se.

Including the surromaling comntry, the product of a very good season has been from $15,000,010(1), 20,(100,000$ quintals of oil (a quintal is 100 kilograns; a kilogram is 2.20469 pounds avoirdupois). The olive tree flowers in March and April. The fruit is gathered from Novem- 
ber to April. The best oil is made from that gathered in Marul and April when the fruit is most mature.

MISCELLANEOUS FRUI'S.

The fig, the peach, and the plum are grown in Mentone, but only for home consumption and in small quantities. They have no place in commerce.

\section{PERFUMERY.}

Perfumery is made from the lemon and orange rinds and from the leaves of the bitter orange; but there is only one establishment, and its exports are principally to Germany and Russia.

$$
\begin{aligned}
& \text { N. VIALE, } \\
& \text { Consular Agent. }
\end{aligned}
$$

United States Consular Agency, Mentone, April 1, 1885.

\section{FRUIT CULTURE IN ZANTE.}

REPORT BF CONSULAR AGENT OROWE.

[Republished from Consular Reporta No. 44.]

In accordance with the instructions contained in the circular addressed by the Department to this agency, in date of December 4, 1883, requesting information on the fruit culture of this island, I have the honor to furnish the following particulars, derived partly from personal observation during my long residence in Greece, and partly from data kindly imparted to me by some of the best and most practical cultivators.

\section{GURRANT-GRAPE VINEYARDS.}

Raisins, such as dre generally known by this term, are not prepared here, though many varieties of the grape grow in profusion in this island. The currant-grape was originally imported here by refugees from Corinth in the year $1530 \mathrm{~A}$. D. It is a small, purple grape, free from seeds, and now forms the staple production of this islaud, the adjacent island of Cephalonia, the Morea (Peloponnesus), and is also cultivated to a certain extent near Missolonghi, Lepanto, and the islands of Ithacil and Santi Maura.

The position of these viueyards is mostly on the plaius bordering the sea-coast; the foot of a wooded bill, the deposits from which enrich the soil below it, with a sunny aspect and good circulation of air, is considered the best position. Although many vineyards extend right down to the sea, the plants withiu 500 or 1,000 yards of it are liable to sufter.

Sea fogs and mists are not considered injurious. Tho,mildew (Oidium 
tuckeri) which first appeared amongst the vines in 1852, is most efficaciously combated by sprinkling finely-powdered sulphar (imported from Sicily) over the shoots and leaves, say, just before the flowering, and if required to be repeated, at intervals before the ripening of the fruit, it is either applied with a small perforated hand iredger or by weans of a bellows with a recipieut made of tin attached to it which contains the sulphur; the latter is more generally in use.

The mode of pruning, in principle, is much the same everywhere, but the height of the stem, and other peculiarities in the form given to the plant, is somewhat differeut here to what it is in the Morea.

The best results are mostly obtained on a rich, light soil, with an admixture of sand in it; but it is a singular lact with the currant-grape that, however carefully it way be cultivated, it will not give the same results as to size of berry, color, saccharine substance, or aroma in all districts. For instance, the Zante currants (as incleed all the island currants) are much smaller in the berry than those produced on the mainland, but they hare more aroma and sweetness than perhaps auy other currants grown. Then, again, commencing from the top of the Gulf of Corinth, sonth ward all along the sea coast of the Morea, right down to Calamata, in Messenia, the quality gradually deteriorates; thus Corintb, Fostizza, and Patras, all within the galf, producing the first quality, then Gastouni and Pirgos, in Elis; after this, Filiatra and Gargaliano, in Trifyllia, and finally the produce of Pylia and Messenia. To a counoisseur there is a marked difference in the arerage quality of these various grades; the market value contirms this.

Whereas Gulf, Vostizza, or Patras may be worth 25s. per huudredweight, Calamata or Pylos would not fetch orer 15s. or 16s. per hundredweight, the redceming point for the grower being that in the southeru districts the vines are more prolific, frequeutly doubling the production of other rineyards.

The best results, as mentioned above, are generally obtained at the foot of the bills; but this is not always the case. The great point is that no trees of any kind be planted in a vineyard; that it should get plenty of sun, and that the air should circulate freely in it. Sometimes during its infancy a vineyard is planted with tomatoes, melons, and such like; but this is strongls deprecated by all good cultivators as teurling to weaken tho soil, and if planted at all, it should be done sparsely.

Planting and cultivation.-Cattings which have been buried since Jauuary are planted out in March, if the soil is dry enough, at a distance of about 4 feet from each other, and should commence bearing in the third or fourth year, but the seventh or eighth is reached before full beuring. I have seen plants over 100 years old, but they waturally produce very little; if carefully attended to, a vineyard should continue to be fruitful up to the fiftieth year, though the system of "ring.cutting" or making an incision all round the stem or principal branches 
has tended to weaken the plants, and in poor soils they have to be renewed every thirty or forty years.

The incision is made after the fruit has set, to keep the sap up and produce a larger berry, or what is linown in commerce as "bold fruit," and as this is in vogue in most consuming markets, by far the greater portion of the crop is this treated, the result being that the keeping properties of the fruit are sacrificed to the fashion of trade.

Irrigation.-There is no system of artificial irrigation, but if the wiuter has been a dry one every means are resorted to to try and irrigate as best one can.

Yield.-The yield, value, and cost of the crop per acre varies according to the soil, cultivation, and other circumstances. The wages of laborers are an important item; as a rule they are much lower in the islands than on the main-land; here 50 cents per diem is cousidered high, whereas in the Morea it sometimes exceeds 75 cents and eren $\$ 1$ per diem. A good average in this island is 260 pounds net fruit per "axiuari," or $2,083 \frac{1}{3}$ pounds per acre, since 8 "axinarias" form an acre; the average value of late years has been $\$ 62.40$ per acre; the cost of the erop as far as cultivation goes, from beginning to end, including sulphuring (about 80 pounds per acre being under ordinary circumstances consumed), is \$22 per acre. 'The cost of a good rineyard would be about 450 per acre.

This island's annual yield of currants is now, on an arerage, neariy 7,000 tons, the acreage under cultivation being over 10,000 acres, but this is going on increasing, as many fine olive groves are being rooted up to make room for the currant plant.

I hope I may prove a false prophet, but this tendency to trust all one's egg's in one basket, [ fear, will in the end prove disastrous to the interests of this beautiful island, where the olive flourishes, and the produce can be collected without much expense, and showing a ralıe, one year with another, of over $\$ 300,000$, and this whilst large tracts of virgin soil in the Morea are annually being brought under cultivation, threatening before very long to bring the total production of currants in excess of the requirements of the world, especially if the condition of the rineyards in France improves since, owing to the ravages of the phylloxera in that country, some 30,000 tons of Iried currants have in recent years been annually imported direct, or via other countries, for wine-making purposes.

The annual total production of currants of late has exceeded 120,000 tons-indeed, had not rain damaged a considerable portion of this last year's crop the yield would have been orer 130,000 tons-and the production could be increased to an almost unlimited extent should an unforeseen demand require it.

The old English firm of Barff \& Co, established in this trade since the early part of this century, gives a tablo showing the production and distribution of the whole currant erop from 1820 to 1883 , of which 1 inclose a copy. 
WINE GRAPES.

Besides the "currant" grape, there are probably sixty or seventy varieties of the grape grown in this island, of which only some sisven or eight are cultivated for making wine, the remainder being for eating pur. poses; amongst the latter, one rcusionally meets with a very luscions black American grape (the Susquehanna, I believe), known here as the " Isabella," in flavor something between a strawberry and a raspberry; a peculiar feature about it is, that the "oidium," or mildew disease, has no effect upon it, and consequently sulphuring is dispensed with, although often grown in the midst of a vineyard of other grapes subject to the disease; the conclusion is that its resistance is owing to its belonging to a much younger stock, and is consequently hardier.

The vineyards producing the best wines are mostly on hill-side, with sunny aspect, or on light shallow and rather stony soil. I have heard of grapes grown in a soil entirely of sand, near the sea, producing excellent wine, though the yield is small. A very superior quality of both white and red wine is made here, resembling the best full-bodied Sicilian, and in the cellars of careful viticulturists a capital imitation of Sherry, and even Port, is to be occasionally met with.

Mode of cultivation.-The cultivation of both the currant and wine grape is very similar to the French method, only that the system of low cultivation prevails, no plant exceeding 4 feet in height; only eating grapes, especially winter species, are trailed up.

Owing to the difference of elimate the various processes are somewhat earlier in these latitudes than in France, and the currant has the attention of the grower before the other vines. The fruit of the former is ready the latter part of July or beginning of August, when the bunches are gathered and laid out on carefully prepared drying grouuds which have been previously besmeared with a coatiug of cow's dung liquified in water, or in wooden trays, and remain exposed for eight, teu, or more days, according to the power of the sun's rays. They are then cleared by a light twig-broom from the stalks, heaped together for about twentyfour hours, and finally passed throngh a winnowing machine, and are then ready for market.

The vintage of the wine grape commences the latter part of Septem. ber. If an extra sweet wine is required the grapes are exposed to the sun for three or four days after being gathered, before they are pressed ont.

\section{ORANGES AND LEMONS.}

There are many varieties of both, including the egg-shaped, the blood, the mandarin or tangerine orange, and splendid lemons, some without pips, the bergamot, etc.; in fact, I should say that they are as fine as those of any country. Trees begin to bear fairly well after the sixth or seventh year, and inay remain fruitful upwards of one hundred jears. Mach devinis upon tho soil and care bestowed upon them. They are reared froin seellings, grafts, and buddings. 
Budding is preferred to grafting. Auother metlod pursued here is to cut a healthy, smooth branch of about $1 \frac{1}{4}$ inches in diameter in to lengths of about 1 foot; they are then buried in the grounc! in January at a depth of rather over a foot, and in the following A vril are planted out, slightly inclining, leaving ouly an inch or so above the surlace. Another plau is clasping a pot or box round a young branch of a tree, keeping it well filled with earth, and alter the third year, when it will have formed strong roots, severing it from the parent stem, and planting it in January or February.

As a rule the trees here have not been troubled with any serious malady. Although in some parts of Greece, uotably in Poros, whole orchards have gradually dried up, no remedy has so far been discovered. The trees are planted 15 to 18 feet apart. Here the orchards snceed best in a sheltered part of the plain or valley, at some distance from the sea; the best results are on a light, sandy soil, though on some rich boggy soil I have seen some marvelous specimens of both orange and lemon. The best orchards, as a rule, are at least a mile away from the sea.

In very hot weather the trees are irrigated at night from wells or cisterns, but there is no regular system in use, aild in certain localities it is not necessary. The ground is aug thrice a year, in March, May, and October. Very little pruning is required beyond keeping the trees in good shape, and free from dead twigs or branches. Manure is laid on every two or three years if the soil is poor. No crops are grown under the trees in properly cultivated orchards, and only the peach tree is in some orchards planted, as it does not last mauy jears, and the soil is not weakened by it.

A first-class orchard yields about $\$ 400$ per acre anuually, expenses being about $\$ 35$, including manure.

\section{OLIVES.}

There are two varieties here, the iuligenons and a variety introduced from Oorone, in Messenia; the latler is the most prolific. Both bear a suall, greenish-black frnit.

Process of eultivation much the waue as the orange tree. The grouud is plowed regularly twice a year, in Mareh and December, and everr fourth year during the summer nanure is sown, resulting in a crop of hay in the following spring.

The Queen olire is not prodneed liere.

The trees come into fnll bearing after the twentieth vear. There ure fruitful trees several centuries old. The averige annual vield per acre of unature tress is 33 gallous of liquid oil ; :325 pounds' woight of olires veld 4 gallons of oil ; mueh depends upon the quality of the soil abd the season.

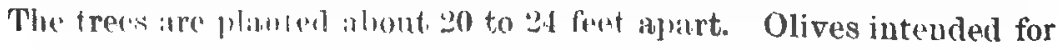


pickling are picked when they are barely ripe, but these are few and ouly for local wants.

The olives for oil-malking are picked, or rather knocked, off the trees when ripe. The process of preparing them for table use is simply salt. ing them, putting them in oil or vinegar; in the latter case they are generally slit on the sides. The process for extracting oil is very primitive. The olives are geverally crushed between millstoues, the upper stoue being turned by a horse. Another process is to put the olives between goat-hair sacks, throw boiling water over them, and then press them as one would grapes. Such oil is never good. The peasantry frequently keep a portion of their crops of olices for a couple of years without crushing them. To do this they are thoroughly sprinkled with salt, and simply left in a corner of their room. It is said that they do not lose either in weight or liquid, but such oil when extracted is liable to be rancid. The process of knocking off the fruit with sticks is much to be deprecated, since many fine shoots are thus destroyed.

Valley, hill-side, or table-laud are all adapted to olive trees. Much depends on the nature of the soil. A hard clay is bad. The best oil is from trees grown on a stony hill-side, but the yield is small.

There is no system of artificial irrigation, but copious rain-falls in winter are indispensable to insure a good crop; even then the olive seldom bears a full one except every second year.

Orchards come right down to the sea-coast. The olive requires plenty of air, and a high wind is indispensable to insure the proper setting of the fruit. Close, sultry weather during the flowering prerents the flower from falling, and a worm is then generated. Of late years many orchards have been attacked by blight, which canses unuch of the fruit to drop off when approaching maturity. The cause is unknown, and on remedy found so far to combat it.

The cost of cultivation is not over $\$ 12$ to $\$ 14$ per acre, and $\$ 6$ to $\$ 8$ more for collecting the fruit, cost of manure not included. As a rule the proprietor of an orchard is satisfied with the benefit derired from the manure, and the person who provides it has the hay in return.

No meteorological observatious are taken here. I am indebted to Mr. W. G. Foster, superintendent of the Eastern Telegraph Company, for the inclosed table showing the temperature during the summers of 1882 and 1883.

\section{FIGS.}

No figs of commerce are grown here. Four or five varieties are produced in abundance, both green and black, but they are eaten fresh, the large orchards bearing fruit after the millle of May and all June. A smailer and sweeter fig ripens in August and September, but these are not grown in orchards, only a tree here and there in gardens.

The cultivation resembles that of the orange and lemon, only that less attention is bestowed on the orchards, and crops of beans and such 
like are trequently grown under the trees. If tigs are grown on a rich soil they are liable to suffer from worm disease.

No figs are dried in this island; an attempt was once made, but it did not succeed. The only part of Greece where figs are cured is at Calamata, in Messenia, but they are very inferior to the Smyrua fig; they are principally exported to Southern Russia or to Trieste, aud thence forwarded to the interior of Germany, where the refuse lots are baked or burnt and then ground and used as a substitute for coflee.

$$
\begin{aligned}
& \text { A. L. CRowe, } \\
& \text { Consular Agent. }
\end{aligned}
$$

\section{United States Consular Agency, Zante, March 15, 1884.}

\section{FRUIT CULTURE IN THE ALPS MARITIME.}

REPORT BY OONSUL TILSON, OF NICE.

[Republished from Consular Reports No. 47.]

The Alps, projected south warls from Lake Geneva, come to an abrapt termination at the Mediterranean Sea, in the department of the Alps Maritime. On the one side high mountains, on the other deep water. The mountains are seamed with sinall rivers, and their bauks and the sea-coast proper are fringed with uarror valleys, which, with the sometimes sloping hill-sides, are the only agricultural lands in the region.

These mountains shelter the valleys from the cold north winds of the Alps, while the sea tempers the sultry south winds of the Great Sabara, producing a soft and equable climate, which the fashionable world has declared to be the most delicious in all Europe.

In the public gardens, and in many private ones, too, the palm trees, the cocoa, the cacti, and the aloe flourish. Flowers bloom in banks of loveliness of color and fragrance on either side of the highways; hedges of rose trees and geraniums guard the orchards of orange and lemon trees, which, bearing both fruit and blossom, make for them a ceaseless round of seed time and harvest, while riolets and jessamine are as plenty as dog daisies on a village common. I saw the other day a heap of violets which had just been bronght to the mill and were on the floor, a pile 20 feet across. They were to be ground up and their fragrance transmitted into the essences and pomades of commerce.

I visited this winter the gardeus of the enthusiastic amatenr, Monsieur Doquin, at Cannes, coverug near '20 acres. They were filled with all sorts of tropical fruits, growing at all seasous in the open air. Be has no plant under glass, ret on my wy home I saw plainly, in the near neighborbood, the smow-corered mountains. This, with the lact that Nice is in abont the same latitule as Pontlami. Me., was to me a matter

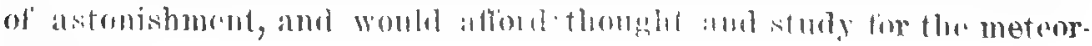
ologist. 


\section{OLIMATE.}

During the thirty years from 1849 to 1878 , inclusive, the wind blew at Nice as follows:

Averages and extremes of temperature at Nice during thirty years, from 1849 to 1878 (thermometer centigrade).

\begin{tabular}{|c|c|c|c|c|c|c|}
\hline Month. & \multicolumn{6}{|c|}{ Temperatare during the day. } \\
\hline 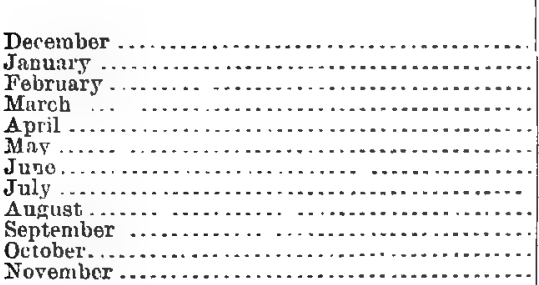 & $\begin{array}{c}\circ \\
11.69 \\
11.19 \\
12.36 \\
14.33 \\
17.74 \\
21.83 \\
24.53 \\
27.47 \\
26.90 \\
23.83 \\
10.85 \\
14.86\end{array}$ & $\begin{array}{c}\circ \\
18.5 \\
19.2 \\
18.9 \\
21.4 \\
37.8 \\
29.6 \\
31.6 \\
39.7 \\
33.2 \\
33.9 \\
31.2 \\
26.7\end{array}$ & $\begin{array}{l}1872 \\
1855 \\
1866 \\
1871 \\
1871 \\
1870 \\
1877 \\
1865 \\
1869 \\
1853 \\
1870 \\
1849\end{array}$ & $\begin{array}{r}0 \\
1.1 \\
3.0 \\
3.2 \\
5.2 \\
7.0 \\
8.7 \\
17.4 \\
20.7 \\
19.2 \\
17.2 \\
11.0 \\
4.2\end{array}$ & $\begin{array}{l}1867 \\
1862 \\
1854 \\
1860 \\
1849 \\
1861 \\
18.55 \\
1851 \\
1857 \\
1852 \\
1869 \\
1851\end{array}$ & 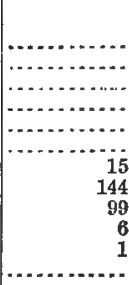 \\
\hline
\end{tabular}

Temperatare daring the night.

\begin{tabular}{|c|c|c|c|c|c|c|}
\hline \multirow{3}{*}{ Montl. } & & & & & & \\
\hline & \multirow{2}{*}{$\begin{array}{c}\text { Daily } \\
\text { average. }\end{array}$} & \multicolumn{2}{|c|}{$\begin{array}{c}\text { Highest tem- } \\
\text { perature. }\end{array}$} & \multicolumn{2}{|c|}{$\begin{array}{l}\text { Lowest tem- } \\
\text { neratace. }\end{array}$} & \multirow{2}{*}{$\begin{array}{c}\text { Number of } \\
\text { timos bolow } \\
\text { zoro. }\end{array}$} \\
\hline & & Night. & Year. & Night. & Year. & \\
\hline
\end{tabular}

The differences between these extremes are as follows: Between the annual averages, 310.60 ; between the greatest extremes in one year, $1859,35^{\circ} .5$; between the least in one jear $270.0,1850$; between greatest extremes in the 30 years, 370.2 ; highest 330.7 , July 10, 1865 ; lowest $3^{\circ} .5$, February 8,1864 .

The average number of rainy days in Nice in each year is 64.4. The most rainy year, 1853, gave 103 ; the least, 1871, 45 days.

This average divides itself among the seasons thus: Winter, 16.1; spring, 19 ; summer, 9.3 ; autumn, 19.8. 
The average rain-fall for ten years (1870-79) was $796.4^{\mathrm{mw1}}$. The maxi. mam (1872) was $1,383.9^{\mathrm{mm}}$; the minimum, $452.9^{\mathrm{mm}}$ (1875). The most frequent rains come from the east and the southwest, but the hardest rains come from the northeast and the south. Scarcely any rain comes from the north or northwest.

\section{SOIL AND AGRICULTURE.}

The country has generally a gravelly limestone soil. Agriculture is difficult and comparatively insiguificant. The farmer has a continuous struggle with nature for a living: but then it is not what we have that makes us happy, but what we neer, and happily for him, his needs are small.

The ground is solid and difficult to dig. It lies usually or frequently in narrow terraces on the mountain-side, each one supported by the rough stones piled up perpendicularly and forming the lower side of the terrace, giving to the whole affair the appearance of an extensive stair-case, up which a giant might climb the mountain. The tread of the steps is the space devoted to agriculture. True, they cultivate the ralley below, but it is also divided into small patches, surrounded by high stone walls, with espaliers (trellises) covered with roses, geraniums, ete., and sometimes peaches or grapes. In all this there is small chance for a plow, first, from the small and irregular shapes, and second, from the groves and trees of lemons, oranges, olives, and figs, which occupy the ground, and spread their roots in every direction. The most of the work of turning up the earth preparatory to planting must be done with the spade. It is hard labor, and shows its effects in the dwarfed and early-bowed forms and the brown and grizzled faces one sees in the market places.

On the mountains and high up their sides one can find numberless opportanities for, and illustrations of, geology, mineralogy, and sometimes archæology, but not of agriculture. Rocks and stones here abound, but, except for the ass and goat, there is scarcels enough regetation to support animal life.

The culture of flowers is fast becoming the more serious and remunerative occupation. They are used for the essences and pomades of commerce. Extensive establishments for these purposes abound throughout the neighborhood.

The principal food of the peasant is the five de marais, a sort of bean (frequently made with other vegetables into soup), vegetables dressed into salad, and black bread made of flour compounded of wheat and rye, or wheat and oats. Their drink is the common wine of the country.

THIN OIIVE AND ITS OLL.

The olive tree is of the highust intiquity. It appears on the earliest page of written history in the leaf which the dove brought to Noah in the ark as evidence of the recoding waters. 
It held the highest rank in the ancient mythology. Minerva taught the Athenians its uses. The peoples of antiquity held it in great respect, and used its oil in their varions religious ceremonies. It was at once the emblem of holiness and peace. The Romans refused to burn the wood, even on their altars.

The olive was brought from Egypt to Greece, and from thence spread over the countries where it is now grown.

It flourishes best in the basin of the Mediterranean sea, betweeu $35^{\circ}$ and $43^{\circ}$ north latitude, though this, as I hare stated, will, owing to the difference of temperature on the same parallel, be but an uncertain guicle in the United States. The oil prodnced on the African shore of the Mediterranean is inferior to that of the north shore.

Some of the islands of the Grecian Archipelago and the Adriatic produce fine oil, but the center, both for quantity and quality, so far at least as coucerns commerce, is at Nice and the surrounding country. From St. Tropez to Savone gencrally, but chiefly from the Var to the Roya, from Cannes to Vintemille, the best oil is produced.

Here the trees have been indigenons since before the Christian era, and here they grow to the largest size and the greatest age. One at Beaulieu, in full vigor and bearing, is 22 feet in circumference and is supposed to be 700 or more years oll.

The slower the fruit ripens the better oil it makes, but as it must be fully ripe and entirely free from blemish to make the choicest oil, and as it requires two years to come to perfection (the crop is only biennial), one can easily comprehend the dangers of climate, season, malady, and accident which must be avoided and the difficulties which nust be overcome in order to obtain final success.

To accomplish this with a plant so tender requires a climate and situation of peculiar adaptation, and unless that is secured any attempt at its cultivation will be fruitless. The fruit freezes at $23^{\circ}$ Fahrenheit and the tree at $16^{\circ}$. Once frozen, no remedy exists; the tree is de. stroyed and nust be cut down.

It speaks volumes for the climate of this region to say that the olive trees have here grown successfully for the centuries I have indicated.

If the weather be too warm and the land too rich the fruit ripens too fast and its good taste is gone. If, on the other hand, it should become too cold, fruit and tree are both destroyed. Possibly I can do no better than answer the question propounded in the circular to which this is a response.

\section{VARIETIES OF OLIVE TREES.}

What varieties of trees produce the best results and at what age?

There are sixteen or seventeen different kinds, each wil $\mathrm{h}$ its botavical name, which have been grown in this rugion, but nearly all as exotics. The tree in common use is the European olive, and all the information given concerns this. It gives the best oil. 


\section{FRUIT·BEARING AGE.}

The tree begins to bear fruit at ten years of age, but it does not come to maturity until from thirty to fifty years.

For the olives of commerce-that is, to eat, either fresh or pickled-the young tree produces the best result; the mature trees produce the best oil.

\section{MODES OF PLANTING AND CULTIVATION.}

What is the process of planting and cultivation?

The reproduction of the olive tree may be accomplisbed by all the modes known for trees. The best mode-planting the seed or pit-is practiced here the least. The people prefer planting the sprouts which come up from the roots of the tree, or which may be artificially made by bending a twig and covering it with earth until it has taken root. At the age of two years this stock may be grafted, or the operation is more like that of "budding." The graft is cut all on one side and introduced under the bark, then bound up in moist earth and allowed to grow. The stock above the graft is cut off.

The earth around and between the trees is tilled each year, and a crop, sometimes of wheat or beans alternately, planted in the spring and gathered in the autumn. The earth is manured every two Jears and the trees are pruned erery four years.

\section{THE BEST TREES.}

What variety of tree produces the best olives of commerce? Are they the selected fruit of the common olive, or a superior variety grown from an improved tree?

It is the same tree and the sime fruit for oil as for commerce. But the best olives for commerce grow on the young trees; thes are larger and plumper, and by selecting the fruit they obtain the finest quality, which are then preserved for commerce. There is a species grown at Nice for which is claimed a superiority of taste and fragrance. It is distinguished by a small black spot on the blossom end of the fruit. These olives are caten in the conntry when ripe, are semi-dried and slightly seasoned with salt.

\section{TIME OF FRUIT GATHERING.}

$\Lambda t$ what age do the trees come to full bearing, and hor long do they remain fruilful?

The trees begin to bear at ten years of age, but they do not reach their full capability or maturity until from thirty to fifty years. They continue fruitful for two and a half or three centuries. This is for grafted fruit. The will olive lives and bears until twice thatage. In Proreuce aud other countries not so well adapted to them, they commence earlier and also die earlier. The trees are sulller and the fruit can be picked 
by hand. There the crop is annual, the harvest being in November and December, while in Nice and surrounding country the hurvest is biennial. Here the blossom or flower comes in Ayril or May, and the first fruit, consisting of the smaller and inferior, is gathered iu November and December, the better-in January and February and March, while the best (for oil) is the last, in April and May. It produces the best oil when it ripens slowly, and in some exceptionally good years the harvest is continued into June and even July. The tree then recuperates until the following spring, when it flowers again. An olive tree, even here, would bear a crop each year if so permitter, but the "whipping" necessary to gather in the fruit destroys the blossoms, which do not come again until the next spring.

\section{HOW THE TREES ARE PLANTED.}

At what distance apart are the trees planted; how wany to the acre? From 10 to 15 yards each way. The larger trees require larger space and the larger the space allowed the larger the trees prodnced. The trees need sun and air, and if crowded it will be to their detriment. This would permit, if I have figured aright, forty to fifty trees to 1 acre. But they do not calculate by the acre, for the trees are planted on the hill-side, usually on made terraces impossible to plow, cultivated with the spade, and it is diffenit to get an acre of olive trees together. In ponrer soil and on the hill-side the trees may be a lesser distance apart, even reducing it 6 to 8 yards.

\section{OLIVE YIELD.}

What is the average yield of mature trees in fruit; in oil; and how much or in what proportion does the fruit produce the oil?

The difference between olive trees in their product is as great as between apple trees. But the average production, per tree, biennially, may be stated thus: In fruit, from 60 to 120 liters; in oil, from 8 to 12 kilograms, or 12 to 18 liters.

The production of oil from the fruit is about as one to five; $i . e$, some 5 liters of the best olives will make 1 liter of oil ; though in many cases it takes 7 liters of olives to make 1 liter of oil.

\section{PICKLED OLIVES.}

The prepared olives of commerce come from Marseilles and farther around the coast. They are outside my district, and my information might not be reliable, therefore, I shall not attempt it. Olives for the table at Nice are usually eaten ripe and fresh. Sornetimes they may be pickled green and preserved in salt or brine, but this is all for the local use and does not enter into commerce.

OLIVES FOR OIL.

When and how are they picked, and what is the process of extracting the oil? 
I have already indicated that the harvest was only biennial, that it commenced in November and lasted until May, or even (as in this year) until June. The fruit is gathered when ripe, or, what is better, just before it comes fully so. When ripe it is apt to become damaged by decay and by attracting bad tastes. For these reasons it can not be allowed to remain on the tree until it falls from its ripeness. The tree is too slight and frail to be climbed, and so a sheet being spread on the ground to receive the fruit, it is whipped off with long switches.

The harvest is divided into three periods, of about two months each.

The first, November and December, produces the oil ordinaire. This is greeuish in color. It is used as food by the common people, while the inferior quality may be used for lubricating purposes.

The second period, January and February, produces oil fine, straw color, and is the oil of commerce.

The third period lasts from March to the close and produces the oil sur fine or sur choix, whiah is the very best, with only a tinge of yellow in it.

MANUFACTURE OF THE OIL.

The olives gathered in either of these periods are taken to the mill where they are ground to pulp; and then put under the press by which the oil is extracted and the fruit and seed left a dry mass.

- The mill consists of a stone about the size and shape of the common millstone, but stood on edge, is made to thus rerolve on its axis around a given center by means of a long wooden arm operated by horse or man power, its weight being on its perimeter, inside a large tub of stone (mason work) with a stone bottom. Into this tub the olires are thrown and the revolving stone crushes them in its path.

Much care and experience is required for all these operations. The olives must be in proper condition; they must have no bruises or decayed places, no unnatural or improper taint or taste; the weight of the millstone must be such as that the fruit sball be macerated but the. stone or pit not broken, for the keruel gives the oil a bitter taste.

The ground pulp is put into a sort of sack or open-work basket, and our or five of these are placed under the press. The oil thus extracted s the best quality for that period. Afterwards a second quality is ob. tained by suaking the re siduum with hot water. The operation of grind. ing and pressing may follow immediately the gathering, but if tha fruit is dry and in good order it will keep for eight or ten dass if spreal out in a dry place to a depth of 2 or 3 inches, and not disturbed.

\section{HOW BEST RESULTS ARE OB'AAINED.}

Are best results obtained on villey, hillside, or table-land

Ou hillside. Not only is the fruit better and more abundant, but it makes finer oil. 


\section{SUITABLE SOIL.}

What character of soil is best adapted to olive trees"

A limestone soil ; marl and clay or any soil wet and cold are not good. It will flourish in almost any kind of soil light and dry. A light limestone, gravelly soil is its delight.

\section{IRRIGATION.}

None is needed here for the olive.

\section{SITUATION OF ORCHARDS.}

How near to the coast are the olive orchards

If on the plaiu, half a mile distant; if on the hillside and protected from the cold winds, they grow and flourish within 20 yards of the seit

\section{DJSEASES.}

To what maladies are the olives subject

The principal ones are the cairon, a small worm (Musca olece), and the morphea, an almost imperceptible bug (Cirnea barbanus).

The slow ripening indispensable to the production of the best fruit causes sometimes a fermentation, by which is engendered the small worm, cairon. It attacks only the fruit, and gives. a bad taste. Its effect is felt most seriously in the next harvest, and thus is produced the succession of good and bad harvests.

The morphia, on the other hand, attacks the tree, and its evil effects are greater, paralyzing the vegetation, rendering the tree fruitless, and frequently causing its death. It flourishes in damp seasons and places, and propagates itself with an astonishing rapidity. It operates by spinning or weaving a sort of web, resembling in some degree that of a spider. This, after a short time, becomes black and dry and resolves itself into a powder which covers the leaves, Howers, and fruit; this powder is corrosive in its effect, and deadens all with which it comes in contact. The insect flourishes on the olive, but the dust spreads and settles on everything; so a country thus infested presents the appearance of a field of death, the valley of the legendary upas tree. No cure has yet been employed with success. It runs its course, and of the trees the fittest only survive.

\section{COSTS AND PROFITS.}

The yield, the proceeds, and protit, and the cost of cultivation.

I have given the yield per tree per crop biennial : In fruit, 60 to 120 liters; in oil, 12 to 18 liters or 8 to 12 kilograms.

In average years, and at average prices, the fruit of a single tree will sell at the foot of the tree for, say, 8 francs; if rendered into oil it will bring, say, from 10 to 15 fruucs. $\Lambda$ ceording to quality the prices are, 
of olives, from 3.50 to 5 francs for 20 liters (a double decaliter); of oil, frum 1 to 2.50 francs per liter. The average product of one tree, then, will be, biennially, in fruit, from 8 to 10 francs; in oil, from 10 to 15 francs.

The cost of cultivation is slight; manure every two years and prun. ing every four. The cost of harvesting is also slight; whip off the olires and gather them up. If this could be done and completed in one operation the cost, would be much reduced. But the wholo cost may be estimated at from 4 to 5 francs per tree biennially, 2 to $2 \frac{1}{2}$ francs anuually. This applied to 40 or 50 trees will make the cost at from 80 to 100 francs per acre. Stretched out, as it is, over a long period of time, it cannot all be done by the peasant with his regular force, and is not, as in our American harvests, forced into a few weeks, requiring a large increase of help, and, consequently, of expense. So the profit on each tree may be estimated at 4 to 8 francs, or possibly 10 , each two jears. This would give from $\$ 20$ to $\$ 40$ per acre per year.

\section{NO MORE OLIVE-TREE PLANTING.}

I am informed, however, that the cultivation of olives is falling into desuetude.

Flowers pay better than fruit. Olive trees are not being cut down or destroyed for the purpose of changing, but when destroyed they are not again planted. The planting of olires here is to be likened to planting forest trees in the United States; and though by every method of figaring it would pay, yet the benefits are postponed for so long timethat no one does it.

This is all made apparent when one considers that the olive does not arrive at maturity for thirty to fifty years, a longer period than the average life of the man who plants it, and that it does not even commence bearing until ten years old.

So the planting of au olive tree is, or may be, regarded as work done for posterity.

\section{ORANGES AND LEMONS.}

The orange flourishes better at Nice than at Mentone, but it is the reverse with the lemon. Mentone is slightly warmer and more sliel. terer.

\section{VARIE'TIES AND VALUF.}

At what age do they come into full beariug and how long do ther remain fruitful?

Thore are the sweet and the sour or bitter oranges. They cultivate fonrteen different varieties-Le Portugal or Borgumotte, Le Chinois, Le Mandarin. The lemon has also its vilieties.

The sweet orange and the munfillin are the most estecmed aud the most cultivated. They furnish the fruits for the market and lor conmerce. 
The bitter orange is cultivated only for its seed, the essence, and the flower. It is not eaten. The tree begins to bear fruit in two or three years after the grafting, but it does not arrive at full maturity until ten years of age. They last for two or three hundred jears.

PROPAGATION.

Are the trees seedlings, gratted, or budded"

All three practices prevail. The bitter orange is grown from the seed, and when it attains the thickness of 1 inch and the height of 5 or 6 feet it is grafted or budded with the sweet orange of whatever variety desired.

The same process in effect is pursued with the lemon trees.

\section{MIALADIES.}

Frost, or freezing, is hardly to be called a malady, but it is equally fatal, and the tree requires care and protection against it.

The principal malady attacking the trees here is that called La Mousse. It seems to be a blight, but whether fungus or not I can not say. It would seem to be produced (I don't know which is cause and which effect) by a superabundance of water in the trunk of the tree under the bark. The symptoms are that the tree withers and becomes yellow, the fruit, flowers, and leaves fall, and all begin to decay and rot. The disease seems to be contagious or infectious. There appears to be no cure, and the only conrse to save the trees or gardens adjacent seems to be the immediate destruction of the diseased trees.

\section{HOW PLANTED.}

At what distance are the trees planted?

Orauges about 5 meters, lemons 3 meters.

\section{SITUATION OF ORCHARDS.}

Are orchards inland or on the sea-coast, hill-side, valley, or upland? Protected from the cold, the orange tree will grow in any of these situations, but that preferable is the valley, where it can be irrigated when necessary. The lemon tree prefers a dry soil, and not having abselute need of irrigation, will flourish on the hill-side. But as both these trees love the warmth, they can not be here transplanted far from the sea. They (especially the lemon) are to be found with the greatest success on an espalier, or trellis, on the protected side of the high stone walls which are the common garden-fence in this country.

How near to the sea-shore are the orchards?

Within 100 meters for the oranges and even less for the lemons.

IRRIGATION.

Iruigation is resuisite for the orange in this country.

I hive given the rain-fall (maximum fall) in ten years, 1870-'79, 1,334 
minimum, 453 millimeters. Average for ten years (1870-79), 796 millimeters, divided by seasons thus:

\begin{tabular}{|c|c|c|c|c|c|}
\hline Serson. & Average. & \multicolumn{2}{|c|}{ Maximum. } & \multicolumn{2}{|c|}{ Minimum. } \\
\hline $\begin{array}{l}\text { Winter } \\
\text { Spring } \\
\text { Summer } \\
\text { Autumn }\end{array}$ & $\begin{array}{r}\text { Millimeters } \\
193 \\
215 \\
80 \\
308\end{array}$ & $\begin{array}{r}\text { Millimeters. } \\
409 \\
460 \\
231 \\
484\end{array}$ & $\begin{array}{l}\text { Year } \\
1873 \\
1879 \\
1870 \\
1872\end{array}$ & $\begin{array}{r}\text { Millimeters. } \\
33 \\
81 \\
3 \\
168\end{array}$ & $\begin{array}{r}\text { Year. } \\
1878 \\
1871 \\
1873 \\
1875\end{array}$ \\
\hline 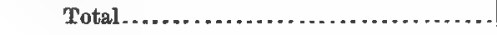 & 796 & ........ & $\ldots$. & . . & $\ldots \ldots$ \\
\hline
\end{tabular}

It will thus be perceived that the rain-fall may be very slight during the summer, so slight that without aid from irrigation the entire crop, and possibly the orchards, would or might be so parched as to be destroyed.

The town of Cannes led the way in procuring a system of artifical supply of water. It brings the water of the Soigne in a canal from St. Cezaide, a distance of 25 miles. Nice has just completed a similar system by means of which waters are brought down through Quartier de Cinsiez, a distance of 10 or 15 miles, and at a height of several hondred feet.

The town of Grasse is agitating the same subject, and soon the valleys along this coast will all be indulging themselves in the luxurious enjoyment of a plentiful supply of pure water fresh from the mountain springs.

\section{HOW THE TREES ARE PLANTED.}

Is the ground between the trees cultivated ?

It is plowed or spaded and manured, but they do not grow anything except some flowers, usually violets.

\section{PRUNING.}

This is done oucereach year, giving the tree the form of a parasol, that it may have sun and air aud to facilitate the gathering of the fruit.

\section{YIELD AND COS'L OF CULTIVATLON.}

Give the yield, proceeds, and cost of cultivation

The gathering or harvest of the fruit is biennial, that is, if the drought, cold, or some malady does not interfere.

The product of the lemon consists here solely of the fruit, whilst in other places the flowers are a source of rereune.

The orange is different. It may be denominated previous. Its branches, its leaves, its flowers, its fruit, and even the skin of the fruit, which would be otherwise valueless, wll these form parts of the regular harvest, while the wood of the tree is in great request as making the finest marquetry. 
The proceeds are somewhat difficult to calculate. A good harvest will produce a minimum of 10 francs per tree; many of them will produce 50 franes tach. This is for fruit alone. Leaves and flowers may bring this up to 15 or 16 franes per tree.

The trees begiu to produce at ten years of age; their best product is during their growth, until their maturity, say to forty or fifty y'ears.

The cost may be approximated as follows:

The grafted stock as sold by the rurserymen, original cost, each, 1.25 francs.

Annual cost:

Irrigation, each. France.

Cultivation and manure

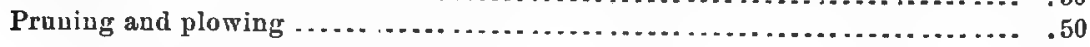

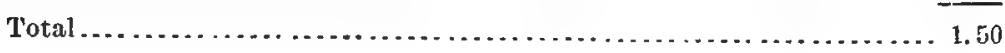

FIGS.

Indicate the kinds of trees producing the figs of commerce.

Among the 67 species of figs which can be counted at Nice, they cultivate the following: LAbicou and Lu Cottignane blunche. These are to be eaten fresh about the last of June. Succeeding them in point of time are the Bernissou noir, Bernissou blane, LaBellone, and Le Col do Dame, to be eaten dried. To be eaten dried-La Bellone (can be eaten either dried or fresh), La Sarrusine noire, La Rollandine blanche. The latter is the fig of Calabre.

\section{MODE OF CULTIVATION.}

Production and process of cultivation.

The fig tree grows from a slip or cutting. They are planted at about 6 meters distance; the warmer and more sheltered the better. Though they will grow in colder climates, yet their tendency is to stunted grow th and a return to a savage state.

The rain suftices for them without irrigation. The earth should be dug and mantured here each year and the tree trimmed. The cost here is about 40 tranes per hundred trees.

The production in the best years at good prices is about equivalent to 30 or 40 francs per tree.

\section{PROCESS OF DRYING AND OURING THE FIG.}

The harvest of some kinds may commence in June or July and it will last until October and Norember.

The ripe fruit is plared ou a trellis or basket work (1 $1 \frac{1}{2}$ to 2 by 2 to 3 meters) in a thin layer and exposed to the sun for ten or twelre days. They are then remored to a dry place under cover, and by keeping them stirred they will not damage for a long time, when at one's leisure 
he can put them in the basket, case, or hoop, and, decorated with peach or laurel leaves, they are pressed in the from in which they are known to commerce over the world.

\section{RAISINS.}

None are raised or prepared in this district. There are vineyards, but not for raisins. They are situated on the hill or mountain sides.

The fruit is sold in the markets to be eaten fresh, though they keep them fresh for a long time. These grapes are sweet and luscious to the taste. They are thus strongly impressed upon my recollection. Those not used thus are made into wine, of which that from Bellet has acquired a local celebrity.

This trade is not sufficiently extensive in comparison with other parts of France to justify a description.

Thomas WiLson, Consul.

\section{UNITED STATES CONSUIAATE, Nice, September 13, 1884.}

\section{THE MANGOSTEEN. \\ REPORT BY OONSUL STUDER, OF SLNGAPORE.}

[Republished from Consular Reports, No. 10.]

TANNIC QUALITIES.

For the benefit of such among our public as are engaged in the manufacture of leather, and who may take an interest in what I am about to state, I have the honor to inform the Department that iu the local paper, the Daily Times, of the $3 d$ iustant, appeared a very interesting as well as important article (taken from a Jara paper), of which the following is a true copy :

Mr. G. Naeff, at Lochun, has made a comparative exa mination of mangosteen shells and oak hark to determine the value of the former as tanning material in leather making. It appeared therefrom that the mangosteen shells contan one-sixth more tannin than oak bark, and that the value of the $f$ rmer may, therefore, be set at about $7 \frac{1}{2}$ guilders per 100 kilograms.

I think it was well that this comparison between mangosteen shells and oak bark was made. I regard this new discovery as very important, in view of the fact that many of our valuable "hard-wood forests" in the Eastern and Middle and, in a great measure, our Western States, have either entirely disappeared or become denuded of oak trees, and this, too, near or around leather-manufacturing districts. True, many substitutes for oak bark, such as hemlock, gambier, and other materials, have been resortod to, but none of these, I beliere, are able to talse the 
place of oak bark, and "oak-tanned leather" still commands the highest price in the market. I do not know the present prices of oak bark in the United States-whether 100 kilograms in a broken state ready to be ground, and bought where grown, would be dear at $7 \frac{1}{2}$ guilders $(\$ 3)$; but if the price of it should be the same as of mangosteen shells bought out here for the same price, the prices of both the same there and herethe mangosteen shells having one-sixth more tannic properties would be more raluable-the difference would more than pay for the freight, besides proving a valuable article of freight for our ships, being easily shipped, and, owing to the hardness of the shell, not liable to spoil or to suffer from sea-water, except after long submersion,

That mangosteen shells contain much tannin and are a very strong astringent $I$ knew long ago. The Malays when they want to check bowel complaints of serious character grate or cut fine the shells, make tea of the same, and use it with good results. This is well known here. About ten years ago an eminent Austrian naturalist aud physician, sent by his gorernment to the Indo-Malayau Archipelago on a scientific tour of exploration, had his attention drawn to the shell of the mangosteen fruit as a powerful astringent, and its common use among the natives as an antilote against the diseases mentioned. It would seem that after his return to Vieuna the imperial family read his report, and noted the medical value of the mangosteen shell, for about six years ago, when cases of Asiatic cholera had occurred in Austria, the Austrian consul here, who was then my near neighbor, was written to by request of Her Majesty the Empress to cause a quantity of mangosteen shells to be procured, and to ship them with dispatch to Vienna, where it was believed they would answer for checking cholera, in case the latter should make progress.

To order mangosteen shells from here for the cure of cholera was it mistake; for no one here ever heard that they had been used for that purpose. Still, as a remedy for dysentery, if taken immediately on being attacked, the astringent is very effective.

THE MANGOSTEEN FRUITS.

The mangosteen is beyond any doubt the choicest, most refreshing, and wholesome fruit in this part of the world, and is found throughout the whole Indo-Malayan A rchipelago, and in Now Guinea, say between the twelfth degrees north and south latitudes. Strange to say, it does not thrive well, if at all, in other tropical countries within the same degrees of latitude. In Siam and in French Cochin China there are large orchards of it ; also on the Malayan peninsula, wherever human habitations are found. It is equally at home, and plenty, on the large and small Sunda Islands, in the Moluccas, and a naturalist told we that he found them growing plentifully in the forests of New Guinea. On the peninsula of Malacca, in Sumatra, and Borneo, large groves of them in a.wild state can be found, generally near the bauks of rivers and creeks. $156 \mathrm{~A}-35$ 
My opinion is that they were originally planted by Malays who lived there, and abandoned their settlements owing to internecine wars, or to change lands. The Malays are more or less of a nomadic disposition. Their abandoned orchards, indigenous as the mangosteen tree is, took care of themselves like other forest fruit trees, and the seeds of the fruits, dropped here and there by birds and monkeys, rooted easily.

The wild mangosteen fruit is just as good as the cultivated, only a little smaller. My experience is that the trees yield fruit, generally very abundantly, about three times in two years, or, to be very safe, four times in three years.

In seasons when rain squalls and fine weather alternate regularly, with a slight preponderance for rain, they bear best. The tree, in ground and atmosphere, likes much moisture. If the natives, throughout the mangosteen-producing countries and islands named, should once become aware that they can sell the shell of the fruit, or that it had become an article of export, there would be no great difficnlty in securing immense quantities of the same, and, the trade once inaugurated, it is my opinion they might be had for less than $\$ 300$ per 100 kilos. The average size of the fruit is about the same as medium-sized apple, while the average thickness of a shell is about one-third of an inch. The fact is, there is "more shell than fruit." I firmly believe that the said shells would make first-class "tanning material," that they are well worth a trial in our tanneries, and it is my opinion they might prove a valuable dyestuff as well.

A. J. STUDER,

Consul.

Consulate of the United States, Singapore, June 14, 1881.

\section{CULTIVATION OF TROPICAL FRUITS.}

SAMOA.

With regard to the circular of September 28, inclosiug a list of questions about different tropical fruits, I am sorry to say that I can gire no information.

Oranges and lemons grow wild in Samoa; they are not cultivated at all. There are no figs or olires grown here.

W. BLACKLOCK,

Tice-Consul.

United States Consulate-General, Apia, Samoa, December 6, 1 \$\$9. 


\section{POLYNESIA.}

HAWAII.

The information sought can not be obtained, owing to the fact that no system of cultivation exists in the orange or fig. These fruits grow well in this climate, while the lemon and olive are scarcely known.

H. W. Severanoe,

Oonsul-General.

Umited States Consulate-General,

Honolulu, December 3, 1889. 



\section{INDEX.}

\section{ORANGES AND LEMONS.}

Continent of AFrica.

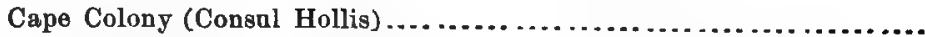

Oranges, 399-insect pests, 399.

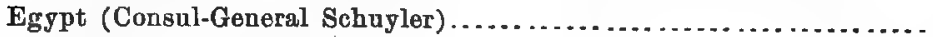

Oranges, 4v0-lemons, 400.

Morocco (Consul Mathews).

Paga

Oranges, 400-varieties, 400,40z-maturity, 400-propagation, 400planting, 400-ineect peste, 400 - situation, 401-irrigation, 401 -cultivation, 401-limes, 403-lemons, 404-citron, 404-pruning, 404.

\section{Continest of America.}

\section{Mexico :}

Guerrero (Consul Sutter)

Oran es, 405-varieties, 405-limes, 405-maturity, 405-propagation, 405-insect pests, 405-planting, 405-situation, 406irrigation, 406- sield, 406.

Sonora (Consul Williams)

Oranges, 407--sitnation, 407-irrigation, 407-propagation, 407planting, 407-yield, 407-insect pests, 407-lemons, 407.

Lower California (Consul Viosca)

Oranges, 407-varieties, 407-situation, 403-climate, 408-irrigation, 408-cultivation, 408-fertilizers, 408-pruning, 408picking, 408-packing and shipping, 409-planting, 409-maturity, 409-insect pests, 409 .

Central America :

Guatemala (Consul-General Hosmer)

Oranges, 409-lemons, 409-situation, 409-cultare, 409.

\section{South America:}

Brazil Bahia (Consul Burke)

Oranges, 410-varieties, 410-cultivation, 410, 411-situation, 410-soil, 410-climate, 411-irrigation, 411-pruning, 411picking, 411-planting, 411-maturity, 411-insect pests, 411lemons, 411-varieties, 411-lime, 411.

British Guiana (Consul Walthal;

Oranges, 412-varieties, 412-situation, 412-climate, 412-irrigation, 413-fertilizers, 413-pruning, 413-planting, 413maturity, 413-insect pests, 413-lemons, 413-limes, 413.

Ecuador (Consul-General Sorsby)

Oranges, 413-varieties, 413-sitnation, 413-climate, 413-cultivation, 414-fertilizers, 414-praning, 414-picking, 414-packing and shipping, 414-planting, 414-maturity, 414-insect pests, 414--lemons, 414-picking, 414-curing, 414-jield 414. 
Continent of Amrrica-Continued.

South America-Continued.

Ecuador (Consul Beach)

Oranges, 415-varieties, 415-matnrity, 415-propagation, 415planting, 415-situation, 415-irrigation, 416-cultivation, 416-yield, 416-lemons, 416-varieties, 416-maturity, 416propagation, 416-insect pests, 416-situation, 416-cultivation, 416-irrigation, 416-yield, 416.

Venezuela (Consul Bird)

Oranges, 416-variety, 416-maturity, 416-cultivation, 416propagation, 416-fertilizers, 416-pruning, 416-insect pests, 417-maturity, 417-situation, 417-lemone, 417-limes, 417.

Maracaibo (Consul Plumacher) .............................

Oranges, 417-varieties, 417-cultivation, 417-lemons, 417varieties, 417-cultivation, 417.

Puerto Cabello (Consul de Blane) ..........................

Oranges, 417-cultivation, 417-lemons, 417-cultivation, 417.

British West Indies:

Bermuda (Consul Beckwith) ..............................

Oranges, 418-situation, 418-Soil, 418-climate, 418-cultivation, 418-praning, 419-picking, 419-ecring, 419-planting, 419-maturity, 419-insect pests, 419

Dominica (Consular-Agent Stedman)

Oranges, 420-varieties, 420-cultivation, 420-situation, 420lemons, 420-situation, 420-picking, 420-situation, 420 .

Jamaica (Consul Haskinson) . . . . . . . . . . . . . . . . . . . . . . . . . . . . 4:0 4:4

Oranges, 420-varieties, 421--propagation, 421-prnning, 422limes, 421-citron, 421.

Jamaica (Counsel Hoskinson) . $424-497$

Oranges, 424-varieties, 424-propagation, 424-maturity, 425lemons, 425-insect pests, 425-planting, 425-situation, 426irrigation, 426-yield, 426.

Trinidad (Consul Sawyer).

Orunges, 427-varieties, 428-situation, 428-climate, 4:28-irrigation, 428-cultivation, 428-fertilizers, 428-pruning, 428picking, 428-curing, 428-packing, 428-planting, 428-matrrity, 428-insect pests, 428-outtings, 428 .

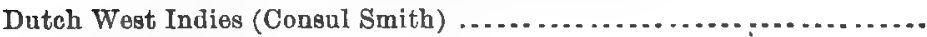

Oranges, 428-lemons, 428.

French West Indies:

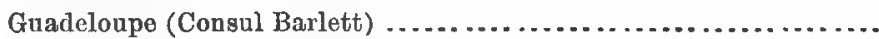

Limes, 429-oranges, 429-varieties, 429-insect pests, 429-cultivation, 425,-fertilizers, 429-pruning, 429 -propagation, 429-maturity, 429.

Spanish West Indies:

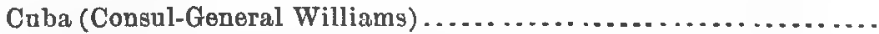

Oranges, 430-planting, 430-lemons, 430-planting, 430.

Santiago de Cuba (Consul Reimer) ...................... 430, 431

Oranges, 430-varieties, 430-situation, 431-climate, 431-lemons, 431.

Porto Rico (Consul Conroy) .............................. $431-433$

Granges, 431-maturity, 432-planting, 432-cultivation, 432-irrigation, 432-climate, 432 . 
Asia Minor (Cousul Eumett)

Oranges, 434-situation, 434-climate, 434-irrigation, 434-culti. vation, 434-fertilizers, 434-pruning, 434-picking and curing, 435-planting and propagation, 435-maturity, 435 .

Mitylene (Consular Agent Fottion)

Oranges and lemons, 435-varieties, 435-maturity, 435-propa435,436 gation, 435-insect pests, 435-sitnation, 435-irrigation, 435, 436-pruning, 435-fertilizers, 435-yield, 436.

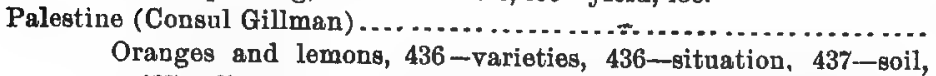
437-climate, 437-irrigation, 437-cultivation, 437-fertilizers, 438-pruning, 438-picking, 438-planting and propagation, 438-maturity, 438-inseot pests, 438.

Syria:

Beirut (Consul Bissinger)

Oranges, 439-varieties, 439-soil, 439-climate, 439-irrigation, 439-cultivation, 439-fertilizers, 439-pruning, 439-picking, 439-planting and propagation, 439-maturity, 440-insect pests, 440-lemons, 440-varieties, 440-propagation, 440.

Beirut (Consul Robeson)

Oranges, 440-varieties, 440-maturity, 440-propagation, 440situation, 440-irrigation, 440-fertilizers, 440-cultivation, 440-yield, 441-lemons, 440-varieties, 440-insect pests, 440situation, 440-fertilizers, 440-irrigation, 440-cultivation, 440.

Haifa (Cousular Agent Schumacher) ........................ 441, 44:

Oranges, 441-varieties, 441-situation, 441-climate, 441-irrigation, 441-cultivation, 441-fertilizers, 442-pruning, 442picking, 442-planting and propagation, 442-maturity, 442insect pests, 442.

Haifa (Consular Agent Schumacher)

Oranges and lemons, 442-varieties, 442-propagation, 442-insect pests, 443-planting, 443-irrigation, 443-cultivation, 443 - yield, 443.

Mersina (Consular Agent Dawson)

Oranges and lemons, 443-varieties, 443-sitaation, 443-soil, 443-climate, 443-irrigation, 443-pruning, 444-picking, 444-curing, 444-shipping, 444-planting and propagation, 444-maturit5, 444-insect pests, 444-packing, 444.

Sidon (Consul Bissinger) ....................................

Oranges, 445-varieties, 445-situation, 445-soil, 445, climate, 445-irrigation, 445-cultivation, 445-fertilizers, 445-pruning, 445-picking, 445-packing, 445-planting and propagation, 445.

Sidon (Consular Agent Abela)

Oranges and lemons, 445-varieties, 445-soil, 446-insect pests, 446-situation, 446-irrigation, 446-yield, 446.

Tarsus (Acting Consular Agent Arania).

Oranges and lemons, 446- varieties, 446-propagation, 447-situation, 447-irrigation, 447-yield, 447.

Tripoli and vicinity (Consul Bissinger)

Oranges and lemons, 447-varieties, 447-situation, 447, climate, 447-irrigation, 448-cultivation, 448-fertilizers, 448-pruning, 448-picking, 448-planting and propagation, 448-maturity, 448-insect pests, 448. 
Continent of Asia-Continued.

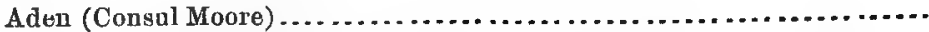

Oranges and lemons, 449.

India (Vice-Consul Bode)

Oranges, 449-varieties, 449-situation, 450-climate, 451-irrigation, 451-cultivation, 452-prnning, 452-picking, 452curing, 452-packing, 452-planting and propagation, 452maturity, 453-insect pests, 453-lemons, 453-citron, 453limes, 453-climate, 454.

Philippine Islands (Consul Webb).

454-457

Oranges and lemons, 454-varieties, 454-situation, 455-climate, 455-irrigation, 456-propagation, 456.

A Ustralasia.

New South Wales (Commercial Agent Dawson)

457,458

Oranges and lemons, 457-varieties, 457-irrigation, 457-planting and propagation, 458 -insect pests, 458.

Australasia (Consul Griffin).

Oranges, 458-variety, 460-lemon, 463-lime, 464-soil, 464climate, 467-planting, 470-propagation, 470-irrigation, 471pruning, 471-picking and packing, 472-curing, 472-maturities, 473-insect pests, 473 .

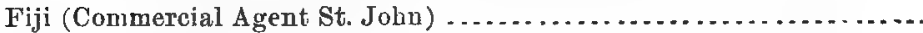

Oranges, 476-lemons, 476.

ConTINent of Europe.

France (Consul Bradley) ........................................

Oran 'es, 477-varieties, 477-lemons, 478-varieties, 478-fertilizers, 479-pruning, 480-propagation, 481-insect pests, 481.

Corsica (Consular Agent Damiani) ............................. 488, 489

Oranges and lemons, 488-situation, 488-cultivation, 488-pruning, 488-climate, 488-insect pests, 489-maturity, 489-varieties, 489.

Marseilles (Consul Trail)

Oranges and lemons, 489.

Mentone (Consular Agent Clericy)

Oranges and lemons, 490-varieties, 490--situation, 490-soil, 490-climate, 490-irrigation, 390-cultivation, 490-pruning, 490-picking and curing, 490-planting and propagation, 490maturity, 490-insect pests, 490-fertilizers, 491 .

Italy :

Carrara (Consnl Rice)

Oranges and lemons, 491-varieties, 491-situation, 491-climate, 491-irrigation, 491-fertilizers, 491-pruning, 491-picking, 491-propagation, 492-maturity, 492-insect pests, 492.

Genoa (Consul Fletcher) .............................. 492-494

Oranges and lemons, 492-varieties, 492-maturity, 492-planting, 49:?-situation, 493-cultivation, 493.

Messina (Consul Jones)

Oranges and lemons, 495-varieties, 495-situation, 495-soil, 495-climate, 495-irrigation, 496-cultivation, 496-fertilizers, 497-pruning, 497-picking, 497-planting, 497-propagation, 497-varieties, 497-maturity, 498-insect pests, 498-beneficial, 498-picking and curing, 498.

Messina (Consul Jones).....................................

Oranges, 499-packing and shipment, 499-situation, 501-soil, 501-lemons, 501-varieties, 502-essences, 502-raw and concontrated lemon juice, 504-fruit in brine, 506 . 
Continent of Europk-Continued.

Italy-Coutinued.

Naples (Consul Camphausen)

Page.

Oranges and lemons, 507-varieties, 507-situation, 507-climate, 508-irrigation, 508-cultivation, 508--pruning, 503-picking, 508-planting and propagation, 508-maturity, 508-insect pests, 508.

Palermo (Consul Carroll)

Oranges and lemons, 508-varieties, 508-planting and propagation, 509-maturit5, 509-insect pests, 509-situation, 510soil, 511-elimate, 511-irrigation, 512-fertilizers, 513-picking and curing, 514.

Sicily (Consul Lamantia)

$516-521$

Oranges and lemons, 516-varieties, 516-situation, 517-climate, 517-irrigation, 517-cultivation, 517-fertilizers, 518-grafting, 518-pruning, 518-picking; 518-planting and propagation, 519-maturity, 519-insect pests, 519-gum disease, 520replanting, 520 .

Sicily (Consul Jones)

Lemons, 521-soils, 522-situation, 522-fertilizers, 52:.

Sicily (Consul Woodcock)...

Oranges and lemons, 522-varieties, 523-insect pests, 524-soil,

524-irrigation, 525-cultivation, 5*5-picking, 525 .

Venetia (Consul Noyes) Portugal :

Lemons, 526-cultivation, 527-fertilizers, 527-propagation, 527.

The Azores (Consular Agent Moreira)

Oranges, 529-varieties, 529-situation, 529-soil, 529-climate, 529-irrigation, 530-cultivation, 530-fertilizers, 530-pruning, 530-picking, 530-curing and packing, 530-planting and propagation, 530-maturity, 530.

The Azores (Consul Dabney)

Oranges and lemons, 531-varieties, 531-cultivation, 531-propagation, 531-packing, 532-soil, 532.

Spain (Consul Lowenstein)

Oranges, 532-cnltivation, 532-clinate, 532-soil, 534-propagation, 536-nurseries, 537-grafting, 540-transplanting, 544cultivation, 547-fertilizers, 553-diseases, 558-climate, 558insect pests, 559-parasitic plants, 562 .

Western Andalusia (Consul Oppenheim) $564-577$

Oranges, 564-varieties and maturity, 565-planting, 565-insect pests, 566-fertilizers, 573-yield, 576.

Barcelona (Consul Scheuch). $577-581$

Oranges, 577-varieties, 577-situation, 578-soil, 576-cultivation, 578-yield, 579-maturity, 587-lemons, 581-cultivation, 581.

Malaga (Consul Marston)

Oranges and lemons, 582-situation, 587-climate, 582-irrigation, 582-cultivation, 582-fertilizers, 582-pruning, $5 \mathrm{k2}$-picking, 582-packing and shipping, 582-planting and propagation, 58\%-maturity, 582-insect pests, 582-packing and curing, $5 \div 2$.

Turkey (Consul-General Heap) .............................. $583-585$

Oranges and lemons, 583-varieties, 583-propagation, 583-insect pests, 583-diseases, 584-planting, 584-situation, 584irrigation, 584-vield, 584. 


\section{OLIVES,}

Continent of Africa

Page.

Morocco (Consul Mathews) 589-594

Varieties, 589-cultivation, and propagation, 590-queen olives, 591-maturity, 591-yield, planting, picking, packing, and oil, 592-situation and soil, 593-irrigation, climate, and pruning, 594.

\section{Contintant of AMerioa.}

Mexico :

Lower California (Consul Viosca)

Varieties, situation, climate, pruning, maturity, planting, and insect pests, 595-8oil, 596.

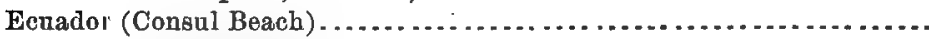

Production, 596.

Venezuela (Consul Bird)

Production, 596.

West Indies :

Bermuda (Consul Beckwith)

Production, 596.

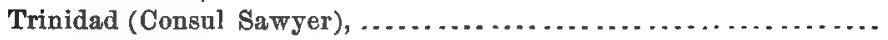

Prodaction, 597.

Cuba (Consul-General Williams)

Production, 597.

Guadeloupe (Consul Bartlett).

Production, 597.

\section{Continent of Asia}

Asia Minor (Consuls Emmett and Stevens)

Varieties, situation, climate, irrigatión, cultivation, and pruning, 598-pickling, picking, oil manufacture, maturity, yield, planting and propagating, and insect pests, 599-situation, 599-cultivation, varieties, picking, ancl expressing oil, 600 .

Palestine (Consul Gillman)

Varieties, climate, irrigation, and cultivation, 601-pruning, picking, pickling, and oil making, 602-maturity, yield, planting, and propagating, 603-insect pests, 604.

Syria :

Aleppo (Consular Agent Poche) ........................ 604,605

Varieties, 604-cultivation, 605.

Beirut (Consul Bissinger) ................................. 605, 606

Varieties, 605-pruning, picking, maturity, yield, and planting, 606.

Beirut (Consul Robeson).

Varieties, cultivation, planting, and yield, 606-picking, irrigation, and climate, 607.

Damascus (Consular Agent Meshaka)

Varieties, situation, climate, 607-irrigation, cultivation, pruning, picking, curing, maturity, rield, planting and propagating, and insect peste, 605 .

Haifa (Consular Agent Schumaker) 609,610

Varieties, situation, climate, irrigalion, cultivation, pruning, picking, 609-maturity, yield, planting and propagating, and insect pests, 610 . 
Contrinent ow Asia-Continued.

Syria-Continued.

Sohwayfat (Consul Bisainger)

Varieties, situation, soil, climate, and irrigation, 610-cultivation, pruning, picking, curing, oil, pickling, maturity, and yield, 611-planting and propagation, and insect pests, 612.

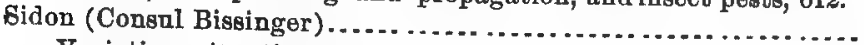

Varieties, situation, climate, irrigation, cultivation, pruning, picking, matarity, yield, planting, and insects, 612.

Sidon (Consular Agent Abela)

Varieties, cultivation, and bearing, 613 -oil, location, 613.

Tripoli (Consul Bissinger)

Varieties, soil, manure, situation, climate, irrigation, cultivation, pruning, 613-pickling, oil, maturity, yield, planting, and propagating, 614 .

Tripoli (Consular Agent Yanni)

Varieties, orchards, maturity, 614-Yield, planting, picking, oil, 614-616

Australlasia : soil, 616-Irrigation, situation, 616.

Australasia (Consul Griffin)

Varieties, 616-planting, soil, situatíon, manufacture of bil, 617 .

Fiji (Commercial Agent St. John)

Production, 618.

CONTINENT OF EUROPR:

France (Consul Trail)

Soil, 619-varieties, 620-cultivation, and fertilizing, 621-pick-

ing and curing, 622-oil manufacture, 624-prices, adulteration, 625.

Southern France (Vice-Consul Martin)

Varieties, soil, sitnation, cnltivation, 627-pruning, fertilizers, irrigation, planting, 628-preparation, 629-diseases, insect pest8, $6: 30$.

Nice (Consul Hathaway)

Varieties, yield of oil, situation, 631-picking, oil manufacture, 632-adulteration, insect pests, 633-diseases, costs, profits, 634-cultivation, soil, situation, 635-propagating, nursery, 636-transplanting, pruning, 637-fertilizers, grafting, 638.

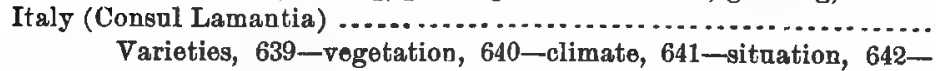
soil, fertilizing, 643-propagation by seed, 644-propagation by ovoli and talee, 645-propagation by polloni, 646-propagating by tronchi vecchi and olivastrelli, .647-grafting, 647treating plants in reservoir, transplanting for final stay, 649praning, 651-insect pests, 653-diseases, 657 .

Italy (Consul-General Richmond)

Varieties, matnrity, green and dried olives, yield, 659-planting, preserving, extracting the oil, soil, climate, irrigation, locality, 660 .

Italy (Consul Crain)

Culture and production, 661-elimate, soil, propagation, 662cultivation, pruning, oil, 663-prices, 664-cotton-seed oil, 664 .

Genoa (Consul Fleteher) $665-669$

Varieties, seeding, planting, 665-olive region, 6l6-production, pickling, 666-oil extraction, results, soil, climate, 667-cost of cultivation, exports and imports of oil, 668 . 
Continent of Europe-Continued.

Italy-Continued.

Lucea (Consul Rice)

Varieties, cultivation, pruning, 669-picking, oil-making, 670propagation, iusect pests, 671 .

Messina (Consul Jones)

Varieties, planting, soil, 671-climate, irrigation, cultivation, pruniog, picking, curing, 672-pickling, maturity, yield, planting, insect pests, 673 .

Naples (Consul Camphausen)

Varieties, climate, cultivation, pruning, picking, maturity, yield, planting, publications, insect peste, 674 .

Palermo (Consul Carroll.

Varieties, climate, 675-soil, 676-cultivation, pruning, 677picking, pickling, manufacture of oil, 678-maturity, yield, planting, cultivation, insect pests, 680 .

Sicily (Consul Lamantia)

Olive in ancient and modern times, 681-production and exportation, varieties, 682-situation, climate, irrigation, cultivation pruning, picking, pickling, 683 .

Sicily (Consul Woodcock)

Varieties, soil, 684-planting and propagating, 685-pruning, cultivation, oil, picking, 686 .

Tuscany (Consul Welsh)

Varieties, 688-planting, pruning, 689-oil, 690-picking, Jield, diseases, culture, 682-climate, export of oil, 693.

Venetia (Consul Noyes)

Cultivation, 694-varieties, 695-culture. manure, protection from cold, 696-pruning, yield, gathering, 697-oil making, 698 , climate, $\% 00$.

Epain (Consul Oppenbeim)

Origin, varieties, 701-planting and propagating, 705-cultivation, 706-pruning, 707-climate, sitnation, 708-soil, pests, 711-picking, pickling, 713-oil pressing, 714-yield, 715-exports, 717 .

Malaga (Consui Marston)

Varieties, situation, climate, irrigation, cultivation, pruning, picking, pickling, 718-maturity, yield, planting, insect pests, 719--varieties, cultivation, maturity, yield, planting, pickling, situation, soil, climate, oil, 720.

Turkey (Consul-General Heap)...

Varieties, cultivation, 721-maturity, yield, planting, picking, pickling, 722-oil making, 723-irrigation, field, soil, 724climate, 725.

Crete (Consul-General Heap)

Harvest, 725-oil yield, export, 726.

Dardanelles (Consular Agent Calvert)

Varieties, trees, situation, soil, climate, fertilizers, cultivation, 726-pruniug, picking, curing, maturit, planting, insect pests, 727. 
Continent of Africa.

\section{FIGS.}

Consul Matherg)

Varieties, 731-planting, propagating, fertilizing, maturity, vield, ouring, 732.

\section{Continent of AMerica.}

Mexico :

La Paz (Consul Viosea) ..............................

Varieties, watering, pruning, picking, 734 .

Ecuador (Consul Beaoh)

Varieties, cultivation, 734-yield, 735.

Venezuela (Consul Bird)

West Indies :

Bermuda (Consul Beckwith)

Production, insect pest, 735 .

Trinidad (Consul Sawyer).

Production, pests, 736.

Cuba (Consul-GeneraI Williams)

Production, 736.

Guadelonpe (Consul Bartlett)

Insect pests, 736.

\section{Continent of Asia.}

Asia Minor (Consul Emmett)

Varieties, situation, soil, climate, irrigation, cultivation, fertilizers, pruning, picking, planting, and propagating, 738-maturity, insect pests, 739 .

Palestine (Consul Gillman)

Varieties, situation, climate, 739-irrigation, cultivation, fertilizers, pruning, picking, planting, maturity, insect pests, cutting, 740 .

Syria :

Beirat and vicinity (Consul Bissinger)

Varieties, situation, irrigation, cultivation, fertilizing, pruning, picking, planting, climate, 741-irrigation, cultivation, fertilizers, pruning, picking, curing, planting, 742-cutting, varieties, situation, soil, climate, irrigation, cultivation, 743fertilizers, prnning, picking, planting, maturity, insect pests, slips. Sidon: varieties, situation, climate, irrigation, cultivation, fertilizers, pruning, picking, caring, 744-planting, maturity, insect pests, cuttings, 745 . Tripoli : varieties, situation, climate, irrigation, cultivation, fertilizers, pruning, picking, curing, 745-planting, maturity, disease, cuttings, 746.

India (Vice-Consul Bocle) . ............................................. fertilizers, praning, picking, planting, size of orchards, maturity, 747-insect pests, cuttings, publications, 748 .

AUgtralasta.

Australasia (Consul Griffin)

Culivation, cuttings, varieties, 748-8ituation, climate, caprification, insèct pests, 749 .

Fiji (Commercial Ageut St. Johnn).

Experiments, blight, 749 . 
Contunent of Europe.

France (Consul Trail)

Varieties, climate, soil, 750-situation, climate, planting, fertilizers, pruning, maturity, picking, 751 -prices, 752-insect pests, reproduction, 753.

Corsica (Consular Agent Damiani).

Varieties, 753-gituation, climate, cultivation, planting, picking, yield, 754.

Southern France (Vice-Consul Martin)

Picking, drying, 755.

Italy (Consul-General Richmond)

Varieties, drying, 756

Catania (Consul Woodcock) .

Varieties, 756-drying, propagating, 757.

Messina (Consul Jones)

Varieties, planting, situation, soil, climate, irrigation, 758-cultivation, fertilizers, pruning, picking, planting, maturity, 759.

Naples (Consul Camphausen) .............................. 760, 761

Varieties, situation, climate, irrigation, pruning, picking, and curing, 760-planting, maturity, insect pests, cuttings, 761.

Palermo (Consul Carroll) ............................... 761, 762

Cultivation, 761-propagation, varieties, 762.

Sicily (Consul Lamantia) ................................ 762-764

Varieties, situation, 762-climate, irrigation, cultivation, fertilizers, pruning, picking, curing, planting, 763-maturity, insect

Portugal : pests, 764 .

The Azores (Consul Dabney) ............................... Spain :

Production, 765.

Malaga (Consul Marston).

Varipties, situation, climate, irrigation, cultivation, fertilizers, pruning,picking, curing, and packing, 765-planting, maturity, insect pests, cuttings, 766.

Turkey (Consul-General Heap)

Production, 766-yield, 767-curing, 768.

Dardanelles (Consular Agent Calvert)

Valieties, trees, 763-soil, climate, irrigation, cultivation, fer768,769 tilizers, pruning, picking, planting, orohards, maturity, caprification, insect pests, 769 .

\section{THE VINE.}

Continent of Africa.

Morocco (Consul Mathews)

Cultivation, plantiug, pruning, 773-propagating, manures, 774phylloxera congress, 775 .

\section{CONTINENT OF AMERICA.}

South America:

Ecuador (Consul Boach)

\section{Continest of Asia.}

Asia Minor

Climate, 777-situation, varieties, pruning, planting, cultivation, 778-maturity, vintage, cultivation, exports, 779. 
Contrnant of Asra-Continued.

Cultivation, 779-pruning, harvest, irrigation, yield, 780 .

Mildew, soil, 780_cultivation, yield, 781.

Aleppo (Consular Agent Poche)

Cultivation, pruning, diseases, 781.

Haifa (Consular Agent Schumacher) ...................... 782, 783

Situation, mildew, 782-pruning, 783.

Sidon (Consular Agent Abela) ............................ 783, 784

Position, pruning, soil, cultivation, bearing, irrigation, 783sield, 784.

Tarsus (Acting Consular Agent Avania)

Situation, yield, 784.

Tripoli (Acting Consular Agent Yauni)

Situation, diseases, planting, 785-yield, 786.

\section{Continent of Europe.}

Austria-Hungary (Consul-General Weaver)

$787-793$

Climate, 787-industry, soil, pruning, situation, 788-yield, production of wine, 789-phylloxera, commerce of wine and argols, 790-duties, 971-prices and consumption, 792.

France :

Southern France (Vice-Consul Martin).

$793-800$

Climate, soil, varieties, 793-planting and culture, 795-fertilizers, 796-yield, diseases, 797-wine making, 799.

Champagne (Consul Frisbie)

Cultivation, 801-vineyards, varieties, 802-picking, harvest, 806-diseases, 807.

Cognac (Consul Preston)

Culture, soil, 809-report of Professor Rivas, 810-fields of demonstration, 810 -reconstructing vineyards with American plants, 811-American vines in calcareous soils, chlorosis in American vines, 813-phylloxera, 825.

Champagne, phylloxera in (Consul Preston, Nice) . ..............825,826

Gironde (Consul Roosevelt) ................................. 826-836

Soils, 826-sub-soils, 827-planting, 828-situation and care, 830 -pruning, 833-expenses of culture, 834.

Italy (Consul-General Richmond)

836,837

Cultivation, 836-yield, expenses, 837 .

Tuscany (Consul Welsh)

Varieties, 837-cultivation, pruning, soil, 838.

Venetia (Consul Noyes)

Climate and fruit and vine growing, 839-island and lagoon vineyards, 840 - vineyards on the mainland, 841-planting and cultivating, 842-varieties, 843-crop, cultivation, profits, 845 .

Russia (Consul-General Stanton)

Culture, 847-yield, 848-Caucasian districts, 849-Russian vs. foreign vines, total product, 850 .

Spain :

Denia (Consurl Arquimbau) 851,852

Production, raisins, 851-American ships, lumber, 852.

Malaga (Consul Marston) $852-859$

Climate, 852-situation, pruning, soil, planting,353-cultivation, maturity, irrigation, yield, picking, 854-extent of cultivation, 855 . 
Continent of Europe-Continued.

Turkey in Europe (Consul-General Heap)

Situation, 859-pruning, soil, cultivation, 860-irrigation, yiold, 863 -varieties, 864-raisin drying, 864-packing, 865-freights, 866.

Salonica (Consular Agent Lazaro) ............................. 86tj, 867 Situation, pruning, soil, cultivation, maturity, irrigation, yield, 866 -climate, 867.

\section{SUPPLEMENT.}

\section{Srystallization of Fruit.}

Marseilles (Consul Masion)............................... 87:-876

Supply of fruit, process, 872-uses of spent sirup, cost and market value, 1874-industry in United States, 875.

Cognac (Consul Irish) ....................................... 876-683

Whitening fruit, 877-sugaring fruit, 878-preparing particular fruits, 879-iced fruits, 881-candied fruits, sugars, 88:.

Rheims (Consul Irish) $88:-36$ Crystallıed, candied, and carameled fruits, 804 .

Bordeaux (Consul Roosevelt) 3xi-:-a: Apricots, 887-ch'rries and chestnuts, 888.

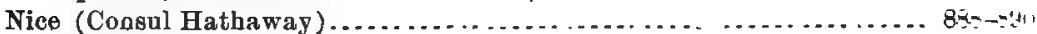
Process of erystallizing fruit, Beaumé barometer, 889-prodaction and cost, 890 .

Clermont Ferrand (Consul Dufais) .......................... $590,0.11$ Processes, 890.

\section{The Date Palm.}

Persia (Minister Pratt) ........................................ 8:11. $99: 2$ Situation, propagation, planting, fecundating, 891 .

\section{- ALMOND TRKE.}

Tangier (Consul Mathews)..................................... $89.3-494$

Cultivation, soil, varieties, 892-propagation, fertilizing, maturity, yield, 893.

Grape-vine Fertilizer.

St. Etienne (Commercial Agent Malmros) ................ . . . . . . $844,-45$ Recipe, 894.

\section{Citron of COMMerce.}

Rome (Consul-General Alden) ............................... 595 , 5 . Situation, crop, frnit, 895-yield, cost of production, iuports and exports, process of preparation, market prices, 896.

Leghorn (Consul Sartori)

Cultivation, candying, 897.

Messina (Consul Jones) ........................................ .48 900

Description of tree, propagation, KIK-cliseases, shipment, prices, and exports, 899.

Naples (Consul Camphausen). $900-902$

Cultivation, 900-packing and preserving, 901.

Sicily (Consul Woodeock) $903-9 \cdot 46$

Location, orchards, 902-proparntion, orebards, 903-ratheriug aud boxing, 904-diseases, exports, 905.

Cuba (Consul Pierce) 
Crtron of Commerce-Continued.

Madeja (Acting Consul Hutchinson)

Cultivation, prices, and shipments, 907 .

Mexico, (Consul Viosca).

Cultivation, exports, 907.

Fruit-Tree Culture.

Cognac (Consul Earle).

Dwarfing, 907-method of planting, 909-shapes, 910.

\section{Fruit Culture.}

Mentone (Consular Agent Viale).

Lemon, 912-diseases, oranges, 913-grape-vine, propagation, pruning, wine, varieties, 914-diseases, olive-tree, propagation, yield, insect pests, cultivation, 916-miscellaneous fruits, perfumery, 916.

Zante (Consular Agent Crowe) 916-922

Currant-grape vineyards, 916-planting and coltivation, 917-irrigation, yield, 918-oranges and lemons, 919-olives, 920-figs, 921.

Alps Maritime (Consul Wilson) 922-934

Palms, cocoa, cactus, and aloe, 922-temperature, climate, 923soil, agriculture, olives, oil, 924-varieties, 925-age of bearing, modes of planting and cultivation, best trees, time of gathering, 926--how planted, olive yield, pickled olives, oil, 927-oil manufacture, 928-irrigatiou, situation, diseases, cost and profits, 929no more olive planting of olive trees, oranges, and lemons, varieties, and valne, 930-propagation, maladies, situation, irrigation, 931-planting, pruping, yield, and cost of cultivation, 932-tigs, cultivation, drying, and curing figs, 933-raisins, 934.

The Mangosteen.

Singapore (Consul Studer) 934-936

Tannic qualities, 934-fruits, 925.

Cultivation of Tropical Fruits.

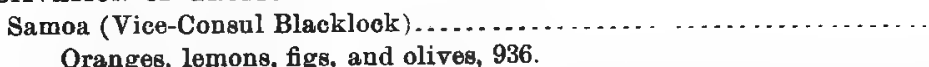

Hawaii (Consul-General Severance)

Oranges, figs, 937. 




